Slavistische Beiträge · Band 428

(eBook - Digi20-Retro)

\title{
Klavdia Smola
}

\section{Formen und Funktionen}

der Intertextualität im Prosawerk von Anton Čechov

Verlag Otto Sagner München · Berlin · Washington D.C.

Digitalisiert im Rahmen der Kooperation mit dem DFG-Projekt „Digi20“

der Bayerischen Staatsbibliothek, München. OCR-Bearbeitung und Erstellung des eBooks durch den Verlag Otto Sagner:

http://verlag.kubon-sagner.de

( ) bei Verlag Otto Sagner. Eine Verwertung oder Weitergabe der Texte und Abbildungen, insbesondere durch Vervielfältigung, ist ohne vorherige schriftliche Genehmigung des Verlages unzulässig. 


\title{
SLAVISTISCHE BEITRÄGE
}

\author{
Herausgegeben von \\ Peter Rehder
}

\begin{abstract}
Beirat:
Tilman Berger • Walter Breu • Johanna Renate Döring-Smirnov Walter Koschmal • Ulrich Schweier • Miloš Sedmidubský • Klaus Steinke
\end{abstract}

BAND 428

\section{VERLAG OTTO SAGNER MÜNCHEN 2004}


Klavdia Smola

Formen und Funktionen der Intertextualität im Prosawerk von Anton Čechov

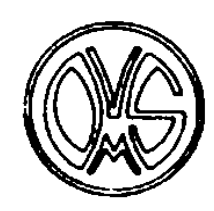

VERLAG OTTO SAGNER

MÜNCHEN 2004 
Gedrucks mit Unterstützung der Friedrich-Ebert-Stiftung

ISBN 3-87690-877-9

(1) Verlag Otto Sagner, München 2004 Abteilung der Firma Kubon \& Sagner D.80328 München

Gedruiks auf alterungsbeständigem Papier

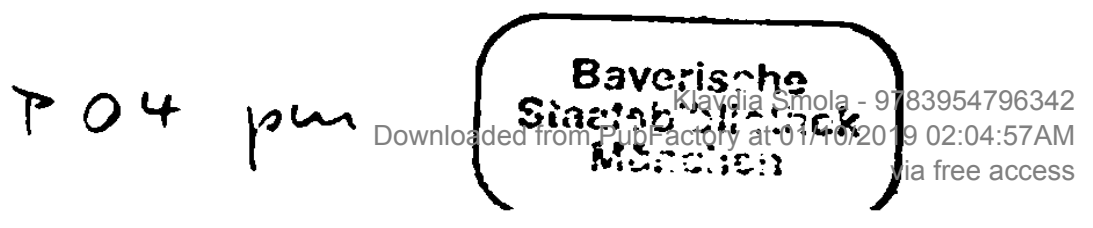




\section{Vorwort}

Die vorliegende Arbeit ist die leicht überarbeitete und ergănzte Fassung meiner Dissertation, die von der Neuphilologischen Fakultăt der Eberhard-Karls-Universaităt Tübingen im Sommersemester 2002 angenommen wurde.

Ich mochte mich hier insbesondere bei meinem Doktorvater Herm Professor Dr. RolfDieter Kluge sowie beim Zweitgutachter meiner Dissertation, Herm Professor Dr. Dietrich Worm, für ihre wichtigen Ratschlăge, Anregungen und kritischen Einwande bei der Niederschrift und Korrektur meiner Arbeit aufrichtig bedanken.

Ohne die Beratung durch Herm Prof. Dr. Vladimir B. Kataev, der mein Interesse am Werk Anton Cechovs wăhrend meines Studiums in Moskau geweckt und mich in meiner Beschăftigung damit stets unterstützt und betreut hat, wăre diese Untersuchung ebenfalls nicht geschrieben worden.

Ich möchte weiterhin der Friedrich-Ebert-Stiftung, die mir die Promotion in Tübingen durch ein Doktorandenstipendium ermöglicht und darüber hinaus eine Druckkostenbeihilfe. für die Veröffentlichung meiner Dissertation gewährleistet hat, sehr herzlich danken.

Beim Deutschen Akademischen Austauschdienst mochte ich mich fü ein Stipendium in der Anfangsphase meiner Arbeit an der Dissertation in Tübingen bedanken.

Ich bedanke mich aufrichtig bei Herm Artschil Zinzabadse und Herm Vladimir Obrant fur ihre Hilfe bei der Beseitigung technischer Probleme, die wăhrend des Abfassens meiner Arbeit des Ofteren entstanden; bei Herrn Michael Raffel und meinem Ehemann Markus Wörz fur die Korrektur meiner Dissertation.

Ein besonderer Dank gilt meinen Eltern Dr. habil. Oleg P. Smola und Ol'ga Smola sowie meinem Ehemann Markus Worz für ihre bestăndige menschliche Unterstützung und Ermutigungen in schwierigen Arbeitsphasen; nur mit ihrem Beistand konnte ich mein Vorhaben zum Abschluß bringen. Dafür móchte ich weiterhin ebenfalls meinem Doktorvater Herm Prof. Dr. Rolf-Dieter Kluge, Frau Maria und Herm Gerhard Worner, Frau Dr. Anette Werberger und Frau Michaela Fischer, M. A. danken.

Meinem Vater Dr. habil. Oleg P. Smola bin ich dafür herzlich verbunden, daß er seine groBen Kenntnisse der russischen Literatur stets großzügig mit mir geteilt und meine Arbeit durch viele Ratschläge gefordert hat.

Einen herzlichen Dank spreche ich schließlich Herm Prof. Dr. Peter Rehder für die Aufnahme meiner Arbeit in die Reihe „Slavistische Beiträge“ aus.

Ich mochte diese Arbeit meinen Eltern, Oleg Petrovix und Ol'ga Grigor'evna Smola, widmen. 


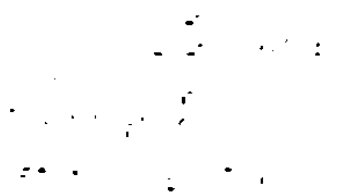

Klavdia Smola - 9783954796342 
Inhaltsverzeichnis

Vorwort

1. Einleitung

2. Theoretische Grundlagen und Stand der Forschung ..............................13

2.1. Intertextualitătstheorie: Entstehungsgeschichte und Hauptkonzepte .................... 13

2.1.1. Zur Zitat- und Allusionstheorie ................................................................ 32

2.1.2. Zur Theorie der .. Texte zweilen Grades"...................................................... 36

2.2. Intertextuelle Beziehungen im Werk Čechovs als Gegenstand der

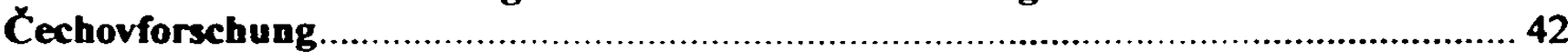

2.3. Das Erkenntnisinteresse der Arbeit ...................................................................... 70

3. Punktuelle Verweise im Kontext der literarischen $A$ bleitungen

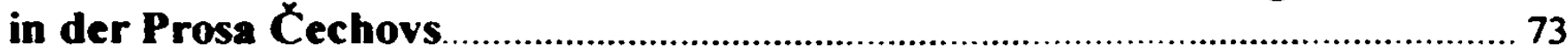

3.1. „Za jablockj" ${ }^{\mu}$ - eine bejahende Nachahmung der Prätexte .................................. 75

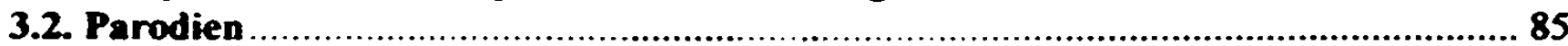

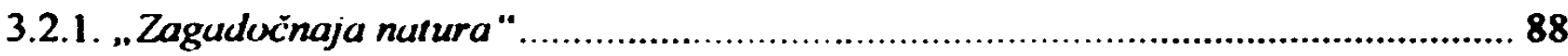

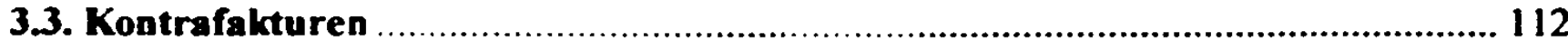

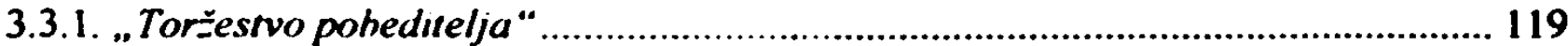

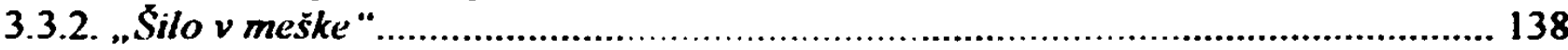

4. Modi der fiktiven Literaturrezeption: punktuelle Verweise im inneren Kommunikationssystem der späteren Prosawerke Čechovs .......... 153

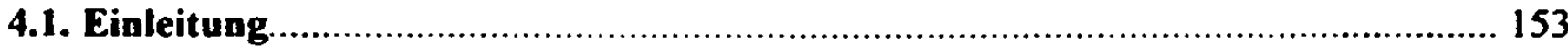

4.1.1. Theoretische Vorüherlegungen und Erlüuterung der Fragestellung................... 153

4.1.2. Allgemeine Charakteristik und Typologie der Modi fiktiver Literaturrezeption

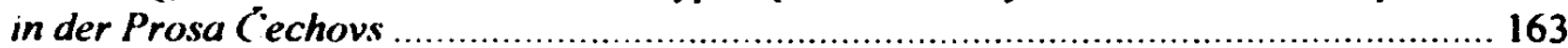

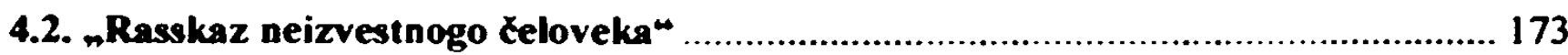

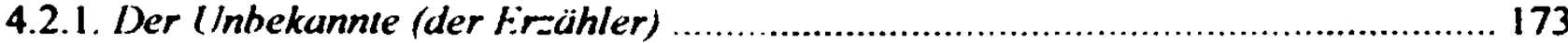

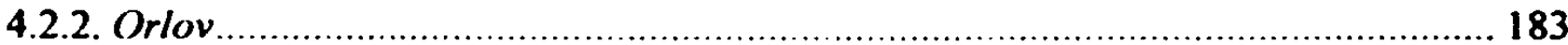

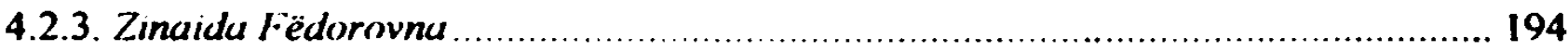

4.3. Spielarten des Modus V: Von ${ }_{n} O$ drame$^{\star}$ zu $_{n}$ Bab'e carstvo $\ldots \ldots \ldots \ldots \ldots \ldots \ldots \ldots . . . .205$

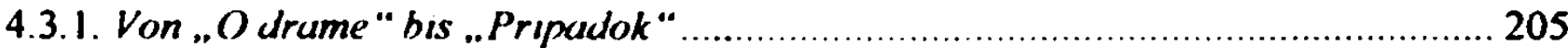

4.3.2. "Buh 'e carstvo": Zwischen der literurischen Selbstinszenierung und

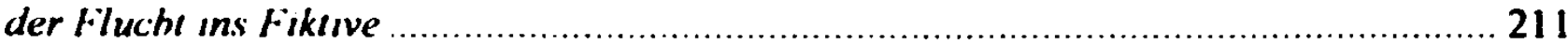

5. Zusammenfassung 222

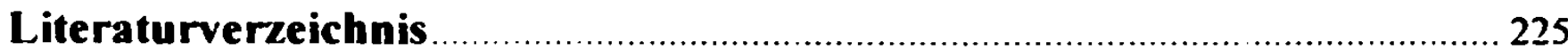





\section{Einleitung}

Ziel dieser Arbeit ist, die wenig erforschten intertextuellen Kontakte im Prosawerk Anton Čechovs zu untersuchen bzw. die intertextuellen Bezüge, auf die die Čechovforscher bereits aufmerksam geworden sind, systematischer und vollständiger darzustellen. Methodisch setzen wir uns zum Ziel, die Bedeutung und die Funktion einzelner "materieller"l Verweise wie Zitate und Allusionen in verschiedenen Texten und Texttypen bei Čechov zu ermitteln (d.h. im Ganzen die Funktion bestimmter Intertextualitäıssignale ${ }^{2}$, wie sie in Form von Allusion oder Zitat an der Oberfläche des Textes ${ }^{3}$ erscheinen, werkübergreifend zu untersuchen).

Im zweiten Kapitel werden zuerst theoretische Konzepte, auf die wir im weiteren, bei der Analyse Cechovscher Texte zurückgreifen werden, vorgestellt (Kap. 2.1.); danach wird der Forschungsstand kritisch aufgearbeitet, d.h. die wesentlichen Beitrăge zur Intertextualităt im Werk Cechovs (Kap. 2.2.).

Im Kapitel 2.1. wollen wir nicht nur diverse theoretische Ansätze im Bereich der Intertextualitat (die wir recht breit auffassen: als Arbeiten, die sich auf theoretischer Ebene mit "TextText-Bezügen “4 beschäftigt haben, auch noch vor der Entstehung des Begriffs ..Intertextualităt"), sondern auch zusammenfassend die Geschichte dieses in den 1960er Jahren eingeführten Begriffs und der Intertextualitătsdiskussion vorstellen. Darüber hinaus wollen wir die Aussagen der Theoretiker zum Phänomen der Intertextualität an sich, z.B. zu ihren formalen Komponenten sowie den semantischen Aspekten, anführen. Bei den Konzepten innerhalb der Intertextualitätstheorie, die uns bei der Textarbeit behilflich sind, handelt es sich um konkrete Bezeichnungen, Modelle und Kategorien, wie beispielsweise die generalisierenden Begriffe Genettes (Hyper-, Para- oder Architext); Lachmanns - ..Similaritäts-“ und ..Kontiguitătsbeziehungen" zwischen Texten oder Pletts ..material - structural Intertextuality": um die Opposition, die Broich als „Einzeltext-“ und .,Systemreferenz“ definiert: die systematischen Untersuchungen Pletts zum Verhältnis des zitierten Segments zu seinem neuen Kontext oder um die Typologie der fiktiven Leser bei Stückrath. Die Allusionsforschung, die wir im betreffenden Kapitel heranzichen. hat uns z.B. geholfen, bestimmte Allusionsformen in der Prosa Čechovs als solche zu erkennen und Allusionen bei ihm im allyemeinen differenzienter und hewußter zu untersuchen (s. am Ende des Kap. 2.1. und Kap. 2.1.1). Wetterhin haben wir hier die Beiträge vorgestellt und erörtert. die verschiedene Erscheinungsformen und Tỵpen

\footnotetext{
'Vyl den Begrifi bei Plett auf'S 28 dieser Arbeit. hinzu Fußn 152

"S die Wortverwendung u a bei Hebel (..intertextual signals". 1991. S 14j) . Is Interteviualitatssignale. von denen im Kap 21 noch gesprochen wird. bezeichnen wir in unserer. Arbeil ..punktuelle* (s den lusdruch $u$ a hei Plister - z.B 1985a. S 28) Venweise wie Zitate und Allusionen seltst. unathangig das on. wic und oh sie graphisch. stilistisch oder anders markiert sind Das Element. das von uns als dem freniden Tevte rugehoriz identifiziert wird. stellt fur uns auch ein ..Signal" fur die Prasenz dieses fremden Textes dar. $d \mathrm{~h}$ eine Art .. Markierung. der Intentextualitat (s daruber auf S 31-32 dieser Arbeit), und veranlaßt uns, eine versteichende 1 mersuchung cinzuleiten

'Lachmann spricht z B von der Intertextualitat, die ..die Textoberflache oreanisiert" ( / (mo. S s?)

'S den Ausdruch bei Lachmann (1990. S 69)
} 
der "Texte zweiten Grades“ (Genette, s. darüber im Kap. 2.1. und 2.1.2.) wie Parodien, Travestien, Pastiches, Kontrafakturen u.a. differenzierend behandeln. Mit ihrer Hilfe wollten wir verschiedene Typen der ,Zweitgradigen“ Texte im (frühen) Werk Cechovs aufdecken und die Funktion einzelner Verweise in ihrem spezifischen Kontext deuten.

Im Kap. 2.2. haben wir versucht, die einschlägigen Beiträge (die Beiträge zu den TextText-Beziehungen im Werk Cechovs) nach den Aspekten der intertextuellen Kontakte, die wir in ihnen (als deren Gegenstand) hervorgehoben haben, aufzuteilen (wenn auch die zwischen verschiedenen Gruppen gesetzten Grenzen oft nur sehr relativ sind). Im darauf folgenden Kapitel „Das Erkenntnisinteresse der Arbeit” (2.3.) formulieren wir dann unsere Ziele und Absichten, u.a. im Verhältnis zu den vorhin vorgestellten Beiträgen anderer Cechovforscher. Für uns haben sich im allgemeinen diejenigen Arbeiten als anregend enwiesen, die die vergleichende Analyse des aktuellen und des Prätextes ${ }^{5}$ in einem deutlicheren Maße aus der Funktion punktueller Verweise auf diesen Prätext wie Zitate und Allusionen entfalten und solche konkreten wörtlichen intertextuellen Verweise mitunter auch zum Titelthema machen. ${ }^{6}$

Im Kap. 3 wenden wir uns den punktuellen Verweisen im Kontext jener Kurzgeschichten Cechovs zu, die wir bei ihm als ..Texte zweiten Grades“ interpretieren; dabei verfolgen wir das Ziel, gestützt auf die in den vorigen Abschnitten der Arbeit ausgewăhlten theoretischen Ansätze (Kap. 2.1.2.), unterschiedliche Arten solcher ,abgewandelten“ Texte im früheren Werk Cechovs zu ermitteln. So haben wir eine affirmative Nachahmung bestimmter Referenztexte (.Za jabločki“ (Wegen den Äpfelchen $\left.{ }^{7}\right)$ ), eine Parodie (,Zagadočnaja natura“ (Eine rätselhafte Natur) und zwei Kontrafakturen („Torżestvo pobeditelja“" (Der Triumph des Siegers) und ..Šilo v meške" (Die Nadel im Sack ${ }^{x}$ )) bei ihm untersucht.

Das 4. Kapitel haben wir den punktuellen Verweisen im Kontext einiger, von uns nicht als abgeleitet interpretierter" späterer Prosatexte Cechovs gewidmet, wobei wir uns auf die intertextuellen Bezüge konzentrieren. die in solchen Werken im Bewußtseinsfeld fiktiver Perso-

\footnotetext{
"S uber die Verwendung des Beyriffs ..Pratexl" z B bei Schmid 1983, S 143 (vgl auch in der Fußn 128)

"Wir werden in unseren Textanalysen dementsprechend jedes Mal Zitate und Allusionen ermitteln. die dann Korrespondenzen und Kontraste auf verschiedenen Ebenen der Geschichte bloßlegen und bestatigen. nach dieser Analyse wird von uns die Intertextualitat bei Cechov in einem gegebenen (Kon)text ggf als ..intersemantisches" Phanomen ausyelegt (wir stutzen uns $v$ a auf die Arteit von Schmid 1983, s bei ihm uber die .,interdiegetische Aquivalenz" (S. 34-35 dieser Arbeit) und uber ..Intersemantızitat" (auf $S 25$ dieser Arbeit)). einfach gesagt, es wird die Funktion der Verweisung im Ganzen interpretien

7 Russische Titel sind hier und im Weiteren transliterien und. falls zum ersten Mal erwahnt. ins Deutsche ubersetzt Lbersetzungen stammen. wenn nicht anders angegeben, von der V'erf

"In der im Weiteren zitierten L'bersetzung unter dem Titel..Der Sack hat ein Loch" s. Tsishechow Bd 1 (1949). S 178 Verweise auf die mehrbandigen Werkausgaben gestalien wir hier und im Weiteren folkenderınaßen zunachst uerden der Band. der das zitiente Werk enthalt. und in Klammern dessen E.rscheinungsjahr. dann die Seite angegetzen $\mathrm{Bel}$ den Werhsommlungen in Einzelbanden werden dementsprechend nur das Erscheinungsjahr und de Seite genannt Die nicht-wissenschaftliche Transliteration der russischen Namen und Titel kommt bei uns ausschließlich dann vor. uenn sic in den zitierten deutschen L'bersetzangen venvendet wird

"Wie das in dieser i,bent noch an eingen Stellen thematisien wird, verbinden wir das Phanomen einer literarischen ..Ableitung" is den Ausdruch bei (ienette. u a Fulin $3(n+$ dieser Arbeit) ausschließlich mit den Prosawerhen aus dem liruhiel ken Sichaflion Cechovs
} 
nen liegen, nach Broich also im ,inneren Kommunikationssystem “l0 untergebracht sind (es

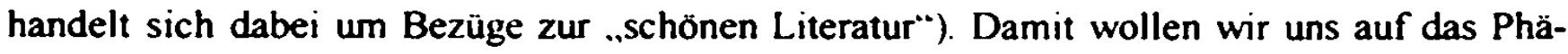
nomen der fiktiven Literaturrezeption beim späteren Cechov, auf das Thema der Wirkung von Fiktion auf die Protagonisten einlassen. Zwar begegnet man dem Phänomen der fiktiven literarischen Rezeption auch in den frühen ,abgeleiteten“ Texten, die den Gegenstand des vorangehenden Kapitels bilden, dort sind aber die intertextuellen Verweise im inneren Kommunikationssystem eine zusătzliche Komponente für den Aufbau einer Parodie oder einer Kontrafaktur, d.h. einer humoristischen Variante der Folie, sie sind also in einen anderen Kontext eingegliedert (s. darüber im Kap. 4.1.1.). Die ,.innerkommunikativen“ Bezüge in den anderen nicht .,abgeleiteten“ frühen humoristischen Texten Cechovs werden hier nicht zum Objekt spezieller Untersuchung.

In diesem (letzten) Kapitel ziehen wir zusätzlich einige Beiträge heran, deren Autoren sich mit dem Phänomen der fiktiv gestalteten literarischen Rezeption bzw. Lektüre anhand unterschiedlicher Texte der Weltliteratur befassen, z.B. eine Typologie der Leserfiguren aufstellen oder das Motiv der ..gelebten Literatur in der Literatur“" erforschen. Wir versuchen hier ebenfalls eine Typologie der Einstellungen Cechovscher Figuren zur Literatur bzw. der dominierenden Modi der fiktiven Literaturrezeption im Prosawerk Cechov zu erarbeiten (dabei beziehen wir in diese Typologie auch die frühere Prosa Cechovs ein). Unsere Ergebnisse vergleichen wir danach mit den Beobachtungen der erwähnten Autoren. Darüber hinaus verfolgen wir anhand einiger Texte die Entwicklung der fiktiven Literaturwahmehmung von den frühen zu den späteren Prosawerken Cechovs. Anschließend werden zum einen die Novelle ..Rasskaz neizvestnogo c̀eloveka“ (Erzählung eines Unbekannten'"), zum anderen ..Bab"e carstvo" (Weiberherrschaft ${ }^{12}$ ) analysiert, wobei wir die letzte in eine Gruppe von Texten Cechovs eingliedern, die vom Modus der in ihnen dargestellten Literaturrezeption her mit diesem Prosastück ..verwandt“' sind. Die Čechovschen Personen als Literaturrezipienten versuchen wir in den beiden Novellen jedes $\mathrm{Mal}$ in unsere Týpologie einzuordnen

Im Ganzen läßt sich sagen. daß die Intertextualität bei Čechov einen Charakter besitzt. den Schmid für die intertextuellen Relationen. soweit sie als Ausdruck der Dialogızitat Bachtins lungıeren'3, formuliert: Cechovs Texte bezichen sich auf dic Fremdrede ..eigenstandig" und ..aktiv..1t, sie demonstricren meistens auch eine sehr selbstbewußte und distanziente Haltung gegenüber dem Prätext. Dies äußert sich oft in den expliziten Refierenzen. dice nicht (oder schwer) zu übersehen sind (z.B die Allusionen. die ım Titel oder am Anfang des elụentlichen Textes markiert sind oder dicjenigen, die Autoren- und Protagonistennamen benennen. ebenfalls Aussagen und Diskussionen handelnder Personen über den Prätext. manchmal kombıniert mit dem Nacherzahlen von dessen Inhalt. so daß der Prätext also oflen angesprochen

\footnotetext{
${ }^{10} \mathrm{~S}$ auf S 30-31 dieser Arbeit

"Tschechow 1960. S. 190

12 In der im Weiteren zitierten ( bersetzung (Tschechow 1960. S 347 ) unter dem Titet II sberwirtshat?"

"Vgl S 22 dieser Arbeit
} 
wird), aber vielmehr und vor allem darin, daß die Texte Cechovs die evozierten Werke oft in hohem Grade reflektiv und selbständig behandeln, sei es als parodistische oder im Rahmen einer Kontrafaktur vollzogene Umschreibung einer Vorlage (was gerade die Aktivität des aktuellen Textes hervorhebt) oder als Gestaltung dessen, wie der Referenztext durch die handelnden Figuren rezipiert und verarbeitet wird (die Lokalisierung der intertextuellen Bezüge im Bewußtsein fiktiver Personen weist jedoch insbesondere dann auf eine bewußte und reflektiv-kritische Art der Verweisung auf den Prätext, wenn Diskrepanzen zwischen dem Rezipierten und dem Aktuellen hervortreten).

Wir ermitteln aber auch die Referenzen, die wir nicht ganz sicher als vom Autor intendierte intertextuelle Bezüge betrachten. Das sind Verweise, die für uns als Allusionen oder auch Zitate fungieren und die Im Cechovschen Text thematisch, graphisch und stilistisch ..aufgehen“, d.h. als „Fremdkorper”, als Elemente aus einem anderen Text im Gegensatz z.B. zu der Benennung eines Namen aus dem Prätext oder zu Zitaten mit der Benennung der Quelle oder zu Zitaten, die in einem stilistischen Kontrast zu ihrem neuen Kontext stehen, nur sehr schwach bzw. nicht markiert sind, die uns die Texte Cechovs jedoch ,bieten“, die wir im Prozeß deren Lektüre entdecken. 


\section{Theoretische Grundlagen und Stand der Forschung}

\subsection{Intertextualitătstheorie: Entstehungsgeschichte und Hauptkonzepte}

Ursprung und Entwicklung der Intertextualitätstheorie wurden in den letzten zwei Jahrzehnten bereits mehrfach zum Objekt literaturtheoretischer Reflexionen. ${ }^{15}$ Wir wollen hier unsererseits und mit Hilfe der Beiträge, die über die Intertextualitătstheorien reflektieren ${ }^{16}$, zusammenfassend Hauptphasen der Intertextualitätsdiskussion angehen und anschließend die für unser Vorhaben wichtigsten Ansätze im Rahmen der Intertextualitätstheorie erơrtern, so $\mathrm{da} B$ einerseits der theoretische Hintergrund unserer Arbeit ersichtlich wird und andererseits die Bezüge auf die heranzuziehenden Konzeptionen - durch einen in diesem Kapitel gebotenen Überblick - künftig erleichtert werden. ${ }^{17}$ Es läßt sich allerdings feststellen, daß aus der ganzen Menge einschlägiger Beitrăge kein einheitliches Verstăndnis und noch weniger eine allgemein geltende Theorie der Intertextualität herauszukristallisieren ist. „Intertextualität [...] bleibt aufgrund der zum Teil äußerst heterogenen Konzeptionen 'polyvalent', eine umfassende und allgemein verbindliche Intertextualitătstheorie ist [...] daher nicht zu erwarten, die Pluralităt von Theorien und Schulen zumeist divergierender Forschungsrichtungen stellt einen Konsens nicht in Aussicht," - lautet die charakteristische Schlußfolgerung eines Literaturwissenschaftlers. ${ }^{18}$ Dieses Fazit geht allmählich in Literaturgeschichtsschreibung und Lexika ein, die die Unterschiedlichkeit der einschlägigen Konzepte und Theorien als ..zentrales Problem aller Intertextualitätstheorien ${ }^{.19}$ bezeichnen. Aus der Sicht mancher Theoretiker deutet das auf eine der Grundeigenschaften des diesen Forschungen zugrunde liegenden Phănomens hin. .Polysemie“ wohnt der Intertextualităt selbst inne: ..[...] der Begriff erscheint vorerst nicht disziplinierbar, seine Polyvalenz irreduzibel" ${ }^{20}$ Ncch deutlicher wird die Idee der prinziptellen Unsystematisierbarkeit mtertextueller Erscheinungen in ihrer Gesamtheit im Vorwort zum im Jahre 1982 veröffentlichen Sammelband ..Dialogizität" formuliert: ..[...] der [...] Begriff der inter/cx/ualıe' [...] entzieht sich akademıscher Zähmung. geht nicht glatt auf weder in einer konsistenten Texttheorie noch in einer svstematischen Analyse.."il

\footnotetext{
"Uber die Geschichte und Konzepte der Intertextualitatstheorie, $u$ a uber die Ideen und Theorien solcher Autoren wie Bachtin, Kristeva. Barthes $s$ z B bes Lachmann 1982b. S 51-62, 1990, S 126-199. (irubel 1983. S 208222. Pfister 1985a.S 1-24. Still Worton 1990. S 15-29. Friednan 1491. S 146-101. Plett 1991. S 3-5. Holthuis 1993. S 12-28. 43-50. Muller 1994. S 147-165. Aczel 1998. S 241-243 S die Aullistung der einschlagigen Arbeiten u a auch hei Greber 1989. S 2-3

is $\mathrm{S} u$ a in der Fußn 15

"Wir wollen gleich am Anfang anmerken, daß wir hier - im Kap 21 - obgleich uir im toulıenden dic Entstehung und den historischen Rahmen des Intertextualitatshegrifts und der Intertevtualitatstheoric nuskicen moch-

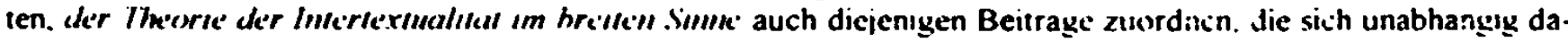
von und ganz allgemein mit den Beziehungen zwischen den Texten betassen (u a tersprelsweise diẹenizen. die noch vor der Entstehung des Beyriffs. Internextualitat" verfaßt wurden)

"Holthuis 1993, S 26

19 Aczel 1998. S 242

${ }^{20}$ Lachmann 1990 . S 56

${ }^{21}$ Lachmann 1982a. S. 9 S uber die Ansichten Lachmanns dieshezuglich bet llolthuis $1(x)$ i. $S$ :0
} 
Der Überblick über die einschlägigen Beiträge läßt jedoch darauf schließen, daß die Vielfalt der Intertextualitătskonzepte nicht notwendigerweise ihre Unkompatibilităt bedeutet: neben den Entwürfen, die sich gegenseitig beinahe ausschließen bzw. zueinander in deutlichem Widerspruch stehen, wurden (vorwiegend in den letzten 20 Jahren) Ansätze geschaffen, die sich nicht nur gut vertragen, sondern einander auf eine durchaus plausible Art ergänzen und bereichern.

Die Theorie der Intertextualität nimmt ihren Anfang in den Arbeiten Michail Bachtins, ohne daß der Begriff "Intertextualităt" in ihnen erscheint und bevor der Terminus in die literaturtheoretische Diskussion überhaupt eingebracht wird. ${ }^{22}$ In seiner Arbeit „Problemy poetiki Dostoevskogo“ (Probleme der Poetik Dostoevskijs) (erste Ausgabe unter dem Titel „Problemy tvorčestva Dostoevskogo“ (Probleme des Schaffens Dostoevskijs) (1929)) bezeichnet Bachtin eine Disziplin, die die Grundlage seiner Untersuchungen bilden soll und die für ihn einen Gegensatz zu der klassischen Linguistik bildet, als „.Metalinguistik“. Metalinguistik soll „dialogische Beziehungen“ der Sprache (d. h. des einzelnen Wortes, „wenn es nicht als unpersönliches Wort der Sprache, sondern als Zeichen eines fremden Standpunktes“ (,знак чужой смысловой позиции“..23), ,als Vertreter einer fremden Äußerung aufgenommen wird ${ }^{\text {.24 }}$ oder aber auch eines Stils oder der Soziolekte, wenn sie als ..sprachliche Weltanschauungen" auftreten) zu erforschen:

Стилистика должна опираться не только и даже не столько на лингвистику, сколько на металингвистику, изучающую слово не в системе языка и не в изъттом из диалогического общения „тексте“, а именно в самой сфере диалогического общения, то есть в сфере подлинной жизни слова. Слово не вещь, а вечно подвижная, вечно изменчивая среда диалогческого общения. („Die Stilistik sol] sich nicht nur, vor allem nıcht so sehr auf die Linguistik, als vielmehr auf die Metalingusssik stützen, die das Wort nicht im System der Sprache und an einem 'Text' studiert, der aus der dialogischen Kommunikation herausgenommen ist, sondern gerade im Bereich dieser Kommunikation selbst, d.h. im echten Lebensbereich des Wortes. Das Wort ist keine Sache, sondern das ewig bewegliche, ewig veränderliche Medium der dialogischen Kommunikation. $\left.{ }^{.25}\right)^{26}$

Zum Gegenstand seiner Untersuchung macht Bachtin das ,.zweistimmige Wort”, das die traditionelle Sprachwissenschaft nicht kennt. Dieses zweistimmige, ..durch die Berürung mit

\footnotetext{
$22 \mathrm{Vgl}$. unten uber die Interpretation Bachtins durch Kristeva

23 Bachtin 1972. S 314

24 Bachtin 1971, S 205

2s Bachtin 1971, S. 225

26 Bachtin 1972. S 345-346
} 
dem 'fremden' entstehende ${ }^{، 27}$ Wort geht in einen offenen und unabschließbaren Dialog sowohl zwischen verschiedenen sozialen Dialekten als auch im literarischen Text ein:

Когда нет своего собственного .,последнего“ слова, всякий творческий замысел, всякая мысль, чувство, переживание должны преломляться сквозь среду чужого слова, чужого стиля, чужой манеры, с которыми нельзя непосредственно слиться без оговорки, без дистанция, без преломления. („Wenn es das eigene 'letzte' Wort nicht gibt, so muß jeder schöpferische Plan, jeder Gedanke, jedes Gefühl und jedes Erlebnis im Medium eines fremden Wortes, eines fremden Stils, einer fremden Manier gebrochen werden, mit denen man nicht ohne Vorbehalt. ohne Distanz, ohne Brechung unmittelbar übereinstimmen kann. $\left.{ }^{.28}\right)^{29}$

In der Prosa bildet Bachtin vier Formen heraus, die ..ihrer Natur nach“ metalinguistisch sind, d.h. ein zugleich auf den Gegenstand der Erzăhlung und auf die fremde Rede gerichtetes Wort zur Grundlage haben: Stilisierung, Parodie, Skaz. und Dialog. Der zweite Kontext, der in diesen Prosaformen anwesend ist, ist für sie sinnkonstitutiv: „Если мы не знаем о существования этого второго контекста чужой речи [...], то мы не поймём этих явлений по существу: стилизация будет воспринята нами как стиль, пародия - просто как плохое пронзведение.“ (.,Wenn wir von der Existenz dieses zweiten Kontextes der fremden Rede nichts wissen [...], dann erfassen wir das Wesen dieser Erscheinungen nicht: wir begreifen die Stilisienung als Stil, die Parodie als mißlungenes Werk.."31) $)^{31}$..Doppelgerichtete“ (.двояко направленные“) Wörter unterscheiden sich grundsätzlich von den ..einstimmigen“, die in Bachtins Klassitikation zwei Erscheinungsarten annehmen können: das direkt auf ..das außerprachliche Referenzobjekt bezogene..32 Wort. z.B. das Wort des Autors - das .,benennende, mitteilende, ausdrückende oder darstellende ${ }^{.33}$ - und das objekthafte, dargestellte Wort (L.B. das mitunter der auktorialen Instanz und Intention vollkommen und ganz untergeordnete Wort der Figuren. Der Konflikt verschiedener Figurenpositionen führ dabei keineswegs zur Abschaffung des monologischen Kontexts, denn eine sich unter den fiktiven Personen ereignende Auseinandersetzung bleibt objekthaft und ist mit dem Konflikt selbstandiger, mit der des Autors gleichberechtigter Sinnpositionen nicht gleichzusetzen). Zwischen dem ersten und dem zweiten Typ des einstimmigen Wortes in einem Errählwerk vollzieht sich keın Dialog. ..Объектное слово [...] яв:ıется предметом чужой авторской направленности. Но

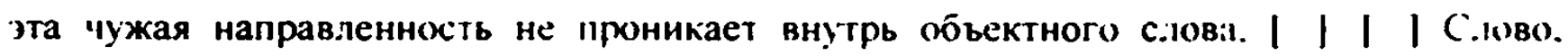

\footnotetext{
27 Lachmann 1982b. S. 51

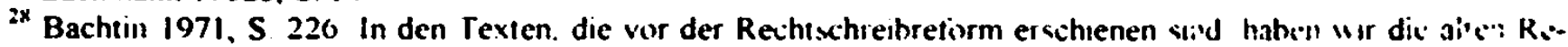
yeln der Rechtschreibung beibehaiten

Bachtin 1972. \& 346-347

"Br" Bachtin 197i. S 206

"Bachtin 1972. S 316

12 Grubel 1983. S 210
} 
ставшее объектом, само как бы не знает об этом, [...].“ (,Das Objekt-Wort ist [...] Gegenstand der fremden Intention des Autors. Aber diese fremde Intention dringt nicht in das $\mathrm{Ob}$ jekt-Wort hinein, [...]. [...] Das Wort, das zum Objekt geworden ist, weiß gleichsam selbst nichts davon, $\left.[\ldots] .{ }^{343}\right){ }^{35}$ Im zweistimmigen Wort werden dagegen zwei gleichberechtigte Sinnpositionen spürbar. Beispielsweise benützt Stilisierung den fremden Standpunkt, wodurch der letzte relativiert wird. Stilisierung sieht Bachtin im Gegensatz zur Imitation, die das Imitierte „aneignet" und verinnerlicht. ${ }^{36}$

Zweistimmige Wörter werden in der Bachtinschen Typologie weiter differenziert: Stilisierung und Skaz zB. unterscheiden sich von den anderen Formen gleichen Typus durch ein gemeinsames Merkmal: die auktoriale Ebene und das fremde Wort geraten nicht aneinander, sie bewegen sich in dieselbe Richtung, während in der Parodie beide präsenten Stimmen gegeneinander kämpfen, entgegengesetzt sind und in der Dialogreplik oder aber auch in der versteckten Polemik die fremde Rede auf verschiedene Art und Weise das Wort des Autors beeinflußt und sogar bestimmt.

In einer anderen Schrift ,.Slovo v romane“ (Das Wort im Roman) (verfaßt 1934-35, erste Ausgabe 1975) zieht Bachtin zwischen dem poetischen (im Grunde zum Monologischen tendierenden) und prosaischen (insbesondere dem des Romans, also offenen, zum Dialog fahigen) Wort eine Grenze. ${ }^{37}$ Der Prosaiker öfnet seine Sprache ,fremden Wörtern, Wertungen und Akzenten ${ }^{.38}$, vor allem aber läßt er die „Redevielfalt“39 (..pазноречне“) der Epoche in seinen Text "hineinstürmen“, so daß seine eigene Stimme nur noch vor dem Hintergrund anderer Stimmen zu hören ist. Wenn das poetische Wort direkt auf seinen Gegenstand gerichtet ist (vgl. Lachmann: „ein Wort, das nur auf sich selbst Rücksicht nimmt ${ }^{40}$ ), entfaltet sich die prosaische Sprache und damit die prosaische Gestalt an der Grenzlinie zwischen dem Eigenen und dem Fremden: „Предмет для прозаика - сосредоточение разноречивых голосов, [...].“ („Für den Prosaschriftsteller ist der Gegenstand eine Konzentration von in der Rede differenzierten Stimmen, $\left.[\ldots] .{ }^{411}\right)^{42}$. Demzufolge versteht Bachtin die poetische Sprache

\footnotetext{
33 Bachtin 1971, S 208

Bachtin 1971, S 211

3s Bachtin 1972. S 323

36 $\mathrm{Vgl}$ dazu Kristeva uber Bachtin (1972. S. 356)

37 Diese Unterscheidung wurde von Bachtin bereits in .Problemy poetiki Dostoevskogo" getroffen .Возможность употреблять в плоскости одного пронзведения слова разных типов в их резкой выраженности без приведения к одному знаменателю - одна из существеннейших особенностей прозы. В этом глубокое отличие прозаического стиля от поэтического“ (.Die Moglichkeit, im Rahmen eines Werkes Worte verschiedener Typen in aller ihrer Schäre ohne Reduktion aut einen Nenner zu gebrauchen, ist eine der wesentlichsten Besonderheiten der Prosa Darin unterscheidet sich der Prosastil erheblich vom poetischen Stil * (Bachtin 1971. S 223)) (Bachtin 1972, S 342).

${ }^{1 *}$ Bachtin 1979. S 169

"Vgl Bachtin 1979, S 192

*' Lachmann 1982b. S. $58 \mathrm{Vgl}$ dazu noch Stıll Worton "Bakhtin distinguishes between double-voiced discourse

I I and poetic or thetorical tropes" (1990.S 16)

"Bachtin 1979. S 171

42 Bachtin 1975. S. 92
} 
als ,autoritär, dogmatisch und konservativ“"43, als eine „einheitliche und einzige ptolemăische Welt“"t4. Im Rahmen der Romangattung ist die innere Dialogizität der Sprache am deutlichsten zu spüren. ${ }^{45}$

Der Übergang vom Bachtinschen Dialogizitătskonzept zum von Julia Kristeva in den 1960er Jahren aufgestellten Konzept der Intertextualität scheint kaum direkt und selbstverständlich, gleichzeitig aber auch keineswegs zufällig zu sein. Kristeva übernimmt zwar wesentliche Aspekte der Konzeption Bachtins, interpretiert sie aber auf eine sehr eigenständige Weise, was zu erheblichen Modifikationen der Bachtinschen Gedanken führt und manche Theoretiker dazu veranlaßt, nicht nur eine scharfe Trennungslinie zwischen den Ideen der beiden Autoren zu ziehen, sondern sie - zumindest zu einem bestimmten Grad - als gegensätzlich zu betrachten. So resümiert M. Pfister seine Analyse der Bachtinschen Theorie folgendermaßen: „Es wurde deutlich, daß Bachtins Konzept der Dialogizität vor allem auf den Dialog der Stimmen innerhalb eines einzelnen Textes oder einer einzelnen Äußerung abzielt. [...]. Demgegenüber erscheint der Bezug der einzelnen Stimmen im Text auf vorgegebene, und damit gerade jener Bezug, auf den die Intertextualitàtsdiskussion abheben ivird, in seiner Analyse als sekundär. Damit ist Bachtins Theorie dominant intratextuell, nicht intertextuell." ${ }^{\text {th }}$ Gerade zwischentextuelle Beziehungen - das, was den Kempunkt der Kristevaschen Ausführungen insbesondere und der später entstandenen Intertextualitătskonzepte im Ganzen ausmacht - spielen in Arbeiten Bachtins, nach Pfister, eine eher geringe Rolle. Andere Theoretiker begreifen dagegen Bachtins Ideen im Sinne und in Termini ihrer poststrukturalistischen Auslegungen. wenn sie von der ..Leugnung der Vorstellung eines autonomen Ich" oder von der prinzipiellen Relativierung der Sinnhaftigkeit in der Auffassung Bachtins sprechen. ${ }^{+7}$ Zweifellos scheint jedoch zu sein, daß Kristeva die Gedanken Bachtins mehr als Ausgangspunkt für ihre eigenen theoretischen Ansätze empfunden hat.

Im Aufsatz ..Bakhtine, le mot. le dialogue et le roman“ $(1967)^{\text {t8 }}$ setzt Kristeva Studien Bachtins der Praxis der ..statıschen Zerlegung der Texte“ entgegen ${ }^{+9}$ : Bachtin war nämlich einer der ersten, der das Modell der ..sich erst aus der Beziehung zu einer anderen Struktur herstellenden" literanschen Struklur angeboten hat, das Modell, in der ..das 'literarische Wort' nicht ein Punkt (nicht eın feststehender Sinn) ist. sondern eine Ciberlagerung von Text-F.be-

\footnotetext{
${ }^{43}$ Bachtin 1979. S 179

thid S 178

"S Vyl die Ausfuhrungen von L.achmann ..Bachtin hat in Dostse' skijs Romanen. die er in ciner his in die . Intıhe zuruckreichenden Tradition einet Gattung schen will die Strukturprinzipien des polemischen Dialogs cier Menippeischen Satire ebens) aufgenommen hat wie Formen des in die Prosabiteratur eingedrungenen Karnevals. die D:alogizitat als Konstruktionsprinzip untersucht. I ]“" (1982b. S 52) und von Pfister uber Bachtin Der new/eitliche 'dialogische' Roman ( I nimmt von Rabelais bis Dostoel skij das subversive Potentıal der M/enıppeisiher: Siltire und des Karnevalesken in sich auf. [ ]." (1985a. S 3)

to Pfister 1985a. S 4 S auch bei Muller 1994 (S 152-153), die in ihrer Darstellung des Kristevaschen Ku:n:epts sich ebenfalls auf Pfister bezieht

$\$$ Volkmann 1998 , S. 32

${ }^{1 x}$ Zum ersten Mal erschienen in Critique XXIII. 1967
}

"Kristeva 1972, S 3.16 
nen“, eine "Überschneidung von Wörtern (von Texten), in der sich zumindest ein anderes Wort (ein anderer Text) lesen läßt. ${ }^{\text {so }}$ Ein wichtiger Punkt, in dem sich die Konzeption Kristevas von der Bachtins unterscheidet, betrifft die Ersetzung des Begriffs „Stimme“ (und der mit ihm verbundenen Begriffe des ein-/ zweistimmigen Wortes) durch den Begriff "Text" und folglich die Umwandlung des Begriffs „Dialogizitat" in den s:Intertextualităt”. Darüber hinaus hebt Kristeva die für die Bachtinsche Theorie entscheidende Opposition „prosaisches - poetisches Wort" auf, indem sie die Fähigkeit zur Aufnahme fremder Wörter und Texte mit der Literatur im Ganzen verbindet. ${ }^{\text {st }}$ Ihre bekannte Formulierung lautet: ,[...] jeder Text baut sich als Mosaik von Zitaten auf, jeder Text ist Absorption und Transformation eines anderen Textes. An die Stelle des Begriffs der Intersubjektivität tritt der Begriff der Intertextualităt, und die poetische Sprache läßt sich zumindest als eine doppelte lesen. ${ }^{.52}$ Kristeva verabschiedet damit die Vorstellung Bachtins über das auf allen Ebenen des Kunstwerkes anwesende und ständig zu spürende Autorbewußtsein. Der Text befreit sıch von seinem Schöpfer, der, wie Pfister schreibt, ,zum bloßen Projektionsraum des intertextuellen Spiels“ wird. „während die Produktivităt auf den Text selbst übergeht ${ }^{.53}$. Diese Produktivität manifestiert sich gerade im Vermogen, zum Gesamtkorpus anderer Texte Bezug zu nehmen und aus ihnen seinen Sinn zu schöpfen. Das Subjekt der Erzählung (d.h. der Autor) wird, nach der radikalen Formulierung Kristevas, ,zur Anonymität, zur Abwesenheit, zur Lücke ${ }^{\text {c.54 }}$.

Neben der Dekonstruktion der Rolle des Autors als Schöpfer eines literarischen Werkes und der Erweiterung der Gruppe von Phänomenen, die mit der Dialogizität vs. Intertextualität verknüpf sind, auf alle Texte schlechthin, konzentriert sich Kristeva, wie Pfister bereits festgestellt hat, primär auf die Beziehungen eines literarischen Textes zum anderen. die bei Bachtin als eine der vielen möglichen Dialogarten fungieren. Insofern kann man ihr konzept als ..eine Verengung gegenüber Bachtin."55 deuten. Jedoch werden in den Arbeiten von Kristeva - infolge ihres extrem erweiterten Textverständnisses - als Texte auch Erscheinungen betrachtet, die mit dem Bereich des Textuellen im Bachtinschen Sinne nicht verknüpft sind. ${ }^{\text {ss }}$

In einigen seiner Ende der 1960er und Anfang der 1970er Jahre entstandenen literaturkritischen Essays verbindet Roland Barthes in Analogie zu Kristeva den Rücktritt des Autors als Vater und Urheber seines Werkes mit der Befreiung des (Inter)textes. In ..La mort de

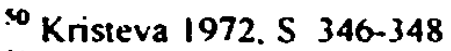

"Zur Transformation des Dialogizitatskonzepts Bachtins in der Interpretation Kristevas s. u a Analysen von Grubel 1983, S 220-222. Pfister 198.5a. S 6-11. Still W'onton 1990, S 16-18. Holthuis 1993, S 14-15, Muller 1994, S 152-154 - die Beitrage, auf die wir uns hier auch stutzen

$\$ 2$ Kristeva 1972. S 348

"3 Pfister 1985. S 8

"Kristeva 1972. S 358

35 Pfister 1985a. S 6-7

36 Zum Textbegriff bei Kristeva S. Pfister 1985a, S 7.8 Zum Textserstandnis franzosischer Theoretiker der Intertextualitat vgl auch die Bemerkung von Torop ..Франузскую исследовательскую традииию характеpи зует свосто рода пантекстуализм" (Franzosische Forschungstradition charakterisien eine An Pantextualismus) und weiter. S 34-35 (1981)
} 
l'auteur" postuliert er eine absolute Selbständigkeit des Schreibens gegenüber dem Schreibenden: Sobald die Stimme sich von ihrem Ursprung lost, stirbt der Autor und beginnt das Schreiben. In diesem Sinne unterscheidet Barthes zwischen dem (traditionellen) Autor und dem .,Schreiber“: der erste wird herkömmlicherweise als seinem Buch gegenüber vorausgehend empfunden (.,The Author, wenn believed in, is always conceived of as the past of his own book: [...]. ${ }^{.57}$ ); der zweite existiert dagegen nur in seinem Text, dem er sich unterwirft: .....], the modern scriptor is bom simultaneously with the text, is in no way equipped with a being preceding or exceeding the writing, [...].". 5.3 Der Text stellt insofern ein Zeichenfeld dar, das keine andere Herkunft hat als die Sprache selbst. Und gerade weil es niemanden mehr gibt, der dem Text den endgültigen und verbindlichen Sinn verleihen würde, gewinnt er seine Offenheit zurück, d.h. wird zum Raum, in dem andere Texte aufeinander treffen. Jeder Text ist deshalb zugleich ein Intertext: „The text is a tissue of quotations drawn from the innumerable centres of culture. ${ }^{.59}$ Intertext bedeutet damit einen beweglichen Textsinn, der sich der Analyse entzieht, was mit der ..Logik der Abstände, der Relationen, der Analogien, der nicht-ausschließenden und transfiniten Gegensătze “ ${ }^{c 0}$ bei Kristeva korrespondiert.

Die Opposition ..Autor - Schreiber“ wird in ..De l'cuuve au texte“ in eine „Werk - Text“ transformiert, wobei das Werk dem Autor und der Text dem Schreiber zuzuordnen wăren. Das Werk gehört seinem Autor, befindet sich in einem chronologischen Verhältnis zu anderen Werken und wird von der Realität bestimmt, es läßt sich mit einem sich natürlich entwickelnden Organismus vergleichen. Der Text hat keinen „Vater“, verweist ausschließlich auf andere Texte bzw. auf die Sprachen der Kultur und ist im Gegensatz zum Werk semantisch prinzipiell unabschließbar (.,The Text is plural. [...] it accomplishes the very plurality of meaning: an irreducıhle [... | plural. ${ }^{.61}$ ). Eine geeignete Metapher für ihn ist das Netz, denn .,if the Text extends itself, it is as a result of a combinatory systematic [...]. Hence no vital 'respect' is due to the Text: it can be hroken [... ...62 Intertextuelle Lektüre bildet für Barthes ein Gegenstück zur Suche nach Quellen und der Ermittlung moglicher Einflüsse: Zitate, aus denen der Text besteht. sind anonym (..quotations without inverted commas....3)

M. Geier bezeichnet in seiner im Jahre 1985 verfaßten Monographie ..Die Schrift und die Tradition. Studien zur Intertextualităt" das Textuelle als Geflecht von ..Schon-Gesagtem". von ..Vor-Konstruiertem“ und als ..Nach-Rede..'地. Er verknüpti die Intertextualităt mit der fèhlenden Homogenität und Selbständigkeit ..eigener Rede“, die ... in threr Autonomıe autgelöst und beinahe sich selber fremd ${ }^{. \cdots 5}$ wird.

\footnotetext{
Barthes 1989a, S 116

st lbid

99 Ibid

wristeva 1972. S 370

-1 Barhes 1989b. S 168

"2 lbid S 170

10.3 Ibid S 169

on Geier 1985. S 10

".s Ibid
} 
Mit Rückgriff u.a. auf Jean Starobinskijs Interpretation Saussurescher Anagramm-Studien $^{66}$ behauptet Geier eine nicht authebbare Pluralität und das Zersplittertsein des Textes: „[...] das 'Inter-Textuelle' [...] zeigt den Text als einen Körper diskursiver Spuren, die ihn vielschichtig werden lassen, mehrstimmig, plural. “67

Der Gedanke an den Text, der, von fremden Wörtern und Stimmen durchdrungen, seine semantische Identität einbüßt, verbindet Geier bis zu einem gewissen Grade mit $\mathbf{H}$. Plett: für den letzteren ist der Intertext vor allem ein Text, der sich selbst übersteigt, über seine eigenen Grenzen hinausragt: "An intertext [...] is characterized by attributes that exceed it. It is not delimited, but de-limited, for its constituens refer to constituens of one or several other texts. ${ }^{.68}$

Sowohl Geier als auch Plett unterscheiden zwischen dem Text, der primăr als "Intratext", d.h. als ,Jineare Verkettung von Signifikanten“ und ..geregelter Zusammenhang sprachlicher Elemente ${ }^{669}$ oder, bei Plett, ,as an autonomous sign structure, delimited and coherent ${ }^{\text {“70 }}$ betrachtet und erforscht wird, und dem, der auf das Intertextuelle befragt wird. Eine analoge Opposition bildet R. Lachmann, indem sie in bezug auf bestimmte Gedächtniskonzepte für die Aufdeckung des intertextuellen Potentials des Textes von einer Lektüreart spricht (artikuliert in diesen Konzepten), die einen .Entzifferungsprozeß in Gang setzt“. " Entziffert werden müssen „die Spuren, Verstrebungen. Schichtungen, Hŏhlungen, Einkerbungen, die die Arbeit [...] des verbergenden Verweises hinterlassen hat. ${ }^{72}$ Lachmann schreibt in diesem Kontext von dem sich dieser Lektüre ständig entziehenden, jeglicher Festlegung entweichenden, gleitenden Textsinn. ${ }^{73}$ Der Text als ..Gedächtnisraum“ nimmt am Prozeß des ..Immer-WiederSich-Neu- und Umschreibens einer Kultur. ${ }^{.74}$ teil; es wird die Gestalt eines ..immer wieder abschreitbaren Raumes“ vermittelt, ...in dem jeder neuc Text die quasi-toten Texte zur Renaissance bringt“. 75

Konzepte der Intertextualıtät, aufgestellt von französischen Theoretikern wie Kristeva oder Barthes, werden von den meısten Kritikern, die über die Positionen der Intertextualitätstheorie reflektieren, als ..radikal. ${ }^{76}$, ...entgrenzend ${ }^{.77}$, ..progressiv ${ }^{.78}$, ..universell-ontologisch“*79 apostrophien. Diese Auffassung argumentien meistens folgendermaßen. In den oben skiz-

\footnotetext{
"' L'ber die intertextuelle Auslegung Saussures in Starobinskijs ..Worter unter Wortern Die Anagramme Ferdinand de Saussures" (1980) s bei Lachmann 1990, S. 78-79

${ }^{67}$ Geier 1985. S 11

tos Plett 1991. S. 5

${ }^{69}$ Geier 1985, S 11

${ }^{20}$ Plett 1991. S. 5

"Lachmann 1990, S 49

$n$ Ibid

${ }^{73} \mathrm{Vgl}$ uber das Konzept Lachmanns bei Holthuis 1993. S 24-25

${ }^{74}$ Lachmann 1990, S 36

75 Ibid S 87

${ }^{76}$ Ptister 1985a. S 11

$\pi$ Muller 1994, $S$ 154

"Plett 1991, S 3 Plett meint jedoch cher ..Intertextualısten" (..Intertextualists"), die die Tradition franzosischer Poststrukturalisten fonsetzten bzw auf sie orientien sind
} 
zierten Beitrăgen sind alle Texte. Aktualisierungen eines anonymen und uneinholbaren Intertextes $^{\left({ }^{*}\right)}$, es gibt demzufolge „in der Kommunikation keine tabula rasa ${ }^{* 81}$; intertextuelle Bezüge werden darüber hinaus lediglich zur Tatsache erklärt und nie einzeln und konkret untersucht. Plett bezeichnet solche Ansätze als philosophisch orientient und mißt ihnen eine denkbar abstrakte Qualităt bei. ${ }^{82}$

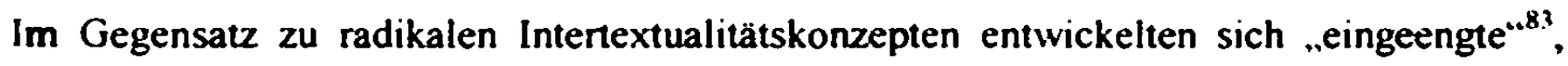
..eingrenzende ${ }^{\prime 84}$, ..textanalytische ${ }^{485}$ Ansätze, die sich von der ersten Gruppe dadurch abheben, daß sie Intertextualität in Form konkreter, „mehr oder weniger bewußter ${ }^{\text {.\$6 }}$ und im Text nachzuweisender Referenzen erforschen ${ }^{87}$ und vielfältige Formen und Typen der Verweise zu systematisieren versuchen. Diesen zwei Richtungen in der Intertextualitătsforschung liegen also unterschiedliche und, wie manche Kritiker glauben. mit einander nicht in Einklang zu bringende Intertextualitătsbegriffe zugrunde ${ }^{88}$. Sie entsprechen verschiedenen Aspekten des Bachtinschen Dialogizitätskonzepts nach der Klassifikation Lachmanns: Der erste. textontologische, ..meint eine generelle Dimension $[\ldots]$ miteinander korrespondierender Texte“, der zweite, textdeskriptive, „bietet [...] die Möglichkeit, Dialogizităt als spezifische Form der Sinnkonstitution von Texten zu beschreiben“, unter anderem auch .,den Dialog mit fremden Texten (Intertextualität) “. 89

Doch bevor ausgewăhlte Beiträge innerhalb der zweiten Gruppe vorgestellt werden, sei hier noch die Frage nach den Definitions- und Abgrenzungsmöglichkeiten des Intertextualitătsbegriffs aufgeworfen, denn hăufig bemühen sich die Theoretiker, die intenextuelle Erscheinungen differenziert und detaillien zu behandeln versuchen, um eine womöglich präzise und faßbare Definition dieses Phänomens und um dessen Einordnung in der terminologischen Landschaft der modemen Literaturwissenschaft.

Einigen Intertcxtualisten ist das noch in Barthes ..De l'cuvre au texte" manifestierte Bestreben gemeinsam, eigene Studien von denen der traditionellen Einflußforschung deutlich zu trennen. wobei Theoretiker wie z.B. Schmid und Peters ähnliche Argumente entwickeln (wenn J. Tynjanov zur Veranschaulichung seiner These der literarischen Kontinuität

\footnotetext{
Aczel 1998. S 242

*at Ibid

${ }^{\mathrm{x}} \mathrm{Pfister} 1985 \mathrm{~S}$. S 11

82 Plett 1991. S 4

${ }^{x 3}$ Pfister 1985a. $S 14$

"Muller 1994. S 154

8: Aczel 1998. S 243

*a. Pfister 1985a. $S$ is

${ }^{x 7} \mathrm{Vgl}$ dazu die Schlußfolgenung von Holthuis .Zentral ist in nahezu allen (tevanalutischen und koni reter .bundesrepublikanischen“ - K S.) Konzeptionen die Ruckführung auf einen restrikis en Intencrtualitaisbegritr. der nur jene Relationen zwischen Texten als intertextuell zulaBt. dic int Tevt tatsitchlich auch heleghar sind " (1993. S 23)

${ }^{* x}$ S z B die Stellungnahme von Aczel...So bleiben die awei Richtungen innerhalb der 1 theorre nicht nur prahtisch. sondern auch theoretisch unvere:nbar Wahiend die I thentie in ihrer tevtanalstisclien Inwen.lun! die i3czuge zwischen einzelnen Texten ermittelt und analysien. stellt sie in ihrer sprachontolugts hen tnwendung pect,adc die Grundlage einer sulchen Auswahl in Frage " (1998. S. 242-243)
}

"I.achmann 1982a. S 8 S danuber Pfister 1985a. S 14-15 
(,литературная преемственность“) als Kampf und Zerstörung des Alten demonstriert, daß Dostoevskij von Gogol' deshalb nicht beeinflußt wird, weil er auf Gogol'sche Werke offen zurückgreift (sie z.B. stilisiert), dann nimmt er diese Argumentation gewissermaßen vorweg $^{90}$ ). J.-U. Peters betont beispielsweise, wenn er über die Konzepte Žirmunskijs und Bachtins spricht, den in diesen Konzepten artikulierten Unterschied zwischen den fremden Texten als Quelle und als Ausgangspunkt (vgl. Tynjanovs „отправление, отталкивание or известной точки“.91 (Ausgehen, Loslösen von einem bestimmten Punkt)), .,vor dessen Hintergrund sich die Eigenart [...] der [...] neuen literarischen Tradition besonders differenziert abheben und beschreiben läßt“.92, er betont .,den Prozeß der Umakzentuierung“" (Bachtin) ${ }^{93}$, der bei der Kommunikation zwischen dem späteren Text und dem ..Referenztext ${ }^{* 44}$ in Gang kommt, und entfaltet seine Analyse aus diesen theoretischen Prămissen. ${ }^{95}$

W. Schmid - wenn er von der Intertextualität ,im Sinne der Bachtinschen ,Dialogizităt “..*\% spricht - setzt der Einflußforschung und Motivgeschichte, die den späteren Text eher als passiv und unselbständig gegenüber dem Prätext betrachten, die Position entgegen, bei der sich dieser spätere Text ..eigenständig[en], aktiv[en], [...], auf seine 'Vorlăufer' zurückverweisend[en] und deren Sinnpotentiale als Elemente der eigenen Konstruktion ausnutzend[en]. ${ }^{497}$ entfaltet ${ }^{98}$ In diesem Sinne ist auch die Aussage K. Stierles zu verstehen, nach der .jeder Text den hereingeholten Text zum Moment seiner eigenen Bewegung macht“*\%. Stierle artikuliert damit die Produktivität des aktuellen Textes, geht aber noch weiter, indem er die Autonomie des früheren Textes in Frage stellt: nicht der präsente Text ist auf den Bezugstext angewiesen, sondern der Bezugstext wird vom aktuellen Text in Besitz genommen und verarbeitet. Insofern verweigen Stierle intertextuellen Relationen die dialogische Dimension: ..Dialog setzt die Autonomie der Aktanten des Dialogs voraus. Gerade diese aber erscheint in der intertextuellen Relation aufgehoben.."I(x)

\footnotetext{
׳о .Н если вспомнить, хак охотно подчеркивает Достоевский Гоголя [ ]. ках слишком явно идет от него. не скрываясь, станет ясно. "то следует говорить скорее о стилизации. нежели о 'подражании', 'влиянии' и т д " (Und wenn man bedenkı, wie gerne Dostuevskij Gogol' hervorhebı [ ]. wic er zu offenbar von ihm ausgeht. ohne es zu verbergen, dann wird es offensichtlich. daß man eher von einer Stilisienung sprechen soltte, als von einer ..Imitation". einem ..EinfluB" u $s w)(1967$, S 415-416) Liber diese Schriti Tynjanovs s u a bei Grubel (1983. S 207)

"Tynjanov 1967. S 412

"2 Peters 1982. S 157

3 Ibid

"S den Begriff hei Lachmann 1990. S 60 (1gl auf S 24 unserer Arbeit)

"S Obwohl Peters hier der EinfluBforschung in erster Linte das Dialogizitatskonzept Bachtins entgegensetzt. wird Intertextualitat im Rahmen der dem Sammelband zugrunde liegenden Diskussion als Teil eines der drei Aspekte dieses Konzepts begriffen und damit in das Bachtinsche Modell integriert (s das Vonwort Lachmann 1982a, S 8) Peters stutzt sich dabet in seıner Argumentation nicht nur auf Bachtin und die vergleichenden Studien Żirmunskijs. sondern erwahnt auch Tynjanovs Theorie der literarischen Evolution (s. Peters 1982. S 156-157) Vgl dazu auch Lachmann uber die Parodietheonen Śklovskijs und Tynjanovs (1990. S 65-66)

*. Schmid 1983. S 143

"I Ibid

"* S daruber (u a uber die angefunne Ansichr von Schmid) auch bei Greber 1989. S 1-2

"Stierle 1984. $S$ 147

100 lbid
} 
Auch M. Riffaterre legt auf die Feststellung Wert, daß der Intertext keine Sammlung literarischer Werke ist, die einen Text möglicherweise beeinflußt haben, sondern „a corpus of texts, textual fragments, [...] that shares a lexicon and, to a lesser extent, a syntax with the text we are reading (directly or indirectly) in the form of synonyms or, even conversly, in the form of antonyms. " 101 Demzufolge lehnt Riffaterre - wie vorher Barthes - den Gedanken an die "genealogische“ Gebundenheit des neuen Textes an den alten ab; es geht bei ihm vielmehr um zwei (oder mehrere) unabhăngige Texte, die entweder bestimmte Ähnlichkeiten aufweisen oder in einem bestimmten Merkmal koritrastieren, wobei sowohl "synonymische“ als auch ,antonymische“ Beziehungen zumindest für den späteren Text sinnkonstitutiv sind.

Obwohl Harold Bloom in seinem bekannten Buch „The Anxiety of Influence" vom Phänomen eines Einflusses spricht, den die älteren Dichter (,,precursors“) auf die jüngeren ausüben, untersucht er gerade Formen „des Kampfes“ dieser letzteren gegen ihre Vorlăufer (,battle between strong equals, father and son “" ${ }^{102}$ ) oder, mit anderen Worten, Formen der Abweichung eines Poeten vom anderen. ${ }^{103}$ In diesem Sinne stehen Blooms Studien in deutlichem Gegensatz zu jener Einflußforschung, von der sich Peters und Schmid zu distanzieren suchen. In seiner psychoanalytisch konzipierten Theorie beschreibt Bloom insgesamt sechs revisionistische Gesten (.,revisionary movements“(104), mit denen die „Väter“ von ihren Söhnen überwältigt werden: Unter anderem sind das, nach der eigenständigen Terminologie Blooms, Clinamen (..corrective movement": wenn ein Dichter, nach der anfänglichen Einigung mit seinem Vorläufer, sich von ihm abhebt und einen anderen Weg weist); Tessera (.completion and antithesis": eine verneinende Vervollständigung oder Ergänzung des vorangegangenen Werkes, Änderung des Sinns unter Beibehaltung der Ausdrucksweise); Apophrades (wenn der Dichter, der die anderen Kampfphasen bereits hinter sich hat, sich dem Werk des Vorläufers auf die Weise offnet, daß es in sein eigenes Schaffen einbezogen, von ihm einverleibt wird).

Zusammen mit dem Problem der Abgrenzung der Intertextualität von verwandten bzw. ähnlichen literarischen Phänomenen wird meıstens auch die Frage erörtert, wie sich Intertext überhaupt definieren läßt, welche minimalen Bedingungen für die Verwirklichung des intertextuellen Verweises notwendig sind und woran der Kontakt eines Textes mit dem anderen erkennbar wird.

Dic Intertextualität kommt, nach Riffaterte, dann zum Vorschein. Wenn an der (Oberfläche eines Textes ..Agrammatikalitäten“ entstehen, d.h. wenn z.B. bestimmte Phrasın oder W'örter in ihren textuellen Kontext nicht zu passen scheinen. Die im Vergleich zu ihrer Limgebung als Fremdkörper empfundenen Textelemente können freilich entschlüsselı werden. subuld der Leser ihren intertextuellen Ursprung entdeckt: ..As soon as the reader bicomes aware of the

\footnotetext{
101 Riffaterte 1984, S 142

102 Bloom 1973. S 11

${ }^{103} \mathrm{~S}$ bei Zima 1994

Ith Bloom 1973. S 10
} 
intertext, the relative ungrammaticality is corrected or palliated". ${ }^{105}$ Solche Textelemente spielen die Rolle eines Bindegliedes („connecter“) zwischen dem ,manifesten “106 und dem Bezugstext, sie „verraten“ Präsenz des fremden Werkes, vor dessen Hintergrund sich der Sinn des Textes entziffern läßt. ${ }^{107}$ Die Idee des allein infolge intertextueller Relationen entstehenden Textsinns greift in bezug auf das frühe Prosawerk Pasternaks E. Greber auf: Für manche literarischen Formen (und speziell für Fragmentformen) erscheint Intertextualität manchmal (wie bei Pasternak) ,als einzig mögliche Lösung des Texträtsels“. ${ }^{108}$ Intertextualität ist in diesem Fall berufen, .,die Unbestimmtheitsstellen des Posttextes“ zu „konkretisieren““ ${ }^{109}$

Das Element, das den an- und den abwesenden Text verknüpft - das den intertextuellen Kontakt markierende .Referenzsignal“"110 - wird von Lachmann in die Reihe von „Größen“ gestellt, die den intertextuellen Venweis als solchen ermöglichen: Das sind außer dem Referenzsignal der manifeste Text und der Referenztext. Dabei wird Intertextualităt als „eine neue textuelle Qualität "'ll' definiert, die aus der gegenseitigen, durch das Referenzsignal bestätigten Berührung beider Texte (der ..Kreuzung zweier Kodes, also [...] Doppelkodierung..1!2) resultiert und „die Ambivalenz oder Polyvalenz des Textes ${ }^{-113}$ demonstriert. ${ }^{114}$ Weiterhin stellt Lachmann den Begriff des impliziten Textes auf. mit dem sie „den Or der Überschneidung von präsentem und absentem Text“ bezeichnet, den Ort der „Interferenz von Texten“, oder ..der dynamischen pluralen Sinnkonstitution“. "is Damit bietet Lachmann eine komplexe, sowohl formale als auch semantische Aspekte einschließende Beschreibung des Intertextualitătsphänomens an ${ }^{116}$; mehrmals betont sie in ihrer Arbeit die infolge des Textkontaktes entstehende ..untilgbare semantische Differenz ${ }^{.117}$, die schon in Bachtins Dialogizitătskonzept artikuliert wurde.

Den semantischen Aspekt des Intertextualitätsbegrifts hebt ebenfalls W. Schmid hervor: Intertextualität - dann. wenn sie die Weiterschreibung und -entwicklung der Bachtinschen Dialogizität darstellt - definicrt er als ..Relation der in den simultan vergegenwärtigten Tex-

\footnotetext{
Ins Riffaterre 1977. S 197

101. Vigl den Ausdruck bei Lachmann 1990. S 59

$107 \mathrm{~V}$ gl. Riffaterres Textanalysen in . Intertextual Representatıon On Mimesis as Interpretive Discourse" (1984) Eine detaillientere Beschreibung intertextualitatstheoretischer Konzepte Riffaterres s bei Still/ Worton 1990, S 24-27 und Lachmann 1990. S 58-59. S auch Stempel 1983. S 88-84)

10x Greber 1989. S 6

10) Ibid S 7

110 Lachmann 1990. S 60

'I' Ibid

112 Ibid S 11

"I'Ibid S 60

1it $\mathrm{S}$ uber dieses Konzept von Lachmann auch bet Helbig (1996. S 37)

"L Lachmann 1990. S 63 Der Begriff des impliziten Textes laßt sich durchaus mit dem des Intextes bei Torop vergleichen ..I ] мн будем пользоваться понятием интекста как семантически насыненной части текста. смысл и функиия которой определяется по крайней мере двойным описанием" (1981. S 39) ([ ] wir werden den Bexriff ..Intext" als einen semantisch reichen Textteil bezeichnen, dessen Sinn und Funktion sich durch eine mindestens doppelte (harakteristik definier ")

"1" Diese Deskription hat Lachmann zuerst in ihrem Aufsatz ..Ebenen des Intertextualıtatsbegriffs" vorgeschlagen (1984. S 136-1.37)

"I.achmann 1990. S 71
} 
ten ausgedrückten Bedeutungen, Sinnpositionen und Ideologien“. $1{ }^{18}$ Intertextualität als Dialog der Texte verbirgt immer auch die .,Intersemantizität“ (Dialog im Sinne Bachtins kommt, wie Schmid formuliert, nur dann zustande, wenn das Verhältnis zwischen den Texten „ein vom Autor intendiertes semantisches Faktum“119 ist), dabei ist „die simultane Präsenz zweier miteinander konkurrierender Sinnpositionen “ unablässig ${ }^{120}$.

An den Vorsatz, allgemeine Charakteristika des Intertextualitätsphänomens zu benennen bzw. formale Komponente und Erscheinungsmerkmale der intertextuellen Relation zu ermitteln, knüpfen Versuche an, das Ganze deskriptiv zu erfassen, d.h. die diesem Bereich zugehörenden Erscheinungen werden häufig in einem gegebenen Kontext aufgezählt, wobei das manchmal Formen der Bezüge, manchmal Typen der semantischen Einstellung des Textes zu seinem Prätext bzw. Funktionen der Verweisung sind (manchmal ist auch beides gemeint). Aus den letzteren nennt Stierle Applikation, Überbietung, Aufbietung einer Autorität, ironische Distanznahme, Erweiterung, Korrektur und .Ausschöpfung eines Spielraumes ${ }^{* 121}$, bei $R$. Lachmann heißt es u.a. .Assimilation. Transposition und Transformation fremder Zeichen“"122, „Dekonstruktion“, „replizierende Weiterführung“, „affirmatives Re-Arrangement ${ }^{.123}$ oder - ganz allgemein - „Weiter-, Wider- und Umschreiben “124, bei M. Pfister "Textverarbeitung gegen den Strich des Originals“, „Anzitieren eines Textes, das diesen ironisch relativiert“, ,distanzierendes Ausspielen der Differenz zwischen dem alten Kontext des fremden Worts und seiner neuen Kontextualisierung“, „die bloße Versetzung von einem Zeichensystem in ein anderes“. ${ }^{125}$ M. Geier spricht u.a. von den „offenen oder kryptischen Anspielungen“, „stilistischen Akkomodationen“, ..Montagen aus Bruchstücken anderer Texte ${ }^{\star 126}$, Th. Wolpers von ..Parodie, Paraphrase, Allusion, Zitat ${ }^{* 127}$ u.S.w.

Wie bereits angeführ, versuchen Vertreter des eingrenzenden Intertextualitătskonzepts solcherart vielfältige Formen und Funktıunen der intertextuellen Kommunikatıon anhand konkreter literarischer Werke zu analysieren und oder sie in ein System zu bringen, d.h. eine typologische Differenzierung intertextueller Bezüge im Ganzen durchzuführen. Im Rahmen dieser klassifikatorischen Ansätze entwickelt sich ein eigenständiges terminologisches Instrumentarium - eine Großzahl von nicht selten synonymischen Begriffen. ${ }^{\text {I:\$ }}$

\footnotetext{
"118 Schmid 1983. S $1+2$

is) Ibid S 143

120 Ibid S. 142

121 Stietle 1984. S 145

12: Lachmanu 1990. S 57

12.1 lbid S 02

124 Ibid S 67 Lachmann bietet damil eine L!mformulienung ihrer Trade ..Panızıpatıon Iropik Transfisrma. tion" (s. S. 27.28 dieser Arbeit)

125 Pfister 1985a. S 29

120 Geier 1985, S 10

127 Wolpers 1986, S 10

12: Das breite Begrifisfeld. das im Zuge der Intertevtualitatsiorschung. abet auch im R.lhmen duersei Intertextualitatstheorien im Ganzen ausgearbeitet wurde. wird in der einschlagigen I iteraiur seelegumtich Jemonstrient ..Der Begriff 'Pratext' [ ] ist also der in Hinsicht auf die Inhalte der Reiation undittier nte ()herbetyiff fur solche Begriffe wie 'Referenztext'. 'Subtext'. 'Prototext'. 'Cienutext'. 'Quellentevi. 'Otjohtivi' u a 'Silinid 
Im Aufsatz „Problema inteksta“ stellt P. Ch. Torop die vor allem in Arbeiten A. Popovičs erarbeitete Theorie der Metatexte vor, u.a. auch deren Typologie: Er nennt vier Typen der Anknüpfung („типы примыкания“) des Metatexts an den Prototext (wobei hier der Begriff "Prototext“ offensichtlich denen des Prätextes oder Referenztextes entspricht; der Metatext entsteht im Kommunikationsprozeß zwischen dem Prototext und dem neuen, aktuellen Text): imitierende (Plagiat, Übersetzung, Zitat); selektive (Parodie, Pastiche), reduzierende (Kommentare, Resümee, Annotation) und komplementäre (Bemerkung, Nachwort) ${ }^{129}$. Allerdings scheinen die hier für die angeführten Typen gewăhlten Bezeichnungen dürftig zu sein, weil sie keine Unterscheidung zwischen den ihnen jeweils entsprechenden intertextuellen Phānomenen zulassen. So könnte man Kommentare dem komplementären oder Parodie/ Pastiche dem imitierenden Anknüpfungstyp zuordnen (Parodie und Pastiche werden traditionell als besondere Formen der Imitation betrachtet ${ }^{130}$ ).

Eine wesentlich differenziertere Klassifikation der Intertextualitätsformen (ein „Versuch, das gesamte Spektrum moglicher Beziehungen zwischen Texten zu untersuchen “131) bietet Gérard Genette an. In „Palimpsestes: La littérature au second degré*132 beschreibt er fünf Typen .,transtextueller Beziehungen“ (Transtextualität versteht Genette ganz allgemein als alles das, was den Text ,,in eine manifeste oder geheime Beziehung zu anderen Texten bringt ${ }^{\text {(133; }}$; der Terminus ist also mit dem für die meisten Theoretiker üblicheren Begriff ..Intertextualităt" austauschbar), wobei bereits am Anfang seiner Untersuchung klar wird, daß er die

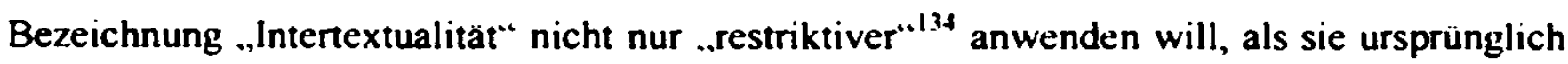
von J. Kristeva gedacht wurde, sondem sie auch auf einige ausgewählte Bezugsarten beschränkt. Intertextualität, die in der Genetteschen Klassifikation den ersten Typ der Transtextualität darstellt, bedeutet hier die ..effektive Prăsenz eines Textes in einem anderen Text ${ }^{* 135}$, die in Form des Zitats, des Plagiats und der Anspielung zum Ausdruck kommt. Mit der Kategorie ..Paratextualität“" (2) gehen ins Konzept Genettes neben den Beziehungen zwischen den Texten, die von verschiedenen Autoren stammen, auch die ein, die sich zwischen den Teilen eines Werkes vollziehen. Mit dem eigentlichen Text in bestimmten Verhältnissen stehende Paratexte sind u.a. Titel, Untertitel, Vorworte, Nachworte, Einleitungen, Fußnoten, Motti u.s.w. Metatextualität (3) tritt zu Tage, wenn ein Text sich mit dem anderen auseinandersetzt. ihn kritisch kommentiert. Hypertextualität (4) - der genuine Gegenstand der Monographie - markiert Beziehungen. bei denen ein Text von einem anderen mit Hilfe bestimmter

1983. S 143). ..Mit 'Subtext'. 'Hypotext'. 'Hypenext', 'Anatext', 'Paratext', 'Intertext'. 'Transtext', 'Text im Text' im Verbund mit 'Geno-:'Phanotext'. 'Metatext' und 'Autotext' - werden Aspekte der komplexen Erscheinung des Text-Text-Kontakts benannt [ .]." (Lachmann 1990. S 55-56) Vyl dazu Helbig 1996 (S 76-78)

${ }^{129}$ Torop 1981. S 36-37

${ }^{130}$ S Z B Delinition der Parodie bei Hempel (1965, S 151). Hutcheon (1985, S 6) und Kuester (1998. S 414). des Pastiches bei Hempel (1965, S 174-175). Genette (1993. S 40-41) und Kuester (1998, S. 415)

13' Muller 1994. S 156

132 Zum ersten Mal erschienen in Paris um Jahre 1982

1.33 Genette 1993. S 9

114 lbid S 10. 
Transformationen abgeleitet ist; der abgeleitete Text nennt sich Hypertext - ein Text .zweiten Grades" 136 - und der frühere, der als Grundlage für die Ableitung fungiert, Hypotext. Schließlich bezeichnet Architextualităt (5) die Zugehörigkeit des Textes zu einer Gattung, was häufig in Paratexten wie Titel oder Untertitel deklariert wird. ${ }^{137}$ Genette befaßt sich, wie erwăhnt, im weiteren ausschließlich mit dem vierten Typ der Beziehungen - mit Hypertexten wie Parodie, Travestie, Pastiche, Persiflage u.a. und ihren Spielarten sowie den Operationen (beispielsweise Transformation oder Nachahmung), die ihre Entstehung auf der Basis anderer Texte ermöglichen. ${ }^{138}$ Genette untersucht weiterhin Hypertexte, die aus einem anderen Text dadurch entstehen, daß sie ihn z.B. fortsetzen, in eine andere Sprache übersetzen, von Prosa in Verse und umgekehrt übertragen, ihn kürzen, erweitern u.s.w. (vgl. die Bezeichnungen Genettes wie "Weiterfuhrungen“, „Versifikation“, „Prosifikation“, „Transmetrisierung“, .Transstilisierung“, „Dehnung“, ..Verknappung“ u.a.) $)^{139}$.

Genette răumt dabei „Verbindungen oder wechselseitige Überschneidungen “1\$0 ${ }^{* w i s c h e n ~}$ den fünf Typen transtextueller Kontakte ein. Beispiele solcher Überlagerungen werden sofort auch demonstriert: So können bestimmte Paratexte (Vorwort u.a.) als eine Form des Kommentars und alle Hypertexte als ein ..gattungsbildender Architext ${ }^{(1+1}$ betrachtet werden. Jedoch werfen die Forscher dem Genetteschen Ansatz nicht nur Mangel an Strenge, sondern und vor allem die Unmöglichkeit vor, die in ihm bereitgestellten Typen hierarchisch zu verbinden. S. Holthuis stellt in ihrer Kritik fest, daB ..die vorgestellten Subtypen [...] auf unterschiedlichen Grundlagen (etwa Funktion oder Gattung) aufbauen ${ }^{\text {“1 } 122}$, nach der Ansicht B. Müllers liegen .,den fünf transtextuellen Kategorien Genettes [...] verschiedene Klassifikationskriterien" zugnunde: die ersten zwei und der fünfte Typ ..fußen [...] auf textsortenspezifischen Charakteristika" ${ }^{\text {"143 }}$, der dritte wird auf seine Funktion hin befragt.

Einige Typologien, die verschiedene Aspekte des Intertextualitätsphänomens zugleich ansprechen, erarbeitet Renate Lachmann. Einer dieser Aspekte betrifft die Art der Einstellung des jüngeren Textes zum älteren (zu den älteren) bzw. die Position, die vom ersten gegenüber dem zweiten eingenommen wird. Lachmann geht von drei Modellen der Intertextualität aus: dem der Partizipation (..das im Schreiben sich vollziehende dialogische Teilhaben an den Texten der Kultur..1+4 ...Wiederholung“ des früher Geschriebenen). der Tropik (Kampf gegen

\footnotetext{
1.15 Ibid Ableitung, als Hypertext

$117 \mathrm{Vgl}$ auch Broich 1985a. S 36-37

${ }^{13 *} \mathrm{~S}$ Darstellung dieses Modells u a bei Muller 1994. S 156.159

130 S Genette 1993

(\$) Ibid. S. 18

1+1 Ibid

1+2 Holthuis 1993, S. 46

14.1 Muller 1094. S 159

its L.achmann 1990. S 38
}

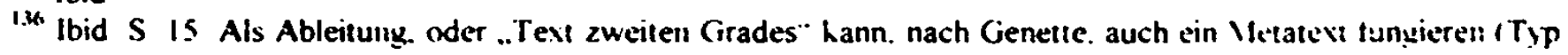
3 der Beziehungen) - ein Text. der ..von eınem anderen Texı I I 'spricht" (ibıd) Es ist dinn aber cinc andere In 
den Vorläufertext im Sinne H. Blooms, „Versuch der Überbietung. Abwehr. ${ }^{4+5}$ ) und der Transformation (eine zugleich distanzierende und ..usurpierende" Haltung, wenn der Bezugstext „verborgen, verschleiert", ..unkenntlich gemacht", „respektlos umgepolt".146 wird). Weiterhin unterscheidet Lachmann zwischen der Kontiguitäts- und der Similaritätsbeziehung. Die erste bedeutet die Reproduktion eines oder mehrerer Elemente des Referenztextes im aktuellen Text, die zweite die Bildung von dem Referenztext äquivalenten Strukturen. Das Zitieren, die Übernahme der Textsegmente wird hier dem „Aufbau von analogen Strategien ${ }^{\text {"147 }}$ entgegengesetzt. ${ }^{148}$ In der (in Anlehnung an Lachmann herausgearbeiteten) Typologie von Monika Lindner übernimmt der neue Text bei der Similaritătsrelation .,Relationen zwischen Elementen, nicht aber die Elemente direkt.149; das ist demzufolge das Differenzkriterium zur Kontiguitätsrelation.

H. F. Plett spricht ebenfalls von .,material“ auf einer und .,structural intertextuality“ auf der anderen Seite. Auch für W. Karrer steht auf einer Seite die Übernahme der prätextuellen Elementen, auf der anderen die Übernahme der im Prätext vorhandenen ..Strukturen oder Relationen “'so. In diesem Sinne grenzt er die Elementen- und die Struktur-Reproduktion gegeneinander ab. Nach Plett, kommt Intertextualität im Ganzen in drei Formen zum Ausdruck: als Wiederholung der Zeichen des Prätextes (materielle Intertextualität), als Wiederholung von dessen Regeln (strukturelle Intertextualität) und als Kombination dieser beiden Typen (materiell-strukturelle Intertextualităt) ${ }^{131}$. Karrer schreibt dazu: „Weder Relation noch Element bleibt ganz unberührt, wenn eins von beiden ausgewechselt wird“. 152

Eine ausführliche Typologie der Transformationen, die der Bezugstext sowohl auf der Ebene seiner Elemente als auch strukturell erlebt, erarbeitet H. F. Plett. Er nennt insgesamt fünf Transformationstypen: Substitution (eine mediale, wenn ein literarisches Werk illustriert oder vertont wird, d.h. linguistische Zeichen gegen visuelle oder akustische ausgewechselt werden (a), eine linguistische, z.B. die Ubertragung eines Werkes in eine Fremdsprache, in einen Soziolekt, in einen anderen Stil (b) und eine strukturelle, z.B. heim Wechsel von der Lyrik zum Epos oder Drama und umgekehrt, oder auch beim Wechsel zu einer anderen Gattung (c)); Addition (Ergänzung entweder in Form einer Weiterschretbung des literarischen Werkes oder in Paratexten wie Epılog. Motto u.s.w.): Subtraktion (verkürzende Darstellung eines Textes oder seiner Teıle, z.B. die Zusammenfassung): Permutation (Zersplitterung des

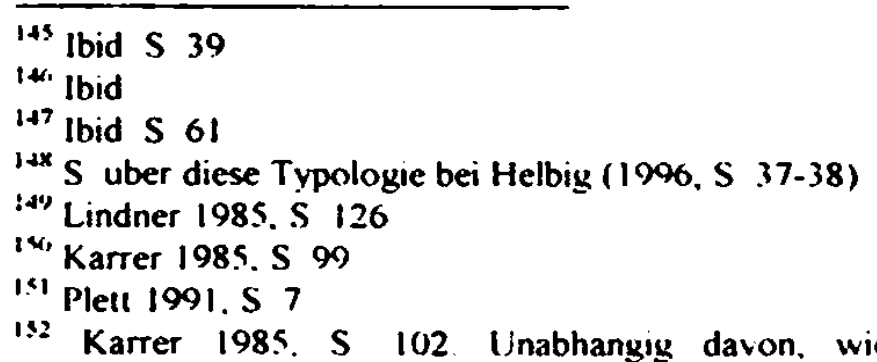
Kontiguitatsbeziehungen. die materielle und die strukturelle Intentextualitat genau auffassen, was unter Elementen und was unter Strukturen verstanden wird. werden wir in unserer Artheit als erste materielle. ... Wontiche" (s hei Karrer 1985. S 98) Venteise. sprich Zitate aus dem Pratext und Allusionen. wie sie hier im Weiteren am Ende 
Werkes in Fragmente und die Zusammensetzung dieser Fragmente in einer anderen Reihenfolge - eine Kollagentechnik, die ebenfalls mehrere Texte einbeziehen kann) und eine komplexe Transformation (syntagmatisch als eine Serie von Fortsetzungen eines literarischen Sujets (z.B. von „Robinson Crusoe“), die verschiedene Transformationsarten zustande bringt Substitution, Permutation u.a.; paradigmatisch als Kondensation, d.h. Kombination verschiedener intertextueller Verfahren und mehrerer Prătexte in einem Werk, z.B. Inversion literarischer und musikalischer Topoi, Motive, Strukturen und Gattungen in der komischen Oper). ${ }^{153}$

Darüber hinaus bietet Plett eine Liste von bewertenden Positionen („evaluative attitu$\operatorname{des}^{\omega 154}$ ) an, die der spătere Text gegenüber dem ălteren einnimmt: Dieser Versuch låßt sich als eine Variante der Lachmannschen Triade „Partizipation - Tropik - Transformation“ interpretieren. Nach der Art der Bewertungshaltung, die sich im manifesten Text offenbart, bilden sich vier Intertextualitătstypen heraus: affirmativer $($,A text [...] re-employs the structural rules and pretexts of the classical canon ${ }^{4155}$ ); negativer (der Text betont seine Originalităt und Andersartigkeit vor dem Hintergrund des anderen Textes); inversiver (am anschaulichsten in der Parodie oder Travestie); und relativierender (in der Collage oder Montage: „Anything can be combined with anything ${ }^{-156}$ ).

Eine Skala von sechs qualitativen und zwei quantitativen Kriterien „für die Intensităt intertextueller Verweise ${ }^{c .157}$ entwirf M. Pfister. ${ }^{158}$ Sein typologischer Ansatz soll die Einbeziehung solcher Gesichtspunkte in die Analyse der intertextuellen Bezüge berücksichtigen wie .die Einstrukturierung und Markierung der Prätexte im Text“, .das Verhältnis von Text und Prätexten“ und „die kommunikativen Aktivitäten von Autor und Rezipient“"159. Pfister versucht damit formale Eigenschaften des Bezuges mit seinen semantischen Qualitäten zu vereinigen. Die qualitativen Kriterien Pfisters sind: Referentialităt, die den Grad der Thematisierung des Prătextes und seines Charakters im aktuellen Text ausmißt (nach diesem Kriterium wird Intertextualität zur Metatextualität insofern, daß der Text bestimmte Aussagen über den Prätext enthălt); Kommunikativität, d.h. der „Grad der Bewußtheit des intertextuellen Verweises beim Autor wie beim Rezipient, der Intentionalität und der Deutlichkeit der Markierung im Text" ${ }_{-1}^{10}$; Autoreflexivităt, die dann zum Ausdruck kommt, wenn nicht nur der Referenztext, sondem auch die interextuelle Verweisung selbst im aktuellen Text thematisient und reflektient wird; Strukturalităt - syntagmatische Eingliederung des Referenztextes in den

dieses und im nachsten Unterkapitel erortert werden. begreifen Die Ahnlichkeiten der Textstrukturen werden dann bestatigt. wenn ein so verstandenes Element aus dem Referenztext im beaugnehmenden Text auftaucht

${ }^{133} \mathrm{~S}$ Plett 1991. S 19-25. Vgl diese Transformationsarten mit denen in den .Hypertexten“ bei Genette (s. S. 27 dieser Arbeit)

ist lbid S 19

155 Ibid

iss Ibid

${ }^{157}$ Pfister 1985a. S 26

"*k Obwohl wir das Konzept Pfisters der zweiten Gruppe der Intertextualitatstheorien zuordnen, bemuht er sich hier um eine Verbindung der beiden Richtungen der radikalen und der eingrenzenden (s. danuber bei Muller 1994. S 16.3)

(s) Pfister 1985a. S 30 
manifesten Text, wobei z.B. Parodie, Travestie, Übersetzung, Kontrafaktur, Imitation nach

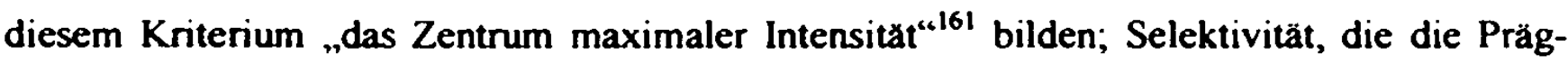
nanz des Bezuges widerspiegelt, d.h. abwägt, wie pointiert und konkret der intertextuelle Kontakt ist (in diesem Sinne ist ein wörtliches Zitat aus einem konkreten Text prägnanter als die Benennung seines Titels oder des Namens einer seiner Figuren bzw. als der Bezug auf eine Gruppe von Prätexten wie Gattungen oder Diskurstypen); und Dialogizităt, die über den Grad der „semantischen und ideologischen Spannung“ ${ }^{162}$ zwischen den Texten entscheidet. Zu den quantitativen Kriterien in der Skalierung Ptisters gehören erstens die Dichte und Häufigkeit der intertextuellen Verweise im Text oder aber im Gesamtwerk einzelner Autoren, zweitens die Anzahl und die Streubreite der herangezogenen Referenztexte. ${ }^{163}$

Weitere Beitrăge des Sammelbands „Intertextualität“, den Pfisters Ansatz eröffnet, stellen Konzepte vor, die seine Thesen in gewisser Weise ergănzen bzw. die in seinem Modell erwähnten Aspekte der Intertextualităt konkretisieren. So greift U. Broich den von Pfister angesprochenen Unterschied zwischen dem Bezug auf einen individuellen Text und dem auf Textsysteme auf und erforscht den ersteren näher. Die beiden Autoren bezeichnen ihn als Einzeltext-, den letzten als Systemreferenz ${ }^{164}$. Die Einzeltextreferenz schließt, so Broich, solche Intertextualitătsformen wie Zitat, Motto oder Übersetzung ein; Pastiche, Allusion oder Parodie können dagegen sowohl die Einzeltext- als auch die Systemreferenz prasentieren. Beide Bezugstypen fallen, wie Pfister und Broich bemerken, in vielen Fällen zusammen: Literarische Werke - wie z.B. Parodien - verweisen nicht selten auf eine Gattung im Ganzen und zugleich auf .einzelne Realisierungen dieses Gattungsmusters“165. In seinem weiteren Beitrag „Zur Systemreferenz" führt Pfister konkrete Ausformungen systemreferenzieller Verfahren an: Das sind Bezuge auf sprachliche Normen der Literatur im allgemeinen, die das Kriterium .Dialogizität" desto mehr erfüllen, je deutlicher sich der aktuelle Text von dieser Norm abhebt und sie dadurch ..bloßlegt ${ }^{\text {lite. }}$; Verweise auf Diskurstypen (wissenschaftliche. philosophische u.s.w. und deren historische Erscheinungsformen); auf literarische Gattungen (u.a. auf ..historisch-spezifische Gattungen wie die comedy of manners, das petrarkistische Sonett. die gothic novel. ${ }^{167}$ ) oder auf Archetypen und Mythen.

Das Problem der Markierung intertextueller Verweise, das in der Typologie Pfisters insbesondere bei den Kriterien ..Kommunikativität" und ..Selektivität" an Relevanz gew innt ${ }^{\text {likn }}$. er-

\footnotetext{
160 Ibid S 27

161 lbid S 28

162 lbid S 29

${ }^{163} \mathrm{~S}$ Darstellung dieses Modells von Pfister u a bei Holthuis 1993. S 48. Muller 1994. S 10:3-164 und bet Helbig 1996. S $01-62$

1.. S Pfister 1985b. S 53 und Broich 1985b. S $48-49$ Broich stutzt sich ebentalls auf die Klassifihation Genettes, der mit dem Begriff ..Architextualitat" einen bestimmten Typ (Gattungsbezugee) det Svstemreteren> bezeichnet

${ }^{165}$ Pfister 1985a. S 18

ise Pfister 1985b. S 54

${ }^{167}$ Ibid S 56

168 Vgl danuber bei Helbig (1996. S 62)
} 
forscht im zweiten Teil des Bandes U. Broich. Er schlägt in seiner Klassifikation drei Formen der Intertextualitătsmarkierung vor: Markierung in Nebentexten wie Fußnoten, Titel, Untertitel, Mottos, Nach- und Vorworte (1); Markierung im inneren Kommunikationssystem, wenn intertextuelle Kontakte im Bewußtseinshorizont der Textpersonen liegen (das kann sich in Form der fiktiven Lektüre oder der literarischen Diskussion außern; darüber hinaus schließt dieser Markierungstyp alle Situationen ein, in denen Literatur von Personen auf verschiedene Art und Weise rezipiert wird, aber auch „Figuren auf Pump“) (2) und Markierung im außeren Kommunikationssystem des eigentlichen Textes, wenn die Bezüge zu anderen Werken den Charakteren nicht bekannt sind, sondern allein dem Leser (wie u.a. intertextuelle Personennamen) (3). ${ }^{169}$

In polemischer Distanz zur Klassifikation Broichs differenziert W. Füger nicht die Orte der intertextuellen Markierung, sondern deren Arten: Er zăhlt zur explizit markierten Intertextualităt die Benennung des Prátextes oder seines Autors, „Figuren auf Pump“ und Verweise, die auf graphischer Ebene signalisiert sind; implizit markierte Verweise artikulieren sich in der Herstellung einer Analogie oder eines Kontrastes zum Prătext. ${ }^{170}$ Dennoch hängt für Füger „der Deutlichkeitsgrad der impliziten Markierung “171 u.a. von der Art der Textstelle ab, an der das Referenzsignal auftaucht (eine besondere Aufmerksamkeit verdienen ,.privilegierte Stellen“, z.B. der Anfang des Werkes). ${ }^{172}$

Die Frage nach den moglichen Markierungsformen intertextueller Referenzen, genauer: einer Gruppe der letzteren - steht im Mittelpunkt der Allusionsforschung. Das Allusionssignal - nach Z. Ben-Porat, ein Textelement, das eine Aktivienung von zwei unabhăngigen Texten hervorruft, oder „a special signal: a sign (simple or complex) in a given text charakterized by an additional larger 'referent'. This referent is always an independent text ${ }^{.173}-$ kann auf syntagmatischer Ebene verschiedene Gestalten annehmen: in diesem Sinne unterscheiden sich auch Markierungsvarianten der Allusion. W. Schmid nennt folgende Signale, die bei ihm eine „diegetische Allusion“ markieren können: ..ein mehr oder weniger direktes“ Zitat, „der Name eines Protagonisten“, „,ein markantes Handlungsdetail”, „,kompositionelle Figuren“ und „vordiegetische Elemente wie lexikalısche Motive, syntaktische Muster, rhythmische Gestalten, vokalische oder konsonantische Instrumentierung "174. Als Allusionssignale gehoren sie zu den Verfahren, die eine diegetische Äquivalenz der Texte ${ }^{175}$ nicht „explizieren“, sondern

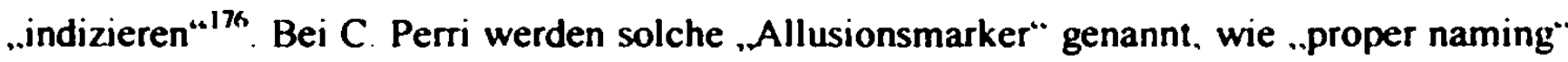
(Zitate und Eigennamen), .,definite descriptions“ (.,the brief echo of content or form“ wie ...

\footnotetext{
${ }^{169}$ Broich 1985a. S. 31-44. Uber diesen Ansatz von Broich s. bei Helbig 1996, S 38-40

${ }^{170}$ Füger 1989. S 182

171 Ibid S 199

in $\mathrm{S}$ uber den Aufsatz Fügers bei Helbig 1996, S 44-47

17 Ben-Porat 1976. S 107-108 Über die Allusionstheorie von Ben-Porat s u a bei Schmid 1983, S 145-146 und Helbig 1996, S. 25-27

${ }^{174}$ Schmid 1983, S 152

${ }^{173} \mathrm{~S}$ daruber weiter (S 34-35 dieser Arteit)

${ }^{176}$ Schmid 1983, S 152
} 
significant word" oder ,repetition of a well known rhythmical phrasing“) und ,paraphrase“ $^{\text {“177 }}$. U. Hebels Allusionstypologie enthält, ähnlich wie die von Schmid, einige der von Perri genannten Signale: sie schließt „onomastic allusions“ und „quotational allusions“ (die bei Perri im ersten Typ vereinigt sind) ein, darüber hinaus werden "titular allusions“ als dritter Typ vorgestellt. ${ }^{178}$ Wãhrend Zitate für Hebel eine relativ präzise Verweisung auf den Prätext gewăhrleisten, besitzen onomastische Anspielungen wie Autorennamen einen wesentlich höheren Abstraktionsgrad: Sie evozieren manchmal das Gesamtwerk eines Autors oder ganze literarischen Traditionen. 179

Als einer der „klassischen“ Allusionsindikatoren gilt, nach der Ausführung S. Holthuis, „die Literatur in der Literatur“ in Form lesender und die Lektüre kommentierender Protagonisten, wobei sich innerhalb dieses intertextuellen Phănomens solche Allusionsmarker vorfinden wie Personennamen, Handlungsorte, Wiedergabe bestimmter Episoden aus dem Referenztext u.a. ${ }^{180}$ Wir werden künftig "Literatur in der Literatur" als eine komplexe thematisch definierte intertextuelle Erscheinung betrachten, die sich mannigfaltiger Arten sowohl der Allusion als auch des Zitats bedient.

\subsection{Zur Zitat-und Allusionstheorie}

Die Zitat- und Allusionsforschung, deren einzelne Aspekte im Kap. 2.1. in Zusammenhang mit dem Problem der intertextuellen Markierung bereits abgehandelt worden sind, bildet einen wesentlichen Bereich der Intertextualitätstheorie. Wir wollen hier aus dem weiten Umfeld der einschlägigen Literatur nur diejenigen Beiträge vorstellen. die sich insbesondere mit zwei Themen befaßt haben: mit der Frage nach der Möglichkeit bzw. der Unmöglichkeit einer deutlichen Abgrenzung der Zitate von Allusionen und mit dem Problem der Typologie verschiedener Zitatformen.

Wie aus den im Kapitel 2.1. vorgestellten Ansätzen zur Klassifikation der Allusionsmarker ersichtlich ist, wird die Auffassung, daß das Zitat eine der Erscheinungsformen der Allusion darstellt, u.a. von Hebel vertreten. In einem Überblick über die Allusionstheorie demonstriert er, wie in den Arbeiten Ben-Porats, Perris, Coombs u.a. eine „Redefinierung“ der Allusion durchgeführt wird. Allusion wird nämlich nicht mehr als indirekter und verborgener Verweis auf ein fremdes Werk begriffen, der zu den offenen und direkten Referenzen wie dem Zitat in Kontrast steht (..the definitional opposition 'covert' vs. 'overt" ${ }^{\text {". }} \mathbf{} \mid$ ): ...Ben-Porats inclusion of $t i-$ tels, names, and [...] 'exact' quotations [...] modifies traditional views of allusion as it recog-

\footnotetext{
in Perri 1978. S 304-30S Uber die betreffende Arbeit von Perri und ihre Allusionsarten s ebenfalls bei Schmid 1983. S. 146-147 und Helbig 1996, S 27-30

17 Hebel 1991. S. 142-144 Uber diesen Aufsatz Hebels s bei lllelbig 1996. S 33-35

179 Hebel 1991, S 145

${ }^{100}$ Holthuis 1993, S 130 Eine detailliente Darstellung der Theorie von Holthuis s bei Helbig 19\%, S 47-52
} 
nizes overt references as allusional markers ${ }^{\text {“182 }}$. Eine solche Redefinition, die die Allusion in erster Linie durch die Präsenz eines als Element des fremden Textes erkennbaren Signals charakterisieren lăßt, erlaubt, wie Hebel formuliert, Integration des Zitats in die übergeordnete Kategorie der Allusion: „The above redefinition of allusion together with the establishing of the latter as a directional signal that refers the reader to another text outside the alluding text, allows for the incorporation of quotations into the larger category of allusion “483.

Andere Intertextualitătsforscher răumen zwar dem Zitat eine unabhăngige Position gegenüber der Allusion ein, verzichten aber gleichzeitig darauf, eine scharfe Trennungslinie zwischen den zwei Referenzformen zu ziehen. Holthuis untersucht in ihrer Monographie Faktoren, die den Unterschied zwischen Zitat und Anspielung entweder relativieren oder verdeutlichen. So wird diese Differenz desto fragwürdiger, je stărker das ,zitierte“ verbale Material im aktuellen Text modifizient wird ${ }^{184}$, d.h. je geringer die Similarităt zwischen dem Zitat und dem Zitienten ist. Eine gewisse Rolle spielt ebenfalls der Umfang des übernommenen Materials: „Problematisch werden Abgrenzungen zwischen Zitat und Allusion(-smarker) vor allem dann, wenn die Menge des übernommenen (nicht-/ modifizierten) Textmaterials relativ gering

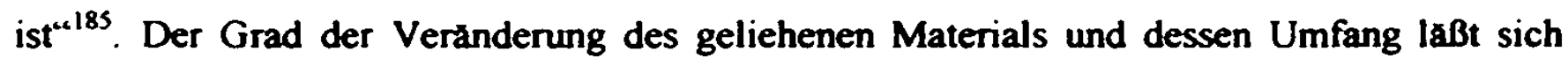
durch einen weiteren Faktor ergănzen: Das Zitat năhert sich der Allusion, wenn es im Text als solches nicht explizit markiert wird (Plett nennt u.a. folgende Zitatmarker: Thematisierung des Zitierensaktes (wie ,ich zitiere...“), Benennung der Zitatquelle, graphische Signale, z.B. Anfühnungszeichen, Leerstellen u.s. . $^{186}$ ). Eine eindeutige Auseinanderhaltung der betreffenden Verweistypen wäre demzufolge kaum möglich, es „sollte daher eher von Gradationen zwischen beiden ausgegangen werden ${ }^{\text {(187 }}$

Wir werden Zitate und Allusionen/ Allusionssignale im folgenden als formal unterschiedliehe Referenztypen behandeln, die jedoch - und hier gilt für uns als Orientierungspunkt die Ansicht von Holthuis - in bestimmten Fällen eine ăußerst geringe Distanz zueinander aufweisen und sogar ineinander übergehen. Bei ihrer Differenzierung sind generell die Lănge des dem Prätext entnommenen Fragments ${ }^{188}$ und manchmal die Prasenz bzw. Absenz der .Zitatindikatoren " in der kontextuellen Umgebung des Bezuges von Bedeutung. Neben Autorennamen besitzen Werktitel und Protagonistennamen einen im Vergleich zum Zitat in der Regel abstrakteren Verweischarakter (im Sinne Hebels, der jedoch Zitate als eine Erscheinungsform der Allusion betrachtet, und Pfisters ${ }^{189}$ ).

\footnotetext{
181 Hebel 1991, S 136

182 Ibid.

183 lbid S. 137

$184 \mathrm{Vgl}$. auch die Formulierung Müllers: „Je mehr die Reproduktion des vorgefertigten Materials gegenuber der Variation dieses Materials in den Hintergnund tritt, desto stărker verblaßt der Zitatcharakter" (1994, S. 169)

${ }^{185}$ Holthuis 1993, S. 126.

186 Plett 1991, S. 12.

187 Holthuis 1993. S 127

${ }^{188}$ Obgleich auch fur Plett der Zitatumfang praktisch uneingeschrankt bleibt: Das ..Zitatsegment" kann sowohl innerhalb eines Wortes oder Satzes als auch innerhalb eines (Teil-)Textes vorkommen (s Plett 1985, S 83)

${ }^{189} \mathrm{Vgl}$. Pfister auf S. 30 und Hebel auf S. 32 dieser Arbeit und auch unten
} 
Weniger entscheidend ist für uns bei der Unterscheidung zwischen Zitat und Allusion der von Holthuis angeführte dritte Faktor: Auch wesentliche Veränderungen der Elemente aus dem Bezugstext löschen Zitateigenschaften der Referenz nicht aus. In diesem Punkt stützen wir uns auf die Auffassung Pletts, der recht unterschiedliche Zitatmodifikationen schildert (Transformationsarten des zitierten Materials hängen im wesentlichen mit denen zusammen, die Plett für intertextuelle Referenzen im Ganzen ausarbeitet (s. Kap. 2.1.), das sind Addition, Subtraktion, Substitution, Permutation und Repetition ${ }^{190}$ ). Zitatanderungen sind im allgemeinen mit der Absicht verbunden, ..die ursprüngliche 'Botschaft' leicht [zu-K. S.] entstellen oder gar [zu - K. S.] verfälschen“, in manchen Situationen gewăhren sie einen .zusătzlichen Spielraum für Polysemie- und Ironie-Phănomene“c191

In unseren Textanalysen werden wir als Allusionen jedenfalls móglichst konkrete punktuelle Verweise auf den Prătext betrachten in der Form, wie die Allusionsmarker bei Perri, Schmid und Hebel beschrieben werden (mit Vorbehalt, daß wir Zitate und Allusionen voneinander abtrennen und die ersten also nicht als Allusionssignale betrachten). Solche Allusionen sind für uns dann auch immer Elemente, die dem Prătext entlehnt sind (wie beim Zitieren); es wird als eine Wiederholung der Zeichen des Prătextes (nach dem Ausdruck von Plett) aufgefaßt - auch bei der Benennung des Namens vom Autor. Bemerkenswert sind die erwähnten Debatten innerhalb der Zitat- und Allusionsforschung, die die Frage nach den moglichen Unterscheidungskriterien zwischen den zwei Referenzformen wie Zitat und Allusion aufwerfen. Wir halten uns an die Auffassung. daB die Übernahme eines fremden Textsegmentes nicht nur beim Z.itieren, sondem ebenfalls beim Alludieren, z.B. bei der Benennung der Figurennamen oder der Werktitel unabdingbar ist. $Z$. Ben-Porat schreibt über die Allusionsmarker: .The marker is always identifiable as an element or pattern belonging to another independent text." ${ }^{192}$ Und bei Hebel: „Quotations, whether cryptic or marked, are nothing more, and nothing less, than specific fillings of the syntagmatic space of the allusive signal ${ }^{-193}$. In unserer Arbeit müssen das jedoch nicht notwendigerweise wortwortliche Entlehnungen aus diesem Prätext sein, sondern ebenfalls thematisch-stilistisch nachgeahmte Phrasen und Aussagen, die also die ursprünglichen variieren, ihnen analog sind, aber für uns als Elemente aus dem Referenztext (eine Kontiguitätsrelation) trotzdem fungieren. Intertextuelle Korrespondenzen bzw. Analogien auf der Ebene des Sujets und/ oder der Personen betrachten wir dann als Entfaltung des semantischen Potentials solcher .,materiellen“ punktuellen Verweise wie Zitate und Allusionen; jedoch konnen manchmal auch ,,markante Handlungsdetails“ (Schmid ${ }^{194}$ ) als Allusionen angesehen werden, wenn sie einen hohen Grad an Konkretheit besitzen. Wir stützen uns dabei auf die Ausführungen Schmids, für den „eine interdiegetische Äquivalenz (d.i. eine Similarität und oder [...] eine Opposition der in T und PT

${ }^{190}$ S Plett 1985, S 82

191 Ibid

192 Ben-Porat 1976, S 108

19' Hebel 1991. S 137 


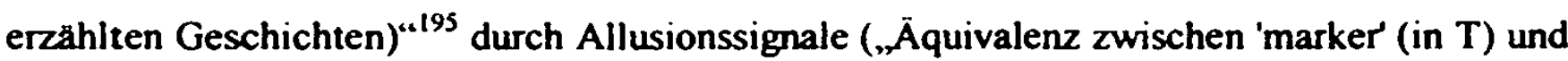
'marked' (in PT), gleichgültig, in welcher Werkschicht diese auftreten“) ,indiziert" wird. ${ }^{19}$ Dieses intertextuelle Phänomen nennt Schmid „diegetische Allusion“ und erforscht es am Beispiel der Novelle Puskkins „Stancionnyj smotritel'“ (,Der Posthalter."197) und ihrer Prátexte. ${ }^{198}$ Wir werden hier jedoch als Allusionen das bezeichnen, was Schmid unter Allusionssignalen versteht, also die einzelnen "linker" zwischen den Texten selbst. Ansonsten werden wir uns auf die Methode der intertextuellen Analyse orientieren, wie sie bei Schmid demonstriert wird. ${ }^{199}$

Pletts typologisches Erfassen der Zitatformen beschrănkt sich allerdings nicht auf die Klassifikation der Modifikationen, denen das Zitiente im neuen Kontext unterzogen wird. Des Weiteren stellt er eine Gruppe von möglichen Arten des Kodewechsels, oder der linguistischen .Interferenzen“ (auch der „Zitat-Indikatoren“) vor, die das zitierte Segment vor dem neuen kontextuellen Hintergrund als Abweichung wahrnehmen lassen. Solche Kodedifferenzen konnen die Sprache (es handelt sich dann um eine interlinguale Interferenz), die Sprachstufe (diachrone Interferenz), die Sprachregion (diatopische Interferenz), den Soziolekt (diastratische Interferenz), das Sprachregister (diatypische Interferenz), die Schriftart (graphemische Interferenz) und die Prosodie (prosodische Interferenz) betreffen. ${ }^{200}$ Nicht selten „verstoßt" das Zitat gegen die Sprachnormen des manifesten Textes zugleich auf mehreren Ebenen; dabei liegt auf der Hand: Je deutlicher die Diskrepanz zwischen den sprachlichen Eigenschaften des aktuellen und des Prătextes ist, desto stărker wird das Zitat in seiner neuen Umgebung als Fremdkörper empfunden, desto auffälliger werden „Nahtstellen und Brüche im Textkontinuum “201.

Schließlich unterteilt Plett Zitate hinsichtlich ihrer Funktion in „authoritative quotations“ (beispielsweise ein Bibelzitat in der Predigt: eine kritische Distanz zur Zitatquelle ist in diesem Fall ausgeschlossen), „erudite quotations“ (vorwiegend in wissenschaftlichen Texten; im Unterschied zum ersten Typ ist hier eine kritische Einstellung zum Zitierten zulässig), „ornamental quotations" (Plett bezeichnet solche Zitate als .,decorative embellishments ${ }^{{ }^{202}}$ ) und ..poetic quotations“. ${ }^{203}$ Ein poetisches Zitat hebt sich von den ersten drei Zitattypen vor allem dadurch $a b$, daß es von praktischen Zwecken (wie etwa die Bekrăftigung der eigenen Aussage durch den Bezug auf einen als Autorität empfundenen Autor oder aber - umgekehrt - die

\footnotetext{
$194 \mathrm{Vgl}$. S. 31 dieser Arbeit

195 Als .Konstituenten“ der Geschichte bzw der ..Diegese“ bezeichnet Schmid ..Situationen. Protagonisten. Handlungen" (1983, S. 148)

${ }^{196}$ Schmid 1983, S. 148

197 Puschkin Bd 3 (1952), S. 57

198 Jedoch sei hier die folgende Einschrankung von Schmid zitien: „Die diegetische Aquivalenz braucht indes nicht explizien [expliziert wird sie nach Schmid ..etwa durch einen Vergleich“ (1983. S 152) - K S ] oder indiziert zu sein, sie kann auch erst im Rekurs auf die dem Autor bekannten Pratexte. auf das in der Tradition gespeicherte Geschichten-Paradizma identifizierbar werden “ (ibid.)

${ }^{199} \mathrm{~S}$ auch seine Monographie „Puskins Prosa in poetischer Lekture“ (1991)

200 Plett 1985, S. 85. Uber die Ansatze Pletts (1985 und 1991) s. bei Helbig 1996. S 41-44. Helbig setzt Akzent $v$ a auf die Unterscheidung der expliziten und impliziten Markierung des Zitats bei Plett)
} 
Durchsetzung der eigenen Meinung durch die Vorstellung derjenigen des Opponenten) befreit ist; „poetisch“ heißt, nach Plett, auch „nutzlos“. Eine unbegrenzte Zahl der Funktionen, die den Zitaten aller vier Klassen im Rahmen konkreter Texte zugebilligt werden kann, schließt die Plettsche Typologie selbstverständlich nicht aus.

\subsubsection{Zur Theorie der "Texte zweiten Grades"}

Im bereits erwăhnten (s. Kap. 2.1.) Vorwort zum Sammelband „Dialogizităt“ unterscheidet R. Lachmann zwischen .Doppelstrukturen“, die den Text im Ganzen umfassen (wie Parodie, Travestie, Stilisierung u.s.w.) und denen, die einzelne Textelemente betreffen (wie Zitat, Replik u.s.w.) ${ }^{204}$. Bis zu einem gewissen Grad in Opposition zu den im vorigen Unterkapitel erörterten punktuellen Verweisen auf den Referenztext in Form eines Zitats oder einer Allusion stehen demzufolge intertextuelle Phänomene, die Genette als "Texte zweiten Grades“, oder „Hypertexte“ bezeichnet. ${ }^{205}$ In seinem fünf Intertextualitătsklassen umschließenden Modell $^{206}$ nimmt Hypertextualităt insofern eine zentrale Stelle ein, daß sie diejenige der funf Kategorien ist, auf die in der Monographie im Weiteren speziell und ausführlich eingegangen wird. Der Hypertext - ein Text also, der von einem früheren (Hypotext) abgeleitet ist, „spricht“, wie es im Fall der Metatextualităt ist, nicht von ihm, sondern „entsteht aus ihm“ infolge gewisser Transformationsverfahren, denen dieser frühere Text unterzogen wird. ${ }^{207}$ Weiterhin untersucht Genette die Transformationstechniken, mit deren Hilfe solche Hypertexte erzeugt werden, wie u.a. Parodie, Pastiche, Travestie, Persiflage und ihre Unterarten.

Wir wenden uns hier $m$ erster Linie den Arbeiten zu, die - wie es ebenfalls bei Genette der Fall ist - die Differenzen zwischen verschiedenen Gattungen und Arten der .zweigradigen Texte“ erörtem und Hypertexten wie Travestie, Kontrafaktur u.a. die gleiche Aufmerksamkeit schenken wie der wesentlich besser erforschten Parodie. Eine gegenseitige Abgrenzung diverser Formen der literarischen ..Ableitungen“" scheint uns im Hinblick auf das Ziel unserer Arbeit insofern von erheblicher Bedeutung zu sein. als auch in der Cechovforschung (das sei im voraus bemerkt) in erster Linie Parodien beachtet worden sind. Wir werden hier weiterhin Überlegungen mancher Theoretiker zur Typologie moglicher Objekte, Figuren und Zielsetzungen bestimmter Hypertexte wiedergeben.

Unter den zahlreichen Parodiedefinitionen ist es deshalb sinnvoller, einige von denen heranzuziehen, die die Parodie vor dem Hintergrund restlicher Hypertexte auszeichnen. In

\footnotetext{
201 Plett 1985, S 91-92

202 Plett 1991. S 14

20.1 Ibid S 12-15

204 Lachmann 1982a, S 8

${ }^{203}$ Genette 1993, S. 14-15

$206 \mathrm{Vgl}$ S. 26-27 dieser Arbeit

${ }^{207}$ Genette 1993. S 15
} 
diesem Sinne ist die Definition L. Hutcheons - Parodie sei „repetition with critical difference $^{، 208}$ - für uns unzureichend, weil sie keine Abgrenzungskriterien bietet. ${ }^{209} \mathrm{O}$. M. Frejdenberg bedient sich dagegen in ihren Studien über die Entstehung der Parodie einer klassischen und gleichzeitig praziseren Definition: „[...] пародией называется подражание, при котором величественная форма наполняется ничтожным содержанием.“ ([...] Parodie ist eine Imitation, in der die erhabene Form mit einem nichtigen Inhalt gefüllt wird.). ${ }^{210}$ Die Formulierung Frejdenbergs stellt im Vergleich zu Hutcheon eine Konkretisierung dar, denn sie laßt auf die Art der ,parodiespezifischen“211 Inkongruenz schließen. ${ }^{212}$ Auch B. Müller betont in ihrer Monographie „Komische Intertextualităt: Die literarische Parodie“ die besondere Art des parodistischen Umgangs mit dem Prătext: Sie weist vor allem auf den Unterschied zwischen der parodistischen Einstellung zu semantischen und zu syntaktischen Eigenschaften des Referenztextes hin: „Wahrend thematische Strukturen des zu Parodierenden in der Parodie nicht reproduziert zu werden brauchen, obwohl of mehr oder minder subtile Parallelen bestehen, dürfen die wichtigsten sprachlichen Strukturen des Modells auf keinen Fall in der parodistischen Bearbeitung fehlen“. ${ }^{213}$ Dabei ergeben sich zusătzlich die für Prosaparodien spezifischen Merkmale: Der Autor der prosaischen Parodie imitiert zwar im wesentlichen den Stil der Vorlage, bezieht sich jedoch „auf ein abstraktes Stilsystem “214, d.h. wiederholt Teile des Prătextes selten wortwörtlich. Sprachliche Eigenschaften des Prătextes werden hăufig durch „übertreibende Hăufungen“215 der für ihn typischen Ausdrücke hervorgehoben. Parodistische Inkongruenz ergibt sich also aus dem Spannungsverhältnis zwischen der stilistischen und der thematischen Ebene des Textes, wobei auch der Stil nicht einfach getreu wiedergegeben, sondern meistens ,gebrochen“" wird.

$\mathrm{Zu}$ den alteren (modemen) Forschungen, in der Travestie und Pastiche geschichtlich wie theoretisch neben der Parodie behandelı werden, gehön der Beitrag von W. Hempel. Ähnlich wie Frejdenberg und Müller definiert er Parodie als literarisches Verfahren, „ein Werk oder eine Gattung des hohen Stils [...] mit übertreibenden oder anderweitig verzerrenden Abănderungen nachzuahmen “216. Die Travestie wird, wie Hempel ausführ, klassischerweise in Gegensatz zu Parodie betrachtet, weil sie .,den erhabenen Stoff beibehalte und diesem eine niedrige Stilform verleihe ${ }^{.217}$ - eine Ansicht, die Hempel allerdings nicht teilt. In der Parodie entgehen weder der Inhalt noch die Sprache des parodierten Textes der Herabziehung, was erlaubt, die Travestie als „eine unter den zahlreichen Möglichkeiten parodistischer Gestal-

\footnotetext{
${ }^{208}$ Hutcheon 1985. S 20

${ }^{209} \mathrm{Vgl}$ uber die Parodiedefinition Hutcheons bei Kuester 1998. S 414

${ }^{210}$ Frejdenberg 1973, S 490

211 Muller 1994, S. 213

${ }^{212}$ Zum Begriff und Interpretation des Inkongruenzphanomens in der Parodie- und Travestieforschung s. Karrer 1977. S 88-100; 113-117

${ }^{213}$ Muller 1994, S 222

214 Ibid S 223.

215 Ibid.

${ }^{216}$ Hempel 1965, S 151

${ }^{217}$ Ibid. S 164
} 
tung" zu bezeichnen. ${ }^{218}$ Der Pastiche hebt sich von der Parodie insofern viel deutlicher ab, als er primăr auf die Ähnlichkeit mit dem Original zielt und im Grunde eine Stilimitation darstellt, ohne daß dabei Diskrepanzen zwischen dem Inhalt und der Form bzw. auf einer der beiden Ebenen entstehen. Ein weiterer Unterschied besteht darin, daß Pastiche nie ein einzelnes Werk zur Folie hat, sondern z.B. das Gesamtwerk eines Autors: Stilistische Nachahmung wird hier vorı der stofflichen Erfindung begleitet. Von Interesse ist die Bemerkung Hempels, daß auch dem Pastiche eine ironische Absicht nicht fremd ist: Die Tatsache, daß der Pasticheverfasser sich einer fremden Sprache bedient, deutet auf seine distanzierte Haltung gegenüber dem Prătext hin. Diese bedeutendsten Differenzen zwischen Pastiche auf einer Seite und Parodie und Travestie auf der anderen bestătigt auch die Übersicht über die einschlăgigen Forschungen, die von $\mathrm{W}$. Karrer unternommen wird. Zusammenfassend stellt Karrer u.a. fest, $\mathrm{da} B$ in dem Pastiche erstens keine Inkongruenzerscheinungen vorhanden sind (.Die wichtigste Relation zwischen Pastiche und Original ist die der Mechanisierung ${ }^{c 219}$ ), zweitens, daß der Umfang der übernommenen Elemente dabei möglichst gering ist.

Im Gegensatz zu Hempel unterscheidet G. Genette Parodie, Travestie und Pastiche eindeutig: „Ich schlage also vor, als Parodie [...] die Bedeutungsănderung durch minimale Transformation eines Textes zu bezeichnen, [...]; als Travestie die stilistisch herabsetzende Transformation [...]; und als Pastiche die ohne satirische Absicht unternommene Nachahmung eines Stils, $[\ldots]{ }^{2220}$ Die ersten zwei Hypertextarten werden also mit Hilfe bestimmter Transformationen der Vorlage erzeugt, die letzte durch deren Nachahmung. Der Pastiche enthălt, wie Genette analog zu Hempel und Karrer akzentuiert, womöglich wenig Entlehnungen aus dem Bezugstext: „Ein Pastiche ist kein Spiel mit fertigen Versatzstücken, sondern bedarf einer Bemühung um Nachahmung, d.h. um Neuschaffung. “221 Den drei genannten Gattungen der Hypertexte entspricht die spielerische (für Parodie und Pastiche) bzw. satirische (für Travestie) Funktion (,Register“); der Hypertext kann jedoch ebenfalls durch ..ernste Transformationen“ entstehen (z.B. Th. Manns ..Doktor Faustus"), für die Genette den Begriff .Transposition" verwendet. ${ }^{222}$

Kaum weichen vom Genetteschen Verstăndnis der parodie- und travestiespezifischen Modifikationen des Prătexts die Ergebnisse der Untersuchung von Th. Stauder zur literarischen Travestie ab. Während in der Parodie die ..Komisierung“ des Textes unter Erhaltung seiner

\footnotetext{
218 Ibid. S. die angefuhren Zitate aus dem Beitrag Hempels auch bei Verweyen und Witting 1987. S 31-32 Der Meinung Hempels schlieBt sich auch Freund an ..Im Grunde verkennt die konventionelle Differenzierung die dialektische Verknupfung von Form und Inhalt Es empfiehlt sich [ ]. die Travestie als ein Vertiahren zu verstehen. das sich zur Realisienung der parodistischen Intention der Senkung der originalen Stilebene bedient" (1981. S 22)

219 Karrer 1977. S 123

220 Genette 1993, S 40

221 Ibid S. 103-104

222 lbid. S 43-44
} 
stilistischen Eigenschaften zu beobachten ist, setzt die Travestie gerade den Stil der Vorlage herab und behalt ihre Fabel. ${ }^{223}$

Der Ansatz von T. Verweyen und G. Witting ist den Texten gewidmet, die wir, gestützt auf den Begriff Genettes, ebenfalls als "Texte zweiten Grades“ bezeichnen würden. Ihre Auslegung der Parodie wird vor dem Hintergrund dreier weiterer Typen der literarischen Ableitungen unternommen: Palinodie, Kontradiktio und Kontrafaktur. ${ }^{224}$ In dieser „Umgebung“ zeichnet sich die Parodie vor allem dadurch aus, daß sie das Original komisierend und herabsetzend ,negativiert". ${ }^{225}$ In Anlehnung an die Untersuchung F.-W. Hoffmanns ${ }^{226}$ definieren die Autoren zunăchst Palinodie als „Umkehr des Lobes in eine Schmahung“, bei dem die Kompositionsformen des Originaltextes beibehalten werden - eine noch im Barock bekannte

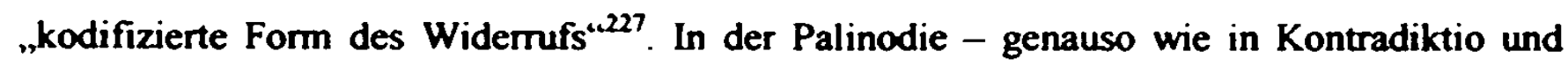
Kontrafaktur - fehlt dennoch jene abwertende Einstellung zum Pratext, die das zentrale Charakteristikum der Parodie bildet: „Ethos und Pathos der Vorlage bleiben [...] unangetastet“, „eine eigene Botschaf" wird „ohne ironische Brechung artikuliert “228. Allerdings richtet der Palinodieverfasser seinen Widerruf gegen den eigenen, früher geschriebenen Text, gegen die eigene, zugleich aber "fremdgewordene ${ }^{\text {.229 }}$ Rede, was haufig vom "Wandel der Einstellung" bzw. der "Neubewertung “230 des dem früheren Text zugnunde liegenden Referenzobjekts zeugt. Kontradiktio ist im Unterschied zur Palinodie auf die fremde Vorlage bezogen und stellt eine Schreibweise dar, die - wie Verweyen und Witting mit Zitat aus der Untersuchung Hoffmanns formulieren - „der in einer fremden Vorlage 'aufgestellten Meinung oder These widerspricht, indem sie ihr eine andere gegensätzliche Meinung oder These entgegenstellt"..23t. In der Kontradiktio H. Vogts „Bert Brechts revidierter großer Dankchoral“, das im Beitrag als Beispiel analysiert wird, werden „die Äußerungen eines Proponenten von einem Opponenten [...] wiederaufgenommen und in bezug auf eigene Interessen und Einstellungen [...] direkt kommentiert“232. Bei der Festlegung des Begriffs „Kontrafaktur" orientieren sich Verweyen und Witting schließlich u.a. auf die Arbeit A. Schơnes ${ }^{233}$, der als erster „eine Bedeutungserweiterung des Ausdrucks" gewagt hat: Er interpretiert Kontrafaktur nicht mehr ausschließlich als „Umdichtung eines weltlichen in ein geistliches Lied“, sondern ordnet dem

${ }^{223}$ S. Stauder 1993. S. 39. Dieselben Unterscheidungskriterien bietet auch das neueste Lexikon der Literatur-und Kulturtheorie (s. Kuester 1998, S. 414).

224 Verweyen und Witting betrachten Kontradiktio und Palinodie letztendlich als „Spezialfalle der Kontrafaktur" (s. 2000, S. 337).

223 Verweyen/ Witting 1982, S. 206-208

${ }^{226}$ F.-W Hoffmann „Die Palinodie als Gedichtform in der weltlichen Lyrik des 17 Jahrhunderts - Ein Beitrag zur Klarung des Begriffs 'Palinodie" (Diss. masch.) Gottingen 1956

${ }_{227}^{27}$ Verweyen/ Wining 1982, S. 211.

228 Ibid S 212.

2290 Ibid

230 Ibid. S 210

231 Ibid. S. 213

232 Ibid. S. 209

${ }^{233}$ A. Schone .,Săkularisation als sprachbildende Kraft - Studien zur Dichtung deutscher Pfarrersohne“ Göttingen 1968. 
Begriff auch weltliche - und das gewahrleistet „den Anschluß an neuere und aktuelle literarische Praxis“234 - Textadaptionen unter. Kontrafaktur ist, nach der prăzisierenden Definition von Verweyen und Witting, ein Text, der sich „die Produktionsstrategien des Ausgangstextes“ "zueigenmacht“ und „auf die Ausnutzung seines kommunikativen Potentials“ zielt, ,um hierdurch die eigene Botschaft zur Wirkung zu bringen ${ }^{\text {c235 }}$. Hier ist - anders als in der Parodie keine "Annihilierung des Themas“ des Originaltextes zu finden, sondern (z.B.) „seine historische Situierung und Perspektivierung ${ }^{\text {(236 }}$. Am Beispiel einiger „Mignonlied“-Kontrafakturen demonstrieren Verweyen und Witting, daß die in ihnen vollzogene „Entpoetisierung kein Akt intendierter 'Beschådigung' des Originals, [...], sondern eine [...] Folge der Benutzung des hochpoetischen Vorbildtextes für die Artikulation [...] des eigenen Anliegens “237 ist. Diese für Kontrafaktur spezifische Einstellung zum Referenztext bedeutet dennoch nicht, daß ihr Aufgaben der Komik und Satire fremd sind: Nur ist die Satire der Kontrafaktur auf „zur Vorlage relativ Extemes“238 gerichtet, so daß das Original nur noch zum „Medium“ der auf andere Wirklichkeitsbereiche bezogenen Kritik wird. ${ }^{239}$

"Hypertexten“ (nach Genette) wie Palinodie, Kontradiktio und Kontrafaktur haften also, wie man aus dem Beitrag schließen kann, gemeinsame Intentionen an: Nicht die herabwürdigende Komisierung des Bezugstextes, sondern vielmehr die Vermittlung einer eigenen Botschaft mit Hilfe eines fremden Textes setzen sie sich zum Ziel. Insofern bilden sie einen Kontrast zur Textverarbeitung ${ }^{240}$ in der Parodie, die „überhaupt keine eigene explizite Äußerungsabsicht des Parodisten“ zulaßt ${ }^{241}$. Manche fur Parodie bzw. Travestie typischen Modifikationen des Referenztextes - wie „auf Komik basierende“ Unter- oder Übererfüllungsoperationen $^{242}$ - finden hier demzufolge keinen Platz. Ändenungsoperationen in Kontrafakturen können jedoch nach Verweyen und Witting unterschiedlich sein.

Wir werden hier auf die mannigfaltigen Änderungstechniken, die Hypertexte wie Parodie, Travestie, Pastiche auf das Original anwenden, sowie auf das semantische Verhältnis zwischen dem präsenten und absenten Text nicht näher eingehen. Ausführlich werden die wesentlichsten syntaktischen und semantischen Eigenschaften der drei Textsorten in der Untersuchung Karrers vorgestellt. ${ }^{243}$ So kann die Parodie Operationen wie Detraktion (Tilgung der Elemente des Prătextes), Transmutation (deren Umstellung), Immutation (deren Ersetzen)

\footnotetext{
234 Verweyen Witting 1982, S. 220.

233 lbid S. 219.

236 Ibid. S. 218.

237 Verweyen/ Witting 1987, S. 100.

238 Jbid. S. 103

239 Ibid.

${ }^{240} \mathrm{Vgl}$. den Ausdruck bei Pfister (s. S. 25 unserer Abeit)

${ }^{2+1}$ lbid S.49 Vgl dazu die Formulienung Freunds: .Ihre (der Parodie - K. S) Triebfeder ist nicht die originale Aktivitat, sondern die Reaktivitat als Antwort auf bereits primar geformte Aussagen“" (1981, S. 14).

242 Verweyen/ Witting 1982. S 209

${ }^{243}$ S Karrer 1977, S 76-78; 119-123.
} 
und Adjektion (Hinzufügung neuer Elemente) enthalten ${ }^{244}$; der Umfang dieser Modifikationen ist variabel (ein Laut, ein Wort oder eine Passage). Travestie kann „alles bis auf die Namen“245 transformieren, dabei häufig durch Adjektion. Was semantische Relationen zwischen der Vorlage und dem Hypertext anbelangt, sind dies in der Parodie die der Inkongruenz und Mechanisierung (die letzte erfolgt z.B. durch Repetition oder Inversion), in der Travestie meistens die der Inkongruenz und im Pastiche allein die der Mechanisierung.

Besprochen werden in der Intertextualitătsforschung hăufig ebenfalls mơgliche Objekte der erörterten Hypertexte. Wăhrend der Pastiche sich im Verstăndnis Hempels und Genettes nicht auf das einzelne, sondern auf mehrere Texte bezieht, $d . h$. keine einzeltextreferenzielle Verfahren verwendet, konnen Parodie und Travestie sowohl ein konkretes Werk als auch eine Textklasse („die Texte eines Autors, einer Gruppe von Autoren einer Richtung, einer Gattung oder einer Epoche ${ }^{.246}$ ) zum Objekt haben. In diesem Sinne differenziert W. Dietze zwischen direkter Parodie (der Einzeltextreferenz zugrunde liegt), indirekter Parodie (die auf mehrere Texte gerichtet ist) und fiktiver Parodie (die sich durch Systemreferenz auszeichnet) ${ }^{247}$. B. Müller erstellt darüber hinaus eine Liste semantischer Merkmale der Vorlage, die fur Parodien traditionell eine besondere Attraktivităt besitzen. Oft parodiert werden z.B. ideologisch und didaktisch stark geprägte, triviale oder durch „Briche zwischen der Ausdrucks- und der Inhaltsebene" markante Texte. ${ }^{248}$ Die fur Parodisten besonders attraktiven Charaktere zeichnen sich dadurch aus, daß sie hăufig eine „strebende, zielgerichtete Kraft“249 verkörpern, Z.B. das Genie (dessen Einzigartigkeit gerne ins Lacherliche gezogen wird), der Moralist (dem eine Diskrepanz zwischen dem Wort und der Tat „unterstellt“ wird), der Sentimentale (der naive und trottelhafte Züge gewinnt) oder der Held. Eine erhebliche Bedeutung "für die Parodierbarkeit eines Textes ${ }^{\text {‘250 }}$ hat ebenfalls der Bekanntheitsgrad der Vorlage - sowohl bei Einzeltext- als auch bei Systemreferenz. Im letzten Fall sind das beispielsweise Gattungen des Sonetts oder des Krimis oder literarische Schulen wie Romantik oder Naturalismus, die am häufigsten zur Zielscheibe der Parodie werden. Zur Handlung der typischsten Parodievorlagen bemerkt Müller ganz allgemein, daß sie .,ein negativ dominiertes Geschehen aufweisen ${ }^{\text {.251 }}$. Schließlich gehören syntaktische und stilistische Qualităten des Referenztextes zu den wichtigsten Motivationskriterien für die Erschaffung der parodistischen Nachahmung: Das stilistisch „Außergewöhnliche“ (,sei es nun die Abweichung von einer ästhetischen Norm“ oder

\footnotetext{
${ }^{244}$.Bevorzugte Mittel” der parodistischen Verzernung sind, nach Freund, „die Reduktion, die Bagatellisienung und die Selektion inhaltlicher Elemente [...]. die Kumulation und die hyperbolische Ubersteigenung". im Ganzen ..substitutive, diminutive und augmentative Verfahren" (1981, S. 14)

${ }_{245}$ Karter 1977 , S. 77

${ }^{246}$ Ibid. S. 76.

${ }^{247} \mathrm{~S}$ die Kommentare zu dieser Typologie bei B. Muller 1994, S. 230

${ }^{248}$ Müller 1994, S 101-108 Vgl dazu die Aussage Freunds. der unter beliebtesten .Angriffszielen“ der (seriosen) Parodie "Verengung des Blickwinkels, dogmatisch und doktrinar verhärete Sichtweisen. monistische Weltanschauungen und ideologische Gruppeninteressen sowie jegliche Form intoleranter, autoritarer und fanatischer Beschrankung" nennt (1981, S. 15)

${ }^{249}$ Müller 1994. S. 108-109

${ }^{250} \mathrm{Ibid}$. S. 129
} 


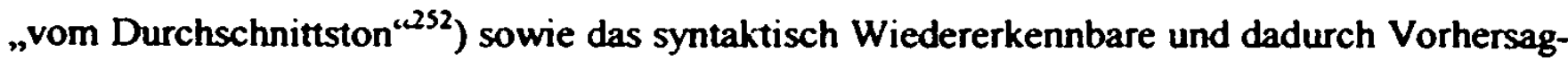
bare (das der Leser auch „, bei einer Verănderung des Inhalts und sogar bei einer gemäßigten Variation der Form “253 zu identifizieren vermag) schaffen Voraussetzungen für die gleichzeitige Nachbildung und Entstellung des Originals.

Sicher treffen die von Müller speziell für die Parodie beschriebenen Charakteristika der Vorlage in gewisser Weise auch für andere Arten der literarischen Ableitungen zu: gemeint ist dabei nicht nur die Travestie, die aus Sicht mancher Theoretiker nicht zufallig eine der vielen parodistischen Modifikationstechniken darstellt, sondern ebenfalls der Pastiche (um so mehr, je deutlicher es eine distanzierende Haltung gegenüber dem Prătext aufweist) und z.T. die Kontrafaktur.

\subsection{Intertextuelle Beziehungen im Werk Čechovs als Gegenstand der Čechovforschung}

Es muß vorweg angemerkt werden, daß eher wenige Arbeiten, die sich mit den Beziehungen der Werke Cechovs zu anderen Texten befaßt haben, die angeführten Konzepte der Intertextualitătstheorie in einem größeren Umfang heranziehen, wenn auch Begriffe wie ,intertextuelle Bezüge bzw. Kontakte“ und ..Intertextualităt" von Cechovforschern nicht selten benützt werden.

Im allgemeinen konzentriert sich ein Großteil der Cechovspezialisten tendenziell auf die inhaltlich-thematischen Aspekte der Text-Text-Beziehungen im Cechovschen Werk, mißt aber zugleich ihrer formalen Natur (für deren differenzierte Behandlung die oben skizzierten theoretischen Konzepte eine sichere Basis bieten), eine geringere Bedeutung bei. Es fehlen z.B. charakteristischerweise Untersuchungen werkübergreifender Intertextualităt im Werk Cechovs, die gerade die formale Art der Kontakte, die die Theorie der Intertextualităt herausarbeitet bzw. differenziert reflektiert, in den Mittelpunkt steilen, d.h. auch zum Titelthema machen (beispielsweise Typen des Zitats oder intertextuelle Paratexte im Werk Cechovs). Die in der einschlägigen Literatur traditionell bevorzugten Prinzipien der Auswahl und der (jruppierung intertex/ueller Bezüge heben vor allem die semantische und thematische Dimension des Intertextualitătsphănomens bei Vernachlässigung der formalen Seite hervor: u.a. können zahlreiche Analysen, die das Ziel verfolgen, die Spezifik der Beziehungen Cechovs zu Shakespeare oder Tolstoj (vgl. z.B. einen in der Cechovliteratur bereits zur Formel gewordenen Ausdruck „tolstovskie rasskazy Cechova“ (Tolstojanische Novellen Cecovs)) zu ermitteln, unsere Beobachtungen exemplarisch bestătigen. ${ }^{254}$

\footnotetext{
251 Ibid. S. 98

252 lbid S. 119

233 tbid. S. 132

${ }^{254}$ Eher selten ist in der Cechovlandschaft auch Beitragen zu begegnen. die im Rahmen einer Einzelanalyse die nach formalen Kriterien ausgewahlten intertextuellen Erscheinungen in den Mittelpunkt stellen, also auch einen 
Die Theorie der Intertextualităt, die wir in einem größeren Masse in die Analyse miteinbeziehen möchten, bietet (das zeigt die Auswahl der Konzepte im Kap. 2.1.) nicht nur die Möglichkeit einer prăziseren und differenzierteren Erforschung der Erscheinungsformen intertextueller Kontakte, konkreter der intertextuellen Signale, sie scheint auch für die Untersuchung von deren semantischer Stellung in den Werken Cechovs fruchtbar zu sein. Erst vor dem Hintergnund der von manchen Theoretikern herausgebildeten generellen - also für die Gesamtheit der Intertextualitătserscheinungen als Meßinstrument geeigneten semantischen Kategorien tritt die Eigenart einer individuellen intertextuellen Poetik im notwendigen Maße hervor: Das im konkreten Text Verwirklichte wird nămlich als Ausformung eines der mehreren - auf der theoretischen Ebene gegebenen - semantischen intertextuellen Verfahren angesehen und dadurch im Rahmen eines breiteren Kontexts eingestuft. Dieser breitere Kontext hat unseres Erachtens in der Cechovforschung bisher gefehlt. Offensichtlich ist dabei jedoch, daß eine solche Einordnung eine bessere Orientierungsmoglichkeit bei der Bewertung eines intertextuellen Phănomens darstellt. Um einen transparenten Überblick über die aus unserer Sicht wesentlichsten Beiträge im Bereich der Cechovforschung zu verschaffen, haben wir versucht, sie in ein System zu bringen. Wir haben die einschlăgigen Ansătze in folgende sechs Gruppen aufgeteilt:

1. Aussagen zur Eigenart der Cechovschen Intertextualität im allgemeinen;

2. Beiträge, die sich mit den intertextuell zu deutenden literarischen Typen und Figuren im Werk Cechovs (wie Hamlet, Faust, Don Juan, Manfred u.s.w.) befassen;

3. Ansătze, die die Übernahme und Transformation fremder Handlungsstrukturen bzw. fremder Sujets im Werk Cechovs zum Gegenstand ihrer Untersuchung machen;

4. Ansätze, die sich auf den Transfer und die Rezeption der aus fremden Texten stammenden Ideen, Ideologien bzw. Theorien in Cechovs Werk konzentrieren; zum Bezugsobjekt werden in diesem Fall entweder Texte aus dem Bereich Philosophie und Publizistik oder Texte der schönen Literatur, die von den Forschem als Medien bzw. Quelle bestimmter Ideen betrachtet werden (besondere Aufmerksamkeit finden dabei Referenztexte, die in Verbindung mit aktuellen Fragen einer Epoche wie z.B. Pessimismus oder Frauenemanzipation stehen oder die selbst Ideen, die zu solchen Fragen geworden sind - wie etwa die Tolstojsche Lehre der Gewaltlosigkeit (.,непротивление злу насилием“) - enthalten);

entsprechenden Titel tragen. S. z.B Kosiny. Bedeutung und Funktion der literarischen Zitate in A. P. Cechovs 'Tri sestry' ('Drei Schwestem' - K. S )" (1971)

Wir wollen hier anmerken. daß wir ausgewahlte Arbeiten uber die intertextuellen Beziehungen im Werk Cechovs bereits besprochen haben (Smola 1998b, S. 509-517, 526-532), u a z B Peace 1986. Lauer 1990, Leithold 1989. Wir haben ebenfalls separat Arbeiten behandelt. die u. a Ideen verschiedener Philosophen bei Cechov bzw. Ahnlichkeiten in ihrer Weltanschauung ermitteln (das uberschneidet sich z.T mit den Beitrayen der Gruppe 4 in unserer Arbeit. s. weiter, vgl. teilweise auch unsere Beurteilung der betreffenden Beitrage in der erwahnten Arbeit und hier (s. Smola 1998b. S. 513-514); jedoch erweisen sich fur uns heute manche von unseren ('rteilen und Formulierungen in bezug auf die einschlagige Literatur dort als unzutreffend) 
5. Arbeiten, deren Verfasser Funktionen ausgewăhlter Intertextualitătsformen - nămlich der Zitate und Allusionen - in einzelnen Texten Cechovs ermitteln; die Forscher stellen in diesem Fall die Bezüge, denen ein bestimmter Typ des intertextuellen Signals nămlich der für das Zitat und die Allusion spezifische - deutlicher als in anderen Untersuchungen in den Vordergnund, (jedoch sind auch die Beiträge der Gruppen 2, 3 und 4 dieser Gruppe zuzuordnen, wenn in ihnen die vergleichende Analyse der aktuellen und der evozierten Handlungsstrukturen und Protagonisten aus der Funktion konkreter intertextueller Signale entfaltet bzw. wenn sich auf solche ,sichtbaren“ Spuren bei dem Vergleich gestützt wird);

6. Arbeiten, die das dialogische Verhältnis Cechovscher Texte zu den Textsystemen wie zB. literarischen Gattungen und Epochen reflektieren. ${ }^{25 s}$

In unserer Typologie haben wir in den einschlägigen Untersuchungen verschiedene Aspekte des Intertextualitătsphänomens hervorgehoben: in den Beiträgen der Gruppe 2, 3 und 4 - bestimmte Ebenen des Referenztextes und entsprechend auch des manifesten Textes (sei es die Ebene der Charaktere, der Handlung oder der Ideen); in den Beiträgen der Gruppe 5 - ausgewăhlte Formen der intertextuellen Bezüge; in den Beitrăgen der Gruppe 6 - die Wahl des Referenztexttyps (individueller Einzeltext vs. Textsystem).

Es ist nicht zu übersehen, daß zwischen den von uns aufgestellten Spektren der Čechovforschung keine scharfen Grenzen liegen: Die Gruppen überlappen sich nămlich gegenseitig in mehreren Gesichtspunkten, was auch als Vorbehalt bzw. Einschränkung unseres Schemas der Cechov-Forschungslandschaft betrachtet werden kann. Beispielsweise lassen sich Studien zur Form und Funktion der Zitate und Allusionen im Werk Cechovs nur sehr schwer von den Beitrăgen abtrennen, die Text-Text-Beziehungen auf bestimmten Ebenen des Referenz- und des aktuellen Textes untersuchen: Kontakte, die auf einzelnen Ebenen eines literarischen Werkes vollzogen werden, werden erst dann zur Tatsache, wenn sie zumindest durch cinen konkreten, im Text nachzuweisenden Bezug .,bestätigt“ sind, und dieser Bezug kann seinerseits die Form eines Zitats oder einer Allusion annehmen. Das im manifesten Text prăsente intertextuelle Signal wie ein Zitat oder eine Allusion schaff, mit anderen Worten, die Basis und die Voraussetzung für den Vergleich der Texte - von deren Figuren, Handlungsabläufe u.s.w. Und deshalb verschmelzen die Beiträge der Gruppe 2, 3, 4 mit denen der Gruppe 5 umsomehr, je deutlicher sie Parallelen auf bestimmten Ebenen der Texte mit der Funktion der Zitate/ Allusionen verknüpfen. In diesem Sinne können manche Ansätze durchaus gleichzeitig verschiedenen Gruppen zugeordnet werden. Noch problematischer erscheint eine gegenseitige Abgrenzung diverser Ebenen eines Bühnen- bzw. Erzählwerkes (d.h. auch der Gruppen 2, 3 und 4), da sie nur als Bestandteile eines integrativen Ganzen begriffen wer-

\footnotetext{
${ }^{235}$ In unserer Dissertation geten wir nicht auf die Arbeiten ein, die sich mit den Beziehungen der Werke Cechovs zu den biblischen und mythischen Pratexten beschaftigen (zu solchen gehor beispielsweise von den jungeren Forschungen die Monographie V Zubarevs (1997))
} 
den können und isoliert voneinander nicht denkbar sind. Unzweifelhaft ist dennoch ebenfalls, daß diese Unterscheidung ihre Motivation bisweilen im realen Sachverhalt findet, d.h. sowohl literarische Fakten als auch das methodische Vorgehen und das Erkenntnisinteresse mancher betreffender Arbeiten widerspiegelt. So werden z.B. manche weltberühmten literarischen Gestalten wie Hamlet oder Don Juan in der russischen Literatur und folglich von ihren Interpreten als Verkörperung und Symbol für eine bestimmte Weltanschauung und eine spezifische Verhaltensweise interpretiert, die im Rahmen recht unterschiedlicher Handlungsablăufe zum Vorschein kommen können; in diesem Fall spielt das Sujet, die Handlung des Prătexts, dem diese fiktive Person entstammt, eher eine geringe Rolle, da sich die so rezipierte literarische Figur von ihrer ursprünglichen kontextuellen Umgebung zu einem gewissen Grad ablöst. In den Vordergrund der Untersuchung rücken also die aus den fremden Texten stammenden Charaktere, die in das neue Werk mehr oder weniger unabhängig von ihrer Geschichte "übergegangen“ sind. Andererseits betrachten viele Čechovforscher auch einige literarische Texte, auf die sich Čechov ihrer Ansicht nach bezieht, als Medien bestimmter Ideen bzw. als Stellungnahme zu einem bestimmten Problem (z.B. gerade zu aktuellen gesellschaftlichen Fragen der Zeit); dann werden auch Cechovs Werke in erster Linie als Antwort auf die durch den Prätext vermittelten Ideen oder als Äußerung zum im Prătext angesprochenen Problem angesehen (zu solchen Prätexten gehör z.B. Klassischerweise „Krejcerova sonata“ (,Kreuzersonate“)). In diesem Sinne haben wir die 4. Gruppe von den Gruppen 2 und 3 abgesondert. Trotz diesen Unterscheidungskriterien konnte man von den meisten Beiträgen behaupten, daß im Laufe der Analyse keine Textebene von der anderen unberührt bleibt, d.h. $\mathrm{da}$ sie alle in die Interpretation einbezogen werden. Wenn eine Person Cechovs intertextuell - in bezug auf eine fremde Figur - gedeutet wird, wird in der Regel auch die Handlung des Referenztextes herangezogen. Wenn ..Duèl““ (..Das Duell”) oder ..Dama s sobačkoj“ („Die Dame mit dem Hündchen“) als Stellungnahme zu der in der ..Kreuzersonate“ vermittelten Predigt der sexuellen Enthaltsamkeit ausgelegt wird, dann werden die Novellen auch auf der Ebene ihrer Sujets und ihrer Charaktere komparatistisch analysiert.

Manche Arbeiten über Cechov werden von uns manchmal in verschiedenen Gruppen erörtert bzw. erwähnt, falls ihr Erkenntnisinteresse - gerade wegen der Verschwommenheit der gesetzten Grenzen - zugleich mit einigen Gruppen zu verbinden ist (es werden aber gleichzeitig nicht alle Arbeiten, die aus verschiedenen Gründen unterschiedlichen Gruppen zugeordnet werden könnten, in jeder Gruppe erörtent).

1. In der Čechovforschung kann man gelegentlich Aussagen begegnen, die den allgemeinen Charakter sowie die Eigenart der Cechovschen Intertextualität betreffen. Dabei sind gewisse Übereinstimmungen der Forscher bezüglich ihrer Grundeigenschaften nicht zu übersehen. So vertreten einige Spezialisten die Meinung. daß intertextuelle Kontakte einen „unverbindlichen" semantischen Hintergrund der Čechovschen Texte bilden. daß sie deren Interpretation zwar bereichern, aber für das Verstăndnis des Werks nicht unabdingbar sind. .'Эхо литературных ассоииаций' [...] не смолкая звучит в чеховской новеллистике. но 
нигде не подчиняет себе сам изображаемый материал, который у Чехова всегда понятен и без обращения к авторитетам.“ (..Das Echo der literarischen Assoziationen“ [...] hallt in Cechovs Novellistik stets wider, aber es ordnet nie den dargestellten Stoff unter, der bei Cechov auch ohne den Bezug zu den Autoritäten immer verständlich bleibt), - schreibt $\mathbf{P}$. I. Ovčarova. ${ }^{256}$ Sie spricht im Allgemeinen von .,leisen“ Verweisen auf Klassiker in Texten Cechovs (,'tichie' napominanija o klassikach“257). Mit dieser Ansicht korrespondiert direkt die Aussage von V. B. Kataev: „Рядом, например, с [...] 'художественным филологизмом' произведений Лескова литературный слой чеховских произведений более тонок, не самодовлеющ, менее заметен“. ${ }^{25 x}$ (Neben dem, z.B. [...] 'künstlerischen Philologismus' der Werke Leskovs ist die literarische Schicht der Werke Cechovs dünner, sie ist nicht selbstgenügsam, weniger sichtbar). Cechov bezieht sich, nach Kataev, auf andere Autoren „вскользь, мимоходом“" (beilăufig, nebenbei) ${ }^{259}$.

2. "Intertextuelle“ Gestalten im Werk Cechovs sind bereits zum Objekt zahlreicher Forschungen geworden, wobei aus vielen fremden literarischen Figuren, die in bezug auf die Personen Cechovs jemals interpretien wurden, u.a. die Gestalt Hamlets mit Sicherheit die großte Beachtung gefunden hat.

Viele Cechovspezialisten sind sich darin einig, daß Cechov nicht so sehr die unmittelbar aus der Tragödie Shakespeares stammende Figur zur Folie hatte, sondern vielmehr ihre eigenstăndige Rezeption in der russischen Literatur und Kritik. Im 1964 geschriebenen Aufsatz .Obraz Gamleta i problema 'gamletizma' v russkoj literature konca XIX v. (80-90 gody)”“ (Die Gestalt Hamlets und das Problem des 'Hamletismus' in der russischen Literatur Ende des XIX Jahrhunderts (80-90 Jahre)) zeigt M. E. Elizarova, wie sich diese Rezeption entwickelte: Sie nimmt ihren Anfang in Turgenevs Aufsatz „.Gamlet i Don-Kichot“ (Hamlet und Don-Quijote). in dem Hamlet in erster Linie als Skeptiker, als ein Mensch, der ..für die Masse nutzlos“ ist, der eher die Fähigkeit zur Zerstōrung, als die zum Schaffen, besitzt, begriffen wird, eine Akzentuierung, die die spätere Wahrnehmung dieser Gestalt in der russischen Kultur am stärksten beeinflußt hat. Gleichzeitig betont Turgenev, wie Elizarova ausführt, daß Hamlet gegen die Lüge und so für die Wahrheit kämptì - für die Wahrheit, ..an die er nicht ganz glauben kann ${ }^{260}$. In den 1880er Jahren werden Hamlet solche Charakter- und Weltanschauungszüge zugewiesen wie ..Kraftlosigkeit, Pessimismus und Nichtsnutzigkeit”:

В его толкование вносился значительный злемент субъективизма и пронзвольности. Всё более укреплялась традиция видеть в Гамлете голько выражение бессилия, пессимизма и никчёмности, то есть творить его по образу и подобию людей 80-х годов. При зтом Гамлет вовсе лишался какой-либо

\footnotetext{
2s* Ovcarova 1985. S 94

257 lbid

258 Kataev 1989. S 33

259 Ibid
} 
целеустремлённости, действенности [...]. [...] „Восьмидесятнику“ был особенно созвучен именно такой герой - Гамлет, превращённый в нытика и чуть ли не в неврастеника. (In seine Deutung brachte man ein beträchtliches Element von Subjektivismus und Willkürlichkeit ein. Es setzte sich immer mehr die Tradition durch, in Hamlet ausschließlich den Ausdruck von Kraftlosigkeit, Pessimismus und Nichtsnutzigkeit zu sehen, d.h. ihn nach Vor- und Ebenbild der Menschen der 80er zu schaffen. Hamlet büßte dabei jegliche Zielstrebigkeit, Tatkraft ein [...] Dem ,Achtziger-Menschen" entsprach im besonderen Masse gerade ein solcher Held - Hamlet, der in einen Norgler und Neurastheniker verwandelt wurde). ${ }^{261}$

Die solchermaßen rezipierte Figur Hamlets wurde bald zum Objekt satirischer Angriffe - von der Seite der Schriftsteller des Kreises der „narodniki“ (народники, Volkstümler) („обличители лжегамлетов“, die Ankläger der falschen Hamlets) ${ }^{262}$, aber auch bei Cechov. Im Feuilleton „V Moskve“ (In Moskau) (1891) bezeichnet sich der „Moskauer Hamlet“, in dem Cechov das Bild der modernen Intelligencija wiedergegeben hat, als „drjan'“ (,дрянь“, Lump) und „kisljatina“ („кислятина“, Miesmacher). Elizarova weist weiterhin darauf hin, daß Hamlet gleichzeitig - in der Literatur der 1880er Jahre und u.a. in Werken Cechovs zum Symbol der modemen Generation, die ihre Ideale, Wünsche und Hoffnungen eingebüßt hat, geworden ist. ${ }^{263}$ Dadurch, daß er die Ratlosigkeit, Enttauschung, zugleich aber die geistige Unruhe des russischen Intellektuellen der $1880 \mathrm{er}$ Jahre verkorpert, gewinnt er seine Würde und seine Tragik zurück. So entstehen auch die Hamletgestalten im Werk Cechovs: Platonov, Ivanov, Silin, Ivašin u.a. Dabei versteht Elizarova unter den Čechovschen Hamlets recht breit alle männlichen Personen, die einen inneren Kampf erleben und keine Kraft finden, Entscheidungen zu treffen, oder - noch breiter - als Menschen, „oderžimye bespokojstvom mysli“ (besessen von der Unruhe des Denkens). ${ }^{264} \mathrm{Um}$ die Person Cechovs mit Hamlet zu vergleichen, benơtigt Elizarova jedoch nicht unbedingt die Prăsenz konkreter .materieller" Verweise im aktuellen Text, sondern baut ihre Interpretation mitunter allein auf thematischen Analogien auf.

In einer umfangreichen Monographie ..Šekspir i russkaja kul'tura" (Shakespeare und die russische Kultur) (1965), herausgegeben von M. P. Alekseev, werden die Wege der russischen Shakespearerezeption verfolgt, dabei wird dem Aufsatz Turgenevs - ähnlich wie bei Elizarova - für die Darstellung und die Auslegung der Hamletfigur in der russischen Literatur in der zweiten Hälfte des 19. Jahrhunderts eine zentrale Bedeutung beigemessen. ${ }^{265}$ Turgenev war der erste, der Hamlet (und Don Quijote) als menschlichen Archetyp betrachtet und seine

\footnotetext{
${ }^{200} \mathrm{~S}$ das Zitat aus dem Arikel von Turgenev bei Elizarova 1964, S 47

261 Elizarova 1964. S. 48

202 lbid S 49

${ }^{263} \mathrm{Vgl}$ danuber auch bei Sach-Azizova 1977

264 Elizarova 1964, S. 56.

26: S das 6. Kapitel ..Sestidesjatye gody". verfaßt von J. D. Levin
} 
geistige "Verwandtschaft" mit der russischen adeligen Intelligenz ins Bewußtsein gerufen hat. In den Novellen „Gamlet Šcigrovskogo uezda“ (Hamlet aus dem Šcigrovkreis) und „Dnevnik lišnego celoveka“ (Tagebuch eines überflüssigen Menschen) verbindet er den ,Hamletismus“ mit der Gestalt des überflüssigen Menschen, dem vor allem die Eigenschaften wie die Făhigkeit zur Selbstreflexion, Egoismus und Individualismus anhaften:

[...], русскому гегельянцу 40-х годов, уже присущи все черты гамлетовского характера, которые впоследствии были охарактернзованы в статье: згоизм, безверие, всепоглощающая рефлексия, страсть к самоуничижению, беспредметные разговоры о самоубнйстве, неспособность к непосредственному чувству, к любви, [...]. ([...] dem nussischen Hegelianer der 40er Jahre, sind bereits alle Charakterzüge von Hamlet eigen, die später im Artikel beschrieben wurden: Egoismus, Ungläubigkeit, verzerrende Reflexion, Neigung zur Selbsterniedrigung, grundlose Gespräche vom Selbstmord, Unfähigkeit zum unmittelbaren Gefühl. zur Liebe, [...]. $)^{266}$

Cechovsche Personen, z.B. Ivanov im gleichnamigen Drama, können im Rahmen dieser von Turgenev angelegten Tradition gedeutet werden. ${ }^{267}$

Die Tatsache, daß Cechov sich in seiner Hamletinterpretation nich auf die Tragödie Shakespeares, sondern vielmehr auf deren Rezeption orientiert hat, d.h. daß sein Erfassen dieses Prätextes durch viele Vermittler gelaufen ist, gehört zu den möglichen Gründen dafür, warum Čechovforscher häufiger auf die Gegensätzlichkeit seiner Personen zum Shakespeareschen Helden aufmerksam werden. R. L. Jackson artikuliert diese Polarität in bezug auf einen der Cechovschen Hamlets - nämlich Treplev - folgendermaßen: ... [..] he has nonetheless, like [...] Hamlet, the option of self-discovery in art of action. This opinion he rejects, for he lacks the courage to face himself, his talent [...]. Like so many Chekhovian heroes, his tragedy consists in his inability to rise to the level of tragedy. He is far from being a Hamlet. ${ }^{2(x)}$ Das Unvermögen der Personen Cechovs, die tragische Größe von Hamlet zu erreichen, wird in der einschlägigen Literatur immer wieder thematisiert. Nach F.-J. Leithold, zeichnen sich die Charaktere in der „Möwe” durch die ..Unfàhigkeit zur Tragödie“ aus. "(n) Um zum tragischen Helden zu werden, fehlt es der Person Cechovs an ..festen Wertvorstellungen“": „Vielmehr ist Treplev auf der Suche nach festen Handlungskriterien. [...] Ein tragischer Konflikt kann nur durch die Auseinandersetzung mit der Außenwelt ausgelöst werden. Treplev lebt jedoch isoliert von der Umwelt auf dem Landgut seines Onkels. “27\%) Für die Erklärung dieser Gestaltung zieht Leithold die von uns skizzierte Rezeptionsgeschichte der Hamletgestalt vor Cechov heran. Analog zu Elizarova und Levin kommt Leithold zum Schluß, daß der Cechovsche

\footnotetext{
${ }^{206}$ Levin 1965, S 464

${ }^{267}$ S. ibid. S. 467-468

26x Jackson 1981. S 13

${ }^{269}$ Leithold 1989, S 118
} 
Hamlet Treplev im wesentlichen der Hamletinterpretation Turgenevs in "Gamlet i Don-Kichot" entspricht ${ }^{271}$, wăhrend Nina nach Leithold Züge eines Don Quijote-Typs und der Arzt Dorn solche von Horatio tragen. Dennoch kopiert Cechov weder literarische Typen Shakespeares noch ihre Turgenevsche Deutung, sondern weicht von den gegebenen Vorlagen bewußt ab: so kămpft Treplev-Hamlet gegen Windmühlen und Dorn-Horatio "verfallt in Gleichgültigkeit ${ }^{\prime 272}$. Der Hamlet des Feuilletons „V Moskve“ ist nach Leithold dagegen nur vor dem Hintergrund der in den 1880er Jahren ausgelosten Hamletismusdiskussion zu verstehen. Einerseits richtet Cechov seine satirische Botschaft auf die ,modernen Kopien“ Hamlets, "verhamletisierte Ferkel“, die insbesondere Literaturkritiker der Narodniki angegriffen und demaskiert haben ${ }^{273}$, andererseits spielt er auf diese stark ideologisch geprägte Kritik selbst an: „Sein 'Moskauer Hamlet' urteilt über das modeme Theater und Drama nämlich: 'Aber wo

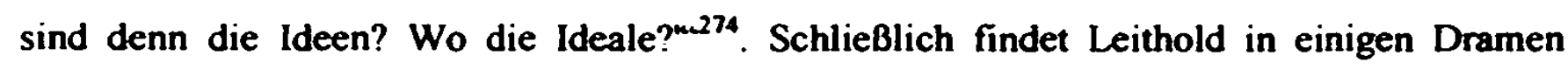
Cechovs ebenfalls Hamlettypen, wobei er sich immer auf die im Text vorhandenen Anspielungen auf die Tragödie orientiert. Dabei entspricht die Entwicklung dieser Gestalt in den Bühnenwerken Cechovs den Phasen der Hamletismusdiskussion Ende der 1870er bis Ende der 1890er Jahre: Von der noch durchaus positiven Bewertung der Hamletfigur durch die dramatis personae im „Platonov“ über ihre negative Umkehrung (ihre Bewertung durch Ivanov selbst) in „Ivanov“ zu der gesunkenen Aktualităt dieses Verweises in der „Mówe“ (hier "wird schlieBlich kein direkter Bezug der Protagonisten zur literarischen Figur des Hamlet ausgesprochen“" ${ }^{275}$ Im Ganzen stützt sich Leithold in seiner Untersuchung auf mehrere konkreten Zitate und Anspielungen auf die Pratexte im Stück, so daB gezeigt wird, wie konkrete Zitate und Allusionen „den Bedeutungsaufbau der 'Möwe' beeinflussen“276.

Die Auffassung, daß die Personen Cechovs als gescheiterte literarische Helden klassischer Werke konzipiert sind, greift als nächster $\mathbf{R}$. Lauer auf. Für ihn stellt Platonov - die zentrale Figur des frühesten Dramas Cechovs - eine .Neufassung vorausgegangener Heldenmodelle ${ }^{\text {c.277 }}$ dar. Parallelen zwischen ihm und seinen literarischen Prototypen werden allerdings jedes Mal von den dramatis personae selbst thematisiert. Wie Cackij verspottet er die Gesellschaft im Salon von Anna Petrovna und wird fur einen Wahnsinnigen gehalten. Platonov wird aber im Gegensatz zu Cackij ..der billige Spaß an der Emiedrigung anderer unterstellt".278. Anna bezeichnet ihn weiterhin als. Дон-Жуан и жалкий трус в одном теле“ (.,Don Juan

\footnotetext{
${ }^{270}$ Ibid S. 120

${ }^{271} \mathrm{~V}_{\mathrm{gl}}$ die Beschreibung des von Turgenev gegebenen Hamlet-Types bei Leithold (1989, S. 129-131) mit der bel Elizarova und Levin (s. S 46-48 dieser Arbeit)

${ }^{272}$ Leithold 1989, S. 136

${ }^{273}$ Leithold stutzt sich u.a auf die Arbeit von Sach-Azizova (1977). die ebenfalls die russische Rezeption der Hamlet-Gestalt in der Cechovs Zeit schildert

274 Leithold 1989, S 141

273 Ibid S 151

${ }^{276}$ Ibid S 109 Uber die Funktion der Verweise auf .Hamlet" in „Cajka” s ebenfalls bei Hubner 1971, S 107. 110

27 Lauer 1990.5611

${ }^{278}$ Ibid S 612
} 
und jămmerlicher Feigling in einem und demselben Korper “279); eine Reihe von Übereinstimmungen mit der Handlungsstruktur sowie mit den einzelnen Details des Don-Juan-Sujets (u.a. Puskins „Kamennyj gost' ${ }^{\prime \prime}$ ) suggeriert ebenfalls die Ähnlichkeit Platonovs mit dem spanischen Helden. Die wichtigste Folie für die Darstellung der männlichen Hauptperson im Drama Cechovs ist jedoch nach Lauer Hamlet oder viel eher noch, wie auch Lauer seinerseits betont, seine Auslegung in Turgenevs „Gamlet i Don-Kichot". Das Bild von Hamlet hängt hier weitgehend mit dem des ..überflüssigen Menschen“ in der russischen Literatur vor Cechov, u.a. gerade im Konzept Turgenevs, zusammen. Diese Beobachtungen bekrăftigt Lauer mit der Analyse der drei Bezüge, d.h. der drei expliziten Verweise auf "Hamlet” in „Platonov“. Resümierend stellt er fest, daß Platonov lediglich der ..schwăchliche Nachfahre“ seiner Vorbilder ist: „Wo Cackij nach Wahrheit strebte, leistet sich Platonov schale Späße; wo Don Juan Leidenschaft und Kühnheit zeigte, erfassen Platonov Feigheit und Kleinmut; wo Hamlet Visionen und Traumgespinste schaute, jammen Platonov um sein Leben“. 200

Auch Kluge kommt in seiner Charakteristik des Jugenddramas Cechovs zum SchluB: .Platonov erweist sich also im Vergleich zu allen Bezugsfiguren in den Prätexten als unterlegen. ${ }^{28_{i}}$. Er fügt hinzu: „Das mag als zeitkritische Intention Cechovs verstanden und gewertet werden. Es kann aber daneben ebensowohl als vorsichtiges Experiment Cechovs in der intertextuellen Begegnung, in der Selbsterprobung und im Sich-Messen mit großen, allgemeingültigen literarischen Leistungen eingeschätzt werden. ${ }^{2 \times 2}$

Die Idee der intertextuellen ..Unterlegenheit“" Cechovscher Personen scheint bereits zum Gemeinplatz der Cechovliteratur geworden zu sein. In der 1966 erschienenen Monographie Th. Winners ..Chekhov and his prose“ begegnet man z.B. dieser These in einigen Einzelanalysen vor allem der Novellen Cechovs. Als etwas lächeriich wird z.B der Selbstvergleich Laevskijs mit den Helden der Weltliteratur begriffen: ..Recurrent details serve to diminish laevki's self-view as a romantic personality, a new Hamlet. a new version of Lermontov's Pechorin. Turgenev“s Bazarov, and Byron`s Cain“. ${ }^{2 \times z}$ In der Novelle „Č̈rny monach“ (Der schwarze Mönch) deutet, nach Winner, vieles auf die Similarităt Kovrins mit Faust hin, doch wieder ist diese Ahnlichkeit mit ironischen Anführungszeichen versehen: ..For, unlike Faust, Kovrin is a mediocre man who only masquerades as an intellectual giant..2kt. Kovrin steht vielmehr in der Reihe der überflüssigen Menschen, ..such as Pushkin's Eugene Onegin, Lermontov`s Pechorin, and Turgenev`s Rudin“.2x5.

Für Ch. Saal-Losq stellen die meisten Personen Cechovs ..Parodien“ oder .. Travestien“ auf tragische Literaturgestalten dar: Laevshij travestiert die ..überflüssigen Menschen“, Vasil "ev -

\footnotetext{
279 Cechov 1974, S 136

${ }^{200}$ Lauer 1990. S 617

281 Kluge 1995, S 31

282 lbid

28: Winner 1966.S 101

284 Ibid S. 116
}

28s Ibid S. 119 Auf die Nahe Cechovsscher Figuren zu den uberflussigen Menschen der russischen L.iteratur, den ..Helden der Epoche" wie Ćackij. Rudin. Oblomov weist u a Peace hin-s 1983, S 8-14 
"Prostituiertenretter" aus den von ihm gelesenen literarischen Werken, Starcev - das lyrische "Ich“ der von ihm gesungenen Romanzen u.s.w. ${ }^{286}$ Dabei ist das Parodieren für Saal-Losq oft auf die literarische Selbst- und Realitătseinschätzung der Personen Cechovs und nicht auf die Prátexte selbst gerichtet: „The juxtaposition of texts which results as Chekhov's charakters refer to literary models serves to deflect the light of the characters themselves and not onto the figures of the background text ${ }^{\text {.287 }}$ (die Inadequatheit der literarischen Selbstbewertung wird auch in den oben vorgestellten Beitrăgen betont). Insofern ist für die Autorin die Perspektive der Figur, aus der die Geschichte erzăhlt wird, von erheblicher Bedeutung. So bedeutet für sie die Feststellung, daß die Gestalten Cechovs parodistische Varianten fremder Figuren sind, nicht (immer), daß die ersteren ein literarisches Diminutiv, eine Herabwürdigung der letzteren darstellen. Sie sind oft vielmehr als neue, andere Personen zu begreifen, die sich vom Erwarteten, mitunter dem literarisch Klischeehaften abheben. Insofern verwendet SaalLosq den Begriff „Parodie“ anders, als wir ihn in unserer Arbeit (s. Kap. 2 und 3.2.) auslegen. Darüber hinaus sind fur uns Parodien Čechovs immer mit der Absicht verbunden, Fremdtexte zu verspotten und so gesehen ,anzugreifen“.

Nach Überzeugung Kataevs stellen viele Čechovschen Personen nicht so sehr „schwăchliche Nachfahren" solcher Gestalten wie Hamlet, Don Juan oder Faust, sie sind vielmehr ihre moderne - und damit auch eine ..kleinere“, gewöhnlichere ${ }^{288}$, aber auch oft komplexere, an die russische Wirklichkeit der letzten zwei Jahrzehnte des 19. Jahrhunderts adaptierte Version. ${ }^{289}$ Der Professor Nikolaj Stepanovið aus „Skučnaja istorija“ (Eine langweilige Geschichte) erlebt z.B. in einem anderen sozialen und geschichtlichen Kontext dieselbe geistige Krise wie sie Faust und noch früher der .Erzăhler“ (.,повествователь“) in „Ekklesiastes“ erlebt haben. Cechov übernimmt, so Kataev, in seine Novelle die Ausgangssituation aus der Tragödie Goethes: hier korrespondieren nicht nur die Protagonisten am Anfang dieser zwei Werke (Faust - Wagner; Nikolaj Stepanovic - Pëtr Ignat'evic), sondern und vor allem der geistige Zustand beider Hauptpersonen. ${ }^{2 n}$ Die Motive dieses Zustandes finden ihren Ursprung in „Ekklesiastes“: .В указании на связь трагедии Гёте с книгой Екклезиаста (Čechov hat nämlich, wie Kataev ausführt, im Brief an Suvorin vom 4 Mai 1889 vermutet, daß Goethe beim Verfassen von "Faust” von "Ekklesiastes“ inspiriert wurde - K. S.) заключено и своё понимание смысла 'Фауста', фаустовской ситуащии. [...] Очевидно,

\footnotetext{
${ }^{286}$ Saal-Losq 1978. S. 23-24

$2 \times 7$ ibid. S 22

${ }^{288} \mathrm{Vgl}$ auch bei Sach-Azizova 1977. S. 243

$289 \mathrm{Vgl}$ z B die Formulierung Kataevs in bezug auf die Personen von ..Tri sestry“. .. Чехов не столько создавал новые типы, сколько осложнял прежние, созданные его предшественниками" (1989, S. 212) (Cеchov schuf nicht so sehr neue Typen. er problematisierte vielmehs die alten, die von seinen vorgangern geschaffen wurden).

200 Den Verweis auf diese Analyse von Kataev $s$ in unserem Aufsatz (Smola, 2001. S 110) Kataev betont. daB Cechov lediglich die ersten vier Szenen aus ..Faust" .ubernimmt“, d h. es wird auf die Gestalt von Faust ausschlieBlich in der Ausgangssituation des Werkes von Goethe verwiesen (s. Kataev 1989. S 87-88) Vgl dazu auch $\mathrm{Ch}$. Jegggle. der darauf hinweist, daß Nikolaj Stepanovic mit Faust iror seiner Evolution verglichen werden kann (s. 1996.S 36)
} 
общее для Чехова заключено в исходных ситуачиях 'Фауста' и 'Екклезиаста'. Утомление, разочарование пройденными путями, в первую очередь 'путями мудрости'. Признание тщетой свершённых дел. [..] И одновременно - незатухающая работа мысли, [...]. [...] Но этой же соломоновской, фаустовской чертой, [...] Чехов наделил и героя своей 'Скучной нсторни'. Фаусту нужно понять 'всю мира внутреннкю связь', герою Чехова нужна 'общая идея'.“ (Der Hinweis auf die Verbindung zwischen der Tragodie von Goethe und dem Buch von Ekklesiastes verbirgt auch sein eigenes Verständnis des Sinns von „Faust”, von der Faustschen Situation. [...] Offensichtlich liegt das Gemeinsame für Cechov in der Ausgangssituation von „Faust“ und „Ekklesiastes“. Erschöpfung, Enttäuschung von den begangenen Wegen, in erster Linie von den „Wegen der Weisheit“. Erklärung der vollbrachten Taten als vergeblich. [...] Und gleichzeitig - eine unauslöschliche Gedankenarbeit, [...]. [...] Aber gerade mit dieser Salomonischen, Faustschen Eigenschaft, [...] stattete Cechov seinen Helden in ..Skučnaja istorija“ aus. Faust muß verstehen, „was die Welt im Innersten zusammenhält“", der Held Cechovs sucht eine „allgemeine Idee“.). ${ }^{291}$ Cechov baut zwischen dem Professor und Faust bewußt Assoziationen auf - mit der Absicht, dem inneren Drama seines Helden und damit auch dem seiner Generation einen tieferen Sinn zu verleihen und es in einen breiteren Kontext des ..ewigen Suchens der Menschheit“" zu stellen.

Wie der ..russische Faust“" Nikolaj Stepanovic kann auch Gurov, so Kataev, als eine neue und keine ..diminutive“ Variante eines literarischen Archetyps betrachtet werden. Im Gegensatz zu den zahlreichen ,zweitklassigen Don Juans“ der früheren Werke Cechovs (wie Kamyšev, Panaurov, Anan'ev u.s.w.) teile Gurov die Würde und die Komplexität seines literarischen Prototyps - nämlich des Don Guan aus ..Kamennyj gost “” von Puškin, eınes Don Juan, der sich ernsthaft verliebt. Während aber der Puskinsche Held für seine Sünden bestraft wird und am Ende sterben muß, beginnt für Gurov gerade am Schluß der Novelle das wirkliche Leben, die Liebe selbst, ..die Liebe im Alltag“" bringt für den Cechovschen Don Juan die ernstesten Probleme mit sich. ${ }^{292}$

3. Ebenso wie die Vorstellung. daß die Figuren Cechovs als ..schwächliche Nachfahren“ ihrer intertextuellen Vorbilder gestaltet sind, von vielen Forschern geteilt wird, gehört u.a. auch die These, daß Cechovsche Werke eine ironische Inversion bekannter literarischer Sujets demonstrieren, zu den verbreitesten Topoi in der Čechovforschung.

So weist nach Winner der allusive Name von Nikitins Pferd, „Graf Nulin“ (Der Graf Nulin) in „Učitel' slovesnosti“ (Der Literaturlehrer) auf eine ironische Umkehrung von Puškins Sujet hin: Nicht Nikitin, sondern Maša und ihre Familie sind diejenigen, die am Ende der Novelle die Rolle des Verführers übernehmen. Ähnlich verdreht auch ..Anna na See“" (Anna am Hals) Sujets von ..Anna Karenina“ und .,Madame Bovary“: Während die ungleiche Ehe und der Seitensprung bei Tolstoj und Flauber tragische Konsequenzen haben, ziehen hier aus dieser Situation beide - sowohl Anna als auch ihr Mann - Nutzen und geben sich mit ihr zufrie-

291 Kataev 1989, S 88-89 
den. Je verblüffender, so Winner, die Parallelen zwischen den Handlungen von „Anna na See“ und „Anna Karenina“ (die Position und das Verhalten des Ehemannes-Beamten, Eisenbahnszenen mit Vronskij/ Artynov u.s.w.) sind, desto offensichtlicher werden auch die Differenzen: Die moralische Botschaft des Toltojschen Romans wird bei Čechov aufgehoben.

Cechov greift in vielen seiner Prosawerke, so die These K. D. Kramers, literarische Produktionen seiner Vorlăufer an, indem er mit den herkömmlichen literarischen Mustern experimentiert - sie z.B. umschreibt. Kramer interpretiert demzufolge "Smert' cinovnika“ (Der Tod eines Beamten) als eine scherzhafte „Neu-schreibung“ (oder, wie es Kramer formuliert,

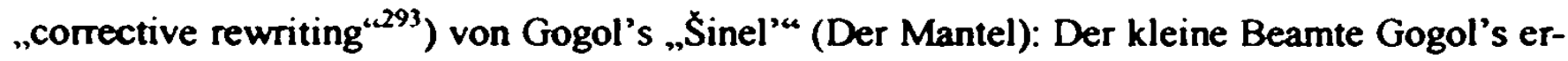
ringt nach seinem Tod die Vergeltung, Cechov verzichtet auf die mystische Fortsetzung der Geschichte und verleiht ihr ein abruptes und groteskes Ende. In "Cvety zapozdalye“ (Verspatete Blumen) und in „Rasskaz neizvestnogo Celoveka“ spielt Cechov mit den Elementen des Sujets eines der Romane Turgenevs, nămlich „Nakanune“ (Vorabend ${ }^{294}$ ). Im Finale von „Cvety zapozdalye“ folgt nicht Marusja-,,Elena“ Toporkov-,Insarov“, sondem umgekehrt Toporkov folgt Marusja; die Hauptperson in ,Rasskaz neizvestnogo celoveka“ Zinaida hălt zuerst Orlov, dann den Erzăhler für Insarov, begreift aber spăter, daß ihre Vorstellungen illusorisch waren, und begeht Selbstmord; „the farce of mistaken identities ${ }^{\text {c295 }}$ stellt das Finale des Turgenevschen Romans wieder auf den Kopf - der Erzahler-, Insarov“ übernimmt die Rolle von Zinaida und wird zur „Mutter" ihres Kindes. ${ }^{29}$ In diesen wie auch in manchen anderen Novellen Cechovs (z.B. in „Duel'“) kommt nach Kramer das Bestreben des Autors, im Rahmen traditioneller literarischer Sujets zu arbeiten, zum Ausdruck. Jedoch kann sich der Schriftsteller dabei vom Parodieren der Vorlagen kaum zurückhalten, deshalb oszillieren seine Geschichten zwischen Emst und Parodie.

Als Parodie auf literarische Werke des 19. Jahrhunderts, genauer, deren Gestalten oder Sujetstrukturen (wobei der Begriff „Parodie“ hier ungewöhnlich breit und eher unkonventionell gefaßt ist, da er auf große spätere Novellen Cechovs übertragen wird) betrachtet $\mathrm{Ch}$. Saal-Losq viele großen Novellen Cechovs. So übernimmt Cechov in „Dama s sobackoj“ die wesentlichsten Handlungselemente eines herkommlichen Ehebruchsujets (,adultery plot ${ }^{4297}$ ), u.a. des Sujets von „Anna Karenina“, und schafft dadurch das Potential für die vom Leser erwartete Entwicklung eines dramatischen Konflikts. Die Lesererwartung wird dennoch nicht erfült, und die Geschichte erweist sich immer mehr als ironische Inversion des Tolstojschen Romans. In Kontrast zueinander stehen z.B. Szenen im Theater in beiden Werken - statt einen Skandal hervorzurufen, bleibt das Rendezvous von Gurov und Anna unbemerkt, wie ihre Bezjehung im Ganzen unbemerkt und von der Gesellschaft "unbestraft" bleibt. Cechov hat,

\footnotetext{
292 S. Kataev 1989. S. 107-110. Vgl über diese Schlußfolgenung von Kataev bei uns (Smola 1998b, S 514)

${ }^{293}$ Kramer 1970, S. 34

294 Turgenjew 1973, S. 5.

${ }^{295}$ Kramer 1970, S. 45.

296 S. ibid. S. 39-40; 43-46

${ }^{297}$ Saal-Losq 1978, S. 30
} 
nach Saal-Losq, eine Novelle geschrieben, in der die außereheliche Liebe nicht tótet, sondern befreit; damit wird die moralische Botschaft von "Anna Karenina“ unmißverstăndlich konterkariert. In „Ionyæ“ spielt Cechov weiterhin mit dem Sujetschema von „Evgenij Onegin“: In den ersten drei Kapiteln der Cechovschen Novelle, vor allem in der Szene, in der Starcev Kotik seine Liebe gesteht, übernimmt er die Rolle der Puškins Tat'jana, während Kotik, wie Onegin, seine Gefühle zurückweist. Im vierten Kapitel kommt es, analog zu dem Prätext, zum Rollentausch („Like Onegin, Ekaterina has found a responsive chord for her old suitor. Like Tat'iana Startsev rejects his admirer's confessions of affection ${ }^{4298}$ ); jedoch stellt das Finale von .Ionyc“ eine Travestie auf die tragische Szene des verspateten Liebesgeständnisses bei Puškin dar - Personen Čechovs sind durch keine außeren Umstănde getrennt, ihrer Vereinigung steht nichts im Wege: „There are no irreversible circumstances which stand between Chekhov's characters ${ }^{* 2^{(*)}}$. Es ist Starcev selbst, der zur Liebe nicht mehr fähig ist, vielmehr interessiert ihn jetzt die praktische Seite des Lebens. Durch die Verschiebung und Substitution der konventionellen Situations- und Rollenschemata schreibt Cechov einen ironischen Kommentar zu den auch in der russischen Literatur traditionell gewordenen Sujetstrukturen. In erster Linie vermeidet er aber dramatische Spannungen und tragische Konflikte, was von der Forscherin als eine bewußte Nichterfüllung der Lesererwartungen interpretient wird. Wenn Laevskij Nadeżda Fëdorovna mit Kirilin erwischt, tōtet er sie nicht, wie das Pozdnyšev in ..Krejcerova sonata“ getan hat. Das Duell zwischen Fon Koren und Laevskij endet ebenfalls nicht mit dem Tod von Laevskij, wie das in „Geroj našego vremeni“ (Der Held unserer Zeit) geschieht (Pečorin tötet Grušnickij). Schließlich führen die Beziehungen von Laevskij und Nadeżda Fëdorovna, im Gegensatz zu denen von Anna und Vronskij, nicht zur Tragödie. ${ }^{300}$ Cechov bezieht sich also explizit auf Werke der russischen Literatur, so daß seine eigenen als eine offensichtliche Abweichung von der Tradition dem Leser ins Auge stechen.

Im Unterschied zu Saal-Losq, neigt Kataev dazu, die Werke Cechovs als eine durchaus ernste Auseinandersetzung („,творческий спор“, kreative Auseinandersetzung) ${ }^{\text {301 }}$ ), als einen Dialog mit den ...Klassikern“ zu begreifen. Gleich mit mehreren Novellen außert sıch Cechov beispielsweise zur ... Krejcerova sonata“ Tolstojs; durch die Variierung des Handlungsablaufes von ..Krejcerova sonata“ widerlegt er auch die moralischen Gebote, die Tolstoj in diesem Werk vermittelt hat. So verzichtet er in ."Tri goda“ (Drei Jahre) auf das für das Sujet Tolstojs entscheidende Faktum des Seitensprungs, zeigt damit aber, wie auch formal sittliche eheliche Beziehungen unglücklich seın können: .И в этом содержится ответ Толстому: семейный покой, семейное счастье зависят отнюдь не от следования религиозной основе брака или уклонения от неё.. (Und darin besteht die Antwort an Tolstoj: die familiäre Harmonie.

\footnotetext{
Ibid S. 73

$2 \%$ Ibid S 74

160 Ibid. S 117

.01 Kataev 1989. S. 71
} 
das Familienglück hăngen nicht vom Befolgen den religiösen Grundlagen der Ehe oder von der Abweichung von ihnen ab). ${ }^{302}$

Da Kataev hier nicht nur Modifikationen der fremden Handlungsstrukturen bei Cechov untersucht, sondern dessen Texte als Polemik mit den vor allem am Ende von „Krejcerova sonata“ ausgesprochenen Ideen Tolstojs betrachtet, nähert sich sein Beitrag der năchsten vierten - Gruppe von Ansätzen innerhalb der Cechovforschung.

4. Es wurde in der einschlăgigen Literatur mehrmals darauf hingewiesen, daß Cechov in seine Werke in einem spürbaren Maße aktuelle Diskussionen und Fragen der Epoche einbezieht, nicht selten in Form fiktiver Gespräche und Auseinandersetzungen. Die Rezeption wichtiger sozialer und kultureller Probleme der Zeit, aber auch konkreter philosophischer Konzeptionen in den (v.a. Prosa-)Texten Cechovs wird in zahlreichen Analysen verfolgt. Frauenemanzipation, Pessimismus, gesellschaftliche Rolle der Kunst, Studentenbewegung, Möglichkeiten der moralischen Rechtfertigung der Gewalt, arztliche Ethik, Ethik des Stoizismus, Sozialdarwinismus u.s.w. - diese Themen(blðcke) scheinen bei Čechov aufgegriffen und kūnstlerisch verarbeitet zu werden. Am anschaulichsten ist diese These bei E. Polockaja formuliert: „В годы, когда ясна стала бесперспективность прежней террористической тактики народников [...], появился 'Рассказ неизвестного человека'. Когда [...] встал вопрос о путях развития русской деревни, Чехов написал своих 'Мужиков' - [...]. На теорию 'малых дел' он откликнулся 'Домом с мезонином', на споры об эмансипашии 'Ариадной', на рост студенческого двкжения - 'Невестой' и 'Вишнёвым садом'.“ (In den Jahren, in denen die Perspektivenlosigkeit der früheren, terroristischen Taktik der Volkstümler offensichtlich wurde [...], erschien .,Rasskaz neizvestnogo celoveka“. Als [...] die Frage nach den Entwicklungswegen des russischen Dorfes erhoben wurde, schrieb Cechov .Mužiki“ (Die Bauern - K. S.) - [...]. Zur Theorie der „kleinen Tate“ äußerte er sich mit „Dom s mezoninom“ (Das Haus mit dem Mezzanin - K. S.), zu den Diskussionen über die Emanzipation - mit ..Ariadna“, zur anwachsenden Studentenbewegung - mit „Nevesta“ (Die Braut - K. S.) und "Višnëvyj sad" (Der Kirschgarten - K. S.). ${ }^{303}$ Solche Themen und Probleme sind, wie ersichtlich ist, mit den konkreten, vorwiegend publizistischen und philosophischen, Texten verknüpft, die entweder als Quelle oder als Echo bzw. Reaktion auf bestimmte Ideen fungieren. ${ }^{304}$

Noch A. P. Skaftymov hat in seinem bekannten Aufsatz .O povestjach Čechova 'Palata №6' i 'Moja žizn”‘ (Über die Novellen Cechovs „Palata №6“ (Das Krankenzimmer No6 - K.

\footnotetext{
302 Ibid. S. 76

${ }^{30.3}$ Polockaja 1979, S 313

${ }^{304} \mathrm{Vgl}$ die Anmerkung Ovčarovas: „Герои активно участвуют в публицистически-злободневных спорах. причем их взгляды 'переклихаются со взглядами писателей и фнлософов. чьи произведения живо обсуждались в печати". (1985, S 95) (Die Protagonisten sind an den publizistisch-aktuellen Auseinandersetzungen aktiv beteiligt. dabei „korrespondieren ihre Ansichten mit den Ansichten der Schriftsteller und Philosophen. deren Werke in der Presse lebendig diskutiert wurden"). In unserem Aufsatz (s. Smola 2001. S 105-108) zeigen wir ebenfalls auf, wie in einigen Texten Cechovs eine damals aktuelle Diskussion uber die Rolle der Kunst und der Literatur, verknüpft mit dem Namen Goethes, in Form fiktiver Debatten widergespiegelt und reflektient wird
} 
S.) und „Moja žizn”“ (Mein Leben - K. S.)) (1958) versucht, die Reflexion bestimmter philosophischer Systeme in den Novellen Cechovs ans Licht zu bringen. Er beweist, daß die Weltanschauung des Arztes Ragin in "Palata №6" nicht auf der Moralphilosophie des Stoikers Mark Aurel oder den ethischen Geboten Tolstojs, denen die Rechtfertigung der Gleichgültigkeit, der geistigen Passivităt und der Nichteinmischung im Grunde fremd war, sondern auf der pessimistischen Philosophie Schopenhauers, genauer, der russischen Rezeption seiner Ende der 1890er Jahre populär gewordenen Ausgabe "Aforizmy i maksimy“ (Aphorismen und Maximen) (1892, übers. von F. V. Cernigovec) fußt. Den Kern dieser Weltanschauung artikuliert Skaftymov folgendermaßen: .Для Рагина и шопенгауэровцев одинаково спешифнчно сочетание пессимизма с призывами к интедлектуциннои созериательности, как единственно возможному источнику чистого 'наслаждения'. Ни у Толстого, ни у стоиков ничего подобного нет“. ${ }^{305}$ (Für Ragin und Schopenhauerianer ist gleichermaßen die Kombination des Pessimismus mit den Aufrufen zur intellekıuellen Kontemplation als der einzig möglichen Quelle des reinen ..Genusses“ spezifisch. Dies findet man weder bei Tolstoj noch bei den Stoikern). Cechov mißbilligt, so Skaftymov, die auf diese Weise rezipierten Ideen Schopenhauers und polemisiert mit ihnen dadurch, daß er sie zur Konfrontation mit dem realen Leben bringt und letztendlich scheitern läßt. Eine direkte Polemik mit den Ansichten Tolstojs - mit seiner Forderung der ..oprošcenije“* (dem Einfachwerden) und der physischen Arbeit für alle als Mittel der geistigen Vervollkommnung - läßt sich dagegen wesentlich deutlicher in ..Moja żizn" "verfolgen. Hier demonstriert Cechov, daß der Verzicht auf Klassenprivilegien und die Übernahme harter körperlicher Arbeit noch keine tiefe geistige Befriedigung mit sich bringt und vor allem kein wirkliches Lebensziel darstellt. Erst die Verbindung physischer Tätigkeit. die eine moralische Rechtfertigung des Daseins vorbringt, mit den intellektuellen und geistigen Bestrebungen und Interessen konnen nach Cechov das Leben eines Menschen erfüllen: ..Там. где речь идёт о содержании жизненного 'счастья', Чехов, не отменяя нравствснных требований. [...], предусматривает необходимость удовлетворения всего богатства духовных стремлений человека. всей сферы общей культуры, красоты, науки и искусства." (Dort, wo es sich um den Inhalt des ..Glücks“ des Lebens handelt, sieht Cechov, ohne die Moralforderungen aufzuheben. [...]. die Notwendigkeit vor, das ganze Reichtum der geistigen Bestrebungen des Menschen, die ganze Sphäre der allgemeinen Kultur, der Schönheit. Wissenschaft und Kunst zu befriedigen.). ${ }^{3 K_{0}}$

Eine Polemik mit dem Tolstojschen Ideal des arbeitsreichen Lebens sieht in ...Moja žizn “* u.a. auch I. P. Vidueckaja: immer deutlicher empfindet der Čechovsche Misail seine neue Betätigung als Arbeiter als Spiel, immer offensichtlicher wird für ihn die Unnaturlichkeit dieser Situation. In ..Dom s mezoninom“ nimmt Cechov, wie Vidueckaja etwas vereinfacht ausführt. die Parteı des Künstlers, der in der Auseinandersetzung mit der Anhängerin der ..malye dela"-Theorie Lida zu beweisen sucht, daß das einzige effektive Mittel, die quälende Diskre-

sos Skaftymov 1958. S 301 
panz zwischen dem Volk und den höheren Gesellschaftsschichten zu überwinden, nicht in der Erschaffung einer besonderen „Volkskultur" besteht, sondern im Versuch, die Bauern der Kultur und der Kunst der höheren Schichten teilhaft werden zu lassen. Nicht die Beschrănkung von Interessen und die „Verbauerung“ der privilegierten Klassen in Rußland wăre das Richtige, sondern die Kultivierung der Interessen der Bauern. ${ }^{307}$

Im Gegensatz zu Skaftymov finden D. Rayfield und G. P. Berdnikov in „Palata No6“ Spuren der Gedanken sowohl Schopenhauers als auch Tolstojs und Mark Aurels. Rayfield setzt die Ideen Schopenhauers denjenigen von Tolstoj nicht entgegen, sondern verbindet sie: Pessimismus, eine tiefe Überzeugung, daß die materielle Welt von Grund auf böse und ungerecht ist, unüberwindbare Furcht vor dem Tod und vieles andere in der Philosophie Schopenhauers habe die Weltanschauung Tolstojs maßgeblich beeinflußt. Dennoch ist der Cechovsche Ragin viel eher ein provinzieller russischer Schopenhauer (,a conceited and glib reciter of Aphorismen zur Lebensweisheir ${ }^{308}$ ) als ein Tolstojanhănger. Nur die Keuschheit Ragins und der Verzicht auf den Kampf gegen soziale Mißstănde könnten als Polemik mit der Tolstojschen Lehre verstanden werden. In seiner Passivität und Unachtsamkeit mißdeutet und karikiert Ragin gleichzeitig die Stoiker, denen - was Čechov zweifelsohne bekannt war - die Gleichgültigkeit gegenüber dem Leiden des Anderen vollkommen fremd war. Für Berdnikov birgt jedoch die stoische Philosophie selbst einige Widersprüche, die Cechov in seiner Novelle, wie er beweist, gerade erforscht und aufdeckt: „Проповедуя добрые дела и даже самоотверженность человека во имя общего блага, стоики в то же время исходили из мысли о фатальной предопределённости человеческого бытия [...].“ (Wăhrend sie gute Taten und sogar die Selbstlosigkeit des Menschen im Namen des Allgemeinwohls predigten, gingen Stoiker gleichzeitig vom Gedanken von einer fatalen Vorherbestimmung des menschlichen Seins aus [...].). ${ }^{309}$ Cechov führt in ..Palata No6" eine exakte Analyse der Gedanken Mark Aurels durch, der Altruismus und Demut nicht zu vereinbaren vermochte. Auch die Popularität sowie die Verflachung einzelner Thesen Schopenhauers und Tolstojs (s. oben) durch die russischen Intellektuellen in der Zeit Cechovs sind hier, so Berdnikov, widergespiegelt: „[...], рагинская философия - это попурри на модные философские темы, [...].“. ([...], die Philosophie Ragins ist ein Potpourri aus den modischen philosophischen Themen, [...].). ${ }^{310}$

Außer „Palata №6" gehört u.a. die Novelle „Cèmyj monach“ zu den Werken, die in erster Linie in bezug auf ihre .,philosophische“ Intertextualităt wohl am stärksten das Interesse der Cechovforscher erweckt hat. So wurden in den Gesprăchen Kovrins mit dem schwarzen Mönch Spuren der philosophischen Gedanken Schopenhauers, Nietzsches und Nordaus entdeckt. „A в чеховском рассказе [...] предугадываются отдельные высказывания $\mathrm{M}$. Нордау о 'вырождении' и Ф. Ницше о новой морали и образе сверхчеловека“, - bemerkt

\footnotetext{
306 Ibid S 311

307 S. Vidueckaja 1980

${ }^{308}$ Rayfield 1975, S. 129

${ }^{309}$ Berdnikov 1978, S. 306
} 
P. Henry. (Und in der Novelle Cechovs [...] ahnt man einzelne Aussagen von M. Nordau über die „Entartung“ und von F. Nietzsche über die neue Moral und über die Gestalt des Übermenschen voraus). ${ }^{311}$ Nach A. Krinicyn entspricht die Konzeption der Gestalt Kovrins - vor allem die Beschreibung der Symptome seiner psychischen Erkrankung und deren Entwicklung den Vorstellungen Nordaus über das krankhafte Genie, die in der berühmt gewordenen und in Rußland viel diskutierten Schrift „Entartung“ artikuliert wurden: „Мы без труда найдём у Коврина все описанные у Нордау симптомы: наследственную предрасположенность к чахотке, тяжёлое переутомление от чрезмерной умственной работы и нездорового образа жизни, болезненную впечатлительность и возбудимость [...]." (Wir finden bei Kovrin ohne Mühe alle bei Nordau geschilderten Symptome: die geerbte Empfänglichkeit für Schwindsucht, schwere Übermüdung infolge einer übermäßigen geistigen Arbeit und der ungesunden Lebensweise, eine krankhafte Sensibilität und Erregbarkeit [...].“). ${ }^{312}$ Das romantische Konzept des Genies, das in seinen krankhaften Phantasien eine Zuflucht vor der banalen Realităt findet, wird nach der Auffassung anderer Čechovforscher in der Novelle Čechovs in Frage gestellt, wenn nicht sogar gänzlich negiert. ${ }^{3 / 3}$

Auch Ideen Nietzsches werden in der Novelle Cechovs nach E. Sebina und M. Bykova in vulgarisienter und vereinfachter Version dargestellt. Wieder handelt es sich bei Cechov nicht um die Philosophie Nietzsches, sondern um ihre Rezeption - um .ммодное нишшеанство“ (das modische Nietzscheanertum). ..поверхностное увлечение модной философией“" (еine oberflächliche Begessterung von der modischen Philosophie) ${ }^{314}$, um Nietzsche ..в 'массовом сознании' русского интеллигента“" (Im ..Massenbewußtsein“" des russischen Intellektuellen) ${ }^{315}$. Die Bekanntschaft mit den Schriften Nietzsches ..erlaubte“ den russischen Intellektuellen, gewisse Tabus und traditionelle ethische Werte zu ignorieren. Den Čechovschen ..Pechvögeln" (..неудачники..31" ), die keine Kraft in sich finden, sich mit der Welt zu konfrontieren, eigene Schwăchen zu bekämpfen und die Verantwortung für ihre Nächsten zu übernehmen. paßt, so Bykova, die mit Nietzsche assoziierte Vorstellung von einem freien, den Pöbel und vor allem die traditionelle Moral verachtenden (Über)Menschen. Diese Rezeptionsweise ist von Cechov u.a. in der Figur Kovrins widergespiegelt worden.

Das Problem der Rezeption und der Bewertung ausgewählter Ideen Tolstojs in Werken Čechovs gehört im Ganzen zu den beliebtesten und am meisten untersuchten Themen in der

\footnotetext{
310 Ibid S 308

"1"' Henry 1997, S 604

112 Krinicyn 1990 . S 173
}

"13 S z.B die Arbeit von Nazirov ..Cechov protiv romantičeskoj tradicii" (Cechov gegen die romantische Tradi(ion) (1975), wo uberzeugend vorgetührt wird. daß Cechov in ..Cernyj monach" gegen die romantische Tradition. in der Wahnsinnszustande als Anzeichen des Erhaben- und Auserwählseins begriffen werden. ..spricht“" Er lehnt die in solchen Werken der russischen Literatur wie ..Sil 'fida" (Die Sylphide) von Vladimir Odoevskij oder ..Stoss" von Michail L.ermontov artikulierte Asthetisierung des Wahnsinns entschieden ab. in den Gesprachen Kovrins mit dem Monch parodiert er nach Nazirov tiefsinnige Dialoge der geistig kranken Helden mit ihren Phantasiegestalten. 314 Sebina 19\%. S 132

31s Bykova 1996. S 137

116 bid 
Čechovliteratur. Th. Winner und A. S. Melkova betrachten beispielsweise eine ganze Reihe von Cechovs Novellen als Antwort auf verschiedene Seiten der Tolstojschen Lehre. U.a. in "Chorošie ljudi“ (Gute Menschen), „Neprijatnost”“ (Eine Unannehmlichkeit), „Vragi“ (Feinde) preist er, so Winner, die Idee der Abkehr von der Gewalt und der Notwendigkeit der physischen Arbeit an, zu der er in „Palata №6“ wieder Distanz nimmt (v.a. über die Gestalt Gromovs, der in der Diskussion mit Ragin diese Idee überzeugend negiert). ${ }^{317}$ Melkova untersucht ihrerseits in einigen Novellen Cechovs der Jahre 1886-1887 nicht nur die Aufnahme bestimmter "Tolstojscher Fragen", sondern ebenfalls die Widerspiegelung jener literarischen Polemik, die diese Fragen ausgelost haben. Unter den Thesen Tolstojs, die in der russischen Offentlichkeit am meisten Aufsehen erregt haben ${ }^{318}$, nennt Melkova außer dem Gebot der Abkehr von der Gewalt die Forderung des Verzichtes auf materielle Privilegien sowie der physischen Arbeit fưr Mănner und der Mutterschaft als Lebensaufgabe für Frauen; die Ablehnung des wissenschaftlichen und technischen Fortschrittes u.a. Die von solchen Kritikem wie N. K. Michajlovskij, A. M. Skabicevskij, L. Z. Slonimskij u.a. ausgesprochene heftige Kritik der Tolstojschen Ideen werde in Form einer fiktiven Diskussion, genauer: in den Argumenten und in dem Redestil einer der Hauptfiguren der Novelle "Sestra“ (Die Schwester) (Chorošie ljudi“) Ljadovskij ironisch wiedergegeben, so daß man dieses Werk Cechovs als direkte Polemik mit den „Verăchtern" Tolstojs betrachten kann. Cechov imitiert nămlich in den Monologen Ljadovskijs, die gegen die Predigt der Abkehr von der Gewalt gerichtet sind, die Ausdrucksweise sowie den Argumentationsgang einiger von den einflußreichen Kritikem und Publizisten der Zeit verfaßten Artikel: „Он высмеял грубость. резкость и высокомерность тона Скабичевского; самоуверенное фразёрство и отсутствие элементарного анализа в статьях Стукалича; присоединился к Оболенскому, упрекавшему Михайловского в нежелании уяснить себе предмет, о котором он судит так категорически. " (Er hat die Grobheit, Schärfe und Überheblichkeit des Tons Skabičevskijs ausgelacht, die selbstsichere Phrasendrescherei und den Mangel an elementarer Analyse in den Aufsătzen Stukaližs; er hat sich Obolenskij angeschlossen, der Michajlovskij den Widerwillen vorwarf, für sich den Gegenstand zu klären, über den er so kategorisch urteilt) ${ }^{319}$. Die Kritik und der Sarkasmus Ljadovskijs haben letzten Endes keine Wirkung auf die Entscheidungen seiner Schwester und halten sie nicht von der Abreise ab. Das Ziel der Novelle Cechovs war dennoch nicht so sehr die Verteidigung der Lehre Tolstojs, zu der Cechov in einem ambivalenten Verhăltnis stand. sondern vielmehr der Appell, seinen Ideen Gehör zu schenken und sie auf einem höheren analytischen Niveau zu behandeln. Melkova erwähnt auch weitere Erzăhlungen Cechovs, die ihrer Meinung nach eine andere Antwort auf diesen Punkt des Tolstojschen ..Programms“ geben: So setze er sich mit der Idee der Abkehr von der Gewalt - und zwar ähnlich wie in

${ }^{317}$ S. Winner 1966, S. 62-68.

${ }^{318}$ Diese Ansichten hat Tolstoj u.a. im Traktat ..Tak cto ze nam delat' ${ }^{\text {* }}$ (Was mussen uir also tun'). dessen Teile 1882 und 1884-1885 in RuBland publizien wurden und im Aufsatz „V cem scastien. (Worin besteht das Gluck?) (1886) propagiert (s. Melkova 1977, S 302) 
"Sestra“ durch die Logik der Sujetentwicklung - in „Vstreca“ (Die Begegnung) eindeutig auseinander. Hier werde vorgeführt, wie ein milder und toleranter Umgang mit dem Verbrecher keine geistige Umwandlung bewirkt: „У Чехова после кратковременного испута вор Кузьма, которого не наказывает обворованный им Ефрем, ведёт себя попрежнему: лжёт, хвастает и т. п.“ (Bei Čechov verhălt sich der Dieb Kuz'ma, den der von ihm bestohlene Efrem nicht bestraft, nach dem kurzen Schrecken wie früher: er lügt, prahlt u.s.w.). ${ }^{320}$ Die Novelle sollte also eine der in der russischen Offentlichkeit bekannt gewordenen Thesen Tostojs widerlegen.

Nach Hahn polemisien Cechov mit Tolstoj - mit seiner Idealisierung des Bauernlebens und der körperlichen Arbeit - in ..Moja žizn”“ und „Mužiki“, in der letzten Erzăhlung besonders effektiv durch eine detaillierte, emotionslose Darstellung der Mißstände im russischen Dorf. $^{321}$

Aus den in fremden Texten thematisierten und aktuell gewordenen Problemen der Zeit, die im Cechovschen Werk ihren Niederschlag gefunden haben, sei hier exemplarisch die Frage der Frauenemanzipation erwähnt. Mit der Cechovschen Auslegung der Frauenproblematik, die in direktem Zusammenhang mit den Aussagen Tolstojs und Nordaus zum Thema (v.a. in "Krejcerova sonata“ und in ..Paradoksy“ (Paradoxe) und "Vyroždenie“ (Entartung)) steht, befaßt sich u.a. A. Krinicyn. Äußerungen Samochins zu den Mängeln der weiblichen Natur in .Ariadna“ spiegeln, nach Krinicyn, Konzepte dieser zwei Denker wider, die z.B. eine natürliche mentale Unterlegenheit der Frau gegenüber dem Mann und die Überflüssigkeit der Ausbildung und der intellektuellen Entwicklung der Frauen, deren einziger Erfolg der bei Männem sei, postulieren sowie die Beschönigung und Idealisierung der Frauengestalt in der Literatur beklagen. Diese Ansichten werden in der Novelle Cechovs jedoch auf verschiedenen Ebenen der Geschichte (u.a. durch die Replik des Erzählers, der auf die Verallgemeinerungen Samochins eher mißtrauisch reagiert) hinterfragt und sogar im Grunde widerlegt ${ }^{322}$.

5. Als weniger typisch betrachten wir in der Cechovforschung die Arbeiten, die konkrete Formen des intertextuellen Signals im Text - des für das Zitat und die Allusion charakteristisehen .,markers“ - nicht nur explizit in den Mittelpunkt der Analyse stellen, sondern sie zum Titelthema machen. Hier wollen wir aber auch die Beiträge anführen, in denen die Untersuchung solcher punktuellen Verweise nicht unbedingt als Titelthema genannt wird (das kann z.B. in einem deutlicheren Maße nur einen bestimmten Teil der Arbeit berühren) ${ }^{323}$. Dabei geraten ins Blickfeld der Forscher, wie es sich versteht, in erster Linie die Werke, in denen die Menge solcher Referenzen auffallig ist und zum Nachdenken veranlaßt.

\footnotetext{
${ }^{319}$ Melkova 1977, S 312

320 lbid. S 315

321 Hahn 1977, S 146, 153-154

${ }^{322}$ S. Krinicyn 1996. S $175-176$

${ }^{323}$ Obgleich offensichtlich ist, daß auch die Beitrage der Gruppen 2, 3, und 4, wie wir oben bemerkt haben, konkrete intertextuelle ..marker", wie wir sie im theoretischen Teil unserer Arbeit aufgelistet haben, berucksichtigen und im unterschiedlichen Masse zum Ausganyspunkt der Analyse haben
} 
So befassen sich einige einschlăgige Beitrăge mit der Ermittlung der Zitatfunktionen in "Tri sestry". Die Autoren versuchen allerdings manchmal, ohne auf die Erscheinungsform und die nähere kontextuelle Umgebung einzelner Zitate in Cechovs Drama besonders ausführlich einzugehen, deren intertextuelle Bedeutung interpretativ zu entschlüsseln. Kataev weist in diesem Sinne (im Kap. „Reminiscencii v Trěch sestrach" (Reminiszenzen in „Tri sestry“) seiner Monographie (1989)) auf das Vorhandensein zahlreicher Zitate im Stück - aus Gogol's „Povest' o tom, kak possorilis' Ivan Ivanovic s Ivanom Nikiforovicem“ (Geschichte des großen Krakeels zwischen Iwan Iwanowitsch und Iwan Nikiforowitsch ${ }^{324}$ ) und ,Zapiski sumassedకego“ (Aufzeichnungen eines Wahnsinnigen), Puskins „Cygany“ (Zigeuner) und "Ruslan i Ljudmila“ (Ruslan und Ljudmila), Tolstojs "Anna Karenina“ sowie lateinischer Aphorismen u.s.f. hin und fragt: „Почему столько цитаr? Н в чём заключалось свое, незаемное?" (Warum so viele Zitate? Und worin bestand das Eigene, das Nicht-Geliehene?). ${ }^{325}$ Das unaufhorliche Zitieren in "Tri sestry" deute darauf hin, daß die Cechovschen Personen in einer alten, literarisch bereits hundertmal wiedergegebenen und darum lăngst banalisierten Welt, in der alles allen bekannt ist, leben: „Tо, что [...] пронсходит, давно известно, 'старые исторни', 'скучные исторни“* (Das, was [...] geschieht, ist lăngst bekannt, ,alte Geschichten“, „langweilige Geschichten“") ${ }^{326}$. Cechov stelle damit die Frage, die für sein ganzes Werk von primärer Bedeutung war: Wie orientieren sich Menschen in dieser Realităt, deren Traditionen, die in der Literatur propagierten „allgemeinen Ideen“ und gesellschaftlich anerkannte Meinungen sich als falsch oder für das Verständnis des Seins nicht ausreichend bzw. angesichts der Komplexităt der Welt hilflos erweisen?

Die Funktion der ausgewählten Zitate und Allusionen in "Tri sestry“ legen R. Peace und N. Adati aus: Peace deutet den Sinn der von Mascha immer wieder ausgesprochenen Zeilen „U lukomorja dub zelènyj..." ("Grün an der Meerbucht ragt die Eiche... “327) im psychologischen Kontext des Werkes (das Zitat suggeriere nämlich den Frust Maschas über ihre unglückliche Ehe, der nur so indirekt - allegorisch - zum Ausdruck kommen könne) ${ }^{328}$; Adati interpretiert auf eine ăhnliche Weise Solënyjs Zitate aus „Cygany“ sowie seinen Selbstvergleich mit Lermontov als Versuch der Flucht vor der sinnentleerten Wirklichkeit, als Versuch der Romantisierung des eigenen Daseins (wobei die Inkongruenz zwischen den durch intertextuelle Referenzen verbundenen Charakteren - Solënyj/ Lermontov, Tuzenbach Aleko - auf die auktoriale Ironie schließen läßt) ${ }^{329}$.

Dem Beitrag W. Kośnys ist eine besonders differenzierte Behandlung der Zitatbezüge und ihrer Funktionen in demselben Drama nachzusagen, wobei manche Analyseergebnisse bei

\footnotetext{
${ }^{324}$ Gogol Bd 2 (1952), S. 293

${ }^{125}$ Kataev 1989. S. 217

326 Ibid

127 Puschkin Bd 2 (1952), S. 217 Alle hier verwendeten lbersetzungen russischer Zitate ins Deutsche sind mit dem Original verglichen und, wo erforderlich, korrigien worden

32x Peace 1986. S. 170

${ }^{.29} \mathrm{~S}$ Adati 1998
} 
ihm denen bei Peace und Adati ăhnlich sind. Er unterscheidet zunăchst auf theoretischer Ebene zwischen der pragmatischen und der semantischen Zeichenfunktion der Zitate im Text. Die erste dient bei Cechov primär der Charakterisierung der handelnden Personen, der Vermittlung ihrer Gefühle und Stimmungen; in diesem Fall erschließt sich die Bedeutung des Bezuges aus dem nächsten situativen Kontext und die Heranziehung des Referenztextes, d.h. eine Gegenüberstellung des aktuellen mit dem Prătext erweist sich als überflüssig (,die Zitate gehen in der Situation auf, $[\ldots] .[\ldots]$ die externe Information übersteigt nicht die interne Information, [...].“330). So deutet das Arien-Fragment „Ljubvi vse vozrasty pokorny...“ („Ein jedes Alter folgt der Liebe....331) im Munde Veršinins nur darauf hin, daß er sich in Maša verliebt hat und daß sein Gefühl erwidert wird (hier tritt v.a. die Symptomfunktion innerhalb der pragmatischen hervor), so wie die lateinischen Sentenzen Kulygins in ihrer pragmatischen Funktion auf eine ,unangenehme Eigenschaft des Gymnasiallehrers ${ }^{.332}$ hinweisen. Im Fall Kulygins wie auch in einigen anderen ,.überwiegt ${ }^{.333}$ darüber hinaus ..die externe Information“ (.die Kommunikation zwischen Autor und Rezipierendem“) ${ }^{334}$ nicht ..die interne Information“ (..die Kommunikation zwischen den Personen des Stückes“) ${ }^{335}$. Die semantische Funktion des Zitats kommt dagegen z.B. dann zum Ausdruck, wenn die Erinnerung an den Prătext sinnmăßig eine Bereicherung des aktuellen Textes mit sich bringt, z.B eine vorausdeutende Aufgabe erfüllt. Wenn Solènyj Tuzenbach mit Aleko vergleicht, enthüllt sich sein Zitieren im Hinblick auf die Sujetentwicklung von „Cygany“ als eine bewußte und auf keinen Fall harmlose Tăuschung seines Rivalen - Solënyj selbst tötet Tuzenbach aus Eifersucht. Auch das Gogol '-Zitat aus .Zapiski sumaš̌edక̌ego“ erlaubt, nicht nur Mašas Trauer zu spüren, sondern ebenso ihre unglückliche Liebe und die darauf folgende Rückkehr ins alte Leben neben die unenvidert gebliebene Liebe Poprišcins sowie sein endgültiges Verfallen in Wahnsinn zu stellen. Unter anderem das letzte Beispiel zeigt, so die Schlußfolgerung Kośnys, daß Zitate mit überwiegend semantischer Funktion in .Tri sestry" bestimmte Textinformationen auf eine spezifische Art zu vermitteln vermögen - sie können z.B. das pessimistische Finale des Dramas verdeutlichen.

Die Funktion und Bedeutung der Zitate und Allusionen in Cechovs Dramen wurden bereits in mehreren Analysen interpretiert. Besonders häufig wird in der einschlägigen Literatur auf die Semantik der Shakespeare- und Maupassant-Zitate in „Cajka“ (Die Möwe) eingegangen, dabei werden zwischen dem Prä- und Posttext üblicherweise Parallelen gezogen, Ähnlichkeiten und Gegensätze festgestellt. ${ }^{336} \mathrm{Da}$ der interpretative Vorgang in diesen Beiträgen dem

\footnotetext{
1.6 Kosny 1971, S. 132

331 Puschkin Bd 2 (1952), S 200

132 Kosंny 1971, S. 134 Lateinische Zitate Kulygins gewinnen aber nach Kosiny auch „neue semantische Inhalte“ (ibid . S. 135) ..Im Jagen nach Zitaten schlayt sich Kulygins Glaube nieder, die Komplexitat des Lebens bannen zu honnen " (ibid)

113 lbid. S 129

334 lbid. S 128

3.15 Ibid

${ }^{166}$ S. z. B Papernyj 1980, S. 58-67
} 
in den oben präsentierten im Grunde ăhnelt, gehen wir zu den Arbeiten über, die sich mit dem Zitieren bzw. Alludieren in der Prosa Cechovs befassen.

Die Funktion der Zitate und Allusionen aus der Lyrik der russischen Romantiker für die Gestaltung der fiktiven Personen in einigen Novellen Cechovs ermitteln Z. S. Papernyj (der seinen Beitrag dem Thema der Tradition Lermontovs bei Cechov in allgemeinen widmet) und A. A. Smirnov. Daß Jarcev beim Gesprăch mit Laptev („Tri goda“) das Gedicht Lermontovs "Son“ (Der Traum) in den Sinn kommt, zeugt nach Papernyj von seiner tief verborgenen Sehnsucht nach dem Hōheren und Nicht-alltäglichen, vom Unzufriedensein mit seinem Gefül gegenüber Polina Nikolaevna, das sich von dem bei Lermontov vermittelten Liebeskummer viel $\mathrm{zu}$ sehr unterscheidet ${ }^{337}$. Auch Zitate aus den romantischen Gedichten Del'vigs (,Kogda, duša, prosilas' ty...“ (Als du, Seele, darum batest...)) und Puškins (,Nox'“ (Die Nacht)) in "Ionyc" weisen, so Smirnov, auf "die Perspektive der gehobenen Gefuhle" eines Verliebten hin („оба текста прнзваны намекнуть на перспективу возвышенных чувств repog“" (beide Texte sind dazu berufen, auf die Perspektive der erhabenen Gefuhle des Helden anzudeuten $)^{338}$ ); das erstere vermittelt den euphorischen Zustand des liebenden Starcev, das zweite bereitet zugleich das später eintretende und unvermeidliche Erloschen der Gefühle vor (der seelische Vorgang, der in der Elegie von Del'vig thematisiert wird) ${ }^{339}$. Papernyj und Smirnov versuchen darüber hinaus, die intertextuelle Analyse über die Ebene der Figuren hinauszuführen und die Aussage Cechovs über den Prătext zu entschlüsseln. Dabei kommen die Kritiker zu folgenden Schlüssen: Wăhrend Papernyj die in der romantischen Lyrik dargestellte Welt und manifestierte Ideale als eine in Cechovs Wahmehmung unerreichbare Große (")iričeskaja točka otšęta“ (der lyrische Ausgangspunkt) ${ }^{340}$ ) betrachtet, deutet Smirnov das romantische Lebenskonzept als in Cechovs Sicht lebensfremd und dadurch lebensunfahig: .....] любой романтический образ осознаётся как изначальный стереотип и как таковой должен быть нарушен.“ ([...] jede romantische Gestalt wird von Anfang an als Stereotyp bewertet und als solcher muß sie destruien werden.) ${ }^{3+1}$ Der Forscher schreibt dazu: „[...] любые ценности теряют свою актуальность в пошлой среде.“ ([...] alle Werte verlieren ihre Aktualităt in einem abgeschmackten Milieu). ${ }^{342}$

Das insbesondere für die zwei letzten Beitrăge charakteristische Ziel, nicht nur die Funktion und die Stellung der intertextuellen Referenzen im geschlossenen Ganzen des Werkes zu bestimmen, sondern die Einstellung Cechovs zum fremden Text zu erfassen (die Analyse, die nicht (ausschließlich) auf die Rolle des Prätextes im Posttext, sondern auf die Rezeption des Prătextes im Posttext abzielt), verfolgt V. A. Košelev im Aufsatz „Oneginskij 'mif v proze Cechova“" (Der Onegin-..Mythos“ in der Prosa Cechovs). Er fürt zahlreiche Zitate und Allu-

\footnotetext{
337 Ibid 1994, S 148

${ }^{338}$ Smimov 1998, S 97

339 Ibid.

340 Papernyj 1994, S. 148

31 Smimov 1998, S. 100.

42 lbid S. 99
} 
sionen zu „Evgenij Onegin“ (Eugen Onegin) aus den Kurzgeschichten und Novellen Cechovs an, um seine These zu bestätigen, daß es sich in erster Linie um eine ironische Darstellung der "Onegin“-Rezeption beim russischen Publikum und in der russischen Kritik der zweiten Hälfte des 19. Jahrhunderts handelt. $\mathrm{Zu}$ den fiktiven Rezeptionsphänomenen gehören beispielsweise „prosaisierende“ und platte Kommentare zum Puškinschen Text sowie eine semantische Verflachung einzelner zitierter Textstellen, deren poetischer Gehalt durch das alltågliche Verwenden oder eine naive Interpretation aufgehoben bzw. deren Sinn entstellt wird, und die Selbstvergleiche der Cechovschen Personen mit den Gestaiten Puškins (besonders hăufig mit der des überflüssigen Menschen Onegin), wodurch letztere parodiert werden. ${ }^{303}$ Auf die Analyse konkreter Erscheinungsformen der Zitate und Allusionen wird im Aufsatz nicht ausführlicher eingegangen, dem Autor geht es vor allem darum, das Phänomen des „Onegin“-Mythos im Werk Čechovs im allgemeinen zu demonstrieren und seinen inhaltlichen Charakter aufzudecken.

Manche Cechovforscher analysieren weiterhin die Allusionen in den Titeln der Prosastūcke Cechovs. So untersucht D. J. Clayton die Novelle "Poprygun'ja“ (Flattergeist ${ }^{344}$ ) im Lichte ihres allusiven Titels, der auf die russische Version der Fabel von La Fontaine „La Cigale et la fourmi““ (I. A. Krylov: „Strekoza i muravej“ (Die Libelle und die Ameise)) verweist. Cechov legt, nach Clayton, die Analogie auf der Ebene der Figuren (die Libelle/Ol'ga Ivanovna; die Ameise/Dymov) nahe, um sie dann in Frage zu stellen und letzten Endes die moralistische Botschaft der Fabel Krylovs aufzuheben. Es ist nicht die "Ameise"-Dymov, die in der Erzăhlung Čechovs für ihren Fleiß belohnt wird und „überlebt“. Es überleben dagegen die Libellen Ol'ga Ivanovna und Rjabovskij, Dymov aber stirbt. Dennoch beinhaltet dieser Handlungsablauf kein moralisches Urteil über Ol'ga Ivanovna: „Instead it is a story of two characters, who are $[\ldots]$ unable to establish any real contact with each other ${ }^{.0345}$. Cechov erzeugt damit eine bewußte Anknüpfung an den fremden Text und relativiert ihn zugleich.

M. Kanevskaja ${ }^{346}$ stützt sich in ihrer Analyse des Titelzitats in der Geschichte „Nevidimye miru slëzy“" (Die für die Welt unsichtbaren Tränen) auf manche Aussagen der Intertextualitătstheoretiker (wie M. Riffaterre und G. Genette) und verwendet Begriffe, die der Intertextualitătstheorie entstammen. Sie konzentriert sich zunăchst auf den Grad und den Charakter der formalen Veränderung des zitierten Segments aus Gogol's ..Mërtvye dušy“ (Die toten Seelen) im neuen Kontext und gelangt dabei zum Schluß. daß Cechov durch das falsche Zitieren den alltäglichen Gebrauch des entsprechenden populären Fragments wiedergibt. Das Zitat demonstriert also u.a. einen trivialen Umgang der Leser mit der pathetischen Rhetorik Gogol's (statt .,nevedomye“ (unbekannt) heißt es bei Cechov ..nevidimye“ (unsichtbar)). Cechov reduziert mit Hilfe der formalen Verzerrung die Semantik des dem fremden Text ent-

\footnotetext{
203 S Košelev 1998, S. 148-154

${ }^{344}$ Tschechow 1966, S 58

${ }^{345}$ Clayton 1990, S 603

${ }^{146} \mathrm{~S}$ Kanevskaja 1994
} 
nommenen Fragments und setzt sie auf das Niveau der naiven oder verbreiteten Rezeption herab. In einer semantischen Reduktion besteht in diesem Fall auch die konkrete Methode der Cechovschen Arbeit mit dem Prätext Gogol's, mit dem so auch polemisiert wird. Kanevskaja führt weiterhin eine feine und detaillierte Analyse durch, in der sie den ursprünglichen und den neuen Kontext des Zitats sowohl auf der stilistischen als auch auf der semantischen Ebene vergleicht und so den Sinn der intertextuellen Referenz entschlüsselt. Cechov bezieht z.B. „die Trănen“, die Gogol' kontextuell mit der hohen moralischen Aufgabe des Schriftstellers verknüpft, ausschließlich auf die banale Situation eines familiăren Streites. Einen komischen Effekt erzeugt ebenfalls die Nebeneinanderstellung solcher Gattungen wie Kurzgeschichte und Roman, das heißt, die ironische Intertextualităt spielt sich auch auf der architextuellen Ebene (Genette) ab. Was die Aussage des Textes Cechovs über den Referenztext anbelangt, so betrachtet Kanevskaja den ersten als Hinweis auf eine bestimmte Rezeptionsgeschichte von „Mërtvye dušy“, u.a. in der russischen Kritik.

Im Ganzen zeichnet sich der Beitrag Kanevskajas nicht nur durch eine Zuwendung zu den theoretischen Grundlagen des intertextuellen Phănomens aus, sondern ebenfalls durch seine sehr präzise und scharfsinnige formale und semantische Analyse.

6. Ähnlich wie der von Genette eingefuhrte Begriff "Text zweiten Grades“ (bzw. ..literarische Ableitung“) benennt auch die bei Pfister und Broich erorterte Bezeichnung „Systemreferenz ${ }^{4347}$ eine Reihe der intertextuellen Erscheinungen, denen ein bestimmtes Merkmal gemeinsam ist. Als Kriterium, das den betreffenden Verweisen Homogenitat verleiht, fungiert in dem Fall der Typ des Prătextes. Systemreferenzielles Verfahren - Verweisung auf Textsysteme wie literarische Gattungen, stilistische Normen bestimmter literarischer Epochen, Diskurstypen u.s.w. und nicht (nur) auf konkrete Fremdtexte - stellt eine intertextuelle Strategie dar, die insbesondere für das frühere prosaische Werk Cechovs charakteristisch ist und insofern auch des Öfteren die Aufmerksamkeit der Cechovforscher auf sich gezogen hat.

In erster Linie wird der spielerisch-humoristische Umgang des experimentierfreudigen Antoła Cechonte mit ausgewählten - vor allem populären bzw. in der zeitgenơssischen Literatur bereits zum Klischee gewordenen - Motiven, Sujetmerkmalen, Charakteren und stilistischen Details, die nicht mehr auf konkrete Referenztexte zurückzuführen sind, sondern sich vielmehr auf Gattungen und Literaturepochen im allgemeinen beziehen, in der Fachliteratur immer wieder zum Thema. Das Spiel mit den literarischen Schablonen in Cechovs Kurzgeschichten der ersten Hälfte der 1880er Jahre analysiert im ersten Kapitel seiner Cechov gewidmeten Monographie Th. Winner. Er betont z.B. die parodistische Behandlung solcher Gattungen wie „comic sketches of the humor journals, popular ghost and melodramatic adventure stories, crime novels, and romantic fiction ${ }^{.348}$. Winner untersucht hauptsăchlich die Techniken, die bei Čechov zu parodistischer Verzerrung des Altbekannten führen: ..In parody,

${ }^{447} \mathrm{Vgl}$. S. 30 dieser Arbeit 
clishés, traditional styles or themes may be exaggerated and thus caricatured or [...] they may be presented in a new and unaccustomed evironment, which renders them absured ${ }^{349}$. Übertriebene Metaphorizitat, ungeschickte Pleonasmen und Stilbrüche, aufdringliche Lautwiederholungen und Kombination des Romantisch-Gehobenen mit dem Alltăglich-Realistischen sowie die Unglaubwürdigkeit des Geschehens kennzeichnen die Parodien auf die romantische Prosa und die Gespenstergeschichten; mit Hilfe bewußter Handlungskomplikationen, falscher Mutmaßungen und verwirrender Indizien, die das Ermittlungsverfahren begleiten und dem überraschenden Finale vorangehen, schaff ¿echov eine treffende Karikatur der weit verbreiteten Kriminalgeschichten. ${ }^{350}$

V. Turbin deklariert anhand nicht nur der frühen parodistischen Prosa die ironischmißtrauische Einstellung Cechovs zu konkreten literarischen und publizistischen Gattungen, gegen deren Normen seine Werke nicht zufallig verstoßen: „Можно смело настаивать на том, что диалог живого, жанрово неоформленного, атипичного со ставшим, застывшим, завершеинным - есть основная закономерность новеллистического творчества Чехова.“ (Man kann darauf ohne Zögem bestehen, daß der Dialog des Lebendigen, von seiner Gattung her Unausgestalteten, Untypischen mit dem Gewordenen, Erstarnen, Abgeschlossenen die wichtigste Gesetzmaßigkeit der Novellistik Cechovs ist.). ${ }^{351}$ Sei es die Gattung des Zeitungsartikels oder der Fabel (die Auseinandersetzung Cechovs mit dieser demonstriert Turbin am Beispiel von „Dom s mezoninom“ und „Tri sestry“), sie gerăt jedes Mal mit der "lebendigen“ Wirklichkeit in Konflikt, die ihre Rahmen und Regeln letztendlich zerstört.

Den Begriff „Dialog“ in bezug auf systemreferenzielle Praxis in der Prosa Cechovs verwendet ebenfalls K. D. Kramer, wobei es wieder um den Dialog Čechovs mit einer stabilen und „abgeschlossenen“ (,завершённый“) literarischen Gattung - nämlich der des Melodrams - geht. In diesem Sinne hălt Kramer den literarischen Dialog mit einem bestimmten Textsystem einerseits und die Parodien auf ein solches offenbar auseinander: Wăhrend in seinen Parodien der Schriftsteller eine offen distanzierende und spielerische Haltung gegenüber dem literarisch Vorgefundenen (..distaste for what he apparantly feels is the literary artificiality.335) zeigt (genannt werden solche Systeme wie "traditional novella and novel“", „foreign literature" oder "the canonized masters of nineteenth-century Russian literature", aber auch Gattungen wie „official report“, ,historical novel“, ..tale of revenge“, .,detective story“, .,fantasies of the future“ oder das Gesamtwerk eines Autors (.,rhetorical style of a Victor Hugo“ $)^{333}$ ), schwankt er beim Dialog mit ihm zwischen Distanz und Aneignung. Eine Reihe von späteren Novellen Cechovs, geschrieben vor 1893, weist nach Kramer eine deutliche Af-

\footnotetext{
148 Winner 1966. S 6. S auch Hielscher 1987, S. 29

${ }^{349}$ Winner 1966, S 5-6

${ }^{350} \mathrm{~S}$. die Aufzahlung der Parodien Cechovs auf bestimmte Textsysteme auch in unserem Aufsatz (Smola 2001, S 102)

351 Turbin 1973, S. 213

${ }^{352}$ Kramer 1970. S 28

${ }^{333}$ Ibid S 28-3I
} 
finităt zum Melodramatischen mit den für diese Gattung charakteristischen Merkmalen - heftige und ereignisreiche Handlung, das Motiv des Ehebruchs und des Mordes als Rache („Baby“ (Die Weiber)), hysterische Ausbrüche der Liebenden (,Poprygun’ja“), politischer Terrorismus (,Rasskaz neizvestnogo celoveka“), Schwarz-Weiß-Malerei in Form einer Dichotomie zwischen dem Bösen und dem Guten bzw. dem Gegensatz „Held - Bösewicht“ (geistige Umkehr Laevskijs in „Duel'“) u.s.w. Čechov, so die Schlußfolgerung Kramers, fürt in dieser Periode seines Schaffens einen Dialog mit dem Melodram, um eigene moralische Werte auszuarbeiten und zu bestimmen, ein Versuch, die Existenz konstanter, klar erkennbarer Werte künstlerisch zu beweisen. Interessant ist, daß P. Bicilli, der in seiner Monographie in manchen Erzăhlungen Cechovs, z.B. in „Rasskaz neizvestnogo celoveka“, ebenfalls schablonenhafte und fur Čechov sonst "wesensfremde" Elemente feststellen muß, halbwegs zu denselben Schlüssen wie Kramer kommt. Er vermutet bei Cechov wăhrend dieser Periode in ahnlicher Weise ein künstlerisches Schwanken, besonders in formaler Hinsicht, in Bezug auf eine andere Gattung: Cechov ,zwang seine Natur" und „versuchte, etwas zu schaffen, was seiner inneren Form nach mit dem klassischen Roman identisch war. ${ }^{354}$.

Eine andere Dynamik im Umgang mit dem Melodram verfolgt Kuznecov im Bühnenwerk Cechovs: nicht mehr die Entwicklung von einer humoristischen Distanznahme zur Aneignung, sondern umgekehrt von der unkritischen Übernahme melodramatischer Effekte in den früheren Stücken zu ihrer ironisch-verfremdenden Funktion in den späten Dramen: „B ранний период драматургического творчества Чехова (до второй редакции 'Нванова' включительно) [...] мелодраматическое понимается как квинтессенция сценичного, сценически эффектного [...]. [...] В поздней же драматургия Чехов использует мелодраматическое клише как сильный отстраняюший приём“ (In der früheren Periode des dramatischen Schaffens von Čechov (bis einschließlich die zweite Redaktion von ..Ivanov“) [...] wird das Melodramatische als Quintessenz des Bühnenwirksamen, des szenisch Effektvollen begriffen [...]. [...] In seinem späten Bühnenwerk verwendet Čechov das melodramatische Klischee dagegen als ein stark befremdendes Verfahren) ${ }^{35 s}$.

Als Beispiele der für die hier besprochene Gruppe reprăsentativen Beituäge seien noch Arbeiten erwähnt, in denen die Beziehungen Cechovscher Werke zur Gattung der Pastorale thematisiert werden. So faßt B. Hahn das Drama „Višněvyj sad“ als eine moderne Ausformung bzw. Version der pastoralen Tradition auf. Allerdings definiert er diese Gattung nicht so sehr im streng literaturhistorischen Sinne, als in allgemein-ideellen typologischen Beschreibungskategorien, wonach beispielsweise auch ..Wordworth's 'nature' poetry“ und ... rot's landscapes “.356, obgleich sie im klassischen Verständnis nicht dazu gehören. von der Botschaft her, die das Kunstiverk beinhaltet, sich durchaus der Tradition anschließen. Diese Botschaft. die das letzte Stück Cechovs der Pastoralgattung typologisch verwandt macht, bestehe

\footnotetext{
354 Bicilli 1966, S. 131

3ss Kuznecov 1996, S 69

356 Hahn 1977. S. 20.
} 
im wesentlichen in einer künstlerischen Idealisierung des Ländlichen (,images of rural contentment ${ }^{.357}$ ), in der wenn auch komplexe Formen annehmenden Opposition zwischen den simplen alten Werten und der Hastigkeit moderner Welt. Solche Inhalte kommen in der Kunst, so Hahn, in Zeiten des raschen sozialen Wandels zum Ausdruck. Details wie das Schăferhom deuten in "Višnëvyj sad" auf die Sehnsucht nach verlorener Unschuld hin, die insbesondere in der Gestalt Ranevskajas vermittelt wird. $R$. Peace betont jedoch die Abweichungen vom pastoralen Thema in demselben Drama Cechovs, die sich vor allem in der Trübung idyllischer Naturbilder äußern, wobei wiederum ein Detail - der Klang der reiBenden Saite - in der ,antipastoralen“ Gestaltung des Bühnenwerkes nicht die geringste Rolle spiele. $^{358}$

Andrew R. Durkin begreift zwar das Pastorale ebenfalls recht breit, d.h. nicht als literaturhistorisch lokalisierte Gattung, sondern eher als ein weltanschauliches Gebilde, das einer solchen Gattung genetisch entspringt, grenzt aber den Wirkungsraum des Pastoralen, auf den sich Cechov orientient, im Unterschied zu Hahn und Peace deutlicher ab. Er spricht nämlich von der pastoralen Tradition in der russischen Literatur des 19. Jahrhunderts, mit der sich Cechovs Werke in erster Linie auseinandersetzten: „In broadest terms, pastoral involves an orientation toward an at least apparent simplification, of life, of style, and of structure. Nature, in its pre-Darwinian perception as changeless, harmonious, $[\ldots]$ is taken as a model or norm, a separate, special, and truer reality. ${ }^{359}$ Diese Tradition komme exemplarisch in Werken Aksakovs und Tolstojs zum Vorschein, in denen die autonome und abgeschlossene $\mathrm{Na}$ turwelt dem Individuum vor allem durch den Akt der Jagd, wenn auch nur für einige Augenblicke zugänglich wird. Weiterhin gibt es, so führt Durkin aus, das soziale und politische Pastorale, in dem soziale Gruppen mit ihren Lebenswelten eine Werteopposition bilden: Dies findet man in der Idealisierung des .narod“ (das Volk) bei Tolstoj und Dostoevskij sowie in der Gegenüberstellung des Landlebens dem korrupten Stadtleben bei Turgenev, Tolstoj und teilweise bei Goncarov. Schließlich erwähnt der Forscher das psychologische Pastorale, in dem das Positive, das Einfache und das Idealisierte mit der Welt der Kindheit verbunden und durch Erinnerung erreicht wird (wieder bei Aksakov, Tolstoj, Goncarov). Für die pastorale Weltanschauung insgesamt seien ein struktureller Binarismus und eine latente Didaktik charakteristisch, auf die Cechov in einigen seinen Texten geantwortet habe. Im Rahmen der Einzelanalysen demonstriert Durkin, wie Cechov die in der russischen Literatur vor ihm hăufig idyllisch dargestellte Jagdthematik ironisch umdeutet und destruiert (Novelle „Petrov den““ (Der Peter's Tag)); das Bild der glücklichen Kindheit wird durch die Begegnung der Kinder mit dern Ungeheuer des Todes zerstör (,.Sobytie“ (Das Ereignis), „Proisšestvie“ (Der Vorfall), „V sarae“ (Im Schuppen), „Beglec“ (Der Flüchtling)), so daß die Beschränktheit und die Verwundbarkeit der pastoralen Kinderwelt hier zum Hauptthema wird. Das soziale Pastorale

\footnotetext{
397 Ibid.

${ }^{358}$ Peace $1983, S 145$

359 Durkin 1990. S 676
} 
lehne Cechov in mehreren seinen spăteren Novellen $a b$, indem er kein einseitig positives Bauernbild gibt (bereits in "Step" (Die Steppe)) und das Scheitern der pastoralen Illusionen der Intelligencija schildert („Novaja dač“ (Die neue Datsche)).

Manche Beiträge, die sich mit den systemreferenziellen Bezügen im Cechovschen Werk befassen, ziehen auch einzelne Prátexte heran, in manchen fehlt dagegen die Analyse konkreter - fur das angesprochene Textsystem reprassentativer - Referenztexte. Kuznecov gründet z.B. seine Untersuchung der melodramatischen Elemente in den Theaterstücken Cechovs auf dem Vergleich der letzten mit den Stūcken Sudermanns, in denen die Merkmale des Melodrams gerade präsent sind. ${ }^{360}$ In manchen Fălen werden zwar typische allgemeine Erkennungszeichen eines konkreten Textsystems - einer Gattung, einer Literaturepoche u.s.w. - genannt und ihre Bearbeitung und Funktion im manifesten Text untersucht, auf die vergleichende Analyse mit Heranziehung individueller Referenztexte wird aber verzichtet (obwohl die letzten mitunter genannt werden) ${ }^{361}$.

Wir haben in diesem Kapitel versucht, Beitrage im Bereich der Cechovforschung zu reflektieren und - je nach Aspekten, die wir in ihnen hervorgehoben haben, - einzuordnen, woraus sich sechs Gruppen einschlagiger Arbeiten ergeben haben (6 Gruppen der Beiträge und nicht der Arbeiten, weil haufig eine und dieselbe Arbeit verschiedenen Gruppen zugeordnet wird bzw. werden konnte). Tendenzen, die sich auf diesem Gebiet beobachten lassen, haben wir am Anfang dieses Unterkapitels bereits erortert: Es sei hier z.B. eine deutliche Hervorhebung inhaltlich-thematischer Aspekte der Intertextualităt im Werk Cechovs und ein eher mangelndes Interesse für die formalen Seiten des Phänomens erwăhnt, was sich in den Prinzipien der für die Analyse getroffenen Auswahl intertextueller Verweise ăußert (das ist nämlich eine geringere Zahl der - u.a. werkübergreifenden - Untersuchungen, die bestimmte Formen der Intertextualität bei Cechov (wie z.B. Zitate) zum Titelthema hătten ${ }^{362}$ ). Wenn man das Bild zu verallgemeinern sucht, fehlt bei vielen Forschern auch das Interesse an einer differenzierten Analyse konkreter intertextueller Signale, die als Ausgangspunkt für eine vergleichende Analyse aufzufassen sind. Eine Ausnahme bilden für uns in dieser Hinsicht vor allem die Aufsätze von W. Kośny und $M$. Kanevskaja - Beitrăge, in denen eine sehr differenzierte formale und/oder semantische Behandlung einzelner Intertextualitătsverweise präsent ist.

\footnotetext{
${ }^{360}$ S. Kuznecov 1996

${ }^{361}$ Das zeichnet beispielsweise auch den Beitrag von Conrad aus, der die romantische Tradition in den einzelnen Novellen Cechovs ermittelt und dabei solche allgemeine „romantische“" Merkmale wie die Betonung des Übernatürichen, Musik. Wahnsinn, existentielle Verzweiflung. geheimnisvolle Landschaften u.s.w nennt, ohne auf konkrete Pratexte der Romantik im einzelnen naher einzugehen (Conrad 1989)

${ }^{362} \mathrm{Zu}$ solchen Untersuchungen gehören jedoch z.B. Arbeiten zu Cechovschen Parodien

${ }^{363}$ Dazu zahlen wir allerdings auch die eher impliziten Bezuge, die zwar von einer Person Cechovs stammen, ihr aber nicht immer im gleichen Maße bewußt sind.
} 
Unabhăngig von den methodischen Aspekten der angefürten Arbeiten bieten sie interessante und für weitere Intertextualitătsstudien hilfreiche Beobachtungen zum Phänomen der Cechovschen Intertextualităt. Insofern werden wir im Weiteren einige von den oben vorgestellten Ansätzen für die in den nächsten Kapiteln speziell zu bearbeitende Problematik heranziehen.

\subsection{Das Erkenntnisinteresse der Arbeit}

In unserem Vorhaben verfolgen wir insgesamt das Ziel (nicht zuletzt unter Zuhilfenahme der Intertextualitätstheorie), eine differenzierte formal-semantische Analyse ausgewăhlter intertextueller Erscheinungen in Cechovs Texten durchzuführen. Dabei stellen wir - in Anlehnung v.a. an die Benträge der Gruppe 5 - bestimmte Formen der intertextuellen Kontakte in den Mittelpunkt unserer Untersuchung, nămlich punktuelle Verweise, wie sie in Form eines Zitats oder einer Allusion an der Oberfläche des Textes erscheinen können. Wir wollen also die Ermittlung der Formen und Funktionen der Zitate/ Allusionen in Čechovs Werk zum primăren Ziel unserer Arbeit machen und somit als Grundlage für die Benennung deren einzelner Teile benutzen Wir lehnen uns ebenfalls an diejenigen Beiträge der Gruppen 2, 3 und 4 an, die die vergleichende Analyse (z.B. auf den Ebenen der Handlung und der Protagonisten) in einem deutlicheren Maße aus der Präsenz und der Funktion konkreter Zitate und Allusionen entfalten.

Es werden zum einen punktuelle Verweise im Rahmen einzelner Typen der (hypertextuellen, nach Genette) literarischen Ableilungen wie ernste Nachahmungen. Parndien und Kontrafakturen in den frühen, zum anderen - punktuelle Verweise im inneren Kommunikutionssystem (im Bewußtseinshorizont der fiktiven Personen) ${ }^{36.3}$ der späteren, von uns als nicht abgeleitet begnffenen Texte Cechovs das Thema sein. Somit werden einzelne „materielle“ Bezüge in verschiedenen Kontexten und so in ihren verschiedenen Funktionen untersucht. Die zwei genannten intertextuellen Verfahren - Zitate und Allusionen innerhalb der frühen .zweitgradigen“" Texte und dieselben im Bewußtseinshorizont der fiktiven Personen späterer Prosawerke werden also zum Thema dieses Vorhabens. Das Phänomen der literarischen Ableitung ist bekanntlich für das frühe Werk - hăufiger im Kontext der spielerischen Internextualităt von Antoša Cechonte - charakteristisch. ${ }^{3 \omega}$ Beim früheren Čechov ist im allgemeinen

${ }_{301}^{30}$ „Bekanntlich“ und traditionell wird das Phanomen einer literarischen Ableitung dem fruhen Schaffen Cechovs zugeordnet, wenn man namlich z B seine Parodien erforscht, die ublicherweise gerade mit seinen Kurzgeschichten Anfang - Mitte der 1880er verbunden werden Da wir aber den Begriff von Genette verwenden, mussen wir anmerken. daß er unter anderem spate große Werke verschiedener Autoren wie beispielsweise ..Doktor Faustus" als literarische Ableitungen bzw Hypertexte. im geyebenen Fall als ernste Transformationen det Vorlage bezeichnet Wir wollen hier insofern feststellen, daß wir diesen Genetteschen Begriff auf das fruh(er)e. meistens spielerische Werk Cechors beschränken, von dessen Charakter im Folgenden gesprochen wird Spatere große Novellen. die eventuell ebenfalls als Werke betrachtet werden konnen (und betrachtet werden). die bestimmte Fremdtexte transformieren (ubet die Moglichkeit, potentiell alle Werke als Hypertexte zu betrachten, s bei Genette selbst. Es 
die Absicht nicht verborgen, andere Texte (bzw. deren Fragmente) - ob affirmativ, ernst (was wesentlich seltener der Fall ist, ein Beispiel - ,Za jablocki“") oder spielerisch - nachzuahmen, oft spielerisch zu transformieren, umzuschreiben (herabsetzend, auf-den-Kopf-stellend, „korrigierend" oder in einen modernen Kontext versetzend). Beim spăteren Cechov wird Literatur nicht mehr zum Objekt des Experimentes oder eines affirmativen Nachbildens, sondern der Reflexion - mit dem literarischen Erbe wird in den spateren großen Novellen Cechovs tendenziell ein fiktiver Dialog geführt (intertextuelle Referenzen im inneren Kommunikationssystem kommen selbstverståndlich auch in den frühen, nicht-abgeleiteten Texten Cechovs, seinen „nicht-zweitgradigen“ Kurzgeschichten vor, sie werden demzufolge speziell nicht zum Objekt der gegenwärtigen Untersuchung). In diesem Sinne unterscheiden jedoch viele Cechovforscher (z.B.) Parodien im frühen Werk von Cechonte von der Intertextualităt späterer Texte, das Experiment, Spiel mit dem Fremden - von seiner spăteren und ofter in einem hơheren Grade „ernsten“ Reflexion (die natürlich ironische Elemente nicht ausschließt). ${ }^{365}$ Wir wollen eine derartige Differenzierung jedoch auf bestimmte Texte und Textarten anwenden, die weniger untersucht wurden, sie z.B. mit unserer Verwendung des Begriffs „Kontrafaktur" verknüpfen.

Selbstverståndlich wurden sowohl Zitate als auch Allusionen im Rahmen der „abgewandelten“ Texte Cechovs (v.a. der Parodien) als auch der spăteren Texte mehrmals untersucht. Innerhalb großerer Monographien werden sogar üblicherweise zunächst die ersten (wie z.B. Parodien) und danach die zweiten in den Einzelanalysen erforscht. Wir wollen hier demzufolge diejenigen Zitate und Allusionen unter die Lupe nehmen, die in diesen zwei Kontexten bei Cechov, um es zu bekräftigen, noch nicht oder weniger erforscht wurden.

Die Auffassung des Intertextualitătsphănomens, formuliert von manchen Intertextualitătstheoretikem, als in ihrer Gesamtheit begriffene Text-Text-Kontakte, die durch die Prăsenz ei-

gibt kein literarisches Werk. das nicht, in einem bestimmten $\mathrm{Maß}$ und je nach Lektüre. an ein anderes erinnert: in diesem Sinn sind alle Werke Hypertexte. Aber [...] sind es manche mehr (oder offensichtlicher, massiver und expliziter) als andere [ .] Je weniger massiv und deklariert die Hypertextualitat eines Werkes ist, desto starker hangt seine Analyse vom grundlegenden Urteil oder Interpretationsentscheidung des Lesers ab [...]. (1993, S. 20)). werden wir als ..abgeleitete" Texte nicht bezeichnen. In diesem Sinne geht es bei uns in bezug auf diesen Begriff um einen anderen, in gewisser Weise um einen engeren Anwendungsbereich als bei Genette Andererseits verzichtet auch Generte ausdrucklich darauf, den hypertextuellen Bereich in seiner Untersuchung zu entgrenzen. .Von einigen Ausnahmen abgesehen, werden wir uns hier der Hypertextualitat von ihrer sonnigsten Seite her nähem, namlich jener, bei der die Ableitung des Hypertexts vom Hypotext zugleich massiv [ ] deklariert wird und mehr oder weniger offiziell erfolgt." (ibid.).

${ }^{365} \mathrm{Vgl}$ in: Smola 2001. S 101-102: 110 Nicht zufallig haben wir in diesem Aufsatz als ersten Typ/ Modus/ Elcuppe der Intertextualitat im Werk Cechovs ..spielerische Intertextualitat" (wobei zu solchen ganz allgemein $\mathrm{Pa}$ rodien. Imitationen. Kontrafakturen, humoristische Zitate und Allusionen u.s.w. zahlen) und als zweiten ..jntertextuelle Diskussion" (wenn Figuren Cechovs uber oder in Verbindung mit bestimmten Fremdwerken oder Autoren Diskussionen führen) herausgebildet (insgesamt schließt die Typologie drei Typen/ Etappen ein). Obgleich diese Klassifikation mit der im gegenwärtigen Vorhaben einiges gemeinsam hat (so wollen wir hier u.a zunachst einen Teil der ..spielerischen" Bezuge in der Prosa Cechovs und danach die Bezüge im Bewußtsein seiner fiktiven Personen in den spateren Texten, von denen ..Diskussion“ wiederum einen Teil darstellt, erforschen), verzichten wir auf sie aufyrund der unspezifischen Kriterien bzw Bezeichnungen, die ihr zugrunde liegen. Hier wollen wir fur die Aufteilung der intertextuellen Kontakte dagegen strengere formale Kriterien aufstellen, was fur unsere Frayestellung auch von primarer Bedeutung ist 
nes textuellen „Fremdkörpers“ (sei er „intertextuelles Signal“, „,intertextuelle Spur“366, „marker" oder „connector“ genannt), der die Interaktion der Texte „verrät", zustande kommt ${ }^{367}$, entspricht dem methodischen Vorgehen unserer Arbeit. Dabei sei hier sofort bemerkt, daß wir den Begriff "Intertextualitätssignal" bzw. .Referenzsignal " in unserer Arbell als Bezeichnung für einen punktuellen .,materiellen" Verweis wie Zitat oder Allusion verwenden, also für ein oder einige Wörter, die den Prätext evozieren, ihn ins Gedächtnis rufen, benützen - unabhängig davon, wie und ob dieser Verweis im Text graphisch, stilistisch oder auf eine andere Weise markiert ist (s. die Einleitung). Die im Rahmen der Theorie angestellte Reflexion, die eine bewußte Scheidung und gleichzeitige Verknüpfung des „materiellen“ und "strukturellen" Intertextes ${ }^{368}$ herbeiführt und darüber hinaus diverse Arten der Markienung einzelner punktueller Verweise reflektiert, stellt für uns den Stützpunkt und die Grundlage für eine prazise und bedachte intertextuelle Analyse bereit. Darüber hinaus bieten uns die der Theorie entstammenden Begriffe und Typologien ein geeignetes Hilfsmittel an, um eine individuelle intertextuelle Praxis - in unserem Fall die Cechovs - systematisch und mit genügender Beachtung der formalen Qualitäten zu erforschen (gemeint sind hier z.B. Begriffe und begriffliche Oppositionen wie „Texte zweiten Grades“, „Paratexte“ (,Nebentexte“) vs. „eigentlicher Text“, „Einzel-“ vs. „Systemreferenz“ u.s.w., die bestimmte intertextuelle Phănomene generalisieren, sowie insgesamt systematisierende Überlegungen zu den Formen der Bezüge, den Typen des Prătextes oder den Textstellen, an denen sich die Interaktion vollzieht). Kurz gefaßt, beschäffigt sich die Intertextualitätstheorie systemutisch mit den Bereichen, die bei einer differenzıerten intertextuellen IIntersuchung berücksichtıgt werden müssen, und fertigt dafür angemessene Modelle vor (man denke hier z.B. an den Skalierungsversuch Manfred Pfisters, der Intertextualitătsaspekte plausibel begrifflich faßt, s. seine Bezeichnungen wie Autoreflexivităt, Strukturalität oder die Dialogizität).

Die Beschăftigung mit den theoretischen Ansătzen im Bereich der Texte zweiten Grades hat uns geholfen, einige Phänomene im Werk Cechovs, die in der einschlägigen Literatur bisher übersehen worden sind (wie z.B. manche nicht parodistische literarische Ableitungen), ans Licht zu bnngen; die Zitat- und Allusionsforschung hat uns erlaubt, punktuelle Verweise auf Fremdtexte in der Prosa Cechovs differenzierter und exakter zu behandeln.

Die Beschreibungsmodelle und -kategorien, auf die wir uns im weiteren Verlauf der Arbeit stützen werden, entstammen zum großen Teil, wie aus dem Überblick im Kapitel 2.1. folgt. der .,eingrenzenden“ und .,analytischen“ Gruppe der theoretischen Beiträge.

\footnotetext{
${ }^{366}$ Der Ausdruck von M. Riffaterre (s. daruber z B bei Greber 1989. S 7)

${ }^{367} \mathrm{Vgl}$ S. 23-24 dieser Arbeit

$368 \mathrm{Vgl}$. S. 28-29 dieser Arbeit
} 


\section{Punktuelle Verweise im Kontext der literarischen Ableitungen in der Prosa Cechovs}

Die Texte Čechovs, die wir als Gegenstand des gegenwărtigen Kapitels ausgewăhlt haben, haben unseres Erachtens vom Charakter ihrer Intertextualitat her ein Merkmal gemeinsam. Auf theoretischer Ebene ist, wie am Anfang des Kapitels 2.1.2. angeführt, zwischen den hier zu besprechenden und den anderen Intertextualitătserscheinungen von Lachmann (im Vorwort zum Sammelband „Dialogizităt“) und Genette eine Grenze gezogen worden. Wir berufen uns noch mal auf diese Differenzierungsansătze. So heißt es bei Lachmann, es gebe Doppelstrukturen, die sich auf den Text in seiner Ganzheit beziehen, wie Parodie oder Stilisierung, und solche, die nur einzelne Textelemente bezeichnen, z.B. ein Zitat. Genette legt die ersteren begrifflich fest, indem er diese den Text als Ganzes umfassenden Doppelstrukturen zu den „Texten zweiten Grades“ zăhlt. „Wir gehen vom allgemeinen Begriff eines Textes zweiten Grades [...], d.h. eines Textes aus, der von einem anderen, früheren Text abgeleitet ist. “369 Im Unterschied zur metatextuellen Ableitung stellt die hypertextuelle nach Genette aber keinen Kommentar zum Prătext dar, sondern entsteht aus ihm durch gewisse Transformationen. Mit solchen Hypertexten bei Cechov wollen wir uns in diesem Kapitel beschăftigen.

Allerdings treten die zwei genannten Typen der intertextuellen Verweisung - der .globale" und der ..partielle، ${ }^{\text {370 }}$ - kaum getrennt voneinander auf. Wie in unserem Überblick bereits thematisier wurde, werden analoge Textstrukturen (z.B. Handlung, Figuren) - deren Aufbau im Rahmen einer hypertextuellen literarischen Ableitung, d.h. auch der Doppelstrukturen des ersten Typs bei Lachmann wie z.B. Parodie, konstitutiv ist - mit der Übernahme einzelner Segmente der Vorlage, wie das beim Zitieren geschieht, kombiniert. ${ }^{371}$ Wir werden im Weiteren die Existenz einer literarischen Ableitung in jedem konkreten Fall bei Cechov mit der Hilfe „wörtlicher Intertextualităt”, d.h. partieller Übernahme des Referenztextes nachzuweisen versuchen. Das für eine literarische Ableitung meistens konstitutive Merkmal - Wiederholung der dem Prätext anhaftenden Regeln, .,Aufbau von analogen Strategien ${ }^{.372}$ - bestătigt sich im Werk Cechovs meistens zusătzlich durch einen .,materiellen“ Intertext. Die intertextuelle Spur (in unserer Arbeit also ein Zitat oder eine Allusion) macht die Kopräsenz zweier Texte (,Doppelkodierung“) erst sichtbar und ..verrät“ die semantische .Polyvalenz“" (Intersemantizität, nach Schmid) des manifesten Werkes. ${ }^{373}$ Wie sich die Kontiguităts- und die

\footnotetext{
${ }^{369}$ Genette 1993, S 15 .

${ }^{370} \mathrm{Vgl}$ die Bezeichnungen .partielle“ und ..totale“ Metafiktion bei Wolf $(1993 . \mathrm{S} 250)$

${ }^{37} \mathrm{Vgl}$ die ..materiell-strukturelle" Intertextualitat bei Plett (S. 28 dieser Arbeit)

${ }^{172} \mathrm{Vgl}$ auf S. 28 dieser Arbeit.

${ }^{373} \mathrm{~S}$ Lachmann auf S. 24 dieser Arbeit
} 
Similaritätsbeziehungen des Lachmannschen Modells - wie wir es verwenden ${ }^{374}$ - innerhalb eines „zweitgradigen Textes“ ergänzen, läßt sich im Weiteren demonstrieren.

$\mathrm{Ob}$ allerdings der manifeste literarische Text als vom anderen abgeleitet verstanden werden kann, kommt auf die Funktion dieser wörtlichen punktuellen Verweise an, die ihrerseits nur interpretativ zu bestimmen ist. Ob diese oder jene Kurzgeschichte Cechovs eine Kontrafaktur oder Travestie des fremden Textes mit den in ihr eingestreuten Zitaten bzw. Allusionen auf diesen Text darstellt oder ob sie ein „selbständiges“ Werk ist, in dem das Zitieren/Alludieren eines Fremdtextes nicht dem Aufbau einer literarischen Ableitung dient, kann insofern anhand konkreter Werke ausgelegt werden. Die Entscheidung hăngt selbstverstăndlich v.a. davon ab, wie man den Begriff „abgeleitet“ versteht, auf welche Texttypen man ihn anwendet. ${ }^{375}$

Wie aus dem Überblick im Kapitel 2.2. (v.a. den Beiträgen der Gruppe 6) teilweise ersichtlich ist, wurde in der Cechovforschung in erster Linie der parodistische Umgang Cechovs mit einzelnen Gattungen und Autoren zum Thema. Wir wollen dagegen sowohl eine weniger erforschte parodistische Ableitung im Werk des Schriftstellers untersuchen als auch weitere "Texte zweiten Grades“ bei Cechov aufdecken. Damit beabsichtigen wir weiterhin, die Gattung der "literarischen Ableitung“ im Rahmen des Prosawerkes Cechovs zu differenzieren und die nicht-parodistischen Cechovschen Hypertexte, wie z.B. Kontrafakturen ans Licht zu bringen. Es gilt hier in bezug auf Kontrafakturen aufzuzeigen, $\mathrm{da} B$ Cechov in seiner frühen Schaffensphase mit dem literarischen Erbe zwar oft spielerisch und experimentierend, aber nicht ausschließlich parodistisch umgegangen ist. Als Stütze für unsere Analyse benützen wir die im Kapitel 2.1.2. ausgewählten theoretischen Ansătze, in denen die Unterschiede zwischen diversen Hypertexten reflektien sowie die Spezifik einiger von ihnen festgelegt wird. Bei der Analyse der nicht-parodistischen Texte wie Kontrafakturen leisten uns diese theoretischen Grundlagen jedoch erst dann Beistand, wenn wir bereits auf interpretativem Wege Abweichungen von den bei Cechov gewohnten, in der Cechovforschung mehrmals geschilderten parodistischen Techniken und Zielen festgestellt haben: für solche textuellen Fälle bieten sie mitunter geeignete Benennungen.

Es geht nicht nur und weniger um die Prätexte, die literaturgeschichtlich, systemreferenziell (z.B. gattungsmäßig) und stilistisch einen augenfalligen Unterschied, nicht selten einen Gegensatz zu den Čechovschen spăteren nicht abgeleiteten Texten aufweisen (zu solchen Bezugstexten zăhlen Romane von Hugo, Verne, de Teraille. Jokai u.a. ${ }^{376}$ ), sondern um diejeni-

${ }^{374} \mathrm{~S}$. Fußn 152

${ }^{775} \mathrm{~S}$. dazu in der Fußn. 364 Was die Unterscheidung von zwei Typen der ..Doppeistrukturen" bei Lachmann betriff, so berufen wir uns hier auf den erwahnten Satz in ihrem Vorwort, in diesem Fall nennt sie als Beispiele des ersteren die Texttypen, die auch wir in bezug auf die Poetik Cechovs zu den .,abgewandelten“ Texten zahlen (z.B Parodie, Stilisierung) - naturlich beim gleichen Verstandnis solcher Texttypen

${ }^{376}$ Auf die hier aufgezahlten u a Autoren bezieht sich Čechonte in seinen beruhmten Parodien wie "Tysjača i

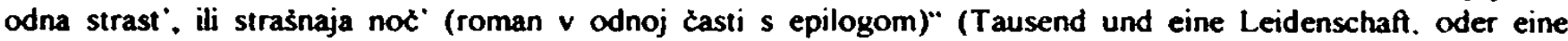
furchtbare Nacht (Roman in einem Teil mit Epilog)). ..Letajušcie ostrova (Soć. Żjulja Verna Perevod A Čechonte)“ (Fliegende Insel (ein Werk von Jules Verne Ubersetzt von A Cechonte), „Grešnik iz Toledo (pe- 
gen, denen Cechovs eigene Poetik in mehreren Beziehungen (z.B. stilistisch) wesentlich näher stand. Zu solchen Vorlagen gehoren beispielsweise Texte von Turgenev oder Gogol'. Schwerer zu ermitteln (vermutlich aus diesem Grund blieben diese Texte in der einschlägigen Literatur weniger beachtet) sind literarische Ableitungen, die nicht auf thematisch-stilistischer Nachahmung der Vorlage basieren, sondern vorzugsweise und vor allem auf ihr Thema und Sujetschema abzielen (wie Kontrafakturen in unserer Auslegung und so mit Erweiterung des Begriffs im Vergleich zu Verweyen und Witting (s. Kap. „Kontrafakturen“)) und insofern einen hơheren Unabhăngigkeitsgrad gegenüber dem Prătext besitzen. In letzteren Fălen ist der von Bachtin gerade in bezug auf literarische Ableitungen erwăhnte, „2weite Kontext ${ }^{377}$ in der Cechovforschung hăufig übersehen worden.

\section{1. „Za jabloxkjw - eine bejahende Nachahmung der Pratexte}

Die im Jahre 1880 verfaßte Kurzgeschichte ,Za jablocki“ stellt unseres Erachtens das Beispiel einer positiven, sprich nicht parodistischen Nachahmung und somit einer ernsten Aneignung bestimmter literarischer Werke (oder ihrer einzelner Episoden) und Werksysteme dar. Im Unterschied zu den Pastiches im fruhen Werk Cechovs, die zwischen der emsten und der ironischen Einstellung zum Referenztext oszillieren (s. darüber Kap. 3.2.), weist diese Geschichte eine eindeutig affirmative ${ }^{378}$ intertextuelle Poetik auf. ${ }^{379}$

In .Za jablocki“ schildert der Erzăhler eine Episode aus dem Leben seines guten Bekannten - des Gutsbesitzers Trifon Semënovic. Der Episode geht eine kurze Charakteristik der Hauptfigur voraus, die sich im Wesentlichen auf die Aufzählung ihrer „Tugenden“ (,dobrodeteli“, „добродетели“) beschrănkt:

Описывать все добродетели Трифона Семёновича я не стану: материя длинная. [...] Я не коснусь ни его плутней в преферансе, ни политики его, в силу которой он не платит ни долгов, ни процентов, ни его проделок над батюшкою и дьячком, ниже прогулок его верхом по деревне в костюме времён Канна и Авеля [...].“ (Alle Tugenden von Trifon Semënovič werde ich nicht beschreiben: das ist eine lange Geschichte. [...] Ich werde seine Gaunerei beim Preferencespiel, seine Politik, derzufolge

\footnotetext{
revod s ispanskogo)" (Der Sunder aus Toledo (Ubersetzung aus dem Spanischen)) oder auch in seinen Pastiches wie ..Nenužnaja pobeda“" (Der unnotige Sieg) Gerade solche parodistischen Texte - auch diejenigen. die Diskurse. Gattungen und literarische Schulen in Ganzen parodieren - sind in der Fachliteratur besonders beliebt: parodistische Techniken des fruhen Cechov werden in den zahlreichen Arbeiten anhand dieser Texte demonstriert (s. dazu exemplarisch Winner 1966, S. 7-16, 237-239, auch in unserem Literaturbericht auf S 65)

${ }^{17} \mathrm{Vgl}$. S. 15 dieser Arbeit.

${ }^{177} \mathrm{Vgl}$ affirmative Intertextualität in der Liste der ..evaluative attitudes" bei Plett (s. S. 29 dieser Arbeit)

379 In diesem Sinne ist der aktuelle Text hier eher weniger als Beispiel der Intertextualitat anzusehen, die u.a Schmid und Peters (s. S. 22 dieser Arbeit) deklarieren, die ..Intersemantizitat” im Sinne von Schmid kommt hier unter den bei uns au analysierenden Werken Cechovs am wenigsten zum Vorschein
} 
er weder Schulden noch Zinsen zahlt, seine Streiche mit dem Priester und dem Kirchendiener, seine Spazierritte durch das Dorf im Kostüm aus den Zeiten von Kain und Abel nicht erwähnen [...].) $(1,39-40) .^{380}$

Das im Folgenden dargestellte Ereignis soll, nach der Absicht des Erzăhlers, das grausame Verhalten und die Gewohnheiten des Gutsbesitzers veranschaulichen. Trifon Semenovic macht an einem schönen Morgen einen Spaziergang durch seinen Garten; ihn begleitet sein Arbeiter und treuer Komplize Karpuska. In einem entlegenen Gartenwinkel unter einem alten Apfelbaum ertappen sie ein junges Bauempaar, wobei der junge Mann die vom Wind abgerissenen Äpfel sammelt und seiner Freundin schenkt. Der Gutsbesitzer und sein Gehilfe erwischen die Verliebten in dem Augenblick, in dem der junge Bauer sich seiner übermütigen Geliebten zuliebe entschließt, einen Apfel vom Baum zu pflücken. Trifon Semënovič beginnt ein höhnisches Gespräch mit den Schuldigen, denen es vor Angst die Sprache verschlägt. Unter anderem befiehlt er dem jungen Bauern, den Anwesenden ein Mărchen zu erzăhlen, wăhrend Karpuska für eine Rute eifrig Brenn-Nesseln pflückt. Die Unterhaltung endet damit, daß auf Befehl von Trifon Semënovič und aus Furcht vor der Bestrafung zunächst die Băuerin ihren Freund, dann dieser sie kräftig verprügelt. Nach den gegenseitigen Schlägen wollen die vor kurzem noch Verliebten nichts mehr voneinander wissen: Er geht nach rechts, sie nach links.

Die Kurzgeschichte ruft einzelne Figuren, Episoden, Szenen und die Darstellungsweise eines bestimmten Textsystems - nämlich zahlreiche Werke der russischen Literatur, die das Thema der Mißhandlung der Bauern durch die Gutsbesitzer aufyreifen, Werke der .,antikrepostničeskaja proza“ ${ }^{381}$ (leibeigenschaftskritische Prosa), auf, sie bezieht sich gleichzeitig auch auf konkrete Texte innerhalb dieses Systems. Cechov greift hier das in einer ganzen Reihe von Texten der russischen Literatur offen oder auch verborgen-ironisch (wie in .Zapiski ochothika“ (Die Aufzeichnungen eines Jägers) Turgenevs) zum Ausdruck kommende Pathos des Protestes gegen die Willkür des ..pomešcik“ gegenüber dem Bauern - ..narod“ auf $^{\mathbf{3 2}}$ und schaft die emste Imitation eines bekannten literarischen Musters, bezogen auf die für ihn moderne Zeit (nach der Authebung der Leibeigenschaft). Es handelt sich hier demzufolge um einen Zusammenhang zwischen System- und Einzeltextreferenz.

\footnotetext{
1200 Wir werden Verweise auf das russische Original der Texte Cechovs und auf die Anmerkungen zu ihnen kunftig folgendermaßen gestalten in Klammern wird zuerst der Band (aus der Gesamtausgabe. $s$. das Literaturverzeichnis) und danach de Seite angegetren. Diese Verweise werden wir im U'nterschied zu allen anderen nicht in den Fußnoten, sondern im Text nach den entsprechenden Zitaten anfuhren

sвt $\mathrm{Vgl} \mathrm{Kataev} 4$ откликается на 'деревенскую тему', одну из главных в русской литтературе 80 rr (рассказ 'За яблочки', связанный с траднциямн еще антикрепостнической сатнры [.. ]) [ ]" (C'еchov antwonet auf das ..Dorfthema“. eines der wichtigsten in der russischen Literatur der 80 er Jahre (die Geschichte ,Za jablocki". die noch mit den Traditionen der gegen die Leibeigenschaft gerichteten Satire verbunden ist ( ]) [ ]) (1990.S 382)

${ }^{3 \times 2} \mathrm{Vgl}$ dazu die Meinung von Kramer ..A classic instance of fairly crude pathos appears in ..Bacause of Little Apples" (Za fablixkl. 1880). [ ] [ ] The outer frame of the story involves a narrator who is describing the
} 
Für die Analyse sinnvoll erscheint uns eine Lektüre, die die an der Oberfläche des Textes verstreuten intertextuellen Signale nach und nach aufspürt und ihre Funktion für den Aufbau dieser literarischen Ableitung erschließt. Dabei ist zu zeigen, wie die durch intertextuelle "markers" - in unserem Verstăndnis also durch Allusionen und Zitate - evozierten Prătexte innerhalb des semantischen Ganzen des Werkes koexistieren und, sich gegenseitig erganzend, den intertextuellen Hintergrund des aktuellen Textes bilden.

Wohl am auffalligsten sind einige Allusionen, die ,Za jablocki“ mit der Skizze Ivan Turgenevs „Dva pomešcika“ (Zwei Gutsbesitzer) (1852) aus dem Zyklus „Zapiski ochotnika“ verbinden. Es geht vor allem um „significant words“ (Perri) bzw. „lexikalische Motive“ oder "markante Handlungsdetails“ (Schmid), die dem Text Turgenevs „entnommen“ sind und die auf bestimmte Satzstrukturen oder Episoden dieses Werkes verweisen.

Schon das an einer, nach dem Ausdruck Fügers, intertextuell ,privilegierten ${ }^{\text {c383 }}$ Stelle des manifesten Textes - im ersten Satz der Geschichte - auftauchende Wort „pomešcizek“ (Gutsherrchen) ruft in Kombination mit der in Form des Ich-Erzählens durchgeführten ironischen Charakteristik eines (dem Erzăhler gut bekannten) Gutsbesitzers den Titel dieses Referenztextes und ebenfalls seinen ersten Satz („, [...] позвольте же мне теперь, кстати (для нашего брата писателя всё кстати), познакомить вас еще с двумя помешиками [...].“ (,[...] gestatten Sie mir jetzt, bei dieser günstigen Gelegenheit (für uns Schriftsteller ist jede Gelegenheit günstig), Sie mit noch zwei Gutsbesitzern bekannt zu machen $\left.[\ldots]^{\text {(384 }}\right)^{385}$ ) ins Gedåchtnis (vgl. bei Cechov: „Между Понтом Эвксинским и Соловками, [...] на своём чернозёме с давних пор обитает помещичек Трифон Семёнович.“ (Zwischen Pontos Euxeinos und den Solovki-Inseln [...] haust von alters her auf seiner eigenen Schwarzerde das Gutsherrchen Trifon Seměnovic.) $(1,39)$ ). Die bei Turgenev in der eingeklammerten Schlußfolgerung, bei Cechov im Diminutiv „,pomešciček“ manifestierte Ironie des Erzählers gegenüber den zu schildernden Personen markiert den entlarvend-kritischen Diskurs beider Texte. Die in der Aufzählung von "Tugenden“ Trifon Seměnovižs erwähnten Streiche mit den Geistlichen („проделки над батюшкою и дьячком“) verweisen weiterhin auf die Episode, in der der zweite Turgenevsche Gutsbesitzer Mardarij Apollonyc Stegunov den jungen und schüchternen Priester - auch ..batjuška“ genannt - dazu zwingt, ein Glas Wodka bei ihm zu trinken. Das im ersten Fall als kurze Szene Dargestellte wird im zweiten zu einem Satzteil zusammengerafft. Der von Trifon Semenoviz stammende .Zungenbrecher“ „Мужички, простачки, чудачки, дурачки проигрались в дурачки“ (etwa wie „Bäuerchen, Einfaltspinselchen, verschrobene Kerlchen. Schafsköpfchen haben bei 'Schafskopfchen'-Spiel den letzten Heller verspielt") evoziert dagegen die Charakteristik des ersten Gutsbesitzers aus ..Dva pomešcika“ Vjačeslav Illarionovic Chvalynskij: ..В карты играть он любит, но только с

moral depths to which human nature can sink the landowner is his primafic'se evidence, and thus, it is made explicitly clear. who the villain is." $(1970$, S. 60).

$3{ }^{23} \mathrm{Vgl}$. S. 31 unserer Arbeit

384 Turgenjew 1971, S. 217 
людьми звания низшего; они-то ему: 'Ваше превосходительство', а он-то их пушит и распекает, сколько душе его угодно.“ („Er spielt gerne Karten, jedoch nur mit Leuten niedrigeren Standes; sie sagen zu ihm 'Euer Exzellenz', er aber schimpft sie aus und putzt sie herunter, soviel sein Herz begehrt. $\left.{ }^{(386}\right)^{387}$.

Aus dem Prătext übernommen und etwas modifiziert scheint ebenfalls ein „,markantes Handlungsdetail“ zu sein: Das "Vergehen“ der Bauern, das den Zom des Gutsbesitzers (bei Turgenev von Mardarij Apollonyc) hervornuft. Bei Turgenev sind das aufs Territorium des herrschaftlichen Gartens geratene Hühner, bei Cechov die aus dem herrschaftlichen Garten gestohlenen Äpfel. In beiden Fällen lost die kleine Schuld eine unangemessen schwere Strafe aus. Wie der Anfang, ist auch das Ende der Cechovschen Kurzgeschichte in bezug auf den genannten Referenztext intertextuell markiert. Ihr letzter Satz variier den ironischmıßbilligenden Ausruf des Erzăhlers im Finale der Novelle Turgenevs: „Вот она, старая-то Русь!" - думал я на возвратном пути.“ („Da haben wir es, das alte Rußland! dachte ich auf dem Heimweg.“388) („Dva pomešcika“) ${ }^{389}$ - „Называй после этого Трифона Семёновича Трифоном Семёновичем!“ (Nenne danach diesen Trifon Semënovic noch „Trifon Semënovi“") $\left(, \mathrm{Za}\right.$ jablocki“") $(1,45)$. $^{390}$

Die vielen intertextuellen Spuren, die ,Za jablocki" mit der Novelle "Dva pomešcika“ verknüpfen, legen Analogien auf verschiedenen textuellen Ebenen dieser Werke bloB. Analogien betreffen den Handlungsablauf bzw. das Sujetschema der Geschichten (das Vergehen der Bauem - ihre Bestrafung durch den Gutsbesitzer - Belustigung desselben), die Personenkonstellation (der Erzähler, sein bekannter Gutsbesitzer, Schuldige bäuerlicher Herkunft und der Vollstrecker der Strafe (Juška ${ }^{391}$ - Karpuška)) ${ }^{392}$, das im den Text abschließenden Ausruf artikulierte Pathos des emporten Erzàhlers.

„Za jablocki" enthält ebenfalls eine Reihe von Allusionen auf weitere Werke innerhalb des genannten Textsystems - auf den Reisebericht Aleksandr Radiščevs „Putešestvie iz Peterburga v Moskvu“ (Die Reise von Petersburg nach Moskau) (1790), auf das zweite Kapitel aus dem Sergej Aksakovs Roman ..Semejnaja chronika“ (Familienchronik) (1856) (..Michajla

\footnotetext{
18: Turgenev Bd 4 (1963), S 176

186 Turgenjew 1971, S 219

387 Turgenev Bd. 4 (1963), S. 178

"\$88 Turgenjew 1971, S. 228

${ }^{389}$ Turgenev Bd 4 (1963), S 185

${ }^{300}$ Ein anderer Satz im Text Cechovs, der ebenfalls die bewertende Haltung des Erzahlers gegenuber dem Verhalten des Gutsbesitzers offenbart. alludient den Ausruf des Erzahlers aus der Novelle von Aleksandr Puskin „Dubrovskij” (1832-33) In der Episode. in der die grausamen Scherze des russischen „barin“ (des Herren) mit den von seiner Macht Abhangigen (wenn auch nichtbauerlicher Herkunf) geschilden werden. ..Таковы были благородные увеселеняя русского барина!" (Puskin Bd. 8 (1948), S 189) (..Das waren so die vornehmen Vergnugungen eines russischen hohen Herrn" (Puschkin Bd 3 (1952), S. 137)) - .Вот как забавляет себя на старости лет Трифон Семенович " (Cechov) (So vergnugt sich also Trifon Semenovic auf seine alten Tage ) (1. 44) Damit wird das noch breitere Thema des Despotismus russischer Gutsbesitzer (mit der Auslassung des Motivs "Leiden der Bavern") in bezug auf ein weiteres literarisches Werk intertextuell artikuliert

91 Juska wird allerdings nur beauftragt. Natalka zu bestrafen

${ }^{192}$ Diese Parallelen beziehen sich ausschließlich auf den zweiten Teil der Novelle Turgenevs, also auf die Episode mit Mardarij Apollonyc
} 
Maksimovic Kurolesov"); in der Kurzgeschichte sind auch Korrespondenzen der Motive bzw. konkrete Verweise auf andere Skizzen aus Ivan Turgenevs Zyklus „Zapiski ochotnika“ und die Novelle "Razvesëloe žit'e“ (Ein heiteres Leben) aus dem Zyklus "Nevinnye rasskazy“ (Unschuldige Geschichten) (1857-63) von Michail Saltykov-Šcedrin zu finden.

So wiederholt die "Einfuhrung" in die zu erzählende Episode bei Cechov - das Verfahren des bedeutungsvollen Nichterwahnens aller grausamen Gewohnheiten des Gutsbesitzers - fast wortwortlich Passagen aus dem Kapitel „Zajcovo“ („Putešestvie iz Peterburga v Moskvu“) und aus „Michajla Maksimovic Kurolesov“ (bei beiden Texten handelt es sich um die grausamen Taten eines Gutsherm gegen seine Bauem). Vergleichen wir die entsprechenden Textstellen: „Много бы мог я тебе рассказать его мудрых распоряжений; но сего довольно для познания моего ироя.“ („Viel konnte ich dir von seinen weisen Anordnungen erzăhlen, aber das Gesagte mag genügen, um meinen Helden zu charakterisieren. “393) (Radiscev) ${ }^{394}$ .Я не стану рассказывать подробно, какую жизнь вёл он в своих деревнях, [...] это была бы самая отвратительная повесть. Я скаку только то, что необходимо для получения настоящего понятия об этом страшном человеке.“ („Ich will hier nicht das Leben ausführlich beschreiben, das er auf seinen Gütern [...] führte; es wăre ein zu ekelhaftes Bild. Ich will nur das erzahlen, was notwendig ist, um dem Leser eine Idee von diesem schrecklichen Manne zu geben...395) (Aksakov) ${ }^{396}$ - „Описывать все добродетели Трнфона Семёновича я не стану: материя длинная. [...] ограничусь одной только сценкой, характернзующей его отношения к людям [...]” (Alle Tugenden von Trifon Seménovič werde ich nicht beschreiben: das ist eine lange Geschichte. [...] ich beschrăke mich nur auf eine kleine Szene, die seine Haltung gegenüber den Menschen charakterisiert [...]. (Cechov I, 39-40)) . Die Passage Cechovs kann man als modifizientes Zitat aus den erwăhnten Werken von Radišcev und Aksakov deuten. In allen drei zitierten Texten kommt das fur den entlarvenden Diskurs charakteristische Pathos des vieldeutigen Verschweigens zum Ausdruck; das unbarmherzige Verhalten der Figur wird vom Erzahler ${ }^{397}$ dadurch auf eine besondere Art betont und verurteilt. Dieses Verfahren wird jedoch ebenfalls in allen drei Făllen mit der ..deskriptiven“ Charakteristik, d.h. der Aufzahlung muncher der eigenwilligen Strafmethoden des Gutsbesitzers kombiniert: .Если кто из крестьян что-нибудь украл у него, того он сёк, [...] но сверх того надевал на ноги колодки, кандалы, а на шею роrarky.“ („Wenn einer seiner Bauem bei ihm etwas gestohlen hatte, lies er ihn prügeln [...], außerdem aber legte er die Füße des Missetăters [seine Füße] ${ }^{398}$ in Block und Ketten und seinen Hals in eine Gabel...399,

\footnotetext{
${ }^{303}$ Radistschew 1952. S 114

${ }^{394}$ Radiscev 1959, S. 110

${ }^{395}$ Aksakow 1919. S. 69.

${ }^{106}$ Aksakov Bd 1 (1955), S. 120

397 In der betreffenden Episode bei Radišcev fungien als Erzahler ein Freund des eigentlichen Erzahlers ..predsedatel' ugolovnoj palaty“ (..der Vorsizzende des Kriminalgerichts" (Radistschew 1952,S 114)) Krest'jankin Seine Stimme und Pathos ..verschmelzen“ jedoch im Ganzen mit denen vom Erzahler.

"io* Korrekturen der Verf. sind hier und im Weiteren in eckigen Klammern angefuhn (vgl Fußn 327)

${ }^{390}$ Radistschew 1952. S 114.
} 
(Radiščev) $^{400}$ - „Досаждал ли кто Михайлу Максимовичу […] сейчас, по знаку своего барина, скакали они (gemeint sind die treuen Knechte des „barin“ - K. S.) к провинившемуся, хватали его [...] привозили к Михайлу Максимовичу, позорили, сажали в подвал в кандалы или секли по его приказанию.“ („Hatte jemand [...] Michail Maximowitsch geärgert [...] so brauchte er nur zu winken, und seine Getreuen machten sich auf den Weg, packten den Delinquenten [...] und schleppten ihn zu ihrem Herm, wo er gemißhandelt, in den Keller gesperrt, gefesselt, of durchgeprügelt wurde [und sie ritten zum Delinquenten, packten ihn [...] brachten ihn zu Michajla Maksimovic, schăndeten ihn, spertten ihn gefesselt in den Keller oder prügelten ihn auf dessen Befehl]. ${ }^{.401}$ ) (Aksakov) ${ }^{402}$ „Вора он или запирает на сутки в погреб, или сечёт крапивой, или же отпускает на свою волю, предварительно только раздев его донага...“ (Den Dieb spert er entweder in den Keller oder verprügelt ihn mit Brenn-Nessel, oder er lāßt ihn nach Hause gehen, wovor er ihn aber ganz entkleidet...) (Čechov 1, 43). Der Komplize bzw. die Komplizen an der Seite des Gutsbesitzers - hörige Vollstrecker seines Willens - gehoren zu den typischen Protagonisten der hier bezeichneten fiktiven Situation (Mißbrauch der Bauern durch den grausamen .,pomescik") - eine Personenkonstellation, die Cechov in ,Za jablocki“ ebenfalls aufgreift. $\mathrm{Vgl}$.: „Он выбрал себе из дворовых и даже из крестьян десятка полтора головорезов, достойных исполнителей его воли [...]. [...] они [...] охотно и смело исполняли все ero безумные приказания. “ (,Er hatte sich unter seinem Gesinde und sogar unter den Bauern ein paar Dutzend verruchter Gesellen zusammengesucht und diese würdigen Vollzieher seiner Einfalle [...] vollstreckten [...] willig und dreist seine wahnsinnigen Befehle. ${ }^{.403}$ ) (Aksakov) ${ }^{404}$ - „Позади Трифона Семёновича шествовал его верный вольнонаёмник, [...]. Этот Карпушка своими добродетелями чуть ли не иревосходил самого Трифона Семёновича." (Hinter Trifon Seme̊novic stolzierte sein treuer Vertragsarbeiter, [...]. Dieser Karpuska übertraf durch seine Tugenden beinahe selbst Trifon Semënovic.). (Čechov 1 , 40). ${ }^{\text {tuS }}$ Darüber hinaus ist die Schlüsselszene der Cechovschen Kurzgeschichte - die Bestra-

\footnotetext{
${ }^{200}$ Radisčev 1959, S 110

${ }^{+01}$ Aksakow 1919, S. 70

${ }^{402}$ Aksakov Bd. I (1955), S 121

${ }^{403}$ Aksakow 1919.S 73

tos Aksakov Bd. 1 (1955), S 121
}

${ }^{105}$ Das Wort ..dobrodeteli“" (Tugenden) - das vor dem Hintergrund des nuchtern-ironischen Stils der Cechovschen Geschichte zweifelsohne ein lexikalischer Fremdkorper ist - verweist in Kombination mit den weiteren erwahnten Bezugen zu diesem Pratext auf die nicht selten didaktisch-pathetische Rhetorik des Werkes Aleksandr Radišcevs - eines Textes der russischen Literatur, in dem das Thema der Mißhandlung der Bauern durch die Gutsbesitzer offen und mit großer Emporung angesprochen wurde Dieses bei Cechov in bezug auf einen grausamen Gutsherren ironisch verwendete Wort spielt eine bedeutende Rolle im moralischen Aufbau von ..Putesestvie iz Peterburga v Moskvu" und steht in Zusammenhang mit dem ersehnten ldeal der Gerechtigkeit und Humanitat. Vgl z.B. Worte eines weisen Adeligen, die er an seine Kinder richtet. „Гонеже добродетель есть вершина деяний человеческих. то исполнение е ничем не долженствует быть препинаемо“" (1959. S 131) (..Nichts Hoheres gibt es fur den Menschen als die Ubung der Tugend, sie darf also durch nichts gehemmt werden." (1952. S. 145)) Hier erkennt man also den intertextuellen Verweis als die von Riffaterre manifestierte ..Agrammatikalitat". als ein in die kontextuelle Umgebung nicht passendes Element, dabei vollzieht sich der von Plett (primar fur Zitate) beschriebene Kodewechsel. in diesem Fall von einem Sprachregister zum anderen (..diatypische Interferenz") (s S 
fung des Bauempaares - auf eine Weise gestaltet, die bestimmte Texte des ,antikrepostniðeskij" Diskurses in der russischen Literatur in ihren einzelnen Fragmenten vergegenwärtigt. Dabei werden die Beziehungen zu den Fremdtexten wiederum durch Allusionen verschiedener Art wie auffällige Handlungsdetails, Namen oder Sprechweise der Figuren markiert. „- Здравствуйте, голубчики! - сказал Трифон Семёнович, подходя к ним. Что, яблочки кушаете? Я, бывает, вам не помешал? [...] - Ну, как твоё здоровье, Григорий? [...] Как живёшь-можешь, паренёк?“ („Ich grüsse euch, meine Lieben!“ - sagte Trifon Semënovič, sich ihnen nähernd. - „Was, ebt ihr Äpfelchen? Habe ich euch nicht zufallig gestort?" [...] „Nun, wie ist dein Befinden, Grigorij? [...] Wie meisterst du dein Leben, Bürschchen?") $(1,41-42)$.

Die angeführte Szene enthălt weitere Bezüge zur „Semejnaja chronika“ Aksakovs, nămlich die ,zärtliche" Anrede der Schuldigen durch den Gutsbesitzer einschließlich der benützten Diminutivformen und zusatzlich eine onomastische Allusion - den Namen des Bauern:

Замечательно, что когда Михайла Максимович [...] добирался до человека с намерением потешиться его муками, он говорнл тихо и дахе ласково: любезный друг, Григорий Кузьмич (вместо обыкновенного Гришки), [...].“ [...] „Поцарапайте его кошечками“, - говорил с улыбкой Михайла Максимович [...]. (,Merkwürdig war, daß Michail Maximowitsch [...] wenn er seine Grausamkeit an jemand auslassen wollte [wenn er die Absicht hatte, sich an den Qualen des Menschen zu erfreuen], sprach [er] mit ruhiger, sogar sanfter Stimme etwa folgendes: Nun, lieber Freund, Grigori Kusmitsch [(statt des gewöhnlichen 'Griska') - K. S. ${ }^{406}$ ] [...]'. [...] 'Kratzt ihn mit den Kätzchen!' sagte er [sagte Michajla Maksimovic] lăchelnd [...].“407) ${ }^{408}$

Cechov bezieht sich hier auf das höhnische Verhalten des Aksakovschen .,pomešcik“, das die Grausamkeit und den Zynismus der Hauptperson noch hervorheben soll. In derselben Reihe steht auch das markante Sujetelement in ,Za jablocki“": der Befehl von Trifon Semennovic, nach dem der vor Angst zitternde Grigorij ein Märchen erzählen muß, sowie der Rat Karpuškas, er solle lieber ein Lied singen; beides Verweise auf die Novelle „Odnodvorec Ovsjanikov“ (Der Freisasse Owsjanikow ${ }^{\text {(U) }}$ ) aus Ivan Turgenevs .Zapiski ochotnika“, in der ein Gutsbesitzer seine bereits erschöpften Leibeigenen zwingt, vor ihm zu tanzen und zu singen: ,- $-[\ldots]$ Девок своих крепостных вовсе замучил. Бывало, всю ночь как есть, до утра хором поют [...]. А станут уставать - [...] Конюха тотчас девок и приободрят.“” (..[...]

35 unserer Arbeit). Vgl. daau auch die Verwendung des Wortes ..dobrodeteli“" im Gedicht von Nikolaj Nekrasov ..Sovremennaja oda“ (Die zeitgemaße Ode) - hier gewinnt es ebenfalls ironische. ja sarkastische Konnotationen. hier wird ebenso das Thema der schlechten Behandlung der Bauern angesprochen

${ }^{+06} \mathrm{~S}$ im Original des Textes von Aksakov Bd 1 (1955)

${ }^{407}$ Aksalow 1919. S. 73

Aksakov Bd. I (1955). S 123-124

${ }^{409}$ Turgenjew 1971. S. 75 
Seine leibeigenen Măgde hat er bis aufs Blut gepeinigt. Die ganze Nacht durch mußten sie manchmal im Chor singen [...]. Wurden sie aber müde [...] Dann machten seine Pferdeknechte die Mägde sogleich wieder munter $[\ldots]^{\prime . .^{410}}$ ). (aus der Erzăhlung Ovsjanikovs) ${ }^{411}$.

Es sei hier noch ein Motiv erwähnt, das ,Za jablocki“" mit einigen - u.a. den oben bereits erwähnten - Texten des genannten literarischen Diskurses korrelieren läßt, und zwar das Motiv der infolge der brutalen Einmischung des Gutsbesitzers nicht stattfindenden Hochzeit des jungen Bauernpaares. So wird in "Putešestvie iz Peterburga v Moskvu“ (dasselbe Kapitel .Zajcovo“) u.a. eine Geschichte erzăhlt, in der die Braut eines Bauem vom Sohn seines Herm beinahe vergewaltigt wird. Die Episode endet tragisch: der Bauer lehnt sich gegen die herrschaftliche Gewalt auf, wird ausgepeitscht, versucht dann noch, seine Braut zu entführen und tötet mit anderen empörten Bauern seine Herren. ${ }^{412}$ In die Novelle "Ermolaj i mel'ničicha“ (Ermolaj und die Müllerin ${ }^{413}$ ) aus dem Zyklus .Zapiski ochotnika“" ist ebenfalls eine Geschichte eingebaut, in der die Hochzeit einer Leibeigenen Arina, die im Haus als Gouvernante dient, mit dem Lakaien Petruska von ihren Herren nicht gestattet wird; Arina wird zum Schluß wegen ihrer Liebe zu Petruška ins Dorf verbannt. ${ }^{+14}$ In Saltykov-Šcedrins Novelle ..Razvesèloe žit'e゙“ aus dem Zyklus „.Nevinnye rasskazy“ werden zwei Leibeigene von dem eifersüchtigen Gutsbesitzer aufgrund ihrer Liebe bestraft, das Ende der Geschichte ist ebenfalls trostlos: Die Băuerin wird auf den Viehhof geschickt und mit einem Witwer verheiratet, der Bauer bricht das Gesetz, indem er flüchtet. ${ }^{415}$ In .Za jablocki“ ist der Gutsbesitzer an den Hochzeitsplänen der jungen Bauern nicht interessiert, er bringt sie jedoch aus Langeweile und Vemichtungslust zum Scheitern.

Von den Referenztexten, die wir hier angesprochen haben, kann man jedoch in erster Linie in bezug auf Turgenevs ..Dva pomešika“ von einer durch mehrere Allusionen zustandegekommenen Evokation des ganzen Vorgangs sprechen.

Cechov schreibt demzufolge eine Geschichte im Geiste seiner Vorgänger, indem er eine thematisch-stilistische Nachahmung bestimmter Szenen aus ihren Werken vomimmt. Konkrete ,wörtliche“ Bezüge zu den Referenztexten werden dabei durch analoge Personen- und Handlungsstrukturen ergänzt. In einer neuen sozialen Situation in Rußland wendet er sich gegen dasselbe soziale Phänomen. Es läßt sich hier, wie wir meinen, vom ersten Modell der Intertextualitat in der Typologie von Lachmann sprechen - dem der Partizipation ${ }^{416}$.

\footnotetext{
$\$ 10$ Turgenjew 1971, S. 80

411 Turgenev Bd 4 (1963). S 65

112 Radišcev 1959, S 110-112

$\$ 13$ Tugenjew 1971, S 22

114 Turgenev Bd +(1963). S 29-32

$\$ 1$ Saltykov-Sxedrin Bd 3 (1965). S 162-173

\$16 Vyl S 27 dieser Arbeit Jedoch mussen wir hier anmerken. daß wir das Konzept Lachmanns - die drei Modelie der Intertextualitat - (auch weiterhin) in unserem Sinne verwenden. dadurch, daß wir sie auf die betreffenden Texte Cechovs beziehen, interpretieren wir dieses Konzept auf unsere Weise. was von seiner Auslegung bei Lachmann in einigem abweichen kann Im wesentlichen ..interpretieren" wir die von uns auf S 27-28 zitierten Formulierungen von Lachmann
} 
Die Intertextualităt der Geschichte ,Za jablocki“" wird durch ein Zitat ergănzt, das aus dem romantischen Gedicht "Poet“" (Der Dichter ${ }^{417}$ ) Aleksandr Puskins stammt. Das Zitat ist am Anfang der Episode, nämlich in der Szene, in der der sich langweilende Trifon Semēnovič in seinem Garten einen Spaziergang macht und die Schönheit der Natur übersieht, „versteckt“: „Но Трифон Семёнович не наслаждался, потому что он далеко не поэт, да и к тому же в это утро душа его с особенною жадностью вкушала хладный сон [...]." (Trifon Semenovic genoß jedoch nicht, weil er bei weitem kein Poet ist, hinzu kam noch, daß seine Seele an diesem Morgen den kalten Schlaf mit besonderer Gier empfing [...].) $(1,40)^{418}$ Der intertextuelle Bezug ist explizit nicht markiert, es fehlen auch jegliche, u.a. graphische Marker, die ihn als Zitat erkennbar machen würden; formal ist das zitierte Segment in den aktuellen Text nahtlos eingebunden. ${ }^{419}$ Dennoch ragt es aus seiner kontextuellen Umgebung stilistisch eindeutig heraus: Die von Lachmann formulierte "Kreuzung zweier Kodes“ bzw. die „Uberschneidung von prasentem und absentem Text ${ }^{\star \star 20}$ artikuliert sich hier sowohl im diachronen als auch im daraus resultierenden diatypischen Kontrast (s. die Typologie Pletts ${ }^{421}$ ). Der mit dem Zitieren verknüpfte Kodewechsel betrifft also die Sprachstufe (die literarische, zusătzlich noch poetische Sprache des ersten Drittels des 19. Jahrhunderts, die sich intensiv der altkirchenslavischen und damit einer denkbar gehobenen Lexik bedient, gerăt in Konflikt mit der literarischen Norm des letzten Drittels des Jahrhunderts) und das Sprachregister (die erhabene, metaphorische Sprache des Puskinschen Gedichtes vor dem Hintergrund einer nüchtern-ironischen Sprache des Čechovschen Erzăhlers) ${ }^{422}$. Das Wort „poèt“, verknüpft mit diesem Zitat, stellt eine Allusion auf die zentrale lyrische Gestalt aus demselben Referenztext dar. Die Funktion der Verweise erschließt sich aus der Gegenüberstellung beider Texte. Dem Gedicht .Poèt“ liegt das romantische Konzept des Auserwăhltseins des Dichters zugnunde. Es besteht aus zwei Teilen, was kompositionell die geistige Gespaltenheit bzw. die doppelte Natur des Künstlers wiedergeben muß: In der ersten Hălfte figuriert er als Mensch unter anderen, der sich mit den nichtigsten Dingen beschäftigt und dem der Kleinmut nicht unbekannt ist. Aus diesem Teil des Gedichtes stammt das von Cechov aufgenommene Zitat:

\author{
Молчит его святая лира: \\ Душа вкушает хладный сон [...] \\ (Seine heilige Lyra schweigt: \\ Die Seele kostet kalten Schlaf, $[\ldots])^{423}$
}

\footnotetext{
${ }^{+17}$ In der im Weiteren zitierten Ubersetzung (Puschkin Bd 1 (1952), S 286) unter dem Titel ..Der Poet"

${ }^{41 x} \mathrm{~S}$. dariber in den Anmerkungen zum Text $(1,564)$.

419 Jedoch betrachten wir diesen Bezug v a wegen der Lange des dem Pratext entnommenen Materials als ein Zitat (s. die Kriterien, die wir fur die Unterscheidung der Zitate von den Allusionen aufgestelit haben)

$420 \mathrm{Vgl} S 24$ dieser Arbeit.

$421 \mathrm{Vgl}$. S. 35 dieser Arbeit
}

${ }^{122}$ S dazu noch die Oppositionen ..naturtich - kunstlich“. .,niedrig - hoch“. ..alt - net" bei Plett (1985. S 91 ) 
In der zweiten Hălfte - der lyrischen Gegenthese zu der ersten - wird der geistige Wandel des Dichters dargestellt: Vom „göttlichen Wort“ („божественный глагол“) inspiriert, wacht er auf, er zieht sich von der Welt zurück und kennt keine Furcht und keinen Zweifel mehr, er wird zum Schopfer:

\section{Но лишь божественный глагол}

До слуха чуткого коснётся,

Душа поэта встрепенётся, [...]

(,Doch kaum vernimmt sein feines Ohr

Des Gottes Ruf, vor ihn zu treten,

Erwacht die Seele des Poeten $\left.[\ldots]^{\text {at24 }}\right)^{425}$.

Denkbar polare Gestalten - der grausame und unnoble Gutsbesitzer und der Puskinsche „poet" werden ironisch verglichen. Das Zitat erfüllt jedoch nicht nur die pragmatische Funktion, die sich aus dem nächsten situativen Kontext erschließt und ausschließlich den ersten Teil des Gedichtes ins Gedăchtnis ruft: es dient nicht nur der Vermittlung der Stimmung von Trifon Seménovic, sondern auch eine semantische Funktion (wir berufen uns hier auf die Typologie der Zeichenfunktion der Zitate Kośnys ${ }^{426}$ ). Es evoziert den ganzen Prätext, d.h. auch dessen zweiten Teil, und übernimmt eine ironisch-vorausdeutende Aufgabe: wie der Dichter, berührt von der gottlichen Eingebung, wird sich auch Trifon Seménovič verwandeln. wenn er begreift, daß er sich wieder einmal gut unterhalten kann: „Трифон Семёнович, предчувствуя скандальчик, встрепенулся, [..] и побежал за Карпушкой“ (Trifon Seménovic erwachte, sobald er ein Skandalchen witterte, [...] und lief Karpuška hinterher.) (1, 41). Das Verb „vstrepenulsja“ (erwachte, fuhr auf) verweist noch einmal deutlich auf den Puškinschen Text (s. das Zitat oben) und bestätigt seine ..strukturierende“ Wirkung auf die Kurzgeschichte ,Za jablocki“. Die Komposition des Gedichtes wird ironisch verdreht: wăhrend der Puskinsche Dichter geistig erwacht, um sich von seiner .Nichtigkeit” zeitweilig zu befreien, wacht Trifon Seménoviz gerade dann auf, wenn er zum nichtigsten unter den Menschen wird. Der intertextuelle Bezug zu Puškins „Poèt“, mit dessen Hilfe das Unvergleichbare

\footnotetext{
${ }^{423}$ Puskin Bd 3 (1948). S 65.

224 Puschkin Bd 1 (1952). S 286

${ }^{425}$ Puskin Bd 3 (1948), S 65 S die Charakteristik dieses Gedichts von Puskin u. a bei Stender-Petersen (1978. S $110-1111$.

${ }_{426} \mathrm{Vgl}$ S. 61-62 dieser Arbeit. Wahrend jedoch Kosiny (da er seine Typologie der Zitatfunktion in bezuy auf ein Drama Cechovs entfaltet) zwischen den pragmatischen und den semantischen ..Inhalten" der Zitate unterscheidet. die handelnde Personen selbst aussprechen und die also zur Charakteristik ihrer Kommunikation miteinander oder auch dessen, was uber deren Grenzen hinausgeht. dienen, ubertragen wir scine Differenzierung auch auf die Bezuge, die außerhalb ihrer Wahrnehmung liegen, $d$ h z B nur dem Autor oder dem Erzahler und dem Leser ..bemerkbar" sind (hier meinen wir die Bezuge selhst und nicht ihre - ob eine pragmatische oder eine semantische Funktion) So verwenden wir das Schema Kosnys auf unsere Ant, wir nehmen nur bestimmte Punkte seiner Differenzierung in Anspruch und beziehen sie auf unser Anliegen
} 
zusammen gebracht wird, verdeutlicht den kritisch-entlarvenden Charakter des Textes Cechovs: Er dient zur Verspottung und Demaskienung des grausamen Gutsbesitzers. ${ }^{427}$

\subsection{Parodien}

Wir wollen unsere Analyse mit der Ermittlung einer literarischen Ableitung im Werk Cechovs fortsetzen, die wir diesmal als Parodie auffassen. Bevor wir zur Textanalyse übergehen, ist es sinnvoll, die im Kapitel 2.1.2. angeführten Überlegungen der Theoretiker zur Abgrenzung der Parodien von anderen Texten zweiten Grades heranzuziehen.

Im Hinblick auf die Eigenar Cechovscher Hypertextualităt ist es unseres Erachtens wichtig, Parodien in erster Linie von Pastiches einerseits und den in Beitrăgen von Verweyen und Witting herausgebildeten Arten der literarischen Ableitung - d.h. v.a. der Kontrafaktur - andererseits zu unterscheiden. Transformationstechniken, die üblicherweise der Travestie zugeschrieben werden, sind dagegen im Rahmen des literarischen Werkes Cechovs im wesentlichen auch für die parodistischen Texte charakteristisch. Die für die Parodie als spezifisch aufgefaßten Merkmale - Diskrepanz zwischen der erhabenen Form und dem nichtigen Inhalt (Frejdenberg); Unvermeidlichkeit der sprachlichen Nachahmung/Verzerrung der Vorlage, in Prosaparodien einer verzerrenden Reproduktion des vorliegenden Stilsystems (Müller); Bedeutungsănderung des Prătextes (Genette) bzw. Komisierung des Prătextes unter Beibehaltung seiner stilistischen Eigenschaften (Stauder) - werden bei Cechov fast immer mit den im strengen Sinne mit der Travestie verknüpften Textverfahren frei kombiniert. Die letzteren bestehen im wesentlichen in der partiellen stilistischen Herabsetzung des Originals (Genette, Stauder). Genau gesprochen sind parodistische sowie travestierende Texte in ihrer reinen Form (d.h. in den im Kap. 2.1.2. angeführten Formulierungen Frejdenbergs, Genettes und Stauders) im Werk von Cechov kaum zu finden. Vielmehr triff auf seine Texte die Auffassung Hempels zu, der die Travestie als eine von mehreren Moglichkeiten der parodistischen Gestaltung definiert und dadurch herkommliche Differenzen zwischen beiden Textarten aufhebt. Tatsăchlich gehören die in den Studien zu den Cechovschen Parodien des Öfteren beschriebenen Stil- und thematischen Brüche (wie die Verbindung des Romantisch-Gehobenen mit dem Alltäglich-Platten, die verschiedene Textebenen berührt) zu den typischen Verfahren solcher hypertextuellen Mischfalle, d.h. parodistischer Fălle, die das Travestieren einschlie-

\footnotetext{
${ }^{427} \mathrm{Vgl}$ die Bernerkung von Kuzičeva. .В ранних пронзведениях Чехова часто с помощью цитаты ив Пушкина, нелепо. неуместно вспыхнвающей в сознаняи персонажа или всплывающей в речи рассказчика. оттенятся по контрасту пошлость, жестокость ситуация, невежество героя или герония ('За яблочки', 'Не в духе', 'Дачница', 'Нарвался') “ (1998, S 58). (In den frühen Werken 'echovs werden die Abgeschmacktheit. Grausamkeit der Situation. Ignoranz des Helden oder der Heldin haufig nach einem Kontrastprinzip durch ein Zitat aus Puskin hervorgehoben. das plump. unangebracht im Bewußtsein des Protagonisten auftaucht oder in der Rede des Erzahlers erscheint (.Za jablocki”. ..Ne v duche“ (Schlechte Laune - K S ). .Dačnica“ (Sommerfischlerin - K. S ). ..Narvalsja“ (Angerannt - K. S.)))
} 
Ben. ${ }^{428}$ Darüber hinaus basieren viele parodistische Ableitungen Cechovs nicht so sehr auf der Spannung zwischen der stilistischen und der thematischen Ebene des Textes (Müller), sondern primăr auf der Entstellung seines stilistischen Bildes (z.B. den „übertreibenden Hăufungen“ von Metaphern, Details u.s.w. ${ }^{429}$ ) oder der extremen Raffung der Romanereignisse im Rahmen einer Kurzgeschichte (Verfahren, die in der einschlăgigen Forschung in bezug auf parodistische Texte Cechovs mehrmals analysiert wurden).

Im Gegensatz dazu steht das unter den „Hypertexten“ Cechovs ebenfalls präsente Pastiche, das eine Stilimitation darstellt, in der jedoch keine Inkongruenz zwischen Inhalt und Form vorhanden ist und keine satirische Absicht zum Ausdruck kommt (Hempel, Karrer, Genette). Als Pastiche fassen wir z.B. solche Werke Cechovs wie "Nenužnaja pobeda“, "Cvety zapozdalye“, „Drama na ochote“ (Das Drama auf der Jagd) auf - Novellen, die in der Cechovforschung im einzelnen „Stilisierungen“430, „parodii-stilizacii“431 („Пародии-стилизашии“, Parodien als Stilisierungen), „farce ${ }^{\text {4332 }}$ und einfach „parodies“433 genannt wurden und im Grunde von einem literarischen Orientierungsprozeß beim frühen Cechov zeugen. ${ }^{434}$ Cudakov sieht in solchen für das frühe parodistische Werk Cechovs weniger typischen Texten eine Schwankung zwischen der ernsten Aneignung literarischer Tradition und ihrer ironischen Verarbeitung:

„Живой товар“, как и другие относительно крупные повествовательные произведения Чехова этого времени [...] отразили колебания и противоречивые тенденции в поэтике раннего Чехова. [...] Ирония не окрашивает пронзведение в целом, но включается своеобразными „квантами“. (,Zivoj tovar“ (Lebendige Ware - K. S.), wie ebenfalls andere verhăltnismäßig große Erzăhlwerke Cechovs aus dieser Zeit [...] spiegelten Schwankungen und widersprüchliche Tendenzen in der Poetik des frühen Cechov wider. [...] Die Ironie färbt das Werk nicht im Ganzen, sondern wird "quantenweise" einbezogen. $)^{435}$

\footnotetext{
${ }^{428}$ Als Beispiel für dieses Verfahren konnte eine vielzitierte Stelle aus Cechovs Parodie „Tysjaca odna strast”, ili strašnja noc" zitien werden, ein Satz. der den nachgeahmten metaphorisch-pathetischen Stil von Hugo bricht .Doż' i sneg - èti mokrye brat 'ja - strašno bili v naši fizionomii") (Regen und Schnee - diese nassen Brudet schlugen stark in unsere Physiognomien) (Cechov 1, 35). Dieses Zitat und uber die Parodien Cechovs s u a bei Damjanova-Dolmova 1980 und Fortunatov 1996 (das genannte Zitat S. ibid., S. 82)

429 S. auf S. 37 dieser Arbeit

${ }^{430}$ Hielscher 1987, S 28-29

431 Fortunatov 1996. S 76

432 Kramer 1970, S. 31

${ }^{433}$ Winner 1966. S. 8 Zur Gattungsspezifik von ..Drama na ochote" und uber die Forschung. in der dieser Text u a als Parodie interpretiert wird. $s$ bei Franz 1990, $S$ 6-7

4i. In unserem Aufsatz (Smola 2001) bezeichnen wir solche Werke wie ..Nenużnaja pobeda" noch als ironische Stilisienung. oder .,ironisches Plagiat" (s. S 103-104, oder Smola 1998a, S 15). S. den Begriff .ironisches Plagiat" in beaug auf bestimmte Elemente in den Romanen Nabokovs bei Lachmann (1990, S. 480)

" Cudakov 1986, S. 59-60 Diese Poetik beschreiben auch wir in bezug auf ..Nenužnaja pobeda" in Smola 2001. S. $103-104$
} 
Für die genannten Texte gilt unserer Ansicht nach die über das Pastiche gemachte Bemerkung Hempels, für den eine stilistische Affinität zum Prătext in dieser Gattung auf keine Weise ihre ironischen Absichten und die Distanz zur Vorlage ausschlieBt ${ }^{436}$. Wir werden jedoch auf die Untersuchung dieser ebenfalls eher weniger erforschten Hypertexte Cechovs in unserer Arbeit nicht eingehen.

Wichtiger erscheinen uns Differenzen, die zwischen Cechovschen Parodien auf der einen und den in der einschlăgigen Literatur übersehenen anderen abgeleiteten Texten in seinem Werk - wie solche, die wir als Kontrafakturen bezeichnen - auf der anderen Seite gezogen werden können. Ohne die letzteren in diesem Kapitel năher zu erörtern, wollen wir die für Cechovs Parodien spezifischen Merkmale vor deren Hintergrund markieren. Die Auffassung Verweyens und Wittings scheint uns dabei am hilfreichsten zu sein. In dieser Auffassung hebt sich Parodie von den „Adaptionsformen“ wie Palinodie, Kontradiktio oder Kontrafaktur vor allem dadurch $a b, d a ß$ sie das Original komisierend herabwürdigt. Die wichtigste Textverarbeitungsstrategie und die Botschaft der Parodie bestehen demzufolge darin, durch bestimmte Verănderungen der Vorlage eine Aussage über sie zu bilden. In der Parodie liegt insofern keine „eigene Äußerungsabsicht“ vor: Sie ist auf den anderen Text fixiert.

Unter den im Kap. 2.1. aufgezahlten Funktionen der Verweisung auf den fremden Text geht es in den meisten Parodien Cechovs, unserer Ansicht nach, in erster Linie um Überbietung, Dekonstruktion fremder Zeichen (Stierle, Lachmann), um das Modell der Tropik (Lachmann). ${ }^{437}$ In der Parodie wird manchmal nicht nur der Fremdtext selbst, sondern auch seine Rezeption verspottet. ${ }^{438}$

Wenn diese Definition auch eine gewisse Einschränkung des parodistischen Begriffs enthält ${ }^{439}$, erfaßt sie jedoch die Eigenart Cechovscher Parodien vor dem Hintergrund anderer literarischer Ableitungen in seinem Werk und erlaubt deshalb eine bisher noch nicht durchgeführe Differenzierung mancher seiner. .zweitgradigen“ Texte.

\footnotetext{
${ }^{430} \mathrm{Vgl}$ S. 38 dieser Arbeit.

437 Und hier distanzieren wir uns bis an einem gewissen Grade vom Parodieverstandnis Genettes Parodie (wie auch Pastiche) ..will“ nach Genette ..als Zerstreuung ohne aggressive oder spottische Absicht lediglich unterhalten [ ]" (1993. S 43). Zur Anwendung des Konzepts von Lachmann s Fußn. 416; in den Parodien tinden wir 2. B keinen ..tragischen Kampf gegen die sich in den eigenen Text notwendig cinschreibenden fremden Texte". den Lachmann dem Modell der Tropik zuschreibt (1990. S. 39) Manche Merkmale. die Lachmann mit dem Modell der Transformation verbindet (2 B. ..Ludismus" (ibid.)). sind gerade auch für Parodien typisch Dementsprechend meinen wir hier jedes Mal einzelne Charakteristika der genannten drei Modelle Lachnianns.

${ }^{438} \mathrm{Vgl}$ bei Karrer 1977, S 50

439 Verweyen und Witting schreiben, daß die ..Erweiterung" des ..Begriffsumfangs" der Kontrafaktur ..die gleichzeitige Einschrankung des Begriffsumfangs von "Parodie" zur Folge hat (s 1987. S 48)
} 


\subsection{1. "Zagadocnaja natura“}

Als eine parodistische Ableitung, die mehrere literarische und literaturkritische Texte zugleich aufruft, betrachten wir die 1883 geschriebene Kurzgeschichte "Zagadočnaja natura“. Das Sujet dieser Geschichte ist folgendes: Eine junge Dame făhrt im Abteil erster Klasse und erzahlt dem ihr gegenübersitzenden angehenden Schriftsteller von ihrem Leben, das voll Leiden ist: Not, enttäuschte Hoffnungen, Kampf mit der Umgebung, Unglauben an das Leben und an sich selbst, schließlich die Heirat mit einem alten reichen General: „- [...] Я обогатила семью, стала путешествовать, делать добро..." (,.'[...] Meine Angehörigen wurden dadurch wohlhabend, ich machte viele Reisen und konnte Gutes tun... $\left.[\ldots]^{\mu .440}\right)(2,91)$. Der Gedanke an den baldmöglichen Tod des Generals hilft ihr jedoch, solch eine qualvolle Existenz auszuhalten. Der General stirbt: „, [...] Теперь-то и жить мне счастливо... Не правда ли, Вольдемар?“ (,,[...] Jetzt wäre der Augenblick gekommen, glücklich zu werden... Nicht wahr, Wolodja [Waldemar]? [... $\left.]^{\text {ndtll }}\right)(2,91)$ - fragt die „Märtyrerin“. Das Glück bleibt der Verzweifelten aber versagt; auf die Frage des Schriftstellers, welche Hindernisse ihr dieses $\mathrm{Mal}$ im Wege gestanden haben, antwortet sie: „Другой богатый старик...“ (,'Ein zweiter [anderer] reicher Greis... $\left.{ }^{\text {c.4s2 }}\right)(2,92)$.

„Zagadočnaja natura“ verfügt über eine vielschichtige Intertextualităt, die vor allem in den im Text verstreuten Allusionen - mehr oder weniger direkten wie auch einen unterschiedlichen Grad an Konkretheit und Deutlichkeit aufweisenden Bezügen zu den Fremdtexten - ihren Ausdruck findet. Wir beginnen die Analyse mit den Verweisen, die bet der ersten Lektüre unmittelbar auffallen, im weiteren sind Referenzen aufzuschlüsseln, die aus verschiedenen Gründen (die im wesentlichen auf ihren impliziten Charakter zurückzuführen sind: So ist z.B. eine direkte Benennung des Autoren- oder Protagonistennamens als Intertextualitätssignal für den Rezipienten einfacher zu erkennen als die Übernahme bestimmter Sprachmerkmale des Prătextes) latent bleiben. Wie in .Za jabločki“ bilden auch die meisten in. Zagadočnaja natura" alludierten Texte ein System, d.h. sie werden im Rahmen der Parodie Cechovs nicht zufallig zusammengebracht, sondern gehören zu eimer bestimmten literarischen Tradition bzw. zu einem bestimmten - wenn auch sehr breit aufgefaßten - literarischen (und literaturkritischen) Diskurs, zu dem Cechov hier künstlerisch Stellung nimmt.

Zwei Allusionen - die erste auf das Werk Fëdor Dostoevskijs als solches, die zweite, komplexere, auf seinen Roman .Prestupleme i nakazanie“" (Verbrechen und Strafe ${ }^{4+3}$ ) (1866) - gehören in ,Zagadočnaja natura" zu den Verweisen, auf die man beim Lesen stößt, die also infolge ihrer Deutlichkeit und Explizitheit nicht zu übersehen sind. So definiert sich die Dame zunăchst als ..Mărtyrerin im Geschmack Dostoevskijs": ..- $[\ldots]$ Я стралалица во вкусе

\footnotetext{
${ }^{400}$ Tschechow Bd. 1 (1949). S 121

t+1 Tschechow Bd I (1949). S 121

$\$ 2$ Ibid S 122

"W' In der im Weiteren zitienten Ubersetzung (Dostojewski 1971) unter dem Titel ..Schuld und Suhne“
} 
Достоевского... Покажите миру мою душу, Вольдемар, покажите эту бедную душу!“ („'[...] Ich bin eine Mărtyrerin im Geschmack Dostojewskijs... Zeigen Sie der Welt meine Seele, Wolodja [Waldemar], zeigen Sie ihr diese arme Seele. [...] $\left.]^{\text {cct4t }}\right)(2,90)$. Etwas spăter „konkretisiert“ ihr verzückter Zuhorer den Bezug: „- Чудная! - лепечет писатель, целуя руку около браслета. - Не вас целую, дивная, а страдание человеческое! Помните Раскольникова? Он так целовал. “445 („'Sie wunderbare Frau!' stammelt der Schriftsteller, indem er wiederum ihre Hand küßt, wo das Armband sitzt. 'Ich küsse nicht Sie, obwohl Sie so hinreißend sind [Sie hinreißende Frau], sondern das Leid der Menschheit [das menschliche Leid]! Erinnern Sie sich an Raskolnikow? Er hat auf die gleiche Art geküßt. $\left.{ }^{{ }^{\alpha 446}}\right)(2,91)$.

Hier (im zweiten Fall), mittels dreifacher Verweisung (ein modifizientes Zitat, eine onomastische Allusion und die „erinnernde“ Benennung der Handlung durch den Protagonisten), wird die Szene aus dem 4. Kapitel des 4. Teils von "Prestuplenie i nakazanie" evoziert ${ }^{447}$, in der Raskol'nikov den Fuß von Sonja Marmeladova küßt und sagt: „- Я не тебе поклонился, а всему страданию человеческому поклонился, [...].“ („'Ich habe mich nicht vor dir verbeugt, ich habe mich vor dem ganzen Menschenleid verbeugt, [...] $\left.]^{\star \prime}\right){ }^{448}$ Diese Referenzen rufen bestimmte Sujetelemente des Romans ins Gedăchtnis, nămlich das Schicksal von Sonja, die sich aus Verzweiflung, in einem Akt der Selbstaufopfenung prostituiert, um ihre Familie vor der ăußersten Not zu retten. Sie erfullen im Rahmen der Kurzgeschichte nicht nur eine pragmatische Funktion (hier eine emotionale, die das Mitleid von Raskol'nikov mit Sonja neben das Vol'demars mit der jungen Dame stellt), sondern auch eine semantische - vorausdeutende ${ }^{49}$. Am Ende der Kurzgeschichte stellt es sich heraus, daß die Dame sich durch ihre Ehen ebenfalls furr Geld „opfert”, nur nicht aus äußerster Not, Verzweiflung und Năchstenliebe, sondern aus Habgier. Das Tragische Dostoevskijs wird ins Triviale herabgezogen. Gleichzeitig banalisien Cechov auch die Gefühle der alludierten Personen: Wăhrend sie bei Dostoevskij durch ein großes gemeinsames Leiden und qualvolle Glaubensfragen verbunden sind, handelt es sich bei den Cechovschen Personen um ein leichtes erotisches Abenteuer, einen .im Geschmack Dostoevskijs“" stilisierten Flir. Der Text zielt einerseits auf den .Mißbrauch“ der Werke Dostoevskijs von Seiten der lesenden Philister ab, beinhaltet womoglich aber auch eine kritische Aussage über die literarische Produktion Dostoevskijs selbst, nämlich über die bis zum äußersten gespannten Gefühle und die Exaltation seiner

\footnotetext{
t4t Tschechow Bd 1 (1949), S. 120

t4s Dieses Zitat erwahnen u a. Bjalyj (1956, S 358). Gromov (1977, S 42) und Berdnikov (1984. S 107-108)

$\mathrm{Vgl}$. auch Johnson "The parody of .An Eniugmatic Nature“ (Gamett) is primarily ained at the admires of the Dostcevskian heroine of suffering" (1993, S 12)

\$6. Tschechow Bd I (1949), S. 120

${ }^{4+7} \mathrm{~S}$. den Hinweis auf diesen Bezug in den Anmerkungen zu .Zagadocnaja natura“ (2.408)

448 Dostoevskij Bd 6 (1973). S 246

449 Wir werden uns auch im weiteren der Terminologie Kosंnys. bei dem zwischen der pragmatischen und der semantischen Zeichenfunktion unterschieden wird, bedienen
} 
Figuren ${ }^{450}$ - in den Werken, die Cechov einmal spăter als "lang und unbescheiden“ bezeichnet hat ${ }^{451}$.

Mit einer parodistischen Entstellung der genannten Sujetlinie von „Prestuplenie i nakazanie“ erschöpft sich die Intertextualität der ,Zagadočnaja natura“ jedoch nicht. Eine der intertextuell „privilegiertesten“ Textstellen, nämlich der Titel, verbirgt eine weitere Allusion: Der Titel der Kurzgeschichte gibt mit minimaler Verănderung den des in Rußland in den Jahren 1860-70 weit bekannten Romans ..Problematische Naturen“ (1861/62) Friedrich Spielhagens wieder - den Titel, wie er in der Übersetzung in der Zeitschrift „Epocha“ (1864) hieB (,Zagadoćnye natury" (Rätselhafie Naturen)). ${ }^{452}$ Dieser Bezug, der im Paratext wie im Titel markiert ist ${ }^{453}$ und darüber hinaus einen Fremdtitel evoziert und sogar fast wiederholt, gibt den Anlaß, den manifesten Text als eine Ableitung, als eine verkürzte Version eines anderen Textes $^{454}$ - in dem Fall eines seiner typischen Ausschnitte - zu betrachten. ${ }^{455}$

In Spielhagens erstem Roman „Problematische Naturen“ treten hoch gebildete, intellektuell und geistig begabte, gleichzeitig aber vom Leben tief enttäuschte Menschen auf - wie Oswald Stein oder der Universitätslehrer Berger, die des Milieus, in dem sie verkehren, überdrüssig sind und sich nach großen Taten sehnen: „Und eben dieses furchtbar peinigende Gefühl der [...] Unausgefülltheit, Tatenlosigkeit, [...] Sehnsucht nach vollerem, bedeutenderem, menschenwürdigerem Leben [...], eben dies Bezeichnende also im Gemütszustande der vormärzlichen Jugend findet sich in Spielhagens erstem Roman. ".456. Im Finale kommen Spielhagens Helden auf den Barrikaden um, sie opfern ihr Leben für die Ideale der Freiheit und der Demokratie. ${ }^{457}$

In seiner Kurzgeschichte greift Cechov sowohl die für die Romane Spielhagens im allgemeinen, exemplarisch aber für „Problematische Naturen“ typischen Schicksale und Gestalten, ihre häufig ebenfalls einem Gesinnungsgenossen erzählten Biographien als auch deren cha-

${ }^{450} \mathrm{Vgl}$ eine ahnliche Deutung der Dostoevskij-Intertextualitat in .Zagadoxnaja natura" bei Berdnikov 1984. S 112-113. Berdnikov nennt diese Geschichte .,dovol no zlaja parodija na maneru Dostoevskogo" (ibid., S. 140) (.довольно злая пародия на манеру Достоевкого", eine zlemlich bose Parodie auf die Ar Dostoevskijs)

¿51 Brief an A S. Suvorin vom S Marz 1889 (Pis'ma 3, 109), s danuber auch bei Berdnikov 1984, S 108

$452 \mathrm{~S}$ uber diese Allusion bei Kataev 1995, S 8 Kataev bezeichnet diesen Verweis wie ebenfalls den auf Schiller in „Torżestvo pobeditelja“ (uber diese Kurzgeschichte s. in Kap. 3.3.1) als Beispiel fur .pxrroklymox ispol'zovanie izvestnych zaglavij” (parcxdisu.sche Verwendung der bekannten Titel) beim Humoristen Čechov (Hervorh von uns)

${ }^{433}$ Zur Markienung der Intertextualitat in Titeln vgl bei Helbig 1996, S $108 \mathrm{Vgl}$ ebenfalls ber Kanevskaja, die sich in ihrer Analyse der Titelallusion in der Kurzgeschichte ..Nedidimye minu slezy" auf den Begriff ..Paratextualitat" von Genette beruft (1994, S 166)

${ }^{444}$ s. bei Genette. .. [...]. und wie alle Gattungskategorien deklariert sich auch die Hypertextualitat sehr haufig mittels eines paratextuellen Hinweises. der Vertragswern hat [ ]. 1/yxies ist, als Anspielung, ein impliziter Vertrag. der den Leser zumindest darauf aufmerksam machen kann, daß es zwischen dem Roman und der (Khrsse' eine Bezjehung geben konnte [ ]" (1993. S 19)

45S Die folgende Analyse der Spielhagen-Intertextualitat in .Zagadočnaja natura" stellt cine veranderte. erweiterte und prazisierte Variante der Analyse in unserem Aufsatz ..Cechov i Fridrich Spil'zagen schodstva $v$ teorii. razlicija v praktike" (Čechov und Friedrich Spielhagen Ahnlichkeiten in Theorie. Unterschiede in Praxis) (Smola 1996, S 44-47) In diesem Aufsatz benutzen wir jedoch eine andere nussische Ausgabe des Romans Spielhagens (.Zagadoznve natury" S -Peterburg 1874) und beziehen uns dort auch aul die anderen Stellen aus diesem Werk

tso Klemperer 1913, S 69

437 Vgl auch in Smola 1996. S 47 
rakteristische Ausdrucksweise (d.h. den Stil der Werke Spielhagens in der russischen Übertragung) auf. Es versteht sich, daß Cechov nicht die Ideale der Spielhagenschen Naturen an sich, sonderm ihre gehobenen, schließlich unkompliziert-positiven, tragisch-heldenhaften Figuren, ihre pathetische, gehobene Sprache angreift - das, was er vermutlich unglaubwürdig schien. ${ }^{458}$ Ebenfalls wird hier die Rezeption Spielhagens durch manche russischen LeserInnen, die das Große der literarischen Vorbilder auf das Eigene, „Kleine“ beziehen, verlacht.

Vergleichen wir die Beichte der Cechovschen Dame mit dem selbsterzahlten Lebenslauf einer der zentralen Figuren in "Problematischen Naturen“ - der von Professor Berger; eine Episode des Romans, die durchaus zur Vorlage für die Parodie "Zagadoxnaja natura" hat werden konnen. ${ }^{459}$ In dieser Episode kommt es zum offenen Gesprăch zwischen den Gesinnungs- und Leidensgenossen Professor Berger und Baron Oldenburg. Der "Autobiographie“ Bergers geht die folgende Überlegung des Erzăhlers voraus:

Для мыслителя - [...] неоценённое счастье встретить человека, который, вследствие-ли таннственного духовного сродства, или-же вследствие сходной судьбы и отытности, дошелл до миросозерцания [...] основанного на базисе обших им принияпов. Такое счастие выпало на долю этим людям, которые с ранней юности искали истины, $-[\ldots]$, оба долгое время носили отчаяние в сердце $[\ldots]$. (Für einen Denker - [..] ist es ein unschătzbares Glück, einem Menschen zu begegnen, der, ob infolge einer geheimnisvollen geistigen Verwandtschaft oder aufgrund eines ähnlichen Schicksals, eine Weltanschauung erreicht hat, [...] die auf der Basis der von ihnen geteilten Prinzipien ruht. Ein solches Glück wurde diesen Menschen zuteil, die seit ihrer frühen Jugend die Wahrheit suchten. $-[\ldots]$, beide trugen lange Zeit Verzweiflung in ihrem Herzen [...].“460 $)^{461}$

Nachdem Berger von seinem Leben erzählt hat, stellt Oldenburg eine eingehende Analyse seines Charakters und seiner Probleme an, er durchschaut die Psychologie seines Freundes. bewahrt zugleich einen großen Respekt vor ihm:

\footnotetext{
4s: $S$ auch in: ibid. S. 45

\$39 Wir beziehen uns auf die russische Ubersetzung des Romans .Problematische Naturen“ (Teil 2). die Cechov bekannt sein konnte: F Spil gagen 12 mraka k svetu. Sankt-Peterburg 1871 (F Spielhayen Durch Nacht zum Licht. Sankt-Peterburg 1871) Die Originalvorlage dieser russischen Ubersetzung konnte nicht ermittelt werden. bis 1871 lagen die deutsche Erstausgabe 1861 und mindestens drei weitere Ausgaben in den gesammetten Werken Spielhagens 1866-67; 1870-72 und 1871-74 vor. Im Augenblick kann das Exemplar. das wir in Moskau benutzt haben. wegen der Schließung der Bibliothek nicht eingesehen werden (wir konnen aus diesem Grund auch nicht belegen. ob es in dieser russischen Ausgabe nicht eine schon fruher erschienene (ibersetzung erneut publiziert murde)

${ }^{400}$ Zitate aus der vorliegenden Ubersetzung sind hier und im Weiteren von uns ins Deutsche .zunickübersetzt". da das Original nicht gefunden werden konnte (s. Fußn. 459)).

t61 Spil'gagen 1871. S. 325
} 
- [...] Так и очерк вашей жизни заинтересовал меня не только как исторня одного замечательного человека, [...] вы кажетесь мне [...] типом для целого ряда современных существований, натуру которых я изучал тем усерднее, [...] и для которых мазстро Гёте изобрёл классическое название „загадочных натур“. (So hat auch der Grundriß Ihres Lebens mein Interesse nicht allein als Laufbahn eines herausragenden Menschen geweckt, [...] Sie erscheinen für mich [...] als ein Typus für eine ganze Reihe der modernen Existenzen, deren Natur ich um so fleißiger studierte, [...] und für die der Maestro Goethe die klassische Bezeichnung "rätselhafte Naturen“ erfunden hat. $)^{462}$

Hier wird also schon die charakteristische Personenkonstellation gestaltet, die Čechov in seiner Geschichte darstellt - der/die Beichtende und der verständnisvolle, bewundernde, analysierende Gesprăchspartner, die offenbar gemeinsame Ideale haben und von denen zumindest einer bereits Verzweiflung erfahren hat. Vgl. bei Cechov:

Он глядит ей в лицо, глядит в упор, с видом знатока. Он наблюдает, изучает, улавливает эту зксцентрическую загадочную натуру, понимает ее, постигает... Душа ее, вся её психология у него как на ладони.

- О, я постигаю вас! - говорит чиновник особых поручений, целуя ее руку около браслета. („Er sieht ihr mit der Miene eines Kenners ins Gesicht und wendet keinen Blick von ihr. Er beobachtet, er studiert sie, er versucht ihre exzentrische, rätselhafte Natur kennenzulernen, er versteht sie bereits, ja er erfaßt sie ganz... Ihre Seele, ihre [ganze] Psychologie liegen vor ihm [wie] offen auf der Hand.

'O, ich verstehe Sie!' sagt der Beamte für besondere Aufträge und küßt ihre Hand dort, wo sie das Armband trägt. .46.3 $)(2,90)$

Auch bei Cechov wird im Weiteren von der Suche nach Idealen und von der Verzweiflung geredet: „- [...] А сомнения? А муки зарождающегося неверия в жизнь, в себя?.. [...] Я жаждала быть человеком! [...] Я жаждала чего-то необыкновенного... не женского!"* (,'[...]Und erst meine Zweifel! [Und die Zweifel?] Und dann die Qualen des immer größer werdenden [des aufkommenden] Unglaubens an das Leben und an mich selber!.. [...] Ich sehnte mich [dürstete] danach, Mensch sein zu dürfen [Mensch zu sein]! [...] Ich dürstete nach etwas Ungewöhnlichem... nicht etwa Weiblichem [nicht Weiblichem]! $\left.[\ldots]^{\text {n.tht }}\right)(2,91)$. In beiden Texten ist der Beichtende von der Analyse seines Gesprächspartners begeistert:

\footnotetext{
42 Ibid., S 329-330.

4.3 Tschechow Bd 1 (1949). S. |20-121

to4 Ibid.
} 
- [...] Не знаю, г-н профессор, на столько-ли удачен мой зскиз, чтобы вы могли узнать в нём оригиналы?

- Совершенно! совершенно! отвечал Бергер, слушавший собеседника с напряжённым участием. (Spielhagen) (,[...] Ich weiß nicht, Herr Professor, wie zutreffend mein Entwurf ist, ob Sie darin Originale erkennen kőnnen?*

„Durchaus! Durchaus! antwortete Berger, der seinem Gesprächspartner mit gespannter Teilnahme zuhorte. $)^{465}$

- "- [...] Не прошло и часа, как мы сидим в купе и говорим, а вы уже постигли меня всю, всю!“” (.'['...] Es ist noch keine Stunde vergangen, daß wir beide hier im Abteil sitzen und miteinander sprechen, und doch haben Sie mich bereits ganz erfaßt, ganz und gar! ${ }^{\text {a } 466}$ ) (Cechov: 2, 90). Zweifelsohne übernimmt Cechov in der Erzăhlung der Dame ebenfalls manche wesentlichen Inhalte der Autobiographie von Professor Berger:

- Досада на жнзнь, [...] которая, [...] как болото с мутным дном и негодной травою, [...] должна-же была наконеи привести $к$ безумию, [...]. [...] Тюрьма на долгие годы уничтожнла во мне любовь и доверие к жизни. [...] Всё вокруг показалось мне очень противно. [...] я и весь свет считал большим сумасшедшим домом. (Der Verdruß am Leben, $[\ldots]$ das, [...] wie ein Sumpf mit dem trüben Boden und unbrauchbarem Tang, [...] mich zum Wahnsinn treiben mußte, [...]. [...] Das Gefangnis tilgte in mir für lange Jahre Liebe und Vertrauen zum Leben. [...] Alles um mich herum schien mir sehr unertrăglich. $[\ldots]$ ich hielt auch die ganze Welt für eine große Irrenanstalt. $)^{+67}$

Schließlich findet er sein Ideal und somit den Lebenssinn: „- [...] Я поклялся, что те годы, которые мне суждено ещё прожить, будут употреблены на исправление моих заблуждений и я вполне посвящу себя делу народа. [...] и отныне все бедные, больные и угнетённые будут моими детьми.“" (Ich habe geschworen, daß die Jahre, die mir noch bleiben sollen, für die Berichtigung meiner Irtümer verwendet werden und ich mich ganz der Sache des Volkes widme. [...] und von heute an werden alle, die arm, krank und unterdrückt sind, meine Kinder.) (Spielhagen) ${ }^{\mathbf{t h} 8}$. Cechov zielt in .Zagadočnaja natura" auf das Pathetische und das unverborgen Belehrende der Beichte Bergers ab: In erster Linie sieht er auf das .hohe“ Leiden der Figur Spielhagens, die, über ihrer Umgebung stehend, die Stumpfsinnigkeit und Grausamkeit dieser Welt über sich hat ergehen lassen müssen (was Berger in seiner ersten Beichte vor Oswald Stein schildert) und deswegen zutiefst verbittert war ${ }^{\text {tiy }}$, deutet aber auch auf ihre schwierige geistige Entwicklung, u.a. auf die in der Vergangenheit begangenen

\footnotetext{
*s Spil'gagen 1871, S. 331

the Tschechow Bd 1 (1949), S. 120.

*67 Spil'gagen 1871. S. 325-327

468 Spil'gagen 1871. S 325-329
} 
Fehler hin (allerdings ohne, wie Berger, darauf ausführlich einzugehen): "- [...] Ax, нe заставляйте меня вспоминать! [...] Уродливое институтское воспитание, чтение глупых романов, ошибки молодости, [...]... А борьба со средой? Ужасно!“ (,'[...] Ach, zwingen Sie mich nicht, daran zu denken! [...] Die abscheuliche Erziehung im Institut, die Lektüre dummer Romane, die Fehler der Jugend, [...]... Und dabei Kampf mit meiner Umgebung [mit dem Milieu?]! Entsetzlich! $\left.[\ldots]^{\kappa \varsigma 470}\right)(2,91)$. Die Selbstaufopferung und die Heldentaten, zu denen die typische Spielhagensche Person fahig und bereit ist, sind auch für die Cechovsche Dame ganz natürlich: Diese Taten vollbringt sie jedoch nicht auf der Barrikade, wie Professor Berger im Finale des Romans, sondern in den Armen ihres betagten Ehegatten: „- [...] Beдs это было самопожертвование, самоотречение, поймите вы! [...] А как я страдала, как невыносимы, низменно-пошлы были для меня объятия этого генерала [...]. Бывали минуты... ужасные минуты!“ (,'[...] Es war nichts als Selbstaufopfenung [Es war doch eine Selbstaufopferung], Selbstentsagung war es, Sie werden mich verstehen [verstehen Sie]! [...] Allein wie litt ich, unerträglich! Wie abscheulich ekelhaft [Allein wie litt ich, wie unerträglich, niedrig] waren für mich die Umarmungen dieses Generals [...]. Es gab Minuten... schauderhafte Minuten! $\left.[\ldots]^{\text {nutl }}\right)(2,91)$.

Es läßt sich vermuten, daß Cechov in seiner Kurzgeschichte eine "Sammelgestalt" geschaffen hat, die die noblen, getragenen Hauptpersonen der "Problematischen Naturen" (wie Professor Berger, Oswald Stein, Baron Oldenburg u.a.), aber vielleicht auch die der anderen unter den russischen Lesem äußerst populären Romanen Friedrich Spielhagens parodiert - die an ihrer Umgebung leidenden, zum Höheren strebenden und auf ihrem schweren, aber edlen geistigen Wege viele Hindernisse in Kauf nehmenden Charaktere. ${ }^{472}$ Profanisiert und verspottet werden - mit Hilfe einiger Allusionen - nämlich Szenen der häufig pathetischen autobiographischen Bekenntnisse dieser Figuren im Gespräch mit einem Gesinnungsfreund - Szenen, die für Romane Spielhagens durchaus typisch sind (in den „Problematischen Naturen“ beichten auf diese Weise viele zentralen Figuren). Wie schon aus den zitierten Textstellen ersichtlich, werden hier ebenfalls typische stilistische Merkmale des Prătextes, wie er ins Russische übertragen wurde, nachgeahmt. Die Dame bedient sich einer ähnlich ,romanhaften“, pathetisch-schwülstigen, sich vor keinerlei Übertreibungen scheuenden Sprache, wie die Helden Spielhagens. ${ }^{473}$ Spielhagensche Personen ..искали истины“ (suchten die Wahrheit), „носили

\footnotetext{
*6 Vgl in: Smola 1996. S. 48

${ }^{470}$ Tschechow Bd 1 (1949). S 120

471 Tschechow Bd 1 (1949). S 121

17 Fedor Dostoevskij hat sich in einem Brief an seinen Bruder Michail uber diese Charaktere und uber den Roman im Ganzen folgendermaßen geaußert „Прочел половину 'Загадочных натур' По-моему. ничего необыкновенного Натуры сикем-таки не загадочные. слишком обыкновенные [ ] Много истинной поззия. но какое же и колбасничество " (Ich habe die Halfte von .Zagadočnye natury" gelesen Meiner Meinung nach nichts Außergewohnliches Die Naturen sind uberhaupt nicht ratselhaft, sondern allzu gewohnlich [ .]. Viel wahre Poesie, aber gleichzeitig was fur eine Wurstelei.) (1985, S.78)

Uber die vermutliche Distanz Čechovs als Schriftsteller gegenuber dem Finale des Romans Spielhagens und gegenuber den Helden, die als Sprachrohr der auktorialen Ideen dienen, $s$ bei uns (Smola 1996, S. 49)

$77 \mathrm{~S}$. daniber auch in unserem Aufsatz (Smola 1996, S 46)
} 
отчаяние в сердце“ (trugen Verzweiflung im Herzen), „каялись перед гением человечества“ (empfanden Reue vor dem Genie der Menschheit), sie wollen ,посвятить себя делу народа“ (sich der Sache des Volkes widmen), reden von den vernichteten „любовь и доверие к жизни“ (Liebe und Vertrauen zum Leben), von „благороднейшие цветы человеческой души“ (edelsten Blūten der menschlichen Seele), „Гений, ум и octpora“ (Genie, Verstand und Scharfsinn), die „пробиваются к свету сквозь все препттствия" (sich zum Licht durch alle Hindernisse durchringen), von „грех против святого духа истины“ (Sünde am heiligen Geist der Wahrheit) ${ }^{47}$. Vgl. bei Cechov: „- Bawa чуткая, отзывчивая душа ищет выхода из лабиринта.. Да! Борьба страшная, чудовищная, но... [...]! Вы будете победительницеи!“ („Thre sensible, empfangliche Seele sucht den Ausweg aus dem Labyrinth... Ja! Es ist ein furchtbarer Kampf, ein ungeheuerlicher,

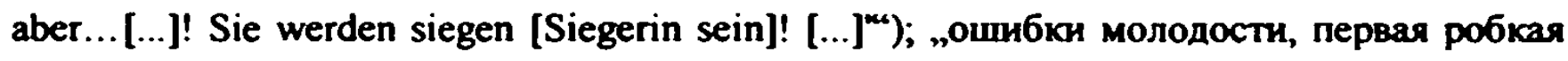
любовь“ ("die Fehler der Jugend, die erste schüchterne Liebe“); "муки зарождающегося неверия в жнзнь, в себя ${ }^{475}$; „Быть человеком - в этом я видела свое счастъе!“ („Mеnsch sein zu dürfen [Mensch zu sein] - darin sah ich mein hochstes Glück [mein Glück]! “); „теперь-то и отдаться любимому человеку, сделаться [...] носительницей его идеалов“ (,Jetzt sich dem Geliebten hingeben [...] die Trăgerin seiner Ideale [...] sein [werden] ${ }^{4476}$ ) u.s.w. $(2,90-91)$.

Cechov verweist hier demzufolge mehrfach auf den Text (die Texte) Spielhagens - durch eine Allusion auf ihn im Nebentext wie Titel und die Wiederholung des allusiven Ausdrucks im eigentlichen Text, durch Übernahme der Personenkonstellation aus einer seiner typischen Szenen, durch Nachahmung der fiktiven Situation dieser Szene (fiktive Autobiographie) sowie die allusive Übernahme mancher inhaltlichen Elemente des fiktiv Erzăhlten, durch die Imitation wesentlicher stilistischer Eigenschaften des Referenzwerkes.

Welche parodistischen Transformationen der Vorlage sind in "Zagadocnaja natura“ eingesetzt? Das Parodieren umfaßt die Kurzgeschichte als Ganze, d.h. berührt textuelle Ebenen wie Handlung (v.a. den Inhalt der von der Dame erzahhlten Geschichte), Personenkonstellation und Stil. Die Inkongruenz auf der Ebene des Sujets entsteht bereits am Anfang des Textes: Sie außert sich im humoristischen Widerspruch zwischen dem vermeintlichen Leiden der Dame, die von ihrer qualvollen geistigen Suche berichtet, und ihrer luxuriosen Toilette bzw. der luxuriosen Umgebung, was in kleinen Details zum Ausdruck gebracht wird:

Купе первого класса.

На диване, обитом малиновым бархатом, полулежит хорошенькая дамочка. Дорогой бахромчатый веер трещит в ее̌ судорожно сжатой руке, [...] брошка на груди то поднимается, то опускается, [...]. (..Ein Abteil erster Klasse.

\footnotetext{
474 Spil gagen 1871. S. 325-331

473 Übers 5 auf S. 92 dieser Arbeit

${ }^{476}$ Die Ubersetzungen s. in: Tschechow Bd. 1 (1949), S. 119-121
} 
Auf dem mit himbeerroten Sammet gepolsterten Diwan liegt in halbsitzender Stellung ein hübsches Dämchen. Ein teurer Spitzenfächer flattert, krampfhaft von ihren Händchen gehalten, auf und ab [knistert in ihrer krampfhaft geschlossenen Hand], [...] die Brosche auf ihrer Brust hebt sich bald in die Höhe, bald senkt sie sich [...]. $\left.{ }^{477}\right)(2,90)$

Der junge Schriftsteller spricht vom „fürchterlichen, ungeheueren Kampf", der seiner Be-

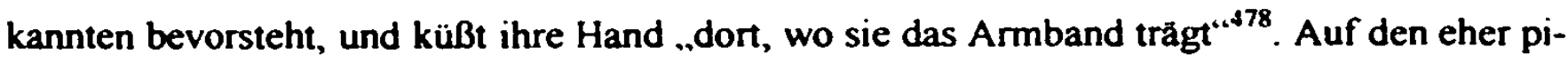
kanten Charakter der Bekenntnisse deutet ebenfalls die Bemerkung des Erzăhlers hin, daß der angehende Autor sich auf Novellen aus dem Leben der höheren Gesellschaft spezialisiert: "[...] как сам он называет, 'новэллы' - из великосветской жизни“ („[...] wie er sie selber bezeichnet, Novellen' aus dem Leben der höheren Gesellschaft $\left.{ }^{\text {“49 }}\right)(2,90)$. Die nicht ganz edlen Motive der Beichte der ,rătselhaften Natur" - nămlich Narzißmus und Ruhmsucht kommen weiterhin in der Aufforderung zum Ausdruck, er solle ihre ,arme Seele“ der Welt zeigen: „- [...] Покажите миру мою душу, Вольдемар, покажите эту бедную душу!“ (2, $90)^{480}$. In der Autobiographie der Dame werden im weiteren gehobene Inhalte und pathetische Rhetorik unablăssig mit den Bemerkungen und Tatsachen kombiniert, die mit dem Gehobenen brechen, das Pathetische herabsetzen, die vor allem eine komische Abweichung der Motive und Interessen der Cechovschen Person von den würdigen Bestrebungen der ,problematischen Naturen" Spielhagens demonstrieren (dazu gehören auch die selbstgefälligen Bemerkungen wie: „К несчастью, я одарена широкой натурой“ (,Zu allem Unglück ist mir eine großzügige Natur beschieden “481 $)(2,91)$ ): „- [.. ] Мне нужна была слава... шум, блеск, как для всякой - к чему скромничать? - недюжинной натуры. [...] И вот... подвернулся на моём пути богатый старик-генерал... [...] Но меня подкрепляла мысль, что старик не сегодня-завтра умрёт [...]...“ („'[...] Ich sehnte mich nach dem Ruhm... nach Musik und Glanz [Ich brauchte den Ruhm... Lärm, Glanz], wie es eine jede - wozu soll ich bescheiden sein? - nicht alltägliche [außergewöhnliche] Natur tut. [...] Und da... da begegnete mir auf meinem Pfade [war da auf einmal] ein reicher Greis, ein General... [...] Und nur der Gedanke hielt mich aufrecht, daß der Greis jeden Tag sterben könnte $\left.[\ldots] \ldots[\ldots]^{\text {s.482 }}\right)(2,91)$. Das Verb „podvemut'sja“483 - das aus einem niedrigen Sprachregister stammt und als solches einen stilistischen Bruch mit seinem Kontext darstellt - „verrät" auf einer lexikalischen Ebene die Diskrepanz zwischen der Form (hoch, edel) und dem Inhalt (niedrig, zynisch) des von der Dame Erzählten.

\footnotetext{
47 Tschechow Bd. 1 (1949). S 119

478 Ibid.

479 lbid.

${ }^{480} \mathrm{~S}$. die Ubersetzung auf $\mathrm{S} 89$ dieser Arbeit

$\$ 1$ Tschechow Bd I (1949). S 119

482 Ibid. S. 121

${ }^{483}$ Seine oben angefuhrte Ubersetzung als "begegnen" vermittelt jedoch nicht den deutlich abwertenden Beigeschmack, den dieses Wort enthalt
} 
Stilistisches Parodieren vollzieht sich einerseits durch die auf die Dame bezogenen Diminutivformen („хорошенькая дамочка“ („hübsches Dämchen“), „хорошенький носик“ („hübsches Năschen“), „хорошенькое личико“ („das hübsche Gesichtchen“484)), die einen Gegensatz zur pathetischen Rhetorik der beiden Personen Cechovs bilden, andererseits gerade durch die maßlos übertriebene Pathetik ihrer Sprache sowie durch die übertriebene Dramatik und Verstiegenheit der ganzen Szene:

Дорогой бахромчатый веер трешит в её судорожно сжатой руке, pince-nez то и дело спадает с ее хорошенького носика, брошка на груди то поднимается, то опускается, точно ладья среди волн. [...] Он глядит её в лицо, глядит в упор, [...]. $[\ldots]-[\ldots]$ Борьба страшная, чудовищная, [..]! [..] - [..] Ax, сколько мук, если бы вы знали! Сколько мук! u.s.w. (,Ein teurer Spitzenfacher flattert, krampfhaft von ihren Hăndchen gehalten, das Pincenez fallt unablăssig von ihrem hübschen Näschen, und die Brosche auf ihrer Brust hebt sich bald in die Höhe, bald wieder senkt sie sich, wie ein Kahn im aufgerührten Element [wie ein Kahn, getragen von Wellen]. [...] Er sieht ihr [...] ins Gesicht und wendet keinen Blick von ihr. [...] '[...] Es ist ein furchtbarer Kampf, ein ungeheuerlicher, [..]! [...] '[...] Ach, welche [wie viele] Qualen, wenn Sie das nur wußten! Welche [wie viele] Qualen!ca485) $(2,90-92)$

Cechov nimmt charakteristische sprachliche Merkmale des Originals in seine Parodie auf (s. die Zitate aus den „Problematischen Naturen“ oben) und steigert sie zugleich bis zu einem Grade, der die stilistische Gestalt der Prosa Spielhagens ins Lächerliche und Unnatürliche umschlagen laßıt, deren Unnatürlichkeit bzw. angesichts der mit ihr verbundenen nichtigen Inhalte zum Vorschein kommt.

.Zagadočnaja natura“ enthălt weitere Bezüge zu der oben angeführten Episode des Romans, also dem Gespräch des Barons Oldenburg mit dem Professor Berger, die eine parodistische Inkongruenz zwischen den Inhalten beider Texte offen legen. Dabei wird wiederum möglicherweise die Rezeption dieser Inhalte durch die Dame verspottet, aber auch die Poetik, bei der die Worte einer literarischen Figur zum direkten Sprachrohr der auktorialen Ideen werden. So liegen die Sympathien der Spielhagenschen Helden auf der Seite ..der Armen und Unterdrückten “\$\$ , sie verachten den Adel und erstreben die Vereinigung mit den einfachen Menschen, dem Volk. Berger. dem früher im Leben nichts wert gewesen ist, der das Menschengeschlecht verabscheut und beinahe endgültig aufgegeben hat, zeigt in seiner Beichte vor Oldenburg eine große Reue; jetzt, nachdem er seine Fehler eingesehen hat, will er

\footnotetext{
4tw Tschechow Bd I (1949), S 119-122

4*5 Ibid S 119-121 Die (an einigen Stellen korrigierte) Ubersetzung einzelner Teile dieses Zitats ist bereits auf S. 92 dieser Arbeit angefuhrt

426 Klemperer 1913, S. 71 
sich den Armen anschließen. Er bezeichnet seine frühere Weltanschauung als Krankheit der Aristokraten „im Geiste“:

Это нравственное пресыщение - болезнь аристократов мысли, [...]. Настоящий труженик незнаком с нею, [...]... [..] Так отказался я [..] от всякой рсскоши, к которой был страшно прнвязан, [...]. [...] я узнал, какая бездна жизненной силы заключается [...] в низших слоях общества [...]. (Diese moralische Übersătigung die Krankheit der Aristokraten im Geiste, [...]. Einem echten Arbeiter ist sie unbekannt, [...]... [...] So verzichtete ich [...] auf jeglichen Luxus, an dem ich sehr hing, [...]. [...] ich habe erfahren, welche Unmenge an Lebenskraft [...] die niedrigen sozialen Schichten in sich bergen $[. .$.$] . )^{487}$

Die Dame aus „Zagadočnaja natura“ bricht auch mit ihrem Kreis - nur strebt sie einen Aufstieg von etwas anderer Art an: „- [..] Родилась я в бедной чиновничьей семье. [...] Нужда, борьба за кусок хлеба, сознание ничтожества... [...] Мне нужно было самой пробивать себе путь... [...] Мне нужна была слава... шум, блеск [...].“ (.,'...] Ich stamme aus einer armen Beamtenfamilie. [...] Die Not, der Kampf um das tăgliche Brot [um ein Stück Brot], die Erkenntnis [das Bewußtsein] der eigenen Nichtigkeit.. [...] Ich mußte mir selber meinen Weg bahnen... [...] Ich sehnte mich nach dem Ruhm... nach Musik und Glanz, [...]. $\left.[\ldots]^{\kappa+488}\right)(2,90-91)$.

Die Werte, die bei Spielhagen abgelehnt und verschmäht werden, - Luxus, Bekanntheit und das Glänzen in höheren Kreisen - werden von der Dame Čechovs ersehnt. Cechov bewahrt die Pathetik, durch welche sich die Sprache der Figur(en) aus dem Prätext auszeichnet, übernimmt weiterhin das autobiographische Schema, das ihrer Erzählung zugrunde liegt. verdreht aber deren Inhalt, tauscht Motive und Fakten aus, so daß sich eine Diskrepanz einerseits zwischen der stilistischen und der inhaltlichen Ebenen im parodierenden Werk ${ }^{\text {JPI }}$, andererseits zwischen den inhaltlichen Ebenen des parodierenden und des parodierten Werkes bildet.

Semantische Reduzicrung und Komisierung des genannten Referenztextes vollzieht sich in „Zagadoxnaja natura“ darüber hinaus architextuell (s. den fünften Typ „transtextueller“ Beziehungen in der Typologie Genettes), d.h. durch die Gegenüberstellung solcher Gattungen wie Roman und Kurzgeschichte - ein charakteristisches intertextuelles Phänomen im frühen Prosaschaffen Cechovs, auf das bereits Kanevskaja in Anlehnung an Genette aufmerksam gemacht hat. ${ }^{400}$

$\$ 27$ F Spil gagen 1871. S. 326-329.

48* Tschechow Bd I (1949), S 120-121 S die korrigierte Ubersetzung einzelner Teile dieses Zitats auf S 96 dieser Arbeit

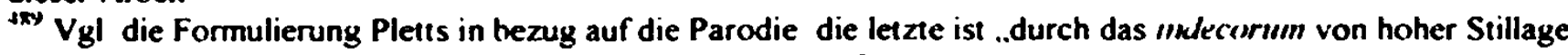
[ ] und Trivialitat der Themen. Figuren und Handlungen definiert" (1985. S 93)

S S S 65 dieser Arbeit Vgl auch zahlreiche parodistische Bezuge zur Romangattung in der fruhen Prosa Cechovs - meistens in den Titeln und Untertiteln der Texte (vgl uber die ...architextuellen" Verweise in Paratex- 
Mit dem Roman bzw. den Romanen Friedrich Spielhagens integriert Cechov in seine Kurzgeschichte eine Reihe weiterer, diesmal russischer, Prătexte, die allerdings, wie oben erwăhnt, zusammen mit „Problematischen Naturen“ innerhalb des manifesten Werkes kein eklektisches Gefüge bilden und also wahrscheinlich nicht zufallig in einem Kontext aufgerufen sind, sondern als zu einem bestimmten literarischen und literaturkritischen Diskurs im breiten Sinne zugehorig betrachtet werden.

Die Romane Spielhagens haben in Rußland eine Rezeption erlebt, die Cechov in , $\mathrm{Za}$ gadočnaja natura" vermutlich berücksichtigt hat und die die Werke des deutschen Schriftstellers mit manchen Texten der russischen Literatur und Literaturkritik verknüpfen läßt. Das Romanwerk Spielhagens genieBt beim russischen Lesepublikum eine besondere Popularităt in den Jahren 1860-70 - in der Epoche der ,radikalen revolutionăren Bewegung“ in Rußland, die Zeit, in der ,die gesamte radikale Intelligenzija von einem idealistischen Taumel des Umdenkens ergriffen“ ist ${ }^{491}$. In den 60 er ,träumt man [...] von den rationalen und humanen Lebensformen der 'neuen Menschen' der Zukunf, wie sie der revolutionăr-demokratische Denker und Literaturkritiker Tschemyschewskij in seinem [...] Roman 'Was tun? von 1862 entworfen hatte ${ }^{\text {c492 }}$. In den 70er erhofft man auch noch eine Umgestaltung der sozialen Struktur Rußlands, diese Jahre sind vom „Radikalismus der sozialistischen Ideen der Narodniki“493 gekennzeichnet. Diesem Zeitgeist entsprachen Werke Spielhagens. Spielhagens nach Idealen suchende Schwärmer, die sich zugleich als heroische Charaktere, Kămpfer für Freiheit und Gerechtigkeit zeigen, riefen unter der radikal gestimmten russischen Jugend eine Begeisterung hervor, die Hauptfigur des Romans ,In Reih und Glied“ Leo Gutmann diente vielen jungen Menschen als Vorbild. ${ }^{494}$ M. E. Saltykov-Scedrin bezeichnet Spielhagen als einen Schriftsteller, der im Gegensatz zu den russischen Prosaikern den .,neuen Menschen“ der Realităt entsprechend ernst und würdig dargestellt habe: .В романе его 'Один в поле не

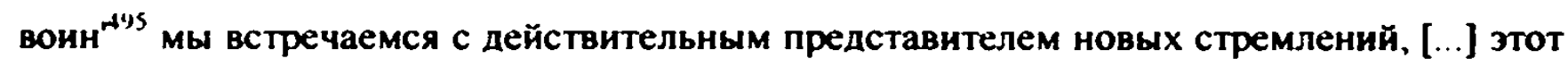
представитель [...] становится во главе социального и политического движения [...].. (In seinem Roman ..In Reih und Glied“' begegnen wir einem wahren Vertreter der neuen Bestre-

ten bei Genette (S. 26 unserer Arbeit) und Broich 1985a, S. 36-37). „Тысяча одна страсть. или Страшная ночь (Роман в одной части с эпилогом)". .ЗЗеленая коса (Маленький роман)" (Die grune Landzunge (Ein kleiner Roman)). .Скверная исторня (Нечто романообразное)" (Eine elige Geschichte (Etwas Romanartiges)): ..Женщина без предрассудков (Роман)" (Frau ohne Vorurteile (Ein Roman)); .Дочь коммерцин советника (Роман)“ (Tochter des Kommerzienrates (Roman)); ..Брак nо расчету (Роман в 2-x частяx)“ (Vernunftheirat (Roman in zwei Teilen)) Hier ware jedoch anzumerken, daß das Wort ..Roman" nicht nur eine Gattungsbezeichnung darstellt. sondern ebenso „Liebesverhaltnis" bzw .Liebesgeschichte“ bedeutet Bui Cechov hommen diese zwei Bedeutungen of zusammen

991 Hielscher 1987. S 11

492 Ibid $S$ 11-12.

493 Ibid S 19

494 Vil Smola 1996. S 43

${ }^{495}$ Russische Ubersetzung des Romans ..In Reih und Glied". wort ..Einer auf dem Feld allein ist noch kein Krieger" 
bungen, $[\ldots]$ dieser Vertreter $[\ldots]$ stellt sich an die Spitze der sozialen und politischen Bewegung [...]. $)^{496}$.

Auch der junge Cechov verband den Begriff des ,neuen Menschen“, der sich auf manche Gestalten der russischen Literatur der 1860-70er Jahre bezieht, mit den Werken Spielhagens; in der Kurzgeschichte „Svetlaja liěnost' (rasskaz idealista)“ (Eine lichte Persönlichkeit (Erzăhlung eines Idealisten)) (1886) stößt man auf den folgenden Satz: „Жалею, что в моей квартире не живёт Аузрбах, Шпильгаген или иной романист, ищущий 'новых людей'... “497 (Ich bedauere, daß in meiner Wohnung kein Auerbach, Spielhagen oder ein anderer Romanautor, der „neue Menschen" sucht, wohnt...) (5, 310). Selbst der Ausdruck „svetlaja ličnost"“ stellt eine ironische Anspielung auf die in Cechovs Sicht wenig glaubwürdigen, mental konstruierten, idealen Gestalten der Romane Spielhagens dar, gleichzeitig aber offenbar auf jene Werke der russischen Literatur, die für ihn vermutlich mit diesen Romanen typologisch, d.h. durch die sie untermauernde Ideologie, bestätigt durch die erwähnten Rezeptionsfakten, in Verbindung standen. ${ }^{498}$ Als fremd empfand Cechov wiederum selbstverständlich nicht die in solchen Werken vermittelten Ideale der Freiheit und der sozialen Gerechtigkeit, sondern vermutlich vor allem das Utopische der Gestalten, die Präsenz handelnder Wunschcharaktere, die Tendenziösitat der literarischen Produktion.

In ,Zagadočnaja natura“" werden neben Spielhagens „Problematischen Naturen“ einzelne Gestalten und Episoden der Romane „Rudin“ (1855) und „Nakanune“ (1860) Ivan Turgenevs und "Čto delat”“ (1863) Nikolaj Cernyševskijs parodiert, es werden weiterhin Texte der russischen Literaturkritik derselben Periode evozien, die für Cechov ein Teil der betreffenden breit verstandenen - literaturideologischen Strömung gewesen sind. ${ }^{+9 \%}$

\footnotetext{
496 Saltykov-Ścedrin Bd. 9 (1970), S. 74 . S uber dieses Zitat und uber die Rezeption Spielhagens in Rußland bei Kataev 1995, S. 8-9 und in unserem Aufsatz (Smola 1996, S 42-43, 53-54. don mit weiteren Verweisen), uber die Rezeption Spielhagens in RuBland s auch bei Danilevskij 1982. S 180-187

${ }^{997}$ Uber diesen Bezug $\mathrm{s}$. in unserem Aufsatz (Smola 1996. S 44. 46) Mit den .anderen Romanautoren, die 'neue Menschen' suchen" ist u a der Schriftsteller A $K$ Seller-Michajlov gemeint, wie das in den Anmerkungen zum Text erklart wird (s 5, 652). Uber den Bezug von.Zagadocinaja natura" zu seinen Werken s weiter auf $S$ 106109 dieser Arbeit

${ }^{498}$ S z B die Kurzyeschichte ..Rara avis" (1886), in der dieser Ausdruck ebenfalls in bezug auf literarische Produktion - diesmal eines Krimiautors - ironisch verwendet wird $(5,230)$..Svetlye ličnosti“- nennt Korolenko ironisch in .Istorija moego sovremennika" (Geschichte meines Zeitgenossen) Helden der Werke mancher Autoren - fiktive Personen, die sich mit den Gestalten Cernyšskskijs vergleichen „Вообще. это были не лица, как у Тургенева, Писемского, Гончарова, а личности, с прибавлением ходячего зпитета 'светлые личности". (Im allgemeinen waren das keine Personen, wie bei Turgenev. Pisemskij. Gončarov. sondern Personlichkeiten. erganzt durch das verbreitete Epitethon , lichte Personlichkeiten") (Bd 4 (1990), S 310) Weiter schreibt Korolenko uber die literarische Produktion dieser Autoren .Положительное было выдуманно " туманно Отрииание - живо " действительно " (Das Positive war erfunden und nebelhaf Die Negation - lebendig und wahr ) (ibid) Jedoch außert sich Korolenko gleich darauf positiv gerade uber die (haraktere Spielhagens, die er als unumstritten glaubwurdig wahrnahm (s ibid S 310-311)

${ }^{+99}$ Uber die Verbindung zwischen den ..neuen Menschen* in der nussischen Literalur (wie bei Turgenev und Cernyševskij) und den Personen Spiclhagens $s$ in unserem Aufsatz (Smola 1996, S 45-46) Wir erwahnen don z.B. daß die russische Kritik einen der Helden Spielhagens Leo Gutmann mit den Figuren wie Bazarov und Rachmetov verglich (s. S. 46) S daruber auch bei Korolenko Bd 4 (1990). S 311 und Danilevskij 1982. S 181-183 Erwahnt sei hier eine ironische Bemerkung Cechovs im Brief an Suvorin. in der er Turgenev mit solchen deutschen Autoren in Verbindung bringt. wie $\mathrm{H}$. Heine und $\mathrm{L}$. Borne Die Ironie richtet sich auf die Rezeption dieser Autoren durch die fiktive Gestalt in einem geplanten Stuck ..16 февраля 1894 r Чехов писал A. С Суворину. 
Im Roman „Rudin“ schildert Turgenev den Typ eines adeligen Intellektuellen, der sich ähnlich wie problematische Naturen Spielhagens - nach dem Höheren und Schönen sehnt und an eigener Tatenlosigkeit bzw. an der Ergebnislosigkeit aller seinen Handlungsversuche leidet. Rudin spricht mit denjenigen, die ihn verstehen und bewundern, von den großen Zielen, die er anstrebt, findet aber für seine geistigen Kräfte in Wirklichkeit keine Verwendung. So schließt sich seine Gestalt der Reihe der „überflüssigen Menschen“ in der russischen Literatur $a^{500}$, gewinnt jedoch in der endgültigen Fassung (zum ersten Mal veroffentlicht im Jahre 1860) Züge, die ihn zum Vorlăufer der ,neuen Menschen“ machen. In der letzten Fassung wird der Roman um ein Finale ergănt, in dem Rudin auf einer Barrikade in Paris sein Leben opfert. Dank diesem Schluß entwickelt er sich zu einer Figur, die letztendlich eine heroische Tat (wie auch die Figuren Spielhagens im Finale seines Romans ${ }^{501}$ ) vollbringt - unabhăngig davon, ob diese Taten die erstrebte Weltverbesserung bewirken oder nicht und vielleicht gerade im Bewußtsein ihrer Fruchtlosigkeit. ${ }^{502}$

Die Gestalt Rudins, die Besonderheiten seiner Sprache, die er in seinen Monologen bzw. in den vertraulichen Dialogen mit anderen Protagonisten des Romans spricht und seine abschließende autobiographische Beichte vor dem ihn bewundernden Ležnev, aber auch bis zu einem gewissen Grad die zentrale Frauengestalt Natal'ja (darüber hinaus ein bestimmter Turgenevscher Frauentyp, wie ihn z.B. ebenfalls Elena in „Nakanune“ repräsentiert) werden zur Zielscheibe der Parodie. Zwar ist die Figur Rudins auf keinen Fall als nur positiv bzw. vorbildlich konzipiert, doch mochte er Cechov als „nobler“ überflüssiger Mensch, den er in der Wirklichkeit nicht finden konnte, unglaubwürdig vorkommen. In innigen Gesprächen mit

что хочет 'вывести в пьесе господина который постоянно ссылается на Гейне "Л Людвига Берне. Женщинам, которые его любя, он говорит, как Ннсаров в «Нахануне»: «Т ах здравствуй, жена моя перед богом и людьми!)"“ (Am 16 Februar 1894 schrieb Cechov an A. S. Suvorin, daB et ,in einem Stück einen Hetren darstellen" will, ..der standig auf Heine und Ludwig Borne verweist. Den Frauen, die ihn lieben, sagt er, wie Insarov in 'Nakanune': 'So grusse ich Dich. meine Frau vor Gott und den Menschen 1".) (Anmerkungen zum Notizbuch II in. Cechov 17, 336) Wie also wesentlich früher in .Zagadocnaja natura", stellt hier Cechov Turgenev erneut in einen breiten literaturhistorischen Kontext, wobei er in erster Linie zu der Tatsache der Verwendung der literarischen Werke dieser Autoren als Pose eine skeptische Stellung nimmt Sicherlich hat Cechov aber ebenfalls die sprachlichen Besonderheiten der Romangestalten von Turgenev im Blick (vgl Fußn 511 und 517)

${ }^{500} \mathrm{Vgl}$ uber Rudin als ..Uberflussigen" und seine Bewertung in der zeitgenossischen Kritik in den Anmerkungen zum Roman (Turgenev Bd 6 (1963). S 560: 566: 574-575).

sos Die Gegenuberstellung der Helden Turgenevs denen von Spielhagen ist keineswegs neu Danilevskij schildert. wie der deutsche Kritiker J Schmidt die Helden von Spielhagens ..Problematische Naturen“ mit Rudin verglich .Шмият догадывался. что типологически Рудин был близок к тому характеру немеикого 'лишнего человека', который возникал в эпоху реакиии и застоя [ ] Шмият заметил. что Рудин напоминает и персонажей первых романов Шпильгагена. подобно Освальду Штейну из 'Проблематических натур' Рудин кончает свою жизнь на баррикадах 1848 r., но не столько из убеждения. сколько от отчаяния [ ] Эти сравнения приходили в голову. вероятно, не одному Ю Шмидту, [. ].“ (Schmidt ahnte. daß Rudin typotogisch dem Charakter des deutschen .uberflussigen Menschen“ nahe stand. der in der Zeit der Reaktion und Stagnation entstand [ ] Schmidt hat bemerkt, daß Rudin auch an die Protagonisten der ersten Romane von Spielhagen erinnert wie Oswald Stein aus .Problematischen Naturen“ endet Rudin sein Leben auf den Barrikaden 1848. aber nicht so sehr aus Uberzeugung, sondern aus Verzweiflung. I ] Diese Vergleiche stellte wahrscheinlich nicht nur Schmidt an [... ].) (Danilevskij 1982. S. 178) Und weiter ..Шпильгагена сравнивали с Тургеневым 4асто. [ ]" (Man verglich Spielhagen of mit Turgenev. [ . ].) (ibid. S. 185) Zur Parallele zwischen den Helden Spiethagens und den ..uberflussigen Menschen" der russischen Literatur vgl auch hei uns (Smola 1996. S 48)

${ }_{002} \mathrm{~S}$. daruber wiederum in den Anmerkungen 2 .. Rudin“ (Turgenev Bd 6 (1963). S 570-\$72. 574-575) 
Natal'ja offenbart Rudin immer mehr seine Natur; einmal beklagt er seine Schwäche und bedient sich dabei folgender Ausdrucksweise: „- [...] если 6 я даже верил в свои силы, - где найти искреннне, сочувствующие души?..“ (..'[...] Selbst wenn ich an meine eigene Kraft glauben würde - wo sollte ich aufrichtige, gleichgestimmte Seelen finden? $\left.{ }^{\text {*c } 503}\right)^{504}$; ein anderes Mal erzăhlt er von vielen Enttăuschungen, die er im Leben in Kauf genommen habe: "[...] сердце моё испьгтало много радостей и много горестей... [...] Мне остаётся теперь ташиться по знойной и пыльной дороге [...]...“ (,,' Kummer erfahren... [...] Mir bleibt jetzt nur noch übrig, mich auf schwüler, staubiger Straße $[\ldots]$ zu schleppen $\left.[\ldots] \ldots[\ldots]^{\mathrm{m.505}}\right)^{506}$. Seine beeindruckte Zuhörerin antwortet:

- [..] кто стремится к великой цели, уже не должен думать о себе; но разве женщина не в состоянии оценить такого человека? [...] Поверьте, женщина не только способна понять самопожертвование: она сама умеет пожертвовать собою. (.'[...] wer einem hohen Ziel zustrebt, darf nicht mehr an sich selbst denken. Aber warum sollte eine Frau nicht imstande sein, einen solchen Mann [Menschen] zu würdigen? [...] Glauben Sie mir, eine Frau ist nicht nur fahig, Selbstaufopferung zu begreifen: Sie kann sich auch selbst aufopfern..$^{\text {r.507 }}$ ) $^{508}$

Vgl. bei Cechov: „- [...] А муки зарождающегося неверия [...] в себя?“ Und weiter: ..- [...] Ведь это было самопожертвование, самоотречение, поймите вы! [...] Сколько мук!“” (2, 91-92) $)^{509}$. Nicht nur dem Roman Spielhagens, sondern auch dem Roman Turgenevs entnimmt Cechov einzelne ,.lexikalische Motive“, die charakteristische Personenkonstellation (jedoch eher im allgemeinen Sinne: der erzăhlende Held und der verstăndnisvolle, zustimmende $Z_{u-}$ hơrer, so wie z.B. Rudin und Leżnev (s. weiter)), die Sprache und partiell den Inhalt des Dialogs. Bemerkenswern ist, daß die ,rätselhafte Natur“ Cechovs einerseits die Partie der männlichen Hauptfigur (Rudin), andererseits der für Turgenevs Romane typischen und zum Objekt mehrerer ironischen Aussagen in der Prosa und in den Briefen Cechovs gewordenen ..sich opfernden" Frauenfigur (wie Elena oder Natal'ja ${ }^{\text {s1o }}$ ) spielt. ${ }^{\text {sIl }}$ Diese Parallele wird v.a. in der folgenden Aussage der Dame angedeutet: ..- [..] Теперь-то и отдаться любимому человеку, сделаться его подругой, помошницей, носительницей его идеалов, [...]...“

\footnotetext{
\$3) Turgenjew 1969, S. 54

Turgenev Bd 6 (1963). S 282

sus Turgenjew 1969. S 80

Turgenev Bd 6 (1963), S 306

307 Turgenjew 1969, S 80

son Turgenev Bd. 6 (1963), S 306

409 Ubers auf den S 92, 94, 97 dieser Arbeit

$\$ 10$ In bezug auf $\mathrm{Natal}$ "ja ware es jedoch angemessen, von einer Bereitschaft zur ..Selbstaufopferung" zu sprechen (sie ist namlich bereit, sich von ihrer Familie zu trennen und Rudin zu folgen. sogar wenn er sie nicht heiraten kann und obwohl er ihr einen Wohlstand zu gewahrleisten nicht imstande ist)

"II Uber die skeptische Einstellung Cechovs zur pathetischen Ausdrucksweise der Frauengestalten Turgenevs s. 2. B bei Semanova 1958. S 222
} 
(.,'[...] Jetzt sich dem Geliebten hingeben kơnnen, seine Freundin sein, seine Kameradin, die Trägerin seiner Ideale, $\left.[\ldots] \ldots[\ldots]^{\kappa .512}\right)(2,91)$. Der zitierte Satz stellt einen Verweis auf zumindest zwei dem Romanwerk Turgenevs entstammende Frauengestalten dar: auf Natal'ja (,Rudin“) und auf Elena (,Nakanune“), Frauen, die an die hohe Berufung der von ihnen geliebten mănnlichen Hauptpersonen wie Rudin und Insarov glauben und bereit sind, an die Seite dieser Helden zu treten und ihr Leben für deren Sache zu opfern. Mit der zitierten Aussage bei Cechov korrespondieren z.B. folgende Aussagen von Elena:

\author{
- Так ты пойдёшь за мною всюду? - говорил он [...]. \\ - Всюду, на край земли. Где ты будешь, там я буду. ('So wirst du mir überallhin \\ folgen? fragte er [...]. \\ 'Überallhin, bis ans Ende der Welt. Wo du bist, da werde auch ich sein. $\left.{ }^{\text {x.s13 }}\right)^{514}$
}

Oder: „[...] но я и после смерти Д. останусь верна его памяти, делу всей его жизни“ („„...] aber ich will auch nach D.s Tode ihm und seinem Lebenswerk treu bleiben. $\left.{ }^{\text {.S15) }}\right)^{516}$ Auch diese Parallele wird in ,Zagadornaja natura“ parodistisch gezogen: Wăhrend Natal'ja von Rudin selbst zurückgewiesen wird. Elena aber aus dem familiären Kreis bricht und ihrem Mann Insarov tatsachlich folgt und damit also auf den Komfort und Wohlstand verzichtet (so lehnt sie auch eine finanziell vorteilhafte Heirat ab), geht die Frau bei Cechov eine zweite Geldehe ein. Nicht der Tod des Helden (,Nakanune“) oder seine seelische Erschopfung (,Rudin“) stehen dem Glück der „Liebenden“ im Wege, sondern ,,der zweite reiche Greis“ ${ }^{\text {“ }} 17$

\footnotetext{
$\$ 12$ Tschechow Bd 1 (1949), S. 121. S Übers teilweise auf S. 95 dieser Arbeit

\$13 Turgenjew 1973. S 119

\$14 Turgenev Bd 8 (1964). S 94

S1s Turgenjew 1973. S. 209.

\$16 Turgenev Bd 8 (1964). S 165
}

${ }^{217}$ Die Kurzyeschichte ..Propascee delo“ (Eine verlorene Sache) (1882), auf deren Analyse wir hier nicht eingehen konnen, stellt eine Parudie dar, die ausschließlich auf dieses genannte Motiv Turgenevscher Romane - die Selbstaufopferung einer Frau fur den armen, seinen noblen Prinzipien aber treuen Helden - abzielt Sowohl in der fruhen Prosa als auch in den spateren Novellen Cochovs stoBt man mitunter auf Verweise auf die idealen, noblen Romanfiguren Ivan Turgenevs, manchmal auf kritische fiknke Außerungen über diese Figuren In den spateren Werken erfullen sie. unserer Meinung nach, in der Regel folgende Funktion Sie sind berufen. den Gegensatz zwischen der ..Literatur" (sprich dem Erdachten, Unglaubwurdigen, nie Vorkommenden), die (u a ) mit den Romanen Turgenevs assoziiert wird. und der bei Cechov dargestelten Wirklichkeit zu betonen Die Turgenev-Intertextualitat wird meistens mit dem Thema der .gelebten Literatur in der Literatur" (s. im Kap 4). der Literaturverblendung. der verfehlten Literaturtezeption verknupft Dabei sind das in vielen Fallen gerade Frauen, die die Lekture mit der Realitat verwechseln. die $v$ a Züge der mannlichen Romantiguren naiv auf ihre bekannten Manner ubentragen und fast immer bitter enttauscht werden $\mathrm{Vgl}$. $\mathrm{B}$. solche Textstellen. .Јеля была убеждена. что. выйдя из института, она неминуемо столкнется с тургеневскими и инымн героями. бойцами за правду и прогресс. [. ]. - (Lelja war uberzeugt davon, daß sie, sobald sie das Institut verlaßt, unvermeidbar den Turgenevschen und anderen Helden begegnet. den Kampfern fur die Wahrheit und den Fortschrit. [ ] .) (..DaẼnica" (3, 12), s. dieses und andere Beispiele u a bei Semanova 1957. Beispiele aus .. Cvety zapozdalye“" und dementsprechend utrer die Rezeption Rudins durch Marusja s. bei Kramer 1970 S 39). .. - Тургенев в своих промзведениях учит. чтобы всякая возвышенная. честно мыслящая девица уходила с любимым мужчиною на край света и служила бы его идее. - сказал Орлов. иронически шуря глаза [ ] Да. душа моя. Тургенев писал. а я вот теперь за мего кашу расхлебывай [ ." (..'Turgenjew lehn in seinen Werken. daB jedes hochstehende. ehrlich denkende Madchen mit dem geliebten Mann bis ans Ende der Welt geht und fur seine Ideen lebt.' erwiderte Orlow. 
In „Zagadocnaja natura“ bezieht sich Cechov jedoch in erster Linie auf die Szene der Beichte Rudins am Ende des Romans. Trotz des expliziteren Bezuges zu den Spielhagenschen „Problematischen Naturen“, steht die Kurzgeschichte unserer Meinung nach dieser Episode am nåchsten. Vergleichen wir das aktuelle Werk mit der genannten Folie im Ganzen und in einzelnen Fragmenten, die sprachlich-inhaltliche Übereinstimmungen der Texte bloßlegen. Die Personenkonstellation in der Beichtepisode von "Rudin“ entspricht durchaus der oben bezeichneten im Roman Spielhagens: Ležnev ist der bewundernde Zuhörer, Rudin der Erzähler, der von seinem Leben in den letzten Jahren berichtet, das gekennzeichnet ist von groBen Plănen, die infolge allerlei Hindernisse (z.B. aufgrund der Stumpfsinnigkeit eines reichen Gutsbesitzers, mit dessen Mitteln Rudin die Dorfwirtschaft vervollkommnen wollte, oder aufgrund den gegen ihn gerichteten Intrigen der Lehrer und der Direktion eines Gymnasiums. in der er beschaftigt war ${ }^{518}$ ) nie verwirklicht werden konnten. "- Всего рассказать нельзя и не стоит... Маялся я много, скитался не одним телом-душой скитался. В чём и в ком я не разочаровался, бог мой!““ („'Alles läßt nicht erzählen, und es lohnt sich auch nicht... Ich habe mich redlich abgeplagt und bin viel herumgeim - nicht nur körperlich, auch seelisch habe ich gelitten. Wer und was hat mich nicht alles enttäuscht, mein Gott! [... $]^{\text {x.519) }}$ (vgl. Cechov: „- [...] Покажите миру мою [...] бедную душу! [..] Ах, не заставляйте меня вспоминать! [...] А муки зарождающегося неверия в жизнь, $\left.[\ldots] ? . .(2,90-91)^{520}\right) ;$.. [...] да и мудрено, брат, стронть, когда [..] самому приходится собственный свой фундамент создавать!“ (,'[...] es ist aber auch nicht leicht, etwas zu bauen, Bruder, wenn man $[\ldots]$ sich sein eigenes Fundament selber schaffen muß! [... $]^{\text {к.521 }}$ ) (Čechov: „Мне нужно было самой пробивать себе путь...“ $\left.(2,91)^{522}\right) ;$ „- $[\ldots]$ Передам тебе два, три случая... те случаи из моей жизни, когда, казалось, успех уже улыбался мне, [...]... (,'[...] Ich werde dir zwei, drei Vorfălle schildern, und zwar jene Vorfâlle aus meinem Leben, wo mir der Erfolg bereits zu lächeln schien $[\ldots]^{[. .523}$ ) (Cechov: ..- [...] Счастье стучится ко мне в окно. Стоит только впустить его, но...нет!“” ('[...] Das Glück klopft an mein Fenster. Ich brauche

und kniff ironisch die Augen zu [ ] ] Ja. mein Bester. Turgenjew hat das geschrieben, und ich muß nun fur ihn die Suppe ausloffein "' (Tschechow 1966, S. 226)) (..Rasskaz neizvestnogo celoveka" 8, 156-157), .. I ] Вско свою жизнь открешивался от роли героя, всегда терлеть не мог тургеневские романы и вдруг. словно на смех. попал в самые настоящие герои " (..I ] Mein ganzes Leben lang habe ich mich gegen die Rolle eines Helden gestraubt. die Romane Turgenjews habe ich nie gemocht, und auf einmal, es ist direkt zum Lachen, bin ich unter die richtigen Helden geraten " (Tschechow 1966. S. 255)) (8. 181); „Она пошла 6ы за мной. но куда? Куда бы я мог увести ес? Другое дело, если бы у меня храс:нвая, интересная жизнь. если 6 я. например. боролся $3 а$ осворождение родины [ ]“" (..Sie wurde mir folgen. aber wohin' Wo konnte ich sie hinfuhren' Anders ware es, wenn ich ein schones, interessantes Leben fuhren wurde, wenn ich zum Beispiel fur die Befreiung der Heimat kampfte [ ]" (Tschechow 1979. S 465-466)) (..O ljubvi“" (Von der Liebe (Tschechow 1979. S. 458)): 10, 72)

"18 $\mathrm{Vgl} \mathrm{mit} \mathrm{den} \mathrm{Elementen} \mathrm{der} \mathrm{Biographie} \mathrm{von} \mathrm{Oswald} \mathrm{Stein} \mathrm{bei} \mathrm{Spielhagen.} \mathrm{dic} \mathrm{in} \mathrm{unserem} \mathrm{Aufsatz} \mathrm{erwahnt} \mathrm{wer-}$ den Smola 1996. S 49

\$19 Turgenjew 1969 . S 135

${ }^{220} \mathrm{~S}$ Ubers auf den S 89, 92, 94 dieser Arbeit

$\$ 21$ Turgenjew 1969. S. 136

$322 \mathrm{~S}$ Übers auf $S 98$ dieser Arbeit

\$23 Turgenjew 1969, S 136 
es nur hereinzulassen, und dennoch... es geht nicht $\left.\left.[\ldots]^{1.4524}\right)(2,91)\right)$; "- [... ropsko почувствовать, что я опять и опять обманулся в свокх ожиданиях.“ (,'[...] mit Bitterkeit erkannte ich, daß ich mich wieder einmal in meinen Erwartungen getăuscht hatte. [...] *us25) (Čechov: n- [...] Onять я чувствую, что счастье моё далеко, далеко!“ („'[...] Wiederum fühle ich, daß mein Glück mir ferngerückt ist, so fern! $\left.\left.[\ldots]^{\text {«s526 }}\right)(2,91-92)\right) ;$ „- [...] не мог же $я$ не чувствовать присутствия сил, не всем людям данных!“ (,'[...] ich konnte dennoch

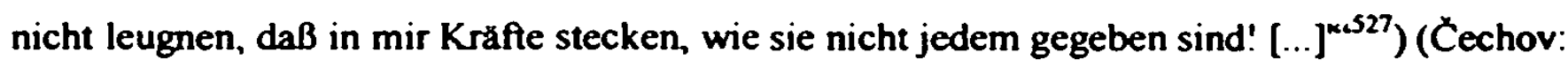
n- [...] Мне нужна была слава... [...], как для всякой - к чему скромничать? недюжинной натуры.“ $\left.(2,91)^{528}\right)$. Auch das gegenseitige Verstăndnis und die gegenseitige Anerkennung der Gesprăchspartner werden in den betreffenden Texten auffallig ăhnlich ausgedrückt: ,- [...] но посмотри, как мы близки друг другу. Ведь мы говорим с тобой почти одним языком, с полунамёка понимаем друг друга [...].“ („,'...] doch siehe, wie nahe wir einander sind. Wir reden miteinander fast die gleiche Sprache; schon durch eine halbe Andeutung verstehen wir einander $\left.[\ldots]^{\kappa .529}\right)^{530}$ (,Не прошло и часа, как мы сидим в купе и говорим, а вы уже постигли меня всю, всю! $\left.{ }^{\text {s31 }}\right)(2,90)$ ).

Der unpraktische Mensch Turgenevs, der Don-Quichote Rudin, der, wenn auch ohne Erfolg, das Gemeinwohl erstrebt und ständig eigene Vorteile vergißt, wird nun, durch mehrere oben angeführten Allusionen und die Anpassung der Personenkonstellation sowie die Übernahme der Beichtesituation kontrastiv neben die habgierige Cechovsche Dame gestellt. Eine ironische Bedeutung gewinnen im Lichte dieser Umschreibung die Worte Ležnevs: „- [...] Ты себе состояния не составишь... Да я люблю тебя за это... [...] Я уважаю тебя за это!“ (,'[...] Du wirst dir kein Vermögen erwerben - gerade deswegen liebe ich dich... [...] Ich achte dich deswegen! $\left.{ }^{\text {m.532}}\right)^{533} ;,-[\ldots]$ ты $[\ldots]$ жертвовал свокми личными выгодами $[\ldots]$ “. (..'[...] daß du deinen persönlichen Vorteil opferst $\left.[\ldots]^{\text {n.534 }}\right)^{535}$.

Vor allem also die sentimental-heroischen Züge der Gestalt Rudins, das ..negativ dominiente Geschehen“ der genannten Romane Turgenevs (und der Spielhagens) (s. Müllers Auflistung semantischer Merkmale der typischen Parodievorlagen ${ }^{536}$ ) sowie die Rezeption seiner Figur (die Dame spricht und beschreibt sich im Stil Rudins, ohne schreiende Diskrepanzen zu merken) mochten für Cechov ein dankbares Parodieobjekt bilden.

\footnotetext{
324 Tschechow Bd I (1949), S 121

325 Turgenjew 1969, S 136

326 Tschochow Bd. I (1949). S 121

327 Turgenjew 1969. S 143

$528 \mathrm{~S}$ Ubers. auf S. 96 dieser Abeit

529 Turgenjew 1969, S. 146

${ }^{530}$ Zitate aus .Rudin“ s. in Bd 6 (1963). S 356-366

\$3I S. Ubers. auf S 93 dieser Arbeit

332 Turgenjew 1969, S 140

\$33 Turgenev Bd. 6 (1963). S 361

534 Turgenjew 1969, S 145

33s Turgeivev Bd 6 (1963). S 36.5-366

${ }^{316} \mathrm{Vgl}$. S 41 dieser Arbeit
} 
Eine wichtige Prätextfigur, Rudin, der Vorlăufer der ,neuen Menschen“ in der russischen Literatur (insbesondere dank des 1860 hinzugefügten Finales), der Vorlăufer von Insarov, den Turgenev als ,soznatel 'no-geroiceskaja natura“" (eine bewußt-heroische Natur) ${ }^{537}$ charakterisiert hat, - verbindet „Zagadoðnaja natura“ Cechovs ebenfalls mit dem drei Jahre spăter verfaßten Werk Nikolaj Cernyševskijs „Cto delat'?“, in dem im Rahmen eines utopischen Gesellschaftsentwurfs ein ,neuer Mensch", Rachmetov, dargestellt wird. Es kann behauptet werden, daß der Ausdruck ,nedjužinnaja/ zagadočnaja natura“ (außergewöhnliche/ rätselhafte Natur) ebenfalls - innerhalb eines literaturideologischen Textsystems - auf die utopischen Gestalten Cerny̌̌evskijs abzielt. ,Да, особенный человек был зтот господин, экземпляр очень редкой породы. [...] люди, как Рахметов, [...]. [...] не следуйте за ними, [...] потому что скуден личными радостями путь, на который они зовут нас; [...].“ (Ja, ein besonderer Mensch war dieser Herr, ein Exemplar von einer sehr seltenen Art. [...] Menschen wie Rachmetov, [...] [...] folgen Sie ihnen nicht, [...] denn ihr Weg, den sie uns zeigen, ist arm an persönlichen Freuden, [...].). ${ }^{538}$ Über neue Menschen wie Rachmetov schreibt Dmitrij Pisarev in seinem bekannten Artikel „Mysljascij proletariat“ (Das denkende Proletariat) (1865): "[...] ценою труда и лишений, ценою потраченной молодости, иеною потерянной любви он купил себе право глубоко и сознательно уважать самого себя.“ ([...] um den Preis der Arbeit und Entbehrungen, um den Preis der vertanen Jugend, um den Preis der verlorenen Liebe hat er sich das Recht erkauf, sich tief und bewußt zu achten.) ${ }^{539}$

Die .Biographie“ der „außergewöhnlichen“ Natur Cechovs mit ihrem „Verzicht” auf das Glück im Privatleben, mit ihren „Opfern“ und der „verlorenen“ Liebe gibt in burlesker Verzerrung einen typischen Lebenslauf des utopischen Helden der 60er Jahre wieder. Diesen Helden, den ,neuen Menschen“, charakterisiert der Kritiker A. M. Skabicevskij im Vorwort zur Gesamtausgabe der Werke (1904-1905) des ,.pisatel'-sestidesjatnik“ (Schriftstellers der 1860er Jahre) A. K. Seller-Michajlov. Als für die literarische Strömung, der Seller-Michajlov angehörte, repräsentativ ist die dort thematisierte Angleichung der fiktiven Welt der Literatur an das wirklıche Leben zu betrachten, genauer: der Versuch, das in Wirklichkeit Erstrebte in der Literatur zu präsentieren und durch Literatur zustande zu bringen ${ }^{540}$ :

[..] разночинщы $[\ldots]$ выставили свои собственные идеалы, [...]. [...] Подобного рода идеал, осуществляемый в жизни и в литературных сферах такими личностями, как Белинский, Добролюбов, Чернышевский и прочие их сподвижники, не замедлил в конце 50-х и начале 60-x годов проявиться и в литературе во образе новых героев [..]. (Die Raznotschinzen [...] propagierten ihre eigenen Ideale, [...] [...] Eine solche Art Ideal, das im Leben und im literarischen Be-

\footnotetext{
${ }^{537} \mathrm{~S}$ in den Anmerkungen zu . Rudin" (Turgenev Bd 6 (1963). S 570)

s38 Cernysevskij 1954. S 305 Zu den weiteren Parallelen zwischen ..Cto delat "r" und .Zagadocnaja natura", die $\checkmark$ a die Sprachebene betreffen. $s$ in unserem Aufsatz (Smola 1996)

319 Pisarev 1968. S 399
} 
reich von solchen Persoonlichkeiten wie Belinskij, Dobroljubov, Cernyševskij und ihren Anhängem verwirklicht wurde, erschien ohne Verzógerung Ende der 50er und Anfang der 60er Jahre auch in der Literatur in der Gestalt der neuen Helden [... ]. $)^{541}$

Die daraus resultierende Tendenziosităt der literarischen Produktion von Autoren wie Seller (dessen Werk zum Gegenstand latenter Kritik Cechovs wurde ${ }^{542}$ ), die eine Vereinfachung der Realităt und hăufig die Aufteilung der fiktiven Gestalten in Kleinbürger (,Philister“) und .ehrliche Arbeiter", „raznoxincy“" beinhaltete ${ }^{543}$ konnte für Cechov ein geeignetes Parodiemotiv sein. Für Cechovs Parodien mußte gerade die ideologische Gepragtheit dieser Texte $^{\text {s+4 }}$ bzw. ihre eine „strebende, zielgerichtete Kraft" verköpernden, idealen Gestalten eine besondere Attraktivităt besitzen (s. Muller ${ }^{\text {s45 }}$ ).

Charakteristisch und für die Aufschlusselung der Intertextualität von ,Zagadočnaja natura“ hilfreich ist die von Skabičevskij entworfene Biographie Seller-Michajlovs, eine Biographie, wie der Kritiker betont, eines ,idealen raznocinec“, der auch in den Romanen Sellers - den „verhüllten Autobiographien“ - im Mittelpunkt steht. Diesen typischen Lebenslauf (moglicherweise den Werken Sellers entnommen) parodiert Cechov im Rahmen des evozierten Textsystems genauso wie den von den beichtenden Personen Spielhagens und Turgenevs: dadurch, daß die Cechovsche Dame einen gesellschafilichen und finanziellen Aufstieg ersehnt und verwirklicht, profaniert sie den kulturell-geistigen und moralıschen Aufstieg der sich hocharbeitenden „raznoxincy“. Verfolgen wir die Biographie (der Figuren) Michajlovs, geschrieben von Skabicevskij, in ihren einzelnen Fragmenten:

Родители Шеллера были бедные люди [...]. [...] не на одних словах, а и [...] всею своею жизнию он осуществлял идеал неустанного труженика. [...] Но не одним только трудолюбием, а и всем своим нравом, всеми привычками Шеллер осуществлял в своей жизни тот новый идеал, [...]. Крайне воздержный, [...] он был до последней степени прост в своей домашней обстановке. (Sellers Eltern waren arme Menschen $[\ldots]$. [...] nicht nur durch Worte, sondern auch [...] durch sem ganzes Leben verwirklichte er das ldeal eines unermudlichen Arbeiters. [...] Jedoch nicht allein durch seinen Fleiß, sondern durch seinen ganzen Charakter, durch alle seinen Gewohnheiten setzte Seller in seinem Leben das neue Ideal um, [...]. Äußerst enthaltsam, [...] war er in seiner Hauseinrichtung im höchstem Grade einfach. $)^{5+6}$

\footnotetext{
\$*0 $\mathrm{Vgl}$ dazu in unserem Aufsatz (Smola 2001, S 108)

sal Skabičevskij 1904. S 7

$\$ 42$ S. weiter, Fußn 548

$343 \mathrm{Vyl}$ danu in Prozorov 1990, S 406

344 Uber den Antiideologismus Cechovs haben viele Forscher geschrieben. 5 z B Cudakov zum .,antidogmatischen Charakter der Idee" (1971. S. 262) bei Cechov (s ibid. S 258-266) oder Kataen (1979. S 162-175)

${ }^{945} \mathrm{Vgl}$ auf S 41 dieser Arbeit

46 Skabicerskij 1904, S 17.
} 
Die Hauptperson des ersten Romans Sellers, „Gnilye bolota“ (Faule Sümpfe), hat die verderbliche Anziehung des Nichtstuer- und Genießermilieus zu überwinden - „среды праздного шалопайства“ (des Milieus des faulen Müßiggangs); schließlich tritt sie auf „den Weg des Wissens, des Guten und der Wahrheit", den Weg der „умственного и нравственного развития“" (der intellektuellen und moralischen Entwicklung). Über die Figuren des späteren Romans „Les rubjat - క̌cepki letjat“ (Wo gehobelt wird, fallen Spăne) schreibt Skabicevskij:

[...] потерпевши fiasco в борьбе с враждебными обстоятельствами жизни, вот к какому горькому сознанию пришли герои Шеллера, [...]:

„Мы сошли со сиены, $[\ldots]$ чтобы начать $[\ldots]$ жизнь с трудом из-за куска хлеба.“ ([...] nachdem sie im Kampf mit den feindlichen Lebensumstănden eine Niederlage erlitten haben, sind die Helden Šellers zu dem folgenden bitteren Schluß gekommen, [...]: „Wir sind vom Schauplatz abgetreten, $[\ldots]$ um [...] das Leben um ein Stück Brot zu beginnen." $)^{\text {s47 }}$

Skabičvskij bezeichnet die Personen Šellers im Ganzen als „положительные типы, идеальные светлые личности" (positive Typen, ideale lichte Persönlichkeiten) ${ }^{548}$. Offensichtlich ist der in der frühen Prosa Cechovs des Ófteren vorkommende ironische Ausdruck „svetlaja liznost'“ (der durch die Spielhagen-Intertextualität indirekt auch mit ,Zagadočnaja natura" verbunden ist ${ }^{549}$ ) nicht ..erfunden“, sondern stellt eine Allusion auf die Texte des genannten literaturideologischen Diskurses dar, wăhrend sich dieser Ausdruck in das Vorwort Skabičevskijs, das - wenn auch etwa zwei Jahrzehnte später geschrieben, als die Cechovsche Parodie, - ein Teil des betreffenden Diskurses gewesen ist, stilistisch reibungslos integrieren läßt. Wie aus dem Zitierten ersichtlich ist, bezieht sich Cechov parodistisch nicht nur auf inhaltliche Aspekte der typischen Biographie der ,idealen, lichten Persönlichkeit“" des raznocinec wie die Geburt in einer armen Familie. Selbsterziehung und -begrenzung, außerste Bescheidenheit im Alltag, harte Arbeit, Konflikt mit der Umgebung, Kampf mit den unfreundlichen Lebensumstånden und eine stolze Verbitterung. Cechov war auch gegenüber der in der russischen Literatur(kritik) der Zeit weit verbreiteten Phraseologie (deren spătes Bei-

\footnotetext{
347 Ibid S 28

"48 Ibid S. 31. In Cechovs Drama ..Ivanov" wird ironisch ein Michajlov-Leser L'vov dargestellt Cechov charakterisien diese Figur im Brief an A S Suvorin folgendermaßen ... I nepexожу к доктору Львову Это тип честного. прямого. горячего. но узкого и прямолинейного человека Про таких умные люди говорят: 'Он глуп, но в нем есть честное чувство' [ . ] Это олицетворенный шаблон. ходячая тенденция [. ] Кто кричит 'Дорогу честному труду". на того он молится. кто же не кричит этого. тот подлец " кулак. Середины нет Он воспитался на романах Михайлова [ ] " ([ ] ich gehe zu Doktor L'vov uber. Das ist der Typ eines ehrlichen, aufrichtigen, hitzigen, aber eines engstirnigen und gradlinigen Menschen Von solchen Menschen sagt man. ..Er ist dumm. aber zu einem ehrlichen Gefuhl fahig " [ ] Das ist eine Schablone in Person, eine wandelnde Tendenz [ .] Wer ...Macht fur die ehrliche Arbeit den Wey frei'” schreit. den betet er an. der das aber nicht schreit, ist ein Schurke und ein Kulak Er kennt keine Mitte Er ist mit den Romanen von Michajlov groß geworden [ ]) (Pis'ma 3. 112 (Briefe 3. 112))
} 
spiel auch der Text Skabicevskijs ist) sensibel, die er in ,Zagadočnaja natura“ verspottet ${ }^{550}$ : Schablonen wie „борьба за кусок хлеба“ (Kampf um ein Stūck Brot), „пробивать себе путь“ (sich den Weg bahnen), „уродливое воспитание“ (abscheuliche Erziehung), „ошибки молодости“ (Fehler der Jugend), „борьба со средой“ (Kampf mit dem Milieu), „я жаждала быть человеком“ (ich sehnte mich danach, Mensch zu sein), „делать добро“ (Gutes tun), „низменно-пошлы“ (niedertrăchtig-platt), „носительница идеалов“ (Trăgerin der Ideale ${ }^{551}$ ) u.s.w. prăgen das stilistische Bild der Beichte in der Kurzgeschichte und harmonieren zugleich durchaus mit dem Stil des narodniks Skabicevskij. ${ }^{552}$ Einen wichtigen Impuls zum stilistischen Parodieren gab Cechov zweifelsohne gerade der hohe Abnutzungsgrad solcher Wendungen, die in den 1880er Jahren ihre Kraft und Wirkung eingebüßt hatten: „Словесные формулы 'либерального', 'прогрессивного' образа мыслей, в большинстве своем унаследованных от эпохи 60-х годов, ко времени Чехова превратились в застывшие и расхожие стилистические стереотипы.“ (Die Wortformeln der ,liberalen“, „progressiven“ Denkweise, die zum großten Teil von der Epoche der 60er Jahre geerbt wurden, sind zur Cechovs Zeit zu stehenden und gangigen stilistischen Stereotypen geworden. “4 ${ }^{553}$. So erfüllen die stilistischen Qualităten der alludierten Texte die wichtigen Motivationskriterien für die parodistische Nachbildung: bei dieser wird das Wiedererkennbare, ja das Vorhersagbare aufgegriffen.

Noch ein weiterer Text, den der junge Cechov gut kannte, kann als Vorlage fur die Parodie "Zagadočnaja natura“ betrachtet werden. Gemeint ist das Stūck „Unsere Sclaven“ von Leopold Sacher-Masoch (russische Übersetzung unter dem Titel „Raby i vladyki“ („Рабы и владыки“, „Sklaven und Herrscher“), S.-Petersburg $1876^{554}$ ), genauer gesagt, eine seiner Szenen. Daß Cechov ungefăhr in der Zeit der Abfassung von "Zagadoxnaja natura" mit diesem Text beschäftigt war, deutet sein Brief an Al. P. Cechov vom 17/18 April 1883 an, geschrieben also etwa einen Monat, nachdem die Kurzgeschichte veroffentlicht wurde. ${ }^{\text {ss }}$ In diesem Brief erzăhlt er von seinem Wunsch, eine Untersuchung zur „Geschichte der Geschlechtsautorität“" zu schreiben und dadurch eine wissenschaftliche Basis für die Diskussion über die Frauenemanzipation zu schaffen (aufgrund naturwissenschaftlicher Beobachtungen versucht Cechov zu beweisen, daß die Gleichheit der Geschlechter von der Natur gegeben und vorausgesetzt ist). Dabei bezieht er sich u.a. auf das genannte Stūck Sacher-Masochs: ..Мысль

\footnotetext{
$599 \mathrm{Vgl}$. S. 100 dieser Arbeit

${ }^{350} \mathrm{~S}$. dazu (auch folgende Beispiele) in unserem Aufsatz (Smola 1996. S. 46)

351 S. die meisten ubersetzien Ausdrucke bei Tschechow Bd. I (1949), S. 120-121

352 Auch die Romane Friedrich Spielhagens, sei hier bemerkt. genossen unter Narodniki eine große Popularitat $\mathrm{Vgl}$ bei Lauer. ..Von den deutschen Erzahlern war in RuBland namentlich Friedrich Spielhagen bekannt Dank ihres kampferischen Freiheitspathos erfreuten sich seine Romane besonderer Beliebtheit in den Kreisen der Narodniki “ (2000, S. 329)

${ }^{353}$ Kataev 1979. S 169 Als Beispiel solcher Klischees nennt Kataev u a gerade Wone der Dame aus. Zagadocnaja natura“" (s. S 168) Vgl auch bei Hielscher .. I ] die großen Ideen der sogenannten "Sechziger" "waren"..zu epigonalem ideologischen Geschwatz verkommen" (1987, S. 19)

"1.4 S Cechov. Pis'ma I. 345-346
} 
Захер-Мазоха: среди крестянства авторитет не так резко очевиден, как среди высшего и среднего сословий. У крестьян: одинаковое развитие, одинаковый труд и т.д.“ (Der Gedanke von Sacher-Masoch: unter den Bauern ist die Autorität nicht so offensichtlich, wie in der Mittel- und Oberschicht. Bei den Bauern: die gleiche Entwicklung, die gleiche Arbeit u.s.w.) (Pis'ma, 1, 66 (Briefe, 1, 66)). In „Unseren Sclaven“ spricht diesen Gedanken Baronin Faustina Lövenberg, eine Kämpferin für die Frauenemanzipation und Gleichberechtigung aus. 556

In ,Zagadočnaja natura“ wird das Gesprăch zwischen Faustina und Paul parodiert, in dem es jener gelingt, ihren Gesprächspartner zu beeindrucken und zu überzeugen: Er beginnt an die Zukunft der Frauen zu glauben. In dieses Gespräch ist auch die selbsterzählte Biographie von Faustina eingebaut. Faustina, die - zumindest in einzelnen Punkten - ein Sprachrohr der auktorialen Ideen darstellt, plädiert für bessere Bildungs- und Arbeitschancen für ihre Geschlechtsgenossen, worauf Paul fragt: „Как дошли вы, баронесса, до этих суждений? Вы, свободная знатная женщина, которой все поклоняются?“" (Wie sind Sie, [Baronesse,] zu diesen Ideen gekommen, Sie, die reiche, angebetete Frau? $\left.{ }^{557}\right) .{ }^{558}$ Die Baronin antwortet: „Своей судьбой“ (Durch mein Schicksal ${ }^{559}$ ). Danach folgt ihre „Autobiographie“, die neben auffalligen Gegensătzen auch erstaunliche Übereinstimmungen mit der der Cechovschen Dame enthălt - inhaltliche und teilweise sprachliche Bezüge Cechovs zu dem Referenztext. „Так выслушайте меня. Я - дочь дворянина, и, как все аристократки, была плохо воспитана." (Hören Sie mich an. [Ich bin Tochter eines Adeligen.] ${ }^{5(x)}$ Wie alle aristokratischen Mådchen wurde ich herzlich schlecht erzogen. $\left.{ }^{561}\right)$ (Vgl.: „- Слушайте. Родилась я в бедной чиновничьей семье. [...] Уродливое институтское воспитание, [...]... (.,.'So hören Sie denn. [So hơren Sie.] Ich stamme aus einer armen Beamtenfamilie. [...] Die abscheuliche Erziehung im Institut, $\left.\left.[\ldots] \ldots[\ldots]^{\text {\%.362 }}\right)(2,90-91)\right)$. „Мне нашли блестящую партию генерала, человека вдвое старше меня; я не долго колебалась и приняла сделанное мне предложение." (Man fand für mich eine glänzende Partie, einen General mit grauem Haare, [einen General, den Menschen, der doppelt so alt war wie ich, ich zweifelte nicht lange und nahm seinen Antrag an. $]^{563}$ ) (Čechov: „- [...] Н вот... подвернулся на моём пути богатый старик-генерал...” $\left.(2,91)^{\text {s.w }}\right)$. .Свет, как мне казалось, создан единственно для

\footnotetext{
sss So wollen wir vermuten. daß Cechov das Werk Sacher-Masochs noch bevor er die Kurzyeschichte im Marz verfaßt hat, bekannt war

":6 $S$ daruber auch in den Anmerkungen zu ..Ariadna" in der Cechovs Gesamtausgabe $(9,476)$

557 Sacher-Masoch 1873, S 17

$\$ \$$ Zitate $s$ in Zacher-Mazoch 1876, S 22-23

3s9 Sacher-Masoch 1873, S 17

360 In eckigen Klammem haben wir hier diejenigen Stellen aus dem russischen Text ins Deutsche ubersetzt, die im deutschen Original fehlen. Demzufolge war Cechov eine etwas veranderte und manchmal erganzte Variante des Stücks bekannt

\$61 Sacher-Masoch 1873, S 17

${ }^{62}$ Tschechow Bd 1 (1949). S 120 S Ubers teilweise auf $S 94$ dieser Arbeit

s.3.3 Sacher-Masoch 1873. S 17

stet S Übers auf S. 96 dieser Arbeit
} 
удовольствий. У меня был великолепный дом, [...] плечи мои покрывались бриллиантами." ([Die Welt ist, wie ich dachte, allein für das Vergnügen geschaffen.] [...] Ich hatte einen Palast [...] und meine Schultern bedeckte der Hermelin einer Fürstin. ${ }^{565}$ ) (Čechov: „- [...] Мне нужна была слава... шум, блеск, [...].“ $(2,91)) ;$, ,..] подобная жнзнь начала тяготить меня, я стала скучать“ ([...] kam die Erkenntnis über mich, wie schwer das Leben ist, [ich habe begonnen, mich zu langweilen.] $\left.{ }^{566}\right)$ („- [...] Ведь это было самопожертвование, $[\ldots]$ ! [...] А как я страдала, $\left.[\ldots] . “(2,91)^{567}\right)$. Spătestens ab diesem Moment beginnt jedoch die parodistische Diskrepanz zwischen den beiden Texten: „[...] мне, - я видела это ясно - для того, чтобы развлечь себя, оставалось одно - изменить моему мужу. Вместо того, чтобы [...] заняться каким-нибудь гусаром или кавалергардом, я занялась Вольтером, Ге́те, Рубенсом, Бетховеном. Начала читать, учиться, работать.“ ([...] Meinem Manne mußte ich, [um mich abzulenken.] untreu werden, das war mir bald klar, aber statt mit einem Husar oder Maler $^{568}$ wurde ich es mit [Voltaire,] Goethe, Rubens, Beethoven. Ich begann [zu lesen], zu lemen, zu arbeiten. ${ }^{569}$ ) (Čechov: „- [...] Но меня подкрепляла мысль, что старик не сегодня-завтра умрёт, что я [...] отдамся любимому человеку, [...]... А у меня есть такой человек, Вольдемар! Видит 6ог, есть!“ („,[...] Und nur der Gedanke hielt mich aufrecht, daß der Greis jeden Tag sterben könnte und daß ich [...] mich dann dem Geliebten hingeben [...] konnte... Und es gibt einen solchen Menschen, Wolodja (Waldemar]! Gott sieht es, es gibt ihn!«s770) $(2,91)$ ). Und weiter bei Sacher-Masoch: „Когда мой муж пал в последней войне, я осталась свободной, молодой, богатой вдовой; во мне заискивали, но я отвернулась от общества, которое я ненавндела от всей глубины моей души. Цепи мои во время моего замужества я носила молча и честно, но поклялась новых больше не надевать. Я начала жизнь по-своему, [...]. Я весела, счастлива, [...].“ (Als mein General in dem letzten Kriege fiel, stand ich frei, jung und reich, von allen Seiten begehrt, einer Gesellschaft gegenüber, die ich aus dem Grunde meines Herzens verachtete. [Die Ketten meiner Ehe trug ich schweigend und ehrlich, aber ich habe geschworen, mir keine neuen anzulegen.] lch begann mein Leben nach meinen Ideen einzurichten - [..] und mein Herz ist heiter. [...]. ${ }^{571}$ ) (Čechov: ..- [...] Сколько мук! [...] Другой богатый старик...” $(2,92))$. Wăhrend also Faustina ihrem ungeliebten Mann treu bleibt, nach seinem Tod aber „,die Fehler der Jugend“ behebt, indem sie sich auf den Weg der Emanzipation begibt, verhălt es sich bei der Dame Cechovs umgekehrt: sie hat offenbar einen Liebha-

\footnotetext{
365 Sacher-Masoch 1873, S 17.

360 lbid

$\$ 67 \mathrm{~S}$ Ubers auf S 94 dieser Arbeit.

\$6: In der russischen Ubersetzung von Kameev steht jedoch statt ..Maler"..Chevaliergardist" Im allgemeinen weicht seine Ubertragung, wie der Vergleich beider Texte ergibt, an mehreren Stellen leicht vom Original ab \$69 Sacher-Masoch 1873, S 17-18

570 Tschechow Bd 1 (1949), S 121. S. Ubers teilweise auf S. 96 dieser Arbeit

571 Sacher-Masoch 1873, S 18
} 
ber und heiratet als Witwe einen anderen reichen Greis. Wăhrend es sich bei Masoch um eine Entwicklung handelt, stellt Cechov eine üble Wiederholung dar.

Es lăßt sich vermuten, daß Cechov, während ihm die Idee der natürlichen Geschlechtsgleichheit imponierte und er folglich die von Faustina verteidigte Frauenemanzipation unterstützt hat ${ }^{572}$, gleichzeitig sofort auf die unverborgene Didaktik der evozierten Szene aufmerksam wurde und sie in .Zagadočnaja natura" verspottet hat. Zur Zielscheibe seines Spottes konnte hier darüber hinaus der Mißbrauch dieser Idee werden, die in manchen Fällen oberflächlich als Mode aufgenommen, als modern stilisiertes und von der Wirklichkeit abweichendes Sprechen (vgl. das naive und das eigene Geschlecht im Grunde demütigende „- [...] Я жаждала чего-то необыкновенного...не женского!.473), „realisiert“" wurde. In der oben erwăhnten Kurzgeschichte "Svetlaja lix̌nost'”, die mit "Zagadoðnaja natura“ u.a. durch Verweise auf Spielhagen, aber auch durch ihr Thema „verwandt“ ist, wird ebenfalls eine „emanzipierte" Frau verspottet, die sich am Ende als nicht emanzipiert, sondern habgierig erweist. Ihr verblendeter Nachbar - der Beobachter - schwärmt: „- Чудное, редкое создание! Последнее слово женской змансипации! [...] Ей доступна гражданская скорбь!“ („Еin wunderbares, seltenes Geschōp? Das letzte Wort der Frauenemanzipation! [...] Ihr ist Ziviltrauer zugänglich! [... $\left.]^{\prime \prime}\right)(5,310)$.

In ,Zagadoznaja natura" parodiert Cechov v.a. eine verkehrte Rezeption, einen Mißbrauch dieser in der Literatur propagierten Idee, eines damals aktiv debattierten gesellschaftlichen Problems durch die Kleinbürger(Innen), bezieht sich dabei spielerisch auf eine fiktive „Vorbildfigur“, die - wie Doktor L'vov von Cechov (s. oben) - als „chodjačaja tendencija“ bezeichnet werden kann. ${ }^{574}$ Damit zielt er einerseits auf das naiv-didaktische literarische Werk Sacher-Masochs „Unsere Sclaven“, andererseits auf ein außerliterarisches Phänomen, nämlich den Mißbrauch der Frauenemanzipationsidee als Mode und Spiel.

\subsection{Kontrafakturen}

Während die Kurzgeschichte „Zagadoznaja natura“ die ihr zugrunde liegenden Fremdtexte bzw. ihre Rezeption zum Objekt des herabsetzenden Komisierens macht, sie verspottet und sich dadurch vor allem zum Ziel setzt, eine bestimmte Aussage über sie zu bilden, sie mittels gewisser Transformationen zu bewerten, behandeln die Hypertexte, die wir im vorliegenden

\footnotetext{
$\$ 72$ Eine ironische Haltung Cechovs gegenuber den Autoren, die eine .natüliche“ Unterlegenheit der Frau gegenuber dem Mann beweisen wollten, ..Belege“ dafur sammelten und publizierten. ist bekannt und kommt z B in der gleichnamigen Parodie auf K Skal 'kovskijs Buch ..O żenscinach" (1886) zum Ausdruck (s in den Anmerkungen zum Text $(5,627-628))$

$\$ 73 \mathrm{~S}$ Ubers auf $\mathrm{S} .92$ dieser Arbeit

374 Obwohl Faustina im Finale des Stucks den Wunsch außen. Sklavin von Paul, in den sie sich verliebt. zu werden. soll dies unserer Meinung nach vor allem den Charakter der Liebesempfindung der Heldin zum Ausdruck bringen Das destruien also kaum ihre oben zitienten Ideen und ihre Haltung, nicht zufallig wird sie von Paul dafur bis zum Schluß bewunder
} 
Kapitel untersuchen wollen, ihre Folien andersartig. Sie stellen zwar ein Um- und Widerschreiben der entsprechenden Fremdwerke dar, heben sich aber von den herkommlichen parodistischen Ableitungen, die beim frühen Cechov am hăufigsten vorkommen, dadurch ab, daß sie im allgemeinen keine Herabsetzung und folglich keine spöttische Kritik dieser Werke beinhalten. Im Kontext des frühen Schaffens von Cechov, in dem die Literatur üblicherweise in Frage gestellt, ja abgelehnt wird, zu ihr am hăufigsten eine ironische Distanz genommen wird, konnen solche ,zweitgradigen“ Texte als Ausnahme angesehen werden. Sie sind als Teil des literarischen Experimentierens des jungen Autors zu begreifen, der Fremdwerke, ohne sie zu parodieren und d.h. anzugreifen, variiert und umgedacht, sie in einen anderen z.B. moderne(re)n und aktuellen - Kontext versetzt oder ihnen eine überraschende Sujetwende verliehen hat. Wir bezeichnen Ableitungen dieser Art bei Cechov als Kontrafakturen und betrachten sie demzufolge im Gegensatz zu Parodien.

Bei der Begriffsfestlegung der Kontrafaktur stützen wir uns in erster Linie auf den im Kapitel 2.1.2. vorgestellten Ansatz Verweyens und Wittings, in dessen Rahmen sich dieser Texttyp zusammen mit den Adaptionsformen wie Palinodie und Kontradiktio von der Parodie dadurch unterscheidet, daß er das „Ethos und Pathos der Vorlage unangetastet“ laß $\mathrm{t}^{575}$. Wenn wir unser Augenmerk speziell auf die Texte Cechovs lenken, die wir Kontrafakturen nennen, bedeutet das jedoch nicht, daß ihnen Negienungszwecke fremd sind: Wie die Parodie gehort sie zu den literarischen Schreibweisen, in denen das eigene und das fremde Wort aneinander geraten, entgegengesetzt sind (s. Bachtins Differenzienung der, zweistimmigen Worter ${ }^{4576}$ ). Negiert werden hier die Bezugstexte jedoch nicht wie in den meisten Parodien Cechovs im Sinne einer Ablehnung, Verspottung. Angriffs, sondem im Sinne einer Umschreibung, Variation. Anpassung (den anderen Umständen). In der Auslegung dieser allgemeinen Textfunktion knüpfen wir an die Beiträge von Verweyen und Witting an. Kontrafaktur Cechovs verzichtet auf bestimmte Strategien des Originals (und, so gesehen, negiert sie), weil sie auf ihrer Basis eine neue, eigene Aussage machen will. Die Gattung der Kontrafaktur zeichnet sich vor allem gerade dadurch aus, daB sie das ...kommunikative Potential" und die .Produktionsstrategien“ anderer Texte ausnützt, um mit ihrer Hilfe und in ihrem .Ko-Text“ .die eigene Botschaft“ zu artikulieren. ${ }^{57}$ So kann z.B. die ,historische Situierung und Perspektivierung“" eines Prätextes zur Aufgabe der Kontrafaktur werden. ${ }^{578}$

Angesichts der Analyse Cechovscher Kontrafakturen ist für uns die Bemerkung dieser Theoretiker von Bedeutung, daß die vorgebrachte Definition den humoristischen und sogar satirischen Charakter dieses Ableitungstyps nicht ausschließt: nur wird das Original in diesem Fall nicht zum Objekt, sondern zum ..Medium“ der auf bestimmte außerliterarische Bereiche

\footnotetext{
375 Vgl S 39 dieser Arbeit

$376 \mathrm{Vgl} S 16$ dieser Arbeit.

$37 \mathrm{~S}$ mederum auf $\mathrm{S} 39$ dieser Arbeit.

${ }^{377}$ In den beiden Kontrafakturen Cechovs - .Torzestvo pobeditelja" und ..Silo v meske" - konnte man eine .besondere Negationsform" sehen. ..die das Bedauern uber die Notwendigheit des Negierens einschlieBt" (s. Verweyen und Witting 1982. S. 218 - uber den Text von J. G Seume)
} 
bezogenen Kritik. Der Kontrafaktur wohnt, anders als der Parodie, eine „eigene Äußerungsabsicht" inne, sie konzentriert sich also nicht darauf, zum Referenztext Stellung zu nehmen.

Die Komik der Kontrafakturen Cechovs ergibt sich zwar mitunter aus der Gegenüberstellung des manifesten mit dem alludierten Text, gegebenenfalls aus der schlichten Unvergleichbarkeit der beiden, wie in „Toržestvo pobeditelja“ ${ }^{479}$ (und hier erweitern wir den Begriff „Kontrafaktur“ im Vergleich zu Verweyen und Witting, wir beziehen ihn auf Texte, die sich von den Kontrafakturen im Beitrag der beiden Autoren deutlich abheben), sie entsteht aber, unserer Meinung nach, nicht infolge der komisierenden Herabwürdigung des einen (oder seiner Rezeption) durch den anderen. Und wenn das aktuelle Werk auch eine deutliche Prosaisierung/,Entpoetisierung“ der Vorlage impliziert, ist das „kein Akt intendierter Beschădigung des Originals, das heißt nicht das Resultat gezielter Einschränkung seines Anspruches“, sondern ,eine [...] Folge der Benutzung des hochpoetischen Vorbildtextes für die Artikulation [...] des eigenen Anliegens ${ }^{.580}$ (wie es auch hier im weiter zu analysierenden „Toržestvo pobeditelja“ der Fall ist).

In unserer Arbeit haben wir u.a. insofem eine gewisse Erweiterung des Kontrafakturbegriffes bei Verweyen und Witting unternommen, als wir ihn erstens auf Prosatexte beziehen, während die genannten Forscher ausschließlich (dem ursprünglichen Anwendungsbereich des Begriffs nah ${ }^{581}$ ) Gedichte als Beispiele der betreffenden Ableitungsform nennen. ${ }^{582}$ Dennoch scheint uns diese Erweiterung gerechtfertigt zu sein, denn auch in bezug auf Prosa behält dieser Begriff, wie er von Verweyen und Witting festgelegt wird, seinen Inhalt und seine Applikationsmoglichkeiten. So wie es sich bei den lyrischen Kontrafakturen im genannten Beitrag um eine Reihe von formalen Äquivalenzen (z.B. „die Zahl der Strophen und Verse“, „versifikatorische Behandlung der Einzelzeile“, Lexik und „das syntaktische Grundmuster“.58i $)$ zwischen Prä- und dem Posttext und vor allem um die im Posttext erkennbare Absicht, mit der Hilfe der im Prätext vorhandenen Strategien eine etgene Äußerung zur (jeltung zu bringen, handelt, so ist dies auch bis =u einem gewissen (irade in den heranzuziehenden Prosatexten Cechovs der Fall. Es geht dabei beispielsweise um die Úbernahme bestimmter Sujetelemente wie fiktiver Situationen, der Personenkonstellation, des Handlungsablaufs u.a. ${ }^{\text {s*d }}$ In diesem Sinne trifft die von Verweyen und Witting vorgeschlagene Auslegung der Kontrafaktur unseres Erachtens in mehreren Punkten auf einige Hypertexte Cechovs zu, die bisher als nicht-parodistische Hypertexte nicht untersucht worden sind.

Wir müssen hier jedoch ebenfalls anmerken, daß unsere Verwendung des Begriffs .Kontrafaktur" sich von der in den Beiträgen von Verweyen und Witting in vielen wichtigen

\footnotetext{
${ }^{379}$ Diese Kurzgeschichte haben wir als Kontrafaktur (in Anlehnung an Verweyen und Witting) in unserem Aufsatz (Smola 2001. S. 102) bezeichnet. ohne dies allerdings zu erlautern

s*0 Verweyen/Witting 1987, S 100

(x) Vyl S 39 dieser Arbeit

$\$ \$ 2$ S z B Verweyen und Witting 1982

38. Ibid S 216

${ }^{484} \mathrm{Vgl}$ Z.B uber die Kontrafaktur in der Prosa Puškins bei Schmid 1983. 1991 (s. S 117 dieser Arbeit)
} 
Punkten unterscheidet: wăhrend die Kontrafaktur bei Verweyen und Witting formal (lexikalisch, stilistisch u.s.w.) sehr eng mit der Vorlage verbunden sein muß, sie in vielem formal wiedergibt, bezeichnen wir als Kontrafakturen u.a. Cechovsche Texte, die nur bestimmte strukturellen Eigenschaften des Prătextes übernehmen, stofflich und stilistisch aber mit ihm nicht verknüpft sind (wie in „Toržestvo pobeditelja“). So sind, technisch gesehen, die Kontrafakturen bei Verweyen und Witting mit denen wie "Toržestvo pobeditelja“ und aber auch wie „Silo $v$ meske“ nicht zu vergleichen, obwohl es bei Cechov auch um eine Anpassung eines Konflikts oder eines Themas im breiten Sinne an die modernen Umstănde und an moderne Realităt geht. Texte Cechovs, die wir in gewisser Anlehnung an die Beitrăge von Verweyen und Witting als Kontrafakturen betrachten (v.a. nach spezifischer Einstellung solcher Texte zum Original), sind also in mehreren Hinsichten nicht so eng mit der Vorlage verknüpft, wie die Kontrafakturen bei diesen Autoren einerseits - und Parodien bei Cechov andererseits. ${ }^{585}$ Darüber hinaus schließen Cechovsche Kontrafakturen für uns das Spielerische, Humoristische und Experimentelle gegenüber dem Prätext nicht aus - wenn sie ihn auch für ihr eigenes Anliegen ,ausnützen“ und nicht verspotten - und so passen sie in den Kontext des früheren Schaffens von Cechonte.

Man kann deshalb von einer durchaus freien Verwendung des Begriffs "Kontrafaktur" wie er bei Verweyen und Witting festgelegt wird - in unserer Arbeit sprechen.

Im Übrigen sei bemerkt, daß der Begriff "Kontrafaktur“ bereits auf ein Prosastück Cechovs angewandt wurde. W. Koschmal betrachtet die Novelle „Nevesta“ (Die Braut) als Kontrafaktur zur folkloristischen Gattung des ,pricitanie“ (Klage ${ }^{586}$ ), wobei er diese Art literarischer Ableitung, ohne sie theoretisch zu erörtem, als ernste (sprich: nicht-parodistische) Widerlegung, als „oppositive Transformation“, ja Destruktion des bekannten Musters im Cechovschen Werk deutet. ${ }^{587}$ Der ..Nevesta“ legt Cechov, nach Koschmal, bestimmte Topoi des .,pricitanie“ zugrunde, nimmt sie in der Erzăhlung wiederholt auf, um sie letzten Endes zu destruieren und die Erzählung als eine Abweichung von dem "vorgegebenen“ Schema zu gestalten (v.a. dadurch, daß er der ..fiktiven Ablehnung der Hochzeit” in pričitanie „die tatsächliche entgegenstellt" und so ..die traditionelle Ausweglosigkeit der Lage für die Braut" verneint). Diese Interpretation der Kontrafakturgattung widerspricht, wie wir meinen, in manchen entscheidenden Aspekten der von Verweyen und Witting, da die Novelle ..Nevesta“ in Koschmals Untersuchung, anders, als es für die oben bezeichneten ..kontrafaktischen“ Textverarbeitungsstrategien angenommen wird, das .Ethos und Pathos“ des folkloristischen Musters antastet, d.h. ablehnt. Sowohl Verweyen und Witting als auch Koschmal grenzen die

\footnotetext{
38s Eine solche wichtige Abweichung unserer Anwendung des Begriffs von der bei Verweven und Witting ist am folgenden Beispiel zu markieren namlich an ihrer Abgrenzung der Kontrafaktur von der "Imitatio“ In bezuy auf die letztere schreiben sie. .Es entsteht so eine Ahnlichkeitsbeziehung zuischen Vorlage und Nachahmung. die im abstrakteren Bereich strukturaler, das heißt hier grammatischer Aquivalenzen, nicht aber im konkreten Bereich augenfallig-ahnlicher Ubereinstimmungen liegt " (1987, S. 68)

sos S bei Koschmal 1988, S 155

\$87 In: Koschmal 1988
} 
Kontrafaktur von der Parodie ab; der Gegensatz „Parodie - Kontrafaktur“ ist für die ersten mit der Opposition „die Folie (spöttisch, ironisch) angreifen/ herabsetzen/ „hinunternummerieren“ - „die Folie für eigene Zwecke ausnützen“, für den letzten mit der Opposition „,ironische, spottische (oberflächliche) - „ernste (synthetische ${ }^{588}$ ) Destruktion der Folie" gleichzusetzen. Bei einer gewissen Schnittmenge (die sich v.a. auf das Verständnis der Parodie fokussiert) ist hier die grundlegende Differenz in der Auffassung der Kontrafaktur, wie es uns scheint, nicht zu leugnen. ${ }^{589}$

Angesichts der bevorstehenden Analyse der Cechovschen Kontrafakturen scheint es uns hier wichtig, zu prazzisieren, in welchem Punkt unsere Inanspruchnahme des Begriffs ..Kontrafaktur" bei gewisser Affinität zum Konzept Verweyens und Wittings sich gleichzeitig auch auf das Verstăndnis Koschmals stützt. Wir heben, wie oben skizzient, in erster Linie auf die Auffassung von Verweyen und Witting ab, Kontrafaktur bezwecke keine „intendiente 'Beschädigung' des Originals“ ${ }^{490}$ und geht gegen dieses Original insofern nicht vor ${ }^{591}$, dennoch schließen wir in dieses Konzept auch die Texte ein, die ihre Folie inversiv bearbeiten, d.h. die, ohne eine negative Aussage über sie zu bilden und ohne sie direkt herabsetzend zu komisieren und z.B. mit dem Ziel, deren eigene Version zu schaffen, den Prătext .,auf den Kopf stellen “592, um- und widerschreiben (was insbesondere auf „Šilo v meške“ zutriff). Damit nühern wir uns jenen Punkten der Analyse Koschmals an, die gerade die Widerschreıben-Strategien von "Nevesta". ihren folgenreıchen Verzicht auf markante Verfahren des Prätextes demonstrieren. Damı gewinnt die Bezeichnung „Kontra-faktur" auch ihre wörtliche Bedeulung als „Gegen-" und ,. Wider-schreiben ${ }^{.593}$ (was jedech auch in den Kontrafakı uren hei Verweyen und Witıng der (Fall ıst). Während aber der Zweck entsprechender Transformationen in „Nevesta“ bei Koschmal darin besteht, die Vorlage .,anzugreifen“, ihr „Ethos und Pathos" zu überwinden und ihr also das Bessere entgegenzusetzen (in diesem Sinne enthält die Novelle auch die Kritik des in der Vorlage zum Ausdruck gebrachten Weltmodells), verhält es sich in den Texten Cechovs, die wir als Kontrafakturen bezeichnen, anders. Die Umdichtung der literarischen Werke wird in ihnen ohne deren humoristische Herabwurdigung (Differenzkriterium zu der Parodie), aber auch shne deren ernsve Krrlsk und Ablehnung (Difierenzkriterium zur Vorgehensiveise Cechovs in ..Nevesta“) vollzogen. Sie ist vielmehr mit den von

\footnotetext{
"sx So wird dieselbe Volksgattuny in ..Tat 'jana Repina". nach Koschmal, parodien. hier kommt es jedoch ..zu keiner poetischen Synthese zwischen Folie und Text der Erzahlung bzw des Dramas wie in "Nevesta" (1988. S 155)

(x) In manchen Kontrafakturen ist jedoch nach Verweven und Witting ein Konkurrenzverhaltnis zur Folie prasent. su daß die Absicht zum Ausdruck kommt. die letzte zu "verdrangen“" (s 1987. S 115-125) Es yeht in diesem Fall um einen ..konkurnerenden Wertstandpunkt und Wertsystem" (ibid. S 119) Solche Kuntrafakturen mahern sich von ihrer Intention her durchaus der Kontrafaktur an. wie sie Koschmal und Schinid (s weiter) ver stehen

$\$ 90$ Verweyen Witting 1987. S 100

(") abyesehen von den Kontrafahturen in ihrem Beitrag. die wir in der Fußn 58") enwahnt haben

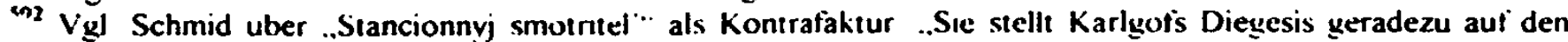
Kopf oder stellt ihr eine spiegelbildliche t:mkehrung entyegen * (1983. S 107)

"9:" $\mathrm{Vgl}$ den Ausdruck...Gegen-Schrift" in bezug u a auf die Kontrafaktur beil I achmann 1990. S 57
} 
Verweyen und Witting beschriebenen Absichten, von einem Fremdwerk eine eigene Äußerung abzuleiten, zu verknupfen.

Auch W. Schmid bezeichnet z.B. die Novelle Puskins, ,Stancionnyj smotritel'“ als Kontrafaktur solcher "sentimentalistischen“ Texte wie „Bednaja Liza“ Karamzins und ,.Stancionnyj smotritel" Karlgofs. Kontrafaktur bedeutet in diesem Fall eine „ironische Kritik“, eine ,nüchterne“ „Korrektur" der Folien. ${ }^{594}$ Schmid grenzt Kontrafaktur ebenfalls von der Parodie ab:

Von der rückwărtsgewandten Parodie, die destruier, unterscheidet sich diese Form durch die neue Konstruktion psychologisch plausiblerer Handlungsmodelle, [...]. Natürlich deckt die Kontrafaktur die „Ungereimtheiten“ (бессмыслицы) des Prătextes auf und drückt auch eine metapoetische Kritik am falschen Weltmodell des Vorgångertextes aus, aber anders, als in der bloßen Parodie wird konstruktiv ein neues Bild von Charakteren und Handlungen entworfen. 595

Wir folgen dem Kontrafakturkonzept von Schmid insofern, als auch fur uns in den Kontrafakturen Cechovs auf Basis alterer Texte eine eigene Aussage (vgl. Verweyen und Witting) und eine der Folie gegenüber alternative Handlung prasentiert wird. Diese Tatsache bildet also auch in unserer Arbeit ein wichtiges Kriterium bei der Unterscheidung der Parodie von der Kontrafaktur: Die Opposition „Parodie - Kontrafaktur" kommt für Schmid der Opposition "destruktiv - konstruktiv“" gleich, und in diesem Punkt stützen wir uns auf seine Interpretation. Wir heben uns von Schmid und seinem Verständnis der Kontrafaktur - ăhnlich wie von dem Koschmals - jedoch dadurch ab, daB die Kontrafakturen Cechovs fur uns keine Kritik (ob eine ironische oder emste) der Vorlage(n) enthalten, keine intendierte Überwindung deren .Weltmodells“. Intertextualitat, wie sie bei Koschmal und Schmid in bezug auf die Kontrafaktur gedeutet wird. kommt erst in der spät(er)en Prosa Cechovs vor. Beim früh(er)en Cechov ăußert sich eine kritische Einstellung zur Literatur vorwiegend parodistisch. Und in seinen frühen Texten. die wir als Kontrafakturen bezeichnen, geht es weniger um eine Kritik, sondem höchstens um eine spielerische Korrektur im Sinne eines literarischen Experiments (aber nicht - trotz der Ähnlichkeit der Bezeichnung - um die ,ironische Korrektur“ wie bei Puškin im Beitrag von Schmid).

Wir wollen an dieser Stelle deshalb erneut betonen, daß literarische Ableitungen (Texte zweiten Grades), deren Erscheinungsformen eine bejahende Nachahmung wie in .Za jablocki“, Parodie, Kontrafaktur oder Pastiche bilden, hier ausschließlich dem frühe(re)n Werk Cechovs, der - im Fall der Parodie oder der Kontrafaktur - mit dem literarischen Erbe

\footnotetext{
\$24 $\mathrm{Vgl}$ Schmid 1991. S. 121-133. Eine .nuchterne“., ,realistische“" Umschreibung der Vorlage findet auch in den Texten Cechovs statt, die wir als Kontrafakturen bezeichnen (s 2 B weiter in . Torzestio pobeditelja") Hier nahern wir der Begriffinterpretation von Schmid an

\$9s lbid S 89
} 
offen experimentiert und gespielt hat, zugeordnet werden, die Novellen wie "Nevesta“ sind aus ihrem Kreis also auszuschließen. Die Kontrafaktur stellt in unserer Sicht auch unter diesem Gesichtspunkt keine im Sinne Koschmals „ernste“ Widerlegung des Bezugstextes (sei es ein Einzeltext oder ein Textsystem) dar. Im Rahmen der spielerischen Poetik des frühen Cechov weigem sich die Texte (es geht v.a. um Kurzgeschichten), die fremde Rede - wie es bei Koschmal in bezug auf eine späte Novelle demonstriert wird - organisch aufzunehmen, zu verinnerlichen, eine Synthese mit ihr zu bilden, um sich von ihr schließlich abzuheben (einen Sonderfall der Synthese mit der Fremdrede, deren bejahenden Nachahmung im frühen Werk Cechovs demonstriert die Kurzgeschichte "Za jablocki“. Das von Koschmal für "Nevesta“ beschriebene intertextuelle Verfahren entspricht bis zu einem gewissen Grade der letzten Bloomschen revisionistischen Geste „Apophrades“, wenn der Dichter sich - nicht zufallig in der letzten Phase seines Schaffens - dem Werk des „Vaters“ offnet und es in sein eigenes einbezieht $^{5 \%}$. In den literarischen Ableitungen der frühen Prosa Cechovs wie Parodien und Kontrafakturen werden die Prătexte dagegen spielerisch zur Schau gestellth sie bleiben nie verborgen, sondern werden meistens demonstrativ umgestülpt. Hier wäre die Distanz unserer Interpretation des Kontrafakturbegriffs zu der von Koschmal zu markieren.

Im Ganzen unterscheiden wir uns also von Genette, wenn wir spăt(er)e Werke Čechovs aus dem Kreis der „Texte zweiten Grades“ grundsätzlich ausschließen; von Koschmal und Schmid, wenn wir auf die spät(er)en Werke (Cechovs) die Bezeichnung ,.Kontrafaktur“ nicht anwenden (und das unabhängig davon, ob Koschmal und Schmid Texte wie ..Nevesta“ oder .,Stancionnyj smotritel”“ als im Sinne Genettes ..abgeleitet“, als „Texte 2. Grades“ betrachten würden) und wenn wir in den Kontrafakturen Cechovs keine Kritik der Vorlage sehen, und von Verweyen und Witting, wenn sie von den Kontrafakturen sprechen, die mit der Folie konkurrieren, sie als „Gegner“ wahmehmen ${ }^{<97}$.

Was die Techniken der „kontrafaktischen“ Textverarbeitung anbelangt, so variieren sie bei Cechov von einer Kurzgeschichte zur anderen und lassen sich nicht zu einer Reihe fester Transformatıonsregeln vereinheitlıchen (was allerdings auch für die Parodien Cechovs, wie im Kap. 3.1. dargestellt, gilt). Man kann jedoch in manchen Punkten eine deutliche Grenze zwischen den typischen Transformationsverfahren, die den Cechovschen Parodien anhaften, und denen, die wir als Kontrafakturen bei ihm bezeichnen, ziehen. So ist z. B. die Form-InhaltDiskrepanz, die aus der (partiellen) Beibehaltung stilistischer Eigenschaften des Originals und gleichzeitig seiner (partiellen) Bedeutungs- und Kontextänderung resultiert (wie das in ..Zagadočnaja natura" der Fall war) - eine klassische Heruhsetzungsstrufegıe beim Parodieren in der Kontrafaktur nicht vorzufinden, wie in ihr auch thematisch-stilistische Brüche nıcht zu finden sind, die wir in den Parodien Cechovs beobachtet haben. Die im folgenden zu analysierenden Texte - Kontrafakturen Cechovs - verfolgen keine stilistische Nachahmung. insofern auch keine stilistische Entstellung der Vorlage, auf denen die parodistische Komik in der

59. Vgl S 23 dieser Arbeit 
Regel beruht. Vielmehr kommt es hier zur Reproduktion bestimmter Strukturen/ Relationen des Prätextes, als zur Übernahme seiner Elemente; viel eher kann hier von einer strukturellen Äquivalenz/Analogie, als von einem regelmäßigen und konsequenten Wiedergeben der Zeichen des Originals bzw. vom Erstellen der Zeichen, die den seinen analog sind (z.B. der in das parodierte Stilsystem passenden sprachlichen Elemente), gesprochen werden (vgl. die Typologien Lachmanns, Pletts, Karrers ${ }^{598}$ ). Kontrafakturen emanzipieren sich deshalb von ihrem Referenztext in einem deutlich größeren Maße als Parodien - nicht nur von der Art der semantischen Beziehung zu ihm (sie bauen eine eigene Aussage auf seiner Basis auf) her, sondern auch der formalen. ${ }^{599}$

Wenn wir auf die im Kapitel 2.1. aufgezăhlten Funktionen der intertextuellen Verweisung zurückkommen, dann würden auf den Fall der Kontrafaktur nicht mehr die „Aufbietung einer Autorităt", sondern eine Erweiterung des Vorgefundenen, seine Korrektur, „Ausschöpfung eines Spielraumes“, „replizierende Weiterführung“, „Ausspielen der Differenz zwischen dem alten Kontext des fremden Wortes und seiner neuen Kontextualisierung ${ }^{6.600}$ zutreffen. Von den drei von Lachmann aufgestellten Intertextualitătsmodellen, die Positionen des jüngeren Textes gegenüber dem älteren widerspiegeln, nimmt die Kontrafaktur tendenziell die letzte in Anspruch: das der Transformation, wenn der Bezugstext "verborgen, verschleier", ,unkenntlich gemacht“, ,respektlos umgepolt" wird ${ }^{601}$.

\subsection{1. „Toř̌estvo pobeditelja“}

Die im Jahre 1883 verfaßte Kurzgeschichte „Toržestvo pobeditelja (rasskaz otstavnogo kolležskogo registratora)“ (Der Triumph des Siegers (Die Erzählung eines verabschiedeten Kollegienregistrators) ${ }^{(102}$ ) könnte man der intertextuellen Gattung des ,realistischen Wiedererzählens “6033, ähnlich wie sie R. Lauer beschrieben hat, zuordnen. Am Beispiel von Lazarevićs Novelle „Verter" (Werther) demonstriert Lauer charakteristische Merkmale dieses Texttyps, den er folgendermaßen definiert: „Hier werden aus der literarischen Tradition bekannte Gestalten und Konflikte, die an bestimmte Gestalten gebunden sind, in die Gegenwart ver-

\footnotetext{
$\$ 97 \mathrm{~S}$ bei Verweyen und Witting 1987. S. 116

$\$ 98 \mathrm{Vgl}$ S 28 dieser Arbeit

599 Das bedeutet verstandlicherweise nucht. daß Cechovsche Kontrafakturen keine worlichen Verweise auf den Bezugstext wie Allusionen oder Zitate enthalten, nur spielen solche Verweise im Fall der Kontrafaktur keine konstitutive Rolle, sie nehmen am Aufbau der literarischen Ableitung einen wesentlich geringeren Anteil als z B in der Parodie und fungieren bisweilen lediglich als intertextuelle Spuren, als Elemente. die die Prasenz eines Fremdtextes im aktuellen Text verraten und damit die ..Doppelkodierung" signalisieren (Signale zur intertextuellen Analyse)

${ }^{6000} \mathrm{Vgl}$. S 25 dieser Arbeit

${ }^{601} \mathrm{Vgl}$. S 28 dieser Arbeit

${ }^{602}$ Tschechow Bd 1 (1949). S. 287.

${ }^{603}$ Das .,realistische Wiedererzahlen“ betrachten wir demnach in diesem Fall als eine Austormung der Kontrafaktur
} 
setzt. Die Handlungen spielen sich in der zeitgenossischen Gesellschaft ab und werden nach dem Muster realistischer Zeitprosa motivier ${ }^{6} .{ }^{604}$ Mit einer modernen Verarbeitung herkommlicher Muster kőnnen bei Cechov sowohl system- als auch einzeltextreferenzielle Verfahren verknüpft werden. So füllt er bisweilen die in Form eines Märchens oder eines Gleichnisses konstruierten Texte mit dem modernen Inhalt, bezieht sich also spielerisch auf in der Regel abgeschlossene, im Sinne Turbins normierte ${ }^{605}$ Gattungen als solche. ${ }^{606}$ „Modernisiert" werden andererseits auch konkrete Prătexte - hăufig sind das allerdings wiederum altbekannte Märchensujets wie z.B. „Der Blaubart“ oder „Däumelinchen“. In eine Episode des Pastiches „Nenužnaja pobeda“ (1882) ist das humoristische Wiedererzăhlen von „Däumelinchen" eingebaut, in dem die in den Mărchendiskurs noch durchaus passenden Elemente mit den modernen Fakten und Attributen kombiniert werden; dem Charakter des ganzen Textes entsprechend, der zwischen Parodie und Stilisierung schwankt ${ }^{607}$, baut sich auch dieses intertextuelle Fragment als unentschieden zwischen Affirmation und Verspottung auf. S. z.B.: „Эта девочка [...] жила в некотором нарстве, в некотором государстве, в большом тюльпане. [...] Ела она один только мёд, который носили ей пчёлы. [...] Специальность её была медицина." (Dieses Mädchen [...] lebte in einem gewissen Reich, in einem gewissen Staat, in einer großen Tulpe. [...] Sie aß nur Honig, den ihr Bienen brachten. $[\ldots]$ Ihr Fachgebiet war die Medizin.) $(1,310)$.

In „Moi žëny (pis'mo v redakciju - Raulja Sinej Borody)“ (Meine Ehefrauen (ein Brief an die Redaktion von Raul', dem Blaubart)) (1885) wird das realistische Wiederschreiben von .Der Blaubart" dadurch zustande gebracht, daß Čechov die zentrale Figur des Märchens den Blaubart - zum Zuschauer der gleichnamigen Operette macht und ihn eine Beschwerde an die Redaktion von "Oskolki“ wegen der verleumderischen Darstellung seiner familiären Angelegenheiten einreichen lăßt (sein Brief bildet das Sujet der Geschichte). Cechov versetzt die bekannte Märchenfabel in die russische Realität der Gegenwart, was die Gelegenheit bietet, .Den Blaubart“ ironisch zu psychologisieren, den Typ eines modernen Misogynen und zugleich sieben Typen der modernen Frau parodistisch zu schildern. Der Referenztext wird ..nach dem Muster realistischer Zeitprosa“ umgestaltet, er gewinnt eine psychologische Perspektive, ja Anzeichen einer Beichte. Durch die Kombination mit dem makabren Geschehen des Märchens gelingt es Cechov, das moderne Phänomen des Frauenhasses auf eine besonders scharfe Art zu verspotten.

${ }^{\cos }$ Lauer 1986a, S. 237

$\cos \mathrm{Vgl} \mathrm{S} 66$ unserer Arbeit

${ }^{60}$ S. z.B die Kurzgeschichte ..Bumažnik" (Die Brieftasche) (1885), in der ein modernes Sujet in Form einer Parabel prasentiert wird Hier wird die didaktische Botschaft der Parabel spielerisch auf ..kleine" Anliegen des Schauspielermilieus ubertragen. was insbesondere am Textende - in der beigefugten Moral - deutlich wird Die gattungsbezogene Intertextualitat Cechovs, u a zahlreiche ironische Verweise auf bestimmte Gattungen in seinem fruhen Schaffen (wohl am haufigsten auf die des Romans). konnten aum Gegenstand einer speziellen Untersuchung werden

${ }^{607} \mathrm{Vgl}$ Smola 2001. 103-104 
Aus den angeführten Beispielen wird deutlich, daß das realistische Wiedererzăhlen bei Cechov auch parodistische Funktionen beinhalten, ebenfalls als Parodie strukturiert werden kann (worauf z.B. stilistisch-thematische Diskrepanzen zwischen dem aktuellen Text und der Vorlage in „Nenužnaja pobeda“ hinweisen, aber auch die primär auf/ gegen diese Vorlage gerichtete Aussage des Widerschreibens) und also nicht nur im Sinne einer Kontrafaktur ${ }^{608}$, als welche wir den nächsten Text Cechovs auffassen, zu analysieren ist. ${ }^{60 y}$

Der Titel der Kurzgeschichte "Toržestvo pobeditelja“ stellt eine Allusion auf Vasilij Żukovskijs Übersetzung (1828) von Schillers Balläde „Das Siegesfest“ (1803) dar. Die Titel der beiden Texte sind - abgesehen von der minimalen grammatischen Modifikation, nămlich dem Ersatz des Plurals durch den Singular - kongruent („Toržestvo pobeditelej“ (Der Triumph der Sieger) (Žukovskij) - „Toržestvo pobeditelja“ (Der Triumph des Siegers) (Čechov)); ein Verfahren, dem wir bei Cechov bereits begegnet sind und das den intertextuellen Kontakt aufgrund der besonderen "Intentionalităt und Deutlichkeit" seiner Markierung im Text ${ }^{610}$ unübersehbar macht. Hinzu kommt der hohe Bekanntheitsgrad der alludierten Vorlage, der neben der privilegierten Markierungsstelle im Text günstigste Bedingungen für die Wahmehmung des Bezuges schaffte und der dem Interpreten die intertextuelle Lektüre der Cechovschen Kurzgeschichte nahe legt. ${ }^{611}$

Das intertextuelle Signal, markiert im Titel des aktuellen Textes („titular allusion“ nach Hebel) bzw. im allgemeinen paratextuell (insbesondere noch im Untertitel und Motto), deutet darüber hinaus häufig auf den Charakter dieses späteren Textes im Ganzen hin. Es läßt ihn als literarische Ableitung betrachten, als eine von der (durch die Berührung mit dem Fremdtext entstandene) „Polyvalenz“ bestimmte Struktur (Lachmann) lesen.

Die Ballade schildert die Sieges- und Totenfeier der Achaier nach der Eroberung von Troja. Der Text ist im Wesentlichen als eine Reihe von Aussagen' Reden der bedeutenden griechischen Helden wie Odysseus, Menelaos, Aias, Neoptolemos u.a. stammenden strukturiert. Die Stimmen der Sieger wechseln mit der des lyrischen Erzăhlers und an einzelnen Stellen mit der Klage der Besiegten. Die Eroberer Trojas gedenken der ihr Leben im Krieg geopferten Freunde und Familienmitglieder, aber auch der mutigen Verteidiger der Stadt (wie Hektor) in Ehre, sie trauern und zählen ihre - menschlichen - Verluste auf. Die Freude an der bevorstehenden Heimkehr und dem Wiedersehen mit der Familie wird vom Bewußtsein der Unwiederbringlichkeit des Eingebüßten. der Vergänglichkeit des Glückes und der Unab-

\footnotetext{
${ }^{60 x}$ Die Geschichte ..Moi Żeny" wollen wir jedoch anhand der im Kap 33 erorterten Verkmale als eine "kontrafaktische" Umschreibung des Pratextes bezeichnen

${ }^{609}$ Wir wollen hier erneut betonen (s bereits auf der $S$ 34-35), daß wir an mehreren Stellen unserer Textanalyse die Termini und z.T die Vorgehensweise von W Schmid (s. z.B 1983) ventenden

${ }^{610} \mathrm{~S}$ das zweite qualitative Kriterium - das der Kommunikativitat - im Modell P'tisters (S 29 dieser Artheit) In der frühen Prosa Cechovs ist dieses Kriterium in der Regel im hohen Grade erfull: Die Intertextualitat wird als unverborgen, demonstrativ, herausfordernd konzipien, sie tragt Zuge eines literartschen Experiments (in der spateren Prosa wird es ebenfalls erfullt, nur auf eine andere Weise)

"1' Uber den Bezug zur Ballade Schillers im Titel dieser Kurzgeschichte und uher die wroble Bekanntheit der Vorlage $s$ bei Kataev 1995. S 8; vgl dazu die Fußn 452
} 
wendbarkeit des Schicksals, das die allmächtigen Gơtter verkorpern, überschattet. Die „erzăhlenden" Strophen wie das Erinnern an die Gefallenen werden mit Vierzeilern philosophischen Charakters kombiniert, die Demut, Tapferkeit und - gerade angesichts der Härte des Lebens - epikureische Freude am Augenblick predigen.

Der intertextuelle Titel der Kurzgeschichte weist zunächst auf die Analogien in der Ebene der den beiden Texten zugrunde liegenden fiktiven Situation hin, d.h. auf das Funktion im aktuellen Werk einer - aus einem bestimmten Grund und in einer bestimmten Umgebung triumphierenden Figur. Bei Cechov geht es tatsăchlich um den Beamten Aleksej Ivanyð̌ Kozulin, der bei einer "maslenica“(,Butterwoche ${ }^{(612}$ )-Feier mit den Kollegen über seinen ehemaligen, ebenfalls anwesenden Vorgesetzten Kuricyn „triumphiert“. Er beschreibt die ihm von dem einst Mächtigen zugefugten Demütigungen; jetzt ist er selbst endlich an der Spitze der Hierarchie angelangt und genießt die Rache an dem ihm mittlerweile untergebenen, gealterten Beamten. Bei oberflăchlicher Betrachtung erfullt die Titelallusion eine primăr emotionale, in der Klassifikation Kosnys eine pragmatische Funktion, $d . h$. sie deutet lediglich auf analoge Gefühle und Stimmungen (hier Freude am Sieg bzw. an der Macht) hin und erschließt sich insofern aus dem nächsten situativen - psychologischen -- Kontext. Dabei wird das emotional und situativ Ferne, ja Unvergleichbare zusammengebracht (Helden des Epos Beamten der russischen Gegenwart). Die Parallelen gehen jedoch über die genannte Ebene weit hinaus und bilden eine komplexe intertextuelle Struktur, deren Entschlüsselung die Heranziehung des Referenztextes im Ganzen wie in Einzelheiten erfordert. Die Žukovskij-Intertextualität berührt den Sujetaufbau der Geschichte mit ihrem zentralen Konflikt und einzelnen Sujetdetails, ihre Personenkonstellation und letztendlich die Botschaft, die ideelle Schicht des Werkes Cechovs. Dabei wird der Text Žukovskijs formal „unkenntlich“ gemacht: Seine Umdichtung vollzieht sich nicht durch das zitierende Verfahren wie in den oben untersuchten Texten, in denen die sprachliche und thematische Gestalt des älteren Textes im jüngeren noch durchaus wieder zu erkennen war, sondern gerade durch einen radikalen Austausch auf verschiedenen textuellen Ebenen.

"Toržestvo pobeditelja“" verfâhrt mit dem Bezugswerk so, daß ein kompletter Wechsel der für dieses Werk konstitutiven inhaltlichen und sprachlichen Elemente zustande kommt. Ausgetauscht werden nicht allein die literarische Grundform (Gedicht $\rightarrow$ Prosa) und die Gattung (Ballade $\rightarrow$ Kurzgeschichte) des Textes ${ }^{613}$, sondern und vor allem sein Thema (das Geschehen) sowie die stilistische Gestaltung (dessen Aspekte nicht zuletzt Sprachstufe und Sprachregister des Textes darstellen: poetisch-gehobene, zum Teil archassche Sprache der Ballade $\rightarrow$ niedrige, vulgäre Sprache der Kurzgeschichte). Die oben genannten Erzählebenen des Referenztextes (Elemente der Diegese wie Handlung und Personen) werden von Cechov unter

\footnotetext{
612 Tschechow Bd 1 (1949). S 90

${ }^{613}$ Vgl. den Begriff ..Prosifikation" bei Genette (1993, S 297-305), vgl auch Transformationstypen Pletts (s. S 28-29 dieser Arbeit) Jedoch geht es bei uns selbstverstandlich nicht um eine mehr oder weniger ..authentische" Ubertragung eines Gedichts in die Prosa.
} 
bestimmten Transformationen auf einen ganz anderen Stoff übertragen und an ihn angepaßt. Hier kommt eine der in unserem Verständnis spezifisch „kontrafaktischen“ Ableitungsformen zum Ausdruck, die auf eine sprachlich-thematische Nachbildung der Folie verzichtet, sie sich dagegen zur strukturellen Grundlage furr eine neue, eigene Aussage zueigen macht. Die Folie bleibt unter diesen Umständen formal meistens verborgen, was jedoch den Grad der Kommunikativităt des betreffenden Hypertexttyps nicht vermindert (s. das Modell Pfisters). Die Deutlichkeit der intertextuellen Markierung wird durch die Präsenz intertextueller ",marker“ vermittelt, die Intentionalităt der Verweisung - durch die im Prozeß der intertextuellen Analyse entschlüsselten Korrespondenzen.

Es ist im Weiteren zu demonstrieren, wie die zwischen Žukovskijs „Toržestvo pobeditelej“ und Cechovs "Toržestvo pobeditelja“ herauszustellenden Āquivalenzen sich durchgangig als Kontrastpunkte zwischen den beiden Texten entblößen und so den Charakter des jüngeren Werkes als Kontra- und Widerschreiben zur Wirkung bringen.

Die Umschreibung der Ballade in der Kontrafaktur beginnt zunăchst auf der Ebene der fiktiven Situation, was bereits am Textanfang manifestiert wird:

Пал приамов град священный,

Грудой пепла стал Пергам;

И, победой насыщенны,

К острогрудым кораблям

Собрались эллины - тризну

В честь минувшего свершить [...] (Žukovskij) $)^{614}$

(Fiel die heilige Stadt von Priamos,

Zum Aschehaufen ist Pergamos geworden,

Und, vom Siege gesăttigt.

Um die spitzbrüstigen Schiffe

Versammelten sich Hellenen - eine Totenfeier

Zu Ehren des Vergangenen abzuhalten $[\ldots]^{615}$ )

- „В пятницу на масленой все отправились есть блины к Алексею Иванычу Козулину.“ (,Am Freitag der Butterwoche begaben sich alle zu Alexei Iwanytsch Kozulin, um die Blini [Blinsen] zu essen.“(16) (Čechov 2, 68). Der Totenfeier bei Žukovskij entspricht eine maslenica-Feier bei Cechov: beide sind nicht nur gemäß dem Kontext als unterschiedlich, sondern

\footnotetext{
614 Siller Bd 1 (1901). S 148 Dieses und weitere Zitate aus dem Text von Żukovskij werden der folgenden Ausgabe entnommen F. Siller Sobranie sozinenij v perevode russkich pisatelej Tom I. Sankt-Peterburg. 1901 (F. Schiller Gesammelte Werke. ins russische ubertragen von nussischen Autoren Band I Sankt-Petersburg 1901) (s. das Literaturverzeichnis)

${ }^{6}$ Da die Ubertragung von Żukovskij zum Teil erhebliche Abweichungen vom Original Schillers aufiveist und diese Tatsache im Weiteren thematisien wird, werden Zitate aus dem ersteren moglichst worgetreu ins Deutsche ruckübersetzt

${ }^{610}$ Tschechow Bd I (1949). S 287
} 
als gegensătzlich gestaltet, so daß die zweite als literarische Widerlegung der ersten betrachtet werden kann. Wăhrend unter den Feiernden im ersten Fall eine tiefe Trauer herrscht ${ }^{617}$, wird bei Cechov gescherzt und gelacht (ob aufrichtig oder aus Liebedienerei): „Мы слушали, а его превосходительство [...] говорил. Сюжетиы были всё больше юморнстического характера, масленичного...“ (m[...] wir horten zu, seine Exzellenz aber [...] sprach. Die Themen [die netten Sujets] waren in der Hauptsache humoristischen, gewissermaßen butterwöchigen Charakters... “618) $(2,68)$. Der offiziell lustige Charakter des Cechovschen Festes wird durch das lexikalische Motiv des Lachens vermittelt, das im Text mehrmals zum Ausdruck kommt:

Не знаю, сказал ли он что-нибудь смеиное. [...]

- Ciиeйcя!

Я раскрывал широко рот и смеялся. Раз даже взвизгнул от смеха [...]. Он глядит на тебя и сиеётся... [...] Мы покатились со смеху.“ („Ich weiß nicht, ob er dabei etwas Lächerliches vorbrachte [sagte], [...]

'Lach doch!'

Und ich offnete den Mund breit und lachte. Einmal kreischte ich sogar vor Lachen [...] '[...] er schaut auf dich und muß selber lachen [...]' [...] Wir wälzten uns vor Lachen. “619) (Cechov, 2, 68-70). ${ }^{620}$

Das Motiv des Lachens wird in deutlicher Weise dem herrschenden Motiv der Trauer/ des Weinens im Bezugstext entgegengesetzt: „И с победной песнью дикой/ Их сливался тихий стон [...]/ И внезапный .ирак печсли/ Отуманил царский взгляд: /[...]/ Тей стрифаниі утоленье! /[...]/ Пей, страбалица! Печсии] Услаждаются вином [..] Но и с нею, безотрадной./ Добрый Вакх недаром был: /[..]/ (корби наши быстро мчит/ Их смывающая Лета:““ (Und mit dem wilden Siegeslied/Vermischte sich ihr leises Siöhnen /[...]/ Und die plotzliche Finstemis der Trauer/ Trübte den Zarenblick: ![...]/ „Trunke der l.etden Linderung! /[...]/ „Trinke, Märtyrerin! Irauer/ Mildert der Wein: /[...]/ Aber auch mit ihr, der (Inıröstlichen」War der gute Bacchus nicht umsonst: /[...]/ Unsere Irauer treibt schnell/ Sie fortschwemmende Lethe. $)^{621}$. Ein Bezug zum Tragischen - das fiktive, von den Charakteren stammende Karikieren der Tragödie „Othello“ - ist in der Szene zu finden, in der Kozulin seinem ehemaligen Vorgesetzten befiehlt, vor den Anwesenden zu schauspielem:

\section{- [...] Курицын!!}

$617 \mathrm{Vgl} \mathrm{z.B} \mathrm{die} \mathrm{Zeile} \mathrm{.Лучших} \mathrm{бой} \mathrm{похıтил} \mathrm{ярый!“} \mathrm{(Die} \mathrm{wutende} \mathrm{Schlacht} \mathrm{hat} \mathrm{die} \mathrm{besten} \mathrm{geraubt!)} \mathrm{(s} \mathrm{dieses}$ Zitat auch weiter)

618 Tschechow Bd. I (1949). S 288

619 Ibid. S. 288-291

${ }^{620}$ Hervorhebung hier und im Weiteren von uns

1.21 Siller Bd. I (1901), S 148-150 
- Чего изволите-с? - спросил Курицын, вставая и вытягиваясь в струнку.

- Трагедию представь!

- Слушаю!

Курицын вытянулся, нахмурился, поднял вверх руку, скорчил рожу и пропел сиплым, дребезжашим голосом:

- Умри, вероломная! Крррови жажду!!

(,'[...] Kurizyn!'

'Was befehlen?' fragte Kurizyn, erhob sich und nahm Haltung an.

'Mach uns eine Tragödie vor!'

\section{'Zu Befehl!'}

Kurizyn reckte sich, legte sein Gesicht in Falten, hob den Arm hoch, zog eine Grimasse und schmetterte mit heiserer, zitternder Stimme los:

'Stirb, Ungetreue! Ich dürrste nach Rache [nach Blut]! (c622 $^{6}(2,70)$.

Das Zitat aus „Othello“ kann als ergänzendes Zeichen der Kontrastierung des aktuellen Werkes zur Tragodie schlechthin ${ }^{623}$, insofern auch als indirekter Verweis auf das Tragische der Hauptfolie von "Toržestvo pobeditelja" gelesen werden, mit dem bedeutenden Unterschied, daß im ersten Fall ein punktueller parodistischer Bezug, im letzten eine „kontrafaktische“ Ableitung vorgeführt wird.

Diegetische Analogien zur Ballade beschränken sich jedoch nicht auf die Ausgangssituation (z.B. die Abhaltung einer Feier), sondern umfassen weiterhin die Sujetstruktur der Kurzgeschichte. In beiden Texten werden die für den gewonnenen Kampf gebrachten Opfer verkündet. Bei Žukovskij zăhlen die Helden in erster Linie ihre menschlichen Verluste auf: ,Благороднейшие пали.../ Мало с ним пойдёт назад. /[...]/ Нет великого Патрокла, /[...]/ Лучших бой похитил ярый!/ Вечно памятен нам будь,/ Ты, мой брат, [...] /[...]/ 'O, Ахилл, о, мой родитель!' /[...] 'Слава Гектору во гробе:/ Он краса Пергама был; [...]“ (Die Edelsten sind gefallen.../ Die Wenigen werden mit ihm zurückkehren. /[...]/ Den großen Patroklos gibt es nicht mehr, /[...]/ Die wütende Schlacht hat die besten geraubt!/ Ewig bleibe uns in Erinnerung, $/$ Du, mein Bruder, $[\ldots] /[\ldots] /$, ,Oh, Achill, oh, mein Vater!“ /[...]/ Ehre dem Hektor im Sarg:/ Er war die Zierde von Pergamos, $[\ldots])^{624}$. Diesen Verlusten - den großen Toten von Troja - stellt Čechov Formen der Diensttyrannei entgegen: ..- Много я претерпел по милости этого смиренника! [...] Я и писал ему, и за пирожками бегал. перья чинил, тёщу его старую по театрам водил. [...] Табак нюхать выучился!" (..'Viel mußte ich von diesem ach so demütigen Menschen erleiden! [...] Ich hatte für ihn zu schreiben, für ihn nach Gebåck zu laufen, ich mußte seine Federn spitzen, ich hatte seine alte Tante [Schwiegermut-

\footnotetext{
\$222 Tschechow Bd 1 (1949). S. 291

${ }^{623}$ Hier verwenden wir den Begriff "Tragodie“ nicht im strengen Sinne als Gattung. sondern weisen vielmehr auf den Charakter des fur das Werk ausgewahlten Stoffes hin

${ }^{624}$ Siller Bd 1 (1901), S 149
} 


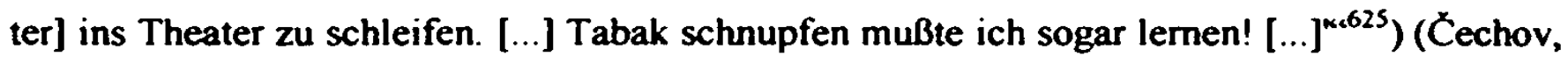
2, 70). Den tatsächlichen tödlichen Wunden der Achaier entsprechen die allegorischen des Beamten: „- $[\ldots]$ И стал он меня есть... Что ни слово - то нож острый, что ни взгляд - то пуля в грудь.“ (..'[...] Er aber begann mich zu fressen... Kein Wort, das nicht messerscharf war, ein jeder Blick von ihm traf mich wie eine Kugel in die Brust. $\left.[\ldots]^{\mu 626}\right)(2,69)$.

Dabei wird von Cechov die polyphonische Struktur des Gedichtes in eine monologische transformiert - Veränderung, die bereits in der Modifikation des alludierten Titels angekündigt wurde. Wăhrend im Referenztext mehrere sprechende Personen fungieren und Kalchas, Odysseus, Ajas, Diomedes u.a. sich beim Erinnern an die Verlorenen abwechseln, erleidet die "Verluste" bei Cechov eine Person, nämlich Kozulin, und die Auflistung der Opfer wird demzufolge von ihm allein durchgeführt. Eine solche Transformation auf der Personenebene des Prătextes - Verschiebung der intertextuellen Parallelen - wollen wir als fur Cechovsche intertextualität in vielen Fällen typisch bezeichnen: Zu demselben Verfahren zăhlt z.B. die bei Cechov häufig vorkommende Inkongruenz der in dem Vergleich nahe gebrachten Figuren, die eine Suche nach neuen „Figuren-Korrespondenzen“ an den Tag bringt (s. darüber auch in den Beiträgen Adatis und Claytons ${ }^{627}$ ). W. Schmid nennt dieses Verfahren, das er in den Novellen Puskins beobachtet, „Aufhebung der primăren (d.h. der am Anfang suggerierten) Korrespondenzen [...] zwischen den [...] Figuren und ihren Prototypen“, „Băumchen-wechsel-dichSpiel“ ${ }^{628}$ In unserem Fall werden in "Torżestvo pobeditelja“ mehrere Protagonisten als Träger der Äußerungen praktisch durch einen ersetzt und die Struktur des Textes wird folglich monologisiert. ${ }^{629}$

Die oben entdeckten Analogien und Oppositionen zwischen den beiden Texten auf den Ebenen der Handlung und der Personen bilden jedoch nur den Rahmen für den Kontrast und die Entgegenstellung der von den fiktiven Charakteren dieser Texte vermittelten Ideen. Die diesem Aspekt des Widerschreibens entspringenden intertextuellen Differenzen der Werke schlagen sich am deutlichsten im Charakter des Grundkonfliktes nieder. In der Ballade Schillers, übersetzt von Žukovskij, wird das Verfeindetsein der Sieger und der Besiegten und der daraus resultierende Triumph und die Freude der ersten mit verschiedenen narrativen Mitteln relativiert und schließlich aufgehoben. Der Sieg wird vom .lyrischen Erzähler" bereits am Anfang des Gedichtes als tragisch geschildert. Getrauert wird (was zunächst durch die Stimme des Erzählers vernehmbar ist) nicht nur über die gefallenen Kampfgenossen, sondern auch über den Untergang von Ттоја: „.Пал Приамов град свяшенный,' Грудой пепла

\footnotetext{
${ }^{625}$ Tschechow Bd I (1949). S 290

${ }^{626}$ Ibid

${ }^{627} \mathrm{Vgl}$. S. 61.64 unserer Arbeit

${ }^{628}$ Schmid 1991. S 126

${ }^{629}$ Den restlichen Figuren in der Kurzyeschichte gehoren nur einzelne Repliken, die keine Entsprechungen denen in der Vorlage finden
} 
стал Пергам; $[\ldots]^{\text {c630 }}$. Das Siegeslied mischt sich mit der Klage der Trojerinnen, deren Stimme an der folgenden Stelle mit der des lyrischen Erzăhlers verschmilzt:

И с победной песнью дикой

Их сливался тихий стон

По тебе, святой, великой.

Невозвратный Илион; [...]

(Und mit dem wilden Siegeslied

Vermischte sich ihr leises Stohnen

Um dich, heiliger. großer,

Unwiederbringlicher Ilion:

$[\ldots])^{631}$

Das so vermittelte Mitleid mit den Besiegten, denen eine mit der lyrischen Erzählerinstanz homogene Stimme verliehen wird ${ }^{632}$, suggeriert eine Überwindung der zentralen Opposition ..Sieger - Opfer". Diese Idee - die moralische Botschaft der Schillerschen Ballade - behauptet sich auch innerhalb des fiktiven Ganzen: Angesichts des Todes, dem niemand entkommt, betrachten die Achaier Rachegefühle als eitel, sie gedenken deshalb auch dem großen Helden von Troja - Hektor - in Ehre:

„Смерть велит умолкнуть злобе!“-

Диомед провозгласил:

„Слава Гектору во гробе:

Он краса Пергама был;

$[\ldots]$

(..Der Tod gebietet dem Zorn zu schweigen!“”-

Diomedes verkündete:

..Ehre dem Hektor im Sarg:

Er war die Zierde von Pergamos:

$\left.[\ldots]^{6.4}\right)^{6.33}$

Nicht nur der Konflikt wird hier auf diese Weise überwunden und so bis zu einem gewissen Grade die Versöhnung mit dem Feind deklariert (was u.a. in der Überreichung des Weins an

${ }^{6.00}$ S̈iller Bd 1 (1901). S 148 S C Cbers. auf S. 12.3 dieser Arbeit

${ }^{631}$ Ibid Ubers S. teilweise auf S. 124 unserer Arbeit

${ }^{632}$ Man muß hier hinzufügen, daß auf dieses Mitleid. das sich in der Stimme des Iyrischen Erzahlers ausdruckt. im Original Schillers nichts hindeutet $\mathrm{Vgl}$. die entsprechenden (die letzten zwei im anyeführten Zitat) Zeilen 
Hekuba und in der Rede von Nestor (s. weiter) expliziert wird), auch der Sieg der Achaier ist nicht unbetrübt und weniger freudebringend als erwartet. In seiner Rede stellt Odysseus das Glück der Heimkehrenden in Frage, er spielt auf den Verrat der Freunde und auf die Untreue der Ehefrauen der Sieger an:

„Н не всякий насладится

Миром, в свой пришедши дом:

Часто злобный ков таится

За домашним алтарём;

[...]

„Счастлив тот, чей дом украшен

Скромной верностью жены!

Жёны алчут новизны:

Постоянный мир им страшен“.

(..Und nicht jeder wird genießen

Den Frieden, heimgekehrt:

Oft verbirgt sich die böse Tücke

Hinter dem Hausaltar;

[...]

Glücklich ist derjenige, dessen Haus geziert ist

Mit der bescheidenen Treue der Frau!

Frauen dürsten nach dem Neuen:

Den ständigen Frieden fürchten sie.) $)^{\text {k34 }}$

Schließlich läßt der von Ajas ausgesprochene Zweifel an der Gerechtigkeit der Götter ${ }^{635}$, die über Leben und Tod der Sterblichen entscheiden, den Sieg der Griechen zur bloßen Folge ihrer Laune entarten, er wird seines unumstrittenen, absoluten Charakters beraubt. ${ }^{636}$

Die im Gedicht Schillers, insbesondere aber in der Übertragung Żukovskijs dargestellte Ablehnung von Hass und Rache (Kern und Demonstration der ethischen Botschaft des Textes, die durch milde, melancholische Töne der Übersetzung Žukovskijs noch verdeutlicht und bekräftigt wird), findet in der fiktiven Welt der Geschichte Cechovs keinen Platz. ${ }^{637}$ Das Wort

\footnotetext{
6.14 lbid

${ }^{635} \mathrm{~S}$ die Fußnote 651

${ }^{6.36} \mathrm{Vgl}$. dazu die folgende Stelle

Ныне жребий выпал Трое.

Завтра выпадет другим

(Heute hat Troja das Los gezogen.

auch weiter)

Morgen werden es die anderen ziehen) (Šiller Bd 1 (1901), S 150, s. dieses Zitat

${ }^{637}$ Obwohl auch in der Ballade die Idee der Vergeltung vermittelt wird.
}

.ГІлод губительной измены. 
.toržestvo" im Titel der Übersetzung Žukovskijs mit seiner aus unserer Sicht eher neutralen Bedeutung „Feier(lichkeit)“, „Fest(lichkeit)“ geht in den neuen Kontext, den Titel der Cechovschen Kurzgeschichte, mit einer markanten Bedeutungsverschiebung über: „toržestvo“ ist hier nicht nur als "Fest“, sondern auch und in erster Linie als "Triumph (über den Feind)“, ..(Schaden)freude“ zu verstehen. Kozulin ist nămlich voller Rachegefühle, Hass und Schadenfreude: „- $-[.$.$] А теперь я... я над ним... Он мою тёщу в театры водит, он мне табакерку$ подаё $[. .$.$] . Хе-хе-хе... Я ему в жизнь перчику... перчику!“ (.,'[...] Jetzt aber... jetzt stehe$ ich über ihm... Er ist es, der meine Schwiegermutter ins Theater schleppt, er muß mir seine Tabatiere reichen [...]. He-he-he... Ich streue ihm Pfefferchen in sein Dasein... Pfefferchen! $\left.[\ldots]^{\mathrm{s} .638}\right)(2,70)$.

Wăhrend den Besiegten in der Ballade eine Stimme zuteil wird, bleibt Kuricyn das Aussagerecht versagt, er fungiert lediglich als Objekt der Belustigung und Verspottung, gehorcht demütig den Befehlen seines ehemaligen Untergebenen und wird als fühlendes Subjekt gar nicht wahrgenommen. Der mehrstimmigen Struktur des Prătextes wird die einstimmige des Posttextes entgegengesetzt. Der Gegensatz wird von einigen markanten Details - kontrastiven Sujetelementen - untermauert. Wăhrend Nestor der Mutter Hektors Hekuba zum Trost einen Becher Wein überreicht und damit das Mitgefühl mit den Besiegten demonstriert („Пей страданий утоленье!/ Добрый Вакхов дар - вино“639), tröstet sich Kozulin bei den Erinnerungen an seine Vergangenheit auf dieselbe Art selbst: „Алексей Иваныч вытер глаза платочком и залпом выпил стакан вина." (.Alexei Iwanytsch trocknete sich die Augen mit einem Tüchlein und goß in einem Zuge ein Glas Wein herunter. $\left.{ }^{c 640}\right)(2,70)$. Der freundlichen Überreichung des Weinbechers in der Vorlage entspricht bei Cechov die Szene, in der Kozulin Kuricyn zur Unterhaltung der Anwesenden zwingt, ein Stück Brot mit Pfeffer zu essen:

- Курицын! Съешь зтот самый кусок хлеба с перчиком!

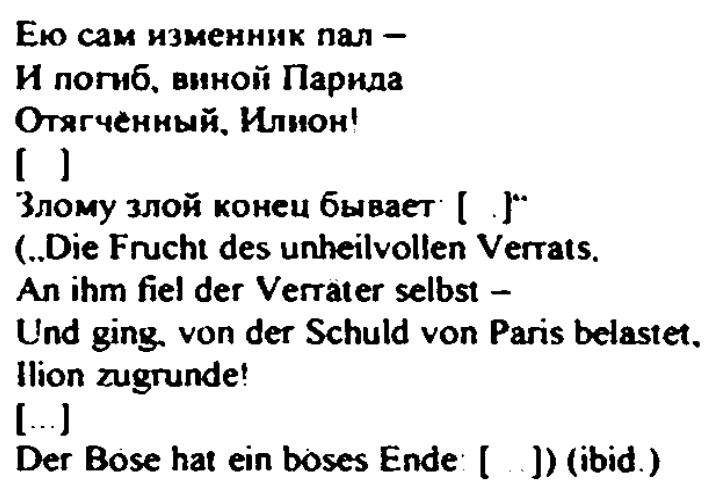

Auch die Zeile der Ballade „И с победной песнью дикой“ (Mit dem wilden Siegeslied) deutet darauf an. daß die Sieger Zukovskijs uber die Besiegten triumphieren, das betrift jedoch nicht die Hauptpersonen. die in ihrer Mehrheit ganz anders besonnen sind.

${ }^{638}$ Tschechow Bd I (1949). S 291

${ }^{639}$ Siller Bd 1 (1901). S 150.S Übers auf S 124 dieser Arbeit

Tschechow Bd I (1949), S 290 
Сытый Курицын взял большой кусок ржаного хлеба, посыпал его перцем и сжевал при громком смехе. (,'Kurizyn! Verspeise mal dieses Stück Brot hier mit Pfeffer!'

Der völlig gesăttigte Kurizyn ergriff ein großes Stück Roggenbrot, schüttelte Pfeffer darauf und kaute es zum lauten Gelächter der anderen.“(ctl) (ibid.)

Während das Glück der Sieger und konkreter ihr Eheglūck bei Schiller-Žukovskij zweifelhaft erscheint (s. das Zitat oben), erwähnt der ..Sieger“ Cechovs neben den anderen „Trophảen“ seinen Dienstprivilegien („блины“ (Blinis [Blinsen]), „наисвежайшая икра“ (allerfrischester Kaviar), „Квартира“ (Wohnung $\left.{ }^{642}\right)$ ) - stolz auch seine Gattin: „Теперь мы [...] жену белотелую ласкаем“ (.,jetzt [...] können [wir - K. S.] [...] ein Weib mit weißem Leibchen liebkosen [liebkosen wir die Frau mit ihrem weißen Körper]. $\left.{ }^{{ }^{6643}}\right)(2,69)$. Während der materielle Gewinn für den Triumphator Čechovs eine durchaus wichtige Rolle spielt, wird er in der Ballade von Žukovskij konsequenterweise nicht übersets $t^{\text {(nt) }}$ : im Vordergrund steht hier die ethische Besinnung und die Weisheit der griechischen Helden, betont wird dementsprechend die Vergänglichkeit des irdischen Glücks sowie die Gleichheit aller Menschen vor der Allmacht der Götter und der Kürze des Lebens. Die Opposition „gesiegt haben - besiegt sein", im Prätext bis zu einem gewissen Grade aufgehoben, neutralisiert, wird in der Kurzgeschichte also wiederhergestellt, die ethischen Werte der Achaier wie Ehrlichkeit, Vaterland und Familie werden durch materielle wie gutes Essen. Wohnung, schöne Ehefrau ersetza. ${ }^{\text {chs }}$

\footnotetext{
$6+1$ Ibid. S 291

Got Ibid. S. 290-291

603 Ibid S 288

64t Das Original von Schiller ist an dieser Stelle zur Kontrafaktur von Cechov namlich naher, als der Ubertragung von Żukovskij Vgl die zitierte Aussage Kozulins mit der folgenden Stelle im Original Schillers
}

Und des frisch erkampften Weibes

Freut sich der Atrid und strickt

Um den Reiz des schonen Leibes

Seine Arme hoch begluckt (Teil 1, Bd 2 (1983). S 190)

ass Diese Substitution der moralischen Werte in der Kontrafaktur Cechovs durch materielle wird besonders anschaulich, wenn man die Textstellen vergleicht. an denen es im Pra- und im Posttext um die Vorteile des Siegers geht. „Счастлив тот, кому сиянье/ Бытия сохранено -/ Тот, кому вазхить дано/ С милой родиной свиданье'" (Selig ist derjenige. dem das Strahlen/ Des Daseins erhalten geblieben ist -/ Derjenige. dem auszukusten beschieden ist Das Wiedersehen mit dem geliebten Vaterland!) (Žukovskij Siller Bd 1 (1901). S. 149) ..- Tеперь мы блины мзшае.м. нансвежайшую икру употребляем [...]." (..jetza verzehren wir Blinis [Blinsen]. wir benutzen dazu den allerfrischesten Kaviar [ ]" (Tschechow Bd 1 (1949), S. 288)) (Cechov, 2, 69) Die von uns kursiv angegebenen verwandten Verben - vkus.s ${ }^{\circ}$ und ktu.xal ${ }^{\circ}$ - markieren auf lexikalischer Ebene die Opposition zwischen den in den Texten deklarierten Wernen Das zweite bedeutet eine Verdinglichung. Materialisienung des ersten, das Wiedersehen mit dem Heimatland wird durch den Essensyenuß ersetzt Die zitierte Aussage aus der Ballade gehorn zwar dem lyrischen Erzahler, seine Perspektive nahert sich aber bei Żukovskij der Perspektive der sprechenden fiktiven Personen. so daß ihre Stimmen sich an vielen Stellen gegenseitig erganzen, die zitierte Replik verschmilz z B mit der darauf tolgenden Aussage von Odvsseus (Ahnlich verhalt es sich mit dem Ich-Erzahler in der Kurzgeschichte Cechovs. Er ist einer der bei der Feier anwesenden kleinen Beamten. gehon also in die fiktive Wirklichkeit des Textes. der Erzahler und seine Perspektive ist in beiden Fallen ein Teil des fiktiven Ganzen. der Diegesis und mit der Sicht der fiktiven Personen insofern vergleichbar) In diesem Sinne reprasentieren beide Aussagen - sowohl die Kozulins als auch die des lyrischen Erzahlers der Ballade - die dargestellte Ebene des Werkes und die in ihm dargestellten fiktiven Werte 
Dem Wissen der Achaier über die Flüchtigkeit des Siegesglückes wird die Freude des Beamten am „Eroberten“ und an der eigenen grenzenlosen Macht über den Verlierer gegenübergestellt.

Eine „kontrafaktische“ Äquivalenz findet in Čechovs Text auch die in der Ballade mehrfach thematisierte Opposition „Helden (Sterbliche) - Götter“. Götter sind im Referenztext allmächtig und (außer Bacchus) gleichgültig und erbarmungslos. Ein eigenwilliger und erbarmungsloser Gott ist bei Čechov der "načal'nik“ (Vorgesetzter) (zum Zeitpunkt des Erzăhlens Kozulin, dem gegenüber alle Anwesenden die Rolle der "Sterblichen“ übernehmen, in der Erzählung Kozulins sein Vorgesetzter Kuricyn, der Sterbliche ist dann Kozulin). Die Korrespondenz zwischen dem Vorgesetzten und dem Gott wird hier auf zweifache Weise suggeriert. Zum ersten Mal am Anfang der Geschichte, wenn der Ich-Erzăhler seinem Vorgesetzten Kozulin allegorisch göttliche Eigenschaften und Merkmale verleiht: „Козулина вы не знаете; [...] для нашего [...] брата, не парящего высоко под небесами, он велик, всемогущ, высокомудр.“ („Sie kennen Kozulin nicht; [...] fur unsereinen aber, der nicht so hoch über den Wolken schwebt, ist er groß, allmăchtig und allweise. $\left.{ }^{(6+6)}\right)(2,68)$. Der Gegensatz „Gott Mensch“ wird hier durch die raumliche Opposition „oben - unten“ bzw. „Himmel - Ende“ betont. Zum zweiten Mal wird die Parallele durch eine onomastische Allusion vermittelt und bezieht sich auf Kuricyn vs. Kozulin: „- [...] Tеперь-то он червячком глядит, убогеньким, а прежде что было! Нептун! Небеса разверзеся!“ („'[...] Jetzt freilich schaut er wie ein Würmchen aus, jetzt ist er ein armseliges Etwas; was aber war er ehedem! Ein wahrer Neptun [Neptun!]! Ein Himmelsstürmer! [...] $\left.{ }^{\mathrm{m} 647}\right)(2,70)$. Der Name des römischen Meeresgottes Neptunus - in der Ballade Schillers erwähnt ${ }^{\text {t48 }}$ - wird bei Žukovskij durch den griechischen .Poseidon“ ersetzt:

И, с предведеньем во взгляде,

Жертву сам Калхас заклал:

, [...]

Буреносиу Поссіи)ну,

Воздымателю валов

[...]"

(Und, mit Prophezeiung im Blick,

Brachte Kalchas selbst das Opfer:

......]

Dem Sturmtreiber Poseidon,

Der die Wogen in die Höhe hebt [... [“" $]^{\text {(n) }}$

\footnotetext{
(146 Tschechow Bd. I (1949). S 287

647 lbid S 290

cas "I ] Und Neptun, der um die Lander/ Seinen Wogengurtel schwingt." (Schiller Teil I. Bd 2 (1983). S 189)

asy Siller Bd 1 (1901). S 148
} 
Die Aktantenkorrespondenzen werden im Cechovschen Text nochmals verschoben ${ }^{650}$; die Opposition „Götter - Menschen [Sieger und Besiegte]“ in der Folie wird durch die Opposition „Sieger [Götter] - Besiegte [Menschen]“ ersetzt. Das im Prätext streng Getrennte, ja unveränderbar Polare wird im aktuellen Text in einer (menschlichen) Person vereinigt - so ist Kozulin zum Zeitpunkt des Erzählens der Sieger und der Gott.

Durch die Projektion der Antithese "Götter - Menschen" auf das Verhăltnis zwischen dem Vorgesetzten und dem Untergebenen in "Toržestvo pobeditelja“ schaff Čechov eine Kontrafaktur der im Prătext festgelegten Weltordnung. Dem unaufhebbaren und unveränderlichen Gegensatz zwischen der Welt der Götter und der der Sterblichen im Prátext steht der verănderliche, inhaltlich umkehrbare Gegensatz zwischen dem Untergebenen und dem Dienstherm im aktuellen Text gegenüber. Der festen Hierarchie der antiken Welt, wiedergegeben in der Ballade, steht die feste, jedoch nicht konstante Hierarchie in der Kurzgeschichte gegenüber; die Rollen erweisen sich im zweiten Fall als austauschbar, „Götter" werden unter veränderten Umstănden zu nichtigen und (ge)demütig(t)en Menschen und diese steigen zum Olymp empor. Götter, die im Gedicht von der Vergänglichkeit unberührt bleiben, sind bei Cechov .falsch“, vergänglich, sie werden zu Sklaven. Wenn die Götter der Ballade zwar ungerecht $\operatorname{sind}^{651}$, die Vergeltung an ihnen aber - nicht nur angesichts der versöhnlichen Botschaft des Textes, sondern auch aufgrund ihrer Unerreichbarkeit, ihrer absoluten Überlegenheit gegenüber den Menschen - undenkbar ist, wird bei Cechov an den entlassenen „Gơttern“ Rache geübt. Eine solche Austauschbarkeit der Rollen (Positionen, Masken. Verhaltensmuster), die Făhigkeit und Neigung der Cechovschen Figuren zur vollkommenen Verwandlung ist mit dem für den frühen Čechov zentralen, in der einschlägigen Forschung wiederholt erörterten Thema des Chamáleons zu verknüpfen. Dieses Thema tritt hier in ihrer relevantesten - sozialkritischen - Funktion auf und wird, wie aus unserer Analyse folgt, auf eine spezifische, intertextuell-dialogische Art behandelt. ${ }^{\text {t52 }}$

${ }^{650} \mathrm{~V}_{\mathrm{gl}}$ bei Schmid 1983. S. 162. den Ausdruck ..korrespondierende Aktanten”'s bei Schmid z.B in. ibid., S. 181.

${ }^{651}$ In der Auseinandersetzung von Menelaos und Ajas setzt sich die Meinung des letzteren durch, der die Gerechtigkeit der Gotter in Frage stellt

\author{
„Пусть веселый взор счастливых \\ [ ] \\ Зрит в ботах ботов правдивых! \\ Суд их часто слеп бывал \\ Скольких бодрых жизнь поблекла' \\ Скольких низких рок щадит' \\ (Moge der heitere Blick der Glucklichen \\ [.] \\ In den Göttern die Gerechten sehen' \\ Ihr Urteil war of blind \\ Von wie vielen Munteren das Leben ist erloschen' \\ Wie viele Niedertrachtige verschont das Fatum!) (Siller Bd I (1901), S 149)
}

C52 Uber das Chamaleon-Motiv beim fruhen Cechov s vor allem in der Monographie von Kramer .The Chameleon and The Dream“" (1970) (vgl im Literaturverzeichnis) Der Forscher findet dieses Motiv in einer Reihe der fruhen Texte und vertindet es in erster Linie mit der mangelnden Fahigkeit der Figuren Cechovs, ihre personliche 
Insofern wird die im Prătext vermittelte Idee der tragischen Unabwendbarkeit des Schicksals und die sich daraus ableitende fatalistische Besinnung der Personen auf der fiktiven Ebene des präsenten Textes, d.h. auf der Ebene der Aussagen der Figuren, demonstrativ widerlegt. Vergleichen wir die Textstellen, die die philosophisch-weltanschaulichen Aspekte des Dargestellten zum Ausdruck bringen. Wie oben bereits erwăhnt, wird der Triumph der Sieger und damit der Gegensatz zwischen den beiden Kriegsseiten - den Achaiern als Sieger und den besiegten Trojem - im Gedicht durch den Gedanken abgeschwächt, daß schließlich alle Sterbliche den höheren Kräften ausgeliefert sind und der Erfolg genauso wie die Niederlage der Menschen von dieser höheren Macht bestimmt wird. Der Ausgang des Krieges ist daher als Geschenk bzw. als Zeichen der (Miss)Gunst der Götter gegenüber den auf dieser oder jener Seite Kämpfenden konzipiert:

\author{
„Всё великое земное \\ Разлетается как дым: \\ Ныне жребиі выпат Трое. \\ Завmpa вwnadem opyzuw." \\ (..Alles irdisch Grosse \\ Lost sich auf wie Rauch \\ Heute hat Troja das Los gezogen. \\ Morgen werden es die anderen ziehen. ") 653
}

Identitat zu bestimmen. Dies sei ein wichtiges Thema auch für die spateren Werke ..In all these stories Cexov employs the chameleon act for essentially comic purposes. but despite the predominantly humorous note here. they carry a whole series of terrifying implications: [ . ] both reader and writer must make the assumption that man lacks a sense of personal identity. This is an extremely distasteful premise the consequences of which $C$ exov persues later in his career, particularly in ..A dreary Story” (Skučnaja istorija). [. ]." (1970. S. 59).

„Torżestvo pobeditelja" wird von Berdnikov erwahnt, wenn er von der Bereitschaft der Cechovschen ..erniedrigten“ Menschen spricht, sich in Despoten zu verwandeln (1961, S. 36). Berdnikov entdeckt die ChamäleonProblematik in ihren unterschiedlichen Varianten ebenfalls in mehreren fruhen Kurzgeschichten Cechovs.

${ }^{653}$ Siller Bd 1 (1901). S 150 (s Ủbers teilweise auf S. 128 dieser Arbeit) Daß diese Zeilen als philosophische Dominante fur das ganze Gedicht aufgefaßt werden konnen, belegen auch die Aussagen der Sieger wie Ajas und Neoptolem Vgl.

.Смертный, царь-Зевес Фортуне

Своенравной предал нас:

[. $]^{\text {"* }}$

(..Sterblicher, der Zar Zeus hat uns Fortuna.

Der eigensinnigen ausgeliefert

[ . ") (ibid)

Oder

. $.1 \ldots$

Жизнь живущих неверна.

Жизнь мтживших неизменна "“

(..l. )

Das Leben der Lebenden ist unzuverlassig.

Das Leben der Abgelebten ist bestandig 1'*) (ibid ) 
Die von uns hervorgehobenen Zeilen ${ }^{654}$, die einen Teil der Aussage der Seherin Kassandra bilden, korrespondieren in der Kurzgeschichte auf eine besondere Art mit den folgenden Worten Kozulins: „[...] всякие перемены бывают, [...] [...] Tozда ты, а теперь я...“ (,,'[..] Allerlei Verănderungen gibt es [...] Damals du, jetzt ich ... [...] “655) (2, 70-71). Die zweite Aussage stellt bei der formalen Similarităt eine Gegenthese zu der ersten dar: Im ersten Fall wird - entsprechend der Grundidee des Textes - die Niederlage der Trojer relativiert, im zweiten dagegen der Sieg und der Triumph Kozulins bekraftigt. Die Idee des potentiellen Wandels der Umstănde, der Umkehr der dargestellten Situation und des möglichen Austauschens der den Protagonisten zugewiesenen Rollen bildet den Inhalt einer fatalistischen Weltanschauung in der Ballade. Der Fatalismus entspringt hier dem Gedanken der Unterwerfung der Menschen und also der Achaier ebenso wie der Trojer unter dem Willen der măchtigen und launischen Götter. ${ }^{656}$ Der genannte Wandel wird vom Čechovschen Beamten, vielmehr noch von der ganzen Logik der Geschichte dagegen als Ergebnis eigener Bemühungen (sprich langjähriger Demut), als eine gut gemachte Karriere präsentiert, die ihm gerade ermöglicht, nicht mehr unterworfen zu sein, ja selbst zu unterwerfen. Dadurch, daß es in der fiktiven Welt Cechovs keine höhere Macht gibt als die der am „Krieg“ Beteiligten, daß die Rolle des unbarmherzigen Gottes der Sieger übernimmt, wird der Fatalismus der antiken Welt bei Žukovskij in der gottlosen Welt der Kurzgeschichte weitgehend destruiert und durch die auf eine andere, besondere Art fatalistische (Lehens)philosophie explizit ersetzt. Im Endergebnis wird hier eine eigenartige Verschiebung weltanschaulicher Akzente vollzogen, indem den philosophischen Schlüsselaussagen des Prätextes Žukovskijs analog-kontrastive fiktive Aussagen des Posttextes entgegengesetzt werden. Zitieren wir die letzte Strophe - das philosophische Fazit - der Ballade (ausgesprochen von Kassandra):

Die Idee der Eitelkeit des irdischen Daseins, der Hilflosigkeit des Menschen und der Vorbestimmtheit der Ereignisse durchzieht wie ein roter Faden den Text und wird in den Mund verschiedener Figuren gelegt ${ }^{694}$ Die letzten zwei zitierten Zeilen stellen allerdings eine freie Ubersetzung der im Original Schillers dar. Vgl.

Rauch ist alles irdsche Wesen.

Wie des Dampfes Saule weht.

Schwinden alle Erdengroßen,

6ss Tschechow Bd 1 (1949). S 291

Nur die Götter bleiben stat (Teil I, Bd 2 (1983), S 193)

os6 Diese fatalistische Weltanschauung kommt allerdings ausschließlich im Text Žukovskijs zum Ausdruck Der letzten Strophe bei Żukovskij widerspricht die folgende bei Schiller

Um das Roß des Reuters schweben.

Um das Schiff der Sorgen her.

Morgen konnen wirs nicht mehr.

Darum laBi uns heute leben! (Teil I. Bd 2 (1983). S 193)

Bei Schiller ist also vielmehr vom Aufbegehren des Menschen gegen die hohere Macht zu sprechen, als von der Demut Cechov schreibt in dieser Hinsicht eine Kontrafaktur vor allem zur Ubertragung und ..Interpretation* Schillers durch Żukovskij 
„Смертный, силе, нас гнетуичей.

Покоряйся и терпи'

Спяший в гробе - мирно спи!

Жизнью пользуйся живуший!“

(,Sterblicher, der Macht, die uns bedrückt.

Füge dich und dulde!

Der im Sarg schlafende - schlafe in Frieden!

Nütze das Leben, Lebende!"“) 657

Und vergleichen wir dagegen das Geleitwort Kozulins an seine Untergebenen: „- [...] He ропияите, не сетуите и вы, пока до конңа не дожсиёте! Всё бывает, ну и всякие перемены бывают..." (.,'[...] Murrt nicht und klagt nicht, solange ihr noch nicht das Ende erlebr habr! Es gibt alles auf der Welt, und es können die eigenartigsten Verănderungen eintreten...[... $\left.]^{\kappa .658}\right)(69) . \grave{Z u k o v s k i j: ~}$

„Сертный, царь-Зевес Фортуие

('военравнои предат нас:

Уловляй же быстрый час,

Не тревожа сердца втуне.

[... $]^{\text {"* }}$

(,Sierblicher, der Zar Zeus hat uns Fortuna,

Der eigensinnigen ausgeliefert:

Nütze die schnelle Stunde.

Ohne dein Herz grundlos zu plagen.

$\left.[\ldots]^{\cdots}\right)^{659}$ -

Cechov: „- [...] Ты теперь, положим, ничтожество, нуль, соринка... изюминка - а кто знаст? Может быть, со временем и того... суоьбы че.ивеческие зи викор возымёиьь! Bсякое бывает!“” (,.'[...] Gesetzt den Fall, daß du heute ein Nichts, eine Null, ein Stäubchen wärst ... ein winziges Rosinchen [ein Rosinchen] - wer aber kann wissen? Vielleicht wird mit der Zeit etwas daraus... die menschlichen Schicksale kunn man mut emem Hirbelwind vergleichen [die menschlichen Schicksale packst du um Schopf]! Es gibt alles auf der Welt!octrot) $(2,69){ }^{\text {(x) }}$

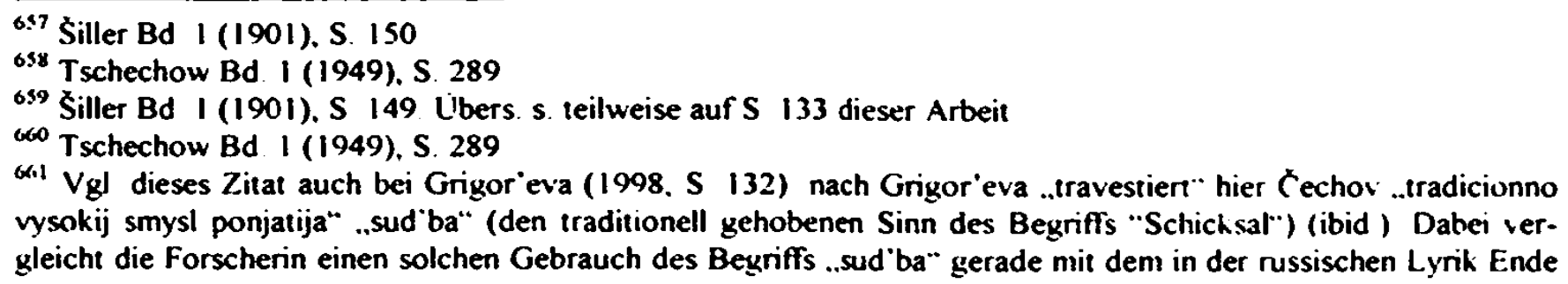


Zwar thematisiert auch der Cechovsche Beamte die Unvorhersehbarkeit der Ereignisse im menschlichen Leben, sein Fatalismus hebt sich aber deutlich von dem der antiken Menschen im alludierten Gedicht ab. Während Resignation und Demut für die Personen Żukovskijs bedingungslos und absolut sind, weil sie auf der Unveränderbarkeit der gegebenen Weltordnung, auf dem konstanten Charakter der existentiellen Hierarchie beruhen, stellt der "Stoizismus“ bei Čechov eine vernünftige Strategie dar, die später - sofern man Glück hat - erlaubt, "das menschliche Schicksal in die eigenen Hände zu nehmen“, selber zu regieren und zu strafen. Im Grunde soll die in der Geschichte thematisierte Wandlung der Umstände und der Austausch der Rollen nicht die Willkür des Schicksals, wie bei Žukovskij, sondern gerade die Logik des staatlichen Dienens und damit des bürokratischen Systems Rußlands der 1880er Jahre demonstrieren. In diesem Sinne ist sie durchaus vorhersehbar und geplant. Um den Gegensatz zwischen den ideellen Schichten beider Texte noch mal zu betonen, trägt die philosophische Besinnung der Achaier zur Eindämmung des Konfliktes, zum milden Umgang mit den Besiegten bei, die Philosophie Kozulins thematisiert die Möglichkeit des Aufstieges, des neuen Sieges, der späteren Rache.

Etwas „verdreht" ist in der Kontrafaktur "Toržestvo pobeditelja“ ebenfalls der in den zitierten Strophen des Gedichtes manifestierte ethische Hedonismus der antiken Figuren. Die Freude am Augenblick, das Genießen des flüchtigen Lebens, von verschiedenen Personen gepredigt, ist im Referenztext von einer existentiellen Resignation bedingt und besitzt wiederum einen explizit humanen Charakter: Das Motiv des tröstenden Weines zusammen mit dem der hedonistischen Freude entfaltet sich aus der oben erwähnten Episode mit Nestor und Hekuba. Die nach dem Trojanischen Krieg Überlebenden. Sieger wie Besiegte, sind die von den Gơttern Begnadigten, ihnen wird das Glück des Lebens noch einmal beschert. Der Begriff „Sterblicher“ (смертный) in den oben angeführten Zitaten deutet bei Žukovskij auf das Einssein von Trojern und Achaiern vor dem höheren Willen hin. Das Ausnützen des Augenblickes, der Appell .Laßt uns heute leben“" (,Жизнью пользуйся живущий!“) bedeuten in diesem Kontext den weisen Umgang mit dem ..großen Schmerz" des Lebens. Dem Appell ..Жизнью пользуйся жнвуший!“” am Ende der Ballade entspricht bei Čechov nicht nur das

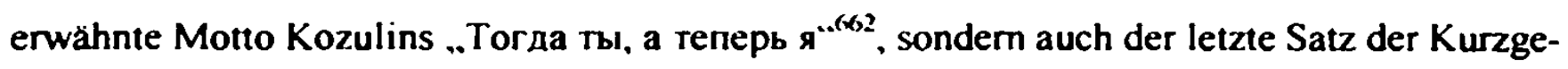
schichte, der Schlußausruf des Ich-Erzählers: „Быть мне помощником письмоводителя!“ (,'Ich werde bestimmt Gehilfe des Schriftführers werden! $\left.{ }^{\mid c \cdot 663}\right)^{\text {nxt }}$. Das (eher abstrakt formulierte) Nützen des Augenblickes in der Ballade wird hier zum Ausnützen der praktischen Vorteile bzw. der Gelegenheit, diese Vorteile zu erlangen. konkretisiert. Der versöhnliche

des XVIII-Anfang des XIX Jahrhunderts - einer Verwendung. die sich auf die .antike Tradition“ bezieht (s. ibid. $S$ 128-132)

${ }_{\infty} \mathrm{s} S$ Übers auf $S .134$ unserer Arbeit

${ }^{\circ} \mathrm{s}$ Ibid

(4) Als der Vater des Ich-Erzahlers am Ende der Geschichte dem Befehl Kozulins ..Бегай вохруг стола и пой neтушком!" (..'Lauf rund um den Tisch und krahe wie ein Hahn"“ (Tschechow Bd I (1949). S 291)) (2. 71) gehorcht, macht der Ich-Erzahier unaufgefordent dasselbe und erhoft sich dadurch eine Befordenung im Dienst. 
Hedonismus entartet zur Ellenbogenphilosophie, zum unverdeckten Eigennutz. Wieder geschieht hier die Materialisierung der im Prătext gepriesenen Werte und die Destruktion der moralischen Absichten der Figuren.

Die Umschreibung von Schillers-Žukovskijs Ballade „Toržestvo pobeditelej“ vollzieht sich in der Kontrafaktur Cechovs zunăchst, wie wir gesehen haben, durch das Herstellen einer Reihe von Äquivalenzen auf der diegetischen Ebene. Auf einen anderen Stoff übertragen, wiederholen sich Elemente der fiktiven Situation und der Sujetstruktur des Prătextes wie u.a. die Abhaltung einer Feier; die im Titel suggerierte Präsenz eines Konfliktes, also von Gegnem und ebenfalls des Sieges einer Seite über die andere; die Aufzăhlung der vom Sieger im .Kampf" gebrachten Opfer. Strukturelemente des alteren Textes unterliegen hier nicht nur gewissen Modifikationen (wie z.B. die Verschiebung der Personenkonstellation, die eine Monologisierung der Textstruktur zur Folge hat), sondern gewinnen in der neuen Umgebung eine andere Semantik, die den Charakter des jüngeren Textes als Widerschreiben ausmachen (so wird der Konflikt zwischen den Protagonisten nicht neutralisiert, wie in der Vorlage, sondern betont und bestätigt, und der Triumph als Feier wird zum Triumph als Schadenfreude). Auch die Verschiebung der den Personen zugewiesenen Rollen (vor allem die Projektion der Antithese „Gotter - Menschen“ auf die „Vorgesetzter - Untergebener“) dient im Rahmen der Kontrafaktur einer Widerlegung der im Referenztext festgelegten Weltordnung. Die Summe der in "Toržestvo pobeditelja“ durchgeführten Transformationen der Vorlage dient im Ganzen zur Erschuffung einer negativen Allernative zum Original auf der Ebene der in ihm dargestellten und fiktiv, d.h. von den Personen, propagierten moralisch-philosophischen Gedanken. Der versöhnlichen, melancholisch gefärbten, belehrenden Botschaft des Gedichtes steht eine ..nackte“ Demonstration der Mißstände, das Schweigen der darstellenden Instanz der Satire Cechovs gegenüber. Die in einem dem Leser Cechovs durchaus bekannten Prătext manifestienten hohen moralisch-weltanschaulichen Werte des fiktiven Altertums werden auf das russische Beamtenmilieu der 1880er Jahre ..übertragen“, für dieses Milieu inversiv ..adaptiert“. 'x.s In seiner Kontrafaktur nützt Cechov das kommunikative Potential der Vorlage aus, um (nicht sie selbst, sondern) mit ihrer Hilfe (mittels einer intertextuellen Kontrastbildung) bestimmte Bereiche der gegenwărtigen Realität zu kritisieren und damit die eigene Botschaft zu artikulieren.

\footnotetext{
coss In diesem Sinne ist hier die Kontrafaktur als ..Prosaisierung“ (vgl. Schmid 1983. S 180-181) des Originals Žukovskijs anzusehen $\mathrm{Vgl}$ die Schlußfolgerung von Schmid nach der Analyse von ..Stancionnyj smotritel ${ }^{\cdots}$ als Kontrafaktur ..Puskins Novelle bietet sich als prosaische [ ] Kontrafaktur au der nicht mehr als wahrheitshaltig anerkannten einseitigen sentimentalistischen Modellierungen von entweder Liebesglück (Karlgof) oder Liebesleid (Karamzin) dar “ (S 181) S dazu auch die Fußn 594 Wie wir jedoch bereits ausgefühn haben. beinhaltet die Kontrafaktur Cechovs keine Ablehnung bzw Kritik oder ..Überwindung“ des im Pratext Vermittelten. Die Interpretation der Vorlage als nicht ..wahrheitshaltig" oder ..einseitig" findet hier keinen Ausdruck Uber die An der ..Prosaisierung" in unserem Fall s. u a auf S. 114 dieser Arbeit
} 


\subsection{2. "Šllo v meske“}

Die im Jahre 1885 verfaßte Kurzgeschichte „Šilo v meške“ stellt ebenfalls den Fall einer hypertextuellen Einzeltextreferenz dar, nämlich ein ums Mehrfache gerafftes Umschreiben und eine Inversion der Komödie „Revizor” (Der Revisor) (1836) von Nikolaj Gogol’ ${ }^{.666}$ Wăhrend aber die Kontrafaktur "Toržestvo pobeditelja“ einen radikalen Wechsel des im Referenztext vorgefundenen Stoffes realisiert, weist „Šilo v meške" eine wesentlich größere thematische Năhe zum Original auf. Die Übernahme der Elemente der fiktiven Situation einschließlich Figurenkonstellation und Handlungsablauf beruht hier nicht mehr ausschließlich auf dem Analogieprinzip (strukturelle Äquivalenzen), sondern wird durch stofflich-thematische Korrespondenzen ergänzt. In "Toržestvo pobeditelja“ kommt ein Austausch des gegebenen Themas zustande, in „Šilo v meške“ - dessen Modifikation, so daß der thematische Kern, die Grundsituation (Besuch eines Revisors in einer provinziellen russischen Stadt) beibehalten wird. Wenn im ersten Fall Cechov eine moderne Version der im Prätext dargestellten Wirklichkeit schafft, schafft er im letzten ihre modernere Variante, die in der Anpassung des ursprünglichen Sujets an die anderen und neuen Umstände besteht. Jedoch fürt eine solche Anpassung und die .Korrektur“ auch hier zu den .,kontrafaktischen“ Transformationen des Vorgefertigten und der jüngere Text bildet in mehreren Punkten einen Kontrast zu dem älteren. Damit manifestiert sich auch diese Kontrafaktur einerseits als Text mit einer eigenen Aussageabsicht, andererseits als Wider-Schreiben des Originals. Wie "Toržestvo pobeditelja“, enthält auch „Silo $v$ meške“" keine parodistischen Textverarbeitungsverfahren. z.B. keine stilistisch-thematische Nachahmung und zugleich Entstellung der Vorlage, die die Form-InhaltDiskrepanzen und -Brüche im aktuellen Text herbeiführt. Bei einer gewissen Zahl der intertextuellen Spuren (also der aus dem Prätext zitierten Elemente) und der erwähnten thematischen Affinität zum Original demonstriert die Kurzgeschichte in erster Linie einen Dialog der Erzăhlstrukturen (der Handlungsabläufe).

In .,Silo v meške“ macht sich der Revisor Pëtr Pavlovič Posudin auf den Weg in eine kleine Provinzstadt (..уездный городишко N.“, ..Kreisstadt N..(667)) mit der Absicht, die ihm in einem anonymen Brief geschilderten Mißstände in dieser Stadt zu enthüllen und die korrupten Beamten auf frischer Tat zu ertappen. Im Laufe des Gesprächs mit dem Kutscher, der von der Identităt des Reisenden nichts ahnt. erfahrt aber Posudin immer mehr die Wahrheit: Die Kreisbewohner wissen nicht nur über seine Qualitäten und Verdienste Bescheid (was seiner Eitelkeit Genüge tut), sondern sind ebenfalls bestens überr seine heimlichen Schwächen und Laster informiert. Wenn der redselige Kutscher Posudin verrät, daß die Bewohner sich auf seine Revisionen immer gut vorbereiten, noch bevor er sein Haus verlassen hat, die Spu-

\footnotetext{
666 Vgl die Bemerkung von Berdnikov ..B paccказе 'Wило в мешке' - чеховская шуточная разработка ситуацин гоголевкого 'Ревнзора', I ] " (In der Geschichte ..Silo v meške" ist die Cechovsche humoristische Ausarbeitung der Situation vom Gogol 'schen..Revizor" zu finden. l J) (1981. S 128)

${ }^{667}$ Tschechow Bd 1 (1949), S. 178
} 
ren verwischen und ihn mit Erfolg an der Nase herumführen, daß er auch diesmal von den Verantwortlichen lăngst erwartet wird, fordert ihn der wütende Posudin auf zurückzukehren:

- Назад! - прохрипел Посудин. - Поезжай назад, ссскотина!

И удивлённый возница повернул назад.“ (,'Zur-rück!' krächzte Posudin. 'Fahr zurück, du Rindvieh!"

Tief erstaunt [Erstaunt] wendete der Kutscher. $\left.{ }^{.6608}\right)(4,257)$.

„Šilo v meške“ enthălt mehrere explizite Verweise auf die Gogol'sche Komödie. So alludiert schon der erste Satz der Kurzgeschichte die fiktive Situation von „Revisor" - die Situation der Revision in einer Provinzstadt: „На обывательской тройке, просёлочными путями, соблюдая строжайшее инкогнито, спешил Пётр Павлович Посудин в уездный городишко N, куда вызывало его полученное им анонимное письмо.“ („Das strengste Inkognito wahrend, hastete Pjotr Pawlowitsch Possudin in einer gewöhnlichen Troika auf Landwegen zur Kreisstadt N., wohin ihn ein anonymer Brief, den er erhalten hatte, rief. ${ }^{\text {(669) }}$ ) $(4,254)$. Im Wort „инкогнито“ ist leicht ein wichtiges lexikalisches Motiv des Gogol'schen Stückes erkennbar, das dort ebenfalls bereits am Textanfang auftaucht: „Городничuй. Ревизор из Петербурга, инкогнито. И ещё с секретным предписанием.“ (,STADTHAUPTMANN: Ja, ein Revisor aus Petersburg, inkognito. Und auch noch mit einer geheimen Order. $\left.{ }^{6670}\right)^{671}$. Diese Allusion - ein Handlungsdetail, dessen intertextueller Ursprung wegen der auffalligen Textstelle, an der es erscheint, und seiner kontextuellen Umgebung schwer zu verkennen ist, wird im nächsten Absatz durch einen weiteren Bezug - ein Zitat aus der ersten Szene des Stückes - noch bestătigt. Posudin stellt sich die ungeheuerliche Wirkung seines Überraschungsbesuches bei den Tätern vor: „'[...] Воображаю их ужас и удивление, когда в разгар торжества послышится: «А подать сюда Тяпкина-Ляпкина!» То-то переполох будет! Ха-ха..."' (.,'[...] Gut kann ich mir ihr Entsetzen und ihre Überraschung vorstellen [Ich stelle mir ihr Schrecken und ihre Überraschung vor], wenn es mitten in ihrem Triumph ertönen wird: Man führe mir den Tjapkin-Ljapkin vor! Das wird ein Durcheinander geben! Ha-ha... $\left.{ }^{\mathrm{k} 672}\right)(4,254) .{ }^{673}$ Posudin gibt das zitierte Segment nicht exakt wieder, er verzert etwas die bei Gogol' vom Stadthauptmann Skvoznik-Dmuchanovskij ausgesprochene Phrase ${ }^{674}$, genauer gesagt, den in ihr genannten Namen des Richters (vgl.: ..A

\footnotetext{
$\cos$ Ibid S 183

\&.9 Ibid S 178

${ }^{670}$ Gogol 1973. S. 11

671 Gogol" 1903. S 11 ..Revisor" wird nach der folgenden Ausgabe zitiert N Gogol Revizor Komedija v pjati dejstvijach i teatral'nyj raz' ezd (Der Revisor Komodie in funf Akten und der Aufbruch nach dem Theaterbesuch) S.-Peterburg 1903 (s. das Literaturverzeichnis). Hervorhebung (auch im Weiteren) von uns

672 Tschechow Bd. I (1949). S 178

${ }^{673} \mathrm{~S}$. uber dieses Zitat auch bei Berdnikov 1981, S 128 und hei Kuzina 1993. S 11

$6: 4 \mathrm{~S}$. in den Anmerkungen aum Text (4,503)
} 
подать сюда Ляпкина-Тяпкина!“ („Also her mit Ljapkin-Tjapkin!“675) ${ }^{676}$ ) - eine Anpassung des Satzes an die alltägliche Sprachgewohnheit, die gerade auf seinen häufigen Gebrauch, ja die Abnutzung durch die Leser der Zeit Cechovs hindeutet. ${ }^{67}$ Auch die von Posudin ausgemalte Szene der Verwirrung, insbesondere die Worte „V razgar toržestva“ ("mitten in ihrem Triumph") rufen die „stumme Szene“ im Finale der Gogol'schen Komödie ins Lesergedächtnis. Das von Skvoznik-Dmuchanovskij Gefürchtete wird hier zum vom Revisor Posudin Erhofften, eine Zukunftsvision wird durch die andere ersetzt, begleitet durch einen Perspektivenwechsel. Auch im Weiteren findet man mehr oder minder explizite, im Text verstreute Referenzen zu „Revizor“. Es ist beispielsweise die Allusion - eine nach der Bezeichnung von Perri, „definite description“ in Form von ., the brief echo of content“678 - eingebaut in die Erzăhlung des Kutschers, der die Unbestechlichkeit von Posudin beteuert: „- $[\ldots]$ Дай ты ему хоть сто, хоть тышу, а он не станет тебе приймать трех на душу..." (, [...] ob du ihm hundert anbietest oder tausend, dieser Sünde verfallt er nicht!.. $\left.[\ldots]^{m .679}\right)(4,254)$. Hier werden die Bestechungsszenen im vierten Akt der Komödie angedeutet, konkreter die Bestechung des vermeintlichen Revisors Chlestakov durch Bobčinskij und Dobxinskij. Nachdem die Gutsbesitzer die verlangten tausend Rubel bei sich nicht finden, sagt Chlestakov: .Да, ну, если тысячи нет, так рублей сто.“ (,Nun, wenn Sie keine tausend haben, dann, sagen wir, hundert [dann hundert]. $\left.{ }^{680}\right)^{681}$. Als der Kutscher etwas spater von der Schwäche Posudins für Frauen spricht, zitiert er (im Unterschied zu Posudin, ohne das zu wissen), Chlestakov: „- A вот тоже насчетт женского пола... Шельма!“ (,'Und so auch hinsichtlich des weiblichen Geschlechts... ist er ein rechter Schelm [ist er Schelm]! ‘6\$2 $)(4,255)$. Vgl. bei Gogol’: „Bor euë насчёт женского пола, никак не могу быть равнодушен.“ (.Ebenso wie für das weibliche Geschlecht - da kann ich einfach nicht gleichgültig bleiben. “683 $)^{684}$. Im ersten Fall wird der Gegensatz zwischen den Pendanten Posudin und Chlestakov suggerier, im zweiten (wo im Grunde ein Zitat aus dem „Revizor“ vorliegt) die Ähnlichkeit.

Außer den hier angeführten intertextuellen Signalen - den wörtlichen Verweisen auf den Prătext, die die Bewußtheit und die Intentionalität des Text-Text-Kontaktes bezeugen, - sind in der Kurzgeschichte mehrere indirekte Hinweise (sprich auch Allusionen) auf die ..Revizor"-Intertextualităt enthalten, die z.B. in den der Vorlage ähnlichen, an sie „erinnernden“ Charakteristiken, Redewendungen und Details ihren Ausdruck finden. Beide Referenztypen

\footnotetext{
67s Gogol 1973, S. 18

${ }^{676} \mathrm{Gogol}^{\circ} 1903$, S. 20

67 Auf eine ahnliche .Adaption" des Zitats aus Gogol" im Laufe seiner Allagsrezeption, die einen trivialen Umgang mit der popularen Literatur demonstriert. weist auch Kanevskaja hin (s S 64-65 dieser Arbeit). vgl ebenfalls Kuziceva (s S. 164 dieser Arbeit)

${ }^{678} \mathrm{Vgl}$. S. 31 unserer Arbeit

"779 Tschechow Bd 1 (1949). S. 179

Gogol 1973, S 90

(4) Gogol' 1903. S 86 Uber die enwahnte Allusion s bei Kuzina 1993. S 41

os2 Tschechow Bd I (1949). S 180

68: Gogol 1973. S 80

Gent' Goyol' 1903, S 82
} 
werden wir im Prozeß der Analyse zu deuten versuchen. Im Allgemeinen vermitteln solche Spuren der Fremdrede die Prăsenz intertextueller Äquivalenzen zwischen „Šilo v meske“ und „Revisor" auf verschiedenen textuellen Ebenen wie der des Sujets und der fiktiven Charaktere. Analogische Äquivalenzen sind hier auf eine eigenartige Weise mit den oppositiven kombiniert und vermischt.

„Šilo v meške“ beinhaltet zwei Geschichten, die das eigentliche Sujet bilden: die erste spielt sich auf diegetischer Ebene ab und ist mit der Reise Posudins und seinen durch die Erzählung des Kutschers gewonnenen Erkenntnissen, die den Entschluß zur Rückkehr vorbereiten, verknüpft; die zweite spielt sich auf metadiegetischer Ebene ab und umfaßt die vom Kutscher erzăhlten, der Reise vorangehenden Ereignisse. ${ }^{685}$ Die erste - diegetische - Geschichte beschreibt die Situation vor der Revision, d.h. das Geschehen vor dem (bevorstehenden) Treffen des Revisors mit den Stadibewohnern. In diesem Sinne entspricht sie dem ersten Akt von „Revizor“ (vor der Zusammenkunft Chlestakovs mit Skvoznik-Dmuchanovskij und den anderen Personen im Gästehaus), mit dem Unterschied, daß dieses Treffen bei Cechov aus der Perspektive des (echten) Revisors, bei Gogol' aus der der aufgeschreckten Kleinstadtbeamten dargestellt wird. Den Mittelpunkt der fiktiven Situation im Prătext bilden dementsprechend die Erwartungen der Beamten, die ein schlechtes Gewissen haben und sich vor dem Revisorbesuch fürchten, Cechov wăhlt dagegen den Blickwinkel des Revisors, der Strafgedanken hegt. Den Erwartungen der (in bezug auf die Sujetentwicklung der Komódie) ahnungslosen Stadtbewohner Gogol's werden Erwartungen des (in bezug auf die Sujetentwicklung der Kurzgeschichte) ahnungslosen Revisors entgegengesetzt. Die metadiegetisch erzahlte Geschichte alludiert in ihren einzelnen Fragmenten die Geschehnisse nach dem Treffen Chlestakovs mit den Stadtbewohnem bis zur Abfahrt des ersten am Ende des vierten Aktes (gemeint ist vor allem der vom Kutscher geschilderte (mehrmalige) Betrug Posudins durch die Kreisbewohner, ihre erfolgreiche Vortäuschung des Wohlergehens der Bürger sowie die Anspielung des Kutschers darauf, daß auch in der Stadt $N$. alle Spuren bereits verwischt sind). Der Unterschied besteht hier jedoch darin, daß der in den Augen der Gogol'schen Figuren betrogene, in Wirklichkeit aber falsche Revisor bei Cechov echt ist und also tatsächlich betrogen wird (von den Beamten anderer Städte des Kreises: ein solcher Betrug wird ebenso auch von den Beamten der Stadt $\mathbf{N}$ geplant, kommt aber wegen der Rückkehr des verzweifelten Posudin nicht zustande). Die Personenstruktur des Stückes wird in der metadiegetischen Geschichte unter diesem Gesichtspunkt vereınfacht: Der Revisor ist echt und wird für einen solchen auch gehalten. der geplante Betrug wird erfolgreich durchgeführt.

Der naheliegende Vergleich zwischen den Hauptpersonen beider Texte, Posudin und Chlestakov, deren Charakteristik sowie einiger mit ihnen verknüpften Handlungsdetails ergibt

\footnotetext{
${ }_{683}$ Wir benufen uns auf die Terminologie Genettes (1994), der zwischen diegetischer und metadiegetischer Ebene

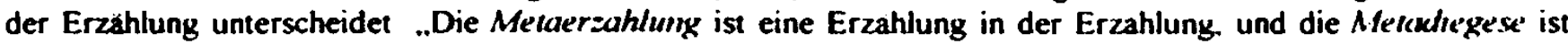
das Universum dieser zweiten Erzahlung, so wie die Ilegesse [ ] das Universum der ersten Erzählung bezeich. net." (S. 163)
} 
eine eigenartige Mischung von Analogien und Gegensătzen. So weist der echte Revisor Posudin, dessen Natur dem Leser in der Erzăhlung des Fuhrmanns bekundet wird, Charakterzüge auf, die stark an den falschen Revisor Chlestakov erinnern. Die durch das erwăhnte Zitat bestärkte Ähnlichkeit der beiden Protagonisten in bezug auf ihre Schwăche für Frauen steht in einer Reihe mit anderen analogischen Portrătdetails. Posudin offenbart sich immer mehr als Genußmensch, der beinahe allen bekannten „Lastern“ verfallen ist: Er ist alkoholsüchtig und triebhafh, eitel, verwöhnt und dazu noch ein Leckermaul. Parallel zu dem Offenbarungsproze $B$ gewinnt er auch immer mehr Āhnlichkeiten mit Chlestakov: „, [...] Приедет, скажем, хоть на почтовую станцию, и начнет!.. Ему и воняет, и душно, и холодно... Ему и шыллят подавай, и фрухтов, и вареньев всяких... [...] Ляжет на станции на диване, попрыщет около себя духами [...]." (,'[..] Nehmen wir mal an, der kommt auf einer Posthaltestelle an, dann geht's gleich los [dann fangt er gleich an]!... Alles riecht ihm schlecht, bald ist es ihm zu schwül, bald wieder zu kalt... Dem muß man junge Hühner servieren und Früchte und allerlei Eingemachtes... [...] Wenn er sich in einer Herberge auf den Diwan legt, dann spritzt er zuvor ringsherum Wohlgerüche aus [...].“686) (4, 256-257). Vgl. bei Gogol’: „Эй, Осип, ступаи, посмотри комнату, лучшую, да обед спроси самый лучший: я не могу есть дурного обеда, мне нужен лучший обед.“" (.,He, Ossip, geh, sieh zu, daß du das beste Zimmer bekommst, und verlang das beste [das allerbeste] Mittagessen - ein schlechtes kriege ich nicht hinunter, ich muß das allerbeste [das beste] haben. ${ }^{\text {r6877) }}$ (aus dem Monolog von Osip ${ }^{688}$ ); „Больше всего любит, чтобы его приняли хорошо, угощение чтоб было хорошее.“ („Am meisten schătzt er es, gut aufgenommen und gut bewirtet zu werden. “689, ${ }^{690}$; , , , признаюсь, это моя слабость, - люблю хорошую кухню.“ („Ich gestehe, ich schătze eine gute Küche, das ist so eine Schwăche von mir [Ich gestehe, das ist eine Schwăche von mir, ich mag eine gute Küche].“691) (eine Selbstcharakteristik von Chlestakov ${ }^{692}$ ); „Привыкши жить [...] в свете и вдруг очутиться в дороге: грязные трактиры, мрак невежества...“ („Wenn man gewohnt ist [...] in der großen Welt zu leben, und plötzlich fortmuß - die schmutzigen Gasthofe, die Finsternis der Unerzogenheit... $\left.{ }^{.693}\right)^{694}$. Posudin nützt also, wie es sich herausstellt, durchaus seine Vorteile als Revisor - so wie Chlestakov das tut, der für einen solchen gehalten wird, ja sich allmăhlich für einen Revisor auszugeben beginnt. In diesem Zusammenhang sind die für Posudin vorbereiteten Speisen und Getränke in der Erzăhlung des Kutschers mit denen für Chlestakov zu vergleichen: ,- [...] Может, уж едет [...],

\footnotetext{
${ }^{6266}$ Tschechow Bd. 1 (1949), S 182

607 Gogol 1973, S. 33

683 Gogol 1903, S 34 Daß die zitierte Schildenung in der Erzahlung des Fuhrmanns an die Charakteristik Chiestakovs durch Osip ..erinnert", s. bei Kuzina (1993, S. 41)

Gogol 1973, S. 75.

${ }^{690}$ Gogol' 1903, S 73

691 Gogol 1973, S. 87

${ }^{692}$ Gogol' 1903, S 83

${ }^{693}$ Gogol 1973, S. 64

${ }^{694}$ Gogol' 1903, S 64
} 
а уж для него, скажи пожалуйста, готово и вино, и сёмга, и сыр, и закуска разная..." (,'[...] er ist vielleicht schon unterwegs [...] und doch, sieh mal an, da ist der Wein schon für ihn bereit, da steht schon der Lachs, der Kăse und allerlei Vorspeisen... [... $\left.]^{\text {๙.695 }}\right)(4,257)$.

Auch die Eitelkeit Posudins, die ihn am Anfang zu Fragen treibt und den Kutscher zum Erzăhlen veranlaßt („Как человек, алчущий популярности, он прежде всего спросил о себе самом: - А Посудина ты знаешь?“ („Als ein Mensch, der auf Popularităt aus ist [der sich nach Popularităt sehnt], fragte er ihn als erstes nach sich selber: 'Kennst du Possudin eigentlich?*696) $(4,254)$ u.s.w.), alludiert die maßlose $R$ uhmsucht Chlestakovs, die in der Lügeszene zum Vorschein kommt. Sogar das physische Erscheinungsbild und die Art Posudins, beschrieben in der metadiegetischen Geschichte, erinnert an seinen intertextuellen "Prototур“: "- [...] Горячий такой. быстрый.. Слова тебе пугём не скажет, а всё - фырк! фырк! Чтоб он тебе шагом ходил, или как - ни боже мой, а норовит все бегом, бегом!“ (,'[...] Ein Hitziger, ein Flinker... Ist nicht imstande, etwas ruhig zu sagen [Er wird dir kein vernüntiges Wort sagen], sondern immer nur - hopp! hopp! Kein Gedanke daran, daß er je im Schritt geht oder so - Gott behüte, er muß immer laufen, alles muß im Laufschritt ge-

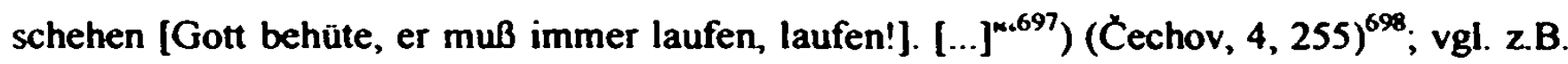
die Schilderung Dobčinskijs: „[...] и глаза такие быстрые, как зверки [...] (",[...] und die Augen so schnell, wie kleine Tierchen [... $]^{\text {‘c }}{ }^{699}$ oder seine vom Autor für die Schauspieler gegebene Charakteristik: „Речь его отрывиста, и слова вылетают из уст его совершенно неожиданно.“ (,Seine Rede ist abrupt, und die Worte kommen aus seinem Mund vollkommen unerwartet." $)^{700}$. Als zusätzliches Porträtdetail dient hier die "Chlestakovsche" Ausdrucksweise Posudins, z.B. die Art, in der er den Fuhrmann beschimpft: „- Поезжай назад, ссскотина!“” („Fahr zurück, du Rrindvieh! ".701) (Čechov, 4, 257) - „А ты уж и рад, скотина, сейчас пересказывать мне всё это.“ („Und dir, Rindvieh, macht es Spaß, all das vor mir zu wiederholen. “702) (Gogol’). ${ }^{703}$

\footnotetext{
${ }^{695}$ Tschechow Bd 1 (1949). S. 183

696 Ibid S. 178

697 Ibid. S. 179

${ }^{698}$ Uber die Ähnlichkeit Posudins Chlestakov in dieser Beschreibung s. ebenfalls bei Kuzina 1993, S 41

${ }^{699}$ Gogol' 1903, S 56

700 Ibid. S. 9

201 Tschechow Bd 1 (1949). S 183

702 Gogol 1973, S 36
}

${ }^{703}$ Gogol' 1903. S. 37. Uber manche der hier erwähnten Verweise - der Ähnlichkeiten und Parallelen in der C.harakteristik Posudins und Chlestakovs - s., wie angemerkt, bei Kuzina (1993). Diese Ahnlichkeiten weisen nach Kuzina darauf hin daß Posudin in den Augen der anderen aum Chlestakov, d.h. zu einem falschen Revisor herabgeset $\pi$ wird und daß Cechov ihm so die Rolle Chlestakovs - also des Nicht-Revisors - zuweist Dieser Schluß bedeutet jedoch unserer Ansicht nach eine eindeutige Vereinfachung der ..Revizor"-Intertextualität von .Silo v meske“" Sowohl weitere Portratdetails als auch der Sujetaufbau der Cechovschen Kurzgeschichte lassen auf ein dialektisches Verhaltnis zwischen den beiden Charakteren, die vielmehr in einer Kontrastrelation zueinander stehen, schließen, was wir im Laufe unserer Analyse demonstrieren werden Daruber hinaus bezeichnet Kuzina die Kurzgeschichte Cechovs als eine parodisfische Variante von .Revizor", als seine Herabsetzung - eine Ansicht, die wir in unserer Interpretation dieses Textes nicht vertreten Gleichzeitig bezeichnet Kuzina (u.a.) diese Geschichte als ..dovol'no točnoe otraženie gogolevskogo sjužeta” (eine ziemlich genaue Widerspiegelung des 
Gleichzeitig bestătigt eine Reihe der Portrătattribute die Gegensătzlichkeit beider Figuren. Wăhrend Chlestakov keine von seinen Schwächen zu verstecken vermag, sich zu ihnen offenherzig, zum Teil kokett bekennt („Вы, как я вику, не охотник до сигарок. А я, признаюсь, это моя слабость. Вот ещё насчёт женского пола, никак не могу быть равнодушен. [...] Я, - признаюсь, это моя слабость, - люблю хорошую кухню.“ („Sie sind, wie ich sehe, kein Liebhaber von Zigarren. Ich dagegen habe, offen gestanden, eine Schwăche für sie. Ebenso wie für das weibliche Geschlecht - da kann ich einfach nicht gleichgültig bleiben. [...] Ich gestehe, ich schătze eine gute Küche, das ist so eine Schwäche von mir. $\left.{ }^{(704}\right)^{705}$ ), sie auch demonstriert (v.a. in der Szene des Werbens zuerst um Anna Andreevna und dann um Mar'ja Antonovna), gibt sich der echte Revisor Posudin seinen Vorlieben geheim hin:

- [...] И .пюди-то его пьяныи не видали, а слава такая про него ходит... При публике, или куда в гости пойдетт, на бал, это, или в обчество, никогда не пьёт. Дома хлещет... [...] И скажи ты на милость: пьёт, и ни в одном глазе! Стало быть, соблюдать себя может." (.,'[...] Und auch die Leute haben ihn nicht trunken gesehen, aber das Gerücht will es wissen [lăuft über ihn herum]... Wenn er sich unter die Menschen mischt [Unter Menschen], oder wenn er zu Gast [oder wenn er einen Besuch macht] oder auf einem Ball oder überhaupt in Gesellschaft ist - da trinkt er nie und nimmer [da trinkt er nie]. Der bedudelt sich nur $z u$ Hause [Der bedudelt sich $z u$ Hause]... [...] Aber ist es nicht zum Staunen: er săuft, und doch ist ihm nichts anzumerken: $\mathrm{Er}$ ist [also] Herr seiner selbst. $\left.[\ldots]^{\text {k.77k }}\right)(4,255)^{707}$; „- А вот тоже насчёт женского пола... [...] Штук десять у него этих самых... вертефлюх... Две у него " доме живут... [...] ('ам я не вифат, но от людей слыхивал.“ (.,'Und so auch hinsichtlich des weiblichen Geschlechts... [...] Stücker zehn hat er... solcher Weiber... Zwei davon wohnen in seinem Hause... [...] Selber habe ich nichts davon gesehen, doch von den Leuten habe ich es erfahren [gehört]. [... $\left.]^{\ldots .7108}\right)(4,255-256)$.

Posudin wird nicht nur als Mensch dargestellt, der seine Unsittlichkeit zu verheimlichen weiß, sondern ebenfalls als kluger, tüchtiger und unbestechlicher Beamte, was als weiterer Kontrusi zu Chlestakov (sowohl zu seiner Rolle als falscher Revisor als auch zu seiner Person en bloc) zu deuten ist und in Kombination mit seinen Schwächen eine Kompltzıerung des re-

Gogol'schen Sujets), die dieses Sujet „vyvoracivaet naiznanku“ (verdreht auf links) (1993. S 40) Wir schließen uns dieser Beobachtung. wie das aus unserer Analyse folgt, an, betrachten die Umkehrung des Sujets Grogol's aber als Kontrafaktur

${ }_{704}$ Gogol 1973, S 85, 87 S die korrigiene Ubers. dieses Zitats teilweise auf S 142 dieser Arbeit

${ }^{\text {ros }}$ Gogol' 1903, S 82-83

Ton Tschechow Bd 1 (1949), S 179-180

${ }^{707}$ Chlestakov laßt sich dagegen willig vom Stadthauptmann betrunken machen und verliert endgultig die Kontrolle uber seine Aussagen

Tschechow Bd I (1949). S 180-181 
lativ schlichten Charakters Chlestakovs mit sich bringt. Die oben angeführte Allusion auf die Bestechungssummen in "Revizor" kann als expliziter Hinweis auf den genannten Charaktergegensatz bezeichnet werden. Dieser direkte Hinweis wird von den Kontrast bestätigenden Charakteristiken umgeben.

- Много добра сделал, дай бог ему здоровья. Железную дорогу выхлопотал, Хохрюкова в нашем уезде увольнит... ${ }^{709}$ [...] Образованный господнн...[...] не гордый... [...] Приехал и всё обделал... ни копейки не взял. Куда лучше прежнего! [...] У нынешнего в голове зтой самой нозги во сто раз больше..." ("'Hat viel Gutes getan, Gott schenke ihm Gesundheit. Da hat er zum Beispiel die Eisenbahn hergeschafft und hat Chochrjukow aus unserem Kreise entfernt [hat Chochrjukov aus unserem Kreise entlassen]... [...] Ein gebildeter Herr... [...] und gar nicht stolz [nicht stolz]... [...] Kam hierher und machte allem ein Ende... und nahm nicht eine Kopeke dafür. [...] Er ist viel besser als sein Vorgänger! [...] Der jetzige, in dem seinem Kopf ist eben hun-

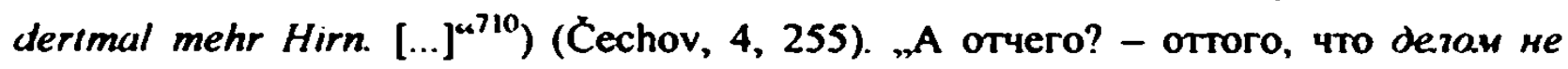
зинимается: вместо того, чтобы в долкность, а он идёт гулять по прешпекту, в картишки итрает. [...] Коли служить, так служи.“ („Und weshalb das alles? Weil er sich um gar nichts kümmert - statt in den Dienst zu gehen, treibt er sich auf dem Prospekt herum und spielt Karten. [...] Dienst ist eben Dienst. “711) (aus der Rede Osips ${ }^{712}$ ); ,.[..] несколько приглуповат и, как говорят, без чаря в голове, - один из тех людей, которых в канцеляриях называют пустейшими. Говорит и действует без всякого соображения. " (, [...] etwas einfältig und, wie man zu sagen pflegt, ein windiger Kopfeiner von denen, die man in den Kanzleien Niete nennt. Spricht und handelt ohne jede Überlegung. “713) (aus der Personenbeschreibung für die Schauspieler ${ }^{714}$ ).

Die Summe von Äquivalenzen läßt die Figur Posudins nach beendeter Lektüre als Korrelat Chlestakovs wahmehmen. Äquivalenzen auf der Ebene der Charaktere werden durch die (oben bereits kurz angesprochenen) Parallelen auf der Ebene des Sujets ergänzt. In erster Linie führen die Eigenschaften und die Rolle Posudins, die ihn zum Gegenteil von Chlestakov machen, direkt zur Gegensätzlichkeit der restlichen fiktiven Personen und der Handlungsstrukturen in beiden Texten, so daß der jüngere Text schließlich als eine ..kontrafaktische“ Umschreibung des älteren erkennbar wird.

\footnotetext{
${ }^{709}$ Dies kann als Anspielung auf die bei Gogol' nicht zustande gekommene. d.h. von Chlestakov verstandlicherweise nicht verwirklichte Entlassung der korrupten Beamten interpretien werden.

710 Tschechow Bd 1 (1949), S 178-179.

"11 Gogol 1973, S 35

112 Gogol' 1903, S. 35

${ }^{713}$ Gogol 1973. S. 8-9

714 Gogol' 1903. S 9
} 
Der auffalligste Kontrast der zu vergleichenden narrativen Strukturen ist mit der Tatsache verbunden, daß das Sujet der (metadiegetischen) Geschichte bei Cechov auf die heimlichen, vermeintlich verborgenen Sünden des Revisors sowie auf das Informiertsein über diese Sünden der Kreisbewohner fokussiert ist, während den Mittelpunkt der Handlung von „Revizor“ dagegen die zu verbergenden Sünden und Vergehen der Stadtbewohner und die mögliche Enthüllung derselben durch den Revisor bilden. Wăhrend bei Gogol' Akzente auf die schwer ubersehbaren Mißstände in der Kleinstadt und die Schuld der Beamten, demzufolge auf den Versuch, die Mißstănde mit allen Mitteln zu verbergen, gesetzt werden, konzentriert sich die (für das Sujet des Textes zentrale) Geschichte des Fuhrmanns auf die geheimen Laster des Revisors und das Allwissen der ihm dadurch überlegenen, schlauen Kreisbewohner. Im Panikanfall, der durch den bevorstehenden Revisorbesuch verursacht wird, spricht der Stadthauptmann einen für den didaktischen Aufbau der Komödie symbolischen Satz aus: „O, oxхо-хо-х! грешен. во многом грешен. [...] Дай только Боже, чтобы сошло с рук поскорее [...]." (Oh, oh, oh! Ich habe gefehlt. in vielem gefehlt [Ich habe gesündigt, in vielem gesündigt]! [...] Gott gebe, daß alles recht bald vorüber ist [Hilf mir Gott, davon zu kommen] $\left.[\ldots]^{\mu 715}\right){ }^{716}$ Für das Geschehen von „Šilo v meške“ ist aber die folgende Stelle schlüssig:

- А Посуднна ты знаешь?

- Как не знать? - ухивьтьнулся возници. - Знаеи .иы его! („'Kennst du Possudin eigentlich?'

"Wie soll ich ihn nicht kennen" grinste der Kutscher. Den kennen wir allerdings [Den kennen wir?]. $\left.{ }^{k .717}\right)(4,254)$.

Die berühmten ersten Repliken des Gogol'schen Stückes vermitteln die Atmosphäre der Angst: Der Revisorbesuch wird von den Stadtbewohnern als ein wichtiges, Furchteinfloßendes Ereignis, fast als Katastrophe empfunden:

Іоробничии. Я пригласил вас, господа, с тем, чтобы сообщить вам пренеприятное известие: к нам едет ревизор.

А.инос Фёдорокич. Как, ревизор?

Apmenuì कuиunnisiı4. Как. ревнзор?

[...]

А.ки. Фё). Вот-те на!

Apm. Фит. Вот не было заботы, так подай!

Лlука Jlyx: Господи Боже! ешё и с секретным предписанием!

\footnotetext{
${ }_{715}$ Gogol 1973, $S$ 29-30.

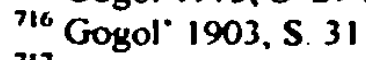

${ }^{717}$ Tschechow Bd I (1949). S. 178 Die Lbers. $S$ zum Teil auf S 143 unserer Arbeit
} 
(.STADTHAUPTMANN: Ich habe Sie hergebeten, meine Herren, um Ihnen eine hochst unangenehme Mitteilung zu machen - zu uns ist ein Revisor unterwegs.

AMMOS FJODOROWITSCH: Wie? Ein Revisor?

ARTEMI FILIPPOWITSCH: Wie? Ein Revisor?

[...]

AMMOS FJODOROWITSCH: Da haben wir's!

ARTEMI FILIPPOWITSCH: Man denkt sich nichts Böses [Gerade hatten wir keine Sorgen], und plötzlich...

LUKA LUKITSCH: Mein Gott! Mit einer geheimen Order! Auch das noch! [Auch noch mit einer geheimen Order! $\left.]^{\cdots 718}\right)^{719}$.

Die Reaktion der Einheimischen auf den Besuch Posudins bei Cechov ist eine demonstrative Kontrafaktur der entsprechenden Reaktion bei Gogol':

- [...] Приедет он, что6 их на месте накрыть, под суд отдать или сменить кого, а они над ним же и посмеются. Хоть ты, скахут, ваие сuяmenьство, и потихоньку приехат, а гляди: у нас всё чисто!.. (... / Народ тут .ловкий, .овкач на

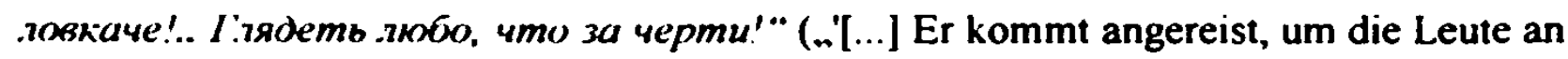
Ort und Stelle zu überraschen, um sie dem Gericht zu übergeben oder jemand abzusetzen, die aber lachen über ihn nur. Die sagen: "Wenn du auch. Eure Durchlaucht, ganz verstohlen hergereist bist. bitte sehr: bei uns ist alles in bester Ordnung!... [...] Das Volk dort [hier] ist geschickt, ein HIInker sitzt dort uuf dem anderen'... Macht. Spaß. zu sehen, was das für Teufel sind! $\left.[\ldots]^{n .720}\right)(4,257)$.

Die Beamten Gogol's werden am Anfang der Komödie von der Nachricht üherrascht (wie sie im Finale von der Ankunft des echten Revisors überrascht und vernichtet werden), sie fürchicn, daß der Revisor längst in der Stadt ist, daß ihnen keine Zeit mehr bleibt, die Spuren zu

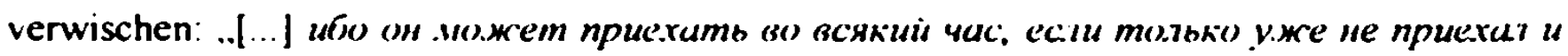

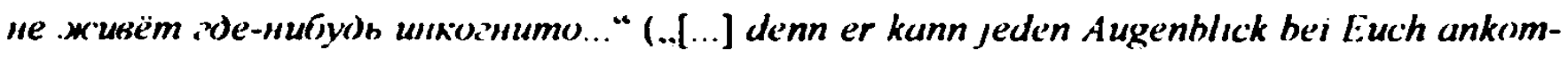
men. wenn er nicht gar schon da ist und sich inkognito bet Fuch aufhält [und irgendwo inkognıso wo/hnt]. $\left.{ }^{.721}\right)^{722}$ Als Skvoznik-Dmuchanovskij erfăhrt, daß der vermeintliche Revisor Chlestakov bereits zwei Wochen im hiesigen Gasthaus verbracht hat, ruft er aus: . Двe недели! (В сторону). Батюшки, сватушки! Выносите, святые угодники' В эти две непели высечена унтер-офицерская жена! Арестантам не выдавали провизии! На улицах кабак. нечистота! Позор, поношенье! (Хватается за голову).“ (.. Vierzehn Tage [Zwei Wochen]!

\footnotetext{
718 Gogol 1973, S 11

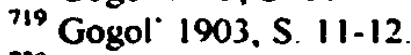

720 Tschechow Bd I (1949). S 182-183

21 Gogol 1973. S 12
} 
Beiseite. Ach, du meine Güte! Rettet mich, ihr Heiligen alle! Innerhalb dieser vierzehn Tage [zwei Wochen] ist die Unteroffiziersfrau ausgepeitscht worden! Die Haftlinge haben keine Lebensmittel zugeteilt bekommen! Auf den Straßen - die Unsauberkeit, die reinste Kneipe! $\mathrm{O}$, Schimpf, o Schande! (Er faßt sich an den Kopf)“723 $)^{724}$ Dem Schock und der Verwirnung in „Revizor" steht die Gelassenheit der Cechovschen Verantwortlichen entgegen: „, [...] П० телеграфу всё известно... [...] уж тут знают, что едешь. Ждут... Посудин ещё у себя из

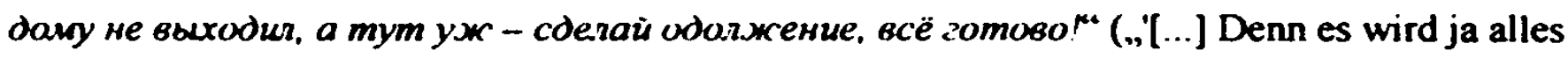
durch den Telegraphen bekannt...[...] man weiß überall [man weiß], daß er kommt. Man wartet auf ihn [Man wartet]... (Ind noch hat Possudin das eigene Haus nicht verlassen, dort aber [hier aber] - bitte schön, ist alles schon bereit [bitte schön, ist alles bereit!]. [... $\left.]^{\text {m.72s }}\right)(4$, 257). ${ }^{726}$

Die Kreisbewohner Cechovs, die vom Revisor alles wissen und über seine Besuche immer im voraus informiert sind, sind auch tatsächlich Betrüger, der Revisor aber der tatsăchlich Betrogene. Darin besteht die eigentliche, die zentrale „kontrafaktische“ Pointe von „Šilo v meške“. Die Pendants tauschen ihre Rollen aus: Der Angeber und Lügner Chlestakov, dem es gelingt, die Stadtbewohner einzuwickeln, wird Posudin gegenübergestellt, der bis zum letzten Augenblick der Naive und mehrfach Hineingelegte ist. ${ }^{727}$ Wenn bei Gogol' der echte Revisor unbekannt bleibt und moglicherweise imstande ist, eine gerechte Strafe zu vollziehen (worauf die Schlußszene des Stückes andeuten soll), wird der echte Revisor bei Cechov (mehrmals) erfolgreich hintergangen. Es wird im aktuellen Text das realisiert, was den korrupten Beamten in "Revizor" vorschwebt, sich aber dort als Tauschung erweist. Der Stadthauptmann Skvoznik-Dmuchanovskij glaubt, den Revisor betrogen zu haben, sein Betrugsversuch richtet sich aber gerechterweise gegen ihn selbst, wie auch gegen andere am Betrug Beteiligten

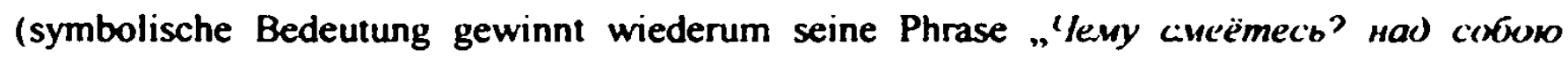
cueëmecb!.." („Ïber wen lacht ihr denn? Über euch selbst [Worüber lacht ihr? I'ber euch selbst lacht ihr'..]!...728 ${ }^{729}$ ). In der Cechovschen Kontrafaktur wird über den Revisor gelacht: ..- [...] Прнедет он, [...] а они нал нии .же и поскеютсх. [...] Он повертится, повертится да с тем и уедет, с чем приехал... Да ещё похвалит, [...]... (...[...] Er kommt angereist, [...]

\footnotetext{
722 Gogol' 1903, S. 13

723 Gogol 1973, S. 25.

${ }^{724}$ Gogol' 1903. S. 27

725 Tschechow Bd 1 (1949), S 182

${ }^{26} \mathrm{Vgl}$. die Formulienung von Berdnikov ..В расказе 'Шило в мешке' особое значение нмеет то строжайшее ннкотнито, хоторое гщится соблюсти чеховскнй ревизор Посудин, стремясь поймать с поличным чиновников уездното городишки N "(In der Geschichte .Silo v meske” hat das strengste .inkognito", das der Cechovsche Revisor vergeblich zu wahren versucht, um die Beamten der Kreisstadt $N$ zu erwischen, eine besondere Bedeutung.) (1981. S 128)

${ }^{27}$ Der in verschiedenen Portratdetails vermittelte Gegensatz zwischen den beiden Protagonisten wird auf der Handlungsebene der Texte bestatigt Gegensatzliche Charakteristiken fuhren in dem Sinne zu gegensatzlichen Rollen innerhalb des fiktiven Ganzen Wie diese Gegensatze miteinander verbunden sind, wird im Weiteren geklant

${ }_{72 x}$ Gogol 1973, S 131

729 Gogol' 1903, S 122
} 
die aber lachen über ihn nur. [...] Er jedoch dreht sich und wendet sich und muß doch wieder genau so abreisen, wie er gekommen ist... [Er dreht sich, wendet sich und reist wieder genau so ab, wie er gekommen ist...] Und muß die dabei noch loben [Und lobt sie auch noch], $\left.\left.[\ldots] \ldots[\ldots]^{\mu .730}\right)(4,257)\right)^{731}$

Die Beamten Gogol's gehen faktisch (d.h. abgesehen von der didaktischen Grundidee des Textes) am Zufall zugrunde (das Zugrundegehen wird in der stummen Szene an- und vorausgedeutet). Die Verwechslung ist hier jedoch psychologisch motiviert: Sie geschieht aufgrund der Angst und der mangelnden Informiertheit der Bewohner. Ein Zufall. eine Verwechslung scheint in der fiktiven Wirklichkeit der Kurzgeschichte gerade deshalb prinzipiell ausgeschlossen zu sein, weil keine Angst vor der Revision empfunden wird - das Betrugssystem funktioniert perfekt, für die Bürger und Beamten gibt es keine Geheimnisse. Der situative Kontrast spiegelt sich insbesondere im in beiden Texten auftauchenden Tarnmotiv wieder. Wenn Chlestakov bei seinem ersten Treffen mit Skvoznik-Dmuchanovskij im Gasthaus seine Zahlungsfähigkeit beteuert, gleich darauf gesteht, daß er zur Zeit kein Geld habe und sagt, daß er es nicht zulasse, da $\beta$ man ihn verprügelt, hält dies der Stadthauptmann für eine feine Verstellung: „О, тонкая штука! [...] какого тумана напустил! разбери, кто хочет! [...] Он хочет, чтобы считали его инкогнитом.“ („Oh, ein ganz raffinierter Dreh! [...] Was für blauen Dunst er uns vormacht! Dem gehe auf den Grund, wer will! Er möchte sein Inkognito wahren [ $\mathrm{Er}$ will, daß man ihn für ein Inkognito hălt]. $\left.{ }^{(732}\right)^{733}$. Während er durch seine falschen Vermutungen Chlestakov die Revisorrolle aufzwingt und ihm Gelegenheit gibt, ihn zu betrügen, sind dieselben Vermutungen bei Cechov vollkommen richtig; Posudins Bemühungen, seine Persönlichkeit verdeckt zu halten, erweisen sich aus verschiedenen Gründen als lăcherlich:

- [...] Да узнать нешто трудно? Камердину или кучеру языка не отрежешь... [...] Посудин [...] норовит съездить потихоньку, быстро, чтоб никто не видал и не знал... Ila-a-теха! [...] Закутается весь, как баба, и всю дорогу хрипит, как старый nёс, чтоб голоса его не узнали. ІІросто кишки порвёшь со смеху, $[\ldots]$... Едет, дурень, и думает, что его узнать нельзя. (..'[...] Ist es denn schwer, so etwas zu erfahren? Weder dem Kammerdiener noch dem Kutscher kann man ja die Zunge abschneiden ... [...] Possudin [...] mag [...] nichts als insgeheim und flugs hinreisen, damit niemand ihn sieht und niemand etwas ahnt... Ein Spaß das! [...] Und dann mummelt er sich ein wie ein Weib und krächzt die ganze Fahrt über heiser wie'n alter Hund. daß

\footnotetext{
?h0 Tschechow Bd I (1949), S 182

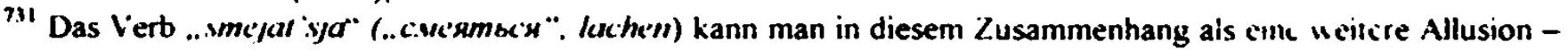
Ubernahme eines wichtigen lexikalischen Motivs des Pratextes - auslegen

$\because 12$ Gogol 1973. S 46-47

${ }^{73.1}$ Gogol' 1903, S $40-47$
} 
man ja nur seine Stimme nicht erkenne. Der Bauch könnte einem vor Lachen platzen, [...]. Und so reist der Narr und denkt, daß keiner ihn erkennen konne. $\left.[\ldots]^{\mu c 734}\right)(4,256)$

Die Kreisbewohner erweisen sich im allgemeinen als wesentlich gewitzter als der kluge Beamte Posudin: „Травда, правда.. - подумал Посудин. - И как я этого раньше не знал!к (,Wahr, wahr... überlegte Possudin. - Und wie bin ich bloß nicht früher darauf gekommen! $\left.!^{\text {cc735 }}\right)(4,257)$.

Die oben beschriebenen, durch Äquivalenzen intendierten Gegensätze zwischen den beiden Hauptfiguren - Chlestakov und Posudin - scheinen uns in diesem Zusammenhang für die Kontrafaktur sinnkonstitutiv zu sein. Posudin, der seine „Chlestakovschen“ Schwăchen zu verheimlichen weiß, der darüber hinaus ein unbestechlicher und kluger Revisor ist, wird erfolgreich hintergangen. Chlestakov lügt dagegen hăufig recht ungeschickt und die Wahmeit schimmert durch seine Lügen bekanntlich nicht selten hindurch, so daß der Glaube der Gogol'schen Beamten selbst fast grotesk erscheint; sein Betrug hat den Charakter einer Improvisation, ist wenig durchdacht (vgl.: „слова вылетают из уст его совершенно неожиданно“ (die Worte kommen aus seinem Mund vollkommen unerwartet) ${ }^{736}$ ), dennoch gelingt es ihm, die erfahrenen korrupten Beamten der Stadt an der Nase herumzuführen. Posudin versucht, geschickt und strategisch zu handeln, trotzdem sind die Kreisbewohner in die kleinsten Details seines privaten und beruflichen Lebens eingeweiht. Der Naivităt der Gogol'schen Stadtbewohner wird also die Naivităt des Cechovschen Revisors gegenübergestellt.

Das Zitat aus Gogol's Komödie im Mund Posudins gewinnt demzufolge eine vorausdeutende Funktion: Durch das Zitieren der Worte von Skvoznik-Dmuchanovskij „A подать сюда Тяпкина-Ляпкина!" vergegenwărtigt Posudin den weiteren Kontext der Vorlage, nämlich das Nichtzustandekommen der erwarteten Aufforderung, also der Revision bei Gogol' und .,prophezeit" sich die Rückkehr, sprich die Abkehr von der Revision. Das Zitat weist gleichzeitig vorausdeutend auch auf die Art seiner bereits durchgeführten Revisionen hin. Eine Revision bleibt also in beiden Făllen das Imaginăre (wenn man vom Sinn des Finales im Stück absieht). ${ }^{7.37}$

Der Übergang von der metadiegetischen zur diegetischen Ebene am Ende von „Silo v meške“, nämlich die Wut des aufgeklärten Posudin, imitiert die Wut der aufgeklärten Stadtbewohner in "Revisor“. Wie die betrogenen Beamten Gogol's in der achten Szene des fünften Aktes von Ahnungslosen zu Wissenden werden, so geht auch der betrogene Posudin vom

\footnotetext{
Th4 Tschechow Bd I (1949), S 181

73 Ibid. S. 182

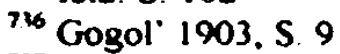

${ }^{737}$ Diese Tatsache kann jedoch kaum den Grund dafur bieten. Posudin mit Chlestakov gleichzusetzen, wie das Kuzina in ihrer Arbeit macht Die Nicht-Verwirklichung der Revision hat in beiden Werken geradezu gegensatzliche Ursachen so wie die zu vergleichenden Protagonisten, wie wir gezeigt haben. gegensatzliche Rollen im Text spielen
} 
Unwissen zum Wissen über. Somit wird der Rollentausch handelnder Figuren im Rahmen der Kontrafaktur - in einer neuen Phase der Sujetentwicklung - vollendet.

Die Kurzgeschichte ist demzufolge als eine - wie am Anfang unserer Analyse angekündigt - spielerisch vorgeführte (modernere ${ }^{738}$ und glaubwürdigere ${ }^{{ }^{739}}$ ) Variante des bekannten Referenztextes interpretierbar. Mit Hilfe intertextueller Transformationen schildert Cechov eine noch schlechtere Wirklichkeit, als Gogol' sie in seiner Satire darstellte. Die schlauen Bürger und Beamten der Kleinstadt fürchten sich nicht mehr vor dem Besuch des Revisors, der Betrug wird ihnen zur Routine, und das bei Gogol' ethisch motivierte, als psychologische und moralische Konsequenz begriffene Sich-Selbst-Hineinlegen ist aufgrund des ausgeklügelten, perfekt funktionierenden Korruptionssystems ausgeschlossen. Die Kontrastierung des echten Revisors mit dem vermeintlichen Gogol's - die Tatsache also, daß die Wahrheit dem echten Revisor verborgen bleibt, lăßt die Mißstände als noch weniger durchsichtig und die im Finale der Komödie angedeutete potentielle Vergeltung (die Ankunft eines echten unbestechlichen Wirtschaftsprüfers) als unausführbar erscheinen.

Das Finale von „Šlo v meške“ bietet jedoch die Mơglichkeit einer Doppellektüre an. Das Sujet der Kurzgeschichte, das sich im Spannungsfeld zwischen der meta- und der diegetischen Erzăhlung entfaltet, demonstrien das Spiel mit dem Kennen/Verkennen: trotz allen Kenntnissen über die Persönlichkeit und die Gewohnheiten Posudins verkennt ihn der Kutscher als Revisor, damit wird er - und mit ihm die korrupten Bewohner - vom Allwissenden zum Unwissenden. Diese Wende beinhaltet ein bewußtes Offenlassen der semantischen Struktur des Textes (was auch den letzten Kontrast zur Vorlage bildet). Der Zorn Posudins und seine Aufforderung zur Rückkehr mögen die Hilflosigkeit des enthüllten Revisors bestätigen und den Verlust seiner Stellung bedeuten, sie verheißen aber auch möglicherweise die ..stumme Szene“ für die Betrüger - die gerechte Bestrafung und die Verhinderung eines neuen Betruges.

In ..Šilo v meške“ wird eine spielerische Korrektur, ja sogar eine ..respektlose Umpolung“ des literarisch Vorgefundenen unternommen sowie, wenn man den Text als eine modernere Version der Gogol'schen Komödie, ihre zeitgemäße Variante begreift (eine Umkehr von einer - zu Cechovs Zeit - weniger wahrscheinlichen Sujetentwicklung zu der wahrscheinlichen), das .,Ausspielen der Differenz zwischen dem alten Kontext des fremden Wortes und seiner neuen Kontextualisierung ${ }^{.740}$. Ähnlich wie in ..Torżestvo pobeditelja“ schafft hier Cuechov eine noch negativere, realistischere Alternative zum Referenzwerk, dem eine didaktische Geschichte von den betrogenen Betrügern zugrunde liegt. Jedoch geschieht das nicht durch die

\footnotetext{
${ }^{7.8} \mathrm{Vgl}$ Berdnikov uber die Verarbeitung des Sujets Gogol's in ..Silo v meske“ „Н вновь комический финал

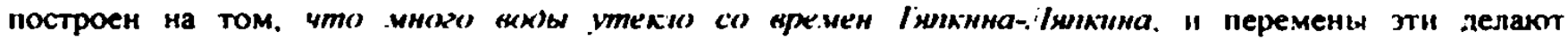
несбыточными надежды ревизора ..По телеграфу все известно [ ] ]' - соойщает возница Посудину."

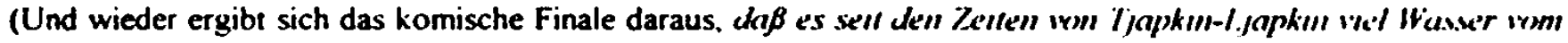
Berge geflars' 1 . und diese Verandenungen machen die Hoffinungen des Revisors unerfullbar ..Durch den Telegraphen wird alles bekannt . [ . ")-teilt der Kutscher Posudin mit.) (1981.S 128-129) (Hervorh von uns) ${ }_{719} \mathrm{Vgl}$ das 2.T mit der Aussage von Schmid zu ..Stancionnyj smotritel'” in der Fußn 594

${ }^{7+0} \mathrm{Vgl}$ Pfister. S 25 dieser Arbeit
} 
komisierende Herabsetzung (s. die Formulierung Verweyens/ Wittings) von "Revizor", sondern durch die Ausnutzung des Sujets, der Personenkonstellation und einiger Details des Gogol'schen Stūckes für die Darstellung bestimmter Wirklichkeitsphanomene. ${ }^{741}$

${ }^{741}$ Wenn wir insbesondere auf die Allusionen bzw. Zitate aufmerksam werden, die Posudin selbst ausspricht, dann laßt es sich über seine nicht-erfullten literarischen Erwartungen sprechen. Schmid schreibt in Verbindung mit diesem Phanomen uber die .narrative Widerlegung falscher Aquivalenzsetzungen“ (in bezug auf „Povesti Belkina“): .Es ist schon mehrfach festgestellt worden, daß sich Erzähler und Helden der Eirzahlungen Belkuns an literarischen Schemata orientieren, die sich im Verlauf der Geschichte als unzutreffend erweisen [...] Die Helden und auch die Ich-Erzahler erscheinen ja samtlich als Leser, [...] [...] Puskin [ ..] stellt die Lebenstauglichkeit existentialisierter Literatur auf die Probe. [...] Puskins Intertextualitat spielt mit der Inertia der Rezeption von Literatur. [ ..] Das Schema führ jedoch in die Irre, das Leben sieht in Wirklichkeit anders aus, als es die Literatur vor-gesehen hat." (1991, S. 89-90) (vgl diese Ausführung mit Saal-Losq. 3. S. S1, 53-54 unserer Atbeit). Dem Phänomen der fiktiv gestalteten Literaturrezeption wollen wir uns jedoch im nächsten Kapitel zuwenden. 


\section{Modi der fiktiven Literaturrezeption: punktuelle Verweise im inneren} Kommunikationssystem der spăteren Prosawerke Čechovs

\subsection{Einleitung}

\subsubsection{Theoretische Vorüberlegungen und Erläuterung der Fragestellung}

Im gegenwärtigen Kapitel wollen wir uns einer Gruppe der punktuellen Intertextualitătsverweise - den Zitaten, Allusionen oder auch komplexeren, aus den elementaren Verweisformen (meistens aus der Summe unterschiedlicher einfacher Allusionssignale ${ }^{742}$ ) zusammengesetzten Referenzen - in den späteren Werken Cechovs zuwenden. ${ }^{743}$ Wenn Lachmann in ihrem am Anfang des Kap. 2.1. erwähnten Ansatz zwischen den Doppelstrukturen, die sich auf den ganzen Text ausbreiten (Parodie, Travestie, Stilisierung), und denen, die lediglich seine einzelnen Segmente beruhren (z.B. Zitat) unterscheidet, wenn weiterhin Genette in seiner in Kap. 2.1. vorgestellten Typologie intertextuelle Formen wie Zitate oder Anspielungen und Hypertexte wie Parodie, Travestie, Pastiche auseinander hălt, dann ist es, um es noch mal zu artikulieren, klar, daß beide intertextuellen Phănomene sich innerhalb eines Textes nicht ausschließen. Punktuelle Verweise auf den Prätext wie Zitate kommen sowohl in den Texten 2. Grades $^{744}$ als auch in denen, die nicht als solche interpretiert werden, in unserem Fall auch in den späteren Novellen Cechovs vor. In den als abgewandelt ausgelegten sowie in den mit punktuellen Referenzen ausgestatteten, ..nicht abgewandelten" literarischen Texten sind sowohl die Kontiguitäts- als auch die Similarıätsbeziehungen zum Prätext, d.h. sowohl der materielle als auch der strukturelle Intertext vorhanden (s. Typologien von Lachmann, Plett, Karrer in Kap. 2.1.). Auch in der Prosa Cechovs geht die Strukturreproduktion mit der Elementenreproduktion, wie wir sie hier auslegen ${ }^{745}$, einher: in diesem Sinne kann man behaupten, daß die erste (=nicht-wörtliche Kontakte) im Rahmen der gegebenen individucllen Intertextualitätspoetik durch die zweite (= wörtliche Kontakte) erst nachweisbar wird. ${ }^{766}$ Andererseits lenken wir in unserer Arbeit das Augenmerk tendenziell auf die Fälle, in denen

\footnotetext{
$742 \mathrm{Vgl} \mathrm{S.} \mathrm{31-32} \mathrm{dieser} \mathrm{Arbeit}$

${ }^{743}$ Innerhalb der Gruppe der intertextuellen Verweise im Bewußtsein fiktiver Figuren. die wir hier untersuchen wollen. tauchen letztere am haufigsten bei den fiktiven Literaturdiskussionen (Buchbesprechungen. Uneilen uber bestimmte Autoren und deren Werke u.s.w ) auf, die im Prosawerk Cechovs kein seltener Fall sind. aber auch bei jeder mehr oder minder entfalteten fiktiven Aussage uber einen Pratext Holthuis nennt dieses Phanomen, innerhalb dessen metrere Allusionsmarker präsent sind, .,die Literatur in der Literatur" (s. S 32 dieser Arbeit)

${ }^{74} \mathrm{Vgl}$. bei Genette: bei ihm heißt es, daß Hypertext auch ohne ..Intertext" (bei Genetic also z. B Zitate und Anspielungen) ...auskommen“ kann, ...aber auch nicht vollstandig. und seien es nur Anspielungen im Text [ J oder Paratext (der Titel (/lysses); [ . . “"(1993. S 18).

${ }^{745} \mathrm{~S}$. Fußn 152

${ }^{76}$ Diese Tatsache ist, nach unserer Uberzeugung, auf die ausgesprochene Deutlichkeit und Bewußtheit Cechovscher Intertextualitat zuruckzufuhren
} 
die wơrtliche Intertextualităt bei Cechov - Übernahme einzelner Segmente aus dem Referenztext - tatsăchlich auch diesen ganzen Referenztext mit den in ihm enthaltenen Sujetelementen und Handlungsablăufen aufruft (bzw. dessen Episoden). Dann ist die intertextuelle Analyse erst "nach abgeschlossener Lektüre von $T$ [Text $-K$. S.] (und nur bei vollständiger Kenntnis von PT [Prätext - K. S.] $)^{\text {(1477 }}$ moglich.

Auf interpretativem Wege wollen wir jedoch die Intertextualităt großer spăterer Novellen Cechovs und die der analysierten frühen Texte auseinander halten. Den Charakter dieser Differenz haben wir an verschiedenen Stellen bereits erläutert. Wir betrachten die in Kap. 3 untersuchten Kurzgeschichten als einen spielerischen Versuch des jungen Autors, bestimmte hăufig zum Klischee gewordene - literarische Modelle, verkorpert in bekannten Werken seiner Vorgänger (bzw. in ihren einzelnen Abschnitten), umzudichten, mit anderen Worten, eine kurze humoristische Version des Vorgefundenen zu schreiben bzw. als einen ernsthaften Versuch, eine affirmative Nachahmung bekannter Werke seiner Vorgănger zu schaffen (wie in „Za jablocki“"). Solche Zeugnisse des frühen literarischen Experimentierens oder des frühen bejahenden Nachbildens von Antosa Cechonte (von den ersteren wurden bisher in der einschlägigen Literatur vor allem parodistische Texte erforscht), ordnen wir der "Gattung“ der literarischen Ableitung zu. Unter anderem diesen Kurztexten - das bezieht sich allerdings aus unserer Sicht v.a. auf Parodien - schreibt Derman „обостренное внимание [...] к господствующим в данную эпоху приёмам мастерства, к литературной технике“ (еine verschărfte Aufmerksamkeit [...] gegenüber den in der betreffenden Zeit vorherrschenden künstlerischen Verfahren, der literarischen Technik), „потребность [...] обобщить литературный приём и оценить еro“" (das Bedürfnis [...] das literarische Verfahren zu verallgemeinem und $z u$ bewerten) $z u .{ }^{74 x}$ Hier ist unsere in Kapitel 3.2. erlăuterte Distanz zum Ansatz von Koschmal zu erwähnen, der die späte Novelle „Nevesta“ als Kontrafaktur - für uns keine ernste, sondern eine spielerische Gattung bei Cechov - bezeichnet. Um es nochmals zu betonen, wir verknüpfen das Phănomen der Kontrafaktur im Gegensatz zur Auslegung Koschmals ausschließlich mit den im Rahmen des literarischen Experiments Cechovs (wenn auch in unterschiedlichem Grade) dem fremden Wort explizit zugewandten, bisweilen auf das fremde Wort fixierten (vor allem Kurz-)Texten.

Auf dieses Verstăndnis des Begriffes „Text zweiten Grades“, angewandt auf die Cechovsche Prosa, heben wir ab, wenn wir darauf verzichten, den späteren großen Werken Bezeichnungen wie ..Kontrafakıur". .. Travestie“ oder „Parodie" zu verleihen. In Verbindung mit den spăteren Novellen Cechovs scheinen uns solche Bezeichnungen im Ganzen problematisch (der Begriff "Kontrafaktur" so wie wir ihn deuten im Unterschied zu Koschmal und Schmid, der Begriff „Parodie“ so wie wir ihn auslegen im Gegensatz zu Saal-Losq). Die späteren Werke Cechovs treten nămlich in eine komplexere semantische Beziehung mit den in sie eingeschriebenen Fremdtexten als die früh(er)en; und obgleich die in ihnen verstreuten

${ }^{747}$ Schmid 1983, S 149 
Verweise nach dem Prinzip „pars pro toto“, genauso wie in seinen „zweitgradigen“ Texten, oft den ganzen Referenztext „evozieren ${ }^{4749}$, d.h. zum Vergleich entsprechender Sujetstrukturen im Ganzen veranlassen, haben sie nicht mehr die Aufgabe der (meistens humoristischen) Umdichtung der Prătexte. So rechtfertigt sich für uns die Abgrenzung literarischer Ableitungen im Werk Čechovs von seinen als nicht-abgeleitet gedeuteten Texten ${ }^{750}$.

Im gegenwärtigen Kapitel richten wir unsere Aufmerksamkeit auf eine bestimmte formalsemantische Gruppe der punktuellen Referenzen - auf Verweise, die im inneren Kommunikationssystem der späteren Texte Cechovs - seiner Novellen - markiert sind (s. Broich ${ }^{751}$ ). Bezüge zu anderen Texten, die im Bewußtseinshorizont der fiktiven Figuren liegen und so die Eigenart und Modi der Literaturrezeption in der dargestellten Welt widerspiegeln, betrachten wir neben dem oben untersuchten Phănomen der literarischen Ableitung als für Cechovs Intertextualităt besonders charakteristisch. Es läßt sich sagen, daß die allermeisten expliziten intertextuellen Verweise in der Prosa Cechovs im Bewußtsein der fiktiven Personen lokalisiert sind. Im ăußeren Kommunikationssystem sind dagegen solche Bezüge markiert, wie z.B. onomastische Allusionen ${ }^{752}$ (vgl. den Namen „Anna“ in „Dama s sobackoj“ oder in „Anna na see“ als Referenz zu „Anna Karenina“"753). Die Wahrnehmung der Literatur durch lesende, Bücher diskutierende, ${ }^{754}$ zitierende und/ oder die Lektüre nachlebende Personen in den spăteren Prosatexten wollen wir im Weiteren in den Mittelpunkt stellen. ${ }^{755}$ Wie aus den im vorigen Kapitel durchgeführten Textanalysen hervorgeht, überschneiden sich bis zu einem gewissen Grad diese zwei Typen der intertextuellen Kontakte: Auch in den „zweitgradigen“ Texten kommen zitierende bzw. alludierende Figuren vor, Figuren, die dadurch zu Subjekten bestimmter Modi der Literaturreflexion werden. Nur wird in solchen Fällen eine Darstellung der fiktiven Rezeption von Literarischem beispielsweise in den Kontext der Parodie (wie in ,Zagadočnaja natura“) oder der Kontrafaktur (wie in ..Silo v meške“) einbezogen, d.h. sie bildet

\footnotetext{
${ }^{748}$ Derman 1959. 5 10-11

${ }_{739} \mathrm{~S}$. Schmid uber das Verstandnis der Intertextualitat bei L. Jenny (1983, S. 142)

${ }^{750}$ Wie wir in unserer Arbeit bereits erwahnten (Kap 2.3.), wird eine solche bzw eine ahnliche Abgrenzung der fruthen Texte Cechovs von seinen spateren bei vielen Cechovforschern durchgefuhn, wenn man z.B Parodien im fruhen Werk erforscht S z.B. die Monographie von Hielscher (1987), in der das zweite Kapitel .Am Anfang stand die Parodie" heißt, oder die Monographie von Kluge (1995), in der u.a von ..parodistischen Elementen" (S 35) beim fruhen Cechov gesprochen wird (parodien werden z.B .,romantische Naturbeschreibungen“ (ibid.))

${ }^{751} \mathrm{Vgl}$. S. 30-31 unserer Arbeit

732 also die Namen der Protagonisten

${ }^{753} \mathrm{~S}$. daruber u.a bei Lauer 1997, S. 547

754 In unserem Aufsatz (Smola 2001) haben wir .intertextuelle Diskussion" im Rahmen einer Klassifikation als einen der drei Modi der Intertextualitat im Werk Cechovs herausgebildet (vgl. die FuBn 365) und anhand der Verweise auf Goethe (der fiktiven Diskussionen mit Erwăhnung seines Namens und seiner Werke) dargestellt (s. S 105-109) Wir ziehen don jedoch gerade Beispiele heran, in denen nicht nur bzw nicht sosehr "wher Goethe diskutiert wird, sondern in denen sein Name und seine Werke in den Kontext einer Diskussion miteinbezogen und so mit diesem oder jenem Thema verknupf wird Da sich unsere Klassifikation der genannten drei Mlodi sowie zum Teil auch die angefuhrten Beispiele fur uns spater als nicht zweckmäßig herausgestellt haben. haben wir auf ihre Weiterentwicklung verzichtet

753 Intertextuelle Bezuge im inneren Kommunikationssystem müssen jedoch von einer tiktiven Person nicht notwendigerweise ausgesprochen oder gedacht werden, zu dieser Gruppe gehoren $>$ B ituch Hinweise (des Erzahlers). daß die betreffende Person das Buch liest. gelesen hat oder auf eine andere An rezipient hat
} 
hier eine zusătzliche semantische Komponente für den Aufbau einer humoristischen Version des Prătextes.

Die Prosa Cechovs offnet sich „fremden Wertungen und Akzenten“ (s. Bachtin in Kap. 2.1.) zum großten Teil im Bewußtsein fiktiver Personen, was auf die Dominanz einer besonders distanzierten und problematisierten, auf die Subjektivităt der Wahmehmung von Fremdem ausgerichteten Prăsentation von Intertextualităt schließen låßt. In den spăteren Novellen, in denen intertextuelle Referenzen nach unserer Beobachtung noch deutlicher in den Bereich des rezipierenden Bewußtseins treten, noch ofter mit dem Phănomen fiktiver Literaturrezeption verbunden sind, entspricht der hier bezeichnete Charakter der Intertextualität zweifelsohne der in der einschlägigen Literatur mehrmals geschilderten Poetik der auktorialen Distanz und der Objektivität bei Cechov. Im Rahmen dieser Poetik wird unter anderem die Bewertung von Fremdrede sowie die Auseinandersetzung mit ihr im wahmehmenden Bewußtsein lokalisiert und so den handelnden Figuren „überlassen“; der Autor laßt sie den Filter der subjektiven Perzeption durchlaufen. Die im manifesten Werk evozierten Texte werden zum Bestandteil und zu einem der Aspekte der subjektiv rezipierten Wirklichkeit, die manchmal sogar keine Rückschlüsse auf die objektiven Sachverhalte erlaubt: „[...] die in den spâten Erzahlungen Cechovs thematisierte Wirklichkeitssicht der Figuren" "spiegelt" "keine objektive, ontologische Wirklichkeitsstruktur" "wider", "sondem" „ist" "vor allem als subjektives Wirklichkeitsverstăndnis, als besondere, subjektive Modellierung von Wirklichkeit zu verstehen“, "ihre Lebenswelt" ist deshalb "hinterfragbar" 756 Das Phänomen fiktiver literarischer Rezeption verbinden wir in diesem Sinne mit dem nach Kataev für die Poetik Cechovs charakteristischen ,gnoseologischen Blickwinkel“457?

[...] интерес автора сосредоточен не столько на явлениях самих по себе, сколько на представлениях о них, на возможности разных представлений об одних и тех же явлениях, на путях формирования этих представлений, на природе иллюзии, заблуждения, ложного мнения. [...] Гносеологичский угол зрения на изображаемую действительность стал одним из слагаемых нового типа художественного мышления. ([...] das Interesse des Autors fokussiert sich nicht so sehr auf die Erscheinungen selbst, wie auf die Vorstellungen von ihnen, auf die Moglichkeit verschiedener Vorstellungen von denselben Erscheinungen, auf die Entstehungswege dieser Vorstellungen, auf das Wesen der Illusion, des Irrtums, der falschen Ansicht. [...] Gnoseologischer Blickwinkel auf die dargestellte Realităt wurde zu einer der Komponenten einer neuen Art des künstlerischen Denkens.) ${ }^{758}$.

\footnotetext{
${ }^{756}$ Penzkofer 1984, S 203

737 Auch Penzkofer, aus dessen Monographie das oben angeführte Zitat stammt. stutzt sich dabei auf Kataev und spricht von einer .gnoseologischen" Funktion der Wirklichkeitsgestaltung in den Erzahlungen Cechovs (s. 1984. S 206). Danuber und mehr uber die Arbeit von Penzkofer s bei uns (Smola 1998b. S 496-499)

7ss Kataev 1979, S. 25-26. Vgl ebenfalls Cudakov uber die im spateren Erzahlen Cechovs dominierende Perspektive der Figuren bzw. des Erzahlers (1971, zusammenfassend auf den S 135-136, 274-275)
} 
Die bevorzugt „innerkommunikative“ Stellung der intertextuellen Bezüge in der Struktur der Prosa Čechovs und somit die Problematisierung der herzustellenden Verknüpfungen betonen noch mal den Charakter der ersteren als aktive und bewußte Verweisung auf den Referenztext (s. die von Tynjanov, Peters, Schmid u.a. formulierte Differenz zwischen dem Beeinflußtsein vom Prätext und dem offenen Zurückgreifen auf ihn (die letzte bildet, nach Schmid, das Wesen der Intertextualitat) ${ }^{759}$ ).

Wir wollen hier, bevor wir zur Analyse der Texte übergehen, das Verhältnis unserer Fragestellung zu einigen der in Kap. 2.2. erwăhnten einschlăgigen Beiträge der Cechovforschung erlăutern.

Wir năhern uns den Arbeiten, die sich mit den intertextuellen Gestalten (Gruppe 2) und mit den intertextuellen Handlungen (Gruppe 3) bei Čechov beschăftigen, insofern an, als die Untersuchung der Fălle fiktiver Literaturrezeption fast unvermeidlich zum Vergleich der rezipierenden mit den rezipierten Figuren und der entsprechenden Sujets fünt. ${ }^{760}$ Wir heben uns deshalb verständlicherweise von jenen Beitrăgen dieser Gruppen ab (z.B. Kataev ${ }^{761}$ ), die den erwăhnten Vergleich aufgrund v.a. der Similarităt der Gestalten und der Handlungsstrukturen anstellen, ohne daB der Fakt der „Bekanntschaft“ des Helden oder der Heldin mit ihren literarischen Pendants auf irgendeine Weise angesprochen, ja vermutet würde. In ăhnlicher Weise distanzieren wir uns von jenen Analysen der Gruppe 4, die auf die Spuren bestimmter, fremden Texten entstammender Ideen im Werk Cechovs hinweisen, ohne daß diese Ideen im dem betreffenden Werk auch nachweisbar ${ }^{762}$ fiktiv rezipiert und verarbeitet worden wăren (z.B. die Philosophie Nordaus in „Cërnyj monach“ in dem Beitrag von Krinicyn oder die Lehre Tolstojs in Novellen wie ..Neprijatnost”“ (Eine ärgerliche Angelegenheit), .,Vragi“, „Vstreča“, .Mužiki“ (Die Bauern) in den Beiträgen Winners und Melkovas).

Unsere Untersuchung nähert sich auch den meisten Beitrăgen der Gruppe 5 insofern an, $\mathrm{da} B$ es in ihnen um Zitate und Allusionen geht, die von fiktiven Personen selbst stammen.

Weiterhin wenden wir uns konkreten Formen, Umstănden, dem Ablauf und den Gründen der fiktiv dargestellten Literaturrezeption im Kontext des gegebenen Werkes zu; damit markieren wir den Unterschied unserer Fragestellung zu der bei Elizarova und Levin, die sich v.a. auf die sozial-literarischen Zusammenhänge konzentrieren, die die Rezeption (der Hamletgestalt) vor und in den Werken Cechovs im allgemeinen geprägt haben. Darüber hinaus bilden nicht der Prătext bzw: seine Personen (gegebenenfalls Hamlet) für uns den Ausgangspunkt für die Intertextualitätsanalyse, sondern der aktuelle Text mit der (in ihm meistens vorhandenen) ..Kreuzung“" und der ..Kopräsenz" mehrerer Prătexte.

\footnotetext{
${ }^{759} \mathrm{Vgl}$ S. 21-22 unserer Arbeit.

$760 \mathrm{Vgl}$. bei Helbig Er spricht z.B von den ..Fälen 'gelebter Literatur in det Literatur'. wo eine individuelle Textrezeption als Voraussetzung der Handlung und Vorlage der Handlungsstruktur fungiert" (1996. S 181) Vgl dazu auch Goetsch. .Doch pragen in einer Reihe von Werken das Lesen, die An und Wirkung der Lekture die Handlungsfuhrung und rücken die Lesergestalt in den Mittelpunkt der Anteilnahme oder Kritik.* (1983. S 208)

${ }^{761} \mathrm{~S}$ seinen Vergleich Nikolaj Stepanovics mit Faust und Gurovs mit Don Guan (S $51-52$ unserer Arteit)

762 mit Hilfe zumindest einer Allusion
} 
Aus den genannten Gründen sind uns tendenziell diejenigen Beitrăge der Gruppen 2 und 4 năher, die mehr oder minder explizit die Rezeption anderer Texte durch fiktive Figuren bei Cechov zum Thema haben bzw. in denen das Vorhandensein einer solchen Rezeption bei der vergleichenden Untersuchung aufgrund deren expliziten Pràsenz im Text stillschweigend vorausgesetzt wird (das sind beispielsweise: der Vergleich Treplevs mit Hamlet bei Leithold; Platonovs mit Cackij, Don Juan und Hamlet bei Lauer; Laevskijs mit Hamlet und den „überflüssigen Menschen“ der russischen Literatur bei Winner und Saal-Losq; die Philosophie der Stoiker, Schopenhauers und Tolstojs in „Palata No6“ bei Skaftymov, Rayfield und Berdnikov; Ideen Nietzsches in "Cérnyj monach“ bei Sebina und Bykova oder Ansichten Tolstojs und Nordaus zur Frage der Frauenemanzipation in .Ariadna“ bei Krinicyn).

Mit einigen Beiträgen der (iruppe 3 verbindet uns ein eher ambivalentes Verhăltnis. Ohne die verbreitete These widerlegen zu wollen, daß die Sujets späterer Novellen Cechovs sich bisweilen in deutlicher und bewußter, nicht selten ironischer Abweichung von den in der $\mathrm{Li}$ teratur vorgegebenen Schemata entwickeln, verzichten wir aus den bereits erlăuterten Gründen (s. oben über die Kriterien und die Auslegung unserer Abgrenzung der „Texte zweiten Grades“ bei Čechov) darauf, sie als Inversionen, scherzhafte Neu-Schreibung, noch weniger als Parodien auf Fremdtexte zu bezeichnen. Da wir großen Wert auf die Unterscheidung früher Kurzgeschichten wie "Zagadocnaja natura“ oder „Silo v meske“ einerseits und der Novellen wie "Duèl"،, "Ionyz“ oder „Dama s sobackoj“ andererseits legen, erscheinen uns die aufgefuhrten Formulierungen in bezug auf die letzteren (z.B. bei Saal-Losq, obgleich sie die Parodie auch anders versteht) als problematisch. Wir stimmen Kramer zu, wenn er die Kurzgeschichte ,Smert' cinovnika“ .corrective rewriting“ von ..Sinel"“ nennt, distanzieren uns aber von ihm, wenn er ..Rasskaz neizvestnogo celoveka“ als eine Halb-Parodie von ..Nakanune" interpretiert. Wir geben Forschern wie Winner oder Saal-Losq ebenso dann recht, wenn sie bei Cechov eine prinzipiell andere Lösung der ..klassischen“, aus den Werken Tolstojs, Flauberts, Puškins oder Turgenevs bekannten, ja herkömmlichen Konflikte und Situationen oder eine gegenüber diesen Werken altemative Sujetentfaltung finden ${ }^{763}$ und so das polemische Potential seiner Novellen aufdecken. Wir betrachten das jedoch - anders, als wir Parodien begreifen also - weder als literarisches Diminutiv der Referenztexte noch als Experiment mit den hergebrachten Mustern, sondem (noch einmal in Anlehnung an Kataev ${ }^{\text {7(n) }}$ ) als eine ernste Auseinandersetzung mit den Vorläufern, als ..schöpferischen Streit““ (..творческий cnop“).

Die vergleichende Analyse wird sich, wie auch in den vorigen Kapiteln, aus der Funktion und dem semantischen Potential punktueller intertextueller Verweise entfalten - Zitate oder Allusionen (wie das u.a. in den Arbeiten von Smirnov, Clayton und besonders Kosiny und Kanevskaja getan wird). Dabei werden wir versuchen, die Rolle intertextueller Bezüge im inne-

\footnotetext{
${ }^{23}$ In diesem Sinne finden wir auch den Gedanken von Saal-Losq uber die bewußre Nicht-Erfullung der Lesererwartungen in der Prosa Cechovs (s S 51. 53-54 unserer Arbeit) durchaus uberzeugend ${ }^{764} \mathrm{Vgl}$ S. 54 dieser Arbeit
} 
ren Kommunikationssystem der Texte Cechovs womöglich vollständig zu ermitteln: sowohl in ihrem psychologisch-pragmatischen Aspekt als auch im ,semantischen“76s.

Mit der Analyse typischer Erscheinungsformen und Trăger der fiktiv gestalteten Literaturrezeption haben sich bereits einige Forscher befaßt. Da ihre Modelle und Beobachtungen uns bei der Untersuchung der Texte Cechovs von Nutzen sein werden, stellen wir sie an dieser Stelle kurz vor.

So führt Wuthenow bekannte Texte der Weltliteratur auf, in denen Leserfiguren und damit das Problem der Wirkung der Lektüre auf die fiktiven Personen im Mittelpunkt stehen. Als Beispiele werden dabei u.a. "Don Quijote“ und die Ritterromane, „Werther“, Homer, Klopstock und „Emilia Galotti“, der von der Gestalt Hamlets faszinierte Wilhelm Meister genannt. Manche lesenden Helden lassen sich durch die Bücher verwirren und verführen (wie Emma Bovary durch empfindsame Romane: „ihre Vorstellungen von Glück sind ein Produkt empfindsamer Lektürestunden “ ${ }^{\text {766 }}$ ), die anderen sind dagegen eher Kenner und Genießer oder sind von der Bücherwelt übersăttigt und verdrossen (wie Faust).

Wer aber liest denn - und warum? Und wie liest er? [...] Manche lesen, um vor der Wirklichkeit zu flüchten, andere lesen aus geistiger Anspannung und Anteilnahme, aus Bildung oder um denken zu lernen; weil man Geschmack und Muße hat, liest man bei Jacobsen oder D'Annunzio. Hier haben die Bücher etwas Zufäliges, sie konnten durch andere Gegenstände notfalls ersetzt werden. ${ }^{767}$

Häufiger zeugt jedoch die Lektüre nach Wuthenow von den inneren Schwankungen des Helden, von der gespannten Suche nach sich selbst: „Das Ich - [...] - erscheint hierbei in einer [...] seltsam gebrochenen Weise, in der die Vergewisserung seiner oder ihrer selbst zugleich von tiefer Unsicherheit zu zeugen scheint [...] in seinem Bewußtsein von sich ist das Ich zugleich auf Spiegelungen angewiesen, die seine Unsicherheit verraten“. ${ }^{768}$

Stückrath geht das Thema systematischer an, indem er eine Typologie der Lesergestalten anhand ebenfalls berühmter literarischer Texte erstellt. Es werden insgesamt fünf Grundtypen der fiktiv Lesenden herausgebildet: 1. der verblendete Phantast (wie Don Quijote; „Der Phantast trăumt einer unmöglichen, weil vergangenen oder gänzlich imaginären Welt nach.769); 2. der Rebell (z.B. der sozialistische Revolutionär Pavel in Gor'kijs Roman ..Die Mutter"; "Der Rebell träumt auch von einer besseren Welt, die aber [...] durch Aktionen in der Gegenwart und Zukunft verwirklicht werden kann. ${ }^{670}$ ); 3. der Künstler (der sich im

\footnotetext{
${ }^{765} \mathrm{~S}$ unsere Verwendung der Typologie Kosinys (s. Fußn. 426 dieser Arbeit)

706 Wuthenow 1980. S 14

${ }^{767}$ Ibid S. 15

768 Ibid. S. 29.

T69 Stuckrath 1984, S 103

70 Ibid
} 
Leseprozeß entwickelt, wie Wilhelm Meister); 4. der pikarische Simplizissimus und der Abenteurer (zB. Simplizissimus oder Robinson; sie „irren vom Weg der Tugend ab und finden wieder zu ihm zurück. An solch entscheidenden Wegmarken begegnen wir ihnen mit dem Buch in der Hand “"71); 5. der gelehrte Büchermensch (Faust oder der Sinologe Kien in Canettis Roman „Die Blendung“). Stückrath fragt abschließend auch nach der Spezifik der Leserinnen-Figuren in der Weltliteratur und beantwortet diese Frage nur sehr flachtig folgendermaßen: ,Zu erwăhnen ist, daß romanistische Forschungen zeigen konnten, daß Flauberts Madam Bovary in ihren markanten Eigenschaften als Leserin - schwärmerische Jugendlektüre, frustrierende Eheerfahrungen, Lesewut, durch erotische Lekture-Vorbilder mitbestimmter Ehebruch - im Frauenbild des Romans des 19. Jahrhunderts kein Einzelfall ist." ."7n2

Im Aufsatz von Goetsch werden nicht nur typische fiktive Leser geschildert (das sind bemerkenswerterweise z.B. „Leser und Zuhorrer“, die „unaufmerksam, ungeduldig und gleichgültig reagieren“ oder "wăhrend der Lektüre einschlafen“; „die von falschen Voraussetzungen ausgehenden, korrekturbedürftigen Lesergestalten, Personen also, die lernen müssen, richtig zu lesen"; ,uneinsichtige Leser“ wie Don Quijote, der "von der Literatur verführt und verblendet worden" ist ${ }^{73}$ ), sondern auch mögliche Erscheinungsformen der Verweisung auf die gelesenen Texte aufgezählt: „eingelagerte Erzăhlung“, „mündliches Vorlesen“, „Zitate und literarische Anspielungen“, ,allgemeine Charakteristik der Gattung“, Beschreibung der „unmittelbaren Reaktion der Lesergestalt", "Diskussion der Lektüre mit anderen Figuren, eine Erorterung, die nicht nur der Charakterisierung der Personen, sondern auch der Vorausdeutung auf die weitere Handlung dienen mag [...]“. ${ }^{774}$ Und weiter: „Schließlich ist moglich, die langfristige Auswirkung der Lektüre auf die Phantasie, das Denken und die Weltsicht der Lesergestalt zu beschreiben. “"77s

Schließlich grenzt Wolpers das Feld der in den drei vorgestellten Arbeiten erörterten Themen insofern ein, als er sich in erster Linie dem Motiv "Gelebte Literatur in der Literatur" zuwendet und versucht, es idealtypisch, jedoch auch anhand konkreter Texte zu beschreiben. In deutlicher Übereinstimmung mit der SchluBfolgerung von Wuthenow weist er zunächst auf die Charakterspezifik des Lektüre .nachlebenden“ Helden in der modernen Literatur (diese beginnt mit „Don Quijote“) hin: Das ist ein „'problematisches Individuum', das in einen fundamentalen Gegensatz zur Umwelt - und zu sich selbst - gerăt. [...] dessen Verhalten von verschiedenen Oppositionen wie Sein und Schein, Wirklichkeitssinn und Imagination, Eigenund Fremderfahrung. Echtheit und Rollenspiel oder Wahrheit und Illusion gekennzeichnet

\footnotetext{
mI Ibid. S 104

72 Ibid S. 104-105

ni. Goetsch 1983, S 210-211

74 Ibid S 207.

77 Ibid

${ }^{\pi 6} \mathrm{~S}$ Wolpers 1986, S. 7
} 
ist" ${ }^{m}$ Dieses Individuum ist nach Wolpers im „Typus des leicht enthusiasmierbaren [...] Schwarmers, auch des wahnhaft handelnden, von einer fixen Idee besessenen Helden" verkörpert; sein Versuch, das Fiktionale zu verwirklichen, basiert ,auf dem Verkennen von Literatur und Leben", ist "meist zum Scheitern verurteilt" ${ }^{\text {"778 }}$. Wolpres spricht in Verbindung mit dem genannten Motiv vom „märchenhaften Ausmalen der Wunschbilder" und vom „Zerbrechen der Trăume an der Realităt" ${ }^{\text {779 }}$. Dementsprechend "werden“ in dem betreffenden Sammelband ,aus naheliegenden Gründen nicht die realistischen, auf die Alltagswelt verweisenden Varianten des Romans als Vorbilder gewăhlt, sondern die idealisierenden, romantisierenden oder empfindsamen Spielarten ${ }^{\text {“780 }}$. Verschiedene Aspekte des gegebenen Motivs sind einerseits „die jeweiligen psychischen Voraussetzungen und Beweggründe wie Lebensunerfahrenheit, Illusionsbedürfnis oder starke Phantasie“, andererseits "die ethische Frage“, „ob und wie das Literaturnachleben gegenüber der als real angenommenen Welt und ihrer Moral zu rechtfertigen und innerlich zu verantworten " ist. ${ }^{781}$

An solche allgemeinen Charakteristika des Motivs "Gelebte Literatur in der Literatur" wie der Heldentyp, der zu seinem Trăger wird, die von dem Motiv berührten Fragen- und Problemenfelder u.s.w. knüpt Wolpers die Beschreibung des Ablaufs eines Nachlebens von Literatur an. Dabei ergibt sich für ihn ein Fünf-Phasen-Modell: 1. fiktive Sachverhalte vor der Begegnung der Figur mit dem Literarischen; 2. Begegnung der Figur mit der Literatur und Beginn der Identifikation mit ihr, 3. Identifikatiosphase: Nachleben des Fiktiven; 4. Austritt aus der Identifikation; 5. Situation und Verhalten danach.

Wie u.a. die Autoren des Sammelbandes "Gelebte Literatur in der Literatur", beschränken wir uns im weiteren bewußt auf jenen Teil intertextueller Referenzen im inneren Kommunikationssystem der Prosawerke Čechovs, bei dem die schöne Literatur als Referenztext fungiert. ${ }^{782}$ Wir wenden uns damit dem Thema der ..An=ichungskrafi ${ }^{.783}$ oder - hreiter - der Wirkung der Fikıion auf die Cechovschen Personen zu. Nur die Fiktion - die andere, dargestellıe Wirklıchkeıt - ermöglicht den sie rezipierenden Figuren, die eigene Lebenssituation, sich selbst und ..die Umgebung. ${ }^{.784}$ (nicht zuletzt die menschliche) mit der fiktiven zu vergleichen; aus diesem, ob emst oder spielerisch gemeinten Vergleich ergibt sich ein besonderes Spannungsverhältnis zwischen den beiden Ebenen des Sujets - der realen und der imaginăren. Wolpers schreibt über die besondere Rolle der schönen Literatur innerhalb des Motivs „Ge-

\footnotetext{
$m_{\text {lbid. }} \mathbf{8} 8$

${ }^{m}$ Ibid. S. 12. Vgl dazu bei Schmid, der ebenfalls uber Diskrepanzen zwischen .dem realen Verhalten der Personen und den literarischen Schemata. denen sie selbst oder die Erzahler folgen" schreibt (1991. S. 90). vgl in der Fußn 741

${ }^{779}$ Wolpers 1986. S 12.

${ }^{7 \times 0}$ Ibid S 13

781 lbid. $S 9$.

${ }^{7 \times 2} \mathrm{Vgl}$ ibid., S 13

77" S bei Wolpers .die Macht der Literatur, ihre Anziehungskraft“ (ibid., S. 18)

${ }^{724} \mathrm{~S}$ ibid. S 22
} 
lebte Literatur in der Literatur": „Denn nur hier wird die oben erörterte Grundspannung des Motivs voll wirksam. Sie resultiert aus der Problematik der unmittelbaren Rūckanwendung einer künstlerischen Konzeption auf das Leben. “ und weiter. ${ }^{785}$ Zweifellos spielt ebenfalls das Thema des Einflusses der philosophischen und publizistischen Texte auf die Personen bei Cechov eine erhebliche Rolle (s. die Beitrăge der Gruppe 4 der Cechovforschung); teilweise zeichnen sich hier dieselben Tendenzen (dieselben Modi der Rezeption) ab wie bei den Bezugen zu fiktionalen Prătexten (so dient die Lektüre beider Textsorten zuweilen als Impuls zu „unmoralischen“, von einer gewissen Grausamkeit gekennzeichneten Handlungen, als Quelle und Rechtfertigung einer solche Handlungen „legalisierenden“ Weltanschauung). ${ }^{786}$

Darüber hinaus werden uns nur die Fălle interessieren, in denen das Phănomen der fiktiven Literaturrezeption für uns explizit wahmehmbar ist, in welcher Form sie auch vermittelt sein mag - ob durch das Zitat bzw. die Allusion, eine metatextuelle Aussage oder den vom Erzăhler thematisierten (von dieser oder jener Gestalt unternommenen) Lektüreakt. Aus diesem Kreis fallen insofem zahlreiche, von den Figuren stammende Verweise auf die Fremdtexte heraus, die z.B. aus unserer Sicht eine rein ormamentale ${ }^{787}$, thetorische Funktion erfülen: So ist das fiktive Zitieren eines in die Rede passenden Satzes im Euvre Cechovs recht verbreitet (vgl. das Zitat aus "Ruslan i Ljudmila“ (Ruslan und Ljudmila) in der von Anan'ev erzählten Geschichte in „Ogni“: „[...] это была [...] Кисочка, та самая, в которую я был по уши влюблён 7-8 лет назад, когда ещё носил гимназический мундир. Дела давно минувших дней, преданья старины глубокой...“ (.Es war [...] Kissotschka, dieselbe, in die ich vor sieben oder acht Jahren bis über beide Ohren verliebt gewesen war, als sie [ich] noch die Schulkleidung trug. Ihr Taten längst vergessener Tage, ihr Sagen uralter Zeiten... “.78R $)(7,117)$ oder das Zitat aus "Hamlet" in „U znakomych" (Bei Bekannten): „- He поговорить ли нам сначала о делах? - сказал он. - Что у вас здесь в Кузьминках новенького? Все ли благополучно в Датском королевстве?” („'Wollen wir nicht zuerst von den Geschäften sprechen?' fragte er. 'Was gibt es Neues bei Ihnen in Kuzminki? Ist alles wohlbestellt im Staate Dănemark? ${ }^{\text {max }}$ (189 $\left.)(10,11)\right)$.

An Bedeutung gewinnt für uns der Bezug also erst dann, wenn er für uns deutlicher auf die Reflexion des Zitıerten durch die Person schließen läßt.

Wenn wir von der Intertextualität im inneren Kommunikationssystem sprechen, meinen wir auch Bezüge, die im Bewußtseinshorizont des Erzählers liegen, falls dieser als Teil der Diegese begriffen werden kann. .. [...] the narrator may or may not be participant in the events he recounts. When he is, we usually speak of a first-person narrative because the first person narrates - [...]- events in which he takes part [..] [...] In cases where the narrator is a

\footnotetext{
ras Ibid. S. 14

${ }^{\text {Tas }}$ Zur Unterscheidung der schonen Literatur von .,nichtbelletristischer" innerhalb des Motivs ..Gelebte L.iteratur in der Literatur" s. bei Wolpers 1986. S 13-15.

$70 \mathrm{Vgl}$. die ..omamental quotations" in der Typologie der Zitate bei Plett (s S 35 bei uns)

7 Tschechow 1965, S. 187

Tschechow 1967. S 319
} 
character, he may play a more or less considerable role in the events [...] he may be the protagonist $[\ldots]$ or an important character [...], or a minor one [...], or even a mere observer [...]. “790. Der unterschiedliche Grad der Beteiligung des Ich-Erzählers - des „embodied narrator" - am Geschehen wird insbesondere in der Typologie von Stanzel reflektiert. So beschreibt er "several stages in this process of the embodiment of the narrator". Die erste Stufe in diesem Prozeß stellt dann der Ich-Erzähler dar, der die Rolle des Verlegers oder des Herausgebers übernimmt oder der Erzahler einer Binnengeschichte ist („closest to the authorial narrator"); auf der zweiten Stufe ist der Erzăhler ein Zeuge, Beobachter, Biograph, ist also in der Peripherie der Ereignisse lokalisiert; auf der dritten ist er der Held der Geschichte (,standing at the centre of the action“) ${ }^{791}$ Auch Genette unterscheidet zwischen dem homodiegetischen Erzăhler - dem, der in der von ihm erzăhlten Geschichte anwesend ist, und dem heterodiegetischen - dem, der in ihr nicht vorkommt. Wenn der Erzăhler im Mittelpunkt der Geschehnisse steht (die dritte Stufe bei Stanzel), nennt ihn Genette einen autodiegetischen Erzähler. ${ }^{792}$

Es ist im Weiteren auszuloten, welchen Status der Erzăhler in Cechovs Texten annimmt, so daß auch seine Rolle als Rezipient der in dieses Sujet eingeschriebenen fremden Texte geklärt wird. ${ }^{793}$

\subsubsection{Allgemeine Charakteristik und Typologie der Modi fiktiver Literaturrezeption in der Prosa Čechovs}

Die Intertextualităt im inneren Kommunikationssystem der Prosawerke Cechovs weist gewisse Tendenzen sowie eine bestimmte Entwicklung auf. Die letzte ist im allgemeinen von der Psychologisierung und zunehmenden Komplexităt sowie der Vielfalt des Phänomens der fiktiven Literaturrezeption gekennzeichnet: Von den zahlreichen parodistisch konzipierten Aussagen der Figuren über diesen oder jenen Autor bzw. über sein(e) Werk(e) geht sie zu den vielfaltigen Formen der ernsthaft fiktiv dargestellten Reflexion über Literatur über, ob als bloßes Literatururteil oder als folgenreiches Erleben des Literarischen gestaltet, bei dem eine tiefe Wechselwirkung zwischen dem Menschen und der fiktionalen Wirklichkeit zutage tritt. $^{794}$

\footnotetext{
${ }^{790}$ Prince 1982, S 13-15

791 Stanzel 1979. S 201-202

${ }^{792}$ Genette 1994, S. 175-176

${ }^{793}$ S. z.B. auch Schmid uber die Ich-Erzahler als Leser bei Puškin (s. Fußn 741)
}

794 Uber die Entwicklung der Intertextualitat bei Cechov im Ganzen, die sich jedoch nur zum Teil mit der hier geschilderten Entwicklung der Bezüge im inneren Kommunikationssystem überschneidet. $\mathbf{s}$. in unserem Aufsatz (Smola 2001) Wie wir aber erwahnten, wurde diese Entwicklung bei Cechov, namlich vom spielerisch-humoristischen Umgang mit Fremdtexten zum .ernsteren“, in der Cechovforschung schon mehrmals beobachtet Vgl z B Nazirov ..По мере того. как Антоша Чехонте вырастал. он переставал отшучиваться от классики. Вместо этого он предпринял пересмотр ее. перешел от зубоскальства к приниипиальному спору." (Im Laufe sei- 
Parodistische Intertextualität im inneren Kommunikationssystem in der frühen Prosa Cechovs, die ihren Ausdruck in erster Linie im falschen Zitieren, aber auch in den uneinsichtigen, profanen Literatururteilen der fiktiven Personen (metatextuellen Aussagen also) findet, - wurde in der einschlägigen Forschung bereits mehrmals thematisiert. ${ }^{795}$ Von der Spezifik ihrer Darstellung spricht u.a. Semanova (in bezug auf Turgenev-Verweise ${ }^{796}$ ) und (in bezug auf Puškin-Verweise bei Cechov) A. P. Kuzičeva. Die letztere betont den klischeehaften Charakter der von den Personen stammenden Äußerungen über Puskin sowie ihrer Rezeption seiner Dichtung im Ganzen: „[...] Чехов выявил стереотипы восприятия Пушкина людьми конца прошлого века." (Čechov [...] hat Stereotypen der Puškinrezeption aufgedeckt, die von den Menschen am Ende des vorigen Jahrhunderts benutzt wurden) ${ }^{797}$. Zu solchen Wahrnehmungsstereotypen gehören, wie die Forscherin ausführt, die Trivialisierung der Puskinschen Zeilen, die so eine sprichwörtliche Bedeutung gewinnen, ihre Verzerrung im Laufe des alltăglichen Gebrauchs (hervorgehoben wird dabei der geringe Bildungsgrad der Zitierenden), die Nennung eines Namens dieser oder jener Gestalt aus dem Werk Puskins als Bezeichnung einer gewissen verbreiteten Situation (Tat'jana $\rightarrow$ die Frau gesteht als erste ihre Liebe). Auch

ner Entwicklung hörte Antoša Cechonte allmahlich auf, die klassische Literatur scherzhaft zu behandeln Statt dessen unternahm er ihre Revision, ging von der Witzelei zu einer prinzipiellen Auseinandersetzung uber [...].) (1994, S. 5).

xos Den Begriff..Metatextualitat" als eine Spielar und aber auch eine besondere Qualită der Intertextualităt verwenden wir im Sinne Pfisters (s seine Typologie (S. 29 dieser Arbeit)). Nach Pfister gewinnt der Bezug zu einem anderen Text dann an Referentialitat, wenn ,.der eine Text den anderen thematisien. [ .] seine Eigenart - [...] - bloBlegt"; in diesem Fall .,wird auch der Folgetext zum Metatext des Pratextes - Metatext hier nicht im bloßen chronologischen Sinn des ".Spater". sondern daruber hinaus im semiotischen Sinn des „Über" So treibt Intertextualitat immer auch zu einem gewissen Grad Metatextualitat hervor, eine Metatextualitat. die den Pratext kommentier, perspektiviert und damit die Anknupfung an ihn bzw die Distanznahme an ihm thematisien " (1985a. S. 26-27). So gesehen kommt gerade bei (fiktiven) Literatururteilen und -bewertungen die metatextuelle Funktion der Intertextualitat am deutlichsten und am direktesten zum Vorschein Der allgemeinen Bedeutung des Begriffs entspricht auch die Definition Genettes (auf S. 26 bei uns) Von Metatextualitat ist dann zu sprechen. wenn ein Text sich mit dem anderen auseinandersetzt. inn kritisch kommentiert Wolf spricht in bezug auf die Metatextualitat im Vergleich zur Intenextualitat von ..einer hoheren logischen Ebene“...einer Metaebene, auf der die Textualitat bzw. der Konstruktcharakter des Objekttextes thematisch wird " (1998b. S 366) Vgl dazu auch den Begriff „Metafiktion“ Wolf unterscheidet z.B zwischen der Eigen-Metafiktion (..der direkte Bezuy auf den eigenen Text" (1998a S. 362), der Fremd-Metafiktion (..der intertextuelle Bezug auf einen anderen Text (wobei Intertextualitat jedoch auch nicht-metafiktionale Phanomene umfaßt, z.B den Bezug auf inhaltliche Elemente des Pratextes ohne foregroumkling von dessen Fiktionsstatus)" (ibid.) und der Allgemein-Metafiktion (..die meta-asthetische Diskussion von Lit. allg “ (ibid )) Wolf formuliert ..das Verhaltnis zwischen Metafiktion und Intertextualitat" (1993. S. 225) weiterhin folgendermaßen. ..Wo Pratexte in den eigenen Text dominant unter dem Gesichtspunkt ihrer scheinbaren Wirklichkeit integriert werden, wo es z B um das bloße Lesen eines bestimmten Buches als einer beilaufig enwahnten Tatigkeit einer Figur geht. wird Intertextualitat selbstverstandlich nicht metafiktional verwendet (Fall I) Wo jedoch durch den Gebrauch von Pratexten im eigenen Text entweder deren Fiktionalitat thematisch wird (Fall 2) oder auch diejenige des eigenen Textes (Fall 3), dort wird Intertextualitat zu einem metafiktionalen Vehikel der Thematisierung von Textualitat Zum Fall 2 gehort die Parodie die als kritische Inszenierung von Pratexten uber deren bloßes Zitieren hinausgeht und insofern eine funktionale. aber auch vermittlungsmaßige Sonderform der Intertextualitat ist " (ibid) Vgl auch bei Genette ..l l, auch der Hypertext kann oft als

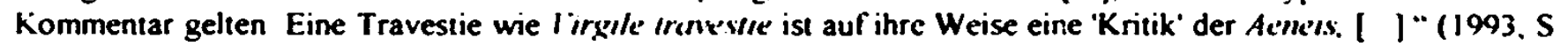
18) In diesem Sinne ist die metatextuelle und die metatiktionale Funktion auch manchen intertextuellen Kontakten zuzuschreiben, die wir im Prosawerk Cechovs bisher untersucht haben (z B gerade der Parodie. Zagaduenaja natura") Im gegenwartigen Kapitel wollen wir jedoch von den metatextuellen und bisweilen den - im Sinne Wolfs - metafiktionalen Aussagen sprechen. die von den liktiven Personen selbst stammen

'*. S Semanova 1957

Kuziceva 1998, 558 
die Beitrăge von Košelev und Kanevskaja, die wir in Kap. 2.2. vorgestellt haben, haben die Wiedergabe der Rezeptionsklischees bei Cechov - v.a. die semantische Reduktion und Verflachung der aufgerufenen Fragmente - zum Thema. ${ }^{798}$

Das frühe Prosawerk Cechovs verfügt tatsăchlich über ein breites Spektrum parodistischer Arten der fiktiven Literaturrezeption: Uns interessieren, um es noch mal zu betonen, diejenigen, die zumindest eine Reaktion des Rezipienten auf das Literarische enthalten (insofern reicht für uns das falsche Zitieren noch nicht aus). Zu ihnen zählen: das Einschlafen beim Lesen („Beznadēžnyj (èskiz)“ (Der Hoffnungslose (€ine Skizze))) ${ }^{799}$; ungeschickte literarische Nachahmung des Gelesenen (z.B. der Naturbeschreibungen Turgenevs in einem Schulaufsatz: „Kanikuljarnye raboty institutki Naden'ki N“ (Die Ferienaufgaben der Pensionatschülerin Naden'ka $N)^{800}$ ) Äußerungen der Protagonisten zu Prătexten. Die Ungehơrigkeit und Lăcherlichkeit der ausgesprochenen Literatururteile kann dabei verschiedene Motive und Ursachen haben: Obrigkeitsmentalităt (dabei fungiert meistens Saltykov-Šedrin als Beispiel der „gefahrlichen“ Lektüre und Symbol von „Liberalismus“ und Zynismus (,Rež' i remešok“ (Die Rede und der Riemen), ,Pis'mo v redakciju“ (Der Brief an die Redaktion)), darüber hinaus Nekrasov, A. K. Tolstoj, Griboedov (,Liberal'nyj duška“ (Das liberale Seelchen))), Ignoranz, Stumpfsinnigkeit oder mangelndes Gefühl für das Poetische („V lando“ (Im Landauer), „Ne v duche“

\footnotetext{
${ }^{798} \mathrm{Vgl}$. S. 63-65 dieser Arteit. Wir sind der Meinung, daß in den spaten Novellen wie z.B. in "Duel" lev ebenfalls als Beispiel des ..Oneginschen Mythos" bei Cechov analysiert (s. Koselev 1998, S. 152-154), keine Sitereorype"l der modernen Literaturrezeption widergespiegelt werden. $\mathrm{DaB}$ die literarischen Selbstdefinitionen Laevkijs den realen Sachverhalten nicht entsprechen. bedeutet für uns nicht. daß sie damit auch klischeehaft und abgedroschen sind Den Versuch. die eigene Situation mit der imaginaren gleichzusetzen, sollte man beim spateren Cechov in den meisten Fallen auf das Imtivichuelle der betreffenden Figur zuruckfuhren und aus dem Individuellen heraus interpretieren Wahrend beim frühen Cechov ungehorige Literatururteile in erster Linie auf die Naivitä oder die Unbildung des Urteilenden hinweisen und so parodistischen Zwecken dienen, wird das Verhältnis zum Literarischen in den spateren Novellen in einem deutlich größeren Maße zum Bestandteil des individuell Psychologischen der Person Nur in seltenen fruhen Prosastucken (wie in .Dačnica“) wird z.B das beim spateren Cechov außerordentlich wichtige Thema angedeutet namlich die gnoseologische (in Aslehnung an den Wortgebrauch von Kataev) Funktion der Lekture. der Leser im ..ProzeB der Welterkenntnis“" (Kataev 1979, S 27) (z.B. Konflikt der rezipierten Literatur mit dem real Gegebenen und Zuerlebenden)

Jedoch auch im letzteren Fall - in den spateren Werken - sind fiktive metatextuelle Aussagen der Personen hăufig mit den in bestimmten Kreisen (z.B bei Symbolisten oder Narodniki) verbrellelen liorstellungen über Literatur verknupft und konnen in diesem Sinne als klischeehaft bezeichnet werden (s. Beispiele solcher Vorstellungen bei Košelev 1998)

${ }^{799}$ In .Beznadeżnyj“ ist die auktoriale Ironie insofern besonders scharf, als die Lekture von Turgenevs Roman .Dvorjanskoe gnezdo“ (Das Adelsnest) fur den Protagonisten zum einzigen Mittel wird. die ihn plagende Langeweile zu besiegen ... его тоскующая душа нашла успокоение в великом писателе [ ..] Барин храпел “(Und sein schwermütiges Gemüt fand beim großen Schriftsteller Ruhe [ .] Der Herr schnarchte .) (3. 222) (s. daruber auch bei Semanova 1957. S. 179, 209) Dem einschlafenden Leser begegnet man auch in der Geschichte „Talant" (Das Talent). in einem allerdings weniger parodistischen Kontext

${ }^{800} \mathrm{Vgl}$ darüber bei Semanova 1957. S 198

\$ol Eine ungeschickte. dem Bildungsgrad der Person entsprechende mumulliche Nachahmung der gelesenen

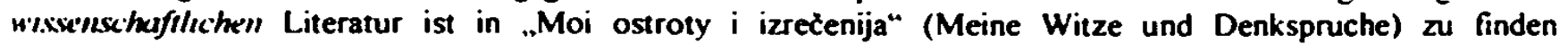
..Превышение власти н административный пронзвол дантиста заключается в вырывании здорового зуб̈а рядом с больным Это сказал один околоточный, читая 'Логику' Мнлля " (Die Machtuberschreitung und die administrative Willkur des Zahnarztes besteht darin. neben dem kranken Zahn auch den gesunden zu ziehen Das sagte ein Polizeirevieraufseher bei der Lekture von Mill's ..Logik“) $(2,253)$
} 
(Schlechte Laune), „Kontrabas i flejta“ (Der Kontrabaß und die Flöte)) ${ }^{802}$; Wichtigtuerei und der Wunsch, als Literaturkenner wahrgenommen zu werden („Rjaženye“ (Die Verkleideten)).

Die Kurzgeschichte „Čtenie (rasskaz starogo vorob'ja)“ (Die Lektüre (Erzählung eines alten Spatzen)) (1884) enthălt zwar ebenfalls eine parodistische Darstellung der fiktiven Literaturrezeption, hebt sich aber von den oben erwähnten frühen Texten dadurch ab, daß in ihr der Prozeß der Wirkung der Lektüre auf die Lesenden verfolgt und das genannte Motiv zum Haupthema entfaltet wird (ein kleiner Beamte wird von seinem Vorgesetzten gezwungen, zu Bildungszwecken ein Buch von Duma zu lesen und vor gewaltiger Anstrengung, es zu verstehen, verliert er den Verstand: er kommt aber zu sich, nachdem es ihm erlaubt wird, die Lektüre zu lassen). Dieser Text bereitet, nach unserer Meinung, bis zu einem gewissen Grade den Übergang zu einer späteren Gestaltung des Motivs vor, die einerseits noch humoristische Züge trăgt, andererseits nicht mehr als parodistisch zu bezeichnen ist - zu einer psychologisch vertieften und perspektivierten Gestaltung der fiktiven Literaturwahrnehmung.

Diese Darstellungsweise lăßt sich in zwei Novellen - „Mal'čiki“ (Die Jungen) (1887) und „Posle teatra" (Nach dem Theaterbesuch) (1892, aller Wahrscheinlichkeit nach aber schon Ende der 1880 er Jahre geschrieben ${ }^{803}$ ) - beobachten. Die zwei Kurznovellen, in derselben Schaffensperiode Cechovs verfaBt, stehen vor allem von der Art der in ihnen dargestellten Literaturrezeption zwischen den oben aufgeführten frühen Texten Čechovs und seinen spateren (und umfangreicheren) Novellen. In den beiden Făllen versuchen Kinder, Literatur (die gelesene oder in einer Theaterinszenierung erlebte ${ }^{804}$ ) nachzuleben und sich in die fiktionale Situation, sprich in die Lage der fiktionalen Charaktere zu versetzten (in "Mal'ciki“" wollen zwei Gymnasiasten eine geheime Reise nach Amerika unternehmen, um dort nach Art der Helden von Reid und Cooper ${ }^{\$ 05}$ wilde Tiere zu jagen, mit Feinden zu kämpfen und Gold zu gewinnen, sie kommen aber nicht weit und werden am nächsten Tag nach Hause gebracht; in „Posle teatra“ schreibt die 16-jährige Nadja Zelenina unter dem frischen Eindruck der „Evgenij Onegin"-Aufführung einen Brief an Offizier Gomyj und den Studenten Gruzdev, die in sie verliebt sind; sie stellt sich dabei vor, daß sie selbst unglücklıch verliebt ist: bald vergißt sie ihren „Kummer“ und es überwältigt sie ein ungeheueres Glücksgefühl: .....] эта 'поэтизированная' схема оказывается настолько нежизнеспособной, что тут же сама собой разрушается восторженным состоянием героини, $[\ldots] \ldots$... ([...] dieses .,poetisierte“ Schema erweist sich als nicht lebensfahig, so daß es sich selber durch die verzückte Stim-

${ }^{022}$ So zeigt Semanova, wie u.a. in der Kurzgeschichte „V lando“ die nach dem Tod Turgenevs entfachte Diskussion um dessen Werk widergespiegelt wird. Cechov parodien profane Außenungen der weniger belesenen Bürger zu einem aktuellen Thema (1957, S. 206-209). Uber die Literaturrezeption in dieser Kurzgeschichte s auch bei Rayfield (1999. S 16). S bei Semanova auch uber die Turgenev-Rezeption in ..Kontrabas i flejta“ (1957, S 210), uber den Rezipienten in ..Ne v duche“" $s$ Košelev 1998. S. 148-150

${ }^{203}$ Über die Tatsachen, die dafur sprechen, s. die Anmerkungen $z u$ der Novelle $(8,437)$

var $\mathrm{Vgl}$ Arten der .Literaturaufnahme“ bei Wolpers ..Dancben gibt es Theater- und Opernbesuche. mundlich tradierte Erzahlungen, Zitate. Liedvortrag. außerdem immer wieder Interpretationen und Gesprache und Reflexionen uber Literatur" (1986. S. 21)

${ }^{20} \mathrm{~V}$ gl. auch die Aussagen Cechovs uber das Thema, das er in diesem Text spater aufgreif, in ..Oskolki moskovskoj zizni“" (Splitter des Moskauer Lebens) (s in den Anmerkungen zu ..Mal 'ciki“ (6. 699)) 
mung der Heldin destruiert, $[\ldots] \ldots)^{806}$ ). Obgleich jedoch dieser Versuch eine krasse Diskrepanz zwischen dem literarisch Imaginăren und der Realităt aufdeckt ${ }^{807}$, ist der Vorgang - allein schon weil es sich um die Wahrnehmung der Literatur durch Kinder handelt - nicht allzu dramatisch und wird eher mit mildem Humor gestaltet; die Rezeption der Lekture trägt hier entweder einen abenteuerlichen oder einen tragisch-sentimentalen, melodramatischen, jedenfalls aber einen naiv-romantischen, infantilen Charakter. Das hier zentrale Motiv "Gelebte Literatur in der Literatur“ gewinnt in anderen Novellen (wie z.B. in „Pripadok“ (Der Anfall) oder „Rasskaz neizvestnogo celoveka“), in denen es auf Erwachsene bezogen ist, an Ernst und Dramatik, ist zunehmend mit dem Thema der verlorenen Illusionen, das auch mit dem der Konfrontation der Verblendeten mit der groben Realităt einherschreitet, des Lebensverdrusses oder auch der literarisch vorgegebenen Zerstorung bzw. Verletzung der anderen verbunden. In diesem Sinne wäre es angemessen, den beiden Kurznovellen eine Sonderstellung im CEuvre Cechovs einzurăumen.

Der (v.a. späteren, d.h. ab 1886 - 1887) Prosa Čechovs ist im Ganzen eine weit verzweigte und recht vielfaltige Darstellung der Rezeption von Literarischem zuzuschreiben. Wir wollen hier von den dominierenden Modi der fiktiven Literaturrezeption in diesem Zeitraum sprechen. ${ }^{2}$ In diesem Sinne haben wir versucht, eine Typologie solcher Modi aufzustellen. Für das Erstellen eines womöglich vollständigen Bildes wird in ihren Kreis unter Modus I auch die parodistische Intertextualităt der frühen Prosa miteinbezogen, jedoch enthălt die frühe Prosa auch seltene Beispiele der nicht oder nicht eindeutig parodistischen, für spätere Werke charakteristischen Modi, was aus der Typologie hervorgehen soll (s. z.B. „Cvety zapozdalye“, „Dačnica“). Darüber hinaus ist es manchmal nicht möglich, parodistische Intertextualităt bei Cechov von der nicht parodistischen (auch im inneren Kommunikationssystem) chronologısch streng abzutrennen. So erwähnen wir im Kap. 3.2.1. in bezug auf „Zagadornaja natura“ die Kurzgeschichte „Svetlaja ličnost”“ als Beispiel der parodistischen Intertextualităt, im weiteren werden wir von der Geschichte „V sude“ (Im Gericht ${ }^{809}$ ) sprechen, die einen nicht mehr parodistischen intertextuellen Kontext demonstriert. Beide Texte sind jedoch im Jahre 1886 verfaßt worden. Fälle der parodistischen Intertextualităt im inneren Kommunikationssystem können durchaus auch in den späteren Werken vorkommen.

So sind in der fiktiven Welt der Prosawerke Čechovs folgende wichtigsten Rezeptionsmodi präsent:

I. Parodistische (iestaltung der Literaturrezeption in der frïhen Prosa (v.a. in den Kurzgeschichten): meistens ungehörige Literatururteile (Texte s. oben);

\footnotetext{
${ }_{8006}^{800}$ Košelev 1998. S 151

${ }^{807} \mathrm{~S}$ daruber in bezug auf ..Mal'ciki“ u.a bei Kramer 1970, S. 79

${ }^{208} \mathrm{~S}$ den Ausdruck ..Rezeptionsmodus/ -modi“ in bezug auf die Lektüre der .,literarischen Helden“ bei Stuckrath (1984, S 106-107)
} 
II. Gelebte Literatur - verblendete und naive Leser ${ }^{810}$ :

1. Kinder (Volodja Korolëv und sein Freund Cecevicyn in „Mal'ciki“; Nadja Zelenina in „Posie teatra“)

2. Idealisten/ -innen (Marusja in „Cvety zapozdalye ${ }^{4811}$, Lelja in „Dačnica“812, Vasil'ev in „Pripadok ${ }^{4813}$; Vlasic in „Sosedi“ (Die Nachbarn) ${ }^{814}$, Zinaida Fëdorovna in „Rasskaz neizvestnogo celoveka" $)^{815}$

3. Unmoralische (Anan'ev in „Ogni“" (Die Lichter) ${ }^{816}$ );

III. Mißtrauen gegenüber Literatur: Entgegensetzen des Eigenen/ des Realen zum Literarischen/ dem Fiktiven, d.h. dem Erdachten - ein Modus, der einen expliziten Gegensatz zum vorherigen bildet (Rezipienten sind z.B.: Travnikov in „Pis'mo“ (Der Brief), Silin in „Strach“ (Die Angst) ${ }^{817}$, Orlov in "Rasskaz neizvestnogo celoveka ${ }^{4818}$, Panaurov in "Tri goda“ (Drei Jahre) $)^{819}$, Samochin in „Ariadna“820, Alechin in „O ljubvi“4821);

809 In der im Weiteren zitierten Übersetzung (Tschechow 1965) unter dem Titel „Im Gerichtssaar"

810 In den allermeisten Fallen wird Literatur durch Lektüre rezipiert, was entweder explizit thematisient oder vorausgesetzt wird, Rezipienten sind dann Leser, die Ausnahme ist hier "Posle teatra“, in der von einer Zuschauerin die Rede ist.

811 S. über die Literaturwahrnehmung von Marusja u.a. bei Semanova 1957, S. 198 und Kramer 1970. S. 39.

12 S. über Lelja als Literaturrezipientin bei Semanova 1957, S. 209. In diesem Text wird allerdings lediglich vage angedeutet, daß Lelja ihren Ehemann ursprünglich für einen Bücherhetden gehalten und später eine schwere Enttruschung ertebt hat.

${ }^{813} \mathrm{Vgl}$. bei Saal-Losq: .As we leam that Vasil'ev ('Pripadok') knows about the purity of prostitutes only from books, we are immediately forewamed that he is a naive character, who is will be disabused of his illusions." (1971, S. 24). S. dazu auch bei Kataev 1979, S. 76. Setzer 1997. S 184 und Dolženkov 1998, S. 231.

814 V.a. seine erste Ehe .im Geschmack Dostoevskijs“. ,.[..] ఇ горячо любил е.. хак униженную и оскорбленную." ([ ...] ich empfand für sie als für eine Gedemütigte und Beleidigte eine flammende Liebe.) (8. 62). S. über diese Bezüge z.B. bei Gromov (1977, S. 43) und bei Berdnikov (1984, S. 109-111).

${ }^{813}$ In den meisten Fallen findet das Nachleben det Literatur bei Cechov in einer (vom Verblendeten stammenden) verfehlten Identifikation der realen Personen mit den literarischen Helden seinen Ausdruck. Vgl diesbezuglich den Ausdruck ,Idealbilder vollkommener Liebe und Ehre“" bei Wolpers (1986, S. 12).

${ }^{816}$ Hier ist die entsprechende - „verderbliche“" - Wirkung der schönen Literatur nur angedeutet Der den „Hamlet" Shakespeares und den „Demon” (Der Damon) Lermontovs alludierende Anan'ev scheint (in seiner Geschichte) das Weltempfinden und das Verhalten der Titelhelden (v.a ihre existentielle Frustration und Zerstönung der sie liebenden Frauen) nachzuahmen (Kluge bezeichnet z.B die frühere pessimistische Weltanschauung Anan'evs, die der letzte zum Zeitpunkt des Erzahlens kritisiert, als das .Lermontovsche Erbe" (s. Kluge 1995, S.72)). Es ist sinnvoll, in bezug auf "Ogni“" von einer überwundenen Literaturverblendung zu sprechen Sowohl in dieser als auch in den anderen Novellen ist jedoch auch das Therna der ahnlichen Wirkung. genauer der Rezeptionsart der philosophische"l und wissenschafilichen Literatur von yroßer Bedeutung (in ..Ogni” sind das u.a. Texte der Stoiker, in „Duel'" Schopenhauer und Spencer, in „Palata Ne6" die Stoiker und Schopenhauer (diese Problematik wurde in der Cechovforschung ofter untersucht; s. Z.B. über die letzte Novelle bei Skaftymov 1958)).

${ }^{817}$ Gemeint ist seine Selbstabgrenzung von Hamlet und von der Angst des letzteren vor dem Jenseits (8, 130 131).

818 wenn Orlov sich gegen die Rolle eines Turgenevschen Helden stemmt $(8,157)$.

819 wenn er die „literarische“ der realen Provinz entgegensetzt $(9,13-14)$.

820 wenn er den idealen literarischen weiblichen Gestalten reale Frauen, d.h vor allem Ariadna entgegenset $\not \lambda(9$, 108)

"21 S die Stelle: „Куда бы м мог увести ее? Другое дело, если бы у меня была храсивая. интересная жизнь, если 6 ж. например. боролся за освобождение родины [ . '“" (.Wo könnte ich sie hinfuhren? Anders ware es. wenn ich ein schönes, interessantes Leben führen wurde. wenn ich zum Beispiel fur die Befreiung der Heimat kampfte [. ]“" (Tschechow 1979, S 465-466)) (10, 72). Hier spielt Alechin auf Insarov aus „Nakanune" an 
IV. Literatur - fiktionale Gestalten und Sachverhalte - als Mittel der Selbstrechtfertigung und der Erklärung der eigenen Situation; hier versucht der Protagonist, eine Analogie zwischen dem Fiktionalen und dem Eigenen herzustellen (Laevskij in „Duèl'“.823); ${ }^{824}$

v. Literatur - das Fiktionale - als Unterhaltung, sprich zeitweilige Ablenkung von der bitteren oder langweiligen Realităt und der eigenen Situation (Unterschied zum Modus II: hier treten nüchterne bzw. desillusionierte oder zumindest nicht unter Realitătsverlust leidende Leser auf ${ }^{825}$, die ins Fiktive zwar (vorübergehend) flüchten, aber keinen Versuch unternehmen, es im eigenen Leben zu verwirklichen; hier ist die unaufhebbare Diskrepanz zwischen dem Fiktionalen und dem Wirklichen den lesenden Figuren bewußt bzw. die bestehenden Parallelen fallen nicht auf und bleiben ihnen verborgen) (die Leser sind $u$. a.: der stellvertretende Staatsanwalt in "V sude“, Orlov in „Rasskaz neizvestnogo celoveka“, Anna Akimovna und der Rechtsanwalt Lysevic in „Bab'e carstvo“, Nikolaj Stepanovic in „Skučnaja istorija ${ }^{\text {(826, }}$ die Mutter von Nadja in ,Nevesta“) ${ }^{827}$;

22 Eine sotche Distanzierung des Protagonisten von den in der (allerdings philosophischen) Literatur propagjerten Werten kommt in der Novelle ..Skučnaja istorija" zum Ausdruck, s. die Aussage von Nikolaj Stepanoviz: .Jerxo сказать: 'трудись', или 'раздай свое имущество бедным', или 'познай самого себл', и потому, что зто летхо сказать, я не знаю, что ответить “ (.Es sagt sich leicht. arbeite! Odet gib dein Hab und Gut den Armen! Oder: erkenne dich selbst! - und gerade weil das sich so leicht sagt, weiß ich nicht, was ich antworten soll." (Tschechow 1965, S. 396)) $(7,298)$.

${ }^{823} \mathrm{~S}$ bei Linkov: ,[...] Лаевский аля оправдания своей распущенности ссьлается на романы Пушкина и Тургенева [ ... " ([...] Laevskij bezieht sich, um seine Haltlosigkeit zu rechtfertigen, auf die Romane von Puskin und Turgenev. [...].) (Linkov 1982. S. 40) S. auch Semanova 1958. S. 197-198. Sach-Azizova 1977, S. 242-243. Kataev 1979. S 159 und über Literaturrezeption in „Duel'" auch Koselev 1998. S. 152-153

${ }^{824}$ Das Verhaltnis von Doktor Ragin in .Palata No6" zu seiner Lektüre schwankt zwischen den Modi II 3 (s. Fußn 816) und IV, d.h. zwischen dem Nachleben der Lebensweisheiten von Mark Aurel u. a. und der Rechtfertigung eigener Passivitat durch die Aneignung seiner Weltanschauung.

${ }^{2}{ }^{\prime} \mathrm{Vgl}$ Wolpers uber die Literatur nachlebenden Personen. Zunachst handett es sich um einen Akt des Erlebens. in dem der Eintritt in die Illusion meist mit gleichzeitigen Anzeichen fur Realitătsverlust [ ..] verbunden ist." (1986, S. 22).

${ }^{226}$ Der Gelehrte bekampt seine Schlaflosigkeit mit Hilfe der Lektüre von Friedrich Spielhagens „Wovon die Schwalbe sang" (s 7. 254); s daruber bei Kataev 1995. S 9 und bei uns (Smola 1996. S. 47); er "unterhalt sich" ebenfalls durch die Lekture franzosischer Literatur

${ }_{827}$ Unter diesem Modus sind jedoch recht unterschiedliche Rezeptionsarten und -situationen sowie verschiedene Rezipiententypen untergebracht So ist die fiktive Wirklichkeit fur Anna Akimovna und Nadja's Mutter offensichtlich Objekt der Traume. Inbegriff des anderen, interessanten Lebens, sie wuirden es verwirklichen, wissen aber, daß das nicht möglich ist (insofern nahem sie sich den Leserinnen des Modus II. sprich den Schwärmerinnen, an); für den Staatsanwalt ist Lektüre blo $B$ eine spannende Beschaftigung. Mittel zur Bekampfung des oden Alltags, ihm falt es nicht ein. Parallelen zwischen dem Fiktionalen und seiner eigenen Situation herzustellen. fur Lysevic ist die schone Literatur darüber hinaus ein angenehmes Spiel, eine Ar Selbstinszenienung. ein Mittel. das eigene Leben und das Leben seiner Mitmenschen zu asthetisieren, er gleicht zwar die Realitat den Romanen oft an bzw wunscht die Veranderung der Realitat. mit der er und Anna Akimovna es zu tun haben. in Richtung Fiktion. nimmt diesen Vergleich aber nicht ernst und steht mit den beiden Füßen auf dem Boden Das Nicht-Ernstnehmen der dargestellten Welt bzw das Spielen mit der letzteren. das ins Zynische umschlagt. ist den letzten zwei Lesern - dem Staatsanwalt aus ..V sude“ und dem Rechtsanwalt Lysevič - gemeinsam. Der erste ist vom fiktiven Mord außerst ergriffen. bleibt dem realen Mord gegenüber aber vollkommen gleichgultig (s. dazu die Anmerkungen zur Novelle - 5, 657-658). den zweiten interessien nur die Anna Akimovna von ihm selbst zugewiesene Rolle. ihre realen Probleme und Leiden lassen ihn dagegen kalt. Diese Art der Literaturwahrnehmung verbindet sie ebenfalls mit dem Medizinstudenten und dem Maler aus ..Pripadok“. die das Sujet von Puškins Poem ..Rusalka" (Die Nixe) wahrend ihres Bordellbesuchs mehrmals aufrufen (durch das Singen von Fragmenten aus 
VI. Nicht-parodtstische Metatextualıät - diverse Literatururteile (Literatur wird hier beurteilt und reflektiert, ohne daß direkt ein Bezug zum eigenen Leben bzw. der Vergleich der fiktionalen Sachverhalte mit der realen - in der betreffenden Novelle dargestellten Wirklichkeit angestellt wird (anders also als beim Modus III); wie beim parodistischen Modus I geht es hier um die „pure“" Metatextuahităt) (die Beurteilenden sind z.B.: Nikolaj Stepanovic in „Skučnaja istorija“828 , Bastanov in „Pis'mo“, Lysevic in „Bab'e carstvo“"829, Nikitin und Varja in „Ucitel” slovesnosti“, Jarcev und Kostja in "Tri goda“"830, Ariadna in "Ari$\left.\operatorname{adna}^{4831}\right)^{832}$

Selbstverstăndlich bestehen hăufiger Übergănge und Zusammenfalle zwischen den hier genannten Modi der fiktiven Literaturrezeption in der Cechovs Prosa. So hăngen besonders eng z.B. Modi Ill und VI zusammen: das Mißtrauen gegenüber der Literatur, das Entgegensetzen des Eigenen, des Wirklichen dem Fiktionalen kann durchaus die Form einer metatextuellen Aussage annehmen, in der der Literatur Unglaubwürdigkeit vorgeworfen wird (wenn z.B. Doktor Blagovo in „Moja żizn”“ sagt, daß die neue Literatur ,intclligentnye truženiki v derevne“ (intelligente Arbeiter im Dorf) nur erdacht hat und sie im russischen Dorf tatsăchlich nicht zu finden sind $(9,230)$, dann gehört er gleichzeitig zu den Rezipienten des Modus III und des Modus VI; jedoch mehr zum Modus VI, weil er im Unterschied z. B. zu Orlov oder Samochin (s. oben) in einem deutlich geringeren Maße den Gegensatz zwischen dem Eigenen und dem Fiktionalen betont, seine Aussage ist abstrakter, bezieht sich mehr auf die Eigenschaften der modernen Literatur, als auf ihn selhst und sein leben und ist deshalb näher der .puren“ Metatextualität). In der Gestalt des Rechtsanwalts Lysevic weiterhin kommen Modi V und VI zusammen: wenn er über Maupassant spricht, dann versetzt er sich allmählich in den Zustand eines literarischen Entzückens, er unterhält sich, zugleich stellt sein Auftritt weitgehend eine entfaltete metatextuelle Aussage dar.

Andererseits begegnet man, wie aus der Typologie folgt, nicht selten dem Fall, in dem einer und derselbe Protagonist in bezug auf verschiedene literarische Texte und in verschiede-

der gleichnamigen Oper Dargomyžskijs), ubersehen aber die Bezuge der realen Situation zu diesem Sujet ( $\mathrm{v}$ a das Thema der Verletzung und Emiedrigung der Frau) Damit bilden sie einen Kontrast zum Jurastudenten Vasil' ev einem verblendeten Leser und Idealisten (eine entfaltete Analyse der fiktiven Literaturrezeption in den erwahnten Texten s. im Kap 4.3.)

${ }^{828}$ z.B. seine Aussagen über .Gore ot uma“ (Geist bringt Kummer (Gribojedow 1948)) $(7,270)$ oder über die moderne nussische Literatur (7. 292-293). vgl daruber bei Polockaja 1979. S 290-291 Die Aussagen von Nikolaj Stepanovic über franzosische Romane als Unterhaltung verknupft sie mit denselben von Travnikov (s. ibid. $\mathbf{S}$. 291)

829 seine Aussagen zu Maupassant im Kapitel III der Novelle

830 Uber die Diskussionen zwischen Jarcev und Kostja uber Kunst und Literatur s. u a bei Polockaja 1979. S. 290-291 Die Forscherin verbindet dabei die Ansichten von Jarcev mit denen von gleichzeitig Baštanov und Travnikov (s. ibid).

811 wenn sie behauptet, daß Boleslav Markevic besser sei. als Turgenev $(9,128)$ 
nen Situationen unterschiedliche Rezeptionshaltungen aufweist und den unterschiedlichen Modi zugehorrt.

Wir haben hiermit wichtige, jedoch nicht alle Beispiele der aufgeführten Rezeptionsmodi im prosaischen Textkorpus Cechovs genannt.

Wie aus unserer Typologie ersichtlich ist, entsprechen einige in der Prosa Cechovs auftauchenden Rezeptionsmodi durchaus den von Wuthenow, Stückrath, Goetsch und Wolpers herausgebildeten und insofern schon in klassischen Texten der Weltliteratur präsenten, konstanten und archetypischen Modellen der fiktiven Literaturwahrnehmung. So basiert die parodistische Gestaltung des Phănomens bei Cechov hăufig auf den bekannten Rezeptionsmustem wie Einschlafen beim Lesen, eine gleichgültige oder noch vielmehr von Ignoranz herrührende ungeduldige und verärgerte Reaktion aufs Vorlesen (s. Goetsch); insbesondere aber der Modus der gelebten Literatur (II), wie er bei den vier Theoretikern geschildert wird, findet seinen Ausdruck im Cechovschen Werk. In erster Linie auf diesen, deutlich jedoch auch auf den Modus IV und zum Teil V trifft die These von Wuthenow und Wolpers von einem suchenden, innerlich gespaltenen, unsicheren, auf Spiegelungen angewiesenen, problematischen LeserIndividuum zu, das in seinem krisenhaften Zustand ins Spannungsfeld zweier Welten - der literarischen und der realen - gerät. Literatur nachlebende Leser/ -innen bei Cechov sind tatsăchlich - pauschal gesagt - mit den Helden wie Don Quijote, Werther, Emma Bovary zu vergleichen - insofern, als sie sich von Büchern verwirren und verführen lassen und daß ihre Lesensart deshalb .,korrekturbedürftig“ ist (s. die Formulierung von Goetsch) (allerdings sind es nur Kinder in "Mal'ciki“", die Lektüre so buchstăblich nachzuleben versuchen wie Don Quijote, meistens außert sich die Verblendung durch Literatur bei Cechovs Personen lediglich in der von einem literarischen Vorbild inspirierten Idealisierung des Anderen: Züge eines modemen Don Quijote tragen Vasil’ev (,Pripadok“), was insbesondere in dem Augenblick, in dem er die weinende Prostituierte mit den reumütigen gefallenen Frauen der russischen Literatur assoziiert, zum Vorschein kommt, und der „leicht enthusiasmierbare Schwärmer“" (Wolpers) Vlasič (..Sosedi“)). Auch den Cechovschen Personen sind Lebensunerfahrenheit (Marusja, Lelja, Vasil'ev, Anan'ev) und das Illusionsbedürfnis (Anna Akimovna, Nadja's Mutter, Marusja u.a.) - nach Wolpers typische Auslöser einer Literaturverblendung - sowie nach Stückrath die speziell für die Leserinnen charakteristische schwärmerische Jugendlektüre (Marusja, Lelja) und frustrierende Eheerfahrungen (Lelja, Nadežda Fėdorovna) nachzusagen. Die Konfrontation der literarisch verblendeten Figuren mit der ganz anderen Realität, die bittere Erkenntnis der Diskrepanz zwischen Literatur und Wirklichkeit sind als charakteristisches ..gnoseologisches “\$33 Ereignis in der Prosa Cechovs zu bewerten. Dieses Ereignis

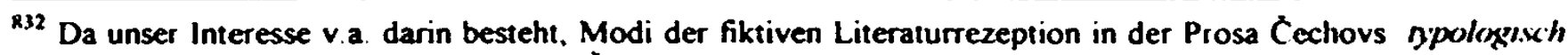
einzuorctiven. gehen wir hier nicht auf die Cechovforschung ein. die sich mit den genannten Texten und mit der in ihnen dargestellten Literaturwahrnehmung (wie sie auch bei uns interpretiert wird) befaßt

${ }^{* 33} \mathrm{Vgl}$ Kataev auf $\mathrm{S} 156$ unserer Arbeit 
wiederholt auf intertextueller Ebene den von Kataev formulierten "Ubergang“ des Cechovschen Menschen von „,kazalos"* (es schien) zu „okazalos"“ (es hat sich herausgestellt); es zeigt „processy poznanija celovekom mira $i$ formy ètogo poznanija“ (den Pozeß der Welterkenntnis bei einem Menschen und die Formen dieser Erkenntnis) ${ }^{834}$, einen Prozeß, der, so Kataev, unabgeschlossen bleibt. ${ }^{835}$

Auch die mit dem Motiv der gelebten Literatur in der Literatur, nach Wolpers, taditionell verknüpfte "ethische Frage“ - inwiefern das Literaturnachleben gegenüber der reılen Welt durch den Nachlebenden zu verantworten ist - ist in Cechovs Prosa (s. Modus I 3: Leser Anan'ev und von Koren) eine der zentralen. Eine Darstellung des vollstăndigen Abaufes des Literatumachlebens, wie er von Wolpers schematisiert wird, ist für Cechov jedoch ther untypisch: Bestimmte Phasen dieses Vorganges werden of lediglich angedeutet - „ohne daß dies expliziert oder [2.B. - K. S.] durch Leseerlebnisse motiviert würde ${ }^{\text {c836 }}$.

Bis zu einem gewissen Grad ăhneln einige Cechovsche Leser den idealtypischen fiktiven Lesern Stückraths (dem verblendeten Phantasten, dem Rebellen (Vlasic, der Ezähler in "Rasskaz neizvestnogo celoveka“ oder von Koren (alle drei sind in unterschiedliciem Grad von der Literatur inspiriert und begreifen sich als Weltverbesserer)) oder dem gelenrten $\mathrm{Bu}$ chermenschen (Nikolaj Stepanovic aus „Skučnaja istorija“ - wie Faust genügt ihn die Bucherwelt nicht mehr (s. darüber $\mathrm{Kataev}^{837}$ )) oder den verbreiteten Leserfiguren Withenows (den verfürten Leserinnen, den Kennem und Genießem (Lysevic aus „Bab'e carst/o“) oder wiederum den vom Bücherwissen verdrossenen Gelehrten a la Faust).

Im Folgenden werden wir versuchen, die Eigenart der fiktiven Literaturrezeption n einigen Novellen Cechovs einzeln zu untersuchen. Von Interesse sind für uns unter ancerem die Werke (s. v.a. das Kap. 4.2.), in denen die hier beschriebenen einfachen Muster und Moxti auf diese oder jene Weise hınterfragt bzw. problemutısıert werden und das Phänomen dơ fiktiven Literaturrezeption so an Komplexităt und Umstrittenheit gewinnt. Weiterhin werdet wir versuchen, Spielarten eines der sechs Modi der fiktiven Literaturwahrnehmung in Čeciovs Prosakorpus aufzudecken (im Kap. 4.3.).

\footnotetext{
Kataev 1979. S. 27

${ }^{835} \mathrm{Vgl}$. Kataev $1979 \mathrm{~S} .20-21 ; 84$. Als einen solchen Erkenntnissubjekt analysiert Kataev u.a. auch Vasilev in Pripadok"

${ }_{836}$ Lauer 1986b. S 260. Vgl auch bei Wolpers. ..In manchen Texten allerdings, so etwa in [ .] Cechos Platownn (um 1900, publ 1923). gehört die Lekture bzw. der Theaterbesuch der im Werk nicht mehr berichteen Vorgeschichte an, die vom Autor stillschweigend vorausgesetzt. aber durch die Vertrautheit des Heldon mit den nachouahmenden Vorbildern und seine intime Kenntnis der zugrunde liegenden Texte belegt wird " (1 186. S. 21). Die Intertextualitat von .Platonov" (s Lauer in unserem Literaturbericht - S 49.50 dieser Arbeit) ahlt Lauer ausdrücklich zum Phanomen der .gelebten Literatur in der Literatur" (s Lauer 1986b)

${ }^{237} \mathrm{Vgl}$. S. 52 dieser Arbeit
} 


\section{2. „Rasskaz neizvestnogo Celoveka"}

Die im Jahre 1893 veroffentlichte ${ }^{838}$ Novelle „Rasskaz neizvestnogo celoveka“ verfügt über vielfaltige Formen der fiktiv gestalteten literarischen Rezeption wie z.B. die in den Mund der Personen gelegten Zitate und Allusionen, fiktive Lektüreakte, Diskussionen der Personen über die früher (vor Beginn der Geschichte) gelesenen Bücher, Nacherzählung von einzelnen Episoden, mehr oder weniger bewußte Übernahme der den gelesenen Werken entnommenen Muster im Alltag und im Umgang mit anderen (dabei geht es sowohl um das sprachliche Imitieren als auch um die Orientierung der Figuren auf das Literarische im Verhalten und im Lebensstil - Zeichen der „langfristigen Auswirkung der Lektüre auf das Denken und die Weltsicht der Lesergestalt ${ }^{(839}$ ) u.a.

Im Endergebnis kommt es in diesem Prosastūck einerseits zu einer Kreuzung verschiedener Lese- und Rezeptionsarten, die miteinander teilweise in einen scharfen Konflikt geraten, andererseits zur Wandlung und Verändenung der literarischen Rezeption, genauer - des Verhăltnisses zur Literatur - innerhalb eines und desselben wahrnehmenden Bewußtseins. Der geistige Wandel der Personen wird hier von einem Wandel ihrer Rezeptionsweise und Literaturwahrnehmung begleitet. Im Laufe dieses Wandlungsprozesses werden bestimmte Prătexte (halbwegs oder vollkommen) verdrängt und von den anderen abgelost.

Wir beziehen in unsere Analyse auch wichtige intertextuelle Verweise ein, die zwar in den Mund der Personen gelegt werden, deren Funktion aber nicht unmittelbar aus ihrer Wahrnehmung durch diese Personen aufzuschlüsseln ist (nicht die pragmatische, sondern die semantische Funktion des Verweises (Kośny) ist dann vordergründig). Der Sinn solcher Bezüge liegt hăufig üher der Ehene des fiktiven Bewußtseins und ist erst nach abgeschlossener Lektüre der Novelle auszulegen (z.B. im bekannten Fall, in dem ein Verweis das spätere Geschehen vorausdeutet).

\subsubsection{Der Unbekannte (der Erzähler)}

Der Unbekannte nimmt in der Novelle insofern eine Sonderstellung ein. als er zum Subjekt der Erzählung wird und so „die Verantwortung“ für die Charakteristik restlicher Figuren übernimmt. Durch die Art seiner Beschreibung bezieht er unverkennbar eine Position zur Person des Anderen und bringt eigene Ansichten zum Ausdruck. ${ }^{2+0}$ Wăhrend er also die männliche Hauptgestalt - den Petersburger Beamten Orlov - gleich im ersten Kapitel ausführlich als

\footnotetext{
${ }^{238}$ Die Arbeit an der Erzahlung begann Cechov jedoch bereits in der zweiten Halfte der 1880er Jahre (zu ihrer Entstehungsyeschichte $s$ in den Anmerkungen in Cechov 8, 466-476)

${ }^{839}$ Goetsch 1983. S. 207.

"Now Nach Wolpers ..kann" z B ..der Erzahler am Schicksal seines literatumachlebenden Helden teilnehmen und es kommentieren" (1986. S. 18)
} 
Leser präsentien, verrăt er auch sein eigenes Verhăltnis zur Literatur, charakterisiert sich als Literaturrezipienten. $^{841}$

[...] когда Орлов брался за газету или книгу, какая бы она ни была, [...] то глаза еro начинали иронически улыбатья и всё лицо принимало выражение лёгкой, не злой насмешки. Перед тем, как прочесть что-нибудь или услышать, у него всякий раз была уже наготове ирония, точно цит у дикаря (,[...] Nahm sich Orlow eine Zeitung oder ein Buch vor, ganz gleich, was es war, [...] dann lăchelten seine Augen ironisch [dann begannen seine Augen ironisch zu lăcheln], und auf seinem Gesicht malte sich leichter, gutmütiger Spott. Bevor er etwas las oder hơrte, wappnete er sich jedesmal mit seiner Ironie wie der Wilde mit dem Schutzschild. $\left.{ }^{48+2}\right)(8,140)^{843}$

An die Beschreibung der Lesehaltung bzw. der Einstellung zum Gelesenen Orlovs knüpft eine bemerkenswerte Charakteristik seiner Korperhaltung beim Lesen sowie seiner Lektüre an:

Я зажигал в кабинете лампу и свечи, а он садился в кресло, протягивал ноги на стул и, разваливиись такии образок, начинал читать. [...] Говорят: скажи мне, что ты читаешь, и я скаку тебе, кто ты. Это, быть может, и правда, но судить об Орлове по тем книгам, какие он читал, положительно нельзя. То была какая-то кашиа. И философия, и французские романы, и политическая зкономия, и финансы, и новые поэты, и издания „Посредника“, - и всё он прочитывал одинаково быстро, и всё с тем же ироническим выражением глаз. („Ich zündete in seinem Zimmer Lampe und Kerzen an, und er setzte sich in einen Sessel, legte die Beine auf einen Stuhl und begann, so hingerekelt, zu lesen. [...] Es heißt: Sage mir, was du liest, und ich sage dir, wer du bist. Das mag auch stimmen, aber Orlow konnte man keinesfalls nach den Büchern beurteilen, die er las. I:s gıng durcheinunder wie Kruut und Rüben. Philosophie, franzosische Romane, politische Okonomie, Finanzwirtschaft, neue Dichter, die Ausgaben des Verlags Posrednik [die Ausgaben des 'Posrednik']- all das las er gleichmăßig schnell und stets mit dem gleichen ironischen Ausdruck in den Augen. $\left.{ }^{\text {(a)t4 }}\right)(8,141)$.

\footnotetext{
841 Der Unbekannte gehort zum Erzählertyp. der eindeutig einen Teil der diegetischen Welt der Novelle darstellt ein „embodied narrator" - in den ersten zehn Kapiteln fungiert er mehr als Beobachter, als eine am Rande des Geschehens handelnde Figur der Ich-Erzahler ist hier irgendwo zwischen ., a minor important character" und .,a mere observer" (Princel. S. S 163 dieser Arbeit) einzustufen, er ist auch ein Ich-Erzahler zweiter Stufe nach Stanzel also ein Zeuge. in den letzten acht Kapiteln agient er als Held. der im Zentrum der Ereignisse steht (..important character", der Ich-Erzähler dritter Stufe, ein autodiegetischer Erzahler nach Genette) Demzufolge ist der Unbekannte mit den anderen Literatur rezipierenden Personen der Geschichte gleichzusetzen und als solcher analytisch gleich as behandein wie Orlov oder Zinaida Fedorovna.

*42 Tschechow 1966, S 207

24. Auch im weiteren Hervorh von uns
} 
Das Interessante in den zitierten Stellen (wie ebenfalls in vielen anderen, die im weiteren zitiert werden) ist eine oben bereits erwähnte Doppelcharakteristik: Thematisiert wird nicht nur die Art der Literaturrezeption des Geschilderten (Orlov), sondern - mindestens genau so deutlich - die des Schildernden (Erzăhler). Die Distanz des Unbekannten gegenüber Orlov als Person im Ganzen, die nicht zufällig mit seiner Kritik an Orlov als Leser zusammenhăngt (diese Kritik kommt insbesondere in den von uns kursiv angegebenen Ausdrücken des Erzăhlers zum Vorschein), weist auf sein eigenes Verhăltnis zum Literarischen hin. Der Unbekannte - ein als Lakai getarnter Revolutionăr, andeutungsweise das Mitglied einer radikalen politischen Gruppierung, das „auf gewaltsamem Weg die Freiheit erlangen“ will" ${ }^{845}$ - stellt sich damit selbst unverzüglich als Literaturrezipienten vor. Wie aus der Beschreibung folgt, rufen vor allem die ironisch-distanzierte, mißtrauische, entspannte Lesensart des "Petersburger Beamten“ und dessen unselektive, systemlose Lektüre in ihm Empörung hervor, sie bilden zentrale Punkte der in den Zitaten suggerierten Kritik. Er wird insofern als Leser konzipiert, der im Gegensatz zu Orlov womöglich Vertrauen und Begeisterung für Literatur verspür, aber auch bestimmte Bücher vorzieht. ${ }^{846}$ Im situativen Kontext der Novelle, nåmlich aufgrund der Tatsache, daß der Erzăhler ein - wenn auch mit unaufhaltsam schwindender Überzeugung handelnder - politischer Rebell und in der nahen Vergangenheit ein seiner Idee ergebener Asket ist, der seine politischen Feinde beseitigen will, ist bei ihm eine gewisse „Einseitig-

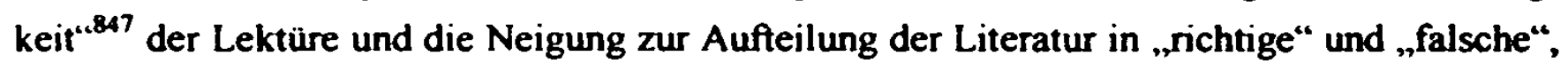
aufklärende und verderbliche zu vermuten. Nicht auszuschließen ist bei ihm ebenfalls der Versuch, bestimmte Literatur im Alltag und in seiner politischen Tătigkeit nachzuleben. ${ }^{\mathbf{8 4 8}}$

Sein literarischer Geschmack wird weiterhin andeutungsweise in einer verachtlichen Charakteristik der Găste Orlovs, insbesondere der von Kukuskin aufgedeckt.

Это был карьерист не до мозга костей, а глубже, до последней капли крови, и прнтом карьернст мелкий, неуверенный в себе, стронвший свою карьеру на одних лишь подачках. [..] $/ / 3$ трусости он .тстит Орлову и Пехарскоку. потому что

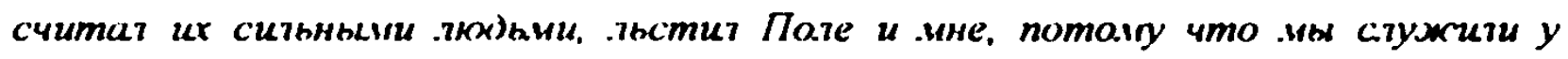

\footnotetext{
244 Tschechow 1966. S. 207

84s Döring 1977, S 108 Döring gibt hier die in den Anmerkungen zur Novelle $(8,467)$ zitierte Aussage von V. N. Figner uber den moglichen Prototyp des Unbekannten, Revolutionàrs Juvacev, wieder

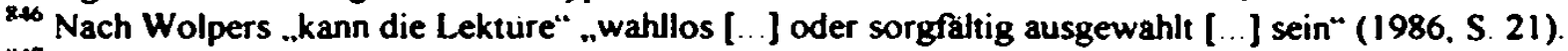

$247 \mathrm{Vgl}$. bei Wolpers 1986, S. 16.

808 Aufschlußreich ist in diesem Zusammenhang z.B. die Bemerkung Dörings, daß der Unbekannte „mit einigen Zügen Insarovs” „ausgestattet“ ist ., . . ] wie dieser gehört er einer politischen Gruppe an, wie dieser erkrankt er an Schwindsucht, wie dieser fahrt er mit der geliebten Frau nach Venedig" (1977, S 87-88). Abgesehen von der Erkrankung konnen die genannten und einige andere Parallelen auf den Einfluß von Turgenevs Roman und der Gestalt Insarovs als (ganz allgemein, bei Verschiedenheit der Ziele und der Aufgaben) einer politisch handelnden Kampferfigur, auf den Cechovschen Helden hinweisen (vgl. dazu in unserem Aufsatz (Smola 2001. S. 105-109) uber die „Debatten“ der Personen Cechovs zum Thema der „Nutzlichkeit von Kunst fur Leben” (ibid.. S. 107) und uber die realen literaturhistorischen Quellen dieser Debatten (ibid., S. 108)) Uber die Spuren des Romans ..Nakanune" in der Novelle und die Parallelitát bzw die Unterschiedlichkeit der Gestalten s. auch bei Semanova 1958 (S
} 
втиятельного человека. (.,Er war ein Karrierist nicht nur bis ins Mark, sondern noch schlimmer [tiefer], bis zum letzten Blutstropfen, und dabei ein kleinlicher Karrierist, der nicht auf sich selber vertraute, sondern seine Karriere allein auf Gnadenerweise aufbaute. [...] Aus Feigheit schmeichelte er Orlow und Pekarski, weil er sie für mächtige Leute hielt, er schmeichelte Polja und mir, weil wir bei einem einflußreichen Mann in Dienst standen. $\left.{ }^{.849}\right)(8,146)$.

Hier alludiert der Unbekannte eine berühmte Replik des Karrieristen Molčalin aus der sozialkritischen Komodie Griboedovs „Gore ot uma“.850.

Мне завещал отец:

Во-первых, угохсать всек .кодям без изъятья -

Хозяину, гве доведётся жить,

Начатьнику, с кек буду я слухсить.

Слуге еzо, который чистит пзатья.

Швейцару, дворнику, для избежанья зла,

Собаке дворника, чтоб ласкова была.

(,Mein Vater riet mir:

Als erstes für alle ohne Ausnahme gefällig zu sein -

Für den Hausherm, bei dem ich wohne,

Für den V'orgesetzten, bei dem ich dienen werde.

Für seinen Diener, der Kleider reinigt.

Für den l'förıner, für den Hauswart, um das Übel zu vermeiden.

Für den Hund des Hauswarts, damit er freundlich ist. “) ${ }^{\mathbf{8 5 1}}$

Die Allusion erfolgt durch eine thematisch-lexikalische Imitation der aufgerufenen Stelle (,ein markantes Handlungsdetail“" nach Schmid oder "the brief echo of content or form", nach Perri): Die synonymische Entsprechung ...ugożdat'” (gefállig sein) zu „l'stit”“ (schmeicheln) wird von einer thematischen .,Synonymie“ begleitet - Kukuskin schmeichelt sich sowohl bei dem „chozjain“ (Hausherr) als auch bei seinem „sluga“ (Diener) ein. Diese Korrespondenz ergänzt der Erzähler durch eine entlarvende Charakteristik, die vielmehr auf den Einfluß bestimmter literaturkritischer Texte der 1860er Jahre auf den Unbekannten verweist.

Durch diese mehr oder weniger bewußte, jedoch deutliche Allusion an "Gore ot uma“ übernimmt der Erzăhler das Pathos und das Vokabular ${ }^{\mathbf{5 i 2}}$ der russischen Satire; wie Cackij

210-213). Bicilli 1966 (S. 23; 194-195). Kramer (1970, S 45, 129 und s. auch in unserem Literaturbericht). Wetzlet 1992 (S. 128)

819 Tschechow 1966, S. 213-214

"so Vgl. Semanova uber Kukuškin ..kar'erist” (Karrierist), ..sovremennyj Molcalin“" (Molčalin der Gegenwart) (1958, S. 194-195)

¿s1 Griboedov 1978. S. 121 
greift er die Speichelleckerei im Staatsdienst und (implizit) diesen selbst an. Also auch mit Hilfe eines intertextuellen Verweises und der in ihm verborgenen, indizierten Analogie zu Cackij manifestiert sich der Unbekannte als einsamer Kămpfer und Fremdling, der gegen die ihn umgebende Gesellschaft vorgeht. ${ }^{853}$ In diesem Sinne erfullt die Allusion eine doppelte Funktion: Einerseits weist sie auf eine der literarischen Quellen der gesellschaftskritischen Aussagen des Erzăhlenden hin, andererseits prazzisiert und bestătigt sie seine Stellung innerhalb der Geschichte (d.h. in erster Linie sein Verhăltnis zu den anderen Personen). In breitem Sinne versteht er sich als Idealist und Weltverbesserer in einer konkreten historischen Situation und in einer gegebenen Zeit (jedoch, im Gegensatz zu Cackij, kein mit den Worten, sondern, wenn auch eher in seiner Vergangenheit, ein mit Tat und Gewalt handelnder Mensch).

Interessant ist, daß die Sprache des Unbekannten oft von melodramatischen und somit auch etwas gekünstelten, ,literarischen“ Elementen geprăgt ist (was beispielsweise in seinem empörten Brief an Orlov in der zweiten Hălfte der Novelle zum Ausdruck kommt; vgl. solche Wendungen wie „вы и я оба упали и уже никогда не встанем“ („Sie und ich, wir beide sind gestrauchelt, wir beide werden nie mehr aufstehen“), „вашей проклятой холодной крови“ („Ihr verwünschtes kaltes Blut"), „голова и сердце горят“ („mein Kopf und mein Herz glühen“), „когда во мне навеки погасли молодость и здоровье“ („als in mir Jugend und Gesundheit für immer erloschen waren“), „приюта у меня нет“ (,ich hatte keine Zuflucht“), „какяе роковые, дьявольские причины помешали вашей жизни развернуться полным, весенним иветом“ (,welche verhängnisvollen teuflischen Gründe haben Ihr Leben gehindert, sich zur vollen [Frühlings]Blüte zu entfalten“(85t) u.a. $\left.(8,188-189)^{855}\right)$.

Dennoch wird parallel dem bereits auf den ersten Seiten der Geschichte angekündigten anbrechenden Sinneswandel des Unbekannten (..начинавшейся перемены мировоззрения“ (,des beginnenden [...] Umschwungs in meiner Weltanschauung “856) $(8,139)$ ) auch eine gewisse Spaltung, genauer gesagt, Schwankung, moglicherweise aber auch eine Wandlung in seiner Literaturrezeption thematisiert. Am Anfang lesen wir: ,[...] мною изо дня в день овладевала страстная, раздражающая жажда обыкновенной, обывательской жизни. [...] я становился мечтателем и, как мечтатель, не знал, что собственно мне нужно“ (,[...] Tag für Tag bemächtigte sich meiner eine leidenschaftliche, aufreizende Sehnsucht nach einem gewöhnlichen Bürgerdasein. [...] Ich wurde zum Träumer und [als Träumer] wußte nicht, was ich eigentlich wollte. $\left.{ }^{\mathbf{8 5 7}}\right)(8,140)$. Das Wort „mečtatel' mečlat' mečtatel 'myj" (Träu-

\footnotetext{
${ }_{852}$ Vgl. auch die in der Charakteristik Kukuskins vorkommenden Ausdrucke ..paбckн ханжнл" (..nach Sklavenart scheinheilig tat"). ..бессовестно врал“" (..verbreitete gewissenlos Lugen“). .льстил [...] испорченности. сытости" (..schmeichelte [. ] der Verderbtheit [ .] Sattheit" (Tschechow 1966, S. 214)) u. a $(8,146-147)$ oder die Definition Orlovs im Brief an ihn als .„фальшивый человек, господин петербургский чнновник“" (..Sie falscher Mensch. Hert Petersburger Beamter" (Tschechow 1966b. S. 263)) (8. 188)

${ }_{833}$ Über das sozialkritische Unteil des Unbekannten über den Kreis Orlovs s bei Semanova 1958 S 194-196

${ }^{254}$ Tschechow 1966, S. 263-264

${ }^{855}$ Uber melodramatische Elemente beim Erzahler s Semanova 1958, S. 212.

236 Tschechow 1966, S. 206

857 Ibid
} 
mer Iräumen' verträumt), bezogen auf sich selbst, verwendet der Erzăhler immer wieder (vgl. "[...] я вспоминал её лицо и запах тонких духов и .кечтат“ („[...] stellte ich mir ihr Gesicht und den Duft ihres [feinen] Parfüms vor und träumte $\left.{ }^{485}\right)(8,143)$ oder .....] когда у меня было прекрасное .мечтательное настроение“ (,„[..] als ich mich in einer wunderbaren verı̈äumten Stimmung befand $\left.{ }^{.859}\right)(8,144)$ ), und am Ende der Geschichte (während seines Aufenthaltes in Venedig mit Zinaida Fédorovna) gewinnt es schließlich an Konkretheit, wird „,aufgeschlüsselt“: „Оба мы: она - злосчастная, брошенная, а я - верный, преданный друг, мечтатель и, если угодно. пишний человек, неудачник, не способный уже ни на что, как только кашлять и мечтать, [.. ]“ („Wir beide: sie - unglücklich, verlassen, und ich - ein treuer ergebener Freund, ein Träumer, und wenn man will, ein überflüsssiger Mensch, ein Pechvogel, nur imstande, zu husten und zu trăumen, $\left.[. . .]^{4860}\right)(8,199)$. Die Wortreihe, in die der Unbekannte im Zuge einer literarischen Selbstreflexion (,лишний человек“, überflüssiger Mensch)) das Wort „мечтатель“, Trăumer) hinstellt, verweist auf die zentrale Figur von Turgenevs Romans .Rudin“. Nicht Insarov, wie einige Cechovforscher annehmen, ${ }^{801}$ - der Held und Tatmensch, der Überzeugte und Entschlossene - sondern Rudin, der Schwärmer, Pechvogel und überflüssiger Mensch, wird zum intertextuellen Pendanten des Erzählers. Im Laufe der erwăhnten Verănderung der Weltanschauung beim Erzăhler vollzieht sich auch seine Abkehr von Insarov, der ihn im breiten Verstăndnis als Tatmensch beeindrucken mochte, hin zu dem vor allem guten, begeisterten Redner, Schwärmer und Schöngeist Rudin.

Die Similarităt des Unbekannten mit letzterem wird mit Hilfe mehrerer Allusionen - thematisch-lexikalischer und stilistischer Elemente, die aus dem Prătext entlehnt sind. - suggeriert. Der Inhalt seiner Träume und Gedanken, die verwendeten Ausdrücke und Metaphern, sein Selbstverständnis erscheinen als mögliche Folge der Lektüre Turgenevs und der immer mehr ins Bewußtsein rückenden Gemeinsamkeit mit der Gestalt Rudins. Vgl.: „[...] To $я$ воображал, как я покупаю десятин пять земли и живу помещиком; то я давал себе слово, что займусь наукой и непременно сделаюсь профессором какого-нибудь провининального университета." (, [...] bald stellte ich mir vor, wie ich fünf Dessjatinen Land kaufen und als (jutsbesıteer leben würde; bald gab ich mir das Versprechen, mich mit der Wissenschaft zu befassen und es unbedingt zum Professor an irgendeıner Provinzuniversıtät $=u$ bringen. “\$62 $)(8,140)$. Diese Pläne erinnem bei einigen Differenzen an die Fakten der spăteren Biographie Rudins, wie er selbst sie am Ende des Romans erzăhlt.. So versucht Rudin zuerst, auf dem Lande eines Gutsbesitzers tätig zu sein und dor die Landwirtschaft zu vervollkommnen, dann wird er Gymnasiallehrer, hält aber vor den Gymnasiasten Vorlesungen wie an einer Universităt. Die auktoriale Ironie besteht jedoch darin, daß Rudin diese Tätig-

\footnotetext{
ss8 Ibid S 209

859 Ibid. S 211

260 Ibid S 277

261 Parallelen zwischen dem Unbekannten und Insarov werden u a von Kramer (1970, S 39-40) und Doring (1977, S. 87-88) betont (s. auch in der Fußn 848)

${ }^{262}$ Tschechow 1966, S. 206
} 
keit, das Leben auf dem Lande wie den Unterricht, als Versuch der Weltverbesserung begreift, der Unbekannte assoziiert sie dagegen mit einer normalen bürgerlichen und bodenständigen Existenz, mit Ruhe und privatem Glück.

Im Brief an Orlov übernimmt der Erzähler - der vermutliche Leser des Romans - nicht nur manche Elemente der Selbstcharakteristik Rudins sowie seiner Charakteristik durch die anderen Figuren, sondem ebenfalls seinen gehobenen Stil, die metaphorische und gezierte Ausdrucksweise:

Отчего я раньше времени ослабел и упал, обяснить не трудно. Я, подобно библейскому силачу, поднял на себя Газские ворота, чтобы отнести их на вершину горы, но только когда изнемог, когда во мне навеки погасли молодость и здоровье, я заметил, что зти ворота мне не по плечам [...]. [...] Я испытал голод, холод, болезни, лишение свободы; личного счастья яе знал и не знаю, приюта у меня нет [...]. („Weshalb ich vor der Zeit schwach geworden und gestrauchelt bin, ist nicht schwer zu erklären. Ich habe mir, dem biblischen Kraftmenschen gleich, die Tore von Gaza aufgeladen, um sie auf den Gipfel des Berges zu tragen, aber erst als ich bereits erschöpft war [als ich erschöpft war], als in mir Jugend und Gesundheit fur immer erloschen waren, bemerkte ich, daß ich diesen Toren nicht gewachsen war [...]. [...] Ich ertrug Hunger, Kälte, Krankheiten und den Entzug der Freiheit; ich habe nie ein persönliches Glück gekannt [und kenne es bisher nicht], ich hatte [habe] keine Zuflucht $\left.[\ldots] .{ }^{4863}\right)(8,189)$.

Vgl. mit Rudin: „- [...] видите вы зту яблоню: она сломилась от тяжести и множества своих собственных плодов. [...] - Она сломилась оттого, что у ней не было подпоры, возразила Наталья.“ („[...] 'betrachten Sie diesen Apfelbaum: Er ist unter der Last und der Menge seiner eigenen Früchte gebrochen. [...]' 'Er ist gebrochen, weil er keine Stütze hatte,' entgegnete Natalja..".tht $)^{865}$ (der Apfelbaum ist hier Allegorie der Person Rudins); ,- [...] Маялся я много, скитался не одним телом - душой скитался. [...] Где не бывал я. по каким дорогам не ходил!.. [...] Строить я никогда ничего не умел: [...]! [...] Горько мне стало тратить попусту время и силы, [...]. [...] я теперь устал [...].“ (,,'[..] Ich habe mich redlich abgeplagt und bin viel herumgeirm - nicht nur körperlich, auch seelisch habe ich gelitten. [...] Wo bin ich nicht überall gewesen, welche Wege nicht gegangen! [...]' [...] Etwas aufbauen, das habe ich nie gekonnt; [..]! [...] Es erbitterte mich, Zeit und Kraft nutzlos vergeudet zu haben. [...]. [...] ich bin jetżt müde [... $]^{\ldots\left(b\left(x_{1}\right)\right.}$ ); der Gesprächspartner Rudins Ležnev sagt zustimmend: ..- [...] а я его [Rudin - K. S.] встречаю голодным, без пристанища...

\footnotetext{
863 Ibid. S 264

Rat Turgenjew 1969. S 63.

86s Turgenev Bd 6 (1963). S. 290

${ }^{200}$ Turgenjew 1969. S 135-146
} 


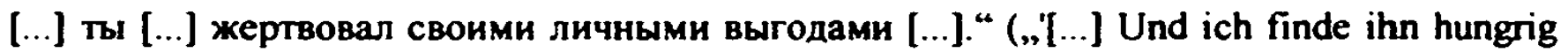
und ohne Obdach... [...] daß du deinen persönlichen Vorteil opfertest $\left.[\ldots]]^{4067}\right)^{868}$ Das bittere Fazit, daß die eigene Tătigkeit ergebnis- und erfolglos beendet werden muß, vermittelt die Ähnlichkeit zwischen dem Unbekannten und Rudin; der Gegensatz besteht jedoch darin, daß der Unbekannte diese Tătigkeit zunehmend als falsch und sinnlos auffaßt, Rudin dagegen seine Grundüberzeugungen nicht åndert.

Auch die immer deutlichere Selbstwahmehmung sowie die Wahrnehmung des Unbekannten durch die anderen als Schwătzer, der seinen Worten keine Tat folgen lassen kann, erinnert an Rudin. So wirft ihm Zinaida vor:

- И труд рабочего, и кровавый пот - это красноречие вы отложите до другого раза, $[\ldots]$ ? [...] зачем вы $[\ldots]$ возбудили во мне сумасшедшие надежды? [..] Когда я все эти месяцы $[\ldots]$ восхищалась своими планами, перестраивала свою жизнь на новый лад, [..] вы [...] поощряли расказами [...]? („Und Tätigkeit des Arbeiters und blutiger Schweiß - diese schönen Phrasen heben Sie sich für ein andermal auf. [...]? [...] Weshalb haben Sie [...] sinnlose Hoffnungen in mir geweckt? [...] 'Als ich diese ganzen Monate [...] mich an meinen Planen berauschte, mein Leben auf eine neue Grundlage stellte, $[\ldots]$ haben Sie $[\ldots]$ mich mit Ihren Erzahlungen noch angespornt $\left.[\ldots]]^{9.869}\right)(8$, 205).

Rudin „verführ" Natal'ja auch mit seinen Reden (so wird auch eines der zentralen Handlungsdetails der Novelle intertextuell gestaltet), und Ležnev bemerkt kritisch: „- [...] cam копейки, волоска не ставит на карту - а другие ставят душу.. [...] слова Рудина так и остаются словами и никогда не станут поступком - а между тем зти самые слова могут смутить, погубить молодое сердие." (..'[...] selber riskiert er keine Kopeke, kein Haar, aber andere riskieren alles [ihre Seele]. [...] daß Rudins Worte eben nur Worte bleiben und niemals zu Taten werden, und dabei können diese Worte ein junges Herz verwirren und ins Verderben stürzen. $\left.{ }^{x \times 870}\right)^{871}$.

So wird durch Allusionen auf „Rudin“ eine strukturelle Analogie zwischen den Texten hervorgehoben (Rudin - Natal'ja; der Unbekannte - Zinaida). Der Unterschied zwischen den

\footnotetext{
867 Ibid S. 145

${ }^{868}$ Turgenev Bd 6 (1963), S. 356-366 Hiet sind teilweise dieselben Zitate aus ..Rudin“ angeführ, die wir in bezug auf die Parodie Cechovs .Zagadocknaja natura" anführen (s. S 104-105 dieser Arbeit). Hier zitieren wir ebenfalls Repliken dieser oder jener Figur in einem Stück, die bei Turgenev manchmal an verschiedenen Stellen innerhalb einer Episode vorkommen

269 Tschechow 1966, S. 283-284

870 Turgenjew 1969, S. 66-67

871 Turgenev Bd 6 (1963). S 293-294
} 
Pendanten ist wiederum, daß Rudin an seine Worte und Ideen glaubt, der Unbekannte sie dagegen innerlich hinter sich gelassen hat und deshalb inkonsequent erscheint. ${ }^{872}$

Infolgedessen gewinnt man den Eindruck, daB der Erzăhler als Literaturrezipient gewisse Schwankungen erlebt: Er behălt die Züge eines sozialen Anklägers, für den ausgewăhlte Bücher eine Anleitung zum Handeln sind („Leser-Rebell“" nach Stückrath), reflektiert über sich selbst aber parallel zu dem Verlust an strikten, festen Überzeugungen gleichzeitig - wiederum literarisch, durch Rudin-Assoziationen - als über einen Nicht-Mehr-Rebellen, einen überflüssigen Menschen. Er befindet sich zu der Zeit des Geschehens allem Anschein nach in einer Situation der Distanzierung von der Literatur im allgemeinen. Diese Distanz erlaubt ihm, (mehr oder weniger bewußt) Parallelen zwischen der eigenen Person und einer solchen wie Rudin zu ziehen. Der Hohepunkt dieser Entwicklung markiert der Augenblick, in dem er sein vorheriges Leben mit einem Melodram vergleicht: „Я мельком, в каком-то полубреду, гочно засыпая, оглянулся на свою странную, бестолковую жизнь, и вспомнилась мне почему-то мелодрама ТТарижские нишие', [...].“ (,Flüchtig und halb im Traum, gerade überm Einschlafen [wie beim Einschlafen], schaute ich auf mein seltsames, sinnloses Leben zurück, und mir fiel, ich weiß nicht warum, das Melodrama 'Pariser Bettler' ein [...]. $\left.{ }^{.473}\right)(8$, 195). Hier wird der Grad der Abwertung der eigenen früheren Tătigkeit besonders deutlich; mit dieser Aussage kehrt der Unbekannte endgültig vom Erdachten, aus seiner jetzigen Sicht Absurden zum Real-Menschlichen um. ${ }^{874}$ Vom mutmaßlichen früheren Vertrauen in die Literatur, ja von der gelebten Literatur kommt er zu einer literarischen Selbstironie. Der Hinweis der Person selbst auf die Ähnlichkeit ihrer Existenz mit dem Melodram relativiert die These Kramers über die Affinität der Novelle im Ganzen zur melodramatischen Gattung ${ }^{875}$. Durch die Tatsache, daß die Parallele im inneren Kommunikationssystem thematisiert wird, daß die dargestellte Realităt dem Unbekannten selbst wie ein Melodram vorkommt, wird der Bezug zum melodramatischen Architext in der Novelle als Reflexion dieses Architextes innerhalb des fiktiven BewuBtseins gestaltet, die auch einen Abstand zu ihm impliziert. Je weiter sich der Erzähler von seinem früheren Leben und seinen früheren Ideen und Zielen entfernt, desto deutlicher empfindet er sie als melodramatisch. ${ }^{876}$

\footnotetext{
${ }^{772}$ Nicht nur uber die Diskrepanzen, die zwischen dem Charakter und der Weltanschauung des Unbekannten und der von solchen Helden Turgenevs wie Insarov entstehen, sondern auch uber die unterschiedliche Rolle, die sie gegenuber der Frau, die in sie glaubt, spielen (der Unbekannte vs Insarov oder Solomin), schreibt u. a. Semanova (1958. S. 212-213; 225) Sie stellt den Unbekannten jedoch nicht neben Rudin, sondern v. a neben den Haupthelden aus dem Roman .Nov“” (Neuland (Turgenjew 1974, S. 239)) Neżdanov (ibid. S. 176. 207-209) In ahnlicher Weise wird auch Zinaida mit verschiedenen Frauenfiguren Turgenevs wie Elena oder Marianna verglichen Wetzler betont ihrerseits Differenzen zwischen den literarischen Helden, die Zinaida inspirieren. und den realen Mannern wie Ortov und dem Unbekannten Sie weist ebenfalls auf eine ..Desillusionierung" der Frauen Cechovs hin (s. 1992, u a. S 127-128).

${ }^{x 73}$ Tschechow 1966, S 271

${ }^{774}$ Gemeint ist hier nicht das Pathos det sozialen Anklage. das der Erzahler als Grundeinstellung bis zum Ende behalt, sondern seine Ideen und die Tatigkeit als Rebell

${ }^{873} \mathrm{Vgl} S$ 66-67 dieser Arbeit.

"76 Elemente des Melodrams im Geiste von Dostoevskij sowie die Bezige zu verschiedenen Werken Dostoevskijs findet in .Rasskaz neizvestnogo celoveka“" jedoch auch Rayfield (1999, S 119-120)
} 
Der Sinneswandel des Erzăhlers ist nicht nur mit seiner Zuwendung zu anderen Texten (wie „Rudin“) bzw. mit den Schwankungen zwischen verschiedenen Texten und Stimmungen verknüpft, sonderm ebenfalls mit dem wichtigen Prozeß seiner Rückkehr zum Realen, der in zwei Schlüsselszenen suggeriert wird. In der ersten wird es ihm bewußt, daß er den Vater Orlovs, der seinen Sohn besuchen kommt, - noch unlängst also einen politischen Feind nicht mehr zu hassen und anzugreifen imstande ist:

[...] я вспоминал, каким страстным, упрямым и неутомимым врагом я был ещё так недавно... Но трудно зажечь спнчку о рыхлый камень. Старое, грустное лицо и холодный блеск звёзд вызывали во мне только мелкие, дешёвые и ненужные мысли о бренности всего земного, о скорой смерти...“ (,„[..] ich dachte daran, was fur ein leidenschaftlicher, hartnăckiger und unermüdlicher Feind ich noch vor kurzem gewesen war... Doch es ist schwierig, ein Streichholz an einem bröckligen Stein zu entzünden. Das alte traurige Gesicht und der kalte Glanz der Sterne riefen in mir nur kleinliche, billige und unnütze Gedanken über die Vergănglichkeit alles Irdischen, über den nahen Tod hervor... “.877) $(8,183)$.

Hier kündigt sich schon das Thema an, das vor allem in bezug auf eine andere Figur - Zinaida Fedorovna - seine volle Relevanz gewinnt. Nicht die Programme und Vorbilder, die letztendlich eine unmenschliche Tat zur Folge haben können, üben immer mehr Macht über die Figuren Cechovs aus, sondern das Reale wie Angst, Liebe und Tod. „Кто же я теперь такой? О чём мне думать и что делать? Куда идти? Для чего я живу?“ („Was für ein Mensch war ich jetzt? Woran sollte ich denken und was sollte ich tun? Wohin sollte ich gehen? Wofür lebte ich? ${ }^{\text {c.878 }}$ ) (ibid.). Je mehr unbeantwortete Fragen für den Erzăhler entstehen, desto fragwürdiger wird für ihn auch die belehrende oder appellative Rolle der Literatur. ${ }^{879}$ Statt den polıtischen Feınd anzugreifen, richtet der Erzăhler seine Aggression (in der zweiten Szene) gegen den Schurken Kukuškin, was seinem geistigen Wandel (der Abkehr vom politisch-dogmatischen zum menschlichen) entspricht.

Die Verănderungen im Verhăltnis des Unbekannten zur Literatur, die wir bei ihm beobachten, seine neue Stimmung werden indirekt, mehr in Form einer Anspielung, im Gespräch Orlovs mit Gruzin vermittelt. Wenn Orlov behauptet, daß Zinaida Fedorovna ihn für einen Turgenevschen Helden - einen Idealisten und einen außergewöhnlichen Menschen - hält, widerspricht ihm Gruzin: „- Причём тут Тургенев, не понимаю, - сказал тихо Грузин и пожал плечами. - А помните, Жоржинька, как он в 'Трёх встречах' идёт поздно вечером

Tschechow 1966, S 257

877 lbid

879 U.a. Kataev schreibt danuber, wie Figuren Cechovs typischerweise von einem strikten und klaren Wertesystem zur Ratlosigkeit und dem Verwimsein übergehen: fruhere Ansichten erweisen sich als unzureichend, schematisch (s. 1979, S. 18-19) S. auch Kataev uber „obscaja ideja“ (allgemeine Idee) bei Cechov (ibid., S. 97-112); s. dazu cbenfalls Penzkofer (1984. S. 205-206). 
где-то в Италии и вдруг слышит: Vieni pensando a me segretamente! - запел Грузин, Xopouno!“" (,'Ich verstehe nicht, was Turgenjew dabei soll', sagte Grusin leise und zuckte mit den Achseln. Erinnern Sie sich, George, wie er in den «Drei Begegnungen» spăt abends irgendwo in Italien die Straße entlang geht und auf einmal hört: Vieni pensando a me segretamente!' flötete Grusin. 'Schön! !c880 $)(8,157)$. Eine der Funktionen des Zitats aus „Tri vstrexi““ (zu den weiteren kommen wir unten) besteht gerade darin, die Opposition zwischen der Rezeption der schönen Literatur einerseits als Nachahmungsobjekt, Ideal und Ort der Aufklărung und andererseits als ästhetisches Objekt und zugleich als Moglichkeit, menschliche Gefühle wie Liebe, Sehnsucht und Trauer auszudrücken, zu artikulieren. Dem Bestreben, der Literatur im Leben nachzueifern oder die in ihr geäußerten Ideen (wenn auch immer auf eigene Weise, im eigenen Kontext) zu befolgen, steht hier eine leichtere und emotionale Wahrnehmung des Fiktiven entgegen, wenn z.B. Analogien zwischen der eigenen Stimmung und der fiktiv vermittelten gezogen werden. Die Antwort Gruzins, der die Geschichte über die Liebe und das Verlassensein schlechthin „zitiert“, harmoniert mit der Sehnsucht des Erzăhlers selbst nach Liebe, mit seinen Träumern von Zinaida Fëdorovna. Der Kontrast zwischen den zwei Rezeptionsweisen wird dadurch betont, daß in beiden Făllen verschiedene Werke eines und desselben Autors alludiert werden. ${ }^{81}$

In diesem Sinne lăuft der Wandlungsprozeß beim Erzăhler auf eine zweifache Weise ab: Einerseits ist es die angedeutete Schwankung zwischen verschiedenen Texten und unterschiedlichen Arten, das Literarische zu rezipieren, andererseits ist es eine Umkehr vom Leben als Melodram, womoglich Leben nach Literatur zum wirklichen Leben, vom programmatisch Klaren zum Unerfaßbaren des Echten. ${ }^{82}$

So erscheint der Unbekannte in erster Linie als Erkenntnissubjekt ${ }^{883}$, dessen Wirklichkeitsverständnis in Zusammenhang mit bestimmten Besonderheiten und Prozessen seiner Rezeption des Literarischen zu betrachten ist. Er gehơrt zu jenen Figuren, deren Gestaltung den für Cechov charakteristischen ..gnoseologischen Blickwinkel ${ }^{\text {(28t }}$ offenbart, dabei wird der ErkenntnisprozeB intertextuell konzipiert und realisiert.

\subsubsection{Orlov}

Orlov wird von Anfang an als ausgesprochener Leser prăsentiert. Er ist die einzige Figur in der Novelle, die immer wieder einen Lektüreakt vorführt, also nachweislich und explizit ei-

\footnotetext{
${ }^{880}$ Tschechow 1966, S. 226.

8x! Uber das Zitieren der Novelle durch Gruzin und seine Funktion vgl bei Semanova (1958. S 219).

882 Das Thema der sich andernden Perzeption bei den Figuren Cechovs, ihres (ibergangs zur anderen, neuen .Wirklichkeitssicht” (s. Penzkofer 1984, S. 156 dieser Arbeit) wurde in der Cechovforschung mehrmals bearbeitet (s. u.a. bei Kataev 1979, S. 10-30: Penzkofer 1984, S. 202-206)

x:3. Vyl. den Ausdruck ..subrekt poznanija“" (..субъект познания“. Erkenntnissubjek 1 ) bei Kataev 1979. S. 18

x*A S Kataev, S 156 dieser Arbeit
} 
nen Kontakt zum Literarischen pflegt. Wăhrend das auffalligste charakteristische Merkmal des Erzählers im wesentlichen im Wort „mectat"“ seinen Ausdruck findet, tritt das Verb ..'itat'“ (lesen) bei Orlov in den Vordergrund. „Почти каждый день он привозил с собой или ему присылали из магазинов новые книги, и у меня в лакейской в углах и под моею кроватью лежало множество книг на трёх языках, не считая русского, уже прочитанныцх и брошенных. Читал он с необыкновенной быстротой.“ (,Beinahe jeden Tag brachte er aus den Laden neue Bücher mit, oder man schickte ihm welche, und in meinem Dienerzimmer lagen in den Ecken und unter dem Bett eine Menge bereits gelesener und dann weggeworfener Bücher in drei Sprachen, die russische nicht gerechnet. Er las ungewöhnlich schnell. ${ }^{\text {.885 })}(8,141)$; sein Überdruß an Zinaida Fëdorovna äußert sich folgendermaßen:

С видом жертвы он разваливался у себя в кабинете в кресле и, заслонив глаза рукой, брался за книгу. [...]

- Можно войти? - говорила Зинаида Федоровна, [...]. - Вы читаете? [...]

- А вы всё читаете... - начала она вкрадчиво, [...]. („Mit der Miene eines Opfers rekelte er sich in seinem Arbeitszimmer im Sessel und machte sich, mit der Hand die Augen schützend, über ein Buch her. [...]

Darf ich eintreten?' fragte Sinaida Fjodorowna, [...] 'Sie lesen? [...]

'Sie lesen immerzu...' begann sie mit schmeichelnder Stimme. $\left.{ }^{.896}\right)(8,163-164)$;

und etwas weiter: „[...] он сидел около стола и, протянув ноги на кресло, обрезывал книгу. Оставил я его углублённым в чтение, и кжига уже не валилась у него из рук, как вечером.“ (.,[...] saß er neben dem Tisch, die Füsse auf einen Sessel gestreckt und schnitt ein Buch auf. Als ich ihn verließ, war er in seine lektüre vertieft, und das Buch glitt ihm nicht mehr aus der Hand wie am Abend vorher. “\$87) $(8,168)$; und im Finale, während des Besuches bei Orlov, bemerkt der Unbekannte: „И на столе, как в прежнее время, лежала какая-то новая книга с заложенным в неё ножом из слоновой кости. Очевидно, читаг до моего прихода." (,Auf dem Tisch lag, wie in früheren Zeiten, ein neues Buch, zwischen dessen Seiten ein Messer aus Elfenbein steckte. Offensichtlich hatte er zu meiner Ankunft gelesen. “" $\left.{ }^{\text {(82) }}\right)(8,210)$. Aus den vorn angeführten Kommentaren des Erzählers zur Lesehaltung Orlovs ist ersichtlich, daß er erstens keine erkennbare Auswahl der Lektüre triff (so daß seine Geschmacksrichtung bzw. seine Vorlieben als Leser nicht zu erahnen sind) und zweitens ein ironisch-distanziertes Verhältnis zu seiner Lektüre pflegt. Das Lesen ist für ihn offensichtlich ein tägliches Ritual, zugleich eine Unterhaltung und fast eine Droge; darüber hinaus ein Zufluchtsort (bei Konflikten mit Zinaida Fëdorovna). Orlov stellt sich demzufolge im allgemei-

\footnotetext{
sss Tschechow 1966, S 207

Ibid. S. 234

207 lbid. S. 239

Ibid. S. 289
} 
nen als Leser dar, der Literatur nach Modus V rezipiert: Durch Lektüre wird er von der Realităt abgelenkt, gleichzeitig ist Literatur für ihn nicht viel mehr als Unterhaltung, er ist nüchtern und grenzt sich von der naiven und leichtglăubigen Rezeptionsart ab; verhohnt z.B. die Moglichkeit einer Nachahmung des Gelesenen.

Dennoch kơnnte die ausgiebige Lektūre Orlovs einige seiner Aussagen und Urteile sowie die mit seiner Gestalt verknüpften intertextuellen Parallelen erklären: Wăhrend er sich von bestimmten Texten laut distanziert, fühlt er sich zu anderen hingezogen, was in der Novelle v.a. mit Hilfe etlicher Allusionen angedeutet wird.

Vom Erzăhler wird Orlov jedoch vordergründig als Mensch bzw. Leser ohne bestimmte Überzeugungen dargestellt (seine chaotische Lektüre ist ein klares Indiz dafür). Dieses zentrale Charaktermerkmal bzw. eine geistige Position - die Tatsache, daß Orlov kein überzeugter Anhănger des Staatssystems, innerhalb dessen er seinen Dienst erfüllt, oder kein leidenschaftlicher Streber wie Kukuškin ist - wird schon am Anfang der Geschichte intertextuell gestaltet. Gruzin - einer der năchsten Freunde Orlovs - „к службе [...] относнлся с редким легкомыслием, и когда при нём серьезно говорили о чннах, орденах, окладах, то он добродушно улыбался и повторял афоризм Пруткова: Только на государственной службе познаёшь истину!к، (,Zu seinem Dienst [...] verhielt [...] sich selten leichtsinnig, und wurde in seiner Gegenwart ernsthaft von Răngen, Orden oder Gehăltern gesprochen, dann lăchelte er gutmütig und wiederholte einen Aphorismus von Prutkow: Nur im Staatsdienst erkennt man die Wahrheit! ${ }^{\text {(x) }}$ ) $(8,147)$. Das gutmütig-ironische Zitieren der bereits im Pratext ironisch gemeinten Āußerung eines eifrigen Beamten verrăt eine demonstrativ lässige Haltung des Beamten Gruzin zu seiner Arbeit, die offen, in Gegenwart des Vorgesetzten (Orlov), artikuliert wird. Die vom Erzăhler, u.a. durch seine Griboedov-Allusion suggerierte alte und klassische Konstellation ..die Anhănger des Systems (die Konservativen) vs. der Systemkritiker, Rebell, Idealist (der Progressive)“" (die ersten sind für den Erzăhler Orlov und seine Freunde, der letzte - er selbst), also die Konstellation „Famusov, Skalozub u.S.w. - Cackij“, wird destruiert. Außer dem archetypischen Karrieristen Kukuskin, der Molcalin wiederholt, erscheint der Kreis Orlovs im Ganzen als eine Gesellschaft von Beamten entweder aus Begabung (so der Pragmatiker Pekarskij) oder aus Zufall ${ }^{8 \times 0}$ bzw. finanzieller Not (wie Gruzin). So wird die klassische Konfrontation der Ideen, der Kampf der Überzeugungen, die Opposition der unterschiedlich denkenden Figuren aufgehoben, klare Werte werden aufgelost. ${ }^{891}$ Damit geschieht hier eine zeitgemäße Inversion des alludierten plots von „Gore ot uma“, er wird in den für Cechov modernen Kontext versetzt: Nicht nur Beamten lassen ihrem Tun und Sein

\footnotetext{
xk9 Ibid. S. 215

800 Der Erzahler charakterisien Gruzin folgendermaßen. .Это была натура рыхлая. ленивая до полного равнодушия к себе и плывшая по течению неизвестно куда и зачем Куда его вели. туда и шел " (..Er war eine schlafe Natur, faul bis zur volligen Gleichgultigkeit gegen sich selbst, er ließ sich von der Strömung treiben, ohne zu wissen, wohin und wozu. Wohin man ihn gehen hieß [führe], dahin ging er " (Tschechow 1966. S. 215)) $(8,148)$

*91 Wie die Konfrontation der Ideen in anderen Novellen Cechovs - z B im Finale von ..Duel'”- auf eine andere Weise aufgehoben und aufgelöst wird, s. bei Kataev 1979, S. 122-129.
} 
gegenüber Ironie zu, sondern auch der Anklăger (der Unbekannte) glaubt immer weniger an seine Ideen. ${ }^{892}$

Die Komödie „Gore ot uma“ wird auch weiterhin von den Personen der Novelle aufgerufen. So zitiert Zinaida Fëdorovna im Streit mit Orlov mit einem Pathos, das dem des Erzählers ähnlich ist: „Мы, женцины, не можем сметь, свое суждение иметь.“ („'Wir Frauen düren es nicht wagen, die eigne Meinung mal zu sagen [zu haben]. $\left.{ }^{m 893}\right)(8,177)^{894}$. Darauf antwortet Orlov: „[...] будьте либеральны и цитируїте каких угодно авторов. [...].“ (.,[...] seien Sie liberal und zitieren Sie beliebige Autoren [...]...895), bzw. etwas früher: „- [...] И что за несчастная способность у наших умных, мыслящих дам говорить с глубокомысленным видом и с азартом о том, что давно уже набило оскомину даже гимназистам.“ (,'[...] Was für ein unglückliches Talent haben unsere klugen, denkenden Damen, mit tiefsinnigen Mienen und mit Eifer über etwas zu reden, was schon lăngst unseren Gymnasiasten zum Halse heraushăngt. $[\ldots]^{\text {c/8\% }}$ ) (ibid.). Hier zeigt sich dieselbe Tendenz: Nicht das Pathos oder die Ideen von Zinaida Fédorovna (deren Zitieren Griboedovs mit ihren Aussagen gegen den Staatsdienst, das Strebertum und über die „echten“ Überzeugungen Orlovs zu verbinden ist) und die von ihr zitierten Autoren wie Griboedov miBfallen Orlov, sondern die Banalitat dieser Ansichten. Die Situation des Ideenkampfes und damit des Kampfes der Pratexte wird also immer wieder relativiert, die Lebensart der Personen ist nicht mehr repräsentativ für ihre Überzeugungen (vgl. die Replik Orlovs im Gespräch mit dem Unbekannten im Finale: „- [...] Да, моя жизнь ненормальна, испорчена, не годится ни к чему, [..]. Но что вы так близко принимаете это к сердиу, [...] тут вы совсем не правы.“ (.,'[..] Ја, mein Leben ist anomal, verdorben, es taugt zu nichts, [...]. Aber daß Sie sich das so zu Herzen nehmen, $[\ldots]$ da sind Sie ganz im Unrecht. $\left.{ }^{\kappa(8) 7}\right)(8,212)$ ). Im Finale, nachdem Orlov von der Existenz seiner Tochter erfahren hat, zitiert auch er, jedoch eher spielerisch, ohne das politische Pathos der Komödie zu evozieren, „Gore ot uma“: „- Что за комиссия, создатель, быть малой дочери отиом!“” (,'Was für eine Kalamităt, o Herr, Vater einer kleinen Tochter zu sein! $\left.[\ldots]^{\kappa .89 \%}\right)(8,486)$. Derselbe Satiriker wird - mit unterschiedlichem Bezug zur Wirklichkeit und unterschiedlicher Bedeutung - von den beiden ..Lager"“ zitiert: ein Indiz dafür, daß die Lektüre bestimmter Texte aufgehört hat, eine einheitliche Weltanschauung zu bilden; Lektüre und Kenntnisse bestimmter Literatur, einst ein klares Zeichen für (z.B.) progressives Denken, werden sowohl von den „Cackijs“ (Elemente der Cackij-Gestalt findet man also bei Zinaida und beim Erzähler) als auch von den „Famusovs“ der Novelle demonstriert.

\footnotetext{
892 was natürlich die sozial-kritische Position des Unbekannten und seine kritische Einstellung zum Kreis Orlovs nicht vermindert ( $v g l$ daruber bei Semanova 1958, S 207). Über die Nahe zwischen dem Unbekannten und Orlov, die die zeitgenossische Kritik hervorhob, $s$. in den Anmerkungen zur Novelle (8, 481-482)

${ }^{893}$ Tschechow 1966, S. 250

5 . in den Anmerkungen (8.485)

999 Tschechow 1966, S. 250.

$20 \%$ Ibid.

297 lbid S. 292

s92 Ibid. S. 291
} 
Noch mehr: Orlov definiert sich selbst als „šedrinskij geroj“, also als Objekt der russischen Satire: "- Мои взгляды? По убеждениям и по натуре я обыкновенный чиновник, щедринский герой.“ („Meine Anschauungen? Meinen Überzeugungen und meiner Natur nach bin ich ein gewơhnlicher Beamter, wie ein Held von Stschedrin. [... $\left.]^{\mathrm{cs99}}\right)(8,165)$.

Das am Anfang der Novelle durch Gruzins Prutkov-Zitat indizierte Auflosen klarer Werte bei den Figuren, das keine Polarisierung ihrer Überzeugungen und folglich keinen Ideenkampf zulaßt, wird insofern weiter intertextuell entfaltet.

Wir haben gezeigt, wie das in „Rasskaz neizvestnogo celoveka“ mehrmals und explizit thematisierte Nichtvorhandensein fester Überzeugungen bei Orlov, genauer gesagt, der klaren und eindeutigen Übereinstimmung, der Harmonie zwischen seinem Leben und seiner Weltsicht (obwohl „క̌̌edrinskij geroj“, stimmt er im Finale dem Erzähler zu: „-[...] Мы ослабели, опустились, пали наконец [...]. “ (,. [...] Wir sind schwach geworden, heruntergekommen und schließlich gestrauchelt $[\ldots]^{\left.{ }^{*}{ }^{900}\right)}(8,212)$ ), intertextuell, mit Hilfe der Verweise auf Fremdtexte im inneren Kommunikationssystem, gestaltet wird.

Weitere intertextuellen Bezüge weisen gleichzeitig darauf hin, daß bestimmte Texte der russischen Literatur moglicherweise das Verhalten und die Ansichten Orlovs gepragt haben; dabei ist nicht anzunehmen, daß er, wie vermutlich der Erzahler vor seinem Sinneswandel, bewußt und gradlinig der Literatur folgt und von Literatur begeistert ist, noch weniger, daß er Literatur nachlebt. Vielmehr sieht es bei ihm nach einer literarischen Pose aus und zugleich nach dem Versuch eines Gebildeten, sich in die (Literatur)Geschichte einzuordnen (ungefahr so wie der Erzähler nach seinem Sinneswandel). Orlov begreif sich auf einer tieferen Bewußtseinsebene ebenfalls als einen „überflüssigen“ Menschen, nur nicht in der Art Rudins (,измельчавший тургеневкий герой“, ein verflachter Turgenevscher Held)), wie Semanova ihn charakterisier ${ }^{901}$. Orlov, der am Ende. ohne daß er sich geistig verăndert, die Vorwürfe des Erzählers annimmt, sich dann auch nüchtern mit der ganzen Generation als ,nevrastenik. kisljaj, otstupnik“" (..Neurastheniker, Nơrgler, Abtrünnige $\left.{ }^{.902}\right)(8,212)$ bezeichnet ${ }^{903}$, ist kaum ein ..šcedrinskij geroj”, vielmehr empfindet er sich als moderner Onegin, Pečorin, russischer Hamlet.

Die Parallele zwischen Orlov und Onegin wird zunăchst (am Anfang) implizit durch das Aufrufen des ..Evgenij Onegin"-Prätextes und der Gestalt Lenskijs vermittelt.

Бывало, сядет за рояль (Gruzin - K.S.), возьмёт два-три аккорда и залоетт тихо:

\footnotetext{
Ibid S. 236

${ }^{900}$ Ibid. S 292

${ }^{901}$ S Semanova 1958, S. 196-198: So heißt es bei Semanova, daß Orlov nicht die .rudinskoe beskorystnoe slużenie istine“" (den Rudinschen uneigennützigen Dienst der Wahrheit) . geerbi“' hat. sondern allein .. bezdejstvie. neresitel'nost'” (Untatigkeit, Unentschlossenheit) (ibid.. S 196)

${ }^{202}$ Tschehcow 1966, S 292

${ }^{903} \mathrm{Vgl}$ in den Anmerkungen zur Novelle. wie die zeitgenossischen Kritiker in den Figuren wie Orlov ein Beispiel der modernen Intelligencija sahen, die die ..uberflüssigen Menschen“ abloste (8, 481-482) (tber Orlov als einen .uberflussigen Menschen"s bei Semanova (1958, S. 196-198)
} 
Что день трядущий мне готовит?

но тотчас же, точно испугавшись, встанет и уйдёт подальше от рояля. (..Manchmal setzte er sich an den Flügel, schlug zwei, drei Akkorde an und sang leise: 'Was bringt er mir, der kūnft'ge Morgen [der kommende Tag]?' Sofort erhob er sich jedoch, gleichsam erschrocken, und entfernte sich vom Flügel.“904) $(8,148)$. ${ }^{905}$

Unmittelbar nach diesem Zitat, das die Figur des Idealisten Lenskijs ins Gedächtnis ruft, folgt die Schilderung der Abende bei Orlov, dabei werden in erster Linie skeptische, nüchterne, bisweilen zynische Urteile der Anwesenden, ihre kalte, spottische Art wiedergegeben. So wird schon hier die Opposition „Überzeugte, Begeisterte (zum Teil Gruzin, aber auch der Erzăhler) vs. Skeptiker, Spötter (Orlov, Pekarskij)“ suggeriert, die aufgrund des Zitats aus „Evgenij Onegin“" eine weitere bildet: „Lenskij(s) - Onegin(s)“.

Начиналось обыкновенно с того, что Орлов со смеюшимися глазами заводил речь о каком-нибудь знакомом, о недавно прочитанной кнщее. [..] и начиналась, по тогдашнему моему настроению, препротивная музыка. Ирония Орлова и его друзей не знала пределов и не шадила никого и ничего. Говорили о религии иронкя, говорили о философии, о смысле и целях жизни - ирония [...]. (.Es fing gewöhnlich damit an, daß Orlow mit lachenden Augen die Rede auf irgendeinen Bekannten, ein kürslich gelesenes Buch, [...] brachte [...] und es begann eine Musik, die mir bei meiner damaligen Auffassung äußerst widerlich war. Orlows und seiner Freunde Ironie kannte keine Grenzen und verschonte niemanden und nichts. Sprach man von der Religion - Ironie, sprach man über Philosophie, über Sinn und Zweck des Lebens - Ironie $\left.[\ldots]{ }^{\text {“966) }}\right)(8,148-149)$.

Die Parallele zwischen Orlov und Onegin entsteht nach beendeter Lektüre erstens dadurch, $\mathrm{da} B$ er im großen Kontext der Novelle als überflüssiger Mensch schlechthin fungiert, der seine Schwăche und „otstupničestvo“ (Abtrünnigkeit) zugibt, zweitens dadurch, daß er wie sein intertextueller Prototyp, der konkrete überflüssige Mensch Puskins, mit gnadenloser Ironie bewaffnet ist und an nichts Hoheres mehr glaubt. Die Charakteristika Onegins wie „резкий, охлаждённый ум“ (ein scharfer, kühler Verstand), .язвительный спор“ (høhnischer Streit), „шутка, с желчью пополам“ (еin „halbgalliger Witz“907) ${ }^{908}$, „безнравственная душа, себялюбивая и сухая“ (еine unsittliche Seele, selbstsüchtig und trocken) ${ }^{909}$ u.a. schei-

\footnotetext{
Tschechow 1966, S. 216

0: Gruzin dient demzufolge schon zum zweiten $\mathrm{Mal}$ als internextuelle ..Vermittlertigur" Die von ihm aufgerufenen Texte werfen Licht vor allem auf die Besonderheiten der Literaturrezeption der anderen bzw auf die Parallelen zwischen den anderen und den pratextuellen Gestalten.

${ }_{906}$ Tschechow 1966. S. 216

907 Puschkin Bd 2 (1952). S. 30

${ }_{908}$ Puskin Bd. 6 (1937), S 23-24

909 Ibid., S 148
} 
nen in diesem Zusammenhang die Charakteristika Orlovs vorwegzunehmen. Diese Schilderung deutet einerseits darauf, daß der Erzăhler in Orlov Onegin sieht bzw. ihn im Geschmack Onegins gestaltet, andererseits darauf hin, daß Orlov selbst sein Verhalten nach OneginMuster inszeniert. Die Lesehaltung Orlovs, zitiert im vorigen Unterkapitel, wiederholt mehr oder weniger die Lesehaltung Onegins:

\author{
Читал, читал - а всё без толку: \\ Там скука, там обман иль бред; \\ В том совести, в том смысла нет; \\ На всех различные вериги: \\ И устарела старина, \\ И старым бредит новизна. \\ (,Er las und las - aber ohne Nutzen: \\ Hier Langeweile, dort Betrug oder Fieberwahn; \\ Hier fehlt es an Gewissen, hier an Sinn; \\ An jedem hăngen andere Fesseln; \\ Das Altertum ist veraltet; \\ Vom Alten träumt das Neue. $\left.{ }^{\text {(9910 }}\right)^{911}$
}

Mogglicherweise kopiert der Leser Orlov den Leser Onegin oder genauer, erweist sich für ihn die von Puškin mit der Figur Onegins verknüpfte Art der Literaturrezeption als passend.

Auf der Sujetebene liefert .Rasskaz neizvestnogo Celoveka" einige Analogien zwischen der Gestalt Orlovs und der der überflüssigen Menschen in der russischen Literatur vor Turgenev. Zu nennen ist beispielsweise die Beziehung Orlovs zu Zinaida Fëdorovna. Wăhrend Semanova in Orlov einen (allerdings seiner Hochherzigkeit verlustig gegangenen) Turgenevschen „russkij celovek na rendez-vous“ (russischen Mann beim Rendezvous) sieht, der nicht imstande ist, sein Leben mit der (geliebten) Frau zu verbinden ${ }^{912}$, neigen wir dazu, ihn als einen russischen Don Juan a la Onegin vs. Pečrin aufzufassen. Die Don Juan-Parallele wird bereits am Anfang thematisiert: Nachdem der Erzähler das unvorteilhafte Äußere Orlovs beschrieben hat, fügt er hinzu: ..[...] к тому же Петербург - не Испания, наружность мужчин здесь не имеет большого значения даже в любовных делах [...].“ (..zudem ist Petersburg nicht Spanien, das Äußere der Männer hat hier selbst in Liebesdingen keine großere Bedeutung $\left.[\ldots]^{\cdots 913}\right)(8,140)$. Durch den Vergleich von Petersburg mit Spanien wird Orlov ironisch neben den großen Verführer Don Juan gestellt, er repräsentiert damit eine russische Version

\footnotetext{
910 Puschkin Bd 2 (1952). S. 29.

911 Puskin Bd 6 (1937), S 23

912 S. Semanova 1958. S. 198

913 Tschechow 1966, S. 207
} 
dieser Figur. ${ }^{914}$ Attribute Onegins als Verführer, beschrieben im ersten Kapitel des Versromans Puskins, finden ihre Entsprechung in der Person von Orlov, werden aber modifiziert. Orlov betrachtet seine Affären mit Frauen als Folge eines körperlichen Bedürfnisses, das seinem Geist widerstrebt (,- [...] На любовь я [..] смотрю как на потребность моего организма, низменную и враждебную моему духу; [...].“ (,'[...] Die Liebe sehe ich [...] als ein Bedürfnis meines Organismus an, gemein und schădlich für meinen Geist [...]. $\left.{ }^{* 915}\right)(8$, 157)) und erscheint somit als deromantisierter, kühler Verführer, ein moderner Don Juan ohne Inspiration und Willen und als ein „Onegin“ des letzten Drittels des 19. Jahrhunderts, enttăuscht und unfähig zur Liebe. ${ }^{916}$ Wenn man die Beziehung Orlovs zu Zinaida Fẽdorovna auf die Onegins zu Tat'jana Larina projizien, kommt die ironische Inversion des vorgegebenen Sujets zum Vorschein: Die Wiedergeburt Onegins zur Liebe findet nicht statt, die Gefühle „Tat'janas“ bleiben unerwidert. ${ }^{917}$

In demselben Maße, jedoch ohne daß konkretere intertextuelle Bezüge zu "Geroj nasego vremeni“ nachzuweisen sind, trăgt Orlov Züge Pecorins: dieselbe „Unfähigkeit zur Liebe“ (vgl. Überlegungen Pečrins: „Любовь дикарки немногим лучше любви знатной барыни; невежество и простосердечие одной так же надоедают, как и кокетство другой“ (,Die Liebe des Naturkindes [einer Wilden] ist nur wenig besser als die Liebe des vornehmen Frăuleins; die Einfalt und die Ursprünglichkeit [Aufrichtigkeit] der einen werden ebenso langweilig wie die Koketterie der anderen. $\left.{ }^{418}\right)^{919}$ mit denen von Orlov: "- [..] В законном и незаконном сожительстве, во всех союзах и сожктельствах, хороших и дурных, - одна и та же сушность.“ (.'...] In der legitimen und der illegitimen [ehelichen Gemeinschaft], in allen Verbindungen und ehelichen Gemeinschaften, den guten wie den schlechten, in allen ist die Hauptsache gleich. $\left.[\ldots]^{\text {m.920 }}\right)(8,178)$ ) und zugleich die Gabe, in den Frauen Liebe hervorzurufen; dieselbe Angst, lächerlich zu wirken, und die Abscheu vor der Heirat bzw. dem Zusammenleben mit einer Frau (Pečrin: „[...] как бы страстно я ни любил женщину, если она мне даст только почувствовать, что я должен на ней жениться - прости, любовь! [...] Я готов на все жертвы, [...] но свободы моей не продам.“ (.,Ich mag eine Frau noch so leidenschaftlich lieben, sobald sie mich auch nur fühlen läßt, daß ich sie heiraten soll - dann Liebe ade! [...] Ich bin zu allen Opfern bereit, [...] aber meine Freiheit ver-

\footnotetext{
924 Vgl. Lauet über Platonov als Don Juan .. [ ] das Adverb 'no-нсnански' [ ] evozient noch einmal die DonJuan-Folie, vor der sich Platonov diesmal selbst als einen russischen Don-Juan erkennt “ (1990, S 614)

${ }_{913}$ Tschechow 1966, S 226

$916 \mathrm{Vgl}$ die intertextuelle Charakteristik von Platonov bei Lauer ..Platonov wird [.. ] als ein Verfuhrer gezeigt, als ein neuer Don-Juan, dem es jedoch [ .] an der Fàhigkeit zu lieben gebricht. [ . ] " (1990, S 613) (s uber den betreffenden Beitrag Lauers in unserem Literaturbericht. S. 49-50)

${ }_{917}$ Uber ironische Inversionen der bekannten Sujets der russischen Literatur (auch des von „Evgenij Onegin“) in der Prosa Cechovs s. z B bei Saal-Losq (vgl in unserem Literaturbericht). $V_{g l}$ unsere Beobachtungen auch mit der Charakteristik Gurovs wie ebenfalls anderer Cechovschen mannlichen Gestalten als Don Juan bei Kataev (s. in unserem Literaturbericht. S. 52)

918 Lermontow Bd 2 (1987), S 290

919 Lermontov 1978, S. 47

${ }^{920}$ Tschechow 1966, S. 251
} 


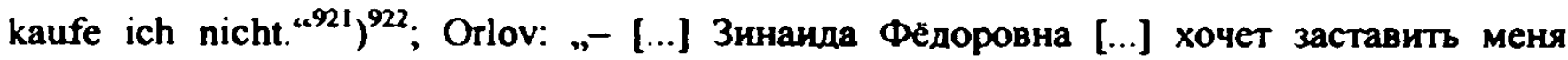
полюбить то, от чего я прятался всю свою жизнь. [...] ей нужно [...] следить за каждым моим шагом, и в то же время искренно уверять, что мои привычки и свобода останутся при мне.“ (.,'[...] Sinaida Fjodorowna will mich [...] zwingen, das zu lieben, wovor ich mich mein Leben lang gegrault habe. [...] Sie muß [...] jeden meiner Schritte verfolgen; gleichzeitig beteuert sie aufrichtig [und gleichzeitig aufrichtig beteuem], mir seien meine Gewohnheiten und meine Freiheit geblieben $\left.[\ldots . .]^{\kappa .923}\right)(8,157-158)$ ). Die auffallige Parallelităt der zitierten Aussagen erlaubt zu vermuten, daß Orlov die Gestalt Pexorins zur Vorlage für eine ihm imponierende „literarische Pose ${ }^{\text {“924 }}$ ausgewahlt hat.

Im Gegensatz zu seinen intertextuellen Prototypen hat sich Orlov mit der eigenen Lebenssituation lăngst abgefunden; eine Unzufriedenheit zeigt er gerade erst dann, wenn der übliche Lebensablauf (durch das Ankommen von Zinaida Fédorovna) gestơrt wird.

Orlov wird dementsprechend als moderner Don Juan, Onegin, Pexorin und - mit Hilfe weiterer Allusionen - als Hamlet der 1880er Jahre konzipiert. ${ }^{925}$ Die Zuweisung der Rolle Hamlets erfolgt wiederum durch eine allusive Identifizienung anderer Personen mit den Figuren der Tragödie Shakespeares und die Entstehung einer intertextuellen Pendantenreihe. Im Fall Orlovs geschieht eine solche Übertragung, wenn seine Geliebte Zinaida Fedorovna mehrmals mit Ophelia assoziiert wird. Nach dem Einzug bei Orlov teilt sie ihm ihre Überlegungen vor der Flucht mit: „- [...] Уійу, думаю, в монастырь [...], откахусь от счастья, [...]. (, ,[...] Ich gehe in ein Kloster [...] dachte ich, ich verzichte auf das Glück [...]. ${ }^{\text {c.926) }}$ (8, 153); am Ende, als sie sich ihrer Lage und des Überdrusses Orlovs bewußt ist, findet zwischen ihr und Gruzin folgendes Gespräch statt: „- [...] Я гак утомилась, что не пошевельну пальцем для своего спасения. - ('тупайте, кума, в монастырь.“ (,,'[...] Ich bin so erschöpft, daß ich zu meiner Rettung keinen Finger mehr rühren kann [rühren werde].' 'Gehen Sie ins Kloster, (jevatterin. $\left.{ }^{\mathrm{k}} 927\right)(8,186)$. Diese Worte stellen ein Zitat aus der Cechov gut bekannten russischen Übersetzung von „Hamlet“ von A. Kronberg dar. Hamlet sagt Ophelia, daß er sie nicht geliebt habe und fügt hinzu: „Ступай в монастырь. Зачем рождать на свет грешников? [...] Иди в монастырь! [...] Ступай в монастырь! [...] В монастырь!“ („Get thee to a nunnery; why, wouldst thou be a breeder of sinners? [...] go thy ways to a nunnery...

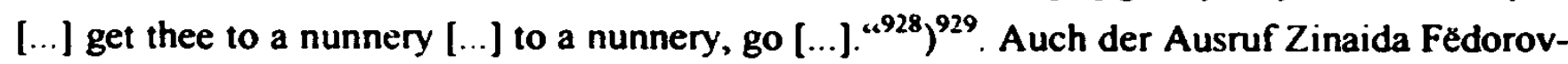

921 Lermontow Bd 2 (1987). S 387

${ }_{922}$ Lermontov 1978. S 155-156.

${ }^{923}$ Tschechow 1966, S. 227.

${ }^{924} \mathrm{Vgl}_{\mathrm{g}}$ Lauer uber ..Platonovs Verhalten als literarische Pose" (1990, S. 617)

925 Als einen modernen .uberflussigen Menschen“, Onegin, Pezorin. Hamlet, Rudin betrachtete die zeitgenossische Kritik z.B. Laevskij aus ,Duel '“ - Anlaß dazu gab v.a. die Selbstcharakteristik Laevskijs (s. darüber in den Anmerkungen zu dieser Novelle (7, 701-702); vgl auch Winner (s. in unserem Literaturbericht. $S$ 50)).

${ }^{226}$ Tschechow 1966. S. 221

927 lbid. S. 260

${ }^{928}$ Shakespeare 1993. S. 100

929 Sekspir 1844. S 100-101 Diese Replik Hamlets wird im Werk Cechovs des Ofteren evozien s z B die Worte Lopachins zu Varja im zweiten Akt von ..Višnevyj sad”. „Охмелия, ияи в монастырь “ (..Ofehlia [Och- 
nas: „Нина! Я обманута!“ („Nina, man hat mich betrogen! “`330) $(8,196)$ alludiert die Replik Ophelias: „Тем более я была обманута.“ („I was the more deceived.“931). ${ }^{932}$ Die Zitate aus "Hamlet“, von denen nur das im Munde Gruzins als bewußter Verweis auf den Prätext empfunden werden kann, erfülen eine rein semantische, hier eine im wesentlichen vorausdeutende Funktion (sie liegen also über der Ebene des Personenbewußtseins und lassen kaum auf eine innerkommunikative Rezeption "Hamlets“ schließen). Sie sagen den Tod von "Ophelia“Zinaida Fëdorovna vorher sowie, wenn man die kontextuelle Umgebung des zitierten Segmentes, nămlich die Hamlets Phrase „Зачем рождать на свет грешников?“ einbezieht, die Geburt des Kindes Orlovs.

Ohne daß im Text explizite Hinweise auf eine Rezeption der Tragodie Shakespeares durch Orlov zu finden sind, fungiert er in der Beziehung zu Zinaida Fẻdorovna als moderner Hamlet, als ein Hamlet, wie er in der russischen Literatur(kritik) seit Turgenevs Aufsatz „Gamlet i Don Kichot" begriffen wurde. Die im Kapitel 2.2. geschilderte Rezeptionsgeschichte der Hamletgestalt auf russischem Boden (s. in den Beiträgen Elizarovas, Levins, Leitholds) hat zweifelsohne ihre Auswirkung auf die Darstellung der Figur Orlovs gehabt. Wenn er sich und seine Generation zum Schluß als "nevrasteniki i nytiki“" (Neurastheniker und Greiner ${ }^{.933}$ ) bezeichnet, dann präsentiert er sich auch als einen russischen Hamlet und einen „überflüssigen Menschen“ der 1880er Jahre (s. zur Charakteristik bei Elizarova und Alekseev). Orlov ist ein Vertreter der Generation, die ihre Ideale und Hoffnungen eingebüßt hat, - einer der Cechovschen Hamlets, der jedoch, anders als es Elizarova darstellt, nicht weiter sucht und nicht von geistiger Unruhe geplagt ist. In der Liebe tritt er als Hamlet der Platonov- ${ }^{934}$ und Ivanov-Art auf; er ist in diesem Sinne auch der konsequente Erbe des Hamlet, wie er nach (und teilweise in) Turgenevs Aufsatz rezipiert wurde, eines Egozentrikers und Zerstörers.

In „Rasskaz neizvestnogo čeloveka“ sind ebenfalls intertextuelle Bezüge zu entdecken, die zeigen, daß das Verhalten und die Ansichten Orlovs nicht nur von den überflüssigen Menschen vor Turgenev beeinflußt sind, sondern von einer der Turgenevschen Gestalten. Dennoch von keiner der Figuren Turgenevs, von denen bisher die Rede war und die in der Novelle v.a. mit der Person des Erzăhlers korrespondieren (wie Insarov und Rudin; es ist verständlicherweise nicht die Figur Insarovs, gegen deren Ähnlichkeit sich Orlov so sträubt und die in ihm tatsăchlich keineswegs wieder zu finden ist), sondern von der Figur Bazarovs, dessen Nüchternheit, Skepsis, materialistische Weltanschauung, Verachtung fürs Romantische

melija], geh in ein Kloster " (Cechov 1973. S 37)) (13, 226). Und in der Liste der bei Cechov enwahnten Autoren und Werke (im Band 18 der Gesamtausyabe, $s$ das Literaturverzeichnis) ist diese Allusion auch vermerkt (18. 513)

${ }_{930}$ Tschechow 1966.S 272.

${ }^{931}$ Shakespeare 1993, S 100

${ }_{932}$ Sekspir 1844, S 100.

${ }^{933}$ Tschechow 1966. S. 292

${ }^{94} \mathrm{Vgl}_{\mathrm{g}}$. dazu z.B den Beitrag von Lauer, der Platonov als einen Hamlet betrachtet wie ihn Turgenev interpretiert (..Analytiker, Skeptiker, Ironiker" (1990. S 615)) und so als einen ..uberflussigen Menschen” (ibid ) 
und dessen Auffassung der Liebe Orlov nahe steht und ihm vermutlich als passend und bequem erscheint. Vergleichen wir an den entsprechenden Stellen des Prä- und des Posttextes Äußerungen der beiden Figuren oder die Aussagen anderer Personen über sie:

- Он нигилист, - повторил Аркадий.

- Нигилист, - проговорил Николай Петрович. [...] это слово означает человека, который... который ничего не признаёт? („'Er ist Nihilist,' wiederholfe Arkadi.

'Nihilist,' sagte Nikolaj Petrowitsch, '[...] mit diesem Wort bezeichnet man wohl einen, der... der nichts gelten låßt. $\left.{ }^{\mathrm{No935}}\right)^{936}$;

$-[\ldots]$ мы отрицаем.

- Bce?

- Bce.

- Как? не только искусство, поэзию...но и...страшно вымолвить...

- Все, - с невыразимым спокойствием повторил Базаров. (,'[...] so verneinen wir eben.'

'Alles?

'Alles!"

'Was? Nicht nur die Kunst, die Poesie? Vielmehr auch... Fürchterlich, es auszusprechen.'

'Alles,' wiederholte Basarow gelassen [mit unbeschreiblicher Gelassenheit]. ${ }^{\mathbf{4 9 3 7}}$ ) $^{\mathbf{9 3 8}}$ (Turgenev, „Otcy i deti“ („Väter und Söhne“))

- „Они говорили, что бога нет и со смертью личность исчезает совершенно; [...]. Истинного блага нет и не может быть, [...]. [...] Интеллигенция безнадёжна; [...]. [...] Науки у нас нет, [...].“ („Sie sagten, es gebe keinen Gott und mit dem Tode verschwinde die Personlichkeit vollständig; [...]. Wahres Heil finde man nicht und könne man auch nicht finden [gebe es nicht und könne es auch nicht geben], [...]. [...] Die Intelligenz sei ohne Hoffnung; $[\ldots] .[\ldots]$ Es gebe bei uns keine Wissenschaft, $\left.[\ldots] . .{ }^{\text {.939 }}\right)(8,149)$ (Čechov); ,- $[\ldots]$ И что за таинственные отношения между мужчиной и женшиной? Мы, физиологи, знаем, какие это отношения. Ты проштудируй-ка анатомию глаза: откуда тут взяться [...] загадочному взгляду? Это всё романтизм, чепуха, гниль, художество.“ (..'[...] Und was sind das für geheimnisvollen Beziehungen zwischen Mann und Frau? Wir Physiologen wissen, was es mit diesen Beziehungen auf sich hat. Studiere doch einmal die Anatomie des Auges: Wo soll denn der rätselhafte Blick [...] herrühren? Das ist alles Romantik, Gefasel, fauler

\footnotetext{
933 Turgenjew 1973, S. 238

936 Turgenev Bd 8 (1964), S 215

${ }^{937}$ Turgenjew 1973, S. 270

${ }^{938}$ Turgenev Bd 8 (1964), S. 243

${ }^{939}$ Tschechow 1966. S. 216-217.
} 
Zauber, das ist alles Machwerk. $\left.[\ldots]^{\kappa .940}\right)^{9+1}$ (Turgenev) - $n-[\ldots]$ На любовь я прежде всего смотрю как на потребность моего организма, [...]. [...] я стараюсь делать её красивой и обставлять множеством иллюзий. [...] изволь-ка убеднть её, что любовь есть только простая потребность, как пища и одежда, [...].“ (,'[...] Die Liebe sehe ich vor allem als ein Bedürfnis meines Organismus an, [...]. [...] bin ich bemüht, sie schön zu verbrämen und mit einer Menge von Illusionen auszustatten. [...] Überzeuge sie mal bitte davon, daß die Liebe nur ein einfaches Bedürfnis wie Nahrung und Kleidung ist [...]. $\left.{ }^{{ }^{* 942}}\right)(8,157-158)$ (Čechov). ${ }^{943}$ Orlov jedoch gibt wiederum einen Bazarov der 1880er Jahre ab: Er besitzt nicht die festen und unerschütterlichen Überzeugungen seines Pendants, die sich in der Auswahl seiner Lektüre zeigen (Ablehnung der Dichtung, ja der schőnen Literatur schlechthin, und Sympathie für die „nützlichen“ Bücher wie Büchners „Kraft und Stoff“944) und nicht den Willen, für das allgemeine Wohl zu arbeiten u.s.w. Auch hier durchlebt Orlov (wie bei der Onegin Tat'jana-Intertextualität) nicht die seelische Entwicklung Bazarovs durch Liebe zu Zinaida Fedorovna - „Odincova“. Seine Meinung über die Liebe, seine Weltanschauung im Ganzen bleibt bis zum Ende unverändert.

\subsubsection{Zinaida Fedorovna}

Das Verhăltnis Zinaida Fëdorovnas zur Literatur, nämlich ihr Versuch, das Gelesene im realen Leben zu finden und zu verwirklichen, das Fiktive also nachzuleben, wird zum Objekt des Spottes und des Zomes Orlovs, der nicht bereit ist, sich in die Rolle des Zinaida nach seiner Meinung faszinierenden Turgenevschen Helden Insarov zu versetzen. ${ }^{4 \$ 5}$ Die These Orlovs über die Betörung seiner Geliebten durch eine literarische Gestalt, konkreter durch Insarov, wurde von mehreren Cechovforschern aufgegriffen und unkritisch aufgenommen. So ist sie indirekt bei Semanova vertreten:

Так обманулась Зинаида Фёдоровна, приняв Орлова за необыкновенного, идейного человека, чуть ли не героя [...] недостаточное знание подлинной жизни, людей приводило Зинанду Фёдоровну к иллюзиям, к ошибкам. В опустошённом, развращённом Орлове она видит идейного, возвышенного человека [...]. (So hat sich Zinaida Fëdorovna geim, wenn sie Orlov für einen außergewöhnlichen, einen der Idee ergebenen Menschen, beinahe einen Helden gehalten hat. [...] mangelnde Kennt-

\footnotetext{
200 Turgenjew 1973, S. 251 .

941 Turgenev Bd. 8 (1964). S. 226

942 Tschechow 1966, S 226-227

943 Interessanterweise sieht Levin in Bazarovs .Egoismus“. Zweifel, Skepsis und Nihilismus Zuge u.a von Hamlet wie er im Aufsatz Turgenevs dargestellt wird (s. 1965, S. 466).

S44 Turgenev Bd 8 (1964), S. 238

94s Über die Allusion der Gestalt Insarovs in der Replik Orlovs s auch in den Anmerkungen (8, 485).
} 
nisse des wahren Lebens, der Menschen führten Zinaida Fëdorovna zu Illusionen, Irrtümern. Im verkommenen, verdorbenen Orlov sieht sie einen der Idee ergebenen, erhabenen Menschen [...].“ “) 946

Zunăchst Orlov und später der Unbekannte sind in Zinaidas Wahmehmung nach Semanova Helden, beide enttăuschen sie. Kramer bemerkt ebenfalls, daß Zinaida Fédorovna zuerst Orlov, dann den Erzahler für Insarov hălt und sich in der Rolle von Elena sieht. ${ }^{947}$ Dorring behauptet: „[...] wobei sie sich zărtlich vor Orlov hin kniet, den sie für einen außergewơhnlichen Menschen hălt. "948 Damit stimmt auch die Ansicht Wetzlers überein: „Zinaida Fedorovna sieht in Orlov einen revolutionăren Freigeist nach dem Vorbild Insarovs; [...]. [...] Die falsche Anwendung literarischer Vorbilder ironisiert die Wünsche und Ziele der Heldinnen [...].“949. Und weiter: „Von Orlov abgewiesen, hofft sie in der Beziehung zum 'Unbekannten' doch noch ihr Ideal [...] erreichen zu kōnnen. Als sie erkennt, daß auch der 'Unbekannte' keine Idee mehr vertritt, verliert sie allen Lebensmut". ${ }^{950}$ Wir wollen jedoch in diesem Unterkapitel demonstrieren, daß die Turgenev- bzw. Insarov-Verblendung Zinaida Fédorovnas in bezug auf Orlov in Čechovs Text nicht eindeutig bestătigh, sondern - u.a. mit Hilfe diverser intertextueller Verweise - hinterfragt, zumindest aber problematisiert wird. So wie der Erzahler in seiner Literaturrezeption zwischen verschiedenen literarischen Ideologien und verschiedenen Haltungen als Leser schwankt bzw. sie in sich zum Zeitpunkt des Erzăhlens vereinbart, geschieht es auch mit Zinaida Fëdorovna, die nicht nur von den Helden/ -innen Turgenevs wie Insarov und Elena, sondern sichtlich auch von ganz anderen Figuren der Weltliteratur beeinflußt ist. $^{951}$ Die auf Zinaida Fëdorovna bezogene Intertextualităt der Novelle zeugt weiterhin von einer Wandlung ihrer Literaturwahmehmung (vermutlich einer ăhnlichen wie beim Erzăhler), die sich im Laufe der Geschichte vollzieht. Für Cechov erscheint der Mensch somit als ein problematisches Individuum, dessen Wahmehmung des Literarischen seine innere Gespaltenheit und Widersprüchlichkeit verrăt. ${ }^{952}$

Einige markante Details in "Rasskaz neizvestnogo celoveka“ weisen darauf hin, daß das Verhalten, die Rede und die Gedanken Zinaida Fedorovnas nach ihrer Flucht vor dem Ehemann und bei der Absicht, mit Orlov ein neues Leben aufzubauen, gleichzeitig von mehreren literarischen Vorbildern bestimmt sowie von verschiedenen literarischen Sujets geprägt sind. Vor dem Gespräch mit dem Ehemann fühlt sie sich „виноватой, ничтожной, неспособной

\footnotetext{
246 Semanova 1958, S. 195, 224-225.

947 Vgl. S. 53 unserer Arbeit

948 Döring 1977, S. 104

949 Wetzjer 1992, S. 128 . Vgl Döring. Zinaida drängt [...] dem Anderen ihre literarischen Klischees und Forderungen auf und verlangt von ihm, sie zu realisieren." (1977, S. 102).

950 Wetzler 1992, S. 134

951 Über die verschiedenen Grade der BewuBtheit vom Literaturnachleben schreibt Wolpers. „Das Nachleben von Literatur kann schließlich - [...] - sowohl bewußt als auch unbewußt bzw halbbewußt vollzogen werden" (1986. S. 22).

${ }^{922}$ Das bezieht sich auch auf Oriov, der sich in unterschiedlichen Personen widerspiegelt und so als widersprüchlich erscheint
} 
на смелый. серьёзный иаз" („schuldig, nichtswürdig und =u einem kühnen, ernsthafien Schritt unfähig“); wăhrend der Erklärung gesteht sie ihm, „что любит другого, что этоm оругой её настояций, саиый законный муж, и она считает долгом совести сегодня же переехать к нему“ („daß sie einen anderen liebe, daß dieser andere ihr richtiger, ihr legitimer Gatte sei und daß sie es für die Pflicht ihres Gewissens halte, noch heute zu ihm zu ziehen“"); $[$ [...] я пала духом. Вы, Жорж, не верите в бога, а я немножко верую $и$ боюсь вознездия. Бог требует от нас терпения, великодуиия, самопожсертвования, а я вот отказываксь терпеть и хочу устроить жизнь на свой лад. Хорошо ли это? $A$ вдруг зто $c$ точки зрения бога нехороиьо?“ ("'[...] da verlor ich den Mut. Sie glauben nicht an Gott, George, aber ich glaube ein bißchen an ihn und fürchte die Vergeltung. Gott fordert von uns Geduld. Großmut. Selbstaufopferung, und da weigere ich mich, Geduld zu üben, und will mein Leben auf eigene Weise einrichten. Ob das gut ist? Vom Standpunkt Gottes es wiederum soll schlecht sein? $\left.[\ldots]^{\mathrm{m.953}}\right)(8,152)$. Und weiter:

[...] наивная, почти детская уверенность, что её тоже крепко любят и будут .пюбить вечно, молодили её лет на пять. [...]

- Нет выше блага, как свобода! - говорила она, заставляя себя сказать чтонибудь серьёзное и значительное. - Ведь какая, подумаешь, нелепость! Мы [...] дрожим перед мнением разных глупиов. Я боялась чужого мнения до последней минуты, но [...] теперь счастлива и всем желаю такого счастъя.

Но тотчас же поряфок .иыстеи у неё (кірывался и она говорита о новои квартире. o6 o6osx, . пuuddax. [...]. (,[...] die naive, beinahe kindliche Ïberzeugung, sie werde ebenfalls innig und ewig geliebt, machten sie um fünf Jahre jünger. [...]

'Es gibt kein großeres Glück als die Freiheit!' meinte sie, als sie sich zwingen wollte, etwas Ernsthaftes und Bedeutungsvolles zu sugen. 'Was für ein Unsinn, wirst du denken. [...] Wir [...] zittern vor der Meinung einiger Dummköpfe. Ich habe die fremde Meinung bis zur letzten Minute gefürchtet, aber [...] jetzt bin ich glücklich und wünsche einem jeden solch ein Glück.'

Sofort aber unterbrach sie ihren Gedankenfluß, und sie sprach von einer neuen Wohnung, von Tapeten. Pferden [...].“954) $(8,154)$

Ihr fester Glaube ans Geliebtwerden, die Tatsache, daß sie den Aufbruch zum geliebten Mann als einen von der Idee getragenen Schritt betrachtet, und der Wunsch, ihn mit ihren sozialen Überzeugungen in Einklang zu bringen (sie ..stilisiert“ Orlov tatsăchlich später als Insarov, wenn sie behauptet, daß er gegen seine Überzeugungen als Beamter dient), verweist auf die Lektüre von „Nakanune“ oder teilweise von „Rudin“. Die Situation des Ehebruches läßt aber in Kombination mit den zitierten Aussagen Zinaida Fedorovnas, die mehrere intertextuelle

953 S Ubersetzungen der Zitate in: Tschechow 1966, S 220-221 
Spuren enthalten, vermuten, daß auch der Roman „Anna Karenina“ seine Wirkung auf sie ausgeubt hat. $\mathrm{Da}$ ist erstens die Furcht vor der Gottesstrafe, die der Interpretation der moralischen Botschaft des Werkes Tolstojs, geăußert im Motto „Мне отмщение, и Аз воздам“ („Die Rache ist mein; ich will vergelten.“"955) entsprungen sein kơnnte, und folglich die Furcht vor dem Ende der Romanfigur Anna. Allerdings ist hier - in der Vermutung einer eigenen moglichen Schuld vor Gott - auch der Einfluß von Turgenevs Elena nicht auszuschließen: „Но [...] если мы должны теперь внести полную уплату за нашу вину? Моя совесть молчала, она теперь молчит, но разве это доказательство невинности? О боже, неужели мы так преступны! [...]“ („Aber [...] Wenn wir jetzt den vollen Preis für unsere Schuld bezahlen müssen? Mein Gewissen hat geschwiegen, es schweigt auch jetzt noch. Aber ist das denn ein Beweis meiner Unschuld? $O$ mein Gott, sind wir wirklich so verbrecherisch?“956 ${ }^{957}$. Da ist zweitens die von Zinaida Fedorovna artikulierte Unabhăngigkeit von der Meinung der anderen - die Unabhăngigkeit, die auch von Anna beschworen und erkămpft wird (vgl. den Verzicht Annas, sich vor der Gesellschaft zu verstecken, ihre Bereitschaft, sich in der Offentlichkeit zu zeigen, z.B. ins Theater zu fahren: „- Почему я не могу ехать? 9 гебя люблю и мне всё равно, [...].“ (,'Warum soll ich nicht in die Oper [nicht fahren]? Ich liebe dich, und alles andere ist mir gleichgültig, $\left.\left.[\ldots] .{ }^{\alpha 958}\right)^{959}\right)^{960}$. Selbst die in der zitierten Stelle vermittelte Anstrengung Zinaida Fedorovnas, ihrem Schritt eine ideelle Grundlage zu verleihen („заставляя себя сказать что-нибудь серьёзное и значительное“ Tatsache, daß eine "seriose“" Rede sehs bald von Gedanken an die neue Wohnung, Pferde u.s.w. abgelöst wird, distanziert sie von der streng überzeugten, zur Askese bereiten Elena aus „Nakanune“.962 Ihre Aussage, daß Orlov ihr wirklicher Ehemann sei, ruft jedoch auf eine eigenartige Weise beide Prätexte ins Gedăchtnis; sie alludient nămlich die Worte Annas vor Vronskij über Karenin „Он не понимает, что я твоя жена, что он чужой“ („Er begreift nicht, daß ich deine Frau bin, daß er ein Fremder ist $\left.{ }^{4093}\right)^{964}$ und die Phrase Insarovs zu Elena: „Так здравствуй же, моя жена перед людьми и перед богом!“" ('So sei denn gegnüß, mein

\footnotetext{
954 Tschechow 1966, S. 222-223.

${ }_{955}$ Tolstoi Bd. 6 (1966), S. 5

${ }_{936}$ Turgenjew 1973, S. 199.

${ }^{957}$ Turgenev Bd. 8 (1964), S. 157.

${ }^{958}$ Tolstoi Bd 7 (1966). S. 155.

${ }^{959}$ Tolstoj Bd 9 (1982), S. 123

\$0 Wăhrend aber die Meinung der Gesellschaft für Anna eine verhängnisvolle Rolle spiett, hat sie in der Novelle Cochovs keine Bedeutung: Die Problematik verlagert sich hier von der Schande des Ehebruchs auf andere Themen (Saal-Losq beobachtet, wie das Urteil der Gesellschaft in „Anna Karenina“ in der sie travestierenden „Dama s sobackoj" an Relevanz verliert. S. S. 53-54 unserer Arteit). Nichtsdestotrotz spricht Zinaida, wie aus der Antwort Orlovs folgt. uber .zlovrednost" vysšego sveta" (..Verderbtheit der besseren Gesellschaft" (Tschechow 1966, S 250)) (8. 177), was in Kombination mit ihrer Kritik an der Ehe bedeutet, daß sie von „Anna Karenina“ inspirient sein dürte

\%1 S Übers auf S 196 dieser Arbeit

962 Zum Vergieich von Zinaida mit den weiblichen Figuren Turgenevs, u.a. zu den Unterschieden zwischen ihnen vgl. hier auch Semanova 1958, S. 222-227

Tolstoi Bd 6 (1966). S. 506

96t Tolstoj Bd 8 (1981), S. 396
} 
Weib vor Gott und den Menschen! $\left.{ }^{\text {«.965 }}\right)^{966}$ Eine derartige gleichzeitige Kreuzung mehrerer Referenztexte im Bewußtsein Zinaidas deckt ihre Ratlosigkeit gegenüber der eigenen Situation auf; so sieht sie sich gleichzeitig in der Rolle mehrerer literarischer Frauengestalten und schwankt zwischen der entschlossenen Elena und der zweifelnden, leidenden Anna. Auf dieses schwankende Selbstverständnis deuten weitere Verweise hin. Obgleich die Parallele zwischen Zinaida und Elena (von Orlov) ausgesprochen wird und zusammen mit einigen Bezūgen zu "Nakanune“ auch naheliegend ist, tragen die vielen Referenzen zur Gestalt Anna Kareninas dazu bei, daß die Figur Zinaidas intertextuell heterogen erscheint. Und je unsicherer, ja unglücklicher sie sich fühlt, desto deutlicher rückt auch der Einfluß des Romans Tolstojs auf sie in den Vordergrund. Vgl. die Eifersuchtsszenen im manifesten und dem alludierten Werk: „- Вы. .иужсчиыы. бываете так гадки! [...] Я не видела, не знаю, но говорят, что вы, мужчины, ещё в детстве начинаете с горничными и потом уже по привычке не чувствуете никакого отвращения. Я не знаю, не знаю, но я даже читала...“ ("'Ihr Männer seid so garstig [eklig]! [...] 'Ich habe es nicht gesehen, ich weiß es nicht, aber man sagt, ihr Männer fangt bereits als Kinder mit den Zofen an und empfindet dann schon aus Gewohnheit keinen Ekel mehr. Ich weiß es nicht, ich weiß es nicht, aber ich habe es sogar gelesen. $\left.[\ldots]^{\mu 467}\right)(8,162)$ (Cechov). Vgl. mit den Worten Annas: "- Kaк вы заdкu, .уужчины! [...] Да ведь вы все любнте эти животные удовольствия, [...].“ („'Wie schlecht [eklig] seld ihr bloß, thr Männer! [...] Nun, für solche tıerischen Genūsse seid ihr doch alle [solche tierischen Genüsse liebt ihr doch alle],' [...].“*68 ${ }^{469}$ (Tolstoj). Vgl. weiterhin die Streitszenen:

- Жорж, дорогой мой, я погибаю! [...] Я изиучитась, утомилась и не моху бхатше.

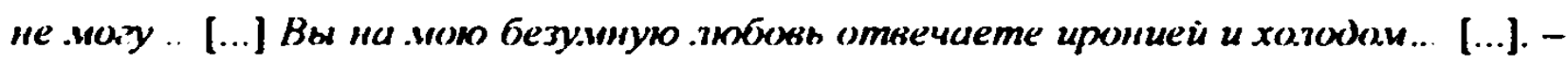
Да, да, я вижу: я вам не жена, не друг, а женцина, которую вы не уважсаете за

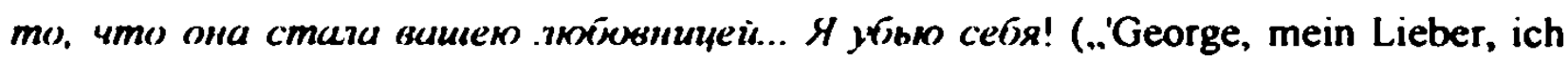
gehe zugrunde! [...] 'Ich bin am tinde, bin ganz erschöpft und kann nicht mehr, ich kann nicht . [..] Auf meine wahnsinnige liebe unıworten Sie mil Kälte und Ironie [mit Ironie und Kälte]... [...] 'Ja, ja, ich sehe - ich bin für Sie keine Gattin, kein Kamerad, sondern eine Fruu, die Sie nicht uchten, weil sie Ihre (jeliebte geworden ist... Ich bringe mich um $\left.{ }^{\text {m.970 }}\right)(8,166)$ (Cechov).

\footnotetext{
\$ss Turgenjew 1973, S. 120

Torot Turgenev Bd 8 (1964). S 95

967 Tschechow 1966, S. 232-233

Tolstoi Bd $6(1966)$. S . 504-505

${ }^{969}$ Tolstoj Bd. 8 (1981), S. 393. 395 Daruber kann Zinaida Fedorovna zweifelsohne auch in ..Krejcerova sonata“ gelesen haben Die Stelle bietet insofern eine doppelte Allusion an - auf den Roman und die Novelle Tostojs Uber die Spuren der Lektüre von „.Krejcerova sonata“ durch die Personen der Novelle. insbesondere in der Textfassung fur die Zeitschrift. $s$ in den Anmerkungen (8. 476)

${ }^{200}$ Tschechow 1966, S 237
} 
Und bei Tolstoj: „- Да, но я не моху! Ты не знаешь, как я изиучалась, ожидая тебя!“ (,Ja, aber ich kann nichts dafür [Ja, aber ich kann nicht!]. Du weißt nicht, wie ich bei diesem Warten auf dich gelitten habe. [...] $\left.]^{\text {s.971 }}\right)^{972}$ (die Eifersuchtsszene); ..- [...] Kmo $я$ ? развратная женцина. Камень на твоей шее. [...] Я освобожу тебя. Ты не пюбииь [...] $]^{\mu+}$ (,'[...] Was bin ich? Eine gefallene Frau! Ein Stein an deinem Halse! [...] Ich gebe dich frei. Du liebst mich nicht [...]." $\left.{ }^{\text {973 }}\right)^{974}$. Oder bei Čechov: „- [...] Я чиста перед богом и людьми, и мне не в чем раскаиваться. Я ушла от мужа к вам и горжусь этим.“ (,,'[...] Ich bin sauber vor Gott und den Menschen, und ich habe nich's zu bereuen. Ich bin von meinem Mann weggegangen und zu Ihnen gekommen, und ich bin stol= darauf. $\left.[\ldots]^{\mathrm{ra975}}\right)(8,179)$. Bei

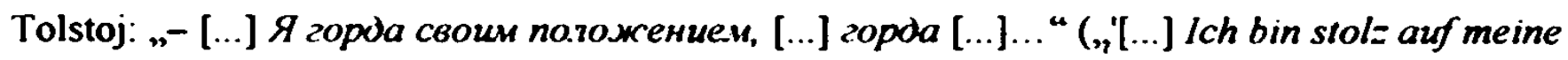

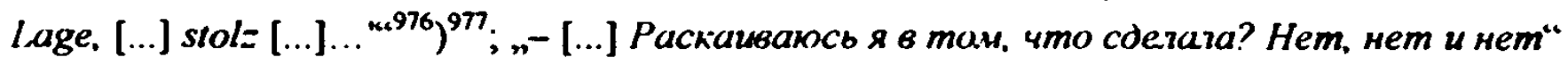
(,.'[..] Bereue ich etwa, was ich getan habe? Nein, nein und nochmals nein! [... $\left.]^{\text {r.978 }}\right)^{979}$. Vgl. hier jedoch auch die Worte der Elena Turgenevs: „- [...] И чего мне стыдиться? Я готова сказать всему свету, что я твоя...“ (,.'[...] Ich habe mich nicht [...] geschämt. Weshalb denn auch [Wovor soll ich mich schämen]? Ich bin bereit, vor aller Welt zu bekennen, da $B$ ich dein bin. $\left.[\ldots]^{\kappa 490}\right)^{981}$. Das idealistische Bild von Orlov, die Meinung, daß er ein ungeworhnlicher und seltener Mensch sei („- [...] Вы честный, великодушный... редкий человек, [...]... [..] необыкновенный человек!'- („,'[..] Sie sind ein ehrlicher, großherziger... einzigartiger Mensch, $[\ldots] \ldots[\ldots]$ ein ungewöhnlicher Mensch! $\left.{ }^{\text {m.982 }}\right)(8,166-167)$ ), verweist jedoch nicht nur auf „Nakanune“, wie in der einschlägigen Literatur angenommen wird, sondern (aufgrund der größeren situativen Ähnlichkeit) mehr noch auf „Anna Karenina“: „Во всём, что он говорил, думал и делал, она видела что-то особенно благородное и возвышенное. [...] она искала и не могла найти в нём ничего непрекрасного“ (,.In allem, was er sprach, dachte und tat, sah sie etwas besonders Nobles und Erhabenes. [...] Sie suchte dann nach irgend etwas, was sie an ihm auszusetzen haben könnte, entdeckte jedoch nichts, was nicht über alles Lob erhaben gewesen wäre [sie suchte und konnte in ihm nichts finden, was nicht schön wäre].." $\left.{ }^{* 8 z}\right)^{\text {s*d }}$. So enthalten die Aussagen Zinaida Fëdorovnas mitunter ganze Zitate aus

\footnotetext{
371 Tolstoi Bd. 6 (1966). S 506

972 Tolstoj Bd 8 (1981). S 395

${ }^{973}$ Tolstoi Bd. 7 (1966), S. 437.

${ }^{974}$ Tolstoj Bd. 9 (1982). S 339

${ }^{975}$ Tschechow 1966. S 252

976 Tolstoi Bd 6 (1966), S 445

molstoj Bd 8 (1981). S 349 .

${ }^{978}$ Tolstoi Bd. 7 (1966). S. 155

979 Tolstoj Bd. 9 (1982). S 123

${ }^{980}$ Turgenjew 1973, S. 163

981 Turgenew Bd 8 (1964). S 129

$9 \times 2$ Tschechow 1966. S. 238

9*3 Tolstoi Bd 7 (1966)., S 42

924 Tolstoj Bd 9 (1982), S. 36 ..Rasskaz neizvestnogo celoveka“ enthalt ebenfalls Bezuge zu ..Anna Karenina”. die außerhaib des rezipierenden Bewußtseins von Zinaida, $\mathrm{d} \mathrm{h}$ im außeren Kommunikationssystem. liegen (7. B die Personlichkeit ihres Ehemanns und insbesondere seine Reaktion auf ihr Gestandnis, die stark an Karenin ennnert). Auf die Parallelen zwischen dieser Novelle Cechovs einerseits und dem Fragment Puskins ..Na uylu ma- 
„Anna Karenina“, sie zitiert (bewußt oder unbewußt) ihr intertextuelles Pendant, dabei gehen diese Zitate in ihrem neuen Kontext stilistisch spurlos auf.

Auch der Luxus, in dem Zinaida Fëdorovna ihr neues Leben beginnt (v.a. die vielen Einrichtungs- und Haushaltgegenstände wie Bett, Damenschreibtisch, Kochtöpfe, Service; teuere Kleider u.s.w.), korrespondiert viel mehr mit dem Lebensstil Annas als mit dem Verlangen Elenas nach Armut und ihrer bedingungslosen Bereitschaft, mit Insarov die materielle Not zu teilen. $^{985}$

Der Eindruck Turgenevscher Gestalten auf Zinaida Fëdorovna wird in der Novelle nicht nur dadurch problematisiert, daß die Macht anderer Texte und Vorbilder über sie demonstriert wird. Die These Orlovs wird mit Hilfe einzelner (u.a. intertextueller) Details unterminiert. So geht seiner Rede über Turgenevsche „devicy“ (Mădchen) eine Bemerkung des Erzăhlers voraus: „Он был не в духе“ (,Er war nicht in Stimmung“486) $(8,156)$. Der Ausdruck „ne $v$ duche“ (,nicht in Stimmung“) alludiert den Titel einer gleichnamigen Kurzgeschichte Cechovs „Ne v duche“ (kann als "Schlechte Laune“ übersetzt werden) (1884), in der ein verărgerter Vater (er hat im Kartenspiel acht Rubel verspielt) hörn, wie sein Sohn im anderen Zimmer Zeilen aus „Evgenij Onegin“ auswendig lemt, worauf der Vater kritische Kommentare zum Werk Puskkins abgibt. Die Urteile dieser Person über Literatur erscheinen nicht nur deshalb fragwürdig und lăcherlich, weil der Urteilende keinen Sinn für das Poetische besitzt und die bei Puskin dargestellte Situation vom alltäglich-praktischen Standpunkt aus betrachtet und kritisiert, sondern weil er auf diese oder jene Weise seinen Zorn und seine Enttăuschung auslassen muß, die außerliterarische Gründe haben. Košelev zeigg ${ }^{187}$, wie diese und ähnliche Verwendungen der Texte Puškins zu ihrer semantischen Verflachung und Prosaisierung führen. Die Situation von „Ne v duche“ wiederholt sich in einem nicht-parodistischen Kontext in .Rasskaz neizvestnogo zeloveka“. Das Urteil Orlovs, d.h. seine Ansicht über Turgenev ${ }^{\text {ssz }}$, aber auch - angedeutet - über die Rezeption Turgenevs durch Zinaida Fëdorovna, werden auf eine analoge Art relativiert: Der Zorn Orlovs, ausgelöst durch den Einzug Zinaidas, ăußert sich literarisch, wird auf abstrakte - literarische - Bereiche verschoben. Zinaida Fedorovna wird zu einer verblendeten Leserin stilisiert. ${ }^{\text {9*9 }}$ Ein weiterer Schritt in der Relativierung der These Orlovs vollzieht sich durch die Reaktion auf diese These Gruzins und durch dessen $\mathrm{Zi}$ tieren eines anderen Textes Turgenevs - der Novelle ,.Tri vstreči“ (Drei Begegnungen). Eine wichtige Funktion dieses Zitats haben wir (Kap. 4.2.1.) bereits formuliert, seine Relevanz er-

len 'koj plošcadi" (An der Ecke des kleinen Platzes) und ..Anna Karenina” andererseits (z B. ..obrjasnenie“" (объяснение. Aussprache) der Heldin mit ihrem Ehemann) weist Kuzizeva hin (1998. S. 59-60)

${ }^{n s} \mathrm{~V} \mathrm{~g}$. Doring. die die Bedeutung der ..Kupferkasserollen”. .,die sie gleich am ersten Tag in die Wohnung Orlovs schaffen laßt" (1977, S. 102) in der Gestaltung von Zinaida betont

926 Tschechow 1966. S 225

927 Koselev 1998, S 148-149

920 Über die Rezeption Turgenevs durch Orlov s. u a bei Semanova 1958. S. 218

9uer die Abhangigkeit der Aussagen und Ideen („оӧусловленность мнений”. Bedingtheit der Meinungen)) der Figuren Cechovs von der Stimmung und von der konkreten Situation und uber die daraus resultierende Relativierung ihrer Ansichten S. Z.B bei Kataev 1979. S 144-152, ebenfalls bei Penzkofer 1984, S 211-214 
gibt sich aus der Tatsache, daß Gruzin der Wahmehmung des Literarischen als Vorbild und Programm seine leichtere und emotionale Wahrnehmung gegenüberstellt, die es erlaubt, ohne Versuch einer Nachahmung das Eigene im Fiktiven zu finden, eine befreiende Parallelităt der Zustände und Stimmungen zu erleben. Abgesehen davon evoziert Gruzin ein Turgenevsches Sujet von Liebe und Verlassensein, wodurch einerseits das Bild Turgenevs im Rahmen des alludierenden Textes an Komplexităt gewinnt und über die Auslegung Orlovs hinausragt ${ }^{990}$, andererseits Zinaida Fëdorovna viel eher als eine unglücklich verliebte und - vorausdeutend verlassene Frau und nur hintergründig als naive, von Ideen begeisterte „Nakanune“-Leserin konzipient wird.

Das nicht nur intertextuell vermittelte Auflösen fester Überzeugungen und damit der sozial-belehrenden Rolle der Literatur bzw. die Problematisierung und das Relativieren einer solchen Rolle ist also nicht nur mit der Gestalt des Erzăhlers, sondern ebenfalls mit der Gestalt von Zinaida Fedorovna verbunden. Dieser Prozeß wird erstens von der zunehmenden Bedeutung anderer fiktiver Figuren für die beiden Personen, als der kampfbereiten Helden und der sich opfernden Frauen, begleitet (als Folge der Enttăuschung durch die früheren Ideale und Vorstellungen), zweitens von der steigenden Macht des Echten (d.h. des Nicht-literarischen) wie Verlangen nach Liebe und Wärme, Leiden an unerwiderten Gefühlen, Einsamkeit u.S.w. Dieser doppelte Vorgang ist damit zu erklären, daß das Echte von den beiden literarısch verarbeitet wird (so z.B. der vermutliche Einfluß der Rudin-Gestalt auf den Unbekannten nach seinem geistigen Wandel). Wenn der Erzăhler sich von den früher annehmbar attraktiven Texten abwendet, gibt er auch seine frühere von uns zu vermutende Haltung als literaturnachlebender Leser auf. Ähnlich geschieht es mit Zinaida Fëdorovna: ohne daß sie ihre Verblendung durch Insarov und Elena endgültig überwindet (in den letzten Kapiteln der Novelle deutet einiges darauf hin, daß sie den Erzăhler erst richtig mit Insarov identifiziert), identifiziert sie sich möglicherweise immer mehr mit anderen literarischen Heldinnen - den verzweifelten Ehebrecherinnen.

Parallel zu diesem Prozeß verdeutlicht sich der Gegensatz zwischen der Beziehung Zinaidas zu Orlov und zum Erzăhler: Während im Verhältnis zu diesem die Insarov-Linie tatsăchlich dominiert. weisen immer mehr Details darauf hin, daß es in der Beziehung zu Orlov keine wirkliche bzw. Keine eindeutig nachweisbare Verblendung durch Insarov gegeben hat, sondern höchstens einen Wunsch nach einer solchen Idealisierung. möglicherweise eine Elena-Pose ${ }^{991}$, in erster Linie aber eine Liebesbeziehung, ausgelöst vermutlich durch entsprechende literarische Vorbilder wie z.B. „Anna Karenina“. Wăhrend Elena in Insarov sowohl den Lehrer als auch einen Geliebten zu sehen vermag, ist Orlov für Zinaida vor alle'm ein Geliebter, der Erzähler ausschließlıch ein Lehrer. Wenn sie dem Erzähler über ihre Gefühle zแ

\footnotetext{
990 Auch Semanova weist darauf hin, daß die Aussagen Ortovs uber Turgenev u a mil Hilfe der Erwahnung von .Tri vstrezi“ durch Gruzin widerlegt werden (s. 1958. S 218-219)

911! Es ist anzunehmen, daB Zinaida Fedorovna zwischen ..Rollenspiel" und ..lllusion" oszilliert. um den Ausdruch von Wolpers zu verwenden (s. S 160 dieser Arbeit). was eine Literaturverblendung bei inr in Frage stellt 
Orlov mit Scham sagt: „Bсе эти любви только туманят совесть и сбивают с толку“ (,'So eine Liebe verwirt nur das Gewissen und stiftet Unruhe [und verwirrt]. [...] $\left.{ }^{\text {n.992 }}\right)(8,200)$ und die Liebe des Erzăhlers zu ihr gleichzeitig abweist und sogar verachtet, ihn aus ihrer intimen Sphäre also ausschließt, dann wird der erwähnte Kontrast deutlicher denn je. Die Möglichkeit einer Liebesbeziehung mit dem Unbekannten befremdet sie, und es gibt im Text keine Zeichen dafür, daß es anders wäre, wenn er tatsächlich ein Vorbild und Lehrer für sie werden könnte. In der kurzen Periode, in der sie an ihn und damit an ihre Zukunft vermutlich noch glaubt (Kapitel XV), bleibt sie, wie das in verschiedenen Szenen angedeutet wird, in der bitteren Vergangenheit vielzu fest gefangen und ist auch in dieser Zeit letztendlich nicht imstande, sich von ihr zu lösen (vgl.: „[...] и Зинаида Фёдоровна, бледная, [...] сидит рядом со мной, крепко стиснув губы и руки. [...] Лнщо, поза и неподвижный, ничего не выражающий взгляд, н до невероятного унылые, жуткие [...] воспомкнания [...]!“ („[...] und neben mir saß Sinaida Fjodorowna, bleich, [...], die Lippen und Hănde fest zusammengepreßt. [...] Ihr Gesicht, ihre Haltung, der unbewegliche, ausdruckslose Blick und die unwahrscheinlich traurigen, schrecklichen [...] Erinnerungen [...].“993) $(8,199)$. Zinaida hört in den Kapiteln XVXVII der Novelle nie auf, in erster Linie als eine von (Orlov verlassene Geliebre (und also weniger als eine vom neuen "Leiter“, dem Unbekannten, inspirierte Frau) aufzutreten. Vgl. dazu folgende Aussagen Zinaidas, wo dies zum Vorschein kommt:

- [...] Выздоравливайте. Как только поправитесь, займёмся нашими делами... Пора.

Когда я, уже простившись, брался за ручку двери, она говорила:

- Как думаете? Поля все ешё живёт у него? (.,'[...] Werden Sie gesund. Sobald Sie genesen sind, befassen wir uns mit Ihren [unseren] Angelegenheiten... Es ist Zeit.'

Als ich mich bereits verabschiedet hatte und nach der Türklinke griff, sagte sie:

'Was meinen Sie? Ob Polja immer noch bei ihm wohnt? $\left.{ }^{\text {*. } 904}\right)(8,201$ ).

Da also die Turgenev-Rezeption und -Verblendung Zinaidas - die Identifikation Orlovs mit Insarov - nicht zu den Fakten der in der Novelle dargestellten Realität gehört, sondern den Inhalt der fiktiven Aussagen (z.B. der Aussagen Orlovs) bildet ${ }^{995}$, war es sinnvoll, unser Augenmerk auf die Details zu lenken, die solche Verblendung in Frage stellen.

\footnotetext{
992 Tschechow 1966, S 278

993 Ibid S. 276

994 lbid. S 279

999 $\mathrm{Vgl}$. die Aussage von Penzkofer auf den S 156 dieser Arbeit Von den funf Phasen des fiktiven Literaturnachlebens, die im Modell Wolpers beschrieben werden. finden wir hier (wenn angenommen wird. daß ein solches Nachleben in der Novelle stattindet) nur die dritte. vierte und fünfte. Die zweite Phase. die belegen soll, daß der Kontakt mit dem literarischen uberhaupt geknupt wird. bleibt eine Vermutung Orlovs (und des Interpreten) Insofern ist die Insarov-Verblendung Zinaidas nur aulkund weulerer I letals entweder zu bestatigen oder zu widerlegen
} 
Wăhrend in "Nakanune" sowie in "Rudin" der Anziehungs- und Annäherungsprozeß zwischen den Liebenden ausführlich dargestellt wird und so die Verwandtschaft ihrer Interessen, Empfindungen, Gedanken und der Lektüre in gemeinsamen Gesprăchen festgehalten wird, bleibt das in bezug auf Zinaida Fédorovna und Orlov ausgeklammert. De facto - in der erzählten Geschichte - begegnet man statt dessen einer Frau, die nach der Flucht vor dem ungeliebten Ehemann vergeblich um die Zuneigung ihres Liebhabers bettelt und sich am Ende aus Verzweiflung das Leben nimmt. Die Auseinandersetzungen zwischen Orlov und Zinaida lassen nicht klar werden, ob es um verschiedene Wertvorstellungen oder viel eher und letzten Endes um die unerwiderten Gefühle geht. ${ }^{9 \%}$ So sagt Zinaida, nachdem Orlov ihr seine Ideenlosigkeit versichert: "- [..] Вы на мою безумную любовь отвечаете иронией и холодом..." $(8,166)^{997}$. Die Liebe Zinaidas zu Orlov und ihr Glaube an seine edlen Überzeugungen und Ideen scheinen einander zumindest nicht zu beeinflussen. „Она льстила Орлову и, чтобы добиться от него неискренней улыбки или поцелуя, стояла перед ним на коленях, паскались как собачонка.“ (.,Sie schmeichelte Orlow und lag vor ihm auf den Knien und bettelte wie ein Hündchen um ein unaufrichtiges Lächeln oder einen Kuß.“998) (8, 169). Je weniger überzeugend die Similarităt Zinaidas mit den Turgenvschen Heldinnen ist, desto auffalliger werden die Parallelen zwischen ihrer Gestalt und den Gestalten der nichtTurgenevschen Heldinnen - Anna Karenina oder Emma Bovary Flauberts. Die zuletzt zitierte Stelle konnte beispielsweise eine Allusion auf den Roman Flauberts und seine zentrale Frauengestalt sein ${ }^{99 \%}$. „Es war eine Art hündischer Anhünglichkeit, voller Bewunderung für ihn [...]" - heißt es über die Beziehung Emmas zu ihrem Liebhaber Rodolphe. ${ }^{1000}$ Emma will mit Rodolphe ebenfalls fliehen, wird von ihm aber verlassen. Als verzweifelte Ehebrecherin a la Anna und Emma erscheint Zinaida Fëdorovna auch dann, wenn sie in den letzten Kapiteln ihre Schwangerschaft zu verstecken versucht und offenbar keine Liebe zu ihrem künftigen Kind verspürt (nach der Entbindung begeht sie Selbstmord) (vgl. die Szenen bei Tolstoj und Flaubert, in denen diese Ablehnung des eigenen Kindes durch die seelisch leeren Frauen thematisiert wird ${ }^{1001}$ ). Dadurch, daB Zinaida Fëdorovna Selbstmord begeht, rückt ihre Gestalt noch näher an die tragisch(-sentimentalen) weiblichen Figuren der Romane Flauberts und Tolstojs. $^{1002}$

\footnotetext{
$996 \mathrm{Vgl}$. Bicilli. ... I Wenn sie (Zinaida - K S.) auch selbst von Orlov 'Idealismus' forderte - [ ] - so ist doch klar, daß das nur Worte sind in Wirklichkeit qualt sie seine Kalte ihr gexenuber und sonst nichts * (1966. S 133) 997 S Ubers auf $\mathrm{S} 198$ unserer Arbeit

498 Tschechow 1966, S 241

Franzosische Literatur und mit ihr indirekt der Roman ..Madame Bovary", dessen Suiet und dessen zentrale Frauengestalt in ..Rasskaz neizvestnogo celoveka" mit Hilfe weiterer Details evoziert werden. wird spater, in XIV Kapitel, von Zinaida Fedorovna ins Gedachtnis gerufen (Zitat aus ..Pere Goriot" ( $($. 19:)) So wird im manifesten Text cin Netz von mehr oder weniger direkten Intertextualitatssignalen geschatteri die die Prasenz eines Pratextes verraten Uber die Lekture franzosischer Literatur durch die Heldinnen der Vol .:lle s hei Halm (1933. S. 73)

${ }^{1000}$ Flauben 1974, S 220

1001 S. z B bei Flaubert 1974. S. 133-134

1002 Uber die Parallelen zwischen...Anna Karenina“" und ..Madame Bovary“ einerseits und ... Inna na see" andererseits s bei Winner (1966. S. 178)
} 
Wăhrend die Turgenev-Einwirkung, erlebt durch eine naive weibliche Figur, in den frühen Prosawerken Čechovs einfach (ironisch) konstatiert wird (s. in "Cvety zapozdalye“: $n-[\ldots]$ При таком уме, как у тебя, с такой честной, любящей душой можно сноснть удары судьбы! [...] И Маруся (простите ей, читатель!) вспомнила тургеневского Рудина [...].“ („Bei deinem Verstand, mit deiner ehrlichen, liebenden Seele ist es möglich, die Schicksalsschlăge zu ertragen! [...] Und Marusja erinnerte sich (Verzeihen Sie ihr das, Leser!) an Turgenevs Rudin [...].“) $(1,393)$ und in „Dacnica“(1003), wird sie in „Rasskaz neizvestnogo celoveka" auf verschiedenen Wegen problematisiert. Im wesentlichen erfolgt diese Problematisierung durch die Verschiedenheit von und den Kampf zwischen den von der betreffenden Person gelesenen und auf sie einwirkenden fremden Texten (aber auch dadurch, daß das die Wirkung Turgenevs hier eine subjektive Wahrnehmung der fiktiven Figuren bleibt). Aus diesem Kampf bzw. der Koexistenz der rezipierten Texte, der ebenfalls für den Erzăhler und bis zu einem gewissen Grad für Orlov gilt, ergibt sich eine besondere Gespaltenheit der Personen als Literaturrezipienten und somit die Gespaltenheit ihrer Selbst- und Wirklichkeitswahrnehmung. An den Schwankungen und Widersprüchen der Literaturrezeption durch Cechovs Helden läßt sich ihre Ratlosigkeit erkennen und messen - ob als Folge einer geistigen Entwicklung (am deutlichsten beim Erzahler) oder als konstanter Zustand. ${ }^{1004}$

\footnotetext{
${ }^{1003}$ S. Fußn. 517
}

1004 In die Novelle „Rasskaz neizvestnogo celoveka” sind daruber hinaus einige Texte der nussischen literatur "eingeschrieben”, deren mögliche Lekture und Rezeption durch die Personen uns weniger interessiert (obwohl sie ebenfalls im inneren Kommunikationssystem - vom Erzahlet oder von Zinaida - alludiert werden), sondem die fur uns vor allem als Varianten. pa Versonen des aktwellen Sujets fungieren (vgl die Aralyse von "Stancionnyj smotritel'" und seiner Prattexte bei Schmid 1983: es handelt sich bei uns hier 2.T um das Thema, das auch manchen Geschichten in der Analyse von Schmid zugnunde liegt, z.T. also um ähnliche Sujets und sogar um die gleichen Pratexte (wie „Bednaja Liza“ (Die arme Liza)). Als einer der Prătexte bei uns fungiert der aktuelle Text in der Analyse Schmids, namlich ..Stancionnyj smotritel'“) Ohne hier auf die intertextuelle Arbeit des manifesten Textes mit den Vorganger-Texten detailliert einzugehen, nennen wir sie sowie die mit ihnen verknupften Intertextualitatssignale. Als Geschichten uber die Flucht einer Frau (aus dem Elternhaus) zu dem geliebten Mann sind in Cechovs Novelle Puskins „Stancionnyj smotritel' ${ }^{\prime \prime}$ und Dostoevskijs .Unižennye i oskorblennye“ (Erniedrigte und Beleidigte) aufgenommen, als Erzahlungen über die vom Geliebten (verfuhrten und) verlassenen Frauen werden Karamzins „Bednaja Liza“ und Turgenevs „Tri vstreci” evozien, einer weiteren aufgerufenen Novelle Turgenevs, „Nescastnaja“" (Die Unglückliche). liegt ein Sujet zugrunde, bei dem eine verzweifelte junge Frau sich letzten Endes aufgrund mangelnder Gegenliebe des von ihr geliebten Mannes - das Leben nimmt (Selbstmord begeht die Heldin auch in "Bednaja Liza"). Auf .Unižennye i oskorblennye" (eine Episode aus Kap. I (13)) spielt der Erzähler in seinem Brief an Orlov an (..В какой-то повести Достоевского старик топчет портрет своей любимой дочери [....” (..In einer [irgendeiner] Novelle von Dostojewski tritt ein alter Mann das Bild seiner Lieblingstochter mit Füssen [. .]" (Tschechow 1966, S 265)) u.s w (8, 190); s. uber diese Allusion z.B bei Bicilli (1966, S. 189) und in den Anmerkungen zur Novelle (8, 485)), „Tri vstrexi“" zitien Gruzin (s. oben), auf eine Szene aus ..Stancionnyj smotritel” (.В комнате прехрасноубранной Минский сидел в задумчивости. Дуня [...] сидела на ручке его кресел [ ] Она с нежностью смотрела на Минского. наматывая черные его кудри на свон сверкающие пальцы“ (.Nachdenklich saß Minskij in einem prachtig eingerichteten Gemach. Dunja aber kauerte [saB] [ . ] auf der Armlehne seines Sessels [ ] Itre Blicke ruhten voll Zartlichkeil auf Minskij [Sie schaute Minskij zärlich an], und sie wickette seine schwarzen Locken um ihre schimmernden Finger " (Puschkin Bd. 3 (1952), S 69)) (Puskin Bd. 8 (1948), S. 104)) wird im Kapitel VI verwiesen (..[ .] сная нa коленях у Орлова, она [...] рассматривала его руки с кольцами [ . ] [ [ .] А Орлов играл ее каштановыми волосами [.. ] " (.. . ..] auf Orlows Knien sitzend [ .] sie [ . ] betrachtete [ ..] die Ringe an seinen Fingern [ ] [...] Orlow spielte mit ihrem kastanienbraunen Haar [...] “ (Tschechow 1966, S 238)) (8. 167), dasselbe Zitat aus 


\subsection{Spielarten des Modus V: Von „O drame“ zu „Bab'e carstvo“}

\subsubsection{Von „O drame“ bis „Pripadok“}

Der Modus V der fiktiv gestalteten Literaturrezeption im Prosawerk Čechovs stellt bis zu einem gewissen Grade einen Gegensatz zu dem zuvor untersuchten Modus II dar. Der gegen-

\footnotetext{
.Stancionnyj smotritel'” s. bei Schmid 1983, S. 176 in beaug auf die Geschichte vom starken Samson). Wenn der Erzähler sagt. .[...] мне представлялось, что оба мы участвуем в кахом-то романе, в старинном вкусе, по названием 'Ззосчастная'. 'Покимутая' или что-нибудь вроде. [...] она - злосчастная броменная [...]..." (.....] da stellte ich mir vor, daß wir beide in einem Roman alten Stils mit dem Titel 'Die Unglückliche'. 'Die V'erlassene' oder so ähnlich mitspietten [..] sie - unglïcklich, verlassen, [...]..." (Tschechow 1966, S. 277 )) (8. 199). dann alludient er den genannten synonymischen Titel der Novelle Turgenevs. Nescastraja" und der Novelle Karamzins „Bednaja Liza“" (zum Vergleich der Ausdrücke „arme Liza“" bei Karamzin und „arme Dunja“" bei Puškin s. bei Schmid 1983, S. 160). Das Attribut .6рошенная" (verlassen) bezicht sich weiterhin intertextuell auf den Sujetvertauf insbesondere von "Bednaja Liza" (über die intertextuellen Bezuge zu "Bednaja Liza" in "Stancionny) smotritel'" s. Schmid 1983). Der letze Pratext ist im manifesten Text auch in folgenden Verweisen zi entdecken: .- Нина, я бабмамута! - тромко зарыдала она." (8, 196. Übers. s. auf S. 192 dieser Arteit) - „. [...] Я верю

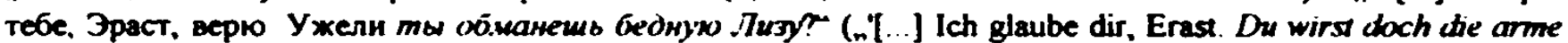
Liza nicht betrügen? [ . . ]" (Karamsin 1952. S. 16)) (Karamzin Bd. 1 (1964), S. 612); бога а я немножко верую и бонось возмезиия “) (8, 152. Ubers. S. auf S. 196 dieser Arbeit) - „- Эраст, Эраст! [.. ] - Мне страшно' Я бокось. чтобы гром ме убит. меня, ках преступницу!'” (.'Erast, Erast! [...] 'Ich habe Angst! Ich fürchie, daß mich Sünderin cker Donner erschlagy!"” (Karamsin 1952. S. 22)) (Karamzin Bd. I (1964), S 616);
}

- Не хочется ехать, да не прндумаешь оттоворки! - сказал он с досадой. - Надо ехать, ничего не поделаешь.

От тахой новости у Зинаиды Федоровны мгновенно покраснели глаза

- Hadvizo?" - ¿nрuскиза она.

- Lmeiu nа numь (.'Ich mochte gar nicht fahren, aber da hilft keine Ausrede [aber man kann keine Ausrede finden]!' sagte er argerlich. 'Ich muß fahren, nichts zu machen'

Von dieser Neuigkeit roteten sich im Nu Sinaidas Fjodorownas Augen

"Fiur lange" fragte sie.

Für fuinf Tage enwa." (Tschechow 1966, S 243)) (8, 171)

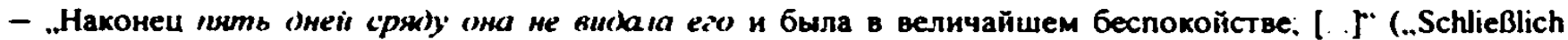
hatle sie thn finf Tage himeremkankter micht mehr gesehen und war in großter Unnuhe [ . ]" (Karamsin 1952. S

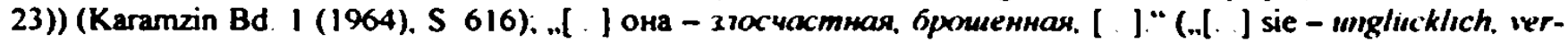

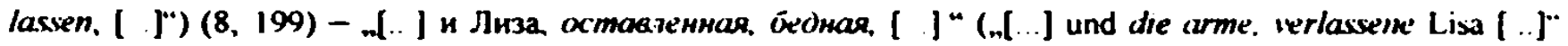

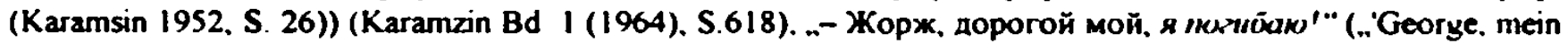

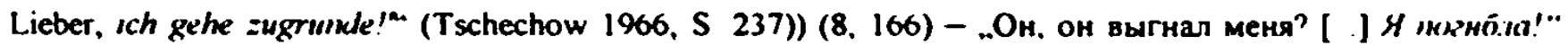
(.Er, er hat mich hinausgeworfen? [. ] /ch hin verloren" (Karamsin 1952. S. 29)) (Karamzin Bd I (1964). S. 620) (s. dieses Zitat bei Schmid 1983. S. 162) Das Sujet von ..Faust" und so das Schicksal von Gretchen wird schließlich durch die Bemerkung Kukuskins hervorgerufen „Tсc! Здесь Маргарıпта мечтает о своем Фаусте * (..'Ps! Hier traumt Margarete von ihrem Faust. "” (Tschechow 1966. S. 224)) (8. 155)

Diese Koexistenz mehrerer Sujetvarianten in der aktuellen Geschichte kann man. nach der Formulierung von Lachmann, als .,das Einspielen von Texten der Vergangenheit in einen 'neuen' textuellen Zusammenhant" 1 imo. S.11) deuten. durch die genannten intentextuellen Verweise wird ..das Immer-Wieder-Sich-Neu- und ( nixihroiben" (ibid S 36) eines literarischen Sujets sichtbar, hier „setzt“ die internextuelle Interpretation erst recthi .cinen Entzifferungsproze $B$ in Gang". .um zum originaren Text-Ont vorzudringen. der sich entzieht" (ibid S \')

Eine vergleichende Untersuchung der in ..Rasskaz neizvestnogo celoveka“ evozierten Sujets (auch des vion . Inna Karenina", ..Nakanune“. „Rudin" und ..Emma Bovary") mit dem aktuellen konnte AufschluB daruker sot.en "wc Cochov das in der Literatur recht bekannte Thema interpretiert. 
sătzliche Charakter dieser zwei Modi wurde in den Kommentaren zu unserer Typologie bereits thematisiert. Die fiktiven Leser des Modus Il übersehen oder verwischen bewußt die Grenze zwischen dem Fiktionalen und dem Wirklichen, ihnen ist deswegen Realitätsverlust nachzusagen; als von der Literatur Verblendete, die die nicht-literarische Realität zu akzeptieren nicht imstande sind, fugen sie bei Cechov sich selbst (II2) (dadurch z.B., daß sie schließlich mit der harten Realităt konfrontiert werden) oder anderen (II3) ${ }^{1005}$ Leiden zu. Unter dem Einfluß der Literatur werden ihre schon vorhandenen Konflikte mit der Umwelt sichtbar. ${ }^{1006}$ Die fiktiven Leser des Modus $V$ sind entweder nicht ernsthaft vom Gelesenen berühr (der Einfluß kann in diesem Fall vorgetäuscht sein, wie z.B. in „O drame“ (Über das Drama)), oder diese Wirkung hălt nur sehr kurz an und ist von der Stimmung des Rezipienten determiniert (wie in „Bab'e carstvo“). Die Wirkung des Fiktionalen auf die Figuren, die Literatur nach dem Modus $\mathrm{V}$ rezipieren, lăßt sie im Gegensatz zu den Figuren des Modus II die Grenze zwischen dem Leben und der Literatur nie wirklich vergessen. Sie treten hăufig als nüchterne oder enttăuschte Charaktere auf, als Gleichgültige (wie z.B. Orlov), bisweilen als Zyniker und sogar Heuchler ${ }^{1007}$ (falls der Einfluß der Literatur - hier des Guten, Vorbildlichen - vorgetâuscht wird). Die Aufnahme literarischer Texte wird dann am ehesten zur Unterhaltung, sie kann als Spiel, als (edle oder originelle) Pose oder auch einfach nur als eine zeitbegrenzte Ablenkung dienen. Wenn Rezipienten des Modus $\mathrm{V}$ ihre Mitmenschen unmoralisch behandeln, dann geschieht dies im Gegensatz zu den Lesem des Modus 113 nicht unter dem Einfluß des Literarischen, sondern ganz unabhängig von ihm; häufig wird die innere Unzulănglichkeit des Protagonisten gerade durch sein tatsächliches nicht-Beeinflußtsein vom Gelesenen hervorgehoben (Beispiele s. weiter).

Wir wollen im Weiteren untersuchen, wie der Modus $V$ in verschiedenen Texten Cechovs variiert wird und gleichzeitig, welche Invarianten der fiktiven Literaturwahrnehmung dabei zu entdecken sind.

Schon in der Kurzgeschichte „O drame“ (1884) kann man die für diesen Modus typische Leser-(bzw. die Zuschauer-)haltung finden (obgleich es sich hier erstens um die Wirkung nicht nur der schönen, sondern z.B. auch der kunstkritischen Literatur handelt und es zweitens weniger um die gelesenen als vielmehr um die aufgefuhrten dramatischen Werke geht). „O drame" gestaltet das Phänomen zwar noch parodistisch (dieser Text kőnnte so gesehen dem Modus I zugeordnet werden), demonstriert aber eine Rezeptionsart, die dem Modus V entspricht. Hier wird das Gespräch des Friedensrichters Poluechtov mit dem Oberst des Generalstabes, Fintifleev, über die echten Werte, die das Drama früher vermittelt habe (Pflicht, Nächstenliebe, Freiheit, Mut), und über den veredelnden Einfluß der Kunst auf die Menschen im allgemeinen der realen Grausamkeit der Gesprächspartner gegenübergestellt. Poluechtov

${ }^{1005} \mathrm{~S}$ Z.B. in der Fußn 816

${ }^{1006} \mathrm{Vgl}$. Wuthenow (S. 159 dieser Arbeit) und Wolpers (S 160-161 dieser Arbeit)

1007 Zum Thema des Chamaleons bei Cechov vgl Kramer 1970 
unterbricht den Dialog mit Fintifleev, indem er seinen Neffen für eine schlechte Note im Griechischen verprügelt, und fahrt fort:

[...] на чём я остановился? Прежде, бывало, сидишь в кресле, глядишь на сцену и чувствуешь! [...] Ты слышишь гуманные слова, видишь гуманные поступки... [...] и... веришь ли?.. я плакал! [...] На меня, вообще говоря, сиена действует воспитывающе... [...] Да процветают искусства и гуманность! [...]

Приятели выпили и заговорили о Шекспи!ре. ('[...] wo war ich stehen geblieben? Früher saß man manchmal im Sessel, schaute auf die Bühne und empfand! [...] Man horte humane Worte, sah humane Taten [...] und... glaubst du mir?.. Ich weinte! [...] Das Theater wirkt auf mich im allgemeinen erzieherisch... [...] Es gedeihen Künste und Humanităt! [...]

Die Freunde tranken einen und fingen an, von Shakespeare zu sprechen.) $(3,96-97)$.

Das Nicht-Ernst-Nehmen der Literatur, das ins Zynische bzw. Inhumane umschlăgt, die Unfahigkeit oder der Verzicht, die Botschaft eines Werkes auf das eigene Leben und die eigene Person zu beziehen, ernsthafi Vergleiche zwischen dem eigenen Verhalten und dem der fiktionalen Charaktere anzustellen (obwohl dieser Vergleich außerhalb ihrer Wahmehmung, in der Sujetstruktur, suggeriert wird), ist weiterhin in „V sude“ (1886) zu beobachten. Dieselbe Einstellung der Figur Čechovs zum Fiktiven wie in .,O drame“ wird hier jedoch psychologisier; die Person behauptet nicht mehr, von der Fiktion positiv beeinflußt zu sein, und wirkt deshalb auch nicht lächerlich (mit ihrer ins Auge stechenden Diskrepanz zwischen dem Artikulierten und dem Tatsächlichen). Derselbe Modus der fiktiven Literaturrezeption wird in einen nicht-parodistischen Kontext übertragen. In „V sude“, einer der „Tolstojschen“ Novelle Cechovs $^{\text {'0x, }}$, findet man die Beschreibung einer Sitzung des Bezirksgerichtes, das emotionslos und mit absoluter Gleichgültigkeit gegenüber dem Gegenstand des Falls einen Mord untersucht (der Bauer Nikolaj Charlamov wird des Mordes an seiner Frau beschuldigt). I(xo9

Говарищ прокурора, полный. упитанный брюнет, в золотых очках и с красивой. выхоленной бородой, сидел неподвижно, как статуя, и, подперев щекку кулаком. читал байроновского ..Канна“. Его глаза были полны жадного внимания и брови уднвлённо приподнимались всё выше н выше... Изредка он откидывался на спинку кресла. минуту безучастно глядел вперёд себя и затем опять погружался в чтение. (..Der stellvertretende Staatsanwalt. ein wohlgenährter, stattlicher Mann mıi goldener Brille, braunem Haar [ein wohlgenährter, stattlicher Brunetter mit golden'', Brille] und einem schönen, gepflegten Bart saß unbeweglich da wie em Standbild :!nd las, die Wange auf die Faust gestützt, den 'Cain' von Byron. In seinen Augen lag wı

${ }^{100 x} \mathrm{~S}$ daruber in den Anmerkungen zur Novelle $\$ .656$ 
Ausdruck gieriger Aufmerksamkeit [Seine Augen waren voll gieriger Aufmerksamkeit], und seine Brauen zogen sich vor Verwunderung immer weiter in die Hohe... Ab und zu lehnte er sich im Sessel zurück, schaute einen Augenblick teilnahmslos vor sich hin und versenkte sich dann emeut in die Lektüre. “1010 $(5,345)$.

Auch weiterhin wird das große Interesse des Staatsanwaltes an seiner Lektüre und zugleich seine vollkommene Gleichgültigkeit am Prozeß betont:

Когда врач кончил, председатель [...] предложил:

- Не имеете ли что спросить?

Товарищ, не отрывая глаз от „Канна“, отрицательно мотнул головой; [...]. („Als der Arzt fertig war, [...] der Vorsitzende [...] sagte:

'Haben Sie noch Fragen?'

Der Staatsanwalt schüttelte, ohne den Blick vom 'Cain' zu heben, vemeinend den Kopf $\left.[\ldots] .^{\text {“1011 }}\right)(5,347)$.

Die intertextuelle Funktion dieses Verweises wird im Kommentar der PSSP wie folgt gedeutet: „Мистерия' Байрона 'Каин' (1821) трактует о первом в мире убийстве, затрагивая проблему виновности и наказания. Драматизм ситуачии, нзображённой Чеховым. состоит в том, что легендарное, книжное и мифическое убийство вызывает у товарища прокурора всепоглощакщий интерес, В то время как к убийству настоящему и реальному он проявляет глубокое равнодушие.“ (Das .Mysterienspiel” „Kain“ (1821) von Byron behandelt den ersten Mord, der auf der Welt begangen wurde, und greift das Problem der Schuld und der Strafe auf. Die Dramatik der von Cechov dargestellten Situation besteht darin, daß der legendäre, literarische und mythische Mord ein überwältigendes Interesse des Staatsanwalts hervorruft, während er dem wirklichen und realen Mord gegenüber eine tiefe Gleichgültigkeit zeigt.) $(5,658)$. Es wäre zu vermuten, daß den Staatsanwalt nicht zuletzt psychologische und weltanschauliche Motive des Mordes, seelische Prozesse und der psychische Zustand des fiktiven Morders Kain im Augenblick des Verbrechens - das, was bei Byron so detailliert und eindrucksvoll geschildert wird - fesseln würden. Gerade aber die Aussagen des Angeklagten über die Umstănde des Mordes, seine Beteuerungen und die Tonart, in der sie ausgesprochen werden (die auf die Möglichkeit einer „rokovaja slučajnost”“ (,schicksalhafter Zufall“'1012) und so auf die Unschuld des Bauern hindeuten), überhört und übersieht er.

${ }^{1009}$ S. uber diese Geschichte bei Halm (1933, S 118)

1010 Tschechow 1965, S. 223

1011 Ibid. S. 226

1012 Ibid. S. 228 
Der Staatsanwalt als Leser steht demzufolge im Widerspruch und bildet gleichzeitig einen Gegensatz zu seinem Amt als Vollstrecker der Gerechtigkeit. ${ }^{1013}$

Obwohl wir Travnikov, einen der beiden Diskutierenden in der Novelle „Pis'mo“1014, als Literaturrezipienten dem Modus III zugeordnet haben, oszilliert seine Wahrnehmung des Fiktionalen zwischen verschiedenen Modi unserer Typologie. Dem Modus III entspricht sie insofern, als Travnikov die schöne Literatur (und mit ihr auch die Philosophie) als Ausdruck der Subjektivität dieses oder jenes Autors und deshalb als Fiktion, der Wahrheit, also dem Realen entgegensetzt und - was noch wichtiger ist - auf das eigene Leben bezieht, $d$.h. für sich und die eigenen Erkenntnisse als unnütz und sogar verderblich auslegt (er baut also einen Kontrast zwischen der Möglichkeit einer Welt- und Wahrheitserkenntnis durch Poesie und Philosophie und der Welt- und Wahrheitserkenntnis auf andere Weise auf ${ }^{1015}$. Er beurteilt die Literatur jedoch gleichzeitig - wenn auch aus eigener Erfahrung - auf einer abstrakten Ebene, verallgemeinernd und deshalb metatextuell im eigentlichen Sinne, und nähert sich deshalb den Literaturrezipienten des Modus VI. Schließlich macht ihn das Bekenntnis, daß er die erwăhnte Literatur inzwischen nur als Unterhaltung betrachte, zum Rezipienten des Modus V (s. 7, 512514). Wir lenken unser Augenmerk auf die Novelle "Pis'mo“, weil die von den Cechovforschern mehrmals zitierten Aussagen Travnikovs über die Fiktion und ihre Wirkung auf ihn bis zu einem gewissen Grade mit der Situation in „V sude“ und folglich mit der Art der Literaturrezeption des Modus V, von der bisher die Rede war, korrespondieren. ${ }^{1016}$

- [..] Когда я имсл неосторожность учиться у красоты мыслить, то она делала из меня пьяного и слепого. Так, читая ..Фауста“, я не замечал, что Маргарита убийца своего ребёнка: в байроновском ..Канне“ для меня были бесконечно симпатичны и сам Каин и чёрт... ('[...] Als ich so unvorsichtig war, bei der Schonheit denken zu lernen, machte sic aus mir einen Berauschten und Blinden. So merkte ich bei

1013 Interessant scheint uns dabei folgendes Detail zu sein Obwohl die Gleichgultukkeit der Mitglieder des Bezirksgerichts in der Novelle ... sude" das eigentliche Thema ist, treten in den Texten Cechovs auch andere Ju-

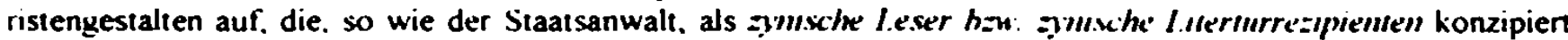
sind (der Friedensrichter Poluechtov in ..O drame“" oder ..izvestnyj advokat" (bekannter Rechtsanwalt) l.ysevic in ..Bab'e carstvo") (vgl. wie Kluge die Arztiguren in den Cechovschen Dramen als zunisch auslegl (s 1997. S 91 . 97)): dennoch ist es in der Novelle ..Pripadok" gerade der Jurastudent Vasil'ev. der sich von seinen Freunden dem Medizinstudenten Majer und dem Kunststudenten Rubnikov - dadurch abhebt. Jaß er eıne deutliche Affinitat zum Modus II der Literaturrezeption (Verblendung durch Literatur) aufweist Majer und Rybnikov sind dagegen indirekt als Rezipienten des Modus V und somit als Gleichgultige bzu Zyniker dargestellt (s unten)

1014 Geschrieben wahrscheinlich Fnde der 1880er - Antang der 1890er Jahre (s die Anmerkungen zum Text.? 718-724) ('ber den Bezug zu „Faust” in der Aussage Travnikovs, von dem unten die Rede ist. $s$ in unserem Aufsatz (Smola 2001. S 107-109) Dieser Bezug ist in der einschlagigen Forschung whon hautig zitien worden In unserem Autsatz erortern wir den enwahnten intertextuellen Verweis im Konten : ler Aussazen der Ftguren Cechovs uber das Verhaltnis zwischen Literatur (Kunst) und der Wirklichkeit. z 13 uher die Norwendigkeit des .praktischen Nutzens I J der schonen Literatur" (ibid. S 108) oder ihrer ideologılschen ..l "nuagements" "ibid. S 107)

1015' Vgl mit Smola 2001, S 107 (ebenfalls das Zitat aus ..Pis'mo" unten)

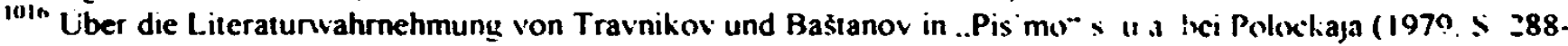
290). Ravfield (1999. S 06) 
der Lektüre von „Faust“ nicht, daß Margarete Mörderin ihres Kindes war; im „Kain“ von Byron waren für mich sowohl Kain selbst als auch der Teufel unendlich sympathisch... $\left.[\ldots]^{\prime}\right)(7,514)$.

Während Travnikov zwischen der Fiktion mit ihrer hetäubenden Wirkung (,.[...] она подкупает, обманывает и сбивает с толку, как мираж. ([...] sie besticht, betrügt und verwirt wie ein Trugbild.) (ibid.)) und dem moralischen, der Wirklichkeit adäquaten Denken eine feste, unuberwindbare Grenze zieht ${ }^{1017}$, wird diese Unüberbrückbarkeit (allerdings in einem anderen Sinne, als das Travnikov auseinandersetzt, und in bezug auf eine konkrete Rezeptionsart) in "V sude“ auf der Ebene der Sujetstruktur demonstriert. Unabhängig von den Inhalten des alludierten und des aktuellen Sujets in ..V sude“, also von der Wirkung einer konkreten fiktiven Erzählung auf eine Person (nichts deutet darauf hin, daß die Lehtüre im allgemeinen und noch weniger die von „Kain“ das gleichgültige Verhalten des Staatsanwaltes verursacht haben könnte; insofern kann von der "Illustration“ der Thesen Travnikovs hier selbstverstăndlich nicht gesprochen werden; auch seine Rezeption von ..Kain“ findet hier keine Entsprechung), gerät die Tatsache der Lehtüre des Staatsanwaltes im Gericht in einen Widerspruch zu einem verantwortichen und angemessenen Handeln, das von ihm hier zu erwarten ist: der Lektüreakt (die faszinierende Wirkung des literarischen Werkes) und die im Kommentar genannte Funktion des gesamten intertextuellen Verweises kommentieren sein Verhältnis zum Realen. Die Überzeugung, daß das Fiktıonale nichts oder wenig mit dem Realen zu tun hat, die Wahrnehmung der Literatur als Illusion und Unterhaltung machen aus Travnikov jedoch keinen zynıschen Leser, sondern vielmehr einen verbılterlen, entlüuschien. Er formuliert die Beziehung der Fiktion zum Leben implizit vom Standpunkt (u.a.) der Verantwortung für dieses Leben (wenn er Margarita als ,.die Mörderin ihres Kindes“ ..verurteilt*), während dem Staatsanwalt selbst die Möglichkeit einer solchen Beziehung verborgen bleibt. Wenn man also Travnikov als Rezipienten des Modus $V$ betrachtet stellt er einen Gegenpol zu den Leserfiguren in „O drame“ und ..V sude“ innerhalb dieses Modus dar. ${ }^{\text {IuIs }}$

Zynische oder gleichgültige Literaturrezipienten kommen, wenn auch nur implizit. ebenfalls in ..Pripadok“" (1889) vor. Der Jurastudent Vasil 'ev und seine Freunde - der Medizinstudent Majer und der Kunststudent Rybnikov - begleiten ihren Bordellbesuch mit dem Singen einzelner Fragmente aus Dargomyžskijs Oper ..Rusalka“ (s. 7, 200, 202. 205, 213) und alludieren dadurch das Sujet des Poems von Puškın. So heißt es uuf de'm Hi'g zu ihrem Zıel: „-

1117 $\mathrm{Vgl}_{\mathrm{gl}}$ bei Wolpers ..Interessanterwcise wird in einigen Bearbeitungen des Motivs [des Motivs ..Gelebte Literatur in der Literatur" - K S ] die jahrhundertealte Diskussion uber die Gefahren der Dichtung und den Nutzen der ubrigen Literatur - besonders der religiosen. philosophischen und padagogischen Schriften I I aufgenommen Mehrfach mussen sich die der schonen L.ttcratur folgenden Helden mit dem schon von Platon [ J erhobenen Voruurf des Scheincharakters und damit der Lugenhaftigheit der Dichtung sowie mit ihrer verwirrenden psychologischen Wirkung auseinandersetzen * (1986.S 15)

10 ix Interessant ist. daß in beiden Novellen derselhe Pratevt evozien wird, so wie die Romane Turgenevs bet den Cechovs Lesern innerhalb des Modus II beliebt sind. wo lesen zugleich zwer Modus V'-Rezipienten bei (echov ..Kain" 
'Невольно к этим грустным берегам, - запел он вполголоса, - меня влечет неведомая сила...' И всю дорогу почему-то у него и у его приятелей не сходил с языка этот мотив, [...].“ (,'Es zieht zu diesen düstren Ufern', sang er halblaut, 'mich eine unbekannte Kraft...' Und den ganzen Weg über ging ihm und seinen Freunden dieses Motiv nicht aus dem Sinn. $\left.[\ldots] .{ }^{* 1019}\right)(7,202)$. Bemerkenswert ist aber, daß nach diesem Besuch nur die letzten zwei Majer und Rybnikov - das Puškinsche Motiv aufrufen, Vasil'ev singt nicht mehr. Neben der pragmatischen Funktion (hier der Symptomfunktion, s. Kośny) - der Unfahigkeit des deprimierten und wütenden Vasil'ev zu singen - hat die ,Rusalka“-Referenz auch eine semantische Funktion. Als nicht zufällig erweist sich in diesem Zusammenhang die Tatsache, daß der Prătext sich den drei Befreundeten aufdrängt, daß sie ihn nicht loswerden. Es drăngt sich nămlich das dem Prătext zugrunde liegende Thema der Verletzung und der Erniedrigung der Frau im weiten Sinne, das Thema der Verantwortung des Mannes für die Frau und der Qualen des Gewissens auf. ${ }^{1020}$ Wăhrend Vasil'ev vom in Bordellen Gesehenen zutiefst erschüttert ist und verstummt (d.h. auch, daß er nicht mehr imstande ist, die evozierten Fragmente nur ästhetisch, z.B. nur musikalisch wahrzunehmen), singen seine Freunde unbeschwert weiter, d.h. sie „übersehen“ die - wenn auch breit begriffenen - Bezüge der realen Situation zu Puskkins Sujet, für sie bleibt die Welt ohne Veränderung, ohne Einsicht und Erleuchtung. Der Prátext bleibt für sie ein ästhetisches Phänomen und seine Rezeption verursacht keine Veränderung in ihrer Wahrnehmung der Realität und in ihrem Verhalten. So erscheinen sie als typische Rezipienten des Modus V, und zwar jener seiner Spielarten, bei der die Verbindung zwischen dem eigenen Leben und dem Fiktiven nicht wahrgenommen wird. Dadurch aber, daß Vasil'ev suggestiv auf den Inhalt des aufgerufenen Textes ..kommt", fungien er im Vergleich zu Majer und Rybnikov nicht nur als die sensiblere Persönlichkeit, sondern auch als der sensiblere Literaturrezipient. Die moralische Taubheit wird durch die literarische Taubheit verdeutlicht.

\subsection{2. .Bab'e carsto": Zwischen der literarischen Selbstinszenierung und der Flucht ins Fiktive}

In der Novelle ..Bab'e carstvo“ (1894) handelt es sich um etwa zwei Tage aus dem Leben ıon Anna Akimovna - einer jungen Fabrikbesitzerin, die sich angesichts der auf ihr lastenden großen Verantwortung für das Geschäft ratlos fühlt und ..mit schlechtem Gewissen an ihrer Überflüssigkeit“" ,Ieidet."1021 An dem geschilderten Weihnachtstag entscheidet sie sich unter anderem beinahe. den ihr imponierenden Vorarbeiter Pimenor zu heıraten. der ihr, wie sie meint, nicht zuletzt die Last der Verantwortung abnehmen und ihrem Leben auch im Ganzen

1019 Tschechow 1965. S. 275

1020 Auf die ..Parallele" zwischen den ..rusalki" ( Nixen) Puskins und den Prostıtuterten in ..Propadok . die durch die aufgenufenen Zeilen aus der Oper Dargomyżskijs suggerien wird. weist z. B Dolżenkor hun (s. 1998. S 231)

in:i Setzer 1997. S 186 
den Sinn und die Richtung geben könnte. ${ }^{1022}$ Sie träumt von einem ..freien“ und .glücklichen" Leben (s. 8, 294), in dem sie keine Schuldgefühle hätte. In der Realität duldet sie jedoch in ihrem Geschäft einen „Firmenjustitiar. ${ }^{1023}$ Lysevic, der sie betrügt und der .,als Anwalt die 20.000 Rubel Jahresgehalt [...] nicht wert ist. “1024 Lysevic begeistert sie als Ästhet und Literaturkenner, dessen Nacherzählen des Gelesenen sie dazu bringt, ihre Sorgen vorübergehend zu vergessen. Am Ende versteht sie, daß der Gedanke an die Heirat mit Pimenov und die Träume von einem sinnerfüllten Leben „vzdor, gluposti“ („Unsinn, Dummheit “i025) $(8,295)$ sind, daß die Menschen wie Lysevic für sie wesentlich näher sind und daß es für sie zu spăt ist, ihre Trăume zu verwirklichen.

In dieser Novelle begegnet man einer Variante der fiktiv gestalteten literarischen Rezeption innerhalb des Modus V, die wir in den Texten „O drame“. .V sude“ und „Pripadok“ vorfinden. In die Reihe der Rezipienten dieses Modus wie Poluechtov, der Staatsanwalt oder Majer und Rybnikov paßt hier besonders reibungslos der Rechtsanwalt Lysevic - ein LeserÄsthet ${ }^{1026}$, der seine durchaus praktischen Interessen, noch mehr seinen Eigennutz und seine Korruptheit (vgl. bei Jackson: ,the cynical and corrupt Lysevich“1027 und bei Winner: ..parasitical lawer, a hypocrite and cynic ${ }^{\text {i028 }}$ ) mit einem feinen literarischen Geschmack vereinbart. Lysevič verbirgt sich nicht hinter dem Schönen. Originellen und mitunter auch Gehobenen, das er in der Literatur bevorzugt, sondern laßt die beiden Welten für sich koexistieren, bekleidet sogar seine Habsucht bisweilen ästhet:sch, stilisiert sie (vgl. z.B. die Textstelle, an der seine Beschăftigung im Fabrikgeschăft von Anna Akimovna geschildert wird: .Анна Акимовна знала. что на заводе ему нечего делать, но отказать ему не могла: не хватало мужества. [...]. Он называл себя её юрисконсультом, а своё жалованье, за которым он присылал аккуратно каждое первое число, - суровою прозой." (..Anna Aki-

$1622 \mathrm{Vgl}$ bei Flath ..Anna's primary concern throughout 'A Woman's Kingdom' has been a search for a man who will solve all her problems. from the complex decisionmaking about the factory and household to the most basic needs of her body " (1998. S 401)

1022 Setzer 1997. S 186

1024 Ibid S 187

${ }^{102^{\circ}}$ Tschechow $1960 . \mathrm{S} 391$

$1026 \mathrm{Vyl}$ seine Charakteristik bei Cechov. die sich vermutlich auch auf seine Literaturwahrnehmung bezieht .Прописная мораль в оригинальной форме вызывает у него слезы “ (.Eine Binsenwahrhett in origineller Form ruhrte ihn au Tränen " (Tschechow 1966. S 373)) (8. 279) Nicht zufallig geht den Aussagen Lyseviès uber L.iteratur. seinen Literaturvergleichen und dem Nacherzahlen des Romans von Maupassant die Schildenung der feinen Speisen beim Mittagessen und der V'orfreude des hungrigen Rechtsanualtes voraus. Lysevic erscheint als literarischer sowie kulinarischer Genießer, Literatur kostet er wie ein gutes Essen bzw einen guten Wein. I'gl dazu seine Außerungen uber Maupassant .. I / он [ .] с чувством рассказывал о том. I ] какой чудесный матлот из налимов умеет готовить злешний повар. - не матлот. а откровение'.. (..l | er I ] erzahlte gefuhlvoll. [ ] was fur ein wundervolles Fischragout aus Aalraupen der hiesige Koch zuzubereiten verstehe - das sei kein Fischragout, sondern eine Offenbarung'". (Tschechow 1966. S 374)) (8. 280) und. ..- Уанвительный художник' [ ] Последняя его вениь истомила меня. опьянила' [ ] надо се смаковать. медленно выжимать сок из каждой стрпіки. miть "' (..'Ein wunderbarer Kunstler' l ]' I ] Sein letztes Werk hat mich erschopft und berauscht' | I muß man es genießen. aus jeder Zeile langsam den Saft auspresien und trinken

I ${ }^{\prime \prime}$ (Tschechou 1\%66. S 379)) (8. 285-286) Vigl die (harakteristih von L.vsevit bei Halm .feiner Kenner und Schatzer der Literatur" (1933. 5 75)

1927 Jackson 1989 . S 97

${ }^{1123 x}$ Winner 11560. 5 125 
mowna wußte, daß er im Werk nichts zu tun hatte, aber sie konnte ihn nicht entlassen - ihr fehlte dazu der Mut, [...]. Er nannte sich ihren Rechtsberater, und sein Gehalt, das er an jedem Monatsersten pünktlich abholen ließ, nannte er die rauhe Prosa. “1029) $(8,279)$ ). ${ }^{1030}$ Es wird hier - im Unterschied zu den in "O drame“ und „Pripadok“ erzăhlten Geschichten - nicht demonstrien, wie das von dieser oder jener Fiktion Suggerierte und Vermittelte vom fiktiven Leser übersehen oder ignoriert bzw. wie aus ihrer Botschaft keine Lehre folgt (die Literaturrezeption verleitet die Protagonisten in „O drame“ und "Pripadok“ nicht zu der erwarteten humanen und respektvollen Behandlung des Nächsten). Auch die Parallelität zwischen der Fiktion und der Wirklichkeit in „V sude“ hebt die Verantwortungslosigkeit und Gleichgültigkeit des lesenden Staatsanwaltes noch hervor; die Lektüre illustriert hier eine gewisse Lebenseinstellung der Figur. Das Thema des gelesenen Werkes, das mit der realen Situation auf diese oder jene Weise korrespondiert, unterstreicht sie. In „Bab'e carstvo“ handelt es sich, zunächst in bezug auf Lysevič, eher um eine bewußte Ausblendung des Realen, hier des Traurigen, Problematischen, Schwierigen, dem man sich stellen muß, durch das Fiktionale. Das Reale wird literarisch verkleidet und inszeniert. Es handelt sich weiterhin um eine literarische Selbstbeschönigung und -veredlung, die den Charakter einer leichten, spielerischen literarischen Selbststilisierung besitzt (also im Grunde keinen ernsten Versuch darstellt, sich zu verstellen) und die ihm wiederum die wahre Realităt (hier seine eigene Persónlichkeit) in ei-

\footnotetext{
1029 Tschechow 1966, S 373.

${ }^{1010}$ Am deutlichsten jedoch wird der Widerspruch zwischen den eigennutzigen Absichten Lysevics und der literarisch-edlen Form, in die er sie einhüllt, in der Szene. in der er sich nach dem ausgiebigen Mittagessen uberzeugt. daß er Anna Akimovna ..platonisch“ liebt und sie gleich darauf um eine Geldpramie anlaßlich der Feiertage (..nagradnye") bittet, vgl
}

Он. по его словам. люйил Тургенева, певца девственной люӧви, чистоты. молодости [.. ]. но сам он любил девственную люйовь не во̆лизи, а понаслышке, как нечто отвлеченное. существующее вне действительной жизни Теперь он уверял себ̆я. что Анну Акимовну он любит платонически. идеально [ ] [ ]

Он припал щекой к ее руке и сказал [ ]

- Дуся моя. зачем вы меня оштрафовали?

- Kak? Koraa?

- Я к праздннку не получнл от вас натрадных

Раньше Анне Акимовне ни разу не приходилось слышать, чтоб̆ы адвокату х праздникам писылались наградные, [ ] А дать было нужно, так как он ждал. хотя смотрел на нее г.лазами полными люб̄ви (..Nach seinen Worten liebte er Turgenjeu. den Sanger der keuschen Liebe. der Reinheit. der Jugend I l. er selbst hat aber die keusche Liebe nicht an sich selbst erfahren. er kannte sie nur vom Horensagen. als etwas Ahstraktes, außerhalb der Wirklichkeit Existierendes Jetzt redete er sich ein. er liebe Anna Akimowna platonisch. ideal. I ] [. I

Er schmiegte seine Wange an ihre Hand und sagte [ ]

Meine Suße. wofur haben Sie mich bestraftr

'Wie' Wann'

'Ich habe num Fest keine Gratifikation von thnen erhalten '

Anna Akimowna. die vorher kein einziges Mal davon gehor hatte. daß deni Rechtsanwalt zu den Feicrtagen Gratifikationen geschickt uurden. [ $]^{\text {T }}$ 'nd geben mußte man ihm etwas. denn er wartete daraut. obwohl er sie mit Augen voller Liebe anschaute " (Tschechow 1966. S i80-381) (8. 286-28?)

Vyl dazu auch bei Flath 1998. S 401 
nem schöneren Licht erscheinen läßt. ${ }^{1031}$ Dabei ereignet sich, um es noch mal zu betonen, keine wirkliche Verblendung durch Literatur, weil die Literatur höchstens als Pose und Spiel benützt wird. Als einen zynischen Rezipienten könnte man Lysevið insofern bezeichnen, als er sich mit Hilfe der literarischen Inszenierung des Realen die Last der wahren Probleme abnimmt, sichtbar die moralische und verantwortliche Einstellung zur Realität zugunsten des Ästhetischen verwirft, wahrscheinlich aber nur einer für ihn bequemen Lebenshaltung und -wahmehmung einen literarischen und ästhetischen Rahmen gibt.

In einer weiteren Hinsicht bildet Lysevic einen Gegensatz zu den Literaturrezipienten des Modus $V$ in den bisher analysierten Texten: Während z.B. Poluechtov oder Majer und Rybnikov keinen Bezug des Fiktiven zu dem eigenen Leben herstellen wollen oder mögen, stellt Lysevič immer wieder mit wahrer Inspiration Vergleiche zwischen dem Realen (der Situation und Persönlichkeit von Anna Akimovna und seiner eigenen) und der Fiktion an; jedoch verhelfen ihm solche Parallelen nicht zum besseren Verständnis der Wirklichkeit, zur Einsicht in die wirklichen Verhältnisse, sondern haben eine Theatralisierung des Lebens und der Umgebung und somit ihre Entstellung zum Ziel und zur Folge.

In der Literaturwahmehmung Anna Akimovnas kommen mehrere Komponenten zugleich zusammen: Das Fiktive ist für sie mit der (vorübergehenden) Flucht vor den Problemen und Pflichten verknüpft, mit denen sie nicht umzugehen weiß (vgl. Saal-Losq: „For Anna Akimovna literature represents an escape from the daily worries about her responsibilities which she does not know how to handle. “1032, ebenfalls Flath: ..Stories, [...] providing their readers with relief from the cares and concerns of our everyday lives, $[\ldots]$.“1033 $)$, mit den sehnsüchtigen Träumen von einem anderen, besseren, interessanten und sinnertüllten Leben, von persönlichem Glück (insofem näher sie sich als Rezipientin innerhalb des Modus $V$ beispielsweise der Mutter von Nadja aus ..Nevesta“ oder ist auch bis zu einem gewissen Grade, bei allen in unserer Iypologie besprochenen Differenzen, mit den ..Nachlebenden“" der Literatur des Modus II zu vergleichen); andererseits versetzt sie das literarische Erlebnıs, genauer, Literatur in der talentıerten mündlichen Wiedergabe durch Lysevič, in eine Art (obgleich nicht lange dauernden) Rauschzustand. dessen Genuß sie letztendlich über ein moralisches Handeln stellt (wenn sie sich nämlich gesteht, daß sie bereit wäre, Lysevič, dessen Unehrlichkeit ihr wohl bekannt ist, für seine Erzählkunst eine wenn auch sehr große Geldsumme zu bezahlen, und ihm schließlich die erwähnte Prämie gibt, statt zu versuchen, dieses Geld verantwortlicher und gerechter auszugeben $\left.{ }^{1034}\right)^{1035}$ In diesem Sinne erscheint sie als eine Rezipien-

\footnotetext{
1031 was vor allem yerade in seiner Rezeption Turgenevs zum Ausdruck kommt (darauf werden wir noch zuruckkommen). dazu s. z B noch Semanova 1958. S 218

${ }^{10.32}$ Saal-Losq 1978. S 144 ('ber die Benuge der Personen von ..Bab'e carstvo“ zur l.iteratur haben auch andere Forscher yeschrieben, s z B Ravtield uber die Literaturwahmehmung von Lysevič (1999, S 123). auch Halm (1933. S. 75-76)

10.? Flath 1998, S 391

I0'4 $\checkmark$ gl dazu die Formulierung von Flath "In 'A Woman's Kingdom' ('Bab'e carstvo'. 1894) Cechov demonstrates the falsity of a world defined by literary cliches and the dangers of giving in to the seductive action of literary plots" Der Einfluß des L.iterarischen hat hier tur Flath ...a denial of responsibility and a inability to act ethi- 
tin vom Schlag Lysevičs: Für sie bietet das Fiktive eine Unterhaltung, die in einen Widerspruch zum ethischen Verhalten auf der Ebene des Realen gerăt.

Das Verhalten und die Denkweise, die vom Moralischen (wie Ehrlichkeit, Verantwortung. Mitgefühl) ganz oder partiell, durchgängig oder gelegentlich abweichen, sind jedoch bei den beiden Protagonisten nie auf die Wirkung der literarischen Fiktion, auf die verfehlte Literaturrezeption zurückzuführen, ist also nicht in diesem oder jenem Referenztext zu suchen (was eine entscheidende Differenz zu den Rezipienten des Modus II3 bildet, die nicht zuletzt infolge einer spezifischen Verarbeitung des Gelesenen Schaden anrichten); das Verhältnis zum Literarischen ergänzt und dokumentiert hier nur bestimmte Charakterzüge, Schwankungen und Widersprüche, die einen durchaus außerliterarischen Ursprung haben. Für Anna Akimovna und den Rechtsanwalt Lysevič spielt Literatur auch nicht die Rolle, die sie hăufiger für die Rezipienten des Modus II spielt; Anna Akimovna unternimmt z.B. keinen ernsten Versuch, ihre Probleme (Gewissensbisse und Zweifel) literarısch, d.h. nach einem literarischen Muster zu bewältigen, wie das unter Umständen bei Zinaida Fëdorovna in „Rasskaz neizvestnogo celoveka“" oder beim Studenten Vasil'ev in .Pripadok“ zu vermuten ist; Literatur ist für Anna Akimovna grundsătzlich nur eine Ablenkung, die sehr zeitbegrenzt helfen, d.h. höchstens auf eine kurze Zeit die Stimmung ändern kann. ${ }^{1036}$

Die literarische Stilisierung der Realität, die Lysevič spielerisch unternimmt, bezieht sich zunăchst auf seine Beziehungen zu Anna Akimovna: ,- Я её обожаю! - продолжал адвокат совершенно искренно, [...]. - Я люблю, но не потому, что я мужчина. а она женшина: когда я с ней. то кажется. что она какого-то третьего пола, а я четвёртого, [..]. Лучше всех определяет подобные отношения Leconte de Lisle." (..'Ich vergöttere sie!' fuhr der Rechtsanwalt [vollkommen] aufrichtig fort. [...]. 'Ich liebe sie, aber nicht, weil ıch ein Mann bin und sie eine Frau: wenn wir zusammen sind. kommt es mir vor, als gehörte sie einem dritten Geschlecht und ich einem vierten [...]. Solche Beziehungen hat am besten Leconte de Lisle beschrieben [beschreibt am besten Leconte de Lisle]. [... $\left.]^{\text {m.1037 }}\right)(8.280)$. Eine derartige Stilisierung, die recht harmlos beginnt, entpuppt sich aber immer mehr als Mittel, sich von den Problemen der anderen abzuschirmen, sie offenbart die Taubheit des spielerisch ge-

cally" zur Folge (1998, S. 391), vgl auch die Interpretation von Jackson ..Lysevich [ ] draws Annu across the moral barrier into his unprincipled and spiritually empty world She gives him the fifteen hundred rubles It is a moment of capitulation and betraval " (1989. S. 97) S wiederum bei Flath "The literary act of seduction has corrupted Anna moraly " (1998. S 401) Mythopoetisch bildet sich fur Jackson danuber hilsaus die folgende (Opposition ..On the mythopoetic plane of the story. then. Chekhor opposes the 'Kingdom of Christ', with its distrine of freedom. responsibility and sacrifice. to the pagan 'woman's kingdom' with its superstition. lottery tickets. fortune-telling and slavery of fate ${ }^{-}(1989 . S 101)$

10." $\mathrm{Vgl}$ dazu Setzer ... [. ] es geht [ ] um die Aura des sublimienten Verlebendizens und die Transponierunt! des Artefaktes in ein rauschhaftes Erlebnis, das die reale Zeit außer Kraft setzt I ] Der asthetisithe und kuiturelle Anspruch hat damit das burgerliche Arbeitsethos verdrangt " (1997. S 187)

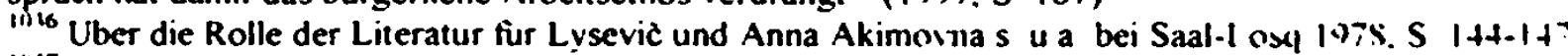

10.17 Tschechow 1960. S 374 
stimmten Rechtsanwaltes solchen Problemen gegenüber. ${ }^{1038}$ Wenn Anna Akimovna über ihre Einsamkeit, ihre Sehnsucht nach Familienglück, nach seelischer Ruhe und Liebe, aus der sie den Lebenssinn schöpfen könnte, erzählt, sagt er: „- Замуж хотите? Что ж, и это можно, [...]. Вам всё нужно испытать: и замужество, и ревность, и сладость первой измены, и даже детей...“ (,'Heiraten wollen Sie. Nun, das kann man [auch],' [...]. 'Sie müssen alles erleben [man muß alles erleben]: Ehe, Eifersucht, die Wonne der ersten Untreue und sogar Kinder... [... ......1039) $(8,282)$. Sowohl dann, als er etwas früher Anna Akimovna eine Existenz als Frau des fin de siècle anrät, als auch in der angeführten Rede orientiert er sich offensichtlich auf bestimmte literarische Situationen und Gestalten, u.a. an Ehebruchssujets, versucht dabei aber im Grunde das Gewöhnliche, das Nichtoriginelle der Wünsche Anna Akimovnas auszublenden: „Annas Rückzug ins Eheleben wăre [für Lysevič - K. S.] die Bejahung der natürlichen Vitalität, der unerotischen und ungeistigen Bestimmung der Frau als Mutter, der Verlust jedes erotischen und kulturellen Reizes. “(10*). Wenn sie sagt, daß sie vielleicht einen Arbeiter heiratet, stellt er zu dieser Absicht einen besonderen literanschen Bezug her: ., $\mathrm{K}$ это не дурно. Герцогиня Джосиана полюбила Гуинплена, и это ей позволяется, потому что она герцогиня; вам тоже всё позволяется, потому что вы необыкновенная.“ (,'Das ist auch nicht übel. Die Herzogin Josiane verliebte sich in Givynplane, und das wurde ihr erlaubt, weil sie eine Herzogin war; Ihnen ist auch alles erlaubt. weil Sie eine ungewöhnliche Frau sind. $[\ldots]^{\left.\cdots \cdot{ }^{(141}\right)}(8,282)$. Die Sehnsucht Anna Akimovnas nach einem Mann (wie Pimenov) mit starkem Willen und den notwendigen Kenntnissen der Welt der Arbeiter deutet und stilisiert Lysevic als ausgefallenen Liebeswunsch, als Marotte einer verwöhnten, sich langweilenden Dame, die - wenn man sich an die evozierte weibliche Gestalt Victor Hugos erinnert - in der Verachtung ihres Liebhabers eine besondere Wonne findet (vgl. im Prätext: ..- Рядом с тобой я чувствую себя униженной, - какое счастье! Быть герцогиней - скука смертная!“ ('Neben dir fühle ich mich erniedrigt - was für ein Glück! Eine Herzogin zu sein, ist tödlich langweilig! [... [ $)^{(0-42}$ ). Die Ernsthaftigkeit solcher Pläne, an die Anna Akimovna eine Zeitlang glaubt, schlıeßt er von vornherein aus und ..übersetzt“ ihre Worte in die ihm verständlichere Sprache des Literarisch-Unglaubwürdigen. So wie Lysevič weiterhin in der modernen Literatur weder Klage noch Schwermut leiden kann, so verschließt er die Ohren vor dem Leiden Anna Akimovnas.

Im Vergleich zu Lysevič weist die Literaturwahrnehmung von Anna Akimovna eine höhere Komplexität auf. Allgemein gesprochen stellt ihr Verhalten und ihr Empfinden eın Oszillieren zwischen der nüchternen und desillusionierten Wahrnehmung ihrer Existenz dar und dem

${ }^{1018} V_{y l}$ dazu u a Saal-Losq...At the same time. these references. which are made by the sly lawer. Lysevich. charekterize his [ ] detachment from the realities of life in general. as well as his inability to understand the concerns of Anna Akimovna " (1978. S 147)

${ }^{10.12}$ Tschechow 1966, S 376

1980) Setzer 1997. S 187

I'w' Tschechow 1966, S 376

I'N2 Gjugo 1985. 5.383 
Versuch, diese Existenz in ein - bisweilen rauschhaftes - literarisches Erlebnis zu verwandeln, sie als solches zu verarbeiten.

Am Anfang der Geschichte entscheidet sich Anna Akimovna, die kleine Geldsummen an die Bittsteller („просители“) zu geben pflegt, eineinhalb Tausend Rubel einem Bittsteller, irgendeinem armen und verzweifelten Menschen zu schenken und ihn dadurch glücklich zu machen. Während sie der Überzeugung ist, daß solche Wohltaten ihr Geschăf, mit dem sie nicht umzugehen weiß, nicht rettet und so die schwere Lage ihrer Arbeiter, die ,schlechter leben, als Sträflinge“ und für die sie verantwortlich ist, nicht verbessert und daß sie damit folglich nur ihr Gewissen beruhigt (sie bezeichnet das etwas später als ..delat' gluposti und obmanyvat' svoju sovest"“ (,eine Dummheit begehen und sein Gewissen betrügen“'1043) (8, 261)), scheint ihr dieser Gedanke zuerst jedoch amüsant und originell zu sein:

Она наудачу потянула из пачки одно письмо и прочла. Какой-то губернский секретарь Чаликов давно уже без места, болен и проживает в доме Гушина; жена в чахотке, пять малолетних дочерей. Гушинский четырехэтажный дом, в котором жил Чаликов, хорошо знала Анна Акимовна. Ах, нехороший, гнилой, нездоровый дом! (,Auf gut Glück zog sie aus dem Packen einen Brief heraus und las ihn durch. Irgendein Gouvernementssekretär Tschalikow, schon lange ohne Stellung und krank, wohnte im Haus Gustschin; seine Frau hatte Lungentuberkulose, und noch fün mindejährige Töchter waren da. Das vierstöckige Haus Gustschin, in dem Tschalikow wohnte, kannte Anna Akimowna sehr gut [kannte Anna Akimovna gut]. Ach, es war ein schlechtes, morsches und ungesundes Haus! $\left.{ }^{\circ 1044}\right)(8,259)$.

Danach faßt sie den Entschluß, Calikov zu besuchen. Die Tatsache, daß Anna Akimovna nicht nur vom Wunsch angetrieben wird. einem verzweifelten armen Menschen zu helfen, sondern daß dieser Einfall ihr amüsant scheint und sie unterhălt (diese Idee .,pokazalas' Anne Akimovne original'noj i zabavnoj i razvlekla eë" (..erschien Anna Akimowna originell und spaßig. er bereitete ihr Vergnügen“(1045) $(8,259)$ ), weist darauf hin, daß sie sich dadurch von ihren Problemen und von ihren Pflichten und Schuldgefühlen gegenüber ihren Angestellten ablenken will. ${ }^{l u 4 k}$ Es ist nicht auszuschließen (was für uns wichtiger ist), daß Anna Akimovna

\footnotetext{
1043 Tschechow 1966.S 351

lots Ibid S 349

lows lbid
}

${ }^{104} \mathrm{~V}_{\mathrm{gl}}$. wie diese Episode im Aufsatz von Jackson interpretien wird - der Forscher zitien (wie wir das hser, nur in bezug auf die vermutliche Literaturwahrnehmung von Anna Akimovna, machen) die Stelle .. This idea seemed original and amusing to Anna and diverted her She drew a letter from the pile at randoin and read it' “' (s. 1989. S 94) und analysien die ganze Szene als Verzicht auf eine selbstandige Entscheiduny. auf Verantwonung und Freiheit $\mathrm{Vgl}$.. The origins of the money are unclean Anna received it as 'damages' in some coun case involving her propenty She is morally uneasy about it [ I But rather than give this money to the workers [ ] her idea is to give all the money to one person. and thus stun him with good fortune [ ] She refuses to make a choice - a firm. considered decision with respect to the distribution of the money Instead. she 'dreu a letter from the pile at random' Thus. her act of gambling constituters. like all gambling. a symbolic surrender of will to fate. in social terms 
sich dabei, nach der Lektüre des Briefes, auch an bestimmte literarische Texte erinnert, was ihrem Unternehmen zusätzlich einen nicht nur sympathischen und edlen, sondern auch literarisch-originellen Charakter verleiht. ${ }^{10+7}$ Die Gestalt eines entlassenen Beamten in Not mit großer Familie evoziert nämlich Figuren Dostoevskijs. So enthält die Episode mit Calikov im Kapitel I der Novelle tatsächlich Verweise auf einzelne Stellen aus „Prestuplenie i nakazanie“. Die Assoziationen, die die Person Calikovs, seine Familiensituation und das Haus, in dem er wohnt, mit der Figur Marmeladovs bei Dostoevskij hervorruft (die ersten Referenzen zu "Prestuplenie i nakazanie“ - Allusionssignale in Form eines „echo of content“ (Perri)), könnten im Bewußtsein Anna Akimovnas eventuell auch nach der Lektüre des Briefes entstanden sein; weitere intertextuellen Details sind jedoch im äußeren Kommunikationssystem, außerhalb ihres Bewußtseinshorizontes, markiert. Auf Details, die Allusionen auf den betreffenden Prătext darstellen, stoßt man in der Episode des Besuches Anna Akimovnas bei Calikov. Das sind in erster Lime die Einzelheiten der Personencharakeristik, Besonderheiten der Ausdrucksweise der Figuren u.s.w. Zu nennen ist beispielsweise die Beschreibung der Töchter Calikovs: „В углу за столом сидел [...], должно быть, сам Чаликов, и с ним пять девочек. Старшей, широколицей и худенькой, [..], было на вид лет пятнадщать, [...].“ (,In der Ecke am Tisch, [...], saßen [...], wahrscheinlich Tschalikow selbst. und [zusammen mit ihm] fünf Mädchen. Das älteste, ein schmächtiges Persónchen, mit einem breiten Gesicht [...], schien dem Aussehen nach nicht älter als fünfzehn Jahre [schien dem Aussehen nach etwa fünfzehn Jahre alt zu sein]. [...]." $\left.{ }^{\text {(u+s }}\right)(8,263)$. Vgl. bei Dostoevskij: „С таршая девочка, лет девяти, высокенькая и тоненькая как спичка, [...], стояла в углу подле маленького брата, [...]” („Das älteste Mädchen, das vielleicht neun Jahre alt war, hoch aufgeschossen und dünn wie ein Streichholz, [...]. stand in der Ecke neben dem Bruder [neben ihrem kleinen Bruder], [...]. $\left.{ }^{\text {(1049) }}\right)^{1050}$. Solche Details wie der trinkende Familienvater, seine an Schwindsucht erkrankte, sehr magere Frau (Katerina Ivanovna ist eine „užasno pochudevšaja ženščina“ (..erschreckend abgemagerte Frau..105i $)^{1052}$, die Frau von Calikov ..malen “kaja, očen' chudaja, s żeltym licom żenščina“ (.,eine kleine, sehr magere Frau; sie hatte ein gelbes Gesicht $\left.{ }^{.1153}\right)(8,263)$ ), die enge Wohnung und der schwere Geruch im Haus (bei Marmeladov

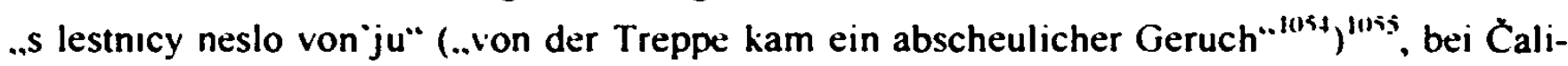

it will constitute in the story a surrender to people. who have no compunctions about taking advantage of the weakness and passivity of others [ ] Her irresponsibility at this moment is underlined by her lighthearted mood (et stalo iewelo) - a mood that recures fater. immediately after she gives the money to Lysevich." (ibid) $\mathrm{Vg}_{\mathrm{g}}$ auch bei Flath "To free herself from drudgery and boredom of meting cut charity in small amounts. Anna decides to give all the money to a single person chosen at random from among the petitioners 1 ] "(1998. S 392)

${ }^{104} \mathrm{~V}$ Vl dazu auch bei Flath (s Fußn 1034)

${ }^{1048}$ Tschechow 1966. S 354

ino Dostojewski 1971. S 34-3.5

${ }^{1050}$ Dostnevskij Bd 6 (1973). S 22

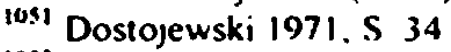

${ }^{1092}$ Dostoerskij Bd 6 (1973). S 22

10s' Tschechow 1906. S 354

1144 Dostojewski 1971. S 34

luss Dostoevskij Bd 6 (1973). S 22 
kov „promozglyj zapach kakoj-to kisloty“ („muffiger und säuerlicher Geruch“1056) (8, 263)) signalisieren die Intertextualität mit Dostoevskijs Roman.

Selbst die etwas melodramatische, gezierte Ausdrucksweise Čalikovs erinnert an die Marmeladovs, wobei sie beim ersteren ins Unnatürliche und Unaufrichtige umschlägt und Anna Akimovna abstößt. An einer Stelle alludiert Calikov sogar unmißverstăndlich Marmeladov: "- [...] По-моему, если человек низкого звания помогает бедным, то он гораздо благороднее какого-нибудь Чаликова, который погряз в нищете и пороке.“ (,'[...] Meiner Meinung nach ist ein Mensch von einfacher Herkunft, der den Armen hilft, viel edler, als irgendeiner Tschalikow, der tief in Armut und Laster steckt. ${ }^{\text {m.1057) }}$ (8, 266). Vgl. mit den Worten Marmeladovs: „- Милостивый rocударь, [...], - бедность не порок, [...]. Но нищета, милостивый государь, нищета - порок-с.“" (,'Verehrter Hert, [...], - Armut ist kein Laster, [...]. [...] Aber das Bettelelend, mein Herr, das Bettelelend - das ist allerdings ein Laster. $\left.[\ldots]^{\kappa .1058}\right)^{1059}$

Während ihres Besuches entscheidet Anna Akimovna, Čalikov die eineinhalb Tausend Rubel nicht zu geben; sie ist enttäuscht, versteht darüber hinaus, daß das Geld, das sie gibt, nicht in die medizinische Behandlung der Frau Calikovs investiert wird, kommt zu dem Schluß, daß die Spende an "Calikovs“ sinnlos ist und beschränkt sie auf eine wesentlich bescheidenere Summe. So scheitert ihre ..amüsante und originelle“ Idee, einen armen Beamten zu beglücken; ihre zu vermutenden bisherigen Vorstellungen und Erwartungen werden nicht bestătigt, realen Personen, so wie sie sind, weiß sie nicht zu helfen. Ihre Vorstellungen erweisen sich als unrealistisch, ausgedacht. Wenn man annimmt, daß Anna Akimovna anfangs u.a. vom Text Dostoevskijs und seinen verzweifelten, tragisch gestalteten Charakteren inspirier wurde, dann könnte man behaupten, daß sie die aus dem Prătext stammenden Personen in der Realităt kaum wieder findet. ${ }^{10 \times 0}$ Obwohl zwischen den alludierten und den manifesten Figuren, wie wir gesehen haben, tatsächlich mehrere Analogien festzustellen sind, sind ebenfalls die Unterschiede nicht zu übersehen. Calikov beichtet nicht und offenbart keine Abgründe der Verzweiflung, der Selbstverachtung, der schmerzenden Liebe zu seiner Familie, wie Marmeladov das tut. Sein Uimgang mit Anna Akimovna. Phrasen des Entzückens u.s.w. wirken unaufrichtig, gespielt, theatralisch. ${ }^{\mid(x, 1}$ Die Selbsterniedrigung Calikovs vor Anna Aki-

\footnotetext{
${ }^{1056}$ Tschechow 1960. S. 354

1037 lbid S 357

${ }_{1058}^{1050}$ Dostojewshi $1971 . \mathrm{S} 18$

${ }^{1050}$ Dostcerskij Bd 6 (1973). S. 13
}

${ }^{1060}$ Als literarisch und unrealistisch charakterisiert die ..amusanten" Erwartungen Annas auch $\mathrm{H}$ lath ...As a fantasy: Anna's plot was amusing. faced with the drunken Calikov and the smelly. dirny appartmert. she is disgusted There is no place for her fantasy in this reality - [ ] " (1998, S 394)

${ }_{106.1} \mathrm{Vgl}$ die Formulienung von Jackson. .Chalikov (a parody of Dostoevsky's Marmeladow ". (1089. S. 93) Auf die Paraltelitat der Szene mit den Episoden aus dem Werk Dostoevskijs weist ebenfalls Johnson hin ..The scene in which Anne gives the clerk the money resembles the compelling depictions of the suftering o! destitute families in Dostoevsky's novels." (1993, S 60) Vgl dazu auch Rayfield .. The first chapter. in which Inna Akimorna intends to bestow on a poor clerk the money she has won in a law-suit. is a scene of munificince thrown in the donor's face that Dostoevsky could have created" (1999, S 122) Auch Flath betrachtet die betreffende Szene als Parodie auf die melodramatischen literarischen Texte und auf Dostoevskij "Literan parod is a major building 
movna verhüllt z.B. das Gefühl der eigenen Überlegenheit: „[...] и было ясно, что он унижал себя потому, что считал себя выше ее.." (, [...] und es war klar, er emiedrigte sich, weil er sich höher dünkte, als sie.“1062) $(8,266)$. Die ganze Episode deckt Schwankungen in der Realitătswahrnehmung und im Verhalten von Anna Akimovna auf. Sie betrachtet ihr Unternehmen, Calikov zu beschenken, bis zu einem gewissen Grade als Spiel, Ablenkung und Experiment, die sie von der trüben Wirklichkeit ablenken können (nicht zufällig heißt es, daß die Idee sie unterhält (,razvlekla“) und ihr amüsant erscheint, und wenn sie sich später sagt, daß sie damit Dummheiten macht und ihr Gewissen beruhigt, langweilt sie sich wieder (.,Eй опять стало скучно [...].“ (,Ihr wurde wieder langweilig [...].“106.3 $)(8,261)$ ). Wenn man vermutet, daß auch die Lektüre Dostoevskijs in diese Handlung miteinbezogen wurde, dann kann sie als Flucht u.a. ins Fiktive bezeichnet werden. Gleichzeitig gesteht sich Anna Akimovna ein, wie schon bemerkt, daß diese Flucht kein Ausweg aus ihrer Situation, keine Befreiung von der sie belastenden Realität ist.

Die Schwankungen, die Spannung zwischen der Flucht vor dem, was Anna Akimovna als ihre Pflicht und ihre wahre Verantwortung ansieht, also auch vor dem eigenen Gewissen, und der Frustration darüber, daß sie das Richtige nicht tun kann, der Realität also nicht gerecht wird, in den weiteren Episoden auch zwischen dem Wunsch, das Gute zu tun, das eigene Leben moralisch zu rechtfertigen, und der Unfahigkeit, dem Unfug zu widerstehen, auch den moralischen Kompromissen ${ }^{100+}$, finden ihren Ausdruck auch in der Art ihrer Rezeption literarischer Werke. Einerseits lehnt sie z.B. die Stilisierung ihrer Person, wie sie Lysevic durchführt, als Frau des fin de siécle und Herzogin aus Hugos Roman, empört ab, diese Vorstellung ist ihr fremd, sie spricht dagegen das Thema der Verantwortung für die Arbeiter, die Fragen des Gewissens an (und mit der Frage der Verantwortung verbindet sie u.a. auch die Idee der Ehe mit einem Arbeiter wie Pimenov: einen ..prazdnyj, neumelyj celovek” (..müßi-

block in the first chapter of 'A Woman's Kingdom'. as we watch Anna Akimovna attempt to act out a stock plot one that we assuciate with melodramatic fiction and drama [ ] Anna has scripted herself a tantasy of rescue. her goal in choosing this dramatic course of action is as much to amuse herself as one amuses oneself in reading literature - as it is to help someone in need I ] Anna's mission in charity takes her staight into the a setting from Dostoevskij, to the appartment of the impoverished civil servant Calikov I I we know it well from bookes as a scene inherited by Dostoevskij from the Natural School I ]. The characters amount to the lampoun of Dostoevskij"s downtrodden. but noble .insulted and injured" underclass I ] The gesures of the drunken Calikov resemble those of a charakter of a cheap meludrama " (1998. S 392-393)

$14 \times 2$ Tschechou 1966. S 357

$10 \times 3$ Ibid S. 351

then $\mathrm{V}_{\mathrm{gl}}$ Jacksons Formulienunug in bezug auf Anna Akimovna ..moral compromise and batrayal" (1989. S 101) Unsere Interpretation der geistigen Haltung von Anna Akimovna kommt der von Jacison nahe. Jackson schreibt . Anna understands the uselessness of philanthropy Indeed, she fieels guilty and ashamed in the face of exploitation. poverty and degradation around her But she is caught between her concience. her instinctive sense of right and wrong. on the one hand. and. on the other hand. her squeamishness. passivity. fear of ridicule. moral weakness and fear of life " (1989. S. 93) So wayt sie es nicht, sich fur den Lehrer der Schule. deren Patronin sie ist. einzusetzen - er wit vom Fabrikdirehtor Nazarve schlecht behandelt - weil sie selbst Angst vor diesem hat (s daruber auch bet Jackson 1989, S 95) So duldet sie auch Lysevic. der bei ihr als Justitiar beschaftigt ist und von dem sie weıß, dalß er sie betrogen hat ..Узнавии об этом об̆мане. Анна Ахимовна торьхо заллакала, но потом прнвыкла" (.Als Anna Akimowna von diesem Betruy erfuhr. weinte sie bitterlich, aber spater fand sie sich damit ab" (Tschechou 1966. S. 373)) (8. 279) 
gen und unfăhigen Menschen“1065) $(8,282)$ wie sie selbst, darf sie, wie sie meint, nicht heiraten). ${ }^{1066}$ Sie verwirft also bis zu einem gewissen Grade die Möglichkeit der Flucht in die Literatur oder eines Lebens wie in der Literatur, die Lysevið evozien, zugunsten der Realität und der Verantwortung. Andererseits gesteht sie sich, daß für den Genuß, Lysevičs Darbietungen des Literarischen zu hören, sie bereit wäre, viel Geld - „не двенадцать тысяч, а втрое больше“ („nicht nur zwölftausend, sondern dreimal mehr“1967) $(8,284)$ - zu bezahlen und verzeiht ihm für diesen Genuß alles. Auf ihre Art (in Form einer vorübergehenden Ablenkung beim Zuhören) und in bezug auf andere Frätexte (in der Novelle z.B. auf einen Roman von Maupassant) flüchtet sie in die Fiktion. ${ }^{10 k 8}$

Am Ende erweisen sich jedoch auch die Träume Anna Akimovnas von der Ehe mit Pimenov, die sie als „ehrlich, erhaben und edelmütig“"1069 empfindet, als etwas Melodramatisches (interessant, daß sie an diesem Abend sentimentale Romanzen singt und dabei von ihm trăumt (s. 8, 294) ${ }^{1070}$ ), Unwirkliches, schließlich als Selbsttäuschung und Flucht vor sich selbst und deshalb vor der Realităt: ,[...] она чувствовала, что Лысевич и даже Крылин для неё были ближе, чем Пименов и все рабочие, взятые вместе.“ (,[...] fühlte sie, daß Lysewitsch und sogar Krylin ihr năher standen als Pimenow und alle Arbeiter. “1071) $(8,296){ }^{1072}$

\footnotetext{
1065 Tschechow 1966. S. 376

1066 Diese Aussagen Anna Akimovnas werden aber auch auf eine besondere Weise relativien ..Анна Акимовна была рада. что высказалась. и повеселела. Ей нравилось, что она так хорошо говорила и так честно " красиво мыслит. [ . ].“ (..Anna Akimowna war froh. daß sie ihre Meinung gesagt hatte [daß sie sich ausgesprochen hat]. und wurde wieder heiter Es gefiel ihr, daß sie so gut sprach, und so ehrenhaft und schön urteilte. [...]." (Tschechow 1966, S 377)) (8. 283-284). S. daruber bei Kataev 1979. S 146

${ }^{1067}$ Tschechow 1966.S 378

$1068 \mathrm{Vgl}$ unsere Bemerkung uber das Schwanken Annas zwischen dem Literarischen und dem Realen mit dem Gedanken Flaths, daß ..she fmdes herself in an in-between place $-[$. . 'middle territory". wobei die Welt ..upstarrs". d.h. die Welt von Lysevic als .,realm of abstraction and literary delusion" bezeichnet wird (s. 1998, S 403).

${ }^{11669}$ Tschechow 1966, S 392; $\mathrm{s}$. in der Originalausgabe 8. 296

${ }^{1070} \mathrm{~S}$ daruber bei Jackson 1989, S 98-99.

1071 Tschechow 1966, S. 392

1072 Diese Stelle zitien Jackson, er bezeichnet die beschriebene Erkenntnis Anna Akimoinas als ..discovery of selfund zugleich als ihre Unterwerfung dem Schicksal (1989. S. 100) Der Forscher kommt dabei jedoch zum Schluß3. daß Anna Akimovna die Heirat mit Pimenov und so die Freiheit und Verantwortung gerade aus Angst vor den! Leben venwirf ..Her alternative choice that was open to her was [ . ]. to master her fate. to take responsibility of her life. [ ]. go downstairs socially, that is. identify herself at least on the moral plane with the world of the poor and the oppressed Anna. Pearing of life [ ] chooses not to take the alternative path Marriage to Pimenov. [ ]. would have meant for Anna a step in the direction of the mastering her fate. a step in the direction of acceptance of conflict and of the responcibilities [ ..]. This step she was incapable to taking" (1989. S 99) Die Idee der Heirat mit Pimenov ist fur Anna Akimovna im Text einerseits tatsachlich mit dem Thema der Verantwortung. also des Realen, $d . h$ bei uns des nicht-Literarischen (das Literarische, wie es von Lysevic prasentien wird) verbunden. andererseits erweist sich diese Idee selbst fur sie am Ende als unrealistisch, kunstlich Nicht zufallig kommt z B Flath zum Schluß, daß die Vorstellungen und Traume Annas vom Leben mit Pimenovi, ihr Findruck von seinem Zimmer ebenfalls literarisch sind ..Surely this promise of relief is akin to that which we experience when we escape from the complexity of our lives into literary fictions " (1998, S 396)
} 


\section{Zusammenfassung}

Nachdem wir einige Prosawerke Cechovs in bezug auf ihre Intertextualität untersucht haben, ist es nicht sinnvoll, manche Ergebnisse der Textanalysen nach den von Pfister aufgestellten qualitativen Kriterien (s. Kap. 2.1.) auszuloten.

So werden die Kriterien der Referentialităt und der Autoreflexivität bei einigen Verweisen im inneren Kommunikationssystem auf eine besondere Art erfüllt, wenn z.B. über den Prătext gesprochen bzw. diskutiert wird und die eigene Situation (d.h. auch die fiktive Situation des aktuellen Textes) mit der aus diesem Prätext verglichen wird. Dann werden erstens der Charakter und die Besonderheiten des fiktiv rezipierten fremden Textes vom fiktiven Rezipienten thematisiert (selbstverständlich werden diese Aussagen zum Prätext selbst zum Objekt distanzierter Darstellung und sind mit der Meinung des Autors nicht gleichzusetzen), zweitens spricht der letztere das Verhältnis des Manifesten (sprich des Eigenen) zum Evozierten an, und so wird der Cechovsche Texte bis zu einem gewissen Grade autoreflexiv, er artikuliert wenn auch in gebrochener Weise, in der subjektiven Wahrnehmung handelnder Figuren - die Relation des in ihm Gestalteten zu dem Fremden; Čechov, ,reflektiert“ deshalb „über die intertextuelle [...] Bezogenheit seines Textes“1073.

Das Kriterium der Kommunikativität wird bei Cechov in einem besonderen Maße erfültt. wenn es um Referenzen geht. die z.B. in Paratexten wie Titeln markiert sind, am Anfang oder am Ende des eigentlichen Textes, beı Benennung des Namens des evozierten Autors oder desjenigen seiner Figuren, bei den graphisch und/oder stilistisch markierten, noch besser allgemein bekannten Zitaten, mitunter mit Erwähnung der Zitatquelle; bei der von den Protagonisten unternommenen Wiedergabe der Inhalte, z.B. einzelner Szenen aus dem Fremdwerk, die gewöhnlich auch von der Benennung der entsprechenden Eigennamen begleitet wird. Solch deutlich und bewußt markierte intertextuelle Referenzen sind als ..kommunikativer" zu betrachten als beispielsweise Verweise, die auf diese $A r t$ nicht markiert sind ( $s$. dazu in der Einleitung).

Das Kriterium der Strukturalität wird am anschaulichsten in den von uns untersuchten literarischen Ableitungen Cechovs demonstriert. wo u.a. die im Prätext gegebenen Strukturen (Handlung und Personenkonstellation) nachgeahmt und - inshesondere in den Kontrafakturen - umgewandelt werden. ${ }^{1074}$

Cechovs Texte manıfestieren sich als besonders ..dialogisch“ im Sinne Pfisters (und auch im Sinne Schmids ${ }^{1075}$ ), wenn sie z.B. eine Parodıe oder eine Kontrataktur der Folie darstellen. also deutliche semantisch-thematısche Differenzen zum Vorgegebenen aufweisen. Die ..se-

1673 Pfister 1985a. S 27

1074 Vyl die Texttypen. die Ptister in bezug auf dieses Kriterium nennt (das sind u a gerade Kuntrafakturen). auf S 30 dieser Arbeit

1075 Vigl. S. 22 unserer Arbeit 
mantische Spannung “1076 zwischen dem Prä- und dem Posttext wird mitunter ebenfalls folgendermaßen zum Ausdruck gebracht: es wird die Rezeption des ersten durch die Personen des letzten reflektiert, wobei die von den Cechovs Figuren stammende Angleichung des Realen an das Literarische nicht bestätigt wird; das Literarische zeigt sich dann möglicherweise als überholt, vereinfacht oder unrealistisch. ${ }^{1077}$ So gesehen geht .,Rasskaz neizvestnogo celoveka“ mit „Nakanune“ wesentlich .,dialogischer" um ${ }^{1078}$, als mit „Anna Karenina“. Weniger „dialogisch“ ist in diesem Sinne auch eine affirmative Nachahmung der Referenztexte, in diesem Fall .geraten“ die eigene und die fremde Stimme nicht aneinander, sondem „bewegen sich in die gleiche Richtung" wie etwa in "Za jablocki“" (s. die Differenzierung Bachtins zwischen verschiedenen Arten des zweistimmigen Wortes, Kap. 2.1.).

Wir fassen hier die Ergebnisse unserer Textanalysen zusammen:

Die Kurzgeschichte, Za jablocki“" evoziert - in erster Linie mittels zahlreicher Allusionen - mehrere literarische Texte, die gegen die Willkür und die Grausamkeit des Gutsbesitzers gegenüber den Bauem gerichtet sind (wie Ivan Turgenevs „Dva pomešcika“, Sergej Aksakovs „Semejnaja chronika“ (Kapitel „Michajla Maksimovic Kurolesov“) u.a.) und stellt im Grunde - in mehreren Punkten und Details - eine emste Nachahmung deren Episoden dar; Cechov schreibt eine Geschichte im Geiste seiner Vorgănger, bezogen auf die ihm gegenwătige Realität und Zeit. Er zieht demzufolge thematisch „verwandte“ Fremdtexte heran, bezieht sich auf sie, um das Phänomen, das in ihnen entlarvt wird, aufs Neue, in einer moderneren Variante, anzugreifen.

In .Zagadoxnaja natura“ nimmt Čechov nach unserer Analyse eine parodistische Bearbeitung einzelner Szenen und Episoden von solchen literarischen Texten vor, wie Friedrich Spielhagens ..Problematische Naturen“, aber auch Ivan Turgenevs ..Rudin“ und ..Nakanune“ oder weiterhin Leopold Sacher-Masochs ..Unsere Sclaven“. Die Geschichte demonstriert eine humoristische Herabwürdigung der Prătexte (mit dem Ziel, ihre bestimmten Eigenschaften oder auch ihre Rezeption zu verspotten), diese erfolgt vor allem durch die Übertragung gehobener Sprache auf nichtige Erscheinungen und Inhalte.

Die Kurzgeschichten „Toržestvo pobeditelja“ und ..Silo $v$ meške“ bezeichnen wir als Kontrafakturen; in ihnen wird eine modern(er)e und in beiden Fällen eine negativ(er)e Variante der Referenztexte (Schillers Ballade „Das Siegesfest” in Vasilij Žukovskijs Übersetzung „Toržestvo pobeditelej“ im ersten und Nikolaj Gogol's ..Revizor“ im zweiten Text) geschaffen, jedoch nicht mit parodistischen Mitteln (nämlich ohne beispielsweise Diskrepanzen gegenüber der Folie auf inhaltlicher Ebene im Sinne der Transformation ..hoch $\rightarrow$ niedrig" bei der Beibehaltung gehobener stilistisch-sprachlicher Merkmale). Aus den Bezugstexten über-

\footnotetext{
1076 Pfister 1985a, S. 23

107 Z. B die Destruktion der Protagonistenrollen von ..Gore ot uma“ in ..Rasskaz neizu estnogo celoveka“ (S 206207 dieser Arbeit) oder uber das Verhaltnis der Cechovs Figuren zu denen von Distivevskij in ..Bab e carstvo“ (S 246 dieser Arbeit) Vgl über dieses Phanomen bei Schmid (s. in der Fußn 741)
} 
nommen werden vor allem bestimmte Strukturelemente wie Personenkonstellationen und/oder Sujetdetails, wobei man im Fall von "Toržestvo pobeditelja“ von einer wesentlich abstrakteren Übernahme sprechen kann als in bezug auf "Silo $v$ meške“. Diese zwei Texte benützen ihre Vorlagen mit dem Ziel, diese oder jene Wirklichkeitsbereiche und nicht die Prätexte selbst zum Objekt der Satire zu machen und zu kritisieren. Durch das Wider- und Umschreiben der Referenzwerke artikulieren sie eine eigene Botschaft.

In "Rasskaz neizvestnogo celoveka“ haben wir die Präsenz und bisweilen die Interaktion unterschiedlicher Rezeptionsarten und unterschiedlicher Prătexte im Bewußtsein der Protagonisten beobachtet. Das ăußert sich exemplarischerweise in der Gestalt Zinaida Fëdorovnas, die, worauf manche Details zeigen, nicht eindeutig und nicht ausschließlich von Vorbildern wie Elena aus „Nakanune“, sondern ebenfalls von solchen wie Anna Karenina beeinflußt ist. Auch Orlov wird z.B. nicht nur als „క̌cedrinskij geroj”, sondern andeutungsweise als moderner Onegin, Pecorin, Bazarov konzipiert; seine partielle Affinităt zu diesen Figuren ist womóglich dadurch zu erklăren, daß er sie als lıterarische Pose und Stütze benützt.

In den Texten „O drame“, „V sude“, „Pripadok“ und „Bab’e carstvo“ wollten wir schließlich Varianten eines bestimmten Rezeptionsmodus (Modus V in der von uns erstellten Typologie) erforschen, bei dem das Literarische, das Fiktionale im allgemeinen als Zeitvertreib. einmal als eine zeitweilige Ablenkung, Unterhaltung, das andere Mal auch als Pose, manchmal zusätzlich als Spiel und Mittel der Selbstinszenierung, zugleich zur Theatralisierung des Realen dient. Die Rezipienten können dabei als gelangweilt bzw. gleichgültig, als verzweifelt oder auch als zynisch erscheinen.

${ }^{107 x} \mathrm{Vgl}$ die Ansichten dazu in der einschlagıgen Literatur, angefuhrt $\angle \mathrm{B}$ in der Fußn 872. 


\section{Literaturverzeichnis}

\section{A. Werkausgaben}

Aksakov, S. T.: Sobranie socinenij v cetyrëch tomach.1955 -1956. Moskva. Band 1 (1955): Semejnaja chronika.

Aksakow, S. T. (1919): Familienchronik (übers. von S. Raczynski, H. Røhl). Leipzig Cechov, A. P.: Polnoe sobranie soxinenij i pisem $v$ tridcati tomach (PSSP). 1974 1983. Moskva

Čechov, A. P. (1973): Der Kirschgarten (übers. von P. Urban). Zürich

Cechov, A. P. (1974): Platonov (übers. von P. Urban). Frankfurt am Main

Cemyševskij, N. G. (1954): Čto delat'? Moskva

Dostoevskij, F. M.: Polnoe sobranie sožinenij v tridcati tomach. $1972-1990$. Leningrad. Band 3 (1972): Unižennye i oskorblënnye. Band 6 (1973): Prestuplenie i nakazanie.

Dostojewski, F. M. (1971): Schuld und Sühne (übers. von H. Rơhl). Berlin und Weimar Flaubert, G. (1974): Madame Bovary. Berlin

Gjugo, V. (1985): Ćelovek, kotoryj smeêtsja. Moskva. [Hugo, V.: L'homme qui rit]

Gogol, N. W.: Gesammelte Werke. Berlin. Band 2 (1952): Geschichte des großen Krakeels zwischen Iwan Iwanowitsch und Iwan Nikiforowitsch (übers. von K. Holm)

Gogol, N. W.: Gesammelte Werke in Einzelbänden. Berlin und Weimar. Darin: Der Revisor (übers. von G. Schwarz), in: Der Revisor. Dramen (1973)

Gogol', N. V. (1903): Revizor. Komedija v pjati dejstvijach i teatral'nyj raz-ezd. SanktPeterburg.

Griboedov, A. S. (1978): Gore ot uma. In: Ders. Izbrannoe. Moskva Gribojedow, A. S. (1948): Geist bringt Kummer (übers. von J. von Guenther). Berlin Karamsin. N. M. (1952): Die arme Lisa (übers. von L. Machaeff). Berlin Karamzin, N. M.: Izbrannye sočinenija v dvuch tomach. Band I (1964): Bednaja Liza Korolenko. V. G. (1990): Sobranie socinenij v pjati tomach. 1989-1991. Leningrad. Band 4 (1990): Istorija moego sovremennika. Knigi pervaja i voraịa.

Lennontov, M. J. (1978): (ieroj našego vremeni. Moskva

Lermontow, M. J. (1987): Ausgewählte Werke in zwei Bänden. Berlin. Band 2 (Prosa und Dramatik) (1987): Ein Held unserer Zeit (übers. von G. Stein )

Pisarev, D. I. (1968): Mysljaščij proletariat. In: Ders. Izbrannye proızvedenija. Lenıgrad

Prutkov, Koz'ma (1953): Izbrannye sočinenija. Leningrad 
Puschkin, A. S.: Ausgewählte Werke in vier Bänden. 1952. Berlin. Band 1: Der Poet. Band 2: Ruslan und Ludmila: Eugen Onegin. Band 3: Der Posthalter; Dubrowskij (übers. von J. von Guenther)

Puskin, A. S.: Polnoe sobranie socinenij. 1937 - 1959. Moskva-Leningrad. Band 3 (1948): Poet. Band 6 (1937): Evgenij Onegin. Band 8 (1948): Stancionnyj smotritel'; Dubrovskij

Radistschew, A. N. (1952): Reise von Petersburg nach Moskau (übers. von A. Bauch). Berlin

Radišcev, A. N. (1959): Putešestvie iz Peterburga v Moskvu. In: Ders. Izbrannoe. Moskva

Sacher-Masoch, L. (1873): Unsere Sclaven. Wien

Sacher-Mazoch, L. (1876): Raby i vladyki. (übers. von M. Karneev). Sankt-Peterburg. [Sacher-Masoch, L. Unsere Sclaven]

Saltykov-Šcedrin, M. E.: Sobranie soċinenij v dvadcati tomach. 1965 - 1977. Moskva.

Band 3 (1965): Razvesěloe žit'ë. [In: Nevinnye rasskazy]. Band 9 (1970): Uličnaja filosofija

Schiller, F.: Schillers Werke. Nationalausgabe. Weinar. Teil I, Band 2 (1983): Das Siegesfest

Shakespeare, W. (1993): Hamlet. Stuttgart

Skal'kovskij, K. (1886): O ženšcinach. Mysli starye i novye. Sankt-Peterburg

Sekspir, V. (1844): Gamlet. (übers. von A. Kronberg). Char kov

Siller, F.: Sobranie sočinenij v perevode russkich pisatelej. Sankt-Peterburg. Band 1 (1901): Toržestvo pobeditclej (übers. von V. A. Żukovskij)

Spil'gagen, F. (1871): lz mraka k svetu. Sankt-Peterburg. [Spielhagen, F. Durch Nacht zum Licht ${ }^{\text {107" }}$ ]

Tolstoi, L. N.: Gesammelte Werke in zwanzig Bänden. 1966-1978. Berlin. Band 6-7 (1966): Anna Karenına (übers. von H. Asemıssen).

Tolstoj, L. N.: Sobranic sočinenij v dvadcati dvuch tomach. 1978-1985 Moskva. Band 8-9 (1981-1982): Anna Karenına

Tschechow, A. P.: Gesammelte Werke. Potsdam. Band I (Heitere Erzählungen) (1949): Eine rätselhafte Natur; Der Triumph des Siegers. Der Sack hat ein Loch (übers. von J. von (juenther)

Tschechow, A. P. Gesammelte Werke in Einzelbänden Berlin. Darin: Lichter (übers. von A. Knipper und G. Dick): Der Anfall (übers. von A. Knipper und G. Dick); Eine langweilige Geschichte (übers. von A. Knipper und G. Dick), in: Die Sieppe. Meislererzihhlungen (1965); Im (jerichtssaal (übers von W. Düwel, G. Dick. G.

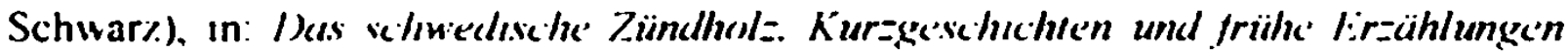


(1965); Flattergeist (übers. von H. von Schulz); Erzăhlung eines Unbekannten (übers. von A. Knipper und G. Dick); Weiberwirtschaft (übers. von A. Knipper uns G. Dick), in: Weiberwirtschaft. Metstererzühlungen (1966); Bei Bekannten (übers. von G. Dick), in: Die Dame mit dem Hündchen. Meistererzählungen (1967)

Tschechow, A. P. (1979): Von der Liebe (übers. von G. Dick). In: Meistererzăhlungen. Berlin

Turgenev, I. S.: Polnoe sobranie sočinenij i pisem v dvadcati vos'mi tomach. 1960 1968. Moskva-Leningrad. Band 4 (1963): Ermolaj i mel'ničicha; Odnodvorec Ovsjanikov; Dva pomeščika [In: Zapiski ochotnika]; Band 5 (1963): Tri vstreči; Band 6 (1963): Rudin; Band 8 (1964): Otcy i deti; Nakanune; Band 10 (1965): Nesčastnaja

Turgenjew, I. S.: Gesammelte Werke in Einzelbănden. Berlin und Weimar. Darin: Rudin (übers. von H. Wotte) (1969); Jermolai und die Müllerin; Der Freisasse Owsjanikow; Zwei Gutsbesitzer [In: Aufzeichnungen eines Jägers] (übers. von $\mathrm{H}$. Wotte) (1971); Văter und Sőhne (übers. von H. Burck) (1973); Vorabend (übers. von D. Pommerenke) (1973); Neuland (übers. von W. Plackmeyer) (1974)

\section{B. Forschungsliteratur}

Aczel, R. (1998): Intertextualitätstheorien und Intertextualităt. In: s. Nünning 1998. S. 241-243.

Adati, N. (1998): Solênyj i drugie (K voprosu o literaturnoj citate v „Trëch sëstrach“). In: Molodye issledovateli Cechova III. Moskva. S. 177-181.

Alekseev, M. (red.) (1965): Šekspir i russkaja kul'tura. Moskva

Alekseev, M. (red.) (1982): Ëpocha realizma. Iz istorii meždunarodnych svjazej russkoj literatury. Leningrad

Bachtin. M. (1971): Probleme der Poetik Dostoevskijs (Hg. von W. Höllerer). München Bachtin, M. (1972): Problemy poètiki Dostoevskogo. Moskva

Bachtin, M. (1975): Slovo v romane. In: Ders. Voprosy literatury i estetikı. Moskva Bachtin, M. (1979): Die Ästhetik des Wortes (Hg. von R. Grübel). Frankfurt a.M.

Baluchatyj, S. (1969): Problemy dramaturgičeskogo analiza. Cechov (Slavische Propyläen. Texte in Neu- und Nachdrucken. B. 68). München

Baricelli, J.-P. (ed.) (1981): Chekhov`s Great Plays. A critical Anthology. New York.

Barthes, R. (1989a): The Death of the Author. In: s. Rice/ Waugh 1989 S. 114-118

Barthes, R. (1989b): From Work to Text. In: s. Rice/ Waugh 1984. S. 166-172

Ben-Porat, Z. (1976): The Poetics of Literary Allusion. In PTI. A Journal for Descriptive Poetics and Theory of Literature, 1. S. 105-128. 
Berdnikov, G. (1961): A. P. Čechov. Moskva-Leningrad

Berdnikov, G. (1978): Čechov. Moskva

Berdnikov, G. (1981): Gogol' i Čechov. In: Voprosy literatury, 8. S. 124-162.

Berdnikov, G. (1984): Čechov i Dostoevskij. In: Voprosy literatury, 2. S. 105-150.

Bicilli, P. M. (1966): Anton P. Cechov. Das Werk und sein Stil. München

Bjalyj, G. (1956): Cechov. In: Istorija russkoj literatury. T. IX. Čast' 2. Moskva-Leningrad. S. 347-432.

Bjalyj. G. (1981): Čechov i russkij realizm. Leningrad

Bloom, H. (1973): The Anxiety of Influence: A Theory of Poetry. London

Broich, U. (1985a): Formen der Markierung von Intertextualităt. In: s. Broich/ Pfister 1985. S. $31-47$.

Broich, U. (1985b): Zur Einzeltextreferenz. In: s. Broich Pfister 1985. S. 48-52.

Broich, U./ Pfister, M. (Hgg.) (1985): Intertextualität. Tübingen.

Bykova, M. (1996): Filosofija Nicše i ,massovoe soznanie“ russkogo intelligenta v tvorčestve Čechova 90-900-ch godov. In: s. Kataev, Kluge 1996. S. 165-180.

Clayton, D. J. (1990): The Importance of Perception. Chekhov's Story "The (irasshoper (Jean de la Fontaine „La Cigale et la Fourmi“; I. A. Krylov). In: s. Kluge 1990. S. $591-605$.

Clayton, J./ Rothstein, E. (ed.) (1991): Influence and Intertextuality in Literary History. Madison.

Conrad, J. L. (1989): Vestiges of Romantic Gardens and Folklore Devils in Chekhov's "Verochka“, „The Kiss”, and „The Black Monk“. In: s. Eekman 1989. S. 78-91.

Cudakov, A. (1971): Poetika Cechova. Moskva

Cudakov, A. (1986): Mir Čechova. Vozniknovenie i utverždenie. Moskva.

Damjanova-Dolmova. D. (1980): Cechov-parodist. In: Russkaja reč, I. S. 29-34.

Danilevskij, R. (1982): Nemeckij realizm 1850-1860-ch godov i russkaja literatura. In: s. Alekseev 1982. S. 141-188.

Derman, A. B. (1959): O masterstve Čechova. Moskva

Dolženkov, P. (1998): „Čajka“ Čechova i ..Rusalka“ Puškina. In: Čechoviana. Čechov $i$ Puskin. Moskva. S. 230-242.

Doring, J. R. (1977): Von Kupferkasserollen und dem ..Ende der Welt“. Zur Auseinandersetzung mit dem Motiv der sich emanzipierenden Frau in Turgenevs ..Nakanune“, Slepcovs „Trudnoe vremja“ und Čechovs .,Rasskaz neizvestnogo čeloveka“. In: Beiträge und Skizzen zum Werk Ivan Turgenevs (Slavistische Beiträge. Bd. 116). München. S. 84-108.

Durkin. A. W. (1990): Pastoral and Anti-Pastoral in Chekhov. In: s. Kluge 1990. S. 675687.

Eekman, T. (ed.) (1989): Critical Essays on Anton Chekhov. Boston. 
Elizarova, M. (1964): Obraz Gamleta i problema „gamletizma“ v russkoj literature konca XIX v. (80-90-e gody). In: Filologičeskie nauki, 1. S. 46-56.

Flath, C. A. (1998): Delineating the Territory of Cechov's „A Woman's Kingdom“. In: Russian Literature, XLIV. S. 389-408.

Fortunatov, N. (1996): Tajny Cechonte: O rannem tvorčestve A. P. Cechova. Materialy speckursa. Nižnij Novgorod

Foucault, M. (1974): Was ist ein Autor? In: Ders. Schriften zur Litertur. München. S. 731.

Franz, N. (1990): Drama na ochote (1884) - eine Parodie? In: s. Kluge 1990. S. 3-16.

Freise, M. (1997): Die Prosa Anton Cechovs. Eine Untersuchung im Ausgang von Einzelanalysen. Amsterdam

Frejdenberg, O. (1973): Proischoždenie parodii. In: Trudy po znakovym sistemam, 6. S. 490-497.

Freund, W. (1981): Die literarische Parodie. Stuttgart

Friedman, S. S. (1991): Weavings: Intertextuality and the (Re)Birth of the Author. In: S. Clayton/ Rothstein 1991. S.146-179.

Füger, W. (1989): Intertextualia Orweliana. Untersuchungen zur Theorie und Praxis der Markierung von Intertextualităt. In: Poetica, 21. S. 179-200.

Geier, M. (1985): Die Schrift und die Tradition. Studien zur Intertextualităt. München

Genette, G. (1993): Palimpseste: die Literatur auf zweiter Stufe. Frankfurt a.M.

Genette, G. (1994): Die Erzählung. München

Goetsch. P. (1983): Leserfiguren in der Erzählkunst. In: Germanisch-romanische Monatsschrift. Bd. 33. S. 199-215

Greber, E. (1989): Intertextualität und Interpretierbarkeit des Textes. Zur frühen Prosa Boris Pasternaks. München

Grigor'eva, E. (1998): Kategorija sud'by v mire Puskina i Cechova (K postanovke problemy). In: Cechoviana. Cechov i Puškin. Moskva. S. 128-136.

Gromov, M. (1977): Skrytye citaty (Čechov i Dostoevskij). In: Čechov i ego vremja. Moskva. S. 39-52

Grübel, R. (1983): Die Geburt des Textes aus dem Tod der Texte: Strukturen und Funktionen der Intertextualität in Dostoevskijs Roman ..Die Brüder Karamazov" in Lichte seines Mottos. In: s. Schmid/Stempel 1983. S. 205-271

Hahn, B. (1977): Chekhov. A Study of the Major Stories and Plays. Cambridge Halm, H. (1933): Anton Tschechows Kurzgeschichte und deren Vorlaufer. Weimar. Hebel, U. J. (1991): Towards a Descriptive Poetics of Allusion. In: s. Plett 1991. S.135. 164

Helbig. J. (1996): Intertextualităt und Markierung. Heidelberg Hempel, W. (1965): Parodie. Travestie und Pastiche. In: Germanisch-romanische Nivnatsschrift. Bd. 15. S. 150-176 
Henry, P. (1997): Genij i bezumie v rasskazach A. P. Cechova i V. M. Garł̌ina. In: s. Kataev, Kluge, Nohejl 1997. S. 601-607

Hielscher, K. (1987): Tschechow. Eine Einführung. München und Zürich

Holthuis, S. (1993): Intertextualität. Aspekte einer rezeptionsorientierten Konzeption. Tübingen

Hübner, F. (1971): Die Personendarstellung in den Dramen Anton P. Cechovs. Amsterdam

Hutcheon, L. (1985): A Theory of Parody: The Teachings of Twentieth-Century Art Forms. New York

Ihwe, J. (Hg.) (1971): Literaturwissenschaft und Linguistik: Ergebnisse und Perspektiven. Frankfurt a.M. Bd. IV 2.

lhwe, J. (Hg.) (1972): Literaturwissenschaft und Linguistik: Ergebnisse und Perspektiven. Frankfurt a.M. Bd.3.

Jackson, R. L. (1981): Chekhov's Seagull: the empty well, the dry lake, and the cold cave. In: s. Baricelli 1981. S. 3-17.

Jackson, R. L. (1989): Chekhov's „A Woman's Kingdom“: A Drama of Charakter and Fate. In: s. Eeckman 1989, S. 91-103.

Jeggle, Ch. (1996): A. P. Čechov und I. - V. Gête. In: s. Kataev, Kluge 1996. S. 32-37.

Johnson, R. L. (1993): Anton Chekhov. A Study of the Short Fiction. New York

Kanevskaja, M. (1994): Iskažěnnaja citata kak ključ k novomu smyslu: Čechov o Gogole. In: Gogolevskij sbornik. Sankt-Peterburg. S. 159-174.

Karrer, W. (1977): Parodie, Travestie, Pastiche. München

Karrer, W. (1985): Intertextualităt als Elementen- und Strukturreproduktion. In: s. Broich/ Pfister 1985. S. 98-116.

Kataev, V. (1979): Proza Cechova. Problemy interpretacii. Moskva

Kataev, V. (1989): Literturnye svjazi Cechova. Moskva

Kataev, V. (1990): Cechov, Anton Pavlovic. In: s. Nikolaev 1990. T. 2. S. $381-391$.

Kataev, V. (1995): Cechov und Deutschalnd (Zur Problemstellung) (Vorträge am Slavischen Seminar der Universităt Tübingen, № 2). Tübingen

Kataev, V., Kluge, R.-D. (red.) (1996): Cechov i Germanija. Moskva.

Kataev V., Kluge R.-D., Nohejl R. (Hgg.) (1997): Anton P. Cechov - philosophische und religiơse Dimensionen im Leben und im Werk. Vorträge des Zweiten Internationalen Cechov-Symposiums, Badenweiler, 20. - 24. Oktober 1994. München.

Klemperer, V. (1913): Die Zeitromane Friedrich Spielhagens und ihre Wurzeln (Forschungen zur neueren Literaturgeschichte. F. Muncker ( $\mathrm{Hg}$.)). Weimar

Kluge, R.-D. (Hg.) (1990): Anton P. Cechov - Werk und Wirkung. Wiesbaden.

Kluge, R.-D. (1995): Anton P. Cechov. Eine Einführung in Leben und Werk. Darmstadt Kluge, R.-D. (1997): Zynische Ärzte in A. P. Čechovs Dramen. In: s. Kataev, Kluge, Nohejl 1997. S. 91-97. 
Koschmal, W. (1988): Cechovs „Nevesta“ als Kontrafaktur des „Pricitanie“. In: Zeitschrift für slavische Philologie, 48. S. 154-169.

Košelev, V. (1998): Oneginskij "mif" v proze Cechova. In: Cechoviana. Cechov i Puskin. Moskva. S. 147-154

Kośny, W. (1971): Bedeutung und Funktion der literarischen Zitate in A. P. Cechovs "Tri sestry“. In: Welt der Slaven, 16. S. 126-150.

Kramer, K. D. (1970): The Chameleon and the Dream. The Image of Reality in Cexov's Stories. The Hague

Krinicyn, A. (1996): Problema „vyroždenija“ u Cechova i Maksa Nordau. In: s. Kataev, Kluge 1996. S.165-180

Kristeva, J. (1971): Probleme der Textstrukturation. In: s. Ihwe 1971. S. 484-507.

Kristeva, J. (1972): Bachtin, das Wort, der Dialog und der Roman. In: s. Thwe 1972. S. 345-375.

Kuester, M. (1998): Parodie. In: s. Nünning 1998. S. 414-415.

Kuzičeva, A. (1998): Puškinskie citaty v proizvedenijach Cechova. In: Cechoviana. Cechov i Puskin. Moskva. S. 54-66.

Kuzina, J. (1993): Transformacija gogolevskich motivov v rasskazach Cechova („Gerojbarynja“, „Šilo v meške“). In: Molodye issledovateli Cechova. Moskva.

Kuznecov, I. (1996): Melodramaticeskie kliš v dramaturgii Cechova i Zudermana. In: S. Kataev, Kluge 1996. S. 61-70.

Lachmann, R. (Hg.) (1982): Dialogizităt. München

Lachmann, R. (1982a): Vorwort. In: s. Lachmann 1982. S. 8-10.

Lachmann, R. (1982b): Dialogizităt und poetische Sprache. In: s. Lachmann 1982. S. $51-62$.

Lachmann, R. (1984): Ebenen des Intertextualitătsbegriffs. In: s. Stierle, Warning 1984. S. 133-138.

Lachmann, R. (1990): Gedächtnis und Literatur: Intertextualităt in der russischen Moderne. Frankfurt a.M.

Lauer, R. (1986a): Realistisches Wiedererzăhlen und „gelebte Literatur”. Zur intertextuellen Struktur von Laza Lazarevićs „Verter“. In: s. Wolpers (Hg.) 1986. S. 231-255.

Lauer, R. (1986b): Die literarischen Folien in A. P. Cechovs .Platonov“. In: s. Wolpers (Hg.) 1986. S. 255-272. Auch: Lauer, R. (1990): Literarische Folien in Cechovs .Platonov“". In: s. Kluge 1990. S. 608-621.

Lauer, R. (1997): Cechovs Anna. In: s. Kataev, Kluge, Nohejl 1997. S. 543-551.

Lauer, R. (2000): Geschichte der russischen Literatur. Von 1700 bis zur Gegenwart. München.

Leithold, F.-J. (1989): Studien zu A. P. Cechovs Drama „Die Möwe“ (Slavistische Beiträge, Bd. 238). Mūnchen

Levin, J. (1965): Glava VI. Śestidesjatye gody. In: s. Alekseev 1965. S. 407-544. 
Lindner, M. (1985): Integrationsformen der Intertextualităt. In: s. Broich/ Pfister 1985. S. 116-135.

Linkov, V. (1982): Chudožestvennyj mir prozy A. P. Cechova. Moskva

Melkova, A. (1977): Literaturnaja polemika serediny 1880-ch godov i "tolstovskie“ rasskazy Čechova. In: Cechov i ego vremja. Moskva. S. 301-321.

Müller, B. (1994): Komische Intertextualităt. Die literarische Parodie. Trier Nazirov, R. (1975): Cechov protiv romantičeskoj tradicii (K istorii odnogo sjužeta). In:

Russkaja literatura 1870-1890 g.g. Sverdlovsk. S. 96-109.

Nazirov, R. (1994): Dostoevskij - Čechov: preemstvennost' i parodija. In: FilologiCeskie nauki, 2. S. 3-12.

Nikolaev, P. (red.) (1990): Russkie pisateli. Bibliografičeskij slovar'. Bd. 1; 2. Moskva. Nünning, A. (Hg.) (1998): Metzler Lexikon Literatur- und Kulturtheorie. Ansătze - Personen - Grundbegriffe. Stuttgart-Weimar.

Ovcarova, P. (1985): Funkcii literaturnych reminiscencij v proze A. P. Cechova. In: Poètǐeskij mir Cechova. Volgograd. S. 92-100

Papernyj, Z. (1980): „Cajka“ Cechova. Moskva

Papernyj, Z. (1994): Ironija i lirika. Lermontovskaja tradicija u Cechova. In: Svjaz’ vremën. Moskva. S.139-152

Peace, R. (1983): Chekhov. A Study of the Four Major Plays. New Haven, London

Peace, R. (1986): Anton Čechov: „Die drei Schwestern“. In: s. Zelinsky 1986. S. 162177

Penzkofer, G. (1984): Der Bedeutungsaufbau in den späten Erzählungen Cechovs. „Offenes“ und „geschlossenes“ Erzăhlen. (Slavistische Beiträge, Bd. 182). München

Perri, C. (1978): On Alluding. In: Poetics, 7. S. 289-307

Peters, J.-U. (1982): Die Entthronung des romantischen Künstlers. Gogol's Dialog mit E. T. A. Hoffmann. In: s. Lachmann 1982. S. 155-168.

Pfister, M. (1985a): Konzepte der Intertextualität. In: s. Broich/ Pfister 1985. S. 1-30.

Pfister, M. (1985b): Zur Systemreferenz. In: s. Broich/ Pfister 1985. S. 52-58.

Plett, H.-F. (1985): Sprachliche Konstituenten einer intertextuellen Poetik. In: s. Broich Pfister 1985. S. 78-98.

Plett, H.-F. (1991): Intertextualities. In: s. Plett (ed.) 1991. S. 3-29.

Plett, H.-F. (ed.) (1991): Intertextuality. Berlin, New Jork

Polockaja, E. (1979): Dviženie chudožestvennoj mysli. Moskva

Prince, G. (1982): Narratology. The Form and Functioning of Narrative. Berlin. New York. Amsterdam

Prozorov, V. (1990): Šeller, Aleksandr Konstantinovič. In: s. Nikolaev 1990. Bd. 2. S. 405-406.

Rayfield, D. (1975): Chekhov. The Evolution of His Art. New York 
Rayfield, D. (1999): Understanding Chekhov. A critical Study of Chekhov's Prose and Drama. Bristol.

Rice, Ph / Waugh. P. (ed.) (1989): Modern Literary Theory. A Reader. London. New York.

Riffaterre, M. (1977): Intertextual scrambling. In: Romanic Review, 68. S. 197-206

Riffaterre, M. (1984): Intertextual Representation: On Mimesis as Interpretive Discourse. In: Critical Inquiry, 11. S. 141-162.

Saal-Losq, Ch. (1978): Literary Allusion in Anton Chekhov's Short Stories (1889 1904). Michigan (Diss., masch.)

Schmid, W. (1983): Sinnpotentiale der diegetischen Allusion. Aleksandr Puskins Posthalternovelle und ihre Prätexte. In: s. Schmid, Stempel 1983. S. 141-187.

Schmid, W. (1991): Puskins Prosa in poetischer Lektüre. Die Erzăhlungen Belkins. (Theorie und Geschichte der Literatur und der schönen Künste, Bd. 82). München

Schmid, W. (1992): Ornamentales Erzählen in der russischen Moderne. Čechov - Babel' - Zamjatin. (Slavische Literaturen. Texte und Abhandlungen. Bd. 2) Frankfurt a.M.

Schmid, W., Stempel, W.-D. (Hgg.) (1983): Dialog der Texte. Hamburger Kolloquium zur Intertextualităt. (Wiener Slawistischer Almanach, Sonderband 11). Wien.

Sebina, E. (1996): Čechov i Nič̌e. Problemy sopostavlenija na materiale povesti „Črnyj monach“. In: s. Kataev, Kluge 1996. S. 126-136.

Semanova, M. (1957): Čechov i Turgenev. In: Ucẻnye zapiski Leningradskogo gos. ped. instituta, 134. S. 177-223.

Semanova, M. (1958): „Rasskaz neizvestnogo celoveka“ A. P. Cechova. K voprosu o turgenevskich tradicijach $v$ tvořestve Čechova. In: Ǔennye zapiski Leningradskogo gos. ped. Instituta, 170. S. 175-230.

Setzer, H. (1997): Fruchtbare Wege des Niedergangs. Phänomene der Dekadenz in den Erzählungen „Tina“, „Pripadok“ und ..Bab'e carstvo“. In: s. Kataev, Kluge. Nohejl 1997. S. 175-191.

Skabizevskij, A. (1904): [Vorwort zu]: A. K. Seller-Michajlov. Polnoe sobranie socinenij. 1904-1905. Sankt-Peterburg. Band 1.

Skaftymov, A. (1958): O povestjach Čechova ..Palata Na 6“", .Moja žizn”“. In: Ders. Stat'i o russkoj literature. Saratov. S. 295-312.

Smola. K. (1996): Čechov i Fridrich Špil'gagen. schodstva v teorii, razlix̌ija v praktike In: s. Kataev, Kluge 1996. S. 42-54. Auch: Smola. K. (1998c): Cechor i Fridrich

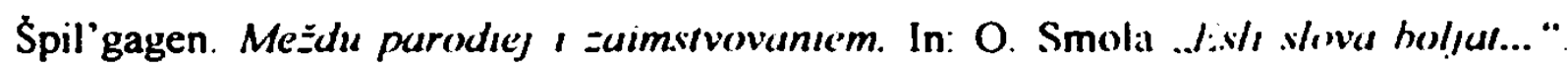
Kniga o poetach. K. Smola () ('echove. Moskva. S. 466-48I.

Smola, K. (1998a): Evoljucija intertekstual'nych svjazej v Iorčestve Čechova. In: Molodye issledovateli Cechova III. Moskva. S. 15-23. Auch Smola, K. (2001): Typen von Intertextualităt im Werk Anton Čechovs. In: Anzeiger tïr slavische Philologie 
Bd. XXVIIV XXIX (Sondernummer zur 3. Tagung des Jungen Forums Slavistische Literaturwissenschaft in Salzburg, September 1999). Graz. S. 101-111.

Smola, K. (1998b): A. P. Čechov v nemeckom literaturovedenii 1980 - 1990-ch godov. In: O. Smola „Esli slova boljat... “. Kniga o poètach. K. Smola $O$ Cechove. Moskva S. 481-534.

Stanzel, F. K. (1984): A Theory of Narrative. Cambridge

Stauder, Th. (1993): Die literarische Travestie. Frankfurt a. M.

Stempel, W.-D. (1983): Intertextualităt und Rezeption. In: s. Schmid, Stempel 1983. S. 85-109.

Stender-Petersen, A. (1978): Geschichte der russischen Literatur. München.

Stierle, K. (1984): Werk und Intertextualităt. In: s. Stierle, Warning 1984. S. 139-150.

Stierle, K., Warning, R. (Hgg.) (1984): Das Gespräch. München.

Still, J./ Worton, M. (1990): Introduction. In: s. Still/ Worton 1990. S. $1-44$

Still, J./ Worton, M. (ed.) (1990): Intertextuality: Theories and Practices. Manchester.

Stūckrath, J. (1984): Der literarische Held als Leser. In: Literatur. Sprache. Unterricht.

Festschrift für Jacob Lehmann zum 65.Geburtstag. Bamberg. S. 102-108.

Šach-Azizova, T. (1977): Russkij Gamlet („Ivano،“ i ego vremja). In: Čechov i ego vremja. Moskva. S. 232-246.

Torop, P. (1981): Problema inteksta. In: Trudy po znakovym sistemam, 14. S. 33-44.

Turbin, V. (1973): $K$ fenomenologii literaturnych i ritoričeskich žanrov $v$ tvorčestve A.

P. Cechova. In: Problemy poetiki i istorii literatury. Saransk. S. 204-216.

Tynjanov, J. (1967): Dostoevskij i Gogol' (k teorii parodii): In: Ders. Archaisty i novatory. München. S. 412-455.

Verweyen, Th./ Witting, G. (1982): Parodie, Palinodie, Kontradiktio, Kontrafaktur Elementare Adaptionsformen im Rahmen der Intertextualitätsdiskussion. In: s. Lachmann 1982. S. 202-236.

Verweyen, Th./ Witting, G. (1987) Die Kontrafaktur. Vorlage und Verarbeitung in Literatur, bildender Kunst. Werbung und politischem Plakat. Konstanz

Verweyen, Th./ Witting. G. (2000): Kontrafaktur. In: Reallexikon der deutschen Literaturwissenschaft. Berlin. New York. Bd. 2.

Vidueckaja, I. (1980): Problema naroda i kul'tury. In: Čechov i Lev Tolstoj. Moskva. S. 96-108.

Volkmann, L. (1998): Bachtin, Michail Michajlovič. In: s. Nünning 1998. S. 32-33.

Wächter, Th. (1992): Die künstlerische Welt in späten Erzählungen Čechovs. (Slavische L.iteraturen. Texte und Abhandlungen, Bd. 1). Frankfurt a.M.

Wetzler, B. (1992): Die Überwindung des traditionellen Frauenbildes im Werk Anton Cechovs (1886 - 1903) (Europäische Hochschulschriften. Reihe XVI. Slawische Sprachen und Literaturen. Bd./ Vol. 40). Frankfurt a.M.

Winner, Th. G. (1966): Chekhov and His Prose. New York 
Wolf, W. (1993): Ästhetische Illusion und Illusionsdurchbrechung in der Erzählkunst. Theorie und Geschichte mit Schwerpunkt auf englischem illusionsstörenden Erzăhlen. Tübingen.

Wolf, W. (1998a): Metafiktion. In: S. Nünning 1998, S. 362-363.

Wolf, W. (1998b): Metatext und Metatextualităt. In: s. Nünning 1998. S. 366.

Wolpers, Th. (Hg.) (1986): Gelebte Literatur in der Literatur: Studien zu Erscheinungsformen und Geschichte eines literarischen Motivs. Gottingen.

Wolpers, Th. (1986) (Entwurf und Schlußfassung) [Gemeinsames Vorwort der Beitrăger]: Zu Begriff und Geschichte des Motivs „Gelebte Literatur in der Literatur". In: S. Wolpers 1986. S. 7-30.

Wơm, D. (1990): Cechovs „Чёрный монах“ und die Archetypenlehre C. G. Jungs. In: s. Kluge 1990. S. 353-394.

Wuthenow, R.-R. (1980): Im Buch die Būcher oder der Held als Leser. Frankfurt a.M.

Zelinsky, B. (Hg.) (1986): Das russische Drama. Düsseldorf.

Zima, P. V. (1994): Die Dekonstruktion. Einfuhrung und Kritik. Tübingen und Basel Zubarev, V. (1997): A Systems Approach to Literature. Mythopoetics of Chekhov's Four Major Plays. London 